I NTELLECTUAL PROPERTY,

INNOVATION AND

ECONOMIC DEVELOPMENT

\title{
Harnessing Public Research for Innovation in the 21st Century
}

An International Assessment of Knowledge

Transfer Policies

Edited by Anthony Arundel, Suma Athreye and Sacha Wunsch-Vincent

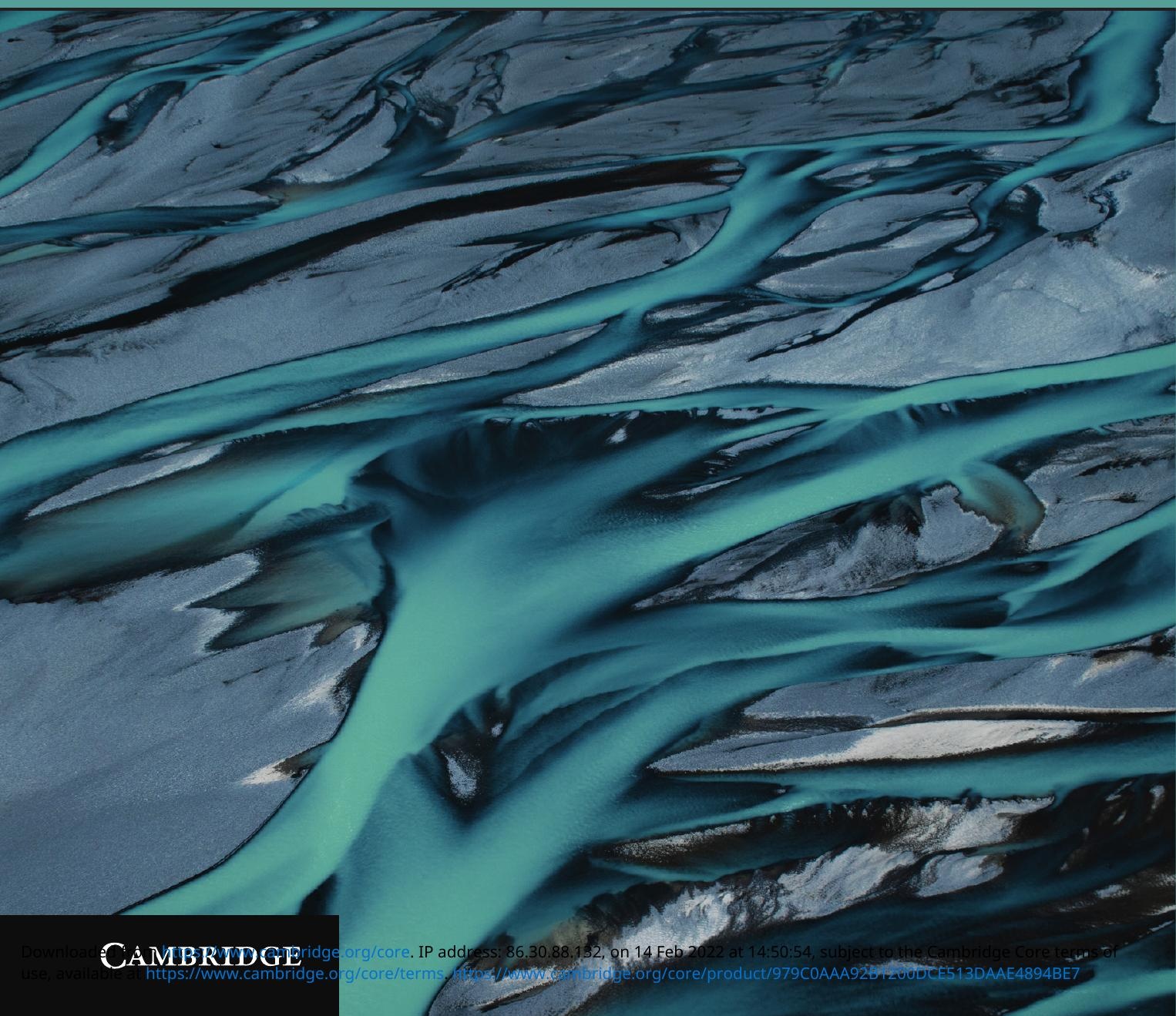


Downloaded from https://www.cambridge.org/core. IP address: 86.30.88.132, on 14 Feb 2022 at 14:50:54, subject to the Cambridge Core terms of use, available at https://www.cambridge.org/core/terms. https://www.cambridge.org/core/product/979C0AAA92B1200DCE513DAAE4894BE7 


\title{
H A R N ES S N G P U B L I C RESEARCH FOR IN NOVATION IN THE $21 \mathrm{ST}$ CEN T UR Y
}

\author{
An International Assessment of Knowledge \\ Transfer Policies
}

Universities and public research institutes play a key role in the innovation ecosystem. Many countries have implemented national strategies to support the commercialization of knowledge produced by public institutions, to help take their innovations and scientific breakthroughs to market and ultimately boost economic growth. Research bodies themselves have also introduced practices to support knowledge transfer activities.

The legal, policy, and institutional approaches to knowledge transfer are diverse, and there is no standardized set of assessment metrics relevant to both high- and middle-income countries. In this context, how can policymakers best help countries and institutions improve the efficiency of their knowledge transfer practices to maximize innovation-driven growth and to seek practical solutions to critical societal challenges?

Comprised of research and insight by esteemed international contributors, Harnessing Public Research for Innovation in the 21st Century addresses this policymaking challenge. It assesses the current role of public research institutions in modern innovation systems and considers how to best optimize existing policies, based on inputs from leading academics, practitioners, and policymakers. It analyses what does and does not work in knowledge transfer practices, policy options, and future measurement priorities, and looks in detail at three high-income and three middle-income country examples. The book provides a useful foundation for future empirical work, the development of appropriate metrics, and for crafting new innovation policy approaches. 
"This book represents a major step towards reaching a systematic approach to the measurement of knowledge transfer practices and outcomes."

Hu Zhijian, President, Chinese Academy of Science and Technology for Development

"Unlike most existing work in this area, this book emphasizes that firms benefit from academic research not only through formal but also more informal channels and from open science, and that there are tensions, as well as complementarities, between these two."

Bhaven sampat, Associate Professor, Columbia University

"Enabling access to cutting-edge research is vital to tackling the challenges countries face, and for policymakers, it is thus ever more important to identify which knowledge transfer practices work and which do not. This research is critical in this regard."

PIPPA HALL, Director of Innovation and Chief Economist, Intellectual Property Office, United Kingdom

"This book does an excellent job of identifying key metrics that should be measured by knowledge transfer offices."

RAgan robertson, Technology Transfer Officer, University of California, Los Angeles, and Association of University Technology Managers (AUTM) Cabinet Member, Metrics and Surveys, United States of America

"Brazil has established a comprehensive legal framework for innovation. But is that enough? There are barriers that can only be overcome with continuous adjustment of policies. In this context, this book provides good guidance."

ANTENOR C.s. CORRÊA, Senior Analyst in Science and Technology, and Fernanda V.M. Magalhães, Specialist in Public Policies and Government Management, Federal Government of Brazil

"Going forward, knowledge transfer will play a pivotal role in driving future growth in Africa. We welcome this book and encourage the African measurement community to invest in related metrics."

philippe kuhutama mawoko, Executive Secretary, African Observatory for Science, Technology and Innovation, African Union Commission 


\section{CAMBRIDGE AND THE WORLD INTELLECTUAL PROPERTY \\ OR G A N I ZA T I O N}

Intellectual Property, Innovation and Economic Development

Intellectual property (IP) is at the heart of modern economic life. In many countries, investment in intangible assets is growing faster than investment in tangible assets. Policy makers - whether in rich or poor economies - seek to promote an IP framework that is conducive to innovation and economic growth.

The series Intellectual Property, Innovation, and Economic Development intends to inform such policy initiatives through rigorous scholarship. Each book in the series examines a major aspect of the interface between IP, innovation and economic development. Economic analysis is complemented by contributions from other academic disciplines to present the latest scholarship and consider its real-world implications. The series builds on studies by the World Intellectual Property Organization, reflecting the research interests of the international policy-making community.

\section{Series Editor}

Carsten Fink, Chief Economist, World Intellectual Property Organization

\section{Editorial Advisory Board}

Megan Macgarvie, Associate Professor, Markets, Public Policy and Law, Questrom School of Business, Boston University, USA

Beth Webster, Director of the Centre for Transformative Innovation, Professor and Pro Vice-Chancellor for Research Impact and Policy, Swinburne University, Melbourne, Australia

Mark Wu, Henry L. Stimson Professor, Harvard Law School, Faculty Director, Berkman Klein Center for Internet and Society, USA

\section{Books in the Series:}

The Informal Economy in Developing Nations - Hidden Engine of Innovation? Edited by Erika Kraemer-Mbula and Sacha Wunsch-Vincent

The International Mobility of Talent and Innovation - New Evidence and Policy Implications

Edited by Carsten Fink and Ernest Miguelez 
Downloaded from https://www.cambridge.org/core. IP address: 86.30.88.132, on 14 Feb 2022 at 14:50:54, subject to the Cambridge Core terms of use, available at https://www.cambridge.org/core/terms. https://www.cambridge.org/core/product/979C0AAA92B1200DCE513DAAE4894BE7 


\title{
H A R N ES S IN G P U B L I C RESEARCH FOR IN NOVATION IN THE $21 \mathrm{ST}$ CENTURY
}

\section{An International Assessment of Knowledge Transfer Policies}

\author{
Edited by \\ A N T H O N Y A R U D E L \\ UNU-MERIT, Maastricht University and University of Tasmania \\ SUMA A THREYE \\ Essex Business School \\ S A C H A W UN S C H - V I N C E N T \\ World Intellectual Property Organization
}




\title{
CAMBRIDGE \\ UNIVERSITY PRESS
}

University Printing House, Cambridge CB2 8BS, United Kingdom

One Liberty Plaza, 20th Floor, New York, NY 10006, USA

477 Williamstown Road, Port Melbourne, VIC 3207, Australia

314-321, 3rd Floor, Plot 3, Splendor Forum, Jasola District Centre, New Delhi - 110025, India

79 Anson Road, \#06-04/06, Singapore 079906

Cambridge University Press is part of the University of Cambridge.

It furthers the University's mission by disseminating knowledge in the pursuit of education, learning, and research at the highest international levels of excellence.

\author{
www.cambridge.org \\ Information on this title: www.cambridge.org/9781108842792 \\ DOI: $10.1017 / 9781108904230$
}

(C) World Intellectual Property Organization 2021

This work is in copyright. It is subject to statutory exceptions and to the provisions of relevant licensing agreements; with the exception of the Creative Commons version the link for which is provided below, no reproduction of any part of this work may take place without the written permission of Cambridge University Press.

An online version of this work is published at doi.org/10.1017/9781108904230 under a

Creative Commons Open Access license CC-BY-NC-ND 4.0 which permits re-use, distribution and reproduction in any medium for non-commercial purposes providing appropriate credit to the original work is given. You may not distribute derivative works without permission. To view a copy of this license, visit https://creativecommons.org/ licenses/by-nc-nd/4.0

All versions of this work may contain content reproduced under license from third parties. Permission to reproduce this third-party content must be obtained from these third-parties directly.

When citing this work, please include a reference to the DOI 10.1017/9781108904230

First published 2021

A catalogue record for this publication is available from the British Library.

ISBN 978-1-108-84279-2 Hardback

Cambridge University Press has no responsibility for the persistence or accuracy of URLs for external or third-party internet websites referred to in this publication and does not guarantee that any content on such websites is, or will remain, accurate or appropriate. 


\section{CONTENTS}

List of Figures

page $\mathrm{x}$

List of Tables

xiii

List of Contributors

xvi

Foreword

xxix

HU ZHIJIAN

Foreword

xxxi

PIP PA HALL

Foreword

xxxiii

B A R T VERSPAGEN

Preface

XXXV

\section{PART I Setting the Context}

1 The Evolving Role of Public R\&D and Public Research Organizations in Innovation

SUMA ATHREYE AND SACHA WUNSCH-VINCENT

Comment 1.1

FABIO MONTOBBIO

Comment 1.2

LIEN VERBAUWHEDE KOGLIN

2 Evaluating Knowledge Transfer Policies and Practices:

Conceptual Framework and Metrics

ANTHONY ARUNDEL AND SACHA WUNSCH-VINCENT

Comment 2.1

B HAVEN SAMPAT

Comment 2.2

RAGAN ROBERTSON

Comment 2.3

ROSEMARY WOLSON

vii 
3 Measuring Global Patenting of Universities and Public Research Institutes

JUAN YANG, INTAN HAMDAN-LIVRAMENTO, BRUNO

LE FEUVRE, SACHA WUNSCH-VINCENT, AND HAO

ZHOU

\section{PART II Selected Comparative Country Studies 139}

4 United Kingdom

FEDERICA ROSSI AND SUMA ATHREYE

5 Germany

DIRK CZARNITZKI AND GEORG LICHT

6 Republic of Korea

KEUN LEE AND HOCHUL SHIN

7 Brazil

FERNANDA DE NEGRI AND CRISTIANE VIANNA

RA UEN

8 China

BAOMING CHEN, CAN HUANG, CHUNYAN PENG, MINGLEI DING, NING HUANG, XIA LIU, AND JUAN Y A N G

9 South Africa

MICHAEL KAHN

PART III The Way Forward

10 Policies and Practices for Supporting Successful Knowledge Transfer from Public Research to Firms 361 ANTHONY ARUNDEL

Comment 10.1

HENRI J.M. THEUNISSEN

Comment 10.2

KERRY FA U L 
11 Policy Recommendations: Aiming for Effective Knowledge Transfer Policies in High- and MiddleIncome Countries

SUMA ATHREYE AND FEDERICA ROSSI

Comment 11.1

ANTENOR CESAR VANDERLEI CORRÊA AND

FERNANDA MAGALHÃES

Comment 11.2

SI KYONG SUNG

12 Toward a Comprehensive Set of Metrics for Knowledge Transfer

ANTHONY ARUNDEL AND NORDINE ES-SADKI

Comment 12.1

PHILIPPE KUHUTAMA MAWOKO

Comment 12.2

GIANCARLO CARATTI

Comment 12.3

460

AMIT SHOVON RAY

Technical Annex: Survey on Policies and Practices for IP-Mediated Knowledge Transfer

Index 


\section{FIGURES}

1.1 Share of R\&D (measured by GERD) in GDP by income group of countries, 2000-16

1.2 Share of public sector in total R\&D, high- and middle-income economies 14

1.3 Share of basic research conducted by the public sector for 2017 or latest available year, as a percentage of all national expenditures for basic research 15

$\begin{array}{ll}1.4 \mathrm{R} \& \mathrm{D} \text { intensity (GERD as a percentage of GDP), case study countries } & 19\end{array}$

1.5 Share of GERD financed by the government, case study countries 20

2.1 Knowledge transfer channels between the public research sector and businesses

3.1 Public research institute and university PCT applications, absolute numbers (left) and as a percentage of total PCT applications (right), 1995-2016

3.2 Trend and share in university and public research institute patent families worldwide, 1995-2014

3.3 Trend in university and public research institute foreign-oriented patent families worldwide and share of total, 1995-2013

3.4 Share of university and public research institute PCT filings for top ten origins in 2007 and 2016

3.5 University and public research institute PCT filings originating from middle-income countries as a share of total university and public research institute PCT filings

3.6 Increase in university and public research institute filings by high- and middle-income groups

3.7 University and public research institute patenting by leading origin countries

3.8 The trend over the past decade in PCT filings for selected origins

3.9 University and public research institute PCT filings in middle-income countries

3.10 University and public research institute patent filings using PATSTAT data

3.11 University and public research institute patent filings for middle-income countries 
3.12 University and public research institute patent applications as a share of total applications for selected countries (\%), 1980-2013

3.13 Distribution of PCT applications by technology sector, 2007-16 108

3.14 Share of PCT applications for the top three fields of technology, 2016109

3.15 Shares of leading technology sectors in PCT applications filed by the top five universities

3.16 Top three technology fields for selected universities and public research institutes, 2010-13

3.17 The share of the business sector in total PCT applications from selected origins

3.18 Nonresident university and public research institute patent applications for selected patent offices, 2006-15

3.19 Share of nonresident university and public research institute patent applications for selected offices, 2006-15

3.20 Patent applications filed abroad by universities and public research institutes for selected origins, 2006-15

3.21 Share of patent applications filed abroad by type of applicant, selected origins, 2006-15

4.1 Cumulative number of degree-awarding institutions active since $1900 \quad 143$

4.2 Universities' sources of income

4.3 Cumulative number of public sector research establishments active since 1950

4.4 Shares of university and PSRE staff involved in different types of knowledge transfer activity

4.5 Patenting and spinout activities of universities 162

4.6 Patenting and spinout activities of PSREs 162

5.1 Number of students at different types of HE college in Germany 184

5.2 Distribution of R\&D expenditure in 2010

5.3 KTT missions and activities of different institutions in German public science

5.4 Patenting in Germany before and after the abolition of professor's privilege

5.5 Trends in German patenting for university and public research institute researchers ("within" transformed), 1995-2008

5.6 Average trends of spinoff activity (within demeaned)

5.7 The firms' perspective on KTT channels

8.1 Share of total R\&D expenditures by enterprises, public research institutes, and universities in China, 2000-16

8.2 Share of 2016 R\&D expenditures in China by application

8.3 Domestic invention patent applications by different types of organization, 1995-2016 
8.4 Number of patent transfers and licenses by universities, 2010-16

8.5 Value of patent ownership transfers and licenses by universities, 2010-16 (million CNY)

8.6 Total annual knowledge transfer agreements by universities, 2008-14

8.7 Total annual value of knowledge transfer agreements by universities, 2008-14 (million CNY)

9.1 Major STI policy documents or acts

10.1 Factors that influence knowledge transfer 369

11.1 The knowledge ecosystem in high-income economies 403

11.2 The public research ecosystem in middle-income economies 406

11.3 Five questions to guide policy toward knowledge exchange from universities 


\section{TABLES}

2.1 Impacts of IP-based knowledge transfer policies on universities/public research institutes and firms

2.2 Socioeconomic effects of IP-based knowledge transfer policies 44

2.3 Impacts on low- and middle-income countries 46

2.4 Knowledge transfer channels and data sources 51

2.5 Basic metrics from KTO surveys 53

2.6 Supplementary metrics from KTO surveys 57

2.7 Variables for standardizing knowledge transfer office (KTO) metrics 59

3.1 Comparison of PATSTAT national patent data coverage for featured countries 86

3.2 Share of patent applications filed in selected technology fields by applicant type, 2013-15

3.3 Top PCT applicants for the university sector in 2016

3.4 Top PCT applicants among governments and public research institutes in 2016

3.5 Top fifty-five patent applicants worldwide, based on total number of patent families, 2010-13

3.6 Top five university and public research institute patent applicants worldwide by selected origins, 2010-13

4.1 Public funding of universities and PSREs

4.2 Indicators of research commercialization activities in UK universities

4.3 Summary indicators of research commercialization activities in UK PSREs

4.4 Collaboration with universities and governments

4.5 Cooperation on innovation activities with universities and government at different geographical levels

5.1 Selected key features of German public research institutes 186

5.2 Top-ranking universities for patent applications, 1990-2009, and research

5.3 Public research institute heads' assessment of their institutes' key tasks (\%)

5.4 KTT by leading German public research institutes at a glance 194

5.5 Leading collaboration partners by sector, 2008-10 
5.6 Main users of public research institute research, as identified by public research institute heads

5.7 University researchers' patent activity by applicant type, 1995-2008

5.8 Academic entrepreneurship before and after the 2002 policy reform (annual mean values), 1995-2008

5.9 Importance of main knowledge transfer channels, by universities and public research institutes, 1997-9

5.10 External funding and channels of commercialization as reported by researchers in 2008

5.11 Key characteristics of the three case study universities

6.1 Public R\&D expenditure and number of Korean public research institutes and universities, 2000-14

6.2 Number of domestic patent applications by public research institutes and universities 2000-15

6.3 Output of R\&D activities by Korean public research institutes and universities - new technologies and knowledge transfer, 2007-14

6.4 Output of R\&D activities by Korean public research institutes and universities - license income, 2007-14

6.5 University knowledge transfer contracts by industry, 2011-13

6.6 Firms reporting universities or research institutes as sources of innovation information, 2011-13

6.7 Primary types of cooperation with public research organizations among surveyed firms

6.8 Knowledge transfer contracts and share of different types of knowledge transfer, 2007-14

6.9 Laboratory companies - sales and employment, 2009-15

7.1 Main policies and instruments for S\&T funding in Brazil in $2012 \quad 274$

7.2 Number of research infrastructures in Brazil by launch period 275

7.3 Number of universities, research universities, and federal technological institutions in Brazil in 2015

7.4 R\&D investment by the main public universities in Brazil in $2012 \quad 278$

7.5 Budget or revenues of the main public research institutes in Brazil in 2014

7.6 Number of patents filed by Brazilian universities and research institutions at the National Institute of Industrial Property, 2000-12

7.7 Firms that innovated using a cooperation agreement with a university or public research institute in 2014

7.8 Knowledge transfer contracts undertaken by Brazilian public research institutes and public universities by type of contract in 2014

8.1 Number of SCI-indexed papers by different organizations in China, 2003-17 
8.2 Share of transaction value of knowledge transfer contracts by seller types, 2009-16 (\%)

8.3 Patent applications, grants, and transfers by 1,497 universities in 2015

8.4 R\&D and licensing modes of universities and public research institutes (\%)

8.5 Patent exploitation rates in 2014 (\%)

8.6 Patent sales (assignments) rates in 2014 (\%) 319

8.7 Patent licensing rates in 2014 (\%)

9.1 R\&D expenditure of leading universities, public research institutes, and state-owned enterprises, 2013-14

9.2 Innovation outputs in 2015

9.3 Share of innovative firms rating sources of information for innovation as "highly important"

9.4 R\&D expenditure and knowledge transfer metrics for four leading universities in 2014

9.5 Metrics of the knowledge transfer activities of South African universities and public research institutes, fiscal year 2013-14

10.1 Policies to support knowledge transfer for differing capabilities of public research organizations and firms

11.1 Convergence of knowledge transfer policies

11.2 Differences between the national systems of innovation of six high- and middle-income countries

11.3 Differences in range of supporting policies

12.1 Data collected for IP-mediated knowledge transfer plus research agreements at the institutional level (results for six countries)

12.2 Data collected for IP policies at the national $(\checkmark)$ or institutional $(\checkmark \checkmark)$ level (results for six countries)

12.3 Metrics at the institutional level for policies and practices to support knowledge transfer

12.4 Data collected in previous surveys of academic engagement

12.5 Knowledge transfer metrics from surveys of academics and firms 


\section{CONTRIBUTORS}

ANTHONY ARUNDEL obtained a bachelor's degree from Simon Fraser University in Canada and a master's in the economics of innovation from Maastricht University in Maastricht, the Netherlands. He is concurrently a Professorial Fellow at UNU-MERIT and an adjunct professor at the University of Tasmania in Australia. He has published extensively on business and public sector innovation. His research interests cover innovation measurement, knowledge transfer, innovation methods and strategies, and environmental innovation.

Suma ATHREYe is Professor of Technology Strategy at Essex Business School. She has worked on several areas of technology management, including research on the technology-related activities of multinational enterprises, as well as the technology licensing behavior of firms. Her recent work has been on patent use by firms and she has studied the incentive effect of patents on firm profits and $R \& D$, the role of technology leadership in encouraging patenting in open innovation contexts, and, more recently, on the barriers to the use of formal protection methods among UK firms.

G I A N C A R L O C A R A T T I is Head of Intellectual Property and Technology Transfer at the European Commission (EC), managing its intellectual property and promoting knowledge transfer. In 2015, he was deputy commissioner general for the EU participation in the World Expo Milano. He worked in the universities of Florence and Pisa as teaching and research assistant in mechanical engineering. He spent one year as visiting scholar at the Georgia Institute of Technology and worked in a private engineering firm before entering the EC in 1986.

в A OMIng CHEN, Director, Comprehensive Development Institute (CDI), Chinese Academy of Science and Technology for Development (CASTED), Ministry of Science and Technology (MOST), Beijing, China. Baoming Chen obtained a $\mathrm{PhD}$ in economics from Renmin University in 
Beijing, China. His research interests lie in S\&T development strategy and policies. He is a core member of revising the law on promoting the transformation of S\&T achievements. He leads many research projects on knowledge transfer, S\&T development planning, international S\&T cooperation, and other S\&T policies.

DIRK CZARNITZKI is a full professor at the Department of Management, Strategy and Innovation at KU Leuven in Belgium. He holds a doctoral degree in economics from the University of DuisburgEssen, and he has been a research fellow at the Centre for European Economic Research (ZEW), Mannheim, Germany, as well as post-doc at UC Berkeley before he joined KU Leuven in 2005. His research interests are mainly in the fields of the economics of innovation and applied micro-econometrics. The lines of research address topics such as the evaluation of public innovation policies, the economics of science, intellectual property rights, corporate governance and innovation, as well as knowledge and technology transfer including academic entrepreneurship. Dirk has published more than sixty articles in international, refereed journals including the Journal of Economics and Business Statistics, the Review of Economics and Statistics, Management Science, the European Economic Review, Journal of Applied Econometrics, Research Policy, and many others.

Minglei Ding, Senior Research Fellow, CDI, CASTED, MOST, Beijing, China. Minglei Ding obtained a $\mathrm{PhD}$ in management science and engineering from Hebei University of Technology and holds postdoctoral certificates on applied economics in NanKai University. His research interests include S\&T innovation policies and strategy, regional and industrial economics, innovation, and entrepreneurial management. He engages in a number of research projects on national and regional S\&T, innovation policy, strategy, and planning. In recent years, he has been a core member of research projects for the Chinese thirteenth five-year STI planning and the law on promoting the transformation of S\&T achievements.

NORDINE ES-SADKI joined UNU-MERIT as a researcher in January 2011. He obtained his bachelor's degree in economics from Maastricht University in 2009. In 2010, he obtained his master's degree in economics from the Erasmus University in Rotterdam with distinction. He is pursuing a $\mathrm{PhD}$ on the topic of knowledge flows from public research to firms. His research interests include knowledge transfer, intellectual 
property rights, the measurement of science, technology and innovation, questionnaire design, surveys and their methodology, and the economics of regional innovation. He also works part-time as an economics teacher at a lyceum in Maastricht.

K E R R Y FA U L, Head, National Intellectual Property Management Office (NIPMO), Ministry of Science and Technology, Pretoria, South Africa. Kerry Faul completed a bachelor of science degree at the University of KwaZulu-Natal (formerly University of Natal (Pietermaritzburg)) in 1994, majoring in chemistry and biochemistry before going on to do a honors degree and thereafter a master of science degree in biochemistry. After a two-year stint of working in London and traveling extensively, she returned to complete a doctor of philosophy in biotechnology through the Institute of Wine Biotechnology at Stellenbosch University. From 2007 to 2011, Kerry was employed by Spoor \& Fisher during which time she completed her legum baccalaureus and patent examination boards and was subsequently registered as a South African patent attorney, and admitted as an attorney of the High Court of South Africa. In December 2013, Kerry Faul was appointed as the Head of NIPMO responsible for ensuring implementation of the Intellectual Property Rights from Publicly Financed Research and Development Act (No. 51 of 2008).

BRUNO LE FEUVRE is senior statistical analyst at Department for Economics and Data Analytics of the World Intellectual Property Organization (WIPO), a specialized agency of the United Nations based in Geneva, Switzerland. He holds a master of advanced studies in public administration and in information system management from the University of Lyon II, France. In 2001, he was hired by WIPO as an examiner at the International Bureau of the Patent Cooperation Treaty (PCT), and joined the statistics section in 2005 where he specialized in patent and PCT statistics.

PIPPA HALL, Director of Innovation and Chief Economist, UK Intellectual Property Office. Pippa Hall obtained a bachelor of science degree in economics at the University of Sheffield, United Kingdom. She also holds a masters in financial and industrial economics from Royal Holloway, University of London, United Kingdom. Her role is to ensure that the UK IPO's policy development activity focuses on key issues and is based on a robust evidence base. She is also responsible for developing strategies and policies to engage business and raise awareness of the importance of intellectual property rights. 
intAN HAMDAN-LIVRAMENTO, economist, Department for Economics and Data Analytics, World Intellectual Property Organization (WIPO), Geneva, Switzerland. Intan Hamdan-Livramento is an economist with experience in international trade law. She obtained her doctoral degree in economics from the École Polytechnique Fédérale de Lausanne (EPFL), France, and holds a master's in international law and economics from the World Trade Institute in Bern, Switzerland. She currently works in WIPO's chief economist division, working on issues at the intersection of the industrial organization and intellectual property rights. She was one of the four co-authors of the World Intellectual Property Report, one of WIPO's main economic publications since its inception in 2011. Intan previously worked at the World Trade Organization and the International Monetary Fund.

CAN HUANG, professor, head of Department of Innovation, Entrepreneurship and Strategy, and co-director of Institute for Intellectual Property Management at School of Management, Zhejiang University, Hangzhou, China. Can Huang holds a $\mathrm{PhD}$ in industrial management from the University of Aveiro, Portugal, an MSc in engineering and a BA in economics from Renmin University of China, Beijing, China. He is a senior editor of Management and Organization Review and a member of the editorial boards of the Journal of International Business Policy, Science and Public Policy, NTUT Journal of Intellectual Property Law and Management, African Journal of Science, Technology, Innovation and Development, International Journal of Innovation Studies, Science and Management (Ke Xue Yu Guan Li), and the UNESCO Science Report (2015 ed.). His research interests include innovation and intellectual property management and science and technology policy analysis.

N IN G H UA N G, research fellow, CDI, CASTED, MOST, Beijing, China. Ning Huang obtained a bachelor of science degree from Shandong University and a doctor of economics degree from the University of International Business and Economics in China. He also holds postdoctoral certificates of applied economics from CASTED and Nankai University in China. He used to be a visiting scholar at the G20 Research Centre of the University of Toronto in Canada. His research focuses mainly on S\&T strategy, innovation policies, and international economic and trade rules. 
MICHAEL KAHN, advisor, and extraordinary professor, CREST and DST/NRF Centre of Excellence in Scientometrics and Science Policy, Stellenbosch University, Stellenbosch, South Africa. Michael Kahn obtained a $\mathrm{PhD}$ in theoretical physics from Imperial College, London, and a master's degree in education policy, planning and management from the University of London. His undergraduate degree is a BSc (hons) from the University of Cape Town. He works internationally as an advisor on R\&D and innovation policy, strategy, planning, measurement and evaluation, and is principal investigator for the project on the Mobility of the Highly Skilled. He has authored 100 peer-reviewed journal articles, chapters in books, and books. He has served on the boards of a number of statutory bodies and NGO trusts.

KEUN LEE is a professor of economics at Seoul National University, and founding director of the Center for Economic Catch-up. He is an editor of Research Policy, an associate editor of Industrial and Corporate Change, and, since 2016, a council member of the World Economic Forum. He served as the president of the International Schumpeter Society (2016-2018), and as a member of the Committee for Development Policy of the UN (2014-2018), and was the winner of the 2014 Schumpeter Prize for his monograph on Schumpeterian Analysis of Economic Catch-Up (2013, Cambridge University Press). He obtained his $\mathrm{PhD}$ in economics from the University of California, Berkeley. One of his most cited articles is a paper on Korea's technological catch-up published in Research Policy, with 1,081 citations (Google Scholar). His H-index is now thirty-seven, with ninety-five papers with more than ten citations. His latest book, The Art of Economic Catch-Up: Barriers, Detours and Leapfrogging in Innovation Systems, was published by Cambridge University Press in 2019.

GEORG LICHT is Head of the research department of Economics of Innovation and Industrial Dynamics at the Centre for European Economic Research (ZEW), in Mannheim, Germany. He has held this position since June 1994. He gained his doctoral degree at the University of Augsburg and holds a degree in economics from the University of Heidelberg. Research interests include the economics of innovation and technical change as well as the economics of small firms and entrepreneurship. He was engaged for some years in the development of the Community Innovation Survey (CIS) and innovation surveys in Germany in manufacturing and service industries. He is consultant to the OECD, the EU Commission and the German Federal Ministry of 
Education and Research in the area of innovation and technology policy. He has been a member of several expert panels in science and innovation policy.

FERNANDA MAGALH ÃES, specialist in public policies and government management, Brazilian Federal Government. She has worked on several areas of public policy, including technological innovation, sustainable development, and international trade. Her previous work was on fostering knowledge transfer from academia and research institutes to the private sector, and she is currently working on environmental issues, biotechnology and nontariff barriers to trade.

PHILIPPE KUHUTAMA MAWOKo, a Congolese national (Democratic Republic of Congo (DRC)), Philippe Kuhutama Mawoko is the interim director of the African Union Observatory for Science, Technology, and Innovation (AOSTI) based in Malabo, the Republic of Equatorial Guinea. He joined the Commission of the African Union in 2011 to help set up AOSTI. He is presently teaching mathematics and statistics at the newly created University of Kwango in DRC. Dr. Mawoko currently serves on the advisory board of the United Nations University Maastricht Economic and Social Research Institute on Innovation and Technology (UNU-MERIT). He is also a member of the advisory board of the Global Innovation Index. Prior to joining AOSTI, he coordinated the African Science, Technology \& Innovation Indicators Initiative (ASTII) and the African Mathematical Institutes Network for the Office of Science and Technology (OST) of the NEPAD Planning \& Coordinating Agency. Before that, he worked as the program manager for the NEPAD eAfrica Commission. Former minister of post and telecommunications in the DRC, Dr. Mawoko led the initial policy reform in the sector. He also served as senior consultant, forecasting new telecommunication products and services in the marketing division of Telkom South Africa. He worked as a senior consultant at NedCoBank in South Africa. In the 1990s, he took a lectureship at the University of Zimbabwe in Harare and at the National University of Lesotho in Roma. He holds a PhD in mathematics from the University of Salzburg in Austria (1988).

fabio montoввio is Associate Professor of economics at the Department of Economic Policy, Università Cattolica del Sacro Cuore in Milan, Italy, contract professor at Bocconi University and visiting fellow at iCRIOS (Bocconi University) and BRICK at the Collegio 
Carlo Alberto, Turin, Italy. Fabio Montobbio's research interests include the economics of innovation, the economics of patents, university knowledge transfer, the new economics of science and technology, and development. His teaching activities include industrial economics, economics of innovation, and intellectual property rights. He has several publications in international journals, including the Scandinavian Journal of Economics, Industrial and Corporate Change, World Development, Research Policy, and the Journal of Economic Behavior and Organization.

FERNANDA DE NEGRI is a research leader at the Institute for Applied Economic Research (Ipea). She holds a PhD in economics from the University of Campinas (UNICAMP) and was visiting researcher at the Massachusetts Institute of Technology in 2015 and 2017 and at Harvard University in 2017. She has always been interested in the effects of science and new technologies on the economy, business competitiveness, and productivity. In the public sector, she held positions related to public policies for productivity and science and technology: she was economic advisor to the Minister of Development, Industry and Foreign Trade (2008) and head of the Monitoring and Evaluation Office of the Ministry of Science and Technology (2010-2012). She was also director (20122017) and deputy director (2009-2010) of Ipea. She is the author of several articles and books and received the BNDES economics award for her dissertation on the commercial performance of foreign companies in Brazil. In 2014, the book she organized on Productivity in Brazil was a finalist in one of the most prestigious literature prizes in the country: the Jabuti Prize.

CHUNYAN PENG, senior research fellow, CDI, CASTED, MOST, Beijing, China. Chunyan Peng obtained a bachelor of economics from Shandong University of Finance and Economics in Jinan and a master's and a doctorate of economics from Renmin University of China. She has contributed to several working papers on Chinese innovation strategy, the law on promoting the transformation of S\&T achievements, and Chinese technology transfer policies. She has authored and co-authored several papers and books on innovation.

Amit SHOVON RAY is Professor of economics at the Centre for International Trade and Development of the School of International Studies in Jawaharlal Nehru University, New Delhi. He was educated at Presidency College, Calcutta, and at the University of Oxford from where 
he received his DPhil in economics in 1988. Professor Ray is a development economist and his primary research areas include the economics of technology and intellectual property rights, the economics of health, the pharmaceutical industry, WTO-TRIPS, foreign direct investment, and a wide range of policy issues pertaining to India's development experience. He has over seventy-five research publications including six books and short monographs plus several articles in reputed international journals and edited volumes. Professor Ray has held teaching and research positions at premier universities and institutions in India and abroad, including Oxford University Institute of Economics and Statistics, International Food Policy Research Institute, Washington, DC, Jawaharlal Nehru University, New Delhi, University of Calcutta (Kolkata), Indian Institute of Technology, New Delhi. He has also served as director of the Centre for Development Studies in Trivandrum. He has been a consultant to various national and international bodies, including the Planning Commission (Government of India), the World Bank, and UNCTAD.

RAGAN ROBERTSON, technology transfer officer, University of California, Los Angeles and AUTM cabinet member, Metrics and Surveys, United States of America (U.S.). Ragan Robertson obtained a $\mathrm{PhD}$ in biological sciences from Columbia University in New York City. He has been actively involved in knowledge transfer for over ten years, focusing on patent protection, technology development, marketing, startups, and licensing within the life science space. He is the lead editor of the AUTM US Licensing Activity Survey, an analytical report of the patenting, licensing, and startup activities performed by US university and research institution technology transfer offices. He has also authored five peer-reviewed scientific publications.

FEDERICA ROSSI, senior lecturer, Department of Management, Birkbeck, University of London, United Kingdom. Dr. Federica Rossi holds a PhD and MSc in economics (University of Turin, Italy) and a BSc in political economy (University of Modena and Reggio Emilia, Italy). She is an expert in the economics of innovation, including innovation and higher education policy. She has published extensively in peerreviewed journals on innovation policy evaluation, university-industry collaboration networks, universities' knowledge transfer management, and performance evaluation.

B HAVEN SAMPAT is an associate professor in the Department of Health Policy and Management at Columbia University and a research associate 
at the National Bureau of Economic Research. Most of his research focuses on issues at the intersection of health policy and innovation policy. His current work includes (1) various empirical studies of drug and life science patent policy in the U.S. and developing countries; (2) evaluating the validity of different approaches to measure science, innovation and science-technology linkages; (3) examining whether and when science is self-correcting; and (4) assessing the impact of federal indirect cost recovery policy on the biomedical research enterprise. His previous work includes research on the political economy of the national institutes of health, patent examination and patent quality, and the roles of academic patenting in university-industry knowledge transfer. His has written numerous articles and a book on the effects of the US Bayh-Dole Act on academic patenting and knowledge transfer.

Hochul Shin, researcher, Center for Distributive Justice, Seoul National University, Republic of Korea. Hochul Shin obtained a PhD in economics from Seoul National University in Republic of Korea. His research area includes innovation, trade, institution, growth, and inequality. He has published several papers about trade, industrial policy, finance, and inequality in peer-reviewed journals.

SI KYONG SUNG, deputy director, Intellectual Property Utilization Division, Korean Intellectual Property Office (KIPO), Daejeon, Republic of Korea. Si Kyong Sung obtained a bachelor of mechanical engineering and a master of mechanical engineering from Korea Advanced Institute of Science and Technology (KAIST) in Daejeon, Republic of Korea. He was a senior research engineer in LG Electronics and co-invented several system air-conditioners.

H.J.M. ( HENRI) THEUN IS SEN, chief valorization officer of Maastricht University and the Brightlands Maastricht Health Campus and CEO of Knowledge Transfer Funds BV. Henri graduated in biology (Radboud University Nijmegen), holds a $\mathrm{PhD}$ in molecular biology (NKI, University of Amsterdam), and was a post-doc in immunohematology (Central Lab of Blood Transfusion, Amsterdam). He worked at Organon International (later Schering-Plough and Merck) in the cardiovascular and reproductive medicine programs and as head of the genomics \& bioinformatics group. As an expat in Cambridge, Massachusetts, U.S., he focused on biotechnology, immunology, and oncology as a senior director, Global Strategy, Portfolio Management and Research 
Alliances, and as vice president and officer of Diosynth RTP, North Carolina, U.S. He was also an MT member of Nobilon BV (Boxmeer) for business development and strategic marketing of human vaccines.

ANTENOR CESAR VANDERLEI CORREA, science and technology senior analyst, Ministry of Science, Technology, Innovations and Communications, Brazilian Federal Government. Antenor Cesar Vanderlei Corrêa has worked for the Ministry of Science, Technology, Innovations, and Communications (MCTIC) since 1985, where he has held various positions in sectors related to industrial, scientific, and technological policy, especially in the area of information and communication technology. He holds a bachelor's degree in engineering from the University of Brasilia, Brazil, and a master's degree in manufacturing systems engineering from the University of Warwick, United Kingdom.

LIEN VERBAUWHEDE KOGLIN, counsellor, IP Policies for Universities, Small and Medium-sized Enterprises and Entrepreneurship Support Division, World Intellectual Property Organization (WIPO). Lien Verbauwhede Koglin obtained a bachelor of law from the Catholic University of Leuven (KUL), Belgium, and the University of Granada, Spain. She also holds a master of law from the Wilhelms-University of Münster, Germany. She has co-authored a series of WIPO publications on IP for businesses and is the main author of the WIPO IP Policy Template for Academic and Research Institutions. She currently spearheads WIPO's activities to assist universities and research institutions in designing and implementing IP policies, and facilitating academic knowledge transfer and commercialization. Before joining WIPO, she was an IP lawyer at Linklaters, Brussels, and Lalive \& Partners, Geneva.

BART VERSPAGEN is the director of UNU-MERIT and the chair of international economics, Economics Department of Maastricht University, the Netherlands. Bart is an economist specialized in the economics of innovation, growth, and development. He did his undergraduate studies at the University of Limburg (now called Maastricht University) in Maastricht from 1984 to 1988. He obtained a $\mathrm{PhD}$ from the same university in 1992. During the subsequent five years, he held a scholarship from the Royal Netherlands Academy of Arts and Sciences (KNAW). In 1998, he became a professor at Eindhoven University of Technology. In 2008, he moved back to Maastricht University, where he became a professor of international economics. In 
2012, he became director of UNU-MERIT. Verspagen's research interests are centered on the process of economic growth and development, especially its relation to innovation and technological change. His research field also covers areas such as international trade, development economics, industrial dynamics, economic history, and applied econometrics, statistics, and mathematical modeling. With regard to the last, he has mainly been applying evolutionary models to economic issues.

CRISTIANE VIANNA RAUEN is general coordinator of professional education at the Brazilian Ministry of Education. She holds a PhD in economics from the University of Campinas (UNICAMP) and was visiting doctoral researcher at Columbia University in 2011. Throughout her career, Cristiane has specialized in topics associated with science, technology and innovation, performing research, teaching, consulting, and public policy formulation activities. She has been a Brazilian civil servant since 2011, holding positions in different organizations, such as the National Institute of Metrology, Quality, and Technology (Inmetro, 2011-2013), where she served as leader of the technology project incubator; Ministry of Science, Technology, and Innovation (MCTI, 2013-2019), where she held the position of advisor to the executive-secretary; Brazilian Institute of Information in Science and Technology (IBICT, 2015-2017), where she worked as a researcher; Institute for Applied Economic Research (Ipea, 2015-2018), where she served as visiting researcher; and, currently, is with the Ministry of Education.

ROSEMARY W OLS ON has a bachelor of sciences (hons) in microbiology, a bachelor of law (LLB) and a master of philosophy (MPhil), all from the University of Cape Town. She chairs a committee of the Association of University Technology Managers (AUTM) which awards scholarships to new entrants to the profession from developing economies and is a member of the Public Interest Intellectual Property Advisors Advisory Board. She has previously served on the National Intellectual Property Management Office Advisory Board; the Southern African Research \& Innovation Management Association Committee; the NEPAD-Southern Africa Network for Biosciences Working Group on Intellectual Property, Indigenous Knowledge and Benefit-Sharing Guidelines; the steering committee for Tilburg University, the Netherlands, Intellectual Property Rights and Development Project and as a lead analyst for the Global Energy Assessment Knowledge Module on Policies for Capacity 
Development. She is passionate about innovation and its potential to change lives for the better.

SACHA WUNSCH-VINCENT is Head of section in the Department for Economics and Data Analytics at the World Intellectual Property Organization (WIPO) and co-editor of the Global Innovation Index. He joined WIPO in 2010 to help set up WIPO's economics work under the chief economist, including the World Intellectual Property Report. Before joining WIPO, he was an economist at the OECD Directorate for Science, Technology, and Industry for seven years. Before that, he was Swiss national science fellow at the Berkeley Center for Law and Technology (University of California, Berkeley, U.S.) and the Peterson Institute for International Economics (Washington, DC). Sacha holds a master in international economics from the University of Maastricht with a master's thesis at MERIT and a $\mathrm{PhD}$ in economics from the University of St. Gallen, Switzerland. He teaches international economics at Sciences Po Paris, and the World Trade Institute in Bern.

LIU XIA graduated from Shanghai University of Finance and Economics, after which she gained her doctorate in quantitative economics in the European Center for Advanced Research in Economics and Statistics (ECARES) from Université de Bruxelles. She has worked as an academic visitor in the Center for Law and Economics at ETH Zurich and as a post-doctorate researcher in the School of Management, Zhejiang University, China. Her research fields include innovation policy, IP management, and applied micro-econometrics. She currently belongs to the Shanghai International College of Intellectual Property, Tongji University, China.

JUAN YANG, research fellow, CDI, CASTED, MOST, Beijing, China. Juan Yang obtained a bachelor of economics from Central China Normal University and got her master of economics from Zhongnan University of Economics and Law, Wuhan, China. She also holds a doctorate degree in economics from the Renmin University of China. She used to be a visiting scholar in Boston University and a clinical researcher for the Shriners Hospitals for Children based in Boston, and also a fellow of WIPO in Geneva, Switzerland. She contributes to some joined research projects on China's foreign direct investment and IP performance evaluation. She is a core member of research projects on China's S\&T open innovation strategy and policies. 
HU ZHIJIAN is president of the Chinese Academy of Science and Technology for Development (CASTED). He joined CASTED as a general secretary in 2009 to build CASTED into a national S\&T strategic think tank. Before joining CASTED, he served as deputy director general, in the Department of Policy, Regulations and Reform of the China's Ministry of Science and Technology. His book National Innovation System: Theoretical Analysis and International Comparison was published by China's Social Sciences Academic Press. He holds a $\mathrm{PhD}$ in innovation and management from the Chinese Academy of Sciences. He also functions as secretary general of the China Federation of Scientific and Technological Institutes, vice chairman of the China Law Association on Science and Technology, and governing board member of the World Economic Forum.

нао zноu, Director of Statistics, Statistics and Data Analytics, Department for Economics and Data Analytics, WIPO. Hao Zhou obtained a bachelor of science in physics from Peking University. $\mathrm{He}$ worked in the Chinese Patent Office as patent examiner and IPC coordinator, then for WIPO as PCT examination coordinator, IT business analyst and senior statistical analyst. $\mathrm{He}$ is in charge of statistical data for WIPO publications. 


\title{
FOREWORD
}

\author{
HU ZHIJIAN
}

President, Chinese Academy of Science and Technology for Development

Promoting public-private partnership knowledge transfer is one of common notice among countries at different economic development levels. A vital question for policymakers today is how to improve the efficiency of these knowledge transfer practices, maximizing innovation-driven growth.

No unique knowledge transfer blueprint is recognized as time-tested and universally optimal. The Chinese government has been continuously highlighting and facilitating the transformation of scientific and technological achievements into real productive forces. The Chinese knowledge transfer law, Promoting the Transformation of Scientific and Technological Achievements, entered into force on October 1, 1996. An amendment to the law was adopted at the meeting of Standing Committee of the Twelfth National People's Congress on August 29, 2015 , and came into force on October 1,2015. The modification mainly includes: refining the science and technology performance assessment system, improving the scientific and technological achievements disposal and distribution right systems, perfecting the market pricing mechanism of scientific and technological achievements, strengthening the awards for main scientific and technological contributors, and so on. Meanwhile, lots of high- and middle-income countries have been developing their national law and policies for spurring on the commercialization of publicly funded inventions. Unfortunately, it is not straightforward for policymakers to access information on what works and what does not. Initial evidence indeed suggests that different approaches are needed for different stages of economic development and even for specific sectors. Nevertheless, these experiences and lessons need refining to be used by political makers.

With this in mind, in 2015, under the auspices of the World Intellectual Property Organization (WIPO) and most of China, a joint research project on knowledge transfer policies and practices was 
initiated with the support of some countries. Two such academic and policy workshops were held with authors and experts in July 2016 and March 2017 to validate the research focus and unify methodologies. We have compiled the main research results into this book.

The main contribution of this book is twofold: To start with, the book develops a conceptual framework to evaluate knowledge transfer practice and outcomes. It provides a six-country study in the same conceptual framework, three middle- and three high-income countries, and also puts forward a standardized set of metrics for assessing national or institutional performance relevant to both high- and middle-income countries' development. With all these efforts, it is possible to do an international comparison at different income levels. The country cases will reveal a wide range of approaches and a variety of tools for policymakers, professional associations, IP offices, and scholars.

I would like to take this opportunity to express my sincere gratitude to the editors and authors for their great contribution to this book. The research represents a major step toward reaching a systematic approach to the measurement of knowledge transfer practice and outcomes. It lays important groundwork for future empirical work, for the development of appropriate metrics, and for crafting new innovation policy approaches. I look forward to the WIPO contributing further valuable works on innovation, intellectual property, and economic development to better benefit its member states at large. 


\title{
FOREWORD
}

\author{
P I P P A H A L L
}

\begin{abstract}
Director of Innovation and Chief Economist, Intellectual Property Office, United Kingdom
\end{abstract}

Knowledge transfer has received considerable attention over the past few decades, and is recognized as playing a key role in a competitive knowledge-based economy. Enabling access to excellent, cutting-edge research is vital to tackling the economic, social, and environmental challenges countries face. Through knowledge transfer, public research organizations can maximize the impact of their research, delivering tangible realworld benefits. For individual businesses, it can enable them to improve performance, increase productivity and gain access to new resources and world-leading expertise. And at a national level, knowledge transfer drives economic growth and delivers social benefits. Internationally, there have been achievements in building partnerships and relationships between businesses, research organizations, and government bodies, to deliver real value. However, challenges remain, not least that of assessing the impacts of knowledge transfer initiatives in order to understand how to improve policies and practices.

This is easier said than done. How do you go about trying to evaluate these impacts? Most data collection, if any, occurs at a national level and there is no standardization of what data are collected. There also needs to be a clear understanding of how the different approaches and different channels of knowledge transfer work, such as the interplay between more open sciencetype approaches with the formal licensing and collaborative agreements.

This book aims to address these gaps. Its contributors are experts in their fields and provide an international perspective on the different approaches to knowledge transfer. It develops a conceptual framework to enable the evaluation of different knowledge transfer policies and practices, with a standardized set of metrics for assessing national or institutional performance. It also makes a valuable contribution in developing a new methodology for how to measure and assess the global volume and distribution of patenting activities carried out by public 
research organizations. The development of a common evaluation framework on the possible costs, benefits, and impacts of knowledge transfer activities is an important step forward, providing a better evidence base on which policy decisions can be taken. By assessing the interaction of existing policies and the underlying innovation system structures, the book identifies what works best under different conditions and makes policy recommendations relevant for both high- and medium-income countries. For policymakers, it is vitally important to identify both what works and what does not work, and in what situations, in order to understand how to improve the efficiency of knowledge transfer activities in order to achieve maximum impact.

I welcome the contribution this book makes to the evaluation of knowledge transfer policies and practices, laying important groundwork for future study and the development of innovative policy approaches. 


\section{FOREWORD}

\section{B A R T VERSPAGEN}

Director, UNU-MERIT

Knowledge produced or built on by public research organizations such as universities and public research institutes is a vital source of new technologies and organizational methods that can contribute to many of the United Nations' sustainable development goals, from improvements in food security and health and a reduction in carbon emissions to economic growth. To achieve social and economic benefits of value to these development goals, relevant knowledge needs to be successfully transferred from public research organizations to firms and government organizations that can use the knowledge to improve or create new services, goods or processes.

Knowledge transfer is a complex process that involves multiple actors and channels for transmitting knowledge. The six case studies in this book for three middle-income and three high-income countries illustrate how the design of policies to support knowledge transfer needs to take into consideration the absorptive capabilities of domestic firms, the research capabilities of universities and public research institutes, and the skills of knowledge transfer professionals. For middle-income countries, in particular, these capabilities and skills are in flux. The case studies show how policies and practices to support knowledge transfer need to both promote capabilities and skills and adapt to changing conditions.

The value of this book lies in its implications for policies and practices to support knowledge transfer and in its practical recommendations to collect a comprehensive set of metrics to ensure that all forms of knowledge transfer, both formal and informal, are placed in perspective. The problems associated with a narrow set of metrics focused on patent licensing have been known for some time. This book provides evidence for why a broader set of metrics, covering contractual, consulting, and informal channels, is important to prevent undue emphasis on some forms of knowledge transfer over others. 
UNU-MERIT has been pleased to support some of the work behind this book, both through the contributions of Anthony Arundel and by hosting a workshop in Maastricht in March 2017 to discuss the conceptual framework provided in Chapter 2 and the six case studies in Chapters 4 to 9. The results should be of value both to future research on knowledge transfer and to the design of policies and practices that are adapted to specific conditions within countries and within individual universities or research institutes. 


\section{PREFACE}

Universities and public research institutes play a key role in enabling the application of scientific breakthroughs and innovations in the marketplace or by government organizations. Their present and potential future contribution to the production and application of knowledge to innovation is undeniable.

To further leverage this role, many countries - developed and developing alike - have implemented national strategies to support the application or commercialization of knowledge produced by public research organizations. In addition, individual universities and public research institutes have introduced practices to support these activities, for instance, by including knowledge transfer to promote innovation as a core part of their mission.

As a result, a vital question for policymakers - and the enquiry of this book - is how to improve the efficiency of these knowledge transfer practices to help maximize innovation-driven growth and/or to seek practical solutions to critical societal challenges.

Unfortunately, it is not straightforward for policymakers or knowledge transfer practitioners to access information on what works and what does not. Countries and institutions have garnered substantial experience with diverse approaches. Yet this information has not been distilled in a way that can provide policy guidance for specific sectors or for countries at varying levels of economic development.

With this in mind, the book pursued the following three objectives:

- to develop a conceptual framework to evaluate knowledge transfer practices and outcomes

- to improve knowledge transfer metrics, surveys, and evaluation frameworks, resulting in a standardized method to assess national or institutional strategies in an internationally comparable way

- to generate findings on what works and what does not, and to propose related policy lessons. 
In pursuit of these objectives, we, as the editors of this book, laid particular emphasis on three important realities.

Number one: Public-private knowledge transfer occurs through a large number of formal channels, such as licensing intellectual property (IP), contract research, and contracting, as well as through informal channels, such as the sharing of research results via personal contacts or by "open science" methods, including conferences and publications. It is important to avoid casting these channels in a mutually exclusive way. Indeed, the many forms and facets of these two channels are often not in contradiction; they have fuzzy boundaries in many cases, and they can be complementary and mutually reinforcing.

Number two: Mirroring the above point, policy options are also more numerous and less binary than implied by commentaries that either focus single-mindedly on knowledge transfer policies based on IP as the only way forward or caution that the formalization of knowledge transfer - and, to some extent, the privatization of the application of knowledge - are serious threats to the functioning of a science system based on the free flow of knowledge. In reality, institutions and countries do not have to choose between these two opposites or two radically distinct policy options. Many nuanced policy approaches are possible.

Number three: No country or institution has yet to uncover the ultimate law or tool that provides a silver bullet for achieving effective knowledge transfer to potential users. Economies and institutions worldwide still have untapped potential to better harness the role of public research for innovation. Knowledge of possible relevance to critical topics such as food security, climate change, or health remains tied to books, journals, and the scientific realm without making sufficient impact on innovation and the realities around us. Much of this knowledge may not be being used for other reasons, for example, because the right regulatory systems are not in place or because multiple other complementary activities are needed before it can be put to use. But the potential is clearly there. This is a source of frustration but, first and foremost, also of important hope for the years to come as we get better at making public research more useful to economies and societies worldwide.

These three points are recurrent themes that underlie this book. They also make the topic of this book timely and particularly important.

Many institutions and individuals deserve thanks for their contributions. The main trigger for this book was a discussion and agreement in 2016 among the then minister of the Ministry of Science and Technology 
of the People's Republic of China (MOST), Wan Gang, and WIPO's director general, Francis Gurry, that more international work is needed in the field of knowledge transfer practices.

Under the minister of MOST, Wang Zhigang, this book's work with respect to China and a workshop were subsequently financially supported and coordinated by Lin Xin, DG, Zhang Jiejun, (Deputy Director General, DDG), Sun Yongjian (former DDG), and Zhang Bingqing (DDG), all from the Department of Policy, Regulation, and Innovation System within MOST.

For their steady support to this the project, we are also indebted to the Chinese Academy of Science and Technology for Development (CASTED) and its President Hu Zhijian. In particular, we thank Chen Baoming, DDG, and Juan Yang, who was supported by CASTED to work as a WIPO fellow for more than a year on this project, and the staff of the CASTED Institute of Comprehensive Development.

In addition, there are many individuals and other organizations to thank for their help with this book - too many to list. First and foremost, special thanks go to the outstanding authors of the country studies that accompanied this project for close to four years. It is rare to be able to work with such an outstanding cast of academics from Asia, Europe, and Latin America. This rollcall was complemented by notable experts from IP offices, by knowledge transfer practitioners, and by leading policymakers. Particular thanks to the South African National IP Management Office, the IP Office of the United Kingdom, and the Korean IP Office, as well as the Brazilian Ministry of Science, Technology, Innovations, and Communications. Rosa Fernandez at the Department for Business, Energy, \& Industrial Strategy, Adrian Day, Lorena Rivera León, and Antanina Garanasvili provided data and analysis for Chapter 1.

We would also like to thank all participants for their contributions to two associated workshops on the International Comparison of Knowledge Transfer Policies and Practices. The first was held with MOST and CASTED in Beijing, July 2016, and the second at the United Nations University, Maastricht Economic and Social Research Institute, on Innovation and Technology (UNU-MERIT) in March 2017.

This collaboration also showed that knowledge can flow in all directions. While high-income economies and their institutions have extensive experience with knowledge transfer policies and practices, many new experiences are emerging in middle-income economies such as Brazil, China, India, and others. These innovative experiences are a possible source of learning for all other countries. 
Thanks for substantive comments go to the editorial advisory board of this book series, Mark Wu, Megan Macgarvie, and Beth Webster, as well as the academic reviewers of this project, Fabio Montobbio and Bhaven Sampat, and also to Carsten Fink, WIPO's chief economist.

Excellent editing was provided by Tobias Boyd, then at WIPO. The project management support and oversight by Charlotte Beauchamp, Head of Publications and Design at WIPO is acknowledged with thanks.

We hope that this book will open a window to future work assessing the diversity of knowledge transfer policies and practices. Its purpose is to lay the groundwork for future empirical work, for the development of appropriate metrics, and for crafting new innovation policy approaches. Ideally, the survey and evaluation framework can also be deployed by WIPO or by other organizations to yield comparable data from multiple countries over time.

\section{Anthony Arundel, Suma Athreye, and Sacha Wunsch-Vincent} Maastricht, Southend-on-Sea, and Geneva 


\section{DISCLAIMER}

The views expressed herein are those of the authors and do not necessarily reflect the views of the World Intellectual Property Organization (WIPO) or its member states. 
Downloaded from https://www.cambridge.org/core. IP address: 86.30.88.132, on 14 Feb 2022 at 14:50:54, subject to the Cambridge Core terms of use, available at https://www.cambridge.org/core/terms. https://www.cambridge.org/core/product/979C0AAA92B1200DCE513DAAE4894BE7 


\section{P A R T I}

\section{Setting the Context}


Downloaded from https://www.cambridge.org/core. IP address: 86.30.88.132, on 14 Feb 2022 at 14:50:54, subject to the Cambridge Core terms of use, available at https://www.cambridge.org/core/terms. https://www.cambridge.org/core/product/979C0AAA92B1200DCE513DAAE4894BE7 


\section{The Evolving Role of Public R\&D and Public Research Organizations in Innovation}

SUMA ATHREYE AND SACHA W UNSCH-VINCENT

\subsection{The Growth in Policies to Leverage Public R\&D}

\subsubsection{Why Invest in Public R\&D?}

Science has consistently been shown to be a fundamental driver of technological progress and economic growth and a source of innovation to the business sector (Jaffe 1989; Adams 1990; Cohen et al. 2002). Its importance for economic progress has grown due to an increase in the role of knowledge as a driver of competitiveness in global markets and from emerging technologies that have opened up new opportunities for development. The increasingly science-based nature of modern technological advances has made interaction with science central to innovation. ${ }^{1}$ Universities and public research institutes are crucial to both the discovery of new technology and the training of students in new techniques and technological developments, with the attendant economic advantages.

Firms and other innovators depend on the contributions of public research and of future scientists to produce innovations of commercial significance (see Nelson 2004). Basic research in science also serves as a roadmap for firms, facilitating the identification of promising avenues for innovation and avoiding the duplication of effort by companies. Close interaction with public research enables firms to monitor scientific

\footnotetext{
Lorena Rivera León, WIPO, and Antanina Garanasvili, consultant to WIPO, provided data and analysis for this chapter. On some of these topics, see, also, WIPO (2011).

${ }^{1}$ See OECD (2017), Paunov et al. (2019), and Section 3.4 on technology-science linkages in OECD (2011). This inference is based on patents citing non-patent literature (forward and backward citations). Patents that rely on scientific knowledge are on the increase in highgrowth industries such as biotechnology, pharmaceuticals, and information and communication technologies (ICT).
} 
advances that could transform their technologies and markets. It also facilitates joint problem solving.

In light of the value of research to many firms rather than to one particular firm or entity, economists have traditionally seen knowledge produced by universities as a public good. Indeed, university knowledge has all the hallmarks of a public good - first, the economic value attached to certain kinds of basic and other research cannot be fully appropriated by the actor undertaking the research, not least because some of it may take several years to emerge. Second, the economic value of such knowledge is often difficult or impossible to judge ex ante. As a result, without subsidy, firms would tend to underinvest in the funding of research, in particular in fields that show little prospect of near-term profitability. To avoid this underinvestment in science and research, governments have funded universities to conduct teaching and basic research (the two traditional missions of the university). Scientists are thus able to pursue bluesky research without the pressure of immediate business considerations. The reward system is based on the scientist's publication and dissemination record, and not on considerations of any kind of private profitability or income.

In many countries, intermediate institutions, in the form of public sector institutions and laboratories, were also set up and funded by government, in order to conduct translational research that could directly benefit industry. Such public research institutes have been important in the history of many high-income countries (the United States of America (U.S.), the United Kingdom) and continue to be important in others (Germany and the Republic of Korea). Scholars such as Nelson, Freeman, and Lundvall see universities and public research institutes as playing a key role in shaping national innovation systems and in the growth and training of scientists more broadly. This is because the magnitude and direction of public research and development $(\mathrm{R} \& \mathrm{D})$ influences the broader innovation system through three mechanisms: providing human capital and training, advancing knowledge through public science, and through activities to transfer knowledge to economic actors. Recent experience with the software industry has shown that many middle-income countries whose universities only performed the teaching mission managed to accumulate human capital in excess of their developmental needs. These countries were also the most able to benefit from the sudden opening of global demand for software programmers (Arora and Gambardella 2005). 
Economic studies have examined the impact of public R\&D on business innovation. While imperfect, aggregate studies have found that academic research, and basic research in particular, has a positive effect on industrial innovation and industry productivity. Importantly, although public R\&D does not directly contribute to economic growth, it has an indirect effect via the stimulation of increased private $R \& D$. In other words, "crowding in" of private R\&D takes place as public $\mathrm{R} \& \mathrm{D}$ raises the returns on private $\mathrm{R} \& \mathrm{D}$.

Studies examining social rates of return to public $R \& D$ are more recent. Social returns to public $R \& D$ are often studied as the effect of public $\mathrm{R} \& \mathrm{D}$ on private sector productivity, and are estimated to have a (median) rate of 20 percent, which is smaller than the impact of private $\mathrm{R} \& \mathrm{D}$ on private sector productivity (estimated to be between 30 and 45 percent). Econometric studies at the firm and country level provide less conclusive results as to the positive impact of public R\&D on private productivity than estimates at the industry level. A more intriguing result in the UK context found that the rate of return of public council funding (i.e., grants to industry often in collaboration with university, distributed through research councils) had higher social rates of return than direct public sector R\&D, often two to three times the rate of return suggested by private $\mathrm{R} \& \mathrm{D}$.

To some extent, the public good argument for public sector R\&D does suggest that we will find such results. To recall, in the case of most public goods, private rates of return are expected to diverge from social rates of return. Public sector investments in R\&D are in basic R\&D that takes more than seven years to translate into commercial products and needs more private investment in $\mathrm{R} \& \mathrm{D}$ to be fully absorbed in industry. In contrast, private $\mathrm{R} \& \mathrm{D}$ has a gestation lag of about three years, is in applied areas that are less technologically risky, and is oriented toward readily available (or creatable) markets.

Several empirical issues also contribute to the observed result that public $R \& D$ does not show a strong direct impact on business innovation and economic growth. Given the many channels of knowledge transfer from public science, estimating all of the economic effects of public $R \& D$ is challenging. Transactions rarely leave a visible trace that can be readily identified and measured. Second, the contribution of public $R \& D$ can also take a long time to materialize and this time lag can differ by sectors of activity. Finally, the noneconomic impact of public research in areas such as health, and others, is even harder to identify. 


\subsubsection{The New Rationale for Public Support of "Third Mission" Policies at Universities}

Public R\&D suffers from a key limitation when compared to private R\&D. When firms undertake R\&D they usually have an idea of the type of knowledge they need to produce and a commercialization strategy that is directly attached to their R\&D expenditure plans. This rarely happens with public sector R\&D, with the people undertaking $R \& D$ working in a separate organization from the potential users of the knowledge. Consequently, there is always a scope for discoveries, even those with commercial potential, to fail to be commercialized. ${ }^{2}$ In other words, public research may produce a lot of inventions, but no significant innovations. It has also led to accusations that academic research lives in an ivory tower, divorced and disengaged from the real world and its problems.

Since the late 1970s, many countries have changed their legislation and created support mechanisms to encourage interactions between universities and firms, including through knowledge transfer (see Van Looy et al. 2011). Placing the output of publicly funded research in the public domain is no longer seen as sufficient to generate the full benefits of the research for innovation (see OECD 2003; Wright et al. 2007). In high-income countries, policy approaches promoting increased commercialization of the results of public research have included reforming higher education systems to include third mission activities creating clusters, incubators, and science parks; promoting university-industry collaboration; instituting specific laws and institutions to regulate knowledge transfer; and encouraging public research organizations to file for and commercialize their IP. The transformation of research organizations into more entrepreneurial organizations is also taking place by increasing the quality of public research, creating new incentives and performance-linked criteria for researchers, enhancing collaboration of universities and public research institutes with firms, and setting up mechanisms for formal knowledge transfer (see Zuñiga 2011).

Contrary to popular perception, it was not the U.S. but Israel that was the first country to implement IP policies for several of its universities in the 1960s. However, in 1980 the US Bayh-Dole Act was the first dedicated legal framework to institutionalize the transfer of exclusive control over federal government-funded inventions developed by universities and businesses. The shift and clarification of ownership over these inventions lowered transaction costs as permission was no longer needed from federal

2 It is also worth noting that there is a long history of mission-oriented R\&D in the public sector that has produced commercially viable products. 
funding agencies, and because this gave greater clarity to ownership rights and therefore greater security to downstream - sometimes exclusive licensees. For instance, the Act also contains rules for invention disclosure and requires institutions to provide incentives for researchers. It also contains march-in provisions reserving the right of government to intervene under some circumstances.

Several European, Asian, and other high-income countries have adopted similar legislation, in particular from the latter half of the 1990s onwards (see Montobbio 2009; Geuna and Rossi 2011). In Europe, in many cases, the challenge was to address the established situation according to which IP ownership was assigned to the faculty inventor - the professor's privilege or to firms that funded the research (see Cervantes 2009; Foray and Lissoni 2010). Since the end of the 1990s, most European countries have been moving away from inventor ownership of patent rights toward university or public research institute ownership. ${ }^{3}$ European policy efforts have sought to increase both IP awareness within the public research system and the rate of commercialization of academic inventions. In Asia, Japan was the first to implement similar legislation in 1998 and, in 1999, shifted patent rights to public research organizations. The Republic of Korea implemented similar policies in 2000.

Policymakers keen to bolster the effectiveness with which publicly funded research can foster commercial innovation today have a rich menu of options thanks to the experimentation with such policies in many countries (see Just and Huffman 2009; Foray and Lissoni 2010). A number of middleand low-income countries have also moved in this direction (for more details, see Zuñiga 2011). In spite of the lack of an explicit policy framework, many of these countries have put in place general legislation regulating or facilitating IP ownership and commercialization by research organizations. ${ }^{4}$ There are four distinct sets of approaches used by countries. In the first set, there is no explicit regulation but rather general rules defined in the law mostly in patent acts - or legislation regulating research organizations or government funding. A second model consists of laws in the form of

${ }^{3}$ Professor's privilege was abolished in Germany, Austria, Denmark, Norway, and Finland during the period 2000-7, but was preserved in Sweden and Italy where, in the latter, professor's privilege was introduced in 2001.

4 See Zuñiga (2011). Thailand and the Russian Federation, for instance, do not have specific legislation defining ownership and commercialization rules for research funded by the federal budget at universities and public research institutes. Yet existing revisions to the patent law or other policies give universities the flexibility to create and own their own IP. 
national innovation laws. A third, adopted in Brazil, China, and more recently in economies such as Malaysia, Mexico, the Philippines, and South Africa, builds on the model of high-income countries that confers IP ownership to universities and public research institutes, spurring them to commercialize. Fourth, some countries, for example Nigeria and Ghana, have no national framework but rely on guidelines for IP-based knowledge transfer.

Large middle-income economies, such as Brazil, China, India, the Russian Federation, and South Africa, have already implemented specific legislation or are currently debating its introduction. China was among the first to adopt a policy framework in $2002 .{ }^{5}$ In addition, a significant number of countries in Asia - in particular Bangladesh, Indonesia, Malaysia, Pakistan, the Philippines, and Thailand - and in Latin America and the Caribbean - Mexico in particular and, more recently, Colombia, Costa Rica, and Peru - have been considering such legislation. ${ }^{6}$ However, only Brazil and Mexico have enacted explicit regulations regarding IP ownership and university knowledge transfer so far. In India, institutional policies have recently been developed at key national academic and research institutes, complementing legislative efforts that aim to implement university IP-based knowledge transfer rules (see Basant and Chandra 2007).

In Africa, most countries other than South Africa have neither a specific law on IP ownership by research organizations nor any knowledge transfer laws. However, several countries have started to implement policy guidelines and to support knowledge transfer infrastructure. Nigeria and Ghana, for instance, do not have specific legislation but are both in the process of establishing knowledge transfer offices (KTOs) in all institutions of higher education. ${ }^{7}$ Algeria, Egypt, Morocco, and Tunisia have been working on

${ }^{5}$ In 2002, the government provided universities with full rights of ownership and commercialization for inventions derived from state-funded research. The Measures for Intellectual Property Made under Government Funding legislation provides specific rules for IP ownership and licensing, inventor compensation, and firm creation.

${ }^{6}$ See Zuñiga (2011) and internal contributions to this report made by WIPO's Innovation and Technology Transfer Section.

${ }^{7}$ Nigeria's policy framework contains no specific law on IP creation and management at publicly funded research organizations. Instead, regulations are set within federal research institutes and the National Office for Technology Acquisition and Promotion (NOTAP) published "Guidelines on Development of Intellectual Property Policy for Universities and R\&D Institutions." These guiding principles explain how each R\&D institution can formulate and implement its IP policy to protect tangible research products in order to make them demand-driven and economically viable. The guidelines also promote the use 
drafts for similar legislation. In 2010, South Africa implemented the Intellectual Property Rights from Publicly Financed R\&D Act, which defines a number of obligations ranging from disclosure, IP management, and inventor incentives, to the creation of KTOs and policies regarding entrepreneurship.

Studies conducted on the group of high-income countries reveal a few important lessons. ${ }^{8}$ First, despite the general trend toward institutional ownership and commercialization of university and public research institute inventions, a diversity of legal and policy approaches persists, in terms of both how such legislation is anchored in broader innovation policy and the specific rules on the scope of university patenting, invention disclosure, incentives for researchers (such as royalty sharing), and whether certain safeguards are instituted to counteract the potentially negative effects of patenting. ${ }^{9}$ Second, the means to implement such legislation, as well as the available complementary policies to enhance the impact of public R\&D and to promote academic entrepreneurship, vary widely. Finally, legal changes alone have not started or contributed to sustained patenting by public research organizations. In the U.S., university patenting is also driven by growing technological opportunities in the biomedical and other high-tech fields, as well as a culture change favoring increased university-industry linkages (see Mowery et al. 2001).

\subsubsection{Conflicts and Tradeoffs between the Old and New Rationales for Public R\&D}

Although, in theory, this rich menu of "third mission" policies was intended to amplify the impact of public $\mathrm{R} \& \mathrm{D}$, in practice, many countries adopting these policies were also looking to cut back on public spending and intended that budget cuts to universities should be compensated by proactive approaches to revenue generation (Vincent-Lancrin 2006). There is increasing evidence that countries seek to recover the full economic cost of research activity in order to allow research organizations to amortize the assets and

of IP for the benefit of society, and strengthen research-industry linkages by establishing intellectual property and technology transfer offices (IPTTO).

${ }^{8}$ Unfortunately, we have very limited knowledge of the mechanisms at play in middle- and lowincome countries and this lacuna is an important reason for our comparative study in this book.

9 These can range from legal approaches (standalone or as part of more comprehensive reforms) and university bylaws, to "codes of practice" or general guidelines on IP ownership and management for fostering greater transparency and consistency. See OECD (2003) and Grimaldi et al. (2011). 
overhead, and to invest in infrastructure at a rate adequate to maintain future capability. Paradoxically, support for the third mission may have come at the expense of cutbacks in funding for public R\&D itself. Thus, in practice, the policies of increasing commercialization of university research and industry funding of public research were often adopted in the context of a tightening of public investments in $\mathrm{R} \& \mathrm{D}$. Thus, far from amplifying the economic effect of public investments in R\&D, commercialization of university research very quickly became a substitute for public funding of research and so its net effect on the economy-wide diffusion of technology may be difficult to gauge.

Second, universities have always regarded themselves primarily as centers of learning, where new knowledge is created and curated through research, and ultimately disseminated via teaching. They see themselves as upholding the four Mertonian norms of communism (common ownership of scientific outputs without resort to secrecy), universalism (universal scientific validity irrespective of who the source of scientific output is), disinterestedness (acting in common scientific interest rather than for personal gain), and organized scrutiny (critical scrutiny of scientific output before acceptance). Academic researchers are a self-selected group who are largely driven by the same set of norms in the pursuit of their individual research careers.

Commercialization activities contradict at least two of the four Mertonian norms, given that they are motivated by private ownership of intellectual property and private gain. This leads to a fundamental tradeoff between the ideal of pure scientific exploration versus profitdriven commercial exploitation. Furthermore, pure scientific exploration is essential to the first mission of the university, the provision of education. Universities caught between scientific exploration and exploitation will struggle to simultaneously reconcile both these aims. Indeed, management science teaches that most organizations struggle both to explore new knowledge and to exploit existing knowledge at the same time (organizational ambidexterity), as the two sorts of activity require a different type of management and entail different risks.

Public research institutes were set up as specialized intermediaries to fulfill the commercialization function: to take up frontier science from universities and adapt them to the needs of local communities and industry. More recently, they have been in (possibly) terminal decline, even in countries where they have been quite successful. The reasons for this decline are not clear and probably deserve a book of their own to explore more rigorously, but it is likely that shifting the locus of commercialization from these specialized intermediaries to universities driven by Mertonian norms may 
have been inefficient in countries where the institutional frameworks to transfer knowledge directly from universities were still immature and poorly developed. Third mission activities in many countries, however, came at the expense of public research institutes. Whether universities' third mission activities can and should replace public research institutes remains an underexplored question.

Lastly, while nobody denies that the payoffs of academic research are maximized when the private sector uses and builds on research carried out in the public sector, these are not one-way exchanges from universities to firms. Industrial research complements and also guides more basic research. It is also a means of "equipping" university scientists with new and powerful instruments. For such knowledge transfer to work, firms need to be able to assimilate and exploit public research. This capability often requires firms to actively engage in upstream research and actively participate in science (see Cohen and Levinthal 1989). In middle- and low-income countries, even large firms may lack this capability, while in high-income economies small firms may behave in this way. Policies to promote outward knowledge transfer from universities and public research institutes are likely to fail if local firms lack sufficient absorptive capacity.

\subsection{Cross-Country Trends in Public R\&D}

The volume of public sector investment in scientific research is traditionally measured through expenditures on $\mathrm{R} \& \mathrm{D}$ financed by government. $\mathrm{R} \& \mathrm{D}$ expenditures, their distribution across industrial sectors, and the proportion spent on applied and basic R\&D are highly variable across countries and have usually evolved with the growth of an economy and the nature of industrial policies to support growth (see also National Science Foundation 2018; UNESCO 2018). The increase in public or private $R \& D$, however, must be seen in the context of the overall growth of $R \& D$. An increase in public $R \& D$ is more effective if business expenditures on $\mathrm{R} \& \mathrm{D}$ are high or rising.

Figure 1.1 shows noticeably different overall trends in the R\&D intensity (share of R\&D expenditures as a percentage of GDP) for high-, middle- and low-income economies between 2000 and 2016. High-income countries spend about 2.5 percent of GDP on R\&D, and this is a much larger share than any other group of countries. The sharpest growth in R\&D, however, has been in the upper middle-income countries. In both high- and lowincome countries, $\mathrm{R} \& \mathrm{D}$ expenditures as a share of GDP have struggled to 
grow, while lower middle-income countries (which includes countries such as India) have seen a decline in R\&D intensity.

Public sector $R \& D$ can be delivered through a variety of institutions. Universities play a big role in high-income economies where industrial capabilities are at the scientific frontier and so benefit from close links to the basic science produced in university science departments. More specialized public research institutes may be preferred in middle- and lowerincome countries that have limited resources to invest in scientific infrastructure and that often prefer to concentrate such investments in a few areas of greatest need to the economy and society. In general, as national income per capita decreases, $R \& D$ by public research institutes plays an increasingly important role in economic development. As firms in these economies possess low levels of technological capability, they need the help of public R\&D to adapt frontier technologies to domestic conditions. Public research institutes generally undertake applied research geared toward the building of prototypes that can be manufactured by local industry.

In high-income economies, the public sector is responsible for anywhere between 20 and 45 percent of annual total R\&D expenditure and
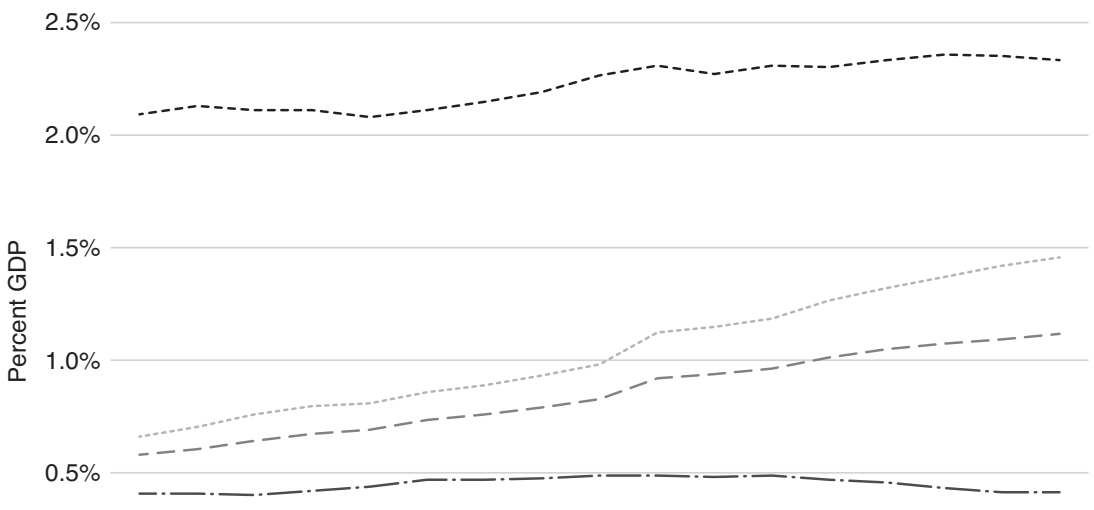

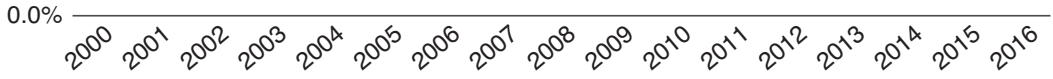

$$
\begin{aligned}
& \text { — Low-income countries } \\
& \text {-.- Lower middle-income countries } \\
& \text {--- Middle-income countries } \\
& \text { Upper middle-income countries } \\
& \text {-.-- High-income countries }
\end{aligned}
$$

Figure 1.1 Share of R\&D (measured by GERD) in GDP by income group of countries, 2000-16

Source: UNESCO Institute for Statistics, March 2019 
almost three-quarters of the expenditure on basic research, with the remaining expenditure on private and applied $R \& D$ coming from the private sector. On average, government funding is responsible for about 53 percent of total $\mathrm{R} \& \mathrm{D}$ in the middle-income countries for which data are available. Thus, the distribution of $\mathrm{R} \& \mathrm{D}$ between public and private sectors shows that as the level of a country's per capita income decreases, governmental funding approaches 100 percent.

The data on public and private $\mathrm{R} \& \mathrm{D}$ are patchy but in Figure 1.2 (panels A and B), we plot the data that are available to demonstrate the variability of public R\&D even within similar income groups. Although not included in Figure 1.2B, the public sector funded 100 percent of R\&D in Burkina Faso in the last year for which data are available (see UNESCO 2018). In Argentina, Bolivia, Brazil, India, Peru, and Romania (also not included in Figure 1.2B) the share of public sector R\&D often exceeds 70 percent of total $\mathrm{R} \& \mathrm{D} .^{10}$

Importantly, with some exceptions, governments usually provide the majority of the funds for basic research. Basic research is experimental or theoretical work undertaken primarily to acquire new knowledge of the underlying foundation of phenomena and observable facts, without any particular application or use in view (for the U.S., see the analysis in Arora et al. 2015). On average, in 2009, the public sector performed more than three-quarters of all basic research in high-income economies. ${ }^{11}$ These contributions to basic research are becoming more vital as firms focus mostly on product development and as multinational companies in high-income countries scale back their basic research in a number of R\&D-intensive sectors (see OECD 2008). In middle-income countries for which data are available (see Figure 1.3), public research is responsible for the majority of basic R\&D: close to 100 percent in China, close to 90 percent in Mexico, about 80 percent in the Russian Federation, and about 75 percent in South Africa. A high share of government in basic research may also be an institutional legacy, often seen in former socialist countries.

${ }^{10}$ Exceptions are Malaysia, China, the Philippines, and Thailand where, for both R\&D funding and performance, the business sector has the largest share but, nonetheless, public research organizations play a key role in contributing to industry R\&D and ensuing innovation.

11 See OECD, Research \& Development Statistics. Depending on the country in question, it accounts for about 40 percent (Republic of Korea) to close to 100 percent (Slovakia) of all basic research performed. 
(a)

- Private sector R\&D Public sector R\&D Others

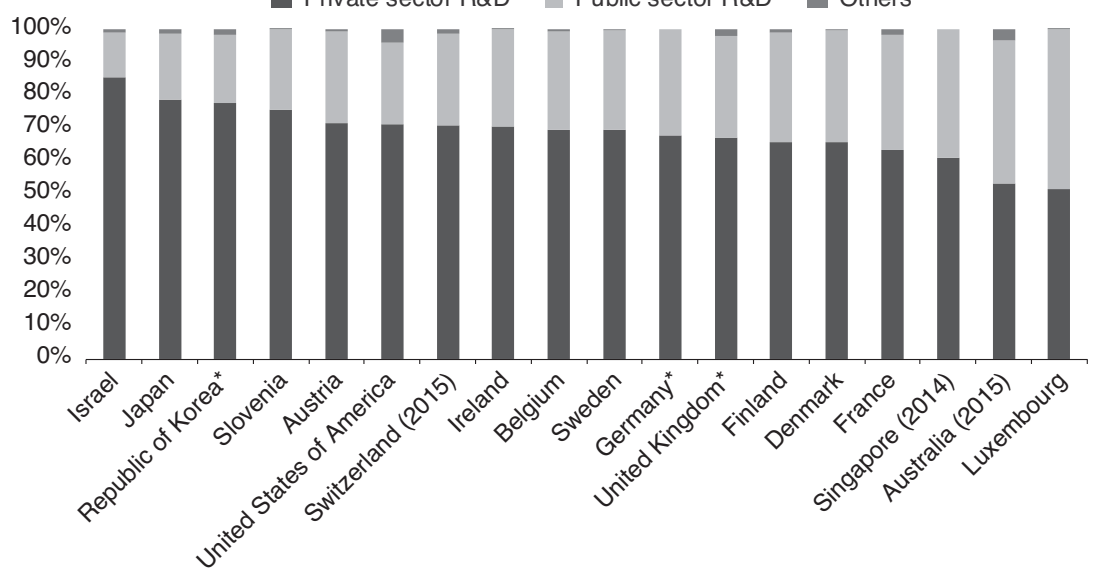

(b)

Private sector R\&D Public sector R\&D Others

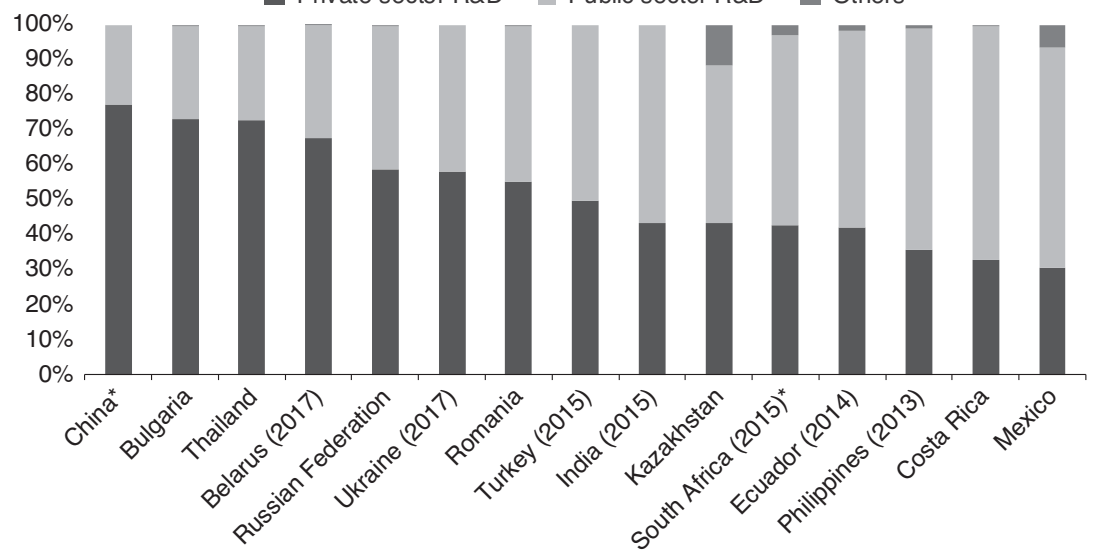

Figure 1.2 Share of public sector in total R\&D, high- and middle-income economies A. Share of public sector in total R\&D in high-income countries, in percent, 2016 or latest available year

B. Share of public sector in total R\&D in middle-income economies, in percent, 2016 or latest available year

\subsection{Challenging Factors in Middle-Income Countries}

The consistent increase in R\&D intensity in upper-middle and middleincome countries - in the latter case much driven by China only - masks several challenges.

Compared to high-income countries, science and technology (S\&T) and innovation conditions in middle- and low-income countries face the following challenges: 


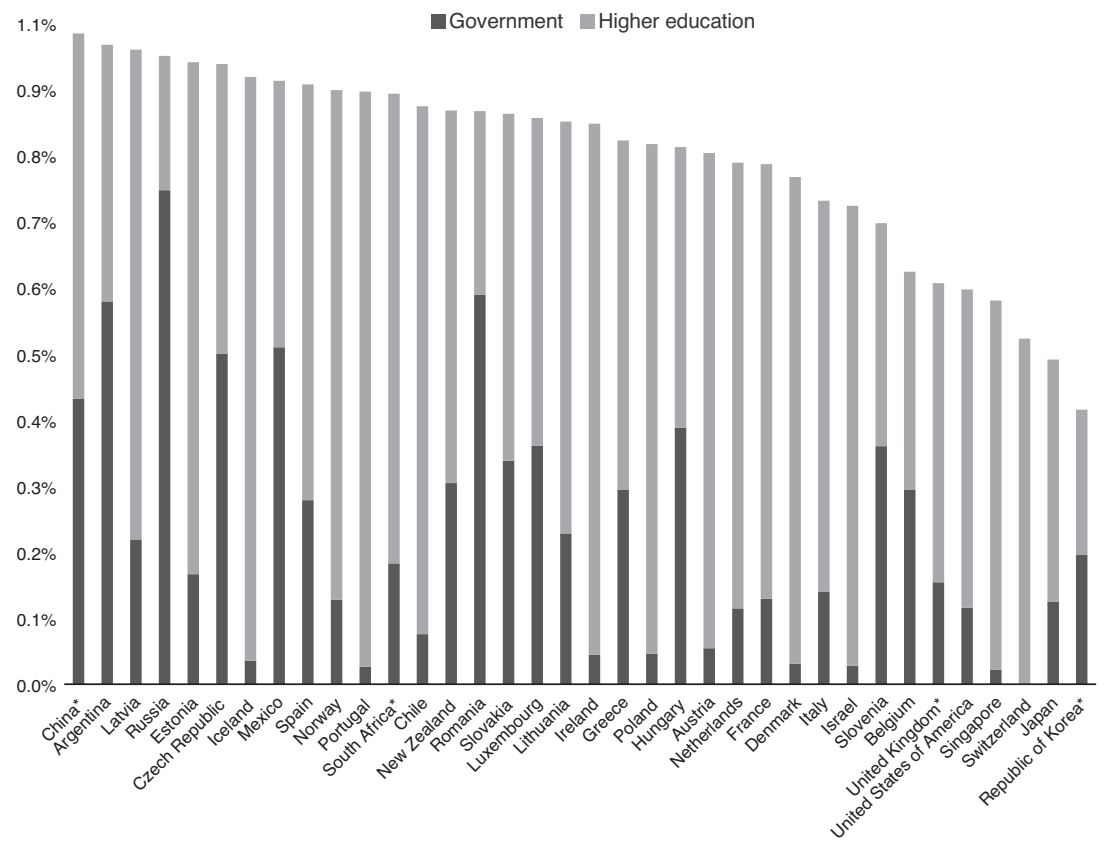

Figure 1.3 Share of basic research conducted by the public sector for 2017, or latest available year, as a percentage of all national expenditures for basic research Source: Organisation for Economic Co-operation and Development (OECD), Research and Development Statistics Database, March 2019

Note: Figure 1.3 provides data from the most recent available years, between 2015 and 2017 for each country. Some of the distinction between higher education institutions universities and government as well as public research institutes - is simply definitional and depends on what is defined as a university or a public research institute in a given country. ${ }^{\star}$ Case study countries

- a lower level of S\&T;

- low research and innovation capabilities of domestic firms, with the result that government and international donors are often the main funders of S\&T and national public research institutes are the main R\&D performers;

- less developed human capital for S\&T activity, particularly a low number of scientists in firms and the best domestic scientists moving abroad ("brain drain" effect);

- lower quality research and relevance of public research to the business sector;

- limited science-industry linkages, explained by a low absorptive capacity of firms combined with an ensuing lack of "business" demand for S\&T; 
- a lack of policies and structures to facilitate academic and other startups; and

- constrained access to financing as a barrier to the development of radical or early-stage innovations.

There are several reasons that explain the limited impact of science on economic development in low- and middle-income countries. First of all, in terms of policy strategies, is the need to address basic economic needs such as poverty and health, with science and technology as second-order priorities. Second-, middle- and low-income countries are a very heterogeneous group, with wide differences in the needs and conditions for knowledge transfer. In most low-income countries, many of the necessary elements for science to have an impact on industrial innovation and society are embryonic, while in middle-income countries the foundations exist but are weakly articulated (WIPO 2011; Zuñiga 2011). It is clear, however, that R\&D capabilities - both in private and public institutions - in many middleincome economies have improved during the last decade and opportunities to enhance technology commercialization through IP are emerging.

As the remainder of this book shows, structural features have also constrained the development of linkages between universities and firms. ${ }^{12}$ Often, commercial activity by universities and researchers has been or is still highly regulated or even forbidden. With few exceptions, most universities fully depend on federal budgets and have weak linkages with regional governments and economies. The lack of absorptive capacity in firms and their natural focus on imitative innovation and acquisition of foreign technology as innovation strategies also contribute to fragmentation in national innovation systems (see Navarro et al. 2010). The technological strategies of firms in lower- and middle-income economies often depend on off-the-shelf imported technology, primarily in the form of machinery and turnkey knowledge transfer from abroad. Often these are also the only options for these firms to access current technology. ${ }^{13}$ The barriers to industry-science collaboration reported by firms include a lack of communication channels with universities, differences in organizational culture (in respect of timing and product

12 See in particular Chapters 10 and 11.

13 See Zuñiga (2011). In Argentina, for example, according to the innovation survey of 1998-2001, 84 percent of firms that cooperated with other actors in the national innovation systems did so for informational purposes and 58 percent for training purposes; only 21 percent engaged in cooperation for R\&D. In Colombia, the percentages of firms (within those that reported links with agents providing technological services) are 31, 50, and 15 percent, respectively. 
delivery), uncertainty of a market need/demand for research results, and high costs for developing and commercializing university research. ${ }^{14}$

In this context, one of the main conclusions of this book is that knowledge transfer policies that are not accompanied by policies to strengthen R\&D capabilities in firms and industry-science linkages are unlikely to be successful. In addition, as in high-income countries, transforming academia into more entrepreneurial institutions requires cultural change - in particular among researchers, and often an increase in university autonomy, including for more competitive hiring and in terms of resource management. Compared to high-income countries, the following are additional barriers to knowledge exchange from the science base in low- and middle-income countries:

- lack of clear knowledge transfer policies for universities and public research institutes;

- weak operative guidelines on patenting, for example on disclosure and commercialization of IP at the institutional level;

- little awareness about and few incentives for researchers to participate in IP-based knowledge transfer; and

- absence of or inadequate resources for KTOs, with staff lacking the necessary skills and experience related to IP and commercialization.

More generally, an additional friction to the development of IP registration and commercialization in many middle- and low-income countries is the sluggish process of patenting at national patent offices and its relatively high cost (see WIPO 2011; Zuñiga 2011; Chapters 10 and 11 of this book).

However, these characteristics are not shared equally across all lowand middle-income countries. For the most part, work is ongoing to improve the systemic weaknesses in national innovation systems and to give greater autonomy to universities. As evidenced earlier, many of these countries are also in the midst of implementing or setting up knowledge transfer policies and practices. Indeed, in some cases this has already led to significant impacts, both in terms of measured knowledge transfer and the related broader impacts on public research organizations, firms and the linkages between them.

Finally, this book emphasizes that high-income countries struggle with many of the same challenges when it comes to putting in place functioning knowledge transfer practices. A blueprint that could easily be adopted across institutions and countries therefore does not yet exist, even in

${ }^{14}$ For evidence from China on this, see Guan et al. (2005). 
high-income economies. Experience and the economic literature show that different stages of development and different innovation systems require different policies and incentives to promote the commercialization of public research (see Guellec et al. 2010). Conditions for knowledge transfer develop over time and depend heavily on research capabilities and science-industry linkages. Having a broad view of the concept of technology commercialization, looking at intermediate steps and broad knowledge transfer activities - not exclusively focused on IP creation and licensing, and academic entrepreneurship - makes for good policy advice.

\subsection{Rationale for the Selection of Country Cases}

The heterogeneity of high- and middle-income countries with regard to basic features about the organization of public R\&D suggests that simply instituting relevant laws and regulations is only a first ingredient to stimulating industry-science linkages. A number of conditions need to be in place at the country and institutional level to reap the resulting benefits. Moreover, diverse stages of development will require different approaches and complementary policies, including safeguards for avoiding the downside risks of university patenting.

Our approach in this book has been to explore in detail the interaction between the institutional frameworks, public policy constraints, and adoption of third mission policies in six countries with a view to distilling lessons from their experience. Although heterogeneous in themselves, this group of countries consists of three high-income economies (the United Kingdom, Germany, and the Republic of Korea) whose experience of third mission policies differs from the oft-cited example of the U.S. Germany is an exemplar of the institution of a collective market economy where public sector R\&D and the state more generally played a large role in economic growth and technological prowess. The United Kingdom, by contrast, is more similar to the U.S. in relying on liberal market institutions to promote third mission policies. The Republic of Korea (like Germany) relied on a strong public research institute sector for technological catch-up but has found the institutional change needed to implement broad-based growth (moving away from reliance on large chaebol companies) hard to achieve. We also include the study of three large middle-income countries, namely Brazil, China, and South Africa. Brazil inherited institutions that are similar to those in continental Europe, but it was also influenced by the US system. China transformed 


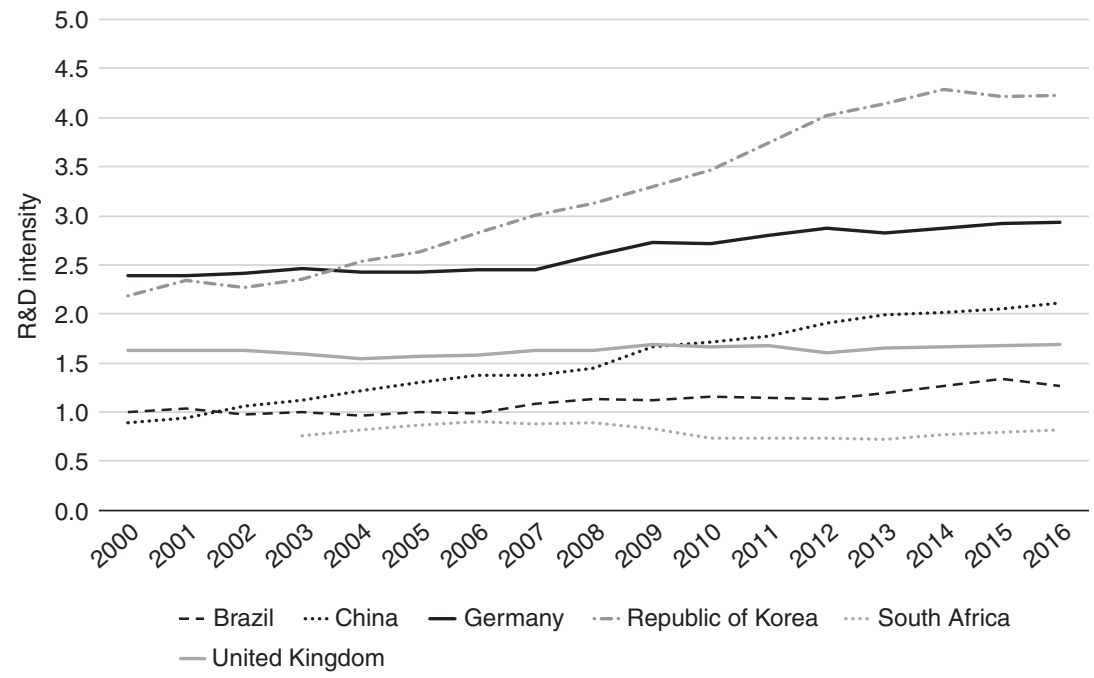

Figure 1.4 R\&D intensity (GERD as a percentage of GDP), case study countries Source: Authors based on data from the UNESCO Institute for Statistics and OECD

itself from a public research institute-led system to one in which universities were reformed to engage with domestic industry. South Africa managed both radical political change and reformed its university system and linkages to industry.

Figures 1.4 and 1.5 build on Figures $1.1-1.3$ for the six countries that we study in this book. They enable us to see the precise nature of differences between countries that may often belong to the same income group classification.

Figure 1.4 on R\&D intensity shows that the Republic of Korea, China, and Germany saw rising shares of R\&D in their economies. The United Kingdom (despite being in the high-income group) had R\&D shares that were almost a whole percentage point lower than those in Germany and lower than China (a middle-income country). The R\&D intensity was stagnant in the United Kingdom and similar trends are observed for South Africa and Brazil. Figure 1.5 shows the percentage of gross expenditure on R\&D that was financed by the government. All countries, except for South Africa, show a declining trend. China and the Republic of Korea show some of the lowest levels, while Brazil and South Africa have markedly higher levels of government-financed R\&D. Thus, the six case studies 


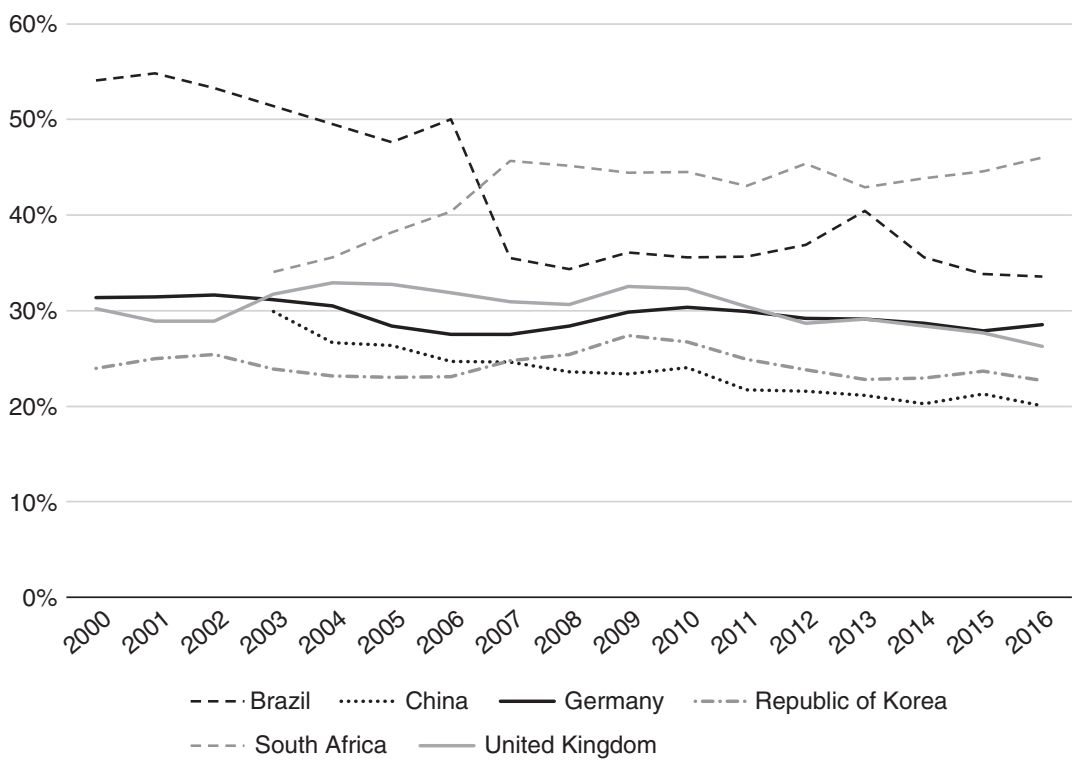

Figure 1.5 Share of GERD financed by the government, case study countries Source: Authors based on data from the UNESCO Institute for Statistics and OECD

confirm that the backdrop against which stronger knowledge exchange policies have been pursued has been a declining share of governmentfinanced $R \& D$ in the context of an overall decline in $R \& D$ intensities.

As we noted in Section 1.3, the distribution of $R \& D$ between the public and private sectors has varied considerably between countries even within a particular group. In general, countries that had a large role for the state also ended up having large public R\&D shares. Figure 1.2 also reports the distribution of public and private sector $\mathrm{R} \& \mathrm{D}$, including for the group of case study countries, except Brazil, for which no data were available. The smallest shares of public R\&D were for the Republic of Korea and China, which have seen a strong role of the state and also public research institutes in their growth histories. South Africa has the largest share of public R\&D followed by Germany and the United Kingdom.

A last indicator worth looking at is the distribution of basic research between the share of universities and the share of the government sector in the six countries we study (see Figure 1.3). Here we find that in China most basic research (over 55 percent) happens in the government and the 
university sector (here institutions of higher education), whereas this is much lower at about 30 percent for the Republic of Korea and Germany and even lower, at 20 percent, for South Africa and the United Kingdom. Basic research in universities is smallest for the United Kingdom and highest for China.

\subsection{Summary and Plan of the Book}

The most appropriate frameworks for spurring the commercialization of publicly funded inventions - whether in public research institutes or publicly funded universities - depends on the institutional context and will vary due to different starting points. Yet, for the most part, a "one glove fits all" approach has dominated policy thinking in this area. At times, policymakers and institutions have been overreliant on the filing of IP as the only instrument to enhance the impact of science on the economy. A more realistic assessment of the state of their research and innovation systems to identify the role that IP can play in such development (given both its opportunities and costs) is missing and sorely needed.

Providing a more nuanced understanding of optimal policies for knowledge transfer is the overriding objective of this book. Such policies need to be grounded both in the historical evolution of universityindustry relations and systematic data underpinned by a rigorous conceptual understanding of what is involved in knowledge exchange between university and industry. In keeping with this objective, we use a recursive approach in the book, as follows.

Part I develops an understanding of broad institutional differences in the nature of public science across countries; a conceptual framework for thinking about knowledge exchange, knowledge transfer metrics, and survey and evaluation frameworks; and a standardized method to assess national or institutional strategies. This first chapter sets out the rationale for third mission activities, shows how policies for third mission activities developed in a fiscal situation that saw a decline in funding for public $\mathrm{R} \& \mathrm{D}$ in many countries, and sets out the main institutional differences between high- and middle-income countries. It also compares basic trends in public R\&D for the six countries studied. Chapter 2 develops a conceptual framework to guide the evaluation of knowledge transfer policies, practices and outcomes. Chapter 3 then looks at what corresponding patent metrics exist to produce (internationally) comparable data on formal knowledge transfer practices. 
Part II (Chapters 4-9) recounts the historical evolution of knowledge exchange policy and outcomes in three high-income countries (the United Kingdom, Germany, and the Republic of Korea) and three middle-income countries (China, Brazil, and South Africa). Country authors use the unique history of their country to produce narratives of policy evolution and the reasons for success or failure of intended outcomes.

Part III uses an inductive approach to distill optimal policies and identify optimum metrics to support a better framework for knowledge exchange. An important differentiating feature of this book is that we recognize that knowledge exchange is a two-way process where the ability of firms to absorb university-generated knowledge is as important as the ability of the university to reach out. Thus, Chapters 10 and 11 outline policies to raise industrial involvement and university involvement in knowledge exchange, respectively. In each chapter, we contrast the experience of high-income and middle- income countries to draw out the policy implications. What knowledge transfer laws and practices have been put in place in high- and middle-income countries? How have new policies to support IP licensing affected other knowledge transfer channels? Which approaches have demonstrated the best outcomes for public institutions and for firms but also at the broader macro-level? Do approaches exist that are particularly relevant to developing countries? Chapter 12 concludes the book by discussing the interplay between the objectives of knowledge exchange policy and the metrics available to evaluate these objectives, and what remains to be done in this regard. Which overall economic and other impacts have been measured and how? What additional data are required to provide a comprehensive set of metrics for use in benchmarking, monitoring, and policy evaluation? What are the possible sources of such data?

\section{References}

Arora, A., S. Belenzon, and A. Patacconi (2015). Killing the Golden Goose? The Decline of Science in Corporate R\&D. NBER Working Paper No. 20902.

Arora, A. and A. Gambardella (2005). "The globalization of the software industry: Perspectives and opportunities for developed and developing countries." In A. B. Jaffe, J. Lerner, and S. Stern (eds.), Innovation Policy and the Economy, Vol. 5. Cambridge, MA: MIT Press.

Adams, J. D. (1990). "Fundamental stocks of knowledge and productivity growth." Journal of Political Economy, 98(4): 673-702. 
Basant, R. and P. Chandra (2007). "University-industry link and enterprise creation in India: Some strategic and policy issues." In S. Yusuf and K. Nabeshima (eds.), How Universities Promote Economic Growth. Washington, DC: World Bank, pp. 209-26.

Cervantes, M. (2009). Academic Patenting: How Universities and Public Research Organizations Are Using Their Intellectual Property to Boost Research and Spur Innovative Start-ups. Retrieved from www.wipo.int/sme/en/documents/ academic_patenting.html.

Cohen, W. M. and D. A. Levinthal (1989).” Innovation and learning: The two faces of R\&D." Economic Journal, 99(397): 569-96.

Cohen, W. M., R. R. Nelson, and J. Walsh (2002). "Links and impacts: The influence of public research on industrial R\&D." Management Science, 48: 1-23.

Foray, D. and F. Lissoni (2010). "University research and public-private interaction.” In B. H. Hall and N. Rosenberg (eds.), Handbook of the Economics of Innovation, Vol. 1. Amsterdam: North Holland, pp. 275-314.

Geuna, A. and F. Rossi (2011). "Changes to university IPR regulations in Europe and the impact on academic patenting." Research Policy, 40(8): 1068-76.

Grimaldi, R., M. Kenney, D. S. Siegel, and M. Wright (2011). "30 years after Bayh-Dole: Reassessing academic entrepreneurship.” Research Policy, 40(8): 1045-57.

Guan, J. C., R. C. M. Yam, and C. K. Mok (2005). "Collaboration between industry and research institutes/universities on industrial innovation in Beijing, China." Technology Analysis and Strategic Management, 17(3): 339-53.

Guellec, D., T. Madies, and J.-C. Prager (2010). "Les marchés de brevets dans l'économie de la connaissance." Les Rapports du Conseil d'analyse économique. Paris: Conseil d'analyse économique.

Jaffe, A. B. (1989). "Real effects of academic research." American Economic Review, 79(5): 957-70.

Just, R. E. and W. E. Huffman (2009). "The economics of universities in a new age of funding options." Research Policy, 38(7): 1102-16.

Montobbio, F. (2009). "Intellectual property rights and knowledge transfer from public research to industry in the US and Europe: Which lessons for innovation systems in developing countries?" In The Economics of Intellectual Property: Suggestions for Further Research in Developing Countries and Countries with Economies in Transition. Geneva: World Intellectual Property Organization.

Mowery, D. C., R. R. Nelson, B. N. Sampat, and A. A. Ziedonis (2001). "The growth of patenting and licensing by U.S. universities: An assessment of the effects of the Bayh-Dole Act of 1980." Research Policy, 30(1): 99-119.

Navarro, J. C., J. Llisterri, and P. Zuñiga (2010). "The importance of ideas for innovation and productivity." In C. Pages (ed.), The Age of Productivity: Transforming Economies from the Bottom Up. Washington, DC: Palgrave Macmillan. 
National Science Foundation (2018). Science and Engineering Indicators 2018. Alexandria, VA: National Science Board.

Nelson, R. R. (2004). “The market economy, and the scientific commons.” Research Policy, 33(3): 455-71.

OECD (2003). Turning Science into Business: Patenting and Licensing at Public Research Organisations. Paris: Organisation for Economic Co-operation and Development.

OECD (2008). "ICT research and development and innovation." Information Technology Outlook. Paris: Organisation for Economic Co-operation and Development.

OECD (2011). Science, Technology and Industry Scoreboard 2011. Paris: Organisation for Economic Co-operation and Development.

OECD (2017). Science, Technology and Industry Scoreboard 2017. Paris: Organisation for Economic Co-operation and Development.

Paunov, C., M. Borowiecki, and N. El-Mallakh (2019). Cross-Country Evidence on the Contributions of Research Institutions to Innovation. OECD Science, Technology and Industry Policy Papers, No. 77. Paris: OECD Publishing.

UNESCO (2018). UNESCO Science Report: Towards 2030. Paris: United Nations Educational, Scientific and Cultural Organization.

Van Looy, B., P. Landoni, J. Callaert, B. van Pottelsberghe, E. Sapsalis, and K. Debackere (2011). "Entrepreneurial effectiveness of European universities: An empirical assessment of antecedents and tradeoffs." Research Policy, 40(4): 553-64.

Vincent-Lancrin, S. (2006). "What is changing in academic research? Trends and future scenarios." European Journal of Education, 41(2): 169-202.

WIPO (2011). "Harnessing public research for innovation: The role of intellectual property." In World Intellectual Property Report 2011 - The Changing Face of Innovation. Geneva: WIPO, Chapter 4, www.wipo.int/export/sites/www/econ_ stat/en/economics/wipr/pdf/wipr_2011_chapter4.pdf.

Wright, M., B. Clarysse, P. Mustar, and A. Lockett (eds.) (2007). Academic Entrepreneurship in Europe. Cheltenham: Edward Elgar.

Zuñiga, P. (2011). The State of Patenting at Research Institutions in Developing Countries: Policy Approaches and Practices. WIPO Economics Research Working Papers. Geneva: World Intellectual Property Organization. 


\section{Comment 1.1}

FABIO MONTOB BIO

This project provides an extremely interesting comparison of research and technological transfer activities across different countries, and, in parallel, promotes the use of a set of metrics. The approach takes its departure from the analysis of the systems of innovation that encompasses the main actors and institutions involved in the process of knowledge transfer. It allows a fine-grained analysis of the different details of the context in which knowledge transfer takes place, exploiting a mixture of quantitative and qualitative analysis. In so doing, it provides a very valuable tool to help policymakers to measure the research, transfer, and commercialization activities in order to design new innovation policy approaches and sustain successful practices. On the one hand, it is important to learn about successful examples and best practices, and, on the other, efforts at emulation could have modest success if not coupled with deep attention to the underlying structural differences among the innovation systems of the different countries. Taking on board the systemic approach, I would like first to discuss my view on possible ways to disentangle the complexity of the different environments in which knowledge transfer takes place and, second, to discuss how normative statements can arise from this perspective. In particular, I would like to underline first how the different systems of innovation depend on a set of structural characteristics, namely: the intensity of the research effort, the technological specialization, and the industrial structures. Second, I would like to underline how systemic failures may occur at different levels, and fixing those failures naturally includes a quite heterogeneous set of policy interventions.

The first comment is that knowledge transfer practices are affected by a set of structural characteristics of the countries. So when addressing a comparison of knowledge transfer practices across countries, it is important to take into account the relative strengths and weaknesses of the public and private systems of R\&D. For example, it emerges that the 
six countries considered in this project have very different R\&D/GDP expenditures (OECD 2017a). In 2015 in China, the R\&D/GDP ratio was 2.1 percent, in Germany, 2.9 percent, in the Republic of Korea, 4.2 percent, in the United Kingdom, 1.7 percent, in Brazil, 1.2 percent, and, finally, in South Africa 0.7 percent. The growth of R\&D intensity has been impressive for China and Republic of Korea. For these countries the figures were 0.5 percent and 2.2 percent in 1995, respectively. It is also worth noting that the share of gross domestic expenditure on R\&D funded by the government is smaller in the Republic of Korea and China (21 percent and 23 percent, respectively, in 2015), denoting a relevant and increasing role of the R\&D funded by the private sector. In parallel, in Germany and the United Kingdom, the share of R\&D funded by the government is about 28 percent. This share for South Africa is 42 percent (OECD 2017b). For Brazil, UNESCO data show that in 2014 the investment in R\&D was BRL 65 billion, and almost two-thirds was funded by the government.

The figures given here show that countries like Brazil and South Africa that have a lower $\& \& D / G D P$ ratio are also the ones that display a weaker role for private sector $\mathrm{R} \& \mathrm{D}$. The relative role of the private sector, in turn, is associated with the profile of the country in terms of technological specialization and with processes of structural change. Technological capabilities tend to be associated to the technological specialization of countries. For example, Brazil and South Africa did not undertake a major process of structural change as China did. In China, a high growth in technological capabilities is associated with a substantial shift toward the electronic and telecommunications equipment industry and computers. These industries are a major driver of the aggregate growth of national and international patenting of the country (e.g., Malerba et al. 2011; Hu et al. 2017).

The distribution of technological capabilities in a country innovation system depends on the presence of different types of organization. In particular, it is important to have a balanced evolution of the different actors, with a growth of the presence of both multinational corporations and domestic innovators. China, for example, has a growing presence of both domestic and foreign companies in electronics. This confirms the major role played by ICT in the growth of the Chinese economy, as well as the role played by foreign companies in China. In parallel, the impressive growth of patenting activity at the Chinese Patent Office is mainly driven by new entrants: firms that were not systematically applying for patents in the past ( $\mathrm{Hu}$ et al. 2017). The dynamism of the domestic private sector witnesses the ability to absorb foreign knowledge and to 
benefit from the big investments in public institutions and infrastructures documented by Chapter 8 in this book.

An additional important aspect is the coherence between the technological activities of the different actors within the country innovation system. In Brazil and South Africa, universities and public research institutes tend to innovate and patent relatively more in chemicals, pharmaceuticals, and biotechnology. This presence has been growing over time and the Brazilian government has supported research in pharmaceuticals and biotechnology in both universities and public research institutes (see Chapter 7 of this volume and Ferrer et al. 2004). In parallel, the specialization profile of domestic multinational companies tends to remain stable in more traditional sectors such as consumer goods, engineering, and transport. Similar considerations could be put forward for South Africa. This potential mismatch between the activities of universities and public research institutes and the technological profile of the companies suggests that well-tuned knowledge transfer policies and practices are key for a balanced and sustainable path of growth (see Chapter 9).

Other structural aspects that might affect the way knowledge transfer takes place are the quality of the research system and the quality of the institutional framework. This book provides an excellent guide to assessing and comparing the complexities of the different countries. In particular it is worth noting that, in general, it is quite difficult to understand all the sources of public research funding in a country. Public funding passes through different levels of governance (e.g., state, regions, municipalities) and different types of organization (e.g., public/private/nonprofit/ foundations). There may be public research institutes that depend entirely on regional administrations or are owned by other public nonresearch entities. A quite heterogeneous set of government acts channels public money into knowledge transfer activities. All these countryspecific features affect the level of knowledge transfer activity but also the channels used and the quality of that transfer. For example, different public research intitutes may have different types of constraint in terms of patenting activity, and they may exploit the formal and informal channels of knowledge transfer to different degrees (see, for example, the discussion in the chapters on Germany and the UK in Chapters 5 and 4 , respectively).

Finally, geographical aspects play an important role. The presence of innovative geographically concentrated clusters could provide, on the one hand, specific agglomeration effects and, on the other, regional 
imbalances. Knowledge transfer practices may vary dramatically according to whether companies and universities and public research institutes are colocated in a technological cluster or in a science park or whether the region is characterized by the prevalence of rural areas.

My second comment discusses how normative statements can arise from this perspective, and I would like to underline that a precise qualitative and qualitative description of the systems of innovation shows where the successes and the potential failures of the processes and practices of knowledge transfer actually are. This book addresses the issue of knowledge transfer with a broad view that institutions and regulations are constitutive elements of the innovation system. In particular, a substantial effort of the different studies is dedicated toward understanding the different specific regulations that different countries adopted. These regulations generate the specific conditions under which firms, individuals, universities, and public research institutes own immaterial assets and the new knowledge they produce. These regulations should create incentives to invest in new knowledge and in parallel facilitate diffusion and commercialization. It is emphasized that the process of knowledge transfer is characterized by a set of formal and informal channels, and these channels depend on different types of regulation: hard regulations and soft regulations (Borrás and Edquist 2014). Soft regulations are not legally binding and hard regulations are a set of rules with some mechanism for monitoring and promoting compliance with the rules.

So systemic failures may take place at different levels, and fixing those failures naturally includes a quite heterogeneous set of policy interventions. The interesting aspect is how to frame precisely normative issues with this approach. Actually, the approach is very flexible and allows, through detailed case studies, the identification of specific problems in the innovation system that could unfold at different levels. For example, at the policy level it is difficult in many cases to be able to clearly argue whether there is the need for more R\&D or more knowledge transfer (or more knowledge transfer offices) or more university-industry cooperation. In many cases, knowledge transfer policies are simply imported from other countries without a precise understanding of the bottlenecks in the system (Ejermo and Toivanen 2018). However this approach beyond simple policy prescriptions on market failures - allows us to identify different types of specific failure and problem in the system and allows for the identification of specific policy answers (Edquist 2011). 
This book provides many different examples of potential design failures, network failures, or capability failures. Design failures occur when a regulation generates incentives that are not compatible with the policy objective; network failures happen because of a lack of linkages between actors. This creates a weak exploitation of complementarities and learning. We observe a network failure also when firms and companies in a country are tightly connected but remain locked in and miss out on new outside developments. Capability failures take place when firms, universities, public research institutes, and, in particular, KTOs lack the capabilities to learn rapidly and effectively and hence remain locked into existing practices. This conceptual framework therefore provides detailed guidance on how to evaluate existing knowledge transfer policies, practices, and outcomes, to identify in a comparative way potential failures and problems, and, finally, to design specific targeted policy intervention.

\section{References}

Borrás, S. and C. Edquist (2014). Institutions and Regulations in Innovation Systems: Effects, Problems and Innovation Policy Design. CIRCLE Working Paper 2014/29. Lund University, Sweden.

Edquist, C. (2011). "Design of innovation policy through diagnostic analysis: Identification of systemic problems (or failures)." Industrial and Corporate Change, 20(6): 1-29.

Ejermo, O. and H. Toivanen (2018). "University invention and the abolishment of the professor's privilege in Finland." Research Policy, 47(4): 814-25.

Ferrer, M., H. Thorsteinsdóttir, U. Quach, P.A. Singer, and A. S Daar (2004). “The scientific muscle of Brazil's health biotechnology.” Nature Biotechnology, 22, Supplement December: DC8-DC12.

Hu, A.G.Z., P. Zhang, and L. Zhao (2017). "China as number one? Evidence from China's most recent patenting surge.” Journal of Development Economics, 124: 107-19.

Malerba, F., F. Montobbio, and V. Sterzi (2011). The Growth and Evolution of Advanced Technological Capabilities in the Main Emerging Countries. Patent analysis, presented at the 9th Globelics International Conference.

OECD (2017a). OECD Science, Technology and Industry Scoreboard 2017: the Digital Transformation. Paris: OECD. http://dx.doi.org/10.1787/9789264268821-en.

OECD (2017b). Main Science and Technology Indicators, Vol. 2017 Issue 1. Paris: OECD. http://dx.doi.org/10.1787/msti-v2017-1-en. 


\section{Comment 1.2}

\section{LIEN VERBAUWHEDE KOGLIN}

Globally, there is a growing interest in the role of universities and public research institutes in the alchemy of innovation, the emphasis being on how they can make more systematic efforts to unlock the commercial value of their research. While many of these feel it is imperative that their knowledge transfer activities work to recover costs, from my experience, revenue generation, in most cases, is not and in my view should not be the primary motivation. The reasons these institutes engage in knowledge transfer is to advance education and research; and at the same time it helps to ensure that public investment in research is impactful, that it contributes to broader socioeconomic development objectives. However, the going is tough, even in high-income countries and the entrepreneurial character of these institutes remains the subject of academic scrutiny. The chapter inspires a deeper understanding of this critical area by examining the evolving role of institutes in national innovation systems. It also examines the impact of legislative and policy initiatives that promote protection of inventions through patenting and their commercialization through licensing and startup formation.

WIPO has developed several programs in an endeavor to help public research organizations set the right institutional policies in order to successfully harness public research for innovation and contribute to socioeconomic development in their regions. ${ }^{1}$ In this context, I have witnessed two particular trends concerning universities' engagement with IP-based commercialization, where improved understanding and additional metrics would seem to be desirable: (1) an expansion of academic incentive schemes and (2) an increased commitment to socially responsible commercialization.

${ }^{1}$ See WIPO's web page on universities and IP at https://www.wipo.int/about-ip/en/universities_research/. To support its activities, WIPO has created an IP Policy Template for Universities and Research Institutions, Guidelines for Customization of the IP Policy Template, and an IP Policy Drafters' Checklist. 


\section{Trend toward Actively Motivating and Empowering Researchers to Participate in Knowledge Transfer}

The direct involvement of academic researchers has proved to be a determinant in the success of knowledge transfer. This clearly calls for cultivating a culture that supports and encourages both invention disclosures and the participation of inventors in the transfer process. There is also a need for a better understanding of the strategies of the various types of inventor/researcher involved and their motivations to participate in the process.

To boost academic entrepreneurial activity, universities, and public research institutes are introducing an ever wider range of incentives for researchers, where IP and commercialization efforts receive greater rewards comparable to publications. Among the specific incentives are: generous royalty and equity terms; tying IP generation and research commercialization to career development; sufficient time to engage in IPrelated activities (leave of absence, course reductions, relief of admin responsibilities, etc.); research funding and infrastructure; internal commercialization support and mentoring; entrepreneurship education programs; recognition through awards and public acknowledgement, etc. Empirical findings seem to suggest that the influence of such incentives (both monetary and nonmonetary) is not always predictable, given the differences in motives, perspectives and cultures of the academic scientists.

Questions that merit further empirical investigation include:

- What drives academics to be engaged in the commercialization of their research outcomes?

- Which factors can have an impact on the attractiveness of academic incentives (such as differences between the researchers in terms of gender, age, research field, characteristics of the ecosystem in which they operate, the seniority of researchers)? Is it therefore possible that a variety of incentives may be required for different types of researchers?

- What is the effect of the royalty share allocated to researchers? A large share can potentially enhance technology licensing, whereas a lower share is more likely to boost spinoffs; at the same time, too low a share allocated to the institution may not be sufficient to cover overall costs and may challenge the quality of services their knowledge transfer offices (KTO) provide.

- Is giving inventors a share of the equity in a spinoff rather than a simple share of returns a more effective way to motivate, considering 
the higher levels of uncertainty over returns, but also the prospect of higher returns than might accrue to licensing?

- What kind of remuneration packages are necessary to attract highly skilled employees at the KTO, noting that internal policies may prevent institutes from providing competitive salaries?

- How can the efficiency of institutes' support services be improved (e.g., by creation of an association of KTOs to pool support efforts)?

- How does the existence of competing incentives affect the engendering of an entrepreneurship culture, considering that researchers tend to have multiple "principals" (mainly the university itself, heads of departments, KTO, research council, government and external agencies) who often incentivize different outputs?

To evaluate the effectiveness of their incentives program, institutes must also establish comprehensive and systematic performance indicators, including some specific to IP-based commercialization. Empirically grounded metrics are critically important to an effective incentive structure. An important caveat is that incentive structures tend to be too focused on the supply side, which is the ability of the university to transfer knowledge. Attention needs also to be paid to the demand side, which involves the demand from industry for assistance in resolving problems and the region's ability to absorb the research results.

\section{Trend toward Socially Responsible Research Commercialization}

It would appear that entrepreneurial institutions around the world face more pressure to be responsive to the needs of society and environmental issues. The growing concern of this social dimension of higher education calls for resolute efforts to devise strategies that will establish them as drivers of societal well-being, while identifying the right indicators to monitor socioeconomic benefit flowing from such engagement. Successful cases prove that institutes have the means at their disposal to integrate a social dimension in their knowledge transfer practices (including those that are IPR-based), such as creating research programs directed to solving social and environmental problems; anticipating which technologies may have applications that address important unmet social needs; adopting socially responsible licensing provisions that increase the availability of medicines and environmental technologies in developing countries; retaining the right to grant additional licenses to manufacturers of generic drugs; negotiating licensing terms 
that allow third parties to access and distribute the innovation and its derivative products; promoting the creation of spinoffs; participation in community-based research; etc. In addition to those, the chapter presents a set of levers for preventing the potentially negative impacts of IPRbased knowledge transfer.

While policymakers and institutes tend to collect and employ mostly quantitative performance indicators to capture scientific productivity and commercial outcomes, the local/regional impact of universities and public research institutes extends far beyond knowledge transfer and tangible outputs (in terms of human capital attraction, formation of entrepreneurship capital within a locale, informal networks, new ideas, etc.). However, as the chapter indicates, establishing clear causal relationships between IPR-based knowledge transfer and these societal benefits is hard. Accordingly, statistics on the number of licenses issued or the number of spinoffs established do not effectively do justice to answering the question of how institutions address tangible socioeconomic outcomes.

Despite the fact that there is a trend afoot in some high-income countries to assess the success of knowledge transfer using alternative criteria, such as social impact or contribution to welfare, there is still no consensus on a set of systematic social impact measurements.

\section{Concluding Observations}

There is no magic formula for harnessing public research for innovation, given that different factors and levels of support interventions affect knowledge transfer outcomes. At the same time, there are magical "elements" or "factors" that the success stories have in common. The chapter does a nice job in elucidating such success factors at the country and institutional level. It is, however, important to note that success is a result of more collaborative efforts within an innovation ecosystem. For example, Yale's success in creating the biotech cluster is to a large extent due to the fact that it implemented changes in collaboration with other players in the region, to push for local economic impact. Countries also need to put into practice initiatives that promote and strengthen academia and business collaborations. One example in Brazil is the ITec platform, which was financed by the Ministry of Science \& Technology and counts on the participation of companies and universities to feed the framework of demands and offers. 
At the micro/institutional level, two efforts deserve closer attention and empirical investigation, namely, getting appropriate incentive structures and the commitment to socially responsible commercialization.

The transformation of institutes to become more entrepreneurial may be supported by creating new incentives and performance-linked criteria for researchers. How academic incentives work, and how they can be used to achieve intended results, remains a contested issue. In the university and public research institute contexts, the pursuit of science and innovation driven by external incentives, especially financial rewards, is considered by some as going against the traditional values of academia. However, international experience shows that institutionalizing an efficient incentive program is a critical precondition for increasing opportunities for commercializing university inventions. The challenge for institutes lies in selecting the types of incentive and their associated metrics, based on the institute's mission, culture, and goals, and the country's innovation ecosystem.

Socially responsible entrepreneurship is in large part a cultural attribute. Institutes can do their bit to encourage its development by, for instance, formulating policies that promote ethically acceptable and socially desirable knowledge transfer coupled with appropriate performance indicators. It would appear that institutes still struggle with (1) defining what "socially responsible" means and (2) measuring the extent to which their socially responsible policies and practices have meaningful impact. Maintaining a system of comprehensive indicators, including variables that can also measure social impact, is crucial for any country, regardless of its level of development, to help institutes better evaluate their roles in the creation of regional innovation and social value through research commercialization. 


\title{
Evaluating Knowledge Transfer Policies and Practices: Conceptual Framework and Metrics
}

\author{
ANTHONY ARUNDELANDSACHA WUNSCH-VINCENT
}

\subsection{Introduction}

As outlined in Chapter 1, a common policy goal in both high- and middleincome countries is to increase the commercialization of research findings produced by the public research sector in order to support economic growth. This process involves the transfer of knowledge produced by public research organizations, including both universities and public research institutes, to private sector businesses or government agencies.

A diverse range of policies have been implemented in many countries to encourage knowledge transfer, including the establishment of knowledge transfer offices (KTOs) ${ }^{1}$ at universities and public research institutes. Other policies include support for open publication and close collaboration between universities/public research institutes and businesses. One important issue is how to evaluate the success of these policies in terms of their economic impacts and their effect on various actors within an innovation system. Possible evaluation methods include case studies and the collection and analysis of knowledge transfer metrics. The latter have often involved the use of IP licensing data.

IP licensing is only one of several channels for transferring knowledge produced by universities and public research institutes to private firms. However, it is an important focus for research on knowledge transfer, both in the research reported in this book and in the academic literature. The research focus on IP licensing partly reflects its importance to knowledge transfer policies in developed countries, as described in Chapter 1, and partly reflects the widespread

${ }^{1}$ KTOs were originally known as "technology transfer offices," or TTOs. The use of "TTO" has fallen out of favor because transferred knowledge can be nontechnological, such as the rights to biological tissue or software programs. 
availability of relevant data, in contrast to a lack of data for other knowledge transfer channels.

This chapter provides a conceptual framework for the country case studies included in this book, and identifies the most commonly used metrics for knowledge transfer mediated by the licensing of IP. It describes different methods of knowledge transfer, policies and practices for supporting knowledge transfer (particularly via IP), and the costs and benefits of IP licensing. One key message from the chapter is that reliance on IP metrics may underestimate the extent of knowledge transfer in the economy and that informal methods of transfer may be a precursor to more formal relationships.

\subsection{Channels of Knowledge Transfer}

The public research sector has three main roles that are supported by government policy. The first is to create trained and educated citizens, the second is to push the frontiers of knowledge by undertaking cutting edge research, and the third is to support economic activity through several channels for transferring knowledge from universities and public research institutes to the business sector (see Figure 2.1). In recent years this third role of knowledge transfer is becoming increasingly important and is often referred to as the "third mission" of universities. Economically useful knowledge can also be transferred to government and nonprofit organizations. The transfer of knowledge to government often occurs through the procurement of research services, with the goal of improving public services or addressing social needs.

Knowledge transfer occurs through both informal and formal channels. Informal channels include reading the literature, attending conferences, hiring trained graduates, ${ }^{2}$ and discussions via personal contacts. These have also been combined under the rubric of "open science" because they make knowledge publicly available at little or no cost (Cohen et al. 2002). Formal channels include licensing, collaboration and research agreements, and contracting-out. In general, informal channels do not require the recipient of the knowledge to make a payment to the institution via a contract, whereas formal channels use a contract to mediate payment. Knowledge can be transferred entirely through informal channels, entirely through

${ }^{2}$ See Foray and Lissoni (2010). Hiring university graduates is one of the most important channels from the perspective of businesses, but is arguably not a formal channel because it does not require a contract with a university. Conversely, hiring academics for a limited period of time, such as in a personnel exchange, requires a contract between a business and a university. 


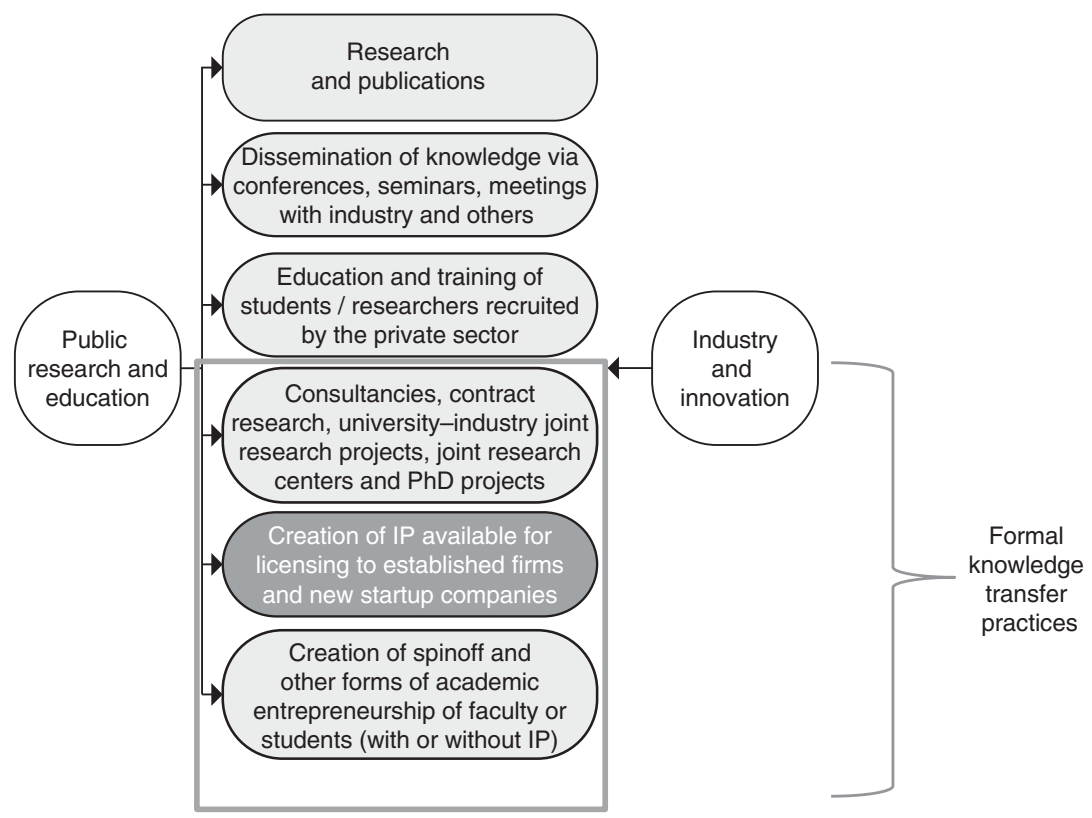

Figure 2.1 Knowledge transfer channels between the public research sector and businesses

Source: WIPO (2011)

formal channels, or through a combination of both, for instance, when informal discussions lead to a research agreement that results in an IP license.

It is important to place knowledge flows from public research to firms in context. They play only a minor role in the flow of knowledge within an innovation system. A 2010 survey of manufacturing firms in the United States of America (U.S.) found that 49 percent of firms obtained the invention behind their most important innovation from external sources, attesting to the importance of knowledge flows to an innovation system, but only 10 percent of them reported that this invention was from a university. Importantly, however, inventions obtained from technology specialists, including universities, were of higher value than inventions obtained from other sources such as customers or suppliers and 37 percent of inventions obtained from technology specialists were based on a formal channel (Arora et al. 2016). ${ }^{3}$

3 The authors do not break down the use of formal channels within the category of technology specialists, which includes universities, independent inventors, and consultants/service providers. 
A consistent issue, identified in multiple studies, is the dependence of knowledge transfer on the ability of firms, particularly firms in the region where the university or public research institute is located, to absorb or use inventions produced by public research. Research shows that knowledge transfer activities increase with the technological capabilities of domestic or regional firms (Van Looy et al. 2011; Curi et al. 2012; HewittDundas 2012; Calderón-Martínez and García-Quevedo 2013; Okamuro and Nishimura 2013; Hussain et al. 2014; Ranga et al. 2016). This is an important issue in low- and middle-income countries and for regional institutions in developed countries, where firms may lack sufficient absorptive capacity (see Chapter 10). In addition to regional differences, firms that rely on informal personal contacts are smaller and have lower levels of absorptive capacity than firms that use formal knowledge transfer methods (Freitas et al. 2013).

Not surprisingly, firm involvement in knowledge transfer from public research organizations increases with the firm's R\&D intensity (Freitas et al. 2013; Okamuro and Nishimura 2013; Kafouros et al. 2015). One study also finds that firm involvement with universities increases with the number of universities in a region, possibly because it increases the probability of a good match between the needs of firms and what universities can offer, or because greater competition between universities increases the flexibility of academic and KTO staff (Okamuro and Nishimura 2013).

Albuquerque et al. (2015) describe an international survey on the use of different knowledge channels by firms in low and middle-income countries in Africa, Asia and Latin America. In two low-income countries (Nigeria and Uganda) informal methods dominate (Kruss et al. 2015), whereas in middle-income countries in Asia (China, Malaysia, and Thailand) the most common methods are consultancy and research contracts (Schiller and Lee 2015). One explanation for the importance of contractual relationships in Asia is their usefulness in building innovative capacity and problem-solving abilities in firms. In four middle-income Latin American countries (Argentina, Brazil, Costa Rica, and Mexico), both contracts and informal channels are used more frequently than IPmediated methods (Dutrénit and Arza 2015).

From a public policy perspective, providing information to businesses at no cost via informal channels will be beneficial if it increases the number of businesses that use the information to develop commercial products and processes. In addition, competition will reduce costs for 
consumers. The exception is when no business will invest in commercializing knowledge without an exclusive license, for instance, when the cost of commercializing knowledge is high but the cost for competitors to copy it is low. In this case, public research institutes and universities need to be able to provide firms with exclusive licenses to IP-protected knowledge.

One of the main purposes of the 1980 Bayh-Dole Act in the U.S. was to allow public research organization to provide exclusive licenses. The Act also led to widespread adoption of the "IP licensing model" for knowledge transfer, defined in this book as the use of IP to mediate the transfer of knowledge. The IP licensing model has been widely used, even when IP is not required for firms to develop and commercialize knowledge, as when an exclusive license is not given. This is partly because universities and public research institutes were attracted by the potential income from both nonexclusive and exclusive licenses, as well as the need to recover the costs of maintaining a KTO. In addition, the IP licensing model can have other benefits, such as signaling the existence of inventions to firms.

Importantly, policies or research that account for only one type of linkage can provide only a partial understanding of the patterns of interaction between the public research sector and businesses. Nevertheless, the focus of this conceptual framework is on knowledge transfer systems that involve, at some point, formal transfer methods, while recognizing that many formal methods will originate in informal relationships between university researchers and private businesses.

\subsection{The Role of Policies and Practices in Promoting Knowledge Transfer}

Policies to support knowledge transfer between public research institutes and universities and firms should be designed to support multiple knowledge channels and should take into consideration the advantages and disadvantages of each channel and the suitability of different types of knowledge for specific channels. The role of KTOs has adapted over time to take these issues into account, with a greater recognition of the need for KTOs to support informal channels (for instance by arranging "meet and greet" events between academics and business), in addition to their traditional role in supporting the IP licensing model. 
Universities and public research institutes can also create a supportive environment for knowledge transfer through secondary activities such as educational programs to teach entrepreneurship to students and faculty and by creating innovation incubators and science parks (Rothaermel et al. 2007). Incubators and science parks can attract businesses to conduct some of their activities close to the university and encourage contacts with researchers and entrepreneurial students and staff.

Relevant policies and practices to support knowledge transfer occur at both the national and institutional level.

A review of existing policy research to date reveals a few important lessons (WIPO 2011). First, despite the general trend toward institutional ownership and commercialization of university/public research institute inventions, a diversity of legal and policy approaches persists in terms both of how legislation is anchored in broader innovation policy and of the specific rules on the scope of patenting, invention disclosure, incentives for researchers (such as royalty sharing), and whether safeguards are instituted to counteract the potentially negative effects of patenting. Second, there is a large variation in the means of implementing such legislation, as well as the available complementary policies to enhance the impact of public $\mathrm{R} \& \mathrm{D}$ and to promote academic entrepreneurship.

\subsubsection{National and Institutional Policies and Practices to Support Knowledge Transfer}

The most common national policy of direct relevance to knowledge transfer concerns the ownership of IP developed in the public research sector. In some countries, such as the U.S., national laws give ownership to the institution, other countries, Sweden, for instance, assign ownership to the inventor, while yet others, such as Canada, leave the decision to the institution.

An extensive literature exists on the factors that are linked to successful knowledge transfer by KTOs, but there is only limited research on the effect of institutional practices at the level of the university or public research institute (Barjak et al. 2015; Belenzon and Schankerman 2009). Relevant practices include:

- activities to create an institutional culture that supports knowledge transfer; 
- the establishment of institutional strategies for knowledge transfer and commercialization, such as rules for transparency in contract negotiations;

- incentives for staff to disclose inventions and support knowledge transfer by working with potential licensees;

- policies that encourage academic startups, such as allowing faculty to create and own a share in a startup or to take a leave of absence, the provision of finance, and supportive infrastructure such as incubators and science parks.

Overall, the evidence stresses the importance of a well-defined IP policy. Universities with internal rules supporting the participation of researchers in knowledge transfer perform better than universities without such rules (Debackere and Veugelers 2005). Further discussion of the effect of institutional policies on knowledge transfer is provided in Chapter 10.

\subsection{Costs and Benefits of the IP Licensing Model}

Since knowledge transfer can occur through multiple channels, an important policy goal is to ensure that the IP licensing model will drive knowledge transfer and business innovation while at the same time preserving open science (Foray and Lissoni 2010) and the benefits of other contractual or informal channels for knowledge transfer (Rosli and Rossi 2014; Veugelers 2016). ${ }^{4}$ Combining informal and formal channels can have a positive effect on innovation outcomes (Siegel et al. 2003; Link et al. 2007; Grimpe and Hussinger 2013). The use of both channels could be especially important to spinoffs (Hayer 2016).

Maintaining multiple channels and supporting positive synergies among them depends on maximizing the advantages and minimizing the disadvantages of existing and potential policy approaches. Effective outcomes also depend on the specific details of IP policy implementation at the national, regional and institutional levels.

The potential costs and benefits of the IP licensing model, as discussed in the literature, are summarized in Tables 2.1 and 2.2. Table 2.1 distinguishes between possible benefits and costs for the two respective main

${ }^{4}$ Czarnitzki et al. (2016) find that the change in Germany from professor's privilege (academics may own the IP) to institutional ownership did not result in an increase in new startups, possibly because the new policy interfered with the previous knowledge transfer system that was based on academic-firm interactions. 
Table 2.1 Impacts of IP-based knowledge transfer policies on universities/ public research institutes and firms

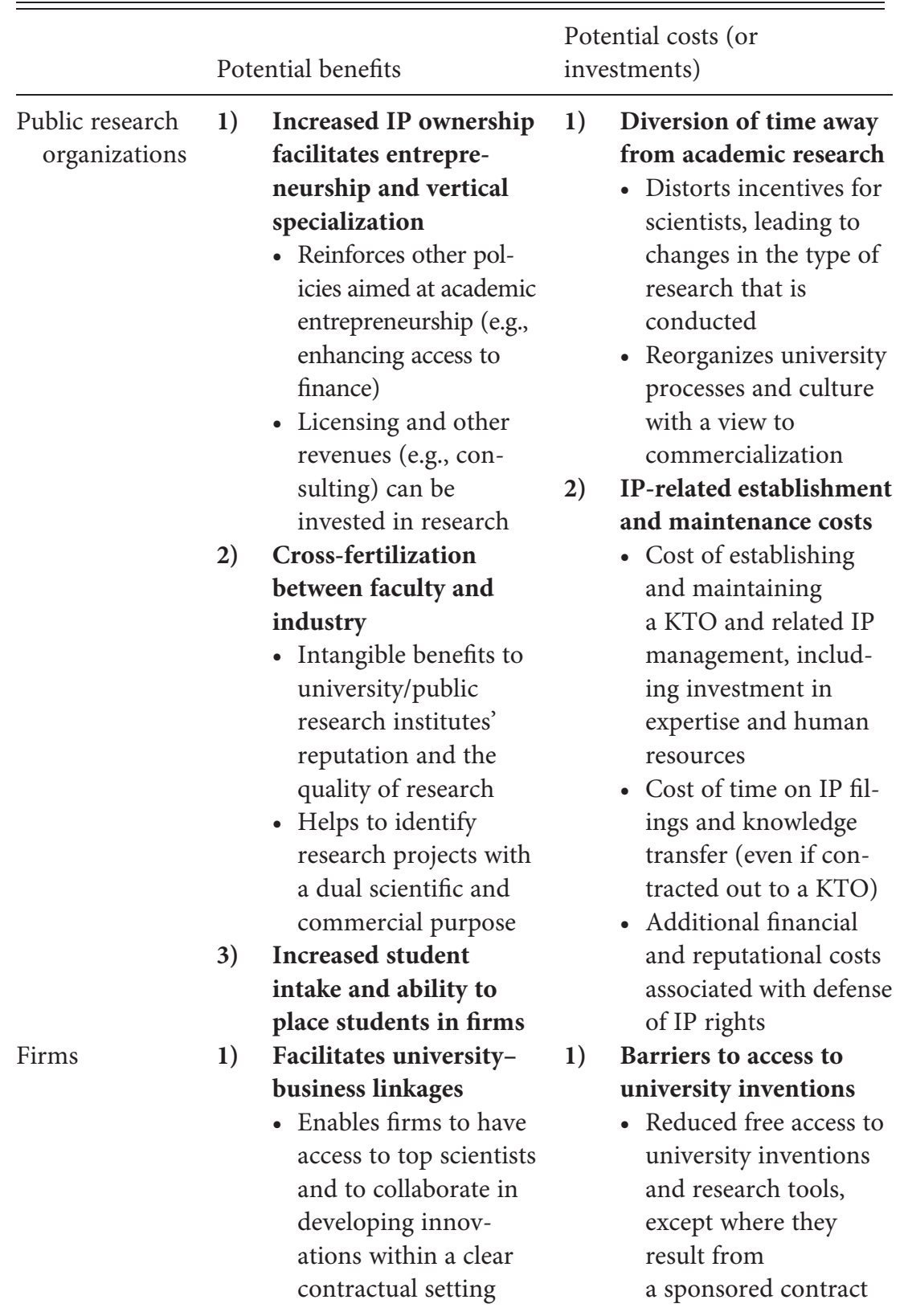


Table 2.1 (cont.)

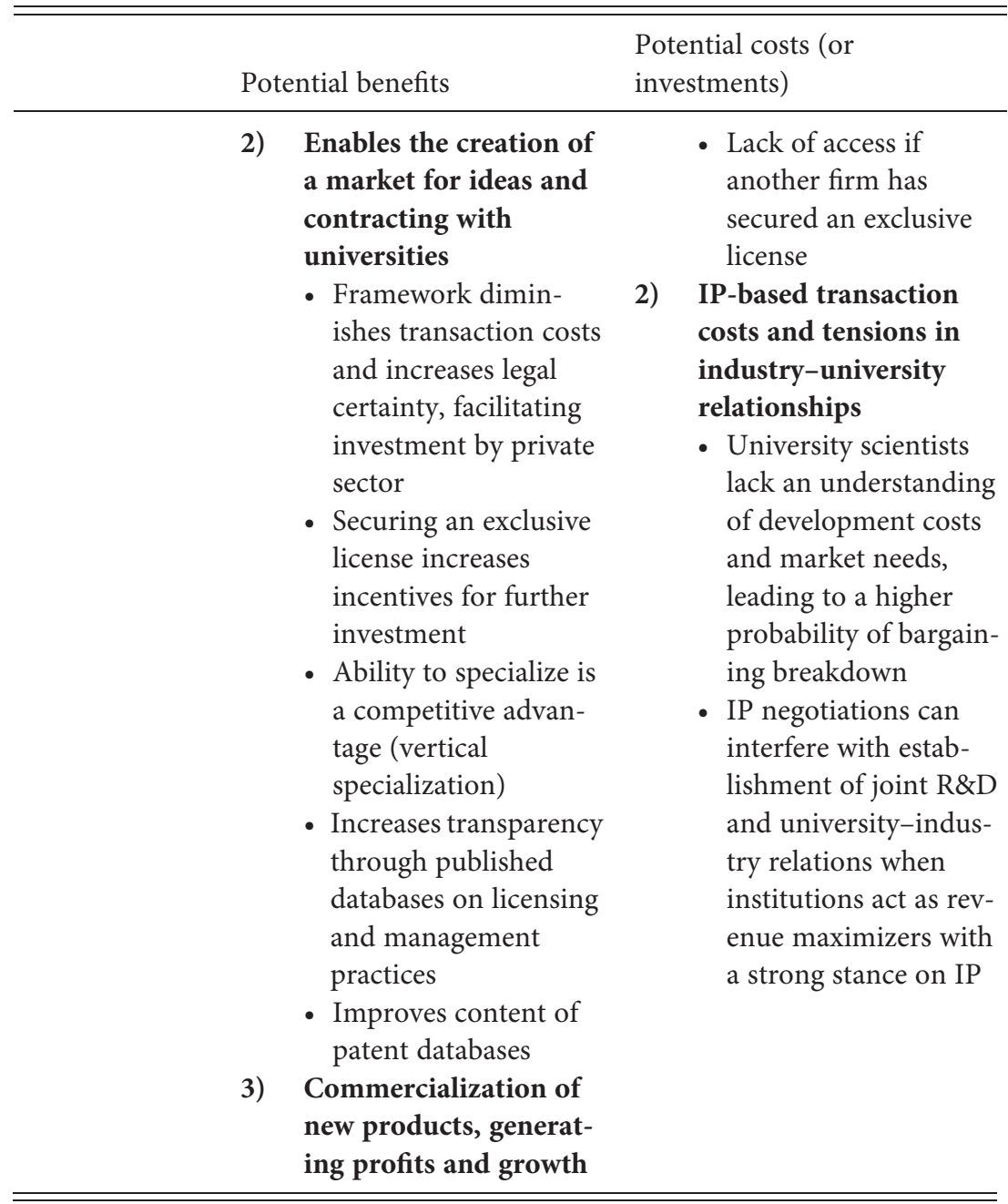

Source: Authors

agents (firms and public research organizations), while Table 2.2 summarizes the systemic impacts of IP licensing on science, the economy, and society. Table 2.3 adds additional notes of relevance to middleincome countries (WIPO 2011; Zuñiga 2011). 
Table 2.2 Socioeconomic effects of IP-based knowledge transfer policies

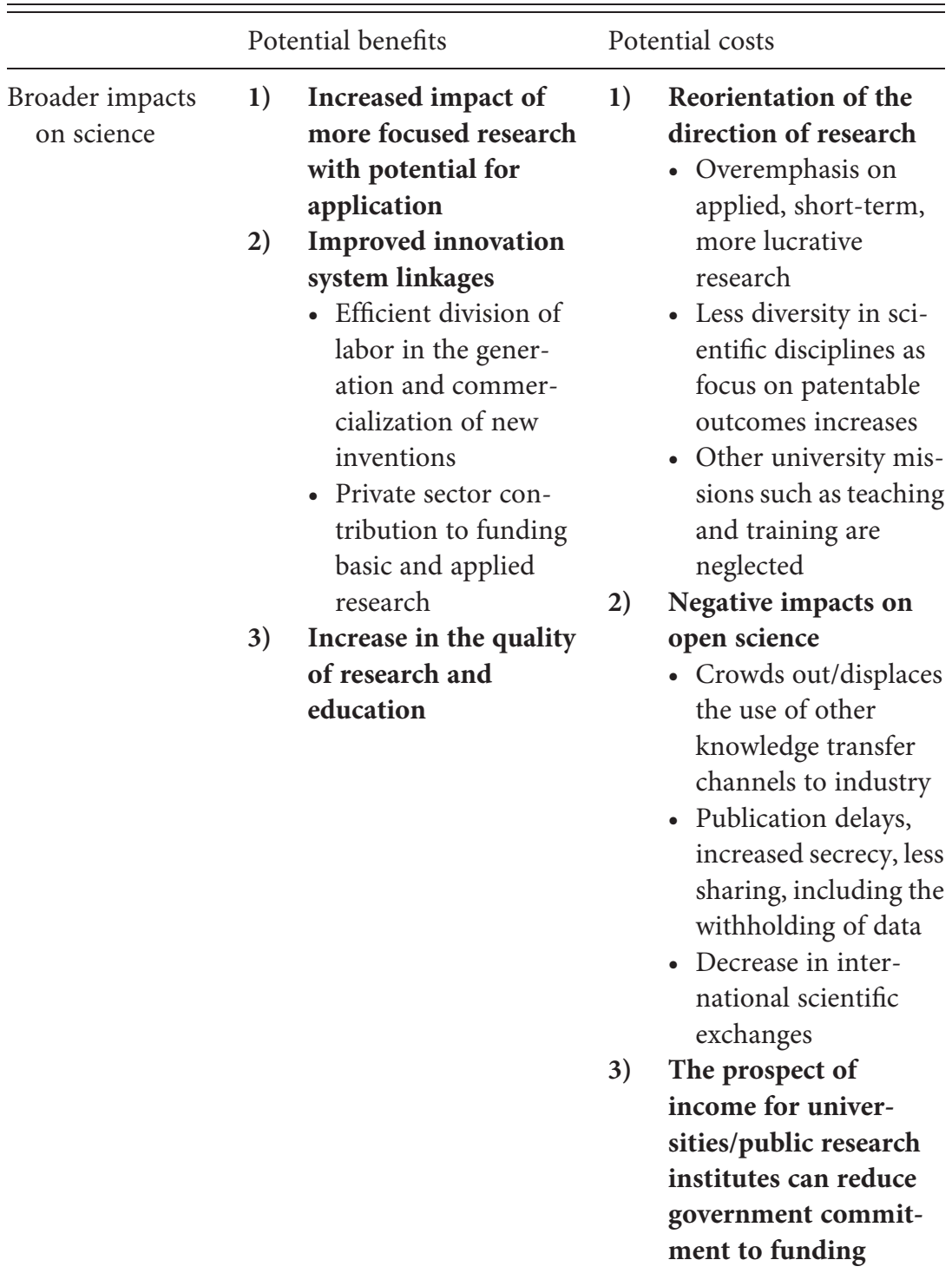


Table 2.2 (cont.)

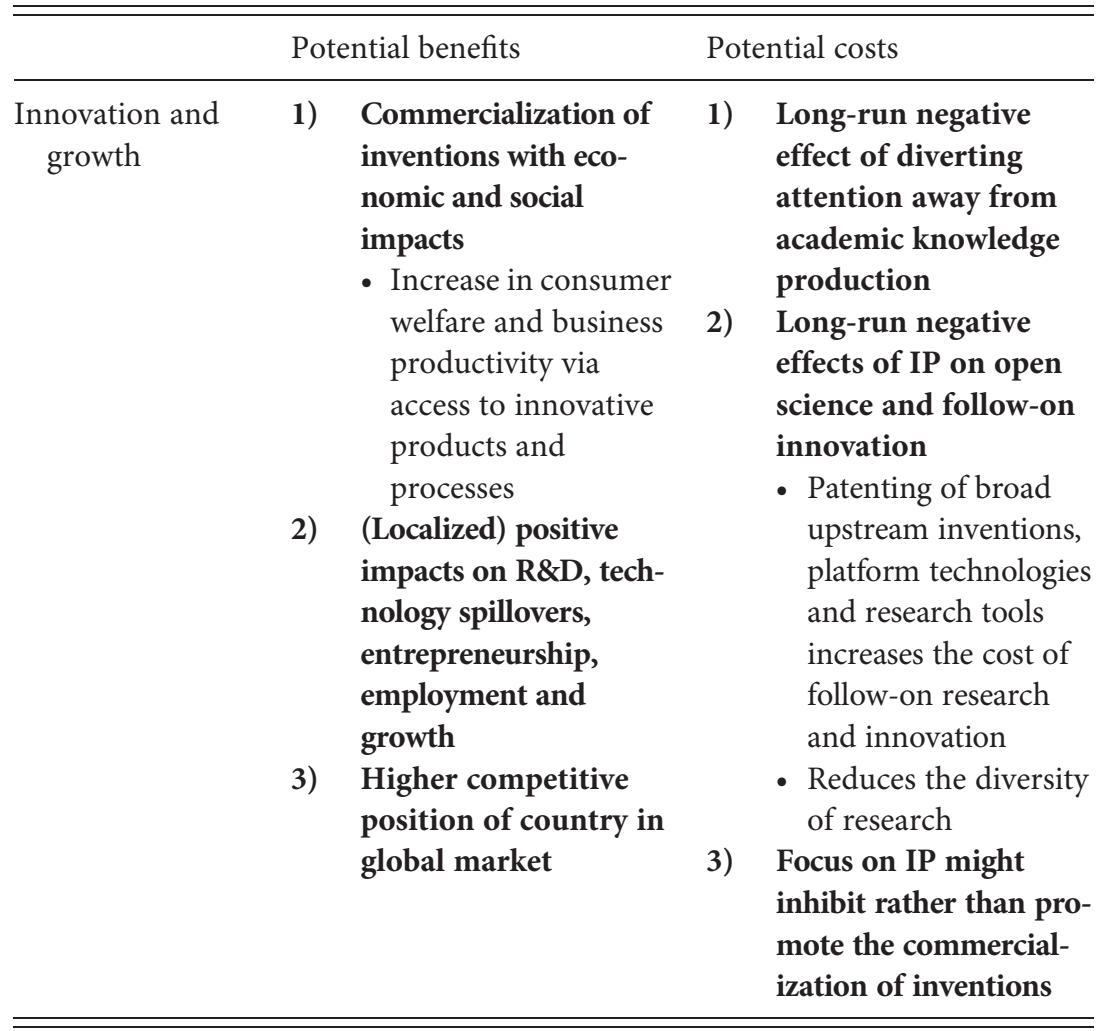

Source: Authors

\subsubsection{Advantages}

Due to data availability (discussed in section 4), we know more about the IP licensing model in high- and middle-income countries than other forms of knowledge transfer. Patents are the classic form of IP, but IP is also used to protect plant varieties (plant breeders' rights), biological tissue, knowhow (protected under secrecy), industrial designs, and copyright (relevant to software outside the U.S.). ${ }^{5}$

Studies show that the IP licensing model has supported the emergence of new industries, such as the scientific instruments industry, semiconductors, computer software, and the nano- and biotechnology industries (Rosenberg

${ }^{5}$ Trademarks constitute another form of IP, but are rarely licensed by universities or public research institutes. 
Table 2.3 Impacts on low-and middle-income countries

Potential benefits

1) All the benefits mentioned above (see Tables 2.1 and 2.2)

This depends, however, on the capacity of businesses to absorb and further develop university inventions - either by domestic firms or by locally present multinational firms - and whether or not these inventions are relevant to the needs of low- and middleincome countries

2) Ability to contribute to local or global markets for university inventions

This depends on the capacity to generate university inventions and file patents

University inventions might also attract the presence of multinational companies and their associated complementary R\&D

Strengthened science-industry links could help reorient research toward local needs

3) Improved visibility of public research inventions

Local firms may find it easier to identify relevant inventions and academics through patent searches than through searches of academic literature
Potential costs

1) All the above-mentioned costs (see Tables 2.1 and 2.2), some of which are amplified given the greater resource constraints of less-developed economies

- Reduced or no access to critical technologies owned by universities in high-income countries

- Overemphasis on applied, lucrative projects may lead to less useful inventions from the point of view of low- and middle-income countries

- The decrease in international scientific exchanges and a reduced willingness of institutions in highincome countries to collaborate as a result of more complex IP ownership issues and secrecy

- High cost of obtaining international patent protection for university inventions and resulting opportunity costs

Source: Authors

and Nelson 1994; Zucker et al. 1998; Di Gregorio and Shane 2003). Startups based on university/public research institute IP are also more likely than established firms to commercialize new technologies that are radical, early stage, or of a general-purpose nature. However, attributing these positive impacts exclusively to the IP licensing model is difficult in the absence of research on the role of other knowledge transfer channels. 
The IP licensing model has secondary benefits other than its primary objective of transferring a specific set of knowledge to one or more businesses. These other benefits depend on the ability of a patent to signal the presence of expertise within a university/public research institute via the information contained in it, which can lead to mutually beneficial collaborative and contract research agreements, placements for graduate students, funded $\mathrm{PhD}$ scholarships and improvements in research quality. The cross-fertilization of ideas, problems, and knowledge between universities/public research institutes and firms can facilitate joint problem solving and open up new avenues for research (Owen-Smith and Powell 2003; Azoulay et al. 2009). While this has been an ongoing trend in high-income economies over the last few decades, it has enormous potential benefits for low- and middle-income economies, particularly in building up the research capabilities of universities.

Many of the secondary benefits extend beyond unidirectional knowledge exchanges between universities or public research institutes and firms. Industrial research can complement and guide the direction of basic research. Contractual arrangements with firms can provide university scientists with funds to purchase advanced equipment and instruments.

The signaling function can also be met through publication in scientific and technical journals, but the focus of patents on inventions with commercial possibilities could have an advantage over publications, where commercial ideas could be more time-consuming (and therefore costly) for businesses to identify. Furthermore, the existence of patents signals the willingness of the institution to license knowledge.

\subsubsection{Disadvantages}

Open science is based on the norms of rapid disclosure of research results and an environment of knowledge sharing, co-authorship and joint projects that contribute to cumulative learning. The patenting of university inventions could have negative effects on these norms by slowing the diffusion of university inventions, including research tools. This could have an unintended effect of stifling private sector innovation (Eisenberg 1989; Heller and Eisenberg 1998; Kenney and Patton 2011). ${ }^{6}$ In particular, the exclusive licensing of patents to single firms could limit the

${ }^{6}$ Kenney and Patton (2011) note that the institutional arrangements within which KTOs are embedded have encouraged some of them to become revenue maximizers rather than facilitators of technology dissemination. 
diffusion of knowledge generated with public funds, reducing the diversity and number of follow-on innovations.

Moreover, strong IP policies could negatively affect other knowledge transfer channels that might be equally or more effective in supporting knowledge transfer under specific conditions. These include informal knowledge exchanges between businesses and academics as well as formal R\&D collaboration, which could be affected by the need for complex negotiations over IP rights.

The nonfinancial disadvantages of close university-industry linkages include a loss of academic freedom, a decline in basic research, ${ }^{7}$ a shift away from research of low commercial interest, and restrictions on or delays in publication due to the interest of commercial partners in secrecy (Van Looy et al. 2004; Tartari and Breschi 2012; Muscio and Pozzali 2013). Examples have been noted of companies restricting the findings of university researchers or researchers denying others access to their data (Campbell et al. 2000; Campbell et al. 2002). Despite these examples, none of the research to date has found strong negative effects that cannot be managed with good university codes of practice (Fabrizio and Di Minin 2008; Czarnitzki et al. 2009; Grimaldi et al. 2011).

The lack of strong evidence of negative impacts could be partly due to research designs that are unable to detect problems. For example, the importance of publication delays is likely to be greatest for early-career researchers such as $\mathrm{PhD}$ candidates and post-doctorates who need to build up a list of publications rapidly. Yet this possible effect is missed in studies that focus on heads of research groups or university departments. This could be one reason why a study of departmental heads finds that publication delays are given a low importance ranking as a barrier to collaboration with industry, whereas the choice of research ranks much higher (Muscio and Pozzali 2013).

The risk of industry exerting an undue influence on academic research is constrained by the small share of university R\&D that industry funds. ${ }^{8}$ In the U.S., for example, industry finances about 5 to 6 percent of all basic

7 Thursby and Thursby (2007) find a small decline in the number of publications in basic science journals in years in which academics disclose a discovery. This could be because disclosure creates work related to patenting and licensing that decreases the time available for basic research.

8 Official statistics show a modest but increasing share of industry-funded R\&D carried out in academia. This has increased in OECD countries from an average of 2.9 percent in 1981 to 6.6 percent in 2007. In Argentina, China, and the Russian Federation, firms also fund a stable or increasing percentage of academic $\mathrm{R} \& \mathrm{D}$. 
and applied academic R\&D, respectively, although its share (and likely influence) is much higher in health-related R\&D.

The adoption by universities of a proactive patenting strategy can create other disadvantages. Long delays in reaching an agreement over IP terms, or university actions to maximize their potential revenue (Alexy et al. 2009; Wadhwa 2011), ${ }^{9}$ can discourage university-industry collaboration. Firms can also be discouraged if institutions use a "one-size-fitsall" approach to patenting research results that ignores the evidence that patents and exclusive licensing play different roles in the development of complex versus discrete technologies (So et al. 2008).

Few studies have assessed the disadvantages of institutional IP strategies. Instead, studies show that often - and despite potential friction university IP, collaboration, and research productivity go hand in hand. Universities that collaborate more with industry also tend to have the most patents.

The IP licensing model could have negative effect on low- and mediumincome countries by raising the costs for businesses to license research tools, databases, and technologies (Boettiger and Bennett 2006; Engel 2008; So et al. 2008; Montobbio 2009). In particular, by increasing prices, stricter IP practices could hinder access to technologies in agriculture, health, and essential medicines that are of critical importance to less-developed economies (Boettiger and Bennett 2006). Another concern is that opportunities for scientific networking or collaboration between scientists in high-income and less-developed countries could be negatively affected by conflicts over university patenting strategies (Clemente 2006).

\subsubsection{Minimizing the Costs of IP-Mediated Knowledge Transfer}

Universities/public research institutes, funding agencies, donors, and governments have two levers for preventing or limiting the potentially negative impacts of IP-based knowledge transfer. First, the patenting and licensing of specific types of invention can be restricted. For instance, guidelines can demand that patents should be sought, and exclusive licenses attributed, only where they are a necessary condition for their commercialization. University policies and government bodies can also declare certain areas offlimits to university patenting: basic research, research tools, or technologies critical to public health in low-income countries.

${ }^{9}$ Firm managers have argued that it has distanced universities from firms in the U.S. and has been one reason why US firms collaborate more with firms abroad (Litan et al. 2008). 
Second, when inventions are patented, the type of and access to downstream licenses can be influenced by legislation or institutional policies. For instance, licensees of government-funded technologies can be required to disclose follow-on investment and the steps taken to commercialize the patent. The goal is to prevent firms from using licensed patents to block follow-on inventions by other firms. Other requirements can ensure that products derived from licensed inventions are sold to consumers or poorer countries on reasonable terms (OECD 2003; So et al. 2008). Field-of-use restrictions can be implemented to ensure that the IP is made available for future research, including to other firms. Governments can also reserve the right to practice the invention or override exclusive licensing rights ("march-in rights").

Universities and public research institutes are experimenting with a number of interesting additional approaches, such as open IP policies. These include patenting and licensing strategies (e.g., granting firms nonexclusive rather than exclusive licenses, making licenses available for free or at low cost if used for humanitarian or not-for-profit purposes or by small firms or startups in selected technologies), and providing easier access to research tools and to copyrighted works such as teaching materials, an often-neglected IP issue.

\subsection{Measuring Knowledge Transfer}

Table 2.4 lists the variety of possible knowledge channels, including informal channels consisting of "open science" and two types of formal channel. There is a lack of consistency in the literature on the definition of formal channels, with some studies combining consultancy and contract research with informal methods in order to focus on the difference between IPmediated channels and all other channels (Tartari and Breschi 2012; Abreu and Grenevich 2013). The formal channels are divided into those that support the creation of new knowledge by a university or public research institutes, and contractual methods for accessing existing knowledge produced by a university/public research institute via IP licensing. Table 2.4 also identifies the main data sources on knowledge transfer for each channel.

With a few exceptions, ${ }^{10}$ surveys show that the most common channels for both firms and academics in high-income countries are open

${ }^{10}$ Shapiro (2012) finds that firm managers in Korea give low importance to informal methods such as publications and conferences. Hiring is given the highest importance, followed by patents and contracts. 
Table 2.4 Knowledge transfer channels and data sources

\begin{tabular}{|c|c|c|}
\hline 1 & 2 & 3 \\
\hline Open science (informal) & Contractual (formal) & IP mediated (formal) \\
\hline $\begin{array}{l}\text { Training of firm staff by } \\
\text { institutions, placement } \\
\text { of postgraduates in } \\
\text { a firm for an internship }\end{array}$ & $\begin{array}{l}\text { Problem solving/ } \\
\text { consultancy with } \\
\text { academics }^{1}\end{array}$ & $\begin{array}{l}\text { Licensing of institutions' } \\
\text { IP (patents, copyright, } \\
\text { industrial designs, } \\
\text { plant breeder's rights, } \\
\text { knowhow, etc.) }\end{array}$ \\
\hline $\begin{array}{l}\text { Hiring university } \\
\text { graduates }\end{array}$ & $\begin{array}{l}\text { Research contracts } \\
\text { (research supported by } \\
\text { financial or in-kind } \\
\text { contributions from } \\
\text { government or } \\
\text { industry) }\end{array}$ & $\begin{array}{l}\text { Spinoffs/startups using } \\
\text { the institute's IP }\end{array}$ \\
\hline $\begin{array}{l}\text { Attending conferences or } \\
\text { workshops }\end{array}$ & $\begin{array}{l}\text { Collaborative R\&D } \\
\text { projects (joint funding } \\
\text { and participation by } \\
\text { the public organization } \\
\text { and government or } \\
\text { industry) }\end{array}$ & $\begin{array}{l}\text { Joint ventures using the } \\
\text { institute's IP }\end{array}$ \\
\hline \multicolumn{3}{|l|}{$\begin{array}{l}\text { Reading academic } \\
\text { literature }\end{array}$} \\
\hline \multicolumn{3}{|l|}{ Personal contacts } \\
\hline \multicolumn{3}{|l|}{$\begin{array}{l}\text { Access to advanced } \\
\text { facilities or equipment }\end{array}$} \\
\hline \multicolumn{3}{|l|}{ Data sources } \\
\hline $\begin{array}{l}\text { Surveys of firms or } \\
\text { academics }\end{array}$ & $\begin{array}{l}\text { Surveys of academics, } \\
\text { firms, or KTOs }\end{array}$ & $\begin{array}{l}\text { Surveys of KTOs, firms, } \\
\text { or public data sources }\end{array}$ \\
\hline
\end{tabular}

Source: Cohen et al. (2002); Cosh et al. (2006); Ramos-Vielba and FernándezEsquinas (2012); Tartari and Breschi (2012)

${ }^{1}$ KTOs may be unaware of many private consultancies between academics and firms, particularly if academics are not legally required to report private consultancies to their institution.

science, followed by contracts for the creation of new knowledge (Cohen et al. 2002; Siegel et al. 2003; Cosh et al. 2006; D'Este and Patel 2007; De Fuentes and Dutrénit 2012; Hughes and Kitson 2012; Grimpe and Hussinger 2013; Freitas et al. 2013; Okamuro and Nishimura 2013; 
Dutrénit and Arza 2015; Kafouros et al. 2015; Kruss et al. 2015; Schiller and Lee 2015). This is also partly reflected in the source of knowledge transfer income. In the United Kingdom, contract and collaborative research account for the majority of university income from knowledge transfer, with IP income accounting for only 2 percent to 4 percent of the total (Cosh et al. 2006; Zhang et al. 2016).

\subsubsection{Basic Metrics of Knowledge Transfer via Licensing}

Metrics include statistics and indicators. Relevant statistics for knowledge transfer include count data such as number of patent applications and the total amount of license income earned. Indicators standardize a statistic, for instance by providing the number of patent applications per 1,000 research academics in the sciences or the amount of license income earned per EUR 1 million in research expenditures. Both statistics and indicators need to refer to a defined time period such as one calendar year.

Indicators are essential for benchmarking performance. Using statistics to compare the number of invention disclosures among a group of universities would be seriously misleading if the group included universities with large differences in the number of academic staff or in the types of discipline. A university that focuses on law and the humanities is likely to have far fewer opportunities for consulting contracts than one that focuses on science, technology, and medicine.

There are three main reasons for collecting knowledge transfer metrics for licensing:

1. to benchmark knowledge transfer activities, for instance to permit comparisons in performance within an institution, across institutions, or over time;

2. for use in analyses to identify the factors that either support or hinder knowledge transfer; and

3. to inform policy, such as determining the effect of a change in policy on knowledge transfer outcomes.

These three reasons are linked because research on the factors that support knowledge transfer can use benchmarking data as an output measure, for example, in a study of the factors that increase the number of patents or the amount of license revenue. Plus, research on "what works" can be of value in developing or improving policies to support knowledge transfer. 


\subsection{Collecting Knowledge Transfer Metrics for Licensing}

The most common source of basic metrics is surveys of KTOs on activities that are part of the IP licensing model. These metrics are available on an intermittent or annual basis in many high-income countries, including the member states of the European Union, the U.S., Canada, Australia, and New Zealand. Most surveys of KTOs follow the definitions and standards set by the AUTM for its surveys of KTOs in the U.S. and Canada. The AUTM has been collecting metrics since the early 1990s.

Table 2.5 summarizes seven basic metrics from KTO surveys: the number of (1) invention disclosures, (2) patent applications, (3) patent grants, (4) research agreements, (5) license agreements, (6) startup establishments, and (7) total license revenue earned. None of these metrics is a direct measure of commercialization. Invention disclosures refer to an

Table 2.5 Basic metrics from KTO surveys

\begin{tabular}{|c|c|c|}
\hline & Statistic & Definition $^{1}$ \\
\hline 1 & $\begin{array}{l}\text { Number of invention } \\
\text { disclosures }\end{array}$ & $\begin{array}{l}\text { Descriptions of inventions or discoveries } \\
\text { that are evaluated by the KTO staff or } \\
\text { other technology experts to assess their } \\
\text { commercial application }\end{array}$ \\
\hline 2 & Number of patent applications & $\begin{array}{l}\text { New priority patent applications. Exclude } \\
\text { double-counting, such as a patent } \\
\text { application for the same invention in } \\
\text { more than one patent jurisdiction }\end{array}$ \\
\hline 3 & Number of patents granted & $\begin{array}{l}\text { Technically unique patents granted. } \\
\text { Count a patent grant for the same } \\
\text { invention in two or more countries as } \\
\text { one technically unique patent. If } \\
\text { a technically unique patent grant has } \\
\text { been counted in a previous year, it may } \\
\text { not be counted again }\end{array}$ \\
\hline 4 & $\begin{array}{l}\text { Number of research } \\
\text { agreements }\end{array}$ & $\begin{array}{l}\text { All contracts where a firm funds the } \\
\text { university or public research institute to } \\
\text { perform research on behalf of the firm, } \\
\text { with the results usually provided to the } \\
\text { firm. Include collaborative agreements }\end{array}$ \\
\hline
\end{tabular}


Table 2.5 (cont.)

\begin{tabular}{|c|c|c|}
\hline & Statistic & Definition \\
\hline & & $\begin{array}{l}\text { where both partners provide funding } \\
\text { and share the results. Exclude cases } \\
\text { where the firm funds a research chair or } \\
\text { other research of no expected } \\
\text { commercial value to the firm }\end{array}$ \\
\hline 5 & Number of licenses executed & $\begin{array}{l}\text { Include all licenses, options and } \\
\text { assignments (LOAs) for all types of IP } \\
\text { copyright, knowhow, patents, etc. } \\
\text { Count multiple (identical) licenses with } \\
\text { a value of less than EUR } 500 \text { each as one } \\
\text { license. A license grants the right to use } \\
\text { IP in a defined field of use or territory. } \\
\text { An option grants the potential licensee } \\
\text { a time period to evaluate the technology } \\
\text { and negotiate the terms of a license. An } \\
\text { assignment transfers all or part of the } \\
\text { right to IP to the licensee }\end{array}$ \\
\hline 6 & Number of startups ${ }^{2}$ & $\begin{array}{l}\text { A new company expressly established to } \\
\text { develop or exploit IP or knowhow } \\
\text { created by the university/PRO and with } \\
\text { a formal contractual relationship for } \\
\text { this IP or knowhow, such as a license or } \\
\text { equity agreement. Include, but do not } \\
\text { limit to, spinoffs established by the } \\
\text { institution's staff. Exclude startups that } \\
\text { do not sign a formal agreement on } \\
\text { developing IP or knowhow created by } \\
\text { the institution }\end{array}$ \\
\hline 7 & Total license revenue earned & $\begin{array}{l}\text { Total income from all types of knowhow } \\
\text { and IP (patents, copyright, designs, } \\
\text { material transfer agreements, } \\
\text { confidentiality agreements, plant } \\
\text { breeders' rights, etc.) before } \\
\text { disbursement to the inventor or other } \\
\text { parties. Include license issue fees, } \\
\text { annual fees, option fees, and milestone, } \\
\text { termination and cash-in payments. }\end{array}$ \\
\hline
\end{tabular}


Table 2.5 (cont.)

\begin{tabular}{ll}
\hline \hline Statistic & Definition \\
\hline & $\begin{array}{l}\text { Exclude license income forwarded to } \\
\text { other institutions than those served by } \\
\text { the KTO or to companies }\end{array}$ \\
\hline \hline
\end{tabular}

Source: Authors

${ }^{1}$ The definitions follow those used by the AUTM, but have been adapted for simplicity and for use in countries other than the U.S. See European Commission (2009).

${ }^{2}$ Startups include both spinoffs established by university/public research institute staff using the institution's IP and new companies that take a license to commercialize an institution's IP, but do not include its staff.

unknown potential for commercialization, with many never patented or licensed. Patent grants can remain unlicensed, research agreements can result in no new knowledge of commercial value, and licenses may never lead to commercialized processes or products.

None of these seven metrics measures the successful commercialization of IP produced in universities and public research institutes - all are metrics of inputs into potential commercialization. ${ }^{11}$ The first three metrics (invention disclosures, patent applications, and patent grants) are the furthest from commercialization, but invention disclosures are the first step in an IP-mediated commercialization process. The next step, if an evaluation of the invention disclosure results in a decision that there is commercial potential, is to file a patent application or seek other forms of IP if a patent is not suitable.

The two metrics that are closest to commercialization are the number of startups established and license revenue earned. Licenses indicate that a firm has an interest in commercializing the licensed IP, but many licenses, particularly for generic technologies or research tools, fail to lead to the commercialization of new goods, services or processes. ${ }^{12}$ Similarly, research agreements and startups indicate that a firm is

${ }^{11}$ Kochenkova et al. (2015) note that there is very little research on the effect of policies to support knowledge transfer on commercialization outcomes, with most studies focusing on intermediate outcomes such as patent counts.

12 An example is the Cohen-Boyer patents, which covered a basic research technique that almost all firms active in biotechnology needed to license. Some of these firms were startups that never produced a commercial product. 
interested in the commercial potential of knowledge produced by institutions, but we do not know if the research agreement produced useful research results or if the startup was able to commercialize a product or process.

Identifying the commercialization of new knowledge produced by universities and public research institutes requires the ability to identify licenses that earn running royalties (royalties earned on and tied to the sales of products) or the ability to follow startups over time and determine if they commercialized IP obtained from the institution. Recent AUTM surveys have collected data on running royalties (AUTM 2015b) and "net product sales," which includes sales from IP licensed to startups. ${ }^{13}$ European KTOs have begun to track outcomes for startups, but there is not yet agreement on the types of outcome that should be collected over time (Arundel et al. 2013).

\subsubsection{Supplementary Metrics from KTOs}

In addition to the basic metrics covered in Table 2.5, KTO surveys can provide a variety of supplementary indicators of relevance to licensing. Table 2.6 lists supplementary indicators and their relevance to policy. The list is limited to indicators of value for benchmarking performance, the development of policies to support knowledge transfer and the ability of KTOs to efficiently manage patent portfolios.

A 2009 review of KTO metrics in Europe and the U.S. found that only two of the supplementary metrics listed in Table 2.6 were collected in most countries: the number of valid patents in the patent portfolio (item 3) and licenses by firm size (item 5). Data on exclusive and nonexclusive licenses were available only for the U.S. and Canada via the AUTM survey and in a Swiss survey (European Commission 2009), but questions on exclusive and nonexclusive patents have been included in later European surveys (Arundel et al. 2013).

Table 2.6 includes counts for PCT patent applications. These can be filed instead of a national application and lead to patent protection in up to 140 countries. The PCT is usually only used when the applicant wishes to acquire a patent in one or more nondomestic countries. In most countries, its use therefore indicates a higher-quality patent with good commercial potential.

13 Question S-3, AUTM (2015b). 
Table 2.6 Supplementary metrics from KTO surveys ${ }^{1}$

Statistic

Supplementary metrics for patents

1 Domestic patent applications or grants

2 Foreign patent applications or grants (USPTO, EPO, PCT, etc.)

$3 \quad$ Number of granted patents in the current portfolio that are valid (patent renewal fees have been paid)

\section{Supplementary metrics for licensing}

4 Number of patents in the current portfolio that have ever been licensed

5 Licenses by licensee type: startups, SMEs, regional firms, etc.

$6 \quad$ Exclusive and nonexclusive licenses
Policy use

These can be "entry-level" patents with limited commercial application, particularly if domestic patenting costs and/or the bar for a patent are low. A continuing high share of domestic patents out of total patents over time could indicate low commercialization potential or that too many low-value inventions are patented

Foreign patents in large markets such as the European Union or the U.S. indicate high commercialization potential. An increase in the share of foreign patents out of all patents indicates an improvement in inventive capabilities/commercialization opportunities over time

Combined with the next indicator, data on the size of the patent portfolio can be used to determine the share of patents that have ever been patented. This should increase over time as the KTO gains greater experience

The share should increase over time.

A stable or declining share could indicate that the KTO is applying for a patent for too many invention disclosures

The share of licenses to regional firms (SMEs or startups) is of interest if the government has a policy of encouraging local development. The disadvantage is that focusing on regional IP partners can reduce license revenue ${ }^{2}$

Nonexclusive licenses are income earners for universities/public research institutes, but are not necessary (no IP 
Table 2.6 (cont.)

\begin{tabular}{|c|c|c|}
\hline & Statistic & Policy use \\
\hline & & $\begin{array}{l}\text { is required) if the policy goal is to get as } \\
\text { many firms as possible to take up the } \\
\text { knowledge covered by the license }\end{array}$ \\
\hline 7 & $\begin{array}{l}\text { Licenses by type of IP (patents, } \\
\text { knowhow, copyright, etc.) }\end{array}$ & $\begin{array}{l}\text { Patentability is limited to specific types of } \\
\text { knowledge, with other types of IP } \\
\text { required for other types of knowledge. } \\
\text { Data on other types of IP used in } \\
\text { licensing can identify if the license } \\
\text { portfolio is commensurate with the } \\
\text { types of knowledge produced by the } \\
\text { university/public research institute }\end{array}$ \\
\hline 8 & $\begin{array}{l}\text { Licenses by technology field } \\
\text { (software, biomedical, } \\
\text { nanotechnology, etc.) }\end{array}$ & $\begin{array}{l}\text { Specific technology fields can dominate } \\
\text { licensing and license revenue (in } \\
\text { Europe, it is the biotechnology/medical } \\
\text { fields). Good benchmarking across } \\
\text { universities and public research } \\
\text { institutes should therefore be based on } \\
\text { comparing metrics by technology field } \\
\text { to compare like with like. Licensing by } \\
\text { field can also be an indicator for } \\
\text { decisions on research investments }\end{array}$ \\
\hline \multicolumn{3}{|c|}{ Supplementary revenue indicators } \\
\hline 9 & $\begin{array}{l}\text { License revenue from running } \\
\text { royalties/sales of products } \\
\text { based on university/public } \\
\text { research institute IP }\end{array}$ & $\begin{array}{l}\text { Measures of commercialization of } \\
\text { knowledge produced by universities/ } \\
\text { public research institutes }\end{array}$ \\
\hline \multicolumn{3}{|c|}{ Supplementary revenue indicators } \\
\hline 10 & $\begin{array}{l}\text { Startups that have } \\
\text { commercialized university/ } \\
\text { public research institute IP }\end{array}$ & $\begin{array}{l}\text { Measure of commercialization of } \\
\text { knowledge produced by universities/ } \\
\text { public research institutes }\end{array}$ \\
\hline 11 & $\begin{array}{l}\text { Startup sales of products from } \\
\text { university/public research } \\
\text { institute IP, employment in } \\
\text { startups with such sales }\end{array}$ & $\begin{array}{l}\text { Measure of commercialization of } \\
\text { knowledge produced by universities/ } \\
\text { public research institutes }\end{array}$ \\
\hline
\end{tabular}

\footnotetext{
Source: Authors

${ }^{1}$ For brevity, this table does not include foreign research agreements or licenses.

${ }^{2}$ Belenzon and Schankerman (2009) find that universities with strong local development objectives generate less license income but have more licenses to local startups.
} 
Standardized Indicators

The metrics in Tables 2.5 and 2.6 should be standardized for both internal and international comparisons. For instance, combining the number of current patents that have been licensed with the total number of valid patents in the university/public research institute's patent portfolio produces an indicator for the share of licensed patents. Many of the metrics can be standardized by calculating the rate per 1,000 academic staff or per USD 1 million in purchasing power parities for research expenditures. ${ }^{14}$ Table 2.7 describes these two standardization variables.

Collecting data on research expenditures is necessary in order to compare results with the U.S., as the AUTM does not collect data on the number of academics. Research expenditures are influenced by differences in purchasing power parities (PPP) in different countries. It is a simple matter to use PPP currency conversions, but PPPs are calculated for all economic costs, not just for research costs.

For international comparisons other than with the U.S., there are advantages in using the number of academics rather than research

Table 2.7 Variables for standardizing knowledge transfer office (KTO) metrics

\begin{tabular}{|c|c|c|}
\hline & Statistic & Policy use \\
\hline 1 & $\begin{array}{l}\text { Total number of academic staff } \\
\text { at a public research } \\
\text { organizations active in fields } \\
\text { with a potential for } \\
\text { commercialization }\end{array}$ & $\begin{array}{l}\text { All basic metrics and most of the } \\
\text { supplementary metrics can be } \\
\text { standardized per } 1,000 \text { academic staff. } \\
\text { Standardization per } 1,000 \text { academics is } \\
\text { less relevant for the supplementary } \\
\text { licensing metrics }\end{array}$ \\
\hline 2 & $\begin{array}{l}\text { Total research expenditures in } \\
\text { fields with a potential for } \\
\text { commercialization }\end{array}$ & $\begin{array}{l}\text { As above, but this information is } \\
\text { necessary to compute standardized } \\
\text { metrics for comparison with the AUTM } \\
\text { surveys for the U.S. and is also required } \\
\text { to calculate the license income share of } \\
\text { total research expenditures }\end{array}$ \\
\hline
\end{tabular}

14 Arundel and Bordoy (2010) explore the possibilities and difficulties of developing internationally comparable output indicators for the commercialization of public science. 
expenditures to produce standardized indicators. The number of academic staff in full-time equivalents (FTEs) is possibly more comparable across studies. National differences per 1,000 academics can also be a useful (albeit not an ideal) indicator of academic performance. An alternative is to standardize by the number of peer-reviewed publications (or a quality-adjusted publication measure) per 1,000 academics. Publication counts are positively correlated with patent applications (Van Looy et al. 2011; Berbegal-Mirabent and Sabate 2015).

Metrics for the Characteristics of the KTO and its Institution

For econometric research, it is important to collect control variables on the characteristics of the KTO itself and the institution to which it is responsible. Relevant KTO variables include its age and number of staff and, if possible, the area of expertise of KTO staff and the KTO budget. The KTO's age is particularly important to obtain because it has a significant effect on many knowledge transfer outcomes, due to a positive relationship between KTO age and institutional experience and knowledge transfer activities (Friedman and Silberman 2003; Conti and Gaule 2011; Berbegal-Mirabent and Sabate 2015).

Data should also be collected on several characteristics of the public research institutes and universities that can influence knowledge transfer activities, including:

- the location of the institution in a dynamic region near innovative firms, venture capital, etc.;

- the size and type of the institution: private universities with a commercial orientation can be more active than public universities;

- the portfolio of disciplines, some of which are more prone to knowledge transfer, such as biomedical research;

- the research quality of the institution, its reputation and network; and

- the extent of existing collaboration between the institution and firms.

\subsection{Conclusions}

This chapter describes the different channels that are used by universities, public research institutes, and firms to transfer knowledge between them and the role of policies and institutional practices in supporting knowledge transfer. The chapter largely focuses on the IP licensing model, due to extensive academic research on this channel and data availability, but 
it is essential for a full understanding of knowledge transfer to also evaluate the role of informal and contractual knowledge transfer channels, as summarized in Table 2.4. Several of the country studies in this book take a more holistic perspective by evaluating the role of each channel and how these channels have changed over time in response to policy changes or economic development.

The collection of metrics on knowledge transfer via licensing is essential for benchmarking, identifying the factors that support or hinder knowledge transfer, and to inform policy. There are seven basic metrics that all countries should collect on the IP licensing model, plus supplementary metrics of relevance to specific policy issues, such as if licensing is benefiting domestic firms or the efficiency of IP use, as measured by the share of IP that is licensed. Additional metrics that would support a holistic perspective on knowledge transfer are discussed in Chapter 12.

\section{References}

Abreu, M. and V. Grenevich (2013). "The nature of academic entrepreneurship in the UK: widening the focus on E activities." Research Policy, 42(2), 408-22.

Albuquerque, E., W. Suzigan, G. Kruss, and K. Lee (eds.) (2015). Developing National Systems of Innovation: University-Industry Interactions in the Global South. Cheltenham: Edward Elgar.

Alexy, O., P. Criscuolo, and A. Salter (2009). "Does IP strategy have to cripple open innovation?" MIT Sloan Management Review, October 1.

Arora, A., W. M. Cohen, and J. P. Walsh (2016). "The acquisition and commercialization of invention in American manufacturing: incidence and impact." Research Policy, 45(6), 1113-28.

Arundel, A., F. Barjak, N. Es-Sakdi, F. Barjak, P. Perrett, O. Samuel, and S. Lilischkis (2013). Knowledge Transfer Study 2010-2012: Final Report. Luxembourg: Publications Office of the European Union.

Arundel, A. and C. Bordoy (2010). Developing Internationally Comparable Indicators for the Commercialization of Publicly-funded Research (UNU-MERIT Working Paper Series, 075). Maastricht: United Nations University - Maastricht Economic and Social Research Institute on Innovation and Technology (MERIT).

AUTM (2015a). 2014 Licensing Survey: Instructions and Definitions. www .autm.net/AUTMMain/media/Resources/Documents/AUTM_FY2014_ Licensing_Survey_Instructions_Definitions.pdf.

AUTM (2015b). 2014 Licensing Activity Survey Questionnaire. www.autm.net /AUTMMain/media/Resources/Documents/AUTM_FY2014_Licensing_ Survey_Questionnaire.pdf. 
Azoulay, P., W. Ding, and T. Stuart (2009). "The impact of academic patenting on the rate, quality and direction of (public) research output." Journal of Industrial Economics, 57(4), 637-76.

Barjak, F., N. Es-Sadki, and A. Arundel (2015). "The effectiveness of policies for formal knowledge transfer from European universities and public research institutes to firms." Research Evaluation, 24, 4-18.

Belenzon, S. and M. Schankerman (2009). "University knowledge transfer: private ownership, incentives and local development objectives." Journal of Law and Economics, 52, 111-44.

Berbegal-Mirabent, J. and F. Sabate (2015). "Balancing basic and applied research outputs: a study of the trade-offs between publishing and patenting." Technology Analysis \& Strategic Management, 27, 1143-58.

Boettiger, S. and A. B. Bennett (2006). "The Bayh-Dole Act: Implications for developing countries." IDEA: The Intellectual Property Law Review, 46(2), 259-79.

Calderón-Martínez, M. G. and J. García-Quevedo (2013). “Knowledge transfer and university patents in Mexico." Academia Revista Latinoamericana de Administración, 26, 33-60.

Campbell, E. G., B. R. Clarridge, M. Gokhale, L. Birenbaum, S. Hilgartner, N. A. Holtzman, and D. Blumenthal (2002). "Data withholding in academic genetics: Evidence from a national survey." Journal of the American Medical Association, 287(4), 473-80.

Campbell, E. G., J. S. Weissman, N. Causino, and D. Blumenthal (2000). "Data withholding in academic medicine: characteristics of faculty denied access to research results and biomaterials.” Research Policy, 29(2), 303-31.

Clemente, F.-P. (2006). "The impact of stronger intellectual property rights on science and technology in developing countries." Research Policy, 35(6), $808-24$.

Cohen, W., R. Nelson, and J. Walsh (2002). "Links and impacts: The influence of public research on industrial R\&D.” Management Science, 48, 1-23.

Conti, A. and P. Gaule (2011). "Is the US outperforming Europe in university technology licensing? A new perspective on the European paradox." Research Policy, 40(1), 123-35.

Cosh, A., A. Hughes, and R. K Lester. (2006). UK plc: Just How Innovative Are We? (Industrial Performance Centre Massachusetts Institute of Technology Working Paper Series). Cambridge and Cambridge, MA: MIT Institute.

Curi, C., C. Daraio, and P. Llerena (2012). "University technology transfer: How (in)efficient are French universities?" Cambridge Journal of Economics, 36(3), 629-54.

Czarnitzki, D., T. Doherr, K. Hussinger, P. Schliessler, and A.A. Toole (2016). "Knowledge creates markets: The influence of entrepreneurial support and 
patent rights on academic entrepreneurship." European Economic Review, 86, 131-46.

Czarnitzki, D., W. Glänzel, and K. Hussinger (2009). "Heterogeneity of patenting activity and its implications for scientific research.” Research Policy 38(1), 26-34.

D'Este, P. and P. Patel (2007). "University-industry linkages in the UK: What are the factors underlying the variety of interactions with industry?" Research Policy, 36(9), 1295-313.

De Fuentes, C. and G. Dutrénit (2012). "Best channels of academia-industry interaction for long-term benefit.” Research Policy, 41(9), 1666-82.

Debackere, K. and R. Veugelers (2005). “The role of academic technology transfer organizations in improving industry-science links." Research Policy, 34(3), 321-42.

Di Gregorio, D. and S. Shane (2003). "Why do some universities generate more start-ups than others?” Research Policy, 32(2), 209-27.

Dutrénit, G. and V. Arza (2015). "Features of interactions between public research institutes and industry in Latin America: The perspective of researchers and firms." In E. Albuquerque, W. Suzigan, G. Kruss, and K. Lee (eds.), Developing National Systems of Innovation: University-Industry Interactions in the Global South. Cheltenham: Edward Elgar.

Eisenberg, R. (1989). "Patents and the progress of science: exclusive rights and experimental use." University of Chicago Law Review, 56, 1017-55.

Engel, N. (2008). "University patenting and its effects: an assessment for developing countries.” In C. S. Krishna (ed.), Technology Transfer: Intellectual Property Rights. Hyderabad: Amicus Books/Icfai University Press.

European Commission (2009). Metrics for Knowledge Transfer from Public research institutes in Europe. Brussels: European Commission.

Fabrizio, K. R. and A. Di Minin (2008). "Commercializing the laboratory: Faculty patenting and the open science environment." Research Policy, 37(5), 914-31.

Fisch, C. O., J. H. Block, and P. G. Sandner (2016). "Chinese university patents: Quantity, quality, and the role of subsidy programs." Journal of Technology Transfer, 41, 60-84.

Fisch, C. O., T. M. Hassel, P. G. Sandner, and J. H. Block (2015). "University patenting: A comparison of 300 leading universities worldwide." Journal of Technology Transfer, 40, 318-45.

Foray, D. and F. Lissoni (2010). "University research and public-private interaction.” In B. H. Hall and N. Rosenberg (eds.), Handbook of the Economics of Innovation (Vol. 1). Amsterdam: North Holland.

Freitas, I. M. B., A. Geuna, and F. Rossi (2013). "Finding the right partners: Institutional and personal modes of governance of university-industry interactions." Research Policy, 42(1), 50-62. 
Friedman, J. and J. Silberman (2003). "University technology transfer: Do incentives, management, and location matter?” Journal of Technology Transfer, 28, 17-30.

Grimaldi, R., M. Kenney, D. S. Siegel, and M. Wright (2011). “30 years after Bayh-Dole: Reassessing academic entrepreneurship.” Research Policy, 40(8), 1045-57.

Grimpe, C. and K. Hussinger (2013). "Formal and informal knowledge and technology transfer from academia to industry: Complementarity effects and innovation performance." Industry and Innovation, 20, 683-700.

Hayer, C. S. (2016). "A trajectory of early-stage spinoff success: The role of knowledge intermediaries within an entrepreneurial university ecosystem.” Small Business Economics, 47, 633-56.

Heller, M. and R. Eisenberg (1998). "Can patents deter innovation? The anticommons in biomedical research." Science, 280, 698-701.

Hewitt-Dundas, N. (2012). "Research intensity and knowledge transfer activity in UK universities.” Research Policy, 41(2), 262-75.

Hughes, A. and M. Kitson (2012). "Pathways to impact and the strategic role of universities: New evidence on the breadth and depth of university knowledge exchange in the UK and the factors constraining its development." Cambridge Journal of Economics, 36, 723-50.

Hussain, W. M. H. W., M. N. A. Rahman, Z. A. Zainol, and N. I. Yaakub (2014). "Mechanism and government initiatives of promoting innovation and commercialization of university invention." Pertanika Journal of Social Sciences and Humanities, 22, 131-48.

Kafouros, M., C. Q. Wang., P. Piperopoulos, and M. S. Zhang (2015). “Academic collaborations and firm innovation performance in China: The role of region-specific institutions," Research Policy, 44(3), 803-17.

Kearnes, M. and M. Wienroth (2011). "Tools of the trade: UK research intermediaries and the politics of impacts.” Minerva, 49, 153-74.

Kenney, M. and D. Patton (2011). "Does inventor ownership encourage university research-derived entrepreneurship? A six university comparison," Research Policy, 40(8), 1100-12.

Kochenkova, A., R. Grimaldi, and F. Munari (2015). "Public policy measures in support of knowledge transfer activities: A review of academic literature." Journal of Technology Transfer, 41, 407-29.

Kruss, G., J. O. Adeoti, and D. Nabudere (2015). "Bracing for change: Making universities and firms partners for innovation in sub-Saharan Africa." In E. Albuquerque, W. Suzigan, G. Kruss, and K. Lee (eds.), Developing National Systems of Innovation: University-Industry Interactions in the Global South. Cheltenham: Edward Elgar.

Link, A. N., D. S. Siegel, and B. Bozeman (2007). "An empirical analysis of the propensity of academics to engage in informal university technology transfer." Industrial and Corporate Change, 16(4), 641-55. 
Litan, R. E., L. Mitchell, and E. J. Reedy (2008). "Commercializing university innovations: Alternative approaches." In A. B. Jaffe, J. Lerner, and S. Stern (eds.), Innovation Policy and the Economy (Vol. 8). Cambridge, MA: MIT Press.

Montobbio, F. (2009). "Intellectual property rights and knowledge transfer from public research to industry in the US and Europe: Which lessons for innovation systems in developing countries?" In The Economics of Intellectual Property: Suggestions for Further Research in Developing Countries and Countries with Economies in Transition. Geneva: World Intellectual Property Organization.

Muscio, A. and A. Pozzali (2013). "The effects of cognitive distance in university-industry collaborations: Some evidence from Italian universities." Journal of Technology Transfer, 38(4), 486-508.

OECD (2003). Turning Science into Business - Patenting and Licensing at Public research institutes. Paris: Organisation for Economic Co-operation and Development.

Okamuro, H. and J. Nishimura (2013). "Impact of university intellectual property policy on the performance of university-industry research collaboration." Journal of Technology Transfer, 38(3), 273-301.

Owen-Smith, J. and W. W. Powell (2003). "The expanding role of university patenting in the life sciences: Assessing the importance of experience and connectivity." Research Policy, 32(9), 1695-711.

Ramos-Vielba, I. and M. Fernández-Esquinas (2012). "Beneath the tip of the iceberg: Exploring the multiple forms of university-industry linkages." Higher Education, 64, 237-65.

Ranga, M., S. Temel, I. M. Ar, R. B. Yesilay, and F. V. Sukan (2016). "Building technology transfer capacity in Turkish universities: A critical analysis." European Journal of Education, 51, 90-106.

Rosenberg, N. and R. R. Nelson (1994). "American universities and technical advance in industry." Research Policy, 23(3), 323-48.

Rosli, A. and F. Rossi (2014). Explaining the Gap between Policy Aspirations and Implementation: The Case of University Knowledge Transfer Policy in the United Kingdom (CIMR Research Working Paper Series no. 20). London: Birkbeck.

Rothaermel, F. T., S. D. Agung, and L. Jiang (2007). "University entrepreneurship: A taxonomy of the literature." Industrial and Corporate Change, 16(4), 691-791.

Schiller, D. and K. Lee (2015). "Are university-industry links meaningful for catch up? A comparative analysis of five Asian countries." in E. Albuquerque, W. Suzigan, G. Kruss, and K. Lee (eds.), Developing National Systems of Innovation: University-Industry Interactions in the Global South. Cheltenham: Edward Elgar.

Shapiro, M. A. (2012). "Receiving information at Korean and Taiwanese universities (add-on by WIPO, Taiwan, Province of China), industry, and GRIs." Scientometrics, 90, 289-309. 
Siegel, D. S., D. Waldman, and A. Link (2003). "Assessing the impact of organizational practices on the relative productivity of university technology transfer offices: An exploratory study." Research Policy, 32(1), 27-48.

Sigurdson, K., C. M. Sa, and A. Kretz (2015). "Looking for the street light: Limitations of mainstream technology transfer indicators." Science and Public Policy, 42, 632-45.

So, A. D., B. N. Sampat, A. K. Rai, R. Cook-Deegan, J. H. Reichman, R. Weissman, and A. Kapcynski (2008). "Is Bayh-Dole good for developing countries? Lessons from the US experience.” PLoS Biol, 6(10): e262.

Tartari, V. and S. Breschi (2012). "Set them free: Scientists' evaluations of the benefits and costs of university-industry research collaboration." Industrial and Corporate Change, 21, 1117-47.

Thursby, G. and M. C. Thursby (2007). "University licensing." Oxford Review of Economic Policy, 23, 620-39.

Trzmielak, D. M. and G. Małgorzata (2014). "Knowledge and technology transfer barriers - Polish universities' perspectives." Paper presented at the International Conference on Management of Innovation and Technology (ICMIT). Singapore: IEEE.

Van Looy, B., P. Landoni, J. Callaert, B. Van Pottelsberghe, E. Sapsalis, and K. Debackere (2011). "Entrepreneurial effectiveness of European universities: An empirical assessment of antecedents and tradeoffs." Research Policy, 40(4), 553-64.

Van Looy, B., M. Ranga, J. Callaert, K. Debackere, and E. Zimmerman (2004). "Combining entrepreneurial and scientific performance in academia: Towards a compounded and reciprocal Matthew-effect?” Research Policy, 33(3), 425-41.

Veugelers, R. (2016). "The embodiment of knowledge: Universities as engines of growth." Oxford Review of Economic Policy, 32, 615-31.

Wadhwa, V. (2011) “Innovation's golden opportunity." Washington Post: www.washingtonpost.com/national/on-innovations/innovations-goldenopportunity/2011/06/09/AGWrnJOH_story.html?noredirect=on

WIPO (2011). "Harnessing public research for innovation - the role of intellectual property." In World Intellectual Property Report 2011: The Changing Face of Innovation. Geneva: World Intellectual Property Organization (WIPO). www.wipo.int/edocs/pubdocs/en/wipo_pub_944_2011-chapter4.pdf.

$\mathrm{Wu}, \mathrm{W}$. (2009). "Managing and incentivizing research commercialization in Chinese universities.” Journal of Technology Transfer, 35(2), 203-24.

Zhang, Q., N. G. MacKenzie, D. Jones-Evans and R. Huggins (2016). "Leveraging knowledge as a competitive asset? The intensity, performance and structure of universities entrepreneurial knowledge activities at a regional level." Small Business Economics, 47, 657-75. 
Zucker, L. G., M. R. Darby, and M. B. Brewer (1998). "Intellectual human capital and the birth of U.S. biotechnology enterprises." American Economic Review, 88 (1), 290-306.

Zuñiga, P. (2011). The State of Patenting at Research Institutions in Developing Countries: Policy Approaches and Practices (WIPO Economics Research Working Papers No. 4). Geneva: World Intellectual Property Organization. www.wipo.int/edocs/pubdocs/en/wipo_pub_econstat_wp_4.pdf. 


\section{Comment 2.1}

B HA VEN SAMPAT

\section{Background}

This chapter provides an excellent overview of how to think about evaluating public sector knowledge transfer activities. It provides both a conceptual framework for doing so, as well as potential metrics. And it also includes a nice review of the now large body of economic and policy literature on these topics that has been developed over the past two decades.

Overall, the conceptual framework seems complete. Unlike much previous work in this area, it emphasizes that firms benefit from academic research not only through what the authors call formal channels (patenting and licensing) but also through more informal channels, often associated with so-called open science. And that there may be tensions, as well as complementarities, between the two channels.

Here, I offer a few additional thoughts on the conceptual framework and the indicators, and also on public policy and evaluation going forward.

\section{Conceptual Framework}

As I mentioned, the conceptual framework seems fairly comprehensive. There are, however, three things that I think are missing from the potential benefits side of the equation.

First, while the authors mentioned financial benefits, it is important to emphasize that these revenues are not "profits" for public research organizations, but rather are typically used to fund future research. That is, the potential benefit is more funding for science and technology, which may be particularly important in resource-constrained environments. I am not 
necessarily endorsing this rationale: as the authors point out, the financial benefits for many organizations may be small, and there are costs as well, But I think it is an important one to keep in mind since it is often a major part of the justification for formal involvement in knowledge transfer activities.

A second motivation for knowledge transfer organizations, and taking out patents and licenses in particular, is to create a way to incentivize inventor involvement and commercialization. I did not see much about this in the chapter. This may be particularly important in countries and contexts where academic involvement has previously been limited or where there are strong cultural norms militating against it. And it is most important for "embryonic" inventions needing further development, where the inventor possesses specialized tacit knowledge. However, in this context, it should be emphasized, at least in countries where inventors rather than the public research organizations previously held title to patents, that it is unclear that shifting toward ownership by the research organizations increases inventor incentives, and could in fact blunt them. Hvide and Jones's (2018) paper in the American Economic Review provides one example. Specifically, in Norway, university researchers used to have rights to their own inventions, under the so-called "professor's privilege." After this was changed to be more like the US model, in which universities took rights, entrepreneurship and patenting rates by academic researchers decreased. But in general, the conceptual framework might also consider the effects of these organizations, and of patent rights, on incentivizing inventor involvement in the commercialization process.

Third, another potential benefit public sector ownership is the ability to harness this ownership to influence downstream outcomes, such as prices, access, or availability. This is mentioned in passing in the discussion of patents and access to medicines in developing countries. But it might be brought into the conceptual framework as well. That said, as far as I know, this potential role for public sector ownership has been used only sparingly.

Another observation is less about the conceptual framework than about its application. I would like to see more recognition in academic knowledge and knowledge transfer in general about what is one of the most robust empirical findings from economics over the past halfcentury: Patents matter more for research incentives in some fields than others. In particular, in drugs and chemical-based industries, patents are more important for appropriating returns from $R \& D$ than 
in other sectors (Cohen et al. 2000). Although there is no direct evidence on this in the context of university or public sector knowledge transfer (at least as far as I can recall), it would stand to reason that patents (and the prospect of exclusive licenses) are more important as commercialization incentives in some fields than others. (Drugs and biotech inventions seem like the strongest case.) In some industries, academic patents and KTOs might simply get in the way of transfer or commercialization (although they may help achieve other objectives noted here and in the chapter, such as financial returns or upstream control of particular technologies). I suspect that the costs and benefits of different channels of knowledge and knowledge transfer presented in the conceptual framework will vary sharply by field, a fact that should be considered in its application.

\section{Indicators}

The list of indicators provided is quite comprehensive. One thing I will add is that at least some of these indicators could be manipulated. For example, it is possible for an organization to increase invention disclosures and patent applications without really increasing the underlying construct of interest, namely, the extent of knowledge or knowledge transfer. Often the policy discussion ends up focusing on the indicator rather than the underlying construct. The fact that there are multiple indicators, not all of which are so easily manipulable, does help here.

But this leads to my second point, one that the authors acknowledge but is important enough to restate. It is much easier to measure the more formal activities than to measure the informal ones. If one accepts that the informal ones are important (maybe even more important based on the qualitative and historical analyses cited in the chapter), this presents a big problem. Specifically, it is possible that KTO activities could be nominally increasing some of the formal indicators but having a detrimental effect on knowledge transfer using informal channels. But evaluators are not really seeing it since we cannot measure the latter well. Even worse, and this is a theme emphasized in personnel economics, if performance is multidimensional but we only have good performance measures for some dimensions and reward based on those, this could distort incentives (for organizations, researchers) toward the better measurable but less important dimensions. I am not sure what to do about this - perhaps better bibliometric measures of more informal contributions would help (see, e.g., Bryan et al. 2019) - but policymakers, 
in particular, should keep this in mind. Mission statements acknowledging that traditional channels of knowledge dissemination are also important to the organization may also be helpful in setting norms.

\section{Beyond Benchmarking: Better Evidence for Policy}

Let's step back a bit. The academic knowledge transfer movement started to accelerate in the United States of America in the 1970s and was codified by the Bayh-Dole Act of 1980. I and others have argued that Bayh-Dole was passed based on questionable evidence that the lack of patents and exclusive licenses on academic research had previously limited social returns from public research in any serious way, with the possible exception of some pharmaceuticals requiring significant investment in clinical trials (Eisenberg 1996; Mowery et al. 2004). Bayh-Dole ignored technology and knowledge transfer through the informal channels, and differences across fields in the importance of patents. And the specific indicators measuring how well the formal channels were (or were not) working were problematic (Eisenberg 1996). Similarly, other countries emulating Bayh-Dole have drawn largely on aggregate evidence of patenting and licensing (and perhaps revenues and startups) to make the case that this policy was a success, with a lack of attention to (a) the extent to which these indicators actually capture knowledge transfer and (b) potential negative effects on informal channels (Mowery and Sampat 2004).

This has been an active debate for several decades, and need not be rehashed here. However, to avoid having this same debate again several decades from now, it might be useful to implement new KTOs and patent policies in a way that facilitates evaluation going forward. That is, drawing on the conceptual framework presented in this chapter, it would be useful to prespecify outcomes and indicators of interest (including effects on formal and informal knowledge transfer), and to be clear about what would constitute evidence that the policies and institutions are working or not. Since prepost analyses can be hard to interpret, some experimentation may also help, for example rolling out policies across institutions or regions or campuses in a way that facilitates quasi-experimental evaluation. The questions raised in this chapter about what works, and potential tradeoffs, are hard ones, and in addition to collecting better indicators, policymakers might implement new laws in a way that helps us learn from new experiences in a more structured way than was possible with Bayh-Dole and its early counterparts in other OECD 
countries. This approach will also force organizations to be transparent and precise about the objectives they hope to achieve.

One type of experimentation that might be particularly fruitful is on licensing practices. As this chapter points out, to the extent that the goals of KTO activities are more than simply financial, patents and exclusive licenses are really only needed only for a subset of research outputs. Codifying this idea in KTO policies and missions, and making better efforts to gauge the need for an exclusive license, could also be useful (Ayres and Ouellette 2016). Building a rebuttable presumption of lowcost non-exclusive licensing into KTO patent policies and practices might be one way to do this. It may work better in some fields and countries than others, but could also create an additional layer of bureaucracy that impedes knowledge transfer, or be subject to gaming. It is quite hard to know theoretically. This is exactly why more experimentation - with a commitment to later evaluation, based on prespecified indicators and hypotheses, drawing on the framework presented in this chapter - could be extremely valuable.

\section{References}

Ayres, Ian and Lisa Larrimore Ouellette (2016) "A market test for Bayh-Dole patents." Cornell Law Review 102: 271.

Bryan, Kevin A., Yasin Ozcan, and Bhaven N. Sampat (2019) In-Text Patent Citations: A User's Guide. No. w25742. National Bureau of Economic Research.

Cohen, Wesley M., Richard Nelson, and John P. Walsh (2000) Protecting Their Intellectual Assets: Appropriability Conditions and Why US Manufacturing Firms Patent (or Not). No. w7552. National Bureau of Economic Research.

Eisenberg, Rebecca S. (1996) "Public research and private development: Patents and technology transfer in government-sponsored research." Virginia Law Review 82: 1663.

Hvide, Hans K. and Benjamin F. Jones (2018) "University innovation and the professor's privilege." American Economic Review 108(7): 1860-98.

Mowery, David C. and Bhaven N. Sampat (2004) "The Bayh-Dole Act of 1980 and university-industry technology transfer: a model for other OECD governments?" Journal of Technology Transfer 30(1-2): 115-27.

Mowery, David C., Richard R. Nelson, Bhaven N. Sampat, and Arvids A. Ziedonis (2004) Ivory Tower and Industrial Innovation: University-Industry Technology Transfer Before and After the Bayh-Dole Act. Stanford, CA: Stanford University Press. 


\title{
Comment 2.2
}

\author{
RAGAN ROBERTSON
}

With the deluge of data generated daily by a knowledge transfer office (KTO), strategic decisions and operational functions rely on metrics to identify areas of improvement or focus. Given the complexity of tasks managed by a KTO, determining what metrics are measured is critical. Coming from an academic background, I've been taught to ask "what is the goal?" or "what is the question?" before setting forth and measuring something. Asking these questions first helps determine the variables being measured, as well as ensuring that the measurers and those who will review the metrics are all in agreement as to what is being asked and answered. When focusing on measuring the functions of a KTO, I ask questions such as "what can be measured?," "why measure?," and "how does a metric affect other metrics?" Addressing these questions typically results in identifying the core functions of a KTO and focusing on the counts of these actions, such as licenses executed and patent applications filed. The AUTM Licensing Activity Survey is an excellent source of some of these measurements, as are the annual reports produced by KTOs. Some of these metrics are also highlighted in Table 2.5 in this chapter. Accumulation of broadly applicable data in a centrally accessible database can help facilitate these goals. This also allows for KTOs to compare their metrics with those of their peers to establish benchmarks. Another benefit of creating data as a shareable resource is the ability to share data with other interested parties, including policymakers and academics. In this way, this practice can further benefit the knowledge transfer field as a whole in addition to the office itself.

As data become more available, and our economies become more complex, KTOs are being asked to do more and more functions. One reason is that the KTO acts as a node, a nexus where industry connects to 
research, where intellectual property connects to contracts, where business development connects to academic pursuits. These connections in and of themselves lead to additional metrics that can be measured. How many meetings with industry occurred in the last quarter? How many different patent application families were put under an exclusive license this past year? How many sponsored research agreements were executed with licensees? As KTOs function in more roles at the interface of academics and business, more measurable data are generated and can be analyzed. However, as the roles of our offices expand, we must ensure that the data we are generating and measuring can lead to potential actions and not just to the act of obtaining data. We must always ask why we are measuring something and what we can do to change it for the better.

Naturally, due to the nature of the knowledge managed by KTOs, offices are becoming more involved within the entrepreneurship ecosystem. Subdivisions within KTOs, and even entire new departments, are being formed to address this growing role. The function as a nexus causes KTOs to be well-positioned to have an incredible impact in this ecosystem. By having the connections to industry, as well as access to new research being conducted, KTOs can identify the opportunities where new research results can lead to the formation of a new company. The ultimate result is that KTOs can have a significant impact on the economy, especially at the local level. New companies formed, new jobs created, new revenue generated, and new taxes paid are some of the more easily identifiable benefits to economic output that can be sourced from the work performed by a KTO. This additional role for KTOs within the entrepreneurship ecosystem can also lead to unintended benefits, such as new institutional donors, or diversification of industry within a local ecosystem.

However, we do have to be careful to assign economic output to KTOs accurately and avoid generalization of data or misattribution of revenue. Skeptics of the industry have focused on return on investment (ROI), typically syncing research dollars sourced from a governmental agency and the licensing revenue received directly by a KTO. While this connection is an oversimplification, expanding to the other extreme of attributing all economic benefit generated by external entities connected to a KTO is also misleading. In addition to drawing conclusions based on overgeneralization of data, KTOs must also be wary of "paralysis of analysis" in which the goal is to gather more data without making a decision, or the confusion that results from an overabundance of data 
from multiple sources. This speaks directly to the question as to what the true impact is downstream of a KTO's activity. This harks back to asking ourselves the question of why we are measuring something and what we can do to change it for the better.

This chapter does an excellent job of identifying key metrics that should be measured by KTOs, along with the reasons why they are measured and the potential economic impact. While these metrics are clear and should be implemented by KTOs, the industry still lacks metrics to measure several important functions of KTOs. These include metrics to measure the effect of a KTO's work on societal impacts. As identified in this chapter, these impacts are very difficult to measure, typically relying on case studies such as those found in the AUTM Better World Project. Case studies, unfortunately, can be overly specific and their conclusions can be difficult to apply to general practice. However, there are metrics that could be used to address this impact. For example, for the past few years, AUTM has been collecting data regarding women inventors, specifically how many disclosures include a woman and how many new patent applications include a woman. What actions can or should be taken related to these data are only now being developed, but it is a start toward how to address a significant societal impact. Expanding on the theme of inclusion, metrics could also be collected related to race or ethnicity. KTOs may already have some of these data, as we must report citizenship within patent applications, but they have yet to be utilized. These data have the potential to have a far-reaching impact outside of the knowledge transfer or academic spheres, and it will be interesting to see what comes of them.

As identified, metrics are a key necessity for any KTO to inform strategic decisions and operational functions. Metrics need not only include the core functions, such as patent application filings and licenses executed, but also other important economic drivers, such as startups formed and investments raised. However, no matter what metrics a KTO measures, they are numbers for numbers' sake if the metrics are not aligned with a KTO's goals. Metrics must be actionable - how can a team affect them and what does that effect mean? By being clear and transparent as to how a metric informs and achieves its goals, a KTO is on the path to making an economic and societal impact. 


\author{
Comment 2.3 \\ ROSEMARY WOLSON \\ Senior Intellectual Property Manager, CSIR
}

The chapter examines various modes of knowledge transfer from universities and public research institutes to industry, together with the policies that support knowledge transfer, in order to develop a conceptual framework for comparative country studies and identify relevant and useful metrics for assessing the economic impact of this activity.

While some common trends can be seen in policy and legislation around the world, a variety of policy instruments and methods are employed in developing and implementing relevant legislation and policy. It is recognized that knowledge transfer takes place through both formal and informal channels, and in different countries and organizations, the predominance and importance of each may differ. The prevailing mix in a particular context must be taken into account in making policy (at both national and institutional levels), to avoid inadvertent consequences of policies aimed at promoting one channel negatively impacting on others that may, in fact, be of greater importance in the relevant environment.

As a starting point, this calls for a comprehensive understanding of the ecosystem and its various actors and institutions. Disruptions to the status quo can yield both positive and negative effects and the possible impact of both must be considered to ensure that potential benefits outweigh potential costs. Assumptions must be validated so that existing strengths can be built on, gaps can be filled, and, ultimately, that fit-forpurpose policy can be developed.

Policy priorities should be clearly articulated. Different policies may be needed to promote different objectives, rather than trying to achieve too many outcomes by means of a single policy, especially when such outcomes might not support one another. Where different bodies are responsible for making policy for different knowledge transfer channels, 
effective coordination between them becomes critical to ensure that conflict does not arise. If tradeoffs are required to achieve an optimal balance, these must be identified and agreed.

It is always useful to draw from experiences and best practice elsewhere when developing policy. Understanding what has not worked well, and why, is arguably as important as examining successful interventions. At the same time, borrowing uncritically without making relevant adaptations for a particular country's own circumstances is likely to lead to suboptimal results. This is perhaps especially true where policies and practices from developed countries are applied in low and middle income countries characterized by less developed innovation ecosystems and an industry sector with inherently less absorptive capacity for new innovations.

New policies must be sufficiently flexible to accommodate responses necessary to correct for unintended consequences that may be experienced. The choice of policy instrument should therefore be carefully considered. At national or regional level, legislation creates certainty and demands compliance, but making amendments becomes onerous. By thesame token, if policy is implemented via nonlegislated policy documents, frameworks, codes of good practice, or guidelines, these can be adapted with greater agility.

Policy should, in the first instance, aim to create an enabling environment that allows knowledge transfer to thrive, by providing support and incentives. Overly prescriptive requirements or those introducing undue administrative burdens carry transaction costs that can detract from productive knowledge transfer activity and disincentivize compliance. One-size-fits-all policies may lead to certain channels of knowledge transfer being neglected.

Once policies are put in place, it becomes critical to evaluate their implementation objectively on a regular basis, to ensure that they are functioning effectively. Measuring performance allows comparisons to be made, trends to be identified and the achievement of targets and goals to be assessed. This yields information on what is working as intended and what needs to be improved or changed, and can be used to inform adjustments in policy and practices to achieve greater impact.

The chapter provides an instructive examination of a range of knowledge transfer metrics that are and, further, that can be collected, together with explanations of the reasons for and value of gathering different types of metric, both basic and supplementary. It also emphasizes the importance of using a variety of data sources to obtain a balanced view. While 
surveys from knowledge transfer offices are perhaps the most common source of data in this regard, they should be supplemented with data from other stakeholders, such as industry and researchers, particularly for knowledge transfer channels other than IP licensing. Recommendations are made in respect of which metrics should be regularly collected, from where, and how frequently.

Designing, collecting, and reporting a suitable set of metrics is not, however, a trivial exercise. In doing so, it is worth recalling William Bruce Cameron's observation that "not everything that can be counted counts, and not everything that counts can be counted." The chapter notes that many of the available data relate to the knowledge transfer channel of IP licensing (in high- and middle-income countries). This can be attributed at least in part to the fact that many of the activities associated with this channel provide several easily quantifiable indicators along the value chain, such as invention disclosures, patent applications, issued patents, licenses executed, and license fees earned. Most of these are, however, indicators of inputs into or progress toward commercialization rather than of economic impact or social benefits, which still remain difficult to measure directly and accurately (since the outcomes concerned are usually not solely attributable to knowledge transfer, but also to a range of other factors and influences).

Metrics can serve as significant drivers of behavior, particularly when linked to individual or institutional performance evaluation frameworks. Overemphasis on input metrics is likely to lead to increased activity in these areas, but will not always result in improved outputs or outcomes, unless appropriate ecosystem support and complementary incentives are in place.

"Vanity" metrics, which may superficially tell a positive story but fail to provide practical information on performance, should be avoided in favor of actionable metrics that can be used as a basis for implementing improvements to policy and practice.

The more comprehensive a set of metrics is the greater its value. But in selecting which metrics to capture, attention must be paid to the ease of acquiring and accessing the requested data by the survey respondents. If the data requirements are too ambitious, there is a risk of lower response rates, and/or supply of incomplete or inaccurate data.

${ }^{1}$ Cameron, William Bruce, "Informal Sociology: A Casual Introduction to Sociological Thinking" (1963). 
Where metrics are used specifically for benchmarking purposes, data must be appropriately normalized (standardized) to ensure that one is comparing "like with like."

Where a set of metrics focuses on a particular knowledge transfer channel, institutions or regions that pursue other channels more actively might be reluctant to participate, fearing that their performance will not reflect favorably when measured against that of other institutions/ regions.

Each of these challenges must be acknowledged and tackled. Nonetheless, the benefits of a robust set of metrics generated on a regular basis cannot be denied. This is achievable with buy-in from all key stakeholders who recognize the value this can bring for improving performance and enhancing impact in their respective spheres, whether as policymakers or practitioners. 


\title{
Measuring Global Patenting of Universities and Public Research Institutes
}

\author{
JUAN YANG, INTAN HAMDAN-LIVRAMENTO, BRUNO LE \\ FEUVRE, SACHA WUNSCH-VINCENT, AND HAO ZHOU
}

\subsection{Introduction}

Policymakers increasingly seek to bolster the effectiveness of academic research in fostering innovation. Universities and public research institutes are encouraged to engage with industry partners and spur knowledge transfer from academia to the private sector.

One way of facilitating this knowledge transfer is by patenting research outputs from universities and public research institutes. Patents, plus close engagement between universities and public research institutes and the private sector, are two important factors that make university-industry knowledge transfer successful (Perkmann et al. 2013).

Collaboration between academic organizations and the private sector is not new. Universities and public research institutes played important roles in propelling developments in agriculture, aviation, and the chemical and pharmaceutical sectors as early as the nineteenth century (Mowery et al. 2004; Rosenberg and Steinmueller 2013; WIPO 2015). Academic patenting has also been used by university researchers since the late 1800s (Mercelis et al. 2017).

Since the late 1970s, many countries have changed their legislation and created support mechanisms to encourage interaction between universities and firms, including through knowledge transfer (Graff 2007). In 1980, the United States of America (U.S.) passed the Bayh-Dole Act, landmark legislation which allowed for patenting of research outputs funded by the government. Many European countries followed suit about a decade later (Wright et al. 2008; Van Looy et al. 2011). A direct effect of this type of policy is a rise in academic patenting and licensing activities in universities and public research institutes across the U.S. and in certain European countries. 
Policies that encourage patent protection of government-funded research work are intended to promote the commercialization of university inventions, with the aim of facilitating innovation-led economic growth (So et al. 2008). As a by-product, this type of policy provides an avenue for generating income for universities (Geuna 2001) and tracking patenting by research organizations has become one way of measuring their performance.

This chapter focuses on how to identify patenting activities by universities and public research institutes so as to develop cross-country comparison of academic patenting activities. In particular, it proposes a harmonized approach to capture patent filings for these public research organizations across different countries using patent data filed through the Patent Cooperation Treaty (PCT) as well as national-level patent data compiled using the PATSTAT database.

Using patent filing data from the PCT and PATSTAT, we present a new data set of universities and public research institutes which allows for better insights into how effective university knowledge transfer mechanisms have been, and will potentially help to analyze their research performance. Our objective is to gauge the patenting outputs of these organizations, allowing us to measure the evolution of patenting activity over time, benchmark the performance of public research organizations, and enable cross-country comparisons.

This chapter is organized as follows. The next section focuses on academic patenting, in particular, what the data tell us as well as their limitations, and discusses how academic patenting may or may not have changed the norm of universities and public research institutes. We present our methodology for capturing the patenting activities of universities and public research institutes in the third section. The penultimate section analyzes the results of our work by showcasing the results from using the PCT and PATSTAT databases through cross-country and cross-technology comparisons. The last section concludes with direction for future research.

\subsection{Why Focus on Patenting in Academia?}

Total patent filings at the national level are often used as an indicator of the innovativeness of a certain country. By the same logic, patent filing activities can measure the innovativeness of a university or public research institute. But this is not the complete story.

The availability of patent data from the US Patent and Trademark Office (USPTO) and the European Patent Office (EPO) has contributed 
to a rise in quantitative analyses of academic patenting (Rothaermel et al. 2007). University and public research institutes patent filing activities have been used by decision makers to assess the effectiveness of their knowledge transfer offices (KTOs), whether research projects are close to the technological frontier and inventive, the performance of their research staff, and so on. But it is important to remember that this metric is an imperfect measure of innovativeness.

\subsubsection{What Do Patent Data Tell Us?}

There are many limitations to using patenting data to track the performance of public research organizations. First, patent data say relatively little about whether the patented inventions actually result in innovations. In particular, patented inventions from universities tend to be further from commercialization potential than those in the private sector (Henderson et al. 1998; Sterckx 2011). In this sense, patent data provide a relatively imperfect measure of technological activity. ${ }^{1}$

Second, patents are used by universities and public research institutes in a somewhat different way from private sector patents. In the private sector, patents are generally used to appropriate the firms' returns on investing in innovation. ${ }^{2}$ Universities and public research institutes, by contrast, do not directly commercialize their inventions and instead rely on patents to attract industry counterparts. Thus, patents are used as a signal to indicate the value of the protected invention.

Third, a significant share of inventions originating from research performed at universities or public research institutes - universityinvented patents - are not patented under the organization's name. Depending on their employment contract and applicable laws, academics and researchers working in these organizations may be able to file the patent under their names and may later assign the rights to universities. Others may prefer to file under their own names to start their own companies later. A small percentage of university faculty assign the university invention under firm names only and not under the university's name, contrary to university policies (Thursby et al. 2009).

In our methodology, applicants are classified according to their names only, without considering their employment relationship or address. Therefore, where a natural person is the applicant filing on behalf of an

1 See Khan and Wunsch-Vincent (2011), Chapter 1.1, Box 3.

2 See Chapter 2 of WIPO (2011). 
educational organization, that application would not be classified as belonging to a university. Instead, it is imperative that the first applicant is the university or public research institutes itself in order to be categorized as a university or public research institutes patent.

Last, many methods of capturing academic patenting are based on keyword searches and a list of university names. Lesser-known universities or public research institutes, or even those who file their patent applications using different names, may not be captured. As a result, a sizable share of patents derived from public research is underestimated.

\subsubsection{How Does This Apply to Public Research Organizations?}

Academic patenting is not new (Mercelis et al. 2017). For a long while before laws such as the Bayh-Dole Act came to pass - academics enjoyed the privilege of having the first commercial rights over their inventions (Kelly 2016). Some filed for patents on their research work to ensure control over how their work was used, others to build their reputations.

Before the Bayh-Dole Act in the U.S., there was a low level of knowledge transfer from universities to industry; only 5 percent of government-owned university patents were commercialized (Schacht 2006). One of the main barriers to the transfer was the issue of relinquishing ownership rights. First, there were approximately twenty-six different agency policies governing how results of federally funded research and development (R\&D) would be used. Second, licensing policies in place did not provide the appropriate incentive mechanisms to facilitate knowledge transfer.

Changes in the rules governing university patenting have had an impact on the academic patenting culture. First, there has been a general increase in university patenting (Geuna and Rossi 2011; Thursby and Thursby 2011). Second, academic patenting has increased the probability that researchers and professors will start their own companies (Aldridge and Audretsch 2011; Kenney and Patton 2011). Third, while publishing research work in journals continues to be important, there are noticeable delays in publication (Blumenthal et al. 1997). These changes and more have led many to consider universities now as entrepreneurs, not merely knowledge generators (Grimaldi et al. 2011). 


\subsection{How to Measure Academic Patenting?}

\subsubsection{Data Source}

The most comprehensive patent data available today are the WIPO PCT and EPO PATSTAT (April 2016 edition) data sets. We use these two data sets complementarily because they are able to capture patenting activities worldwide. The difference between them is that PATSTAT compiles national patent data from many countries while the PCT captures patents filed through the international PCT system.

The advantage of using the PCT database is that the information is complete and comparable across countries. Patent applicants who wish to file for patent protection in multiple jurisdictions may use the simplified PCT patent filing system. An applicant may deposit their international patent application directly with WIPO either online or by mailing it in, or through national IP offices that send the application to WIPO later. All PCT member countries are able to use this simplified patent filing system.

However, PCT filing is only a subset of all patenting activities. First, applicants who decide to use the PCT route do so because they are interested in filing in several national patent offices and the PCT system allows for a simplified application process (see Box 3.1). It is generally accepted that patented inventions that have been filed at more than one large IP office are of higher value than those that are filed domestically (Dernis and Khan 2004). In this regard, patent applications under the PCT may be considered of higher value due to the potential to acquire patent rights in multiple jurisdictions.

Second, applicants may use the PCT filing system as a business strategy. Universities and public research institutes that choose the PCT system may do so because of the thirty-month transition time between filing for a patent and national phase entry. Anecdotal evidence suggests that some KTOs in universities prefer using the PCT system because it gives them additional time to find commercialization partners for their university inventions. Other applicants may use the PCT system to assess the likelihood of their invention being patentable (Guellec and van Pottelsberghe de la Potterie 2007).

Third, PCT filing may also reflect universities' and public research institutes' stronger or weaker propensity to file abroad.

These factors point to the drawback of using PCT data - that they may underrepresent the total universe of academic patenting, and may merely reflect the strategic patent filing behavior of different universities and public research institutes. 
BOX 3.1 DEFINING PATENT FAMILY

A patent family is a set of interrelated patent applications filed in one or more offices to protect the same invention. The patent applications in a family are interlinked by one or more of: priority claim, PCT national phase entry, continuation, continuation-in-part, internal priority, and addition or division.

A special subset comprises foreign-oriented patent families - those patent families that have at least one filing office different from the office of the applicant's country of origin. Some foreign-related patent families include only one filing office because applicants may choose to file only with a foreign office. For example, if a Canadian applicant files a patent application directly with the USPTO without having previously filed with the patent office of Canada, that patent family will constitute a foreign-oriented patent family with just one office.

Moreover, there are also cost considerations in filing through national IP offices or through the PCT system. The PCT system is a rational filing method if the applicant intends to file in multiple jurisdictions; if not, the costs of application may outweigh the benefits.

The EPO's PATSTAT database, by contrast, allows us to examine a larger set of university and public research institute patenting activities. The PATSTAT data set comprises patent data from different national IP offices that share their data with the EPO, making it easier to capture universities and public research institutes that choose to apply in a single jurisdiction.

But unlike the PCT filing data, the PATSTAT data set is not always complete. Many IP offices in high-income countries provide their patent data to the EPO; the same cannot be said for less-developed economies. Missing data for some offices and years makes the use of this database to run cross-country analysis challenging.

One way to check PATSTAT country and year coverage is to compare the total counts of patents listed in PATSTAT with information collected by WIPO. WIPO conducts an annual survey of national and regional patent office data on patent applications filed. PATSTAT includes only data on published patent applications. A small discrepancy between the two groups - filed versus published - is to be expected: the former is always larger, since some applications are withdrawn before publication, and there is a time lag between filing and publication. If the difference between the numbers as reported to WIPO and PATSTAT for a particular national IP office is small then we can consider PATSTAT coverage of that country reliable; if the difference is large then the data should be analyzed with caution. 
Table 3.1 Comparison of PATSTAT national patent data coverage for featured countries

\begin{tabular}{|c|c|c|c|}
\hline National IP office & $\begin{array}{l}\text { In } \\
\text { PATSTAT }\end{array}$ & PATSTAT coverage & $\begin{array}{l}\text { Incomplete } \\
\text { information }\end{array}$ \\
\hline Brazil & Yes & Good & $2011-14$ \\
\hline China & Yes & Good & 1984 \\
\hline Germany & Yes & Good & \\
\hline South Africa & Yes & $\begin{array}{l}\text { Mostly good, patchy for } \\
\text { some }\end{array}$ & $\begin{array}{l}1986-9,2008-10, \\
2013-14\end{array}$ \\
\hline Republic of Korea & Yes & $\begin{array}{l}\text { Mostly good, patchy for } \\
\text { some }\end{array}$ & $1985-97$ \\
\hline United Kingdom & Yes & Good & $1980-82$ \\
\hline
\end{tabular}

Source: WIPO Department for Economics and Data Analytics Internal Documents, September 2017

Table 3.1 provides a quick overview of national patent data coverage at PATSTAT for the six countries studied in this book. It compares the number of patent filings at the different jurisdictions as reported to WIPO with the number provided by PATSTAT. For South Africa and the Republic of Korea, there are significant discrepancies between the total number of patents filed as reported to WIPO and PATSTAT. There are many possible explanations for this. National events or even changes in legislation in a country may be reflected in its reported IP data.

\subsubsection{Identifying Public Research Organizations}

Identifying universities and public research institutes using patent data is not straightforward. Due to the differences in the patent data contained in the PCT and PATSTAT databases, we employ similar methods but with a few important variations to capture academic patenting activities.

First, patent documents do not contain standardized information on the applicant type, so we rely on the information contained in the applicant's name or address in developing search algorithms to identify university and public research institute patents.

Using the PCT database, we search the names of applicants or their addresses as recorded in patent documents, and determine whether the applicant is a university, public research institute, company, or individual using certain words, for example, "university," "college," 
"school," "government," and "ministry." We perform this search in various languages to make sure that we also capture organizations in non-English-speaking countries. Moreover, we have a list of universities and public research institutes that we use specifically in the context of PCT filings to help us identify academic patents.

The PATSTAT database provides a table which categorizes applicant types by the following four categories: individuals, private business firms, universities and higher education organizations, and government agencies. ${ }^{3}$ This applicant classification was developed by the Catholic University of Leuven in Belgium, which employed a similar search strategy to ours. ${ }^{4} \mathrm{We}$ use this categorization to target the subcategory of patent applicants that have been classified as "universities and higher education institutions."

Second, name-cleaning is tedious. Applicant names provided in the PCT and PATSTAT are neither standardized nor harmonized, making it challenging to identify universities and public research institutes by either keywords or names. In addition, applicant names and addresses may be in languages other than English and may be written in non-Latin characters.

Ensuring that the list of university and public research institute names captured is representative of the different languages as well as non-Latin characters would require additional lists of keywords or similar name matches. In this respect, the PCT database provides an advantage over PATSTAT. PCT filing requires applicants to provide their names in a standardized English version as well as in the nine other languages accepted. ${ }^{5}$ The applicants' names and addresses have to be indicated in Latin characters, either as transliteration or translation into English. ${ }^{6}$

The national IP data provided for PATSTAT, however, can be in any language, including exotic languages, and the applicants' names and addresses may be listed in non-Latin characters. Accordingly, we employ a WIPO-created list of university and public research institute names and the associated keywords to capture academic applicants that may have been unintentionally omitted by PATSTAT through its applicant type table.

This list was created through direct contact with government officials, and verified by consulting government websites as well as university and public research institute directories. It contains the names of universities

3 This category was developed by the KU Leuven group. See Du Plessis et al. (2010).

${ }^{4}$ See Du Plessis et al. (2010).

${ }^{5}$ Applicants may fill their patent applications in any of the following ten official languages: Arabic, Chinese, English, French, German, Japanese, Korean, Portuguese, Russian, and Spanish.

${ }^{6}$ See Rule 4.16 of the Regulations under the Patent Cooperation Treaty (1970). 
in fifty-four countries and public research institutes in thirty-eight countries. ${ }^{7}$ We mined the list to identify keywords that would help us tag universities and public research institutes in the different languages. We further added to this list the top 200 publishing organizations from sixty-two different countries that we have established using Scopus, a database containing citations and abstracts for scientific journal articles. ${ }^{8}$ And last, we use the Scimago Institutions Rankings World Report (2010) to include the top publishing organizations in the world $-2,833$ in total.

Third, the name-matching processes for academic organizations under PCT and PATSTAT differ due to the volume of data to process. At the last count, PATSTAT covers over 100 million patent documents while the PCT covers 3.5 million patent documents. ${ }^{9}$

For the PCT, once we have identified patents from universities and public research institutes, we manually match all the names that seem similar. In the case of PATSTAT, we focus on the top filers, assign a similarity value based on the similarities of the names, and try to match them. So for example, if we wish to identify the top 100 academic organizations we look at the top 300 filers, find those that are similar and then match them manually.

Fourth, the decision on patent family definition (see Box 3.1) should be tailored to the research question, especially in the case of PATSTAT. ${ }^{10}$ Since PATSTAT provides all available national patent data collection, universities and public research institutes that have filed for patents in multiple jurisdictions for one invention would need to be accounted for

7 The fifty-four countries for which a university list has been compiled are: Argentina, Australia, Austria, Bangladesh, Belgium, Brazil, Bulgaria, Canada, Chile, Colombia, Cuba, Czech Republic, Denmark, Egypt, Estonia, Ethiopia, Finland, France, Germany, Greece, Hungary, Iceland, India, Indonesia, Iran (Islamic Republic of), Ireland, Israel, Italy, Japan, Republic of Korea, Luxembourg, Malaysia, Mexico, Netherlands, New Zealand, Nigeria, Norway, Philippines, Poland, Portugal, Russian Federation, Serbia, Slovakia, Slovenia, South Africa, Spain, Sweden, Switzerland, Turkey, United Kingdom, Ukraine, U.S., Uzbekistan, and Venezuela. The thirty-eight countries for which a public research institute list has been compiled are: Argentina, Australia, Austria, Belgium, Brazil, Canada, Chile, Colombia, Czech Republic, Denmark, Estonia, Ethiopia, Finland, France, Germany, Greece, Hungary, Iceland, Ireland, Israel, Italy, Japan, Republic of Korea, Luxembourg, Mexico, Netherlands, New Zealand, Norway, Poland, Portugal, Slovakia, Slovenia, Spain, Sweden, Switzerland, Turkey, United Kingdom, and the U.S.

8 The Scopus database contains 12,400 organizations in total.

9 Based on PATSTAT Spring 2017 edition and PCT 2017 edition.

${ }^{10}$ See Martínez (2011) for the different patent family types and how they relate to the research question. 
so that we do not double-count those filings. This is not the case for PCT, as it is just a patent-filing method.

For the purposes of this chapter, we define a patent family based on the earliest filing and where all other filings claim this first filing as a priority. In particular, we focus on patent families that are associated with patent applications with inventions and exclude those associated with utility model applications. The benefit of this patent family definition is that it enables us to track where the invention was first filed and where the applicant later sought protection for that particular invention (Martínez 2011).

And last, assigning the origin of the university and public research institute patent is usually done based on the residence - not the nationality - of the first applicant. In the case of PCT data, it is simply the first applicant's residence as noted in the PCT filing document. For PATSTAT, it would be the residence of the first applicant of the first filing for that patent family.

\subsubsection{Quality Checks}

One of the main issues in identifying patent activities by public research organizations is to ensure that we have correctly captured applicants who fall within this category.

When carrying out the strategy of identifying public research organizations, researchers need to ask themselves which problem is worse: including applicants who do not fall under the category of public research organizations (false positive) or excluding those applicants who do fall under the category (false negative)?

Several quality checks have been performed, especially on the method used to extract university and public research institute patents from the PATSTAT database. Two issues emerged: first, whether the data compiled by PATSTAT has good country and time coverage; and, second, whether the search method employed performed well in identifying the academic organizations.

The first question can be addressed by comparing PATSTAT data on aggregate applications per year per country of origin to aggregate numbers reported to WIPO by national and regional patent offices, as we did to produce Table 3.1 above.

To verify how well the search method identifies organizations, we compare the results obtained with government reports for selected countries wherever available. 


\subsection{Who Is Patenting and Where?}

Academic patenting - measured by patent filing activities by universities and public research institutes worldwide - is on the rise. Since 1995, the number of PCT applications filed by universities and public research institutes has been steadily increasing (see Figure 3.1). The growth in PCT applications filed by university and public research institute applicants combined since 1995 can be divided into two periods. In the period 1995-2008, the average annual growth rate in academic patent filings was 13.3 percent. The period 2009-16 saw average annual growth of 2.4 percent in PCT applications, 2.3 percent in university applications and -0.4 percent in public research institute applications. Growth in public research institute and university PCT filings declined during and after the economic downturn of 2009 compared to the previous period of high growth.

Patent filings captured by PATSTAT data also show an increase in academic patenting. Figure 3.2 shows the total number of patent families created by universities and public research institutes. In 2014, about 162,000 patent families were created by university and public research institute applicants worldwide. On average, the total number of university and public research institute patent families (16.5 percent) grew much faster than overall total number of patent families (4.9 percent) over the period from 1995 to 2014 . As a result, the share of university and public research institute patent families in total families has been increasing rapidly - especially for universities - reaching 11.4 percent in 2014, up from 1.5 percent in 1995.

Again, the trend in university and public research institute patent families can be divided into two distinct periods. The period 1995-2004 saw average annual growth of 12.1 percent, with patent families from universities (12.3 percent) and public research institutes (11.8 percent) growing at almost same pace. The period 2005-14 saw even faster growth. The average annual growth rate for this period was 5.4 percent for all families and 19.6 percent for university and public research institute families combined. However, patent families from universities (22.4 percent) grew much more quickly than those from public research institutes (11.3 percent).

The slowdown of the growth in PCT patent filings and the increasingly rapid growth of PATSTAT patent filings seem to contradict one another. However, this is not necessarily the case.

The share of foreign-oriented patent filings by academic organizations has been decreasing. Figure 3.3 shows the number of foreign-oriented patent families created by universities and public research institutes from 1995 to 2013 and the share of foreign-oriented patent families in total patent families for each type of applicant. 


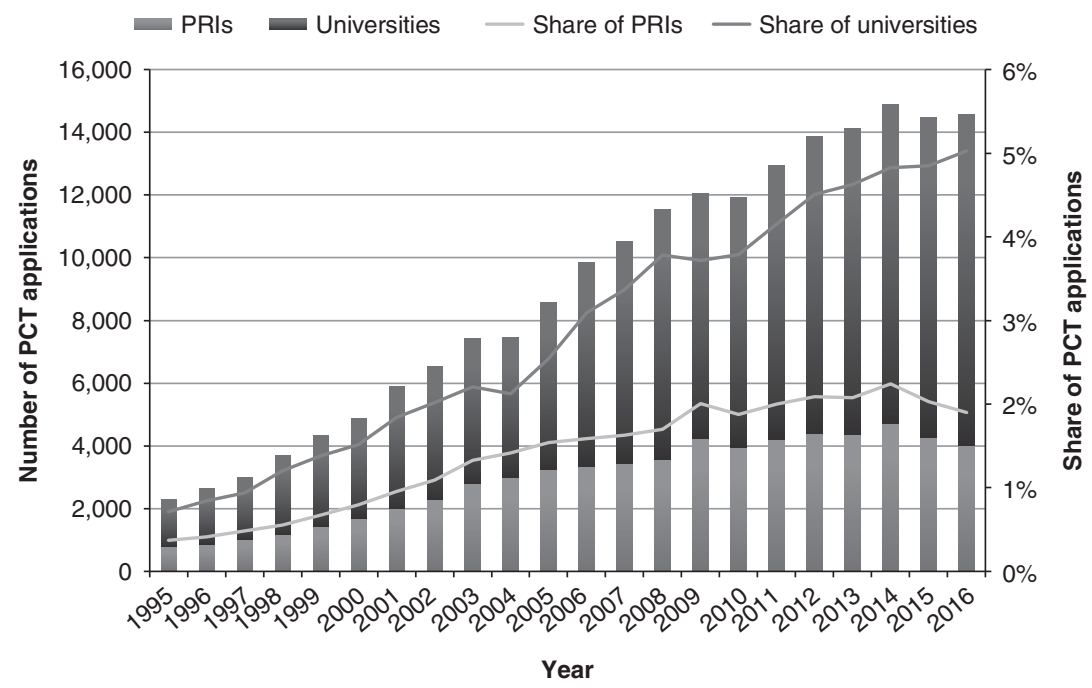

Figure 3.1 Public research institute and university PCT applications, absolute numbers (left) and as a percentage of total PCT applications (right), 1995-2016 Source: WIPO Statistics Database, July 2017

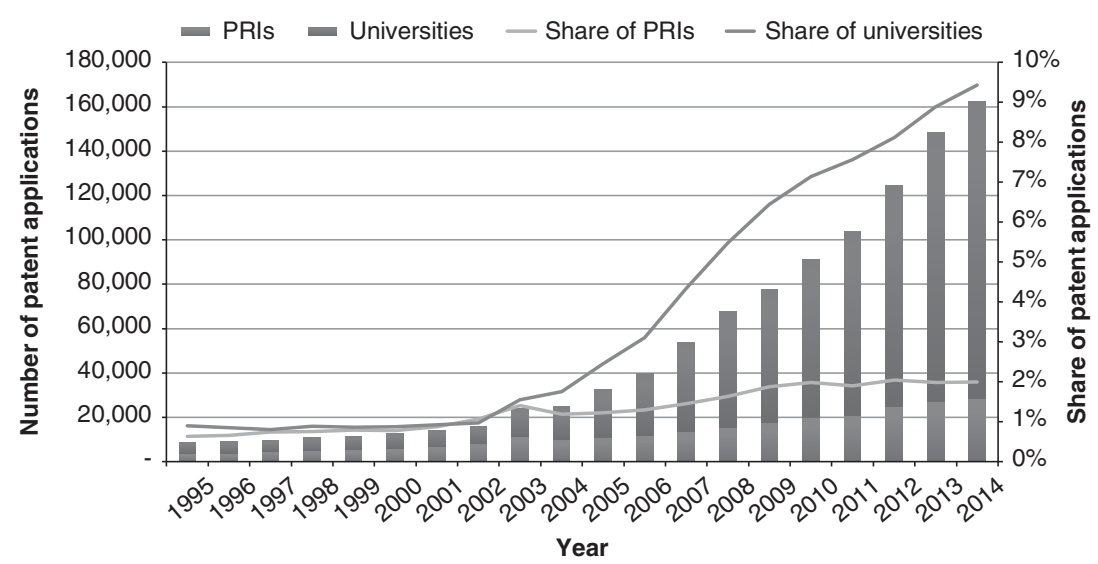

Figure 3.2 Trend and share in university and public research institute patent families worldwide, 1995-2014

Sources: WIPO Statistics Database and EPO PATSTAT database, July 2017 


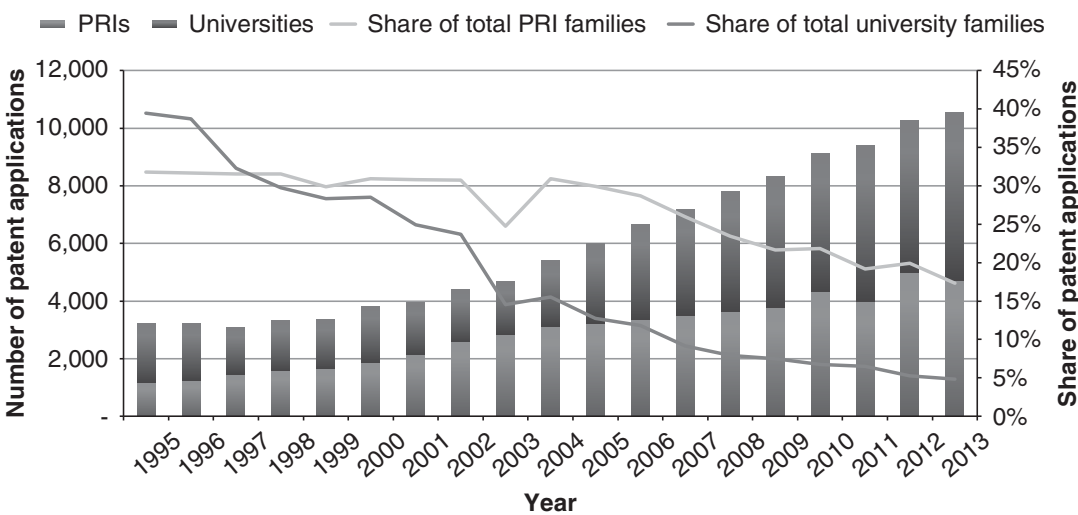

Figure 3.3 Trend in university and public research institute foreign-oriented patent families worldwide and share of total, 1995-2013

Sources: WIPO Statistics Database and EPO PATSTAT database, July 2017

Figure 3.3 shows that while the number of foreign-oriented patent families from universities and public research institutes increased steadily over the past two decades, their respective shares of total patenting activity by those organizations decreased sharply. In 1995, universities created 2,058 foreign-oriented patent families and public research institutes created 1,177. In 2013, universities and public research institutes created three to four times more foreign-oriented patent families $-5,858$ and 4,702, respectively. The combined total of foreign-oriented patent families for universities and public research institutes increased each year between 1998 and 2013 to reach 10,560 in 2013.By way of contrast, the share for universities decreased from 39.5 percent of foreign-oriented patent families in 1995 to 4.8 percent in 2013. This indicates that the number of patent families that have no international dimension is increasing much more rapidly than the number of foreign-oriented patent families.

What explains the drop in foreign-oriented patent filings by universities and public research institutes? That is outside the scope of this chapter. It may indicate a change in academic patenting strategy, with more universities and public research institutes preferring to file in one office rather than several. But it could also be due to the filing strategy of academic organizations of one country: China.

\subsubsection{By Income Level}

In the PCT data, European and US universities and public research institutes have traditionally accounted for the bulk of academic filings 
globally. ${ }^{11}$ These high-income countries accounted for the vast majority of university ( 87 percent) and public research institute ( 80 percent) PCT filings in 2016. US universities accounted for 38 percent of all PCT applications filed by universities in 2016, about 11 percentage points below their 2007 share (Figure 3.4). In the same year, the shares of the top five public research institute origins in total public research institute filings ranged from 19 percent for France to 9 percent for Germany. ${ }^{12}$

However, Asian academic organizations, led by China, have been catching up quickly over the past few decades. The top five origins of university PCT filings in 2016 were the U.S. $(4,050)$, China $(1,169)$, the Republic of Korea $(1,139)$, Japan $(985)$, and the United Kingdom (446). In contrast, the top five origins of university PCT filings in 2007 were the U.S., Japan, France, the United Kingdom, and Germany. The change in top five origin ranking between 2007 and 2016 can be explained by the sharp rise in PCT patent filings from China and the Republic of Korea by 9 and 7 percentage points, respectively.

Shares for the middle-income group increased rapidly between 2007 and 2016, by 10 percentage points for universities and by 13 percentage points for public research institutes (see Figure 3.5). Chinese universities accounted for 83 percent of total middle-income university filings in 2016, while Chinese public research institutes represented 72 percent of total middle-income public research institute filings. The other main middle-income origins in 2016 for universities were South Africa (fortyseven applications), Turkey (thirty-six), India (thirty-three), Malaysia (thirty-two), Colombia (twenty-eight), Brazil (twenty-five), Mexico (nineteen), and Morocco (eighteen); and for public research institutes they were India (132), Malaysia (fifty), South Africa (twelve), Turkey (eleven), and Brazil (nine).

\section{Comparing Academic Patenting in High- and Middle-Income Economies}

Figure 3.6a shows the share of university and public research institute PCT applications in the total number of PCT applications by income group. The shares for high-income countries grew consistently during

11 The country assigned to an application is the country of residence of the first applicant. Data are classified either by origin (all applications with the first applicant originating from that country) or by office (all applications filed in that country).

12 Public research institutes in France filed the most PCT applications in 2016, with 745 PCT filings, followed by China (573), the U.S. (569), the Republic of Korea (491) and Germany (372). 
Share of PCT filings for universities, 2007

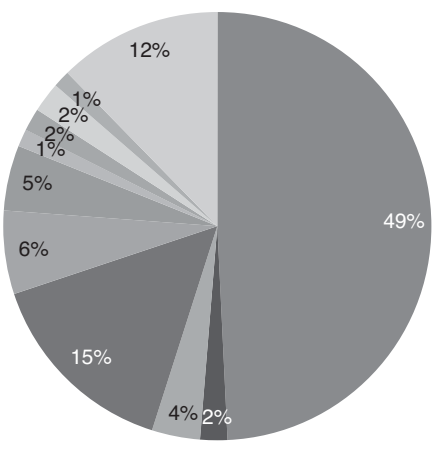

Share of PCT filings for PRIs, 2007

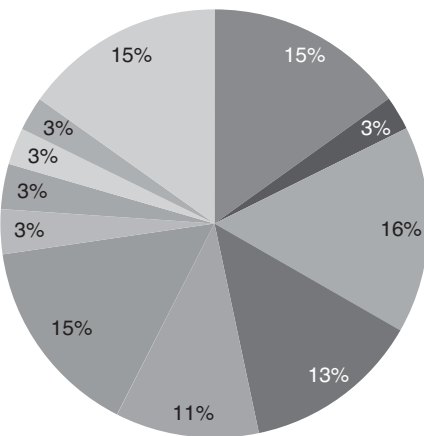

- United States of America

- China

Republic of Korea

- Japan

- United Kingdom

- Germany

- France

- Spain

- Canada

- Australia

Others

- China

United States of America

- Republic of Korea

- Germany

॥ Japan

- Singapore

- India

- Spain

Australia

Others
Share of PCT filings for universities, 2016

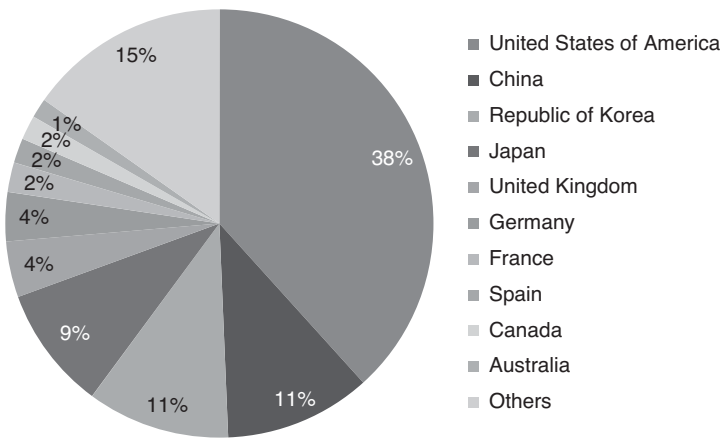

PCT filings from PRIs, 2016

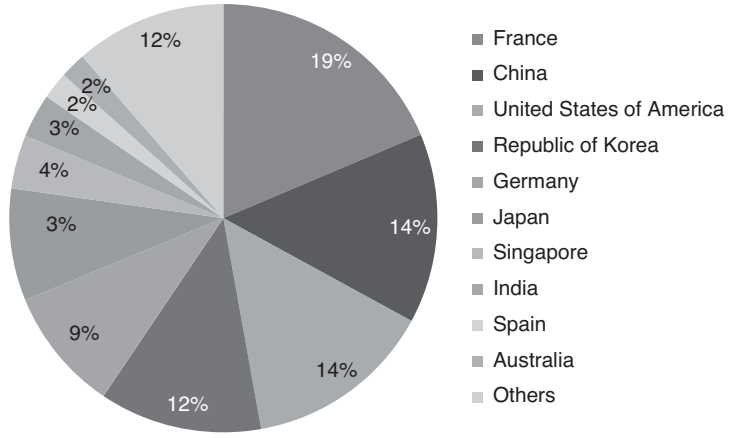

Figure 3.4 Share of university and public research institute PCT filings for top ten origins in 2007 and 2016 Source: WIPO Statistics Database, July 2017

Note: PCT data are based on the publication date and first-named applicant. Universities include all types of educational organizations, and public research institutes include private nonprofit organizations and hospitals. 


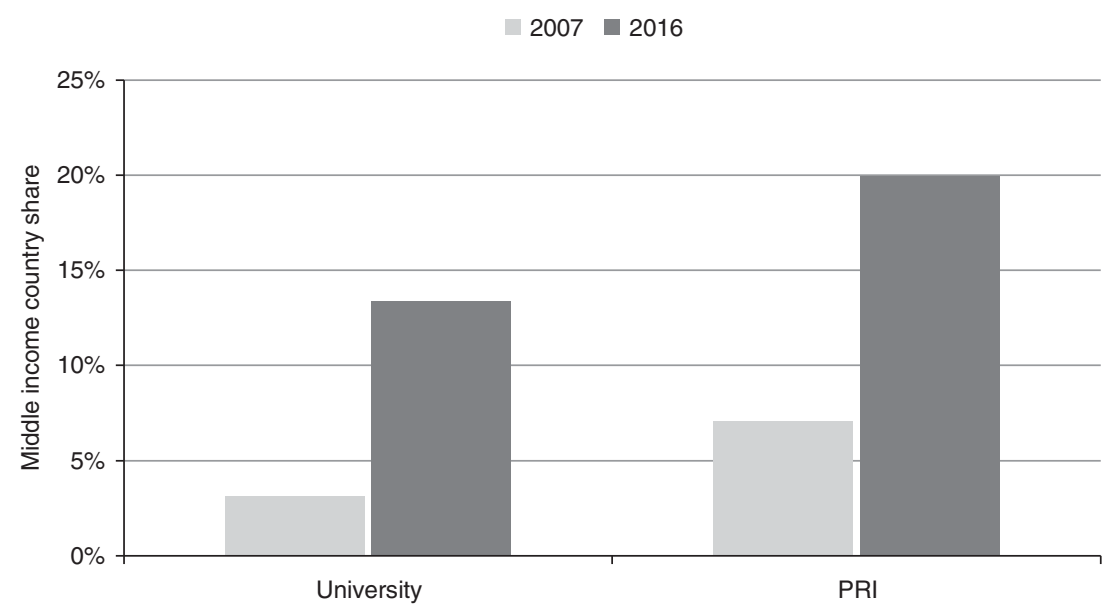

Figure 3.5 University and public research institute PCT filings originating from middle-income countries as a share of total university and public research institute PCT filings

Source: WIPO Statistics Database, July 2017

Note: PCT data are based on the publication date and first-named applicant.

Universities include all types of educational organization, and public research institutes include private nonprofit organizations and hospitals.

the period $1980-2015$, and ranged from 5.1 percent to 8.5 percent. In the period 1980-90, university and public research institute PCT applications from middle-income economies represented just over 2.8 percent of those countries' PCT applications. That share increased dramatically to over 8.0 percent in $1991-2000$, and was fairly stable at almost 9.1 percent during the period 2001-15. PCT filings from China could potentially bias the middle-income share due to the high filing activity in that country. However, if China is removed from the count, the share of university and public research institute PCT applications in the total number of PCT applications from middle-income countries actually increases to 10 percent. This shows that universities and public research institutes play an important role in the innovation capability of a number of middle-income economies.

Figure $3.6 \mathrm{~b}$ depicts the share of university and public research institute patent applications in total patent applications by income group. For high-income economies, this share increased gradually from about 1.2 percent to 5.1 percent between $1980-90$ and 2011-13. Most of this 

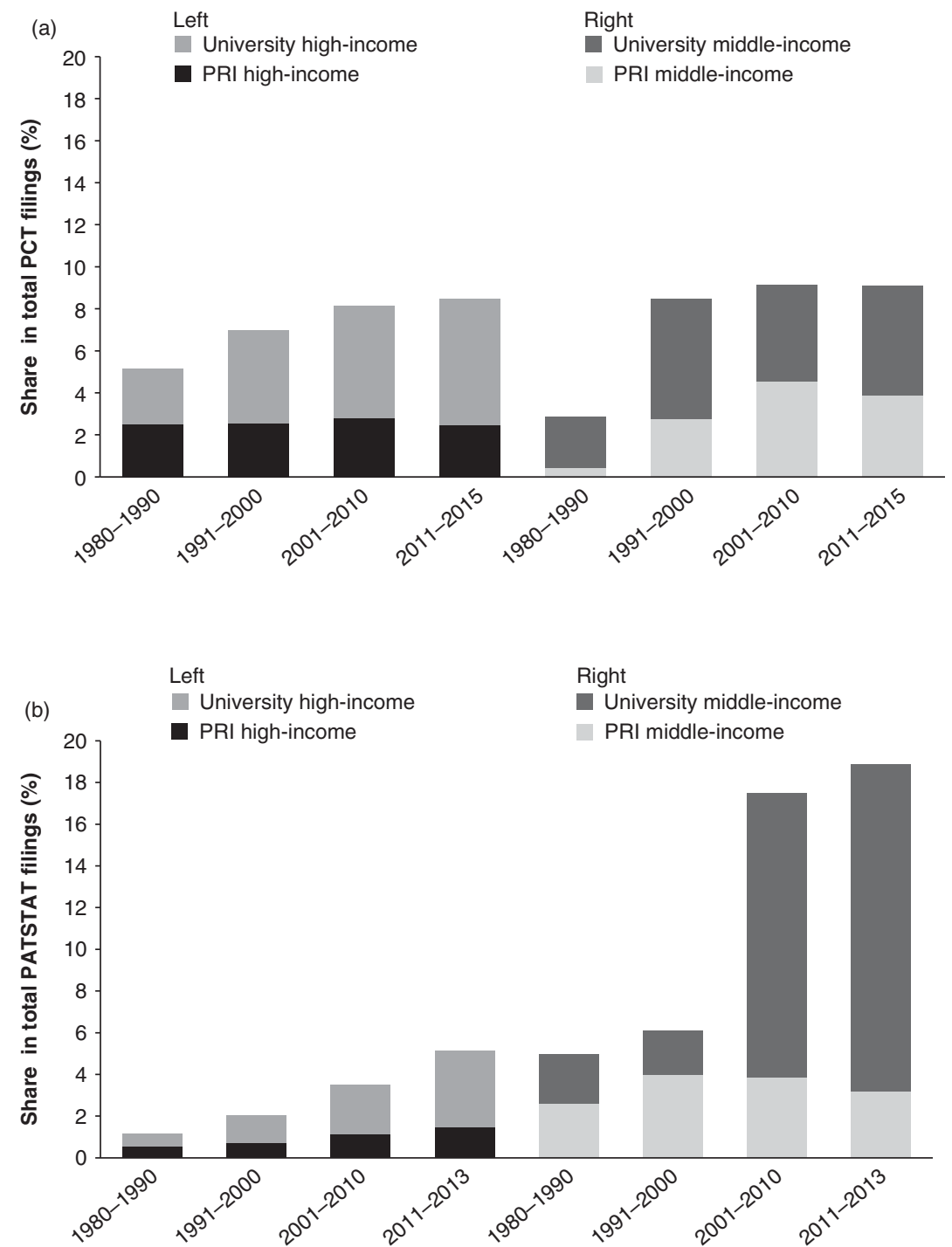

Figure 3.6 Increase in university and public research institute filings by high- and middle-income groups

3.6a Share of university and public research institute filings in total PCT applications by income group (\%), 1980-2015

3.6b Share of university and public research institute applications in total patent applications by income group (\%), 1980-2013

Source: WIPO Statistics Database, April 2016 
increase originated from universities. The share of university and public research institute applications in middle-income countries has exceeded that of high-income economies since 1980, and increased sharply from about 5.0 percent in 1980-90 to nearly 18.9 percent in 2011-13.

Figure 3.7 decomposes the patenting activity for the most active countries over the last decade. As Figure 3.7a shows, in 2004-13 China accounted for slightly less than half (49.0 percent) of all patent applications filed by universities across the world. It was followed by the U.S. (14.0 percent), and the Republic of Korea (11.3 percent). These top three countries combined accounted for nearly three-quarters ( 74.3 percent) of the filings originating from the world's universities.

Filings from public research institutes are less concentrated than those from universities, as shown in Figure 3.7b. Public research institute filings from China (31.2 percent), the Republic of Korea (23.3 percent), and France (12.5 percent) combined accounted for 67.0 percent of total filings -7.3 percentage points below the combined share for the top three countries in university filings (74.3 percent). These shares also reflect a shift in university and public research institute filings from the U.S. and Europe toward Asia.

Figure 3.8 shows the trend over the past decade in PCT filings for selected origins. The key findings can be summarized as follows: US university PCT filings represented about 7.6 percent of total US PCT filings between 2006 and 2015. The number of US university PCT filings remained relatively stable throughout this period, varying between a minimum of 3,560 in 2010 and a maximum of 4,573 in 2014. US public research institute PCT filings accounted for slightly more than 1 percent of total US PCT filings over the past decade and amounted to 753 PCT filings in 2015.

The shares of university and public research institute PCT filings from Germany were also quite stable, each representing between 2 percent and 3 percent of total PCT filings from Germany between 2006 and 2015. For universities, the total number of PCT filings in 2015 was 490 and for public research institutes 456 .

PCT filings by French universities accounted for between 3.2 and 7.5 percent of the country's PCT filings since 2006. The number of PCT filings from French universities increased from 204 in 2006 to 671 in 2015. The share of French public research institute PCT filings was nearly 12 percent in most of the reported years, and their number of PCT filings increased from 646 in 2006 to 1,165 in 2015. 
(a)

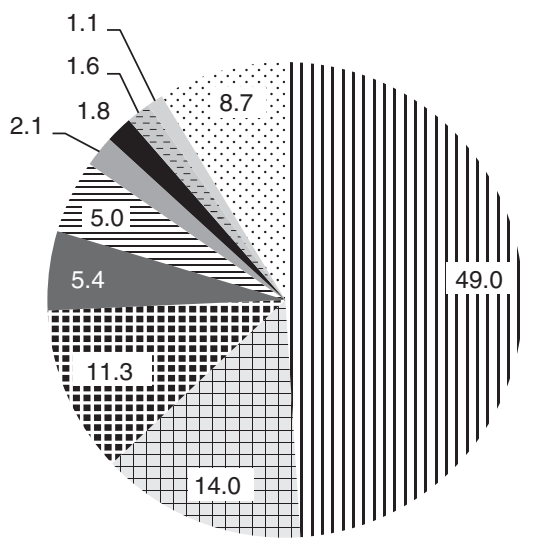

| IChina

\pm United States of America

I Republic of Korea

Russia

三Japan

United Kingdom

Germany

Erance

Poland

Others

| / China

壮 Republic of Korea

HFrance

Japan

$\equiv$ Germany

United States of America

- Singapore

Russia

EIndia

Spain

Others

Figure 3.7 University and public research institute patenting by leading origin countries

3.7a University patent applications in the world for selected countries (\%), 2004-13

3.7b Public research institute patent applications in the world for selected countries (\%), 2004-13

Sources: WIPO Statistics Database and EPO PATSTAT database, April 2016 
As for the share of university PCT filings from the United Kingdom, it tended to increase slightly over time and accounted for 10.3 percent of total UK PCT filings in 2015. The number of PCT filings reached 545 in 2015. The share of UK public research institute PCT filings was 1.1 percent in 2015 and represented only fifty-seven PCT filings.

The share of Japanese university and public research institute PCT filings tended to decrease over time. The share for universities decreased from 5.3 percent in 2006 to 3.1 percent in 2015, while that for public research institutes fell from 2.6 percent to 1.1 percent. These declines are due to a fall in the number of PCT filings originating from Japanese
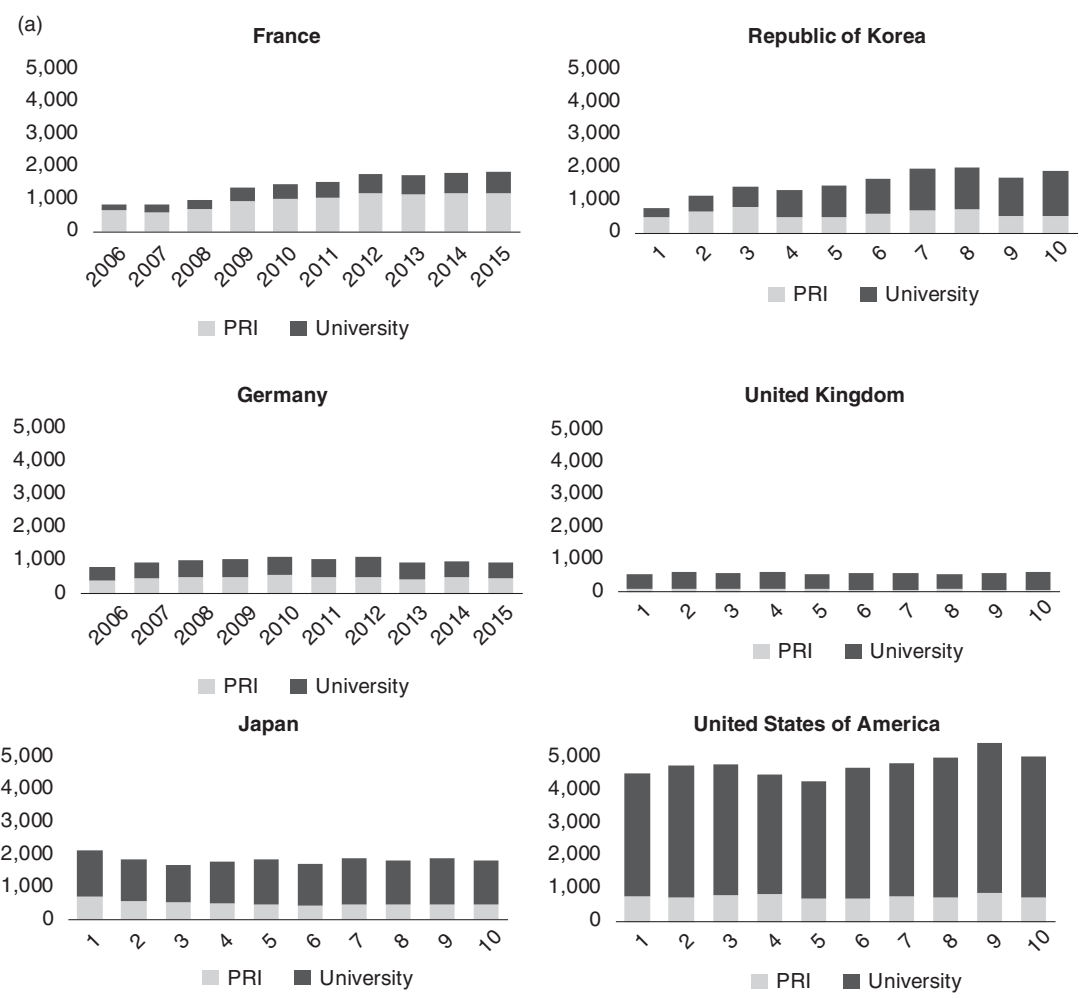

Figure 3.8 The trend over the past decade in PCT filings for selected origins 3.8a Public research institute and university PCT applications from high-income countries, absolute numbers, 2006-15

3.8b Share of public research institute and university PCT applications from highincome countries, country shares (\%), 2006-15

Sources: WIPO Statistics Database and EPO PATSTAT database, April 2016 

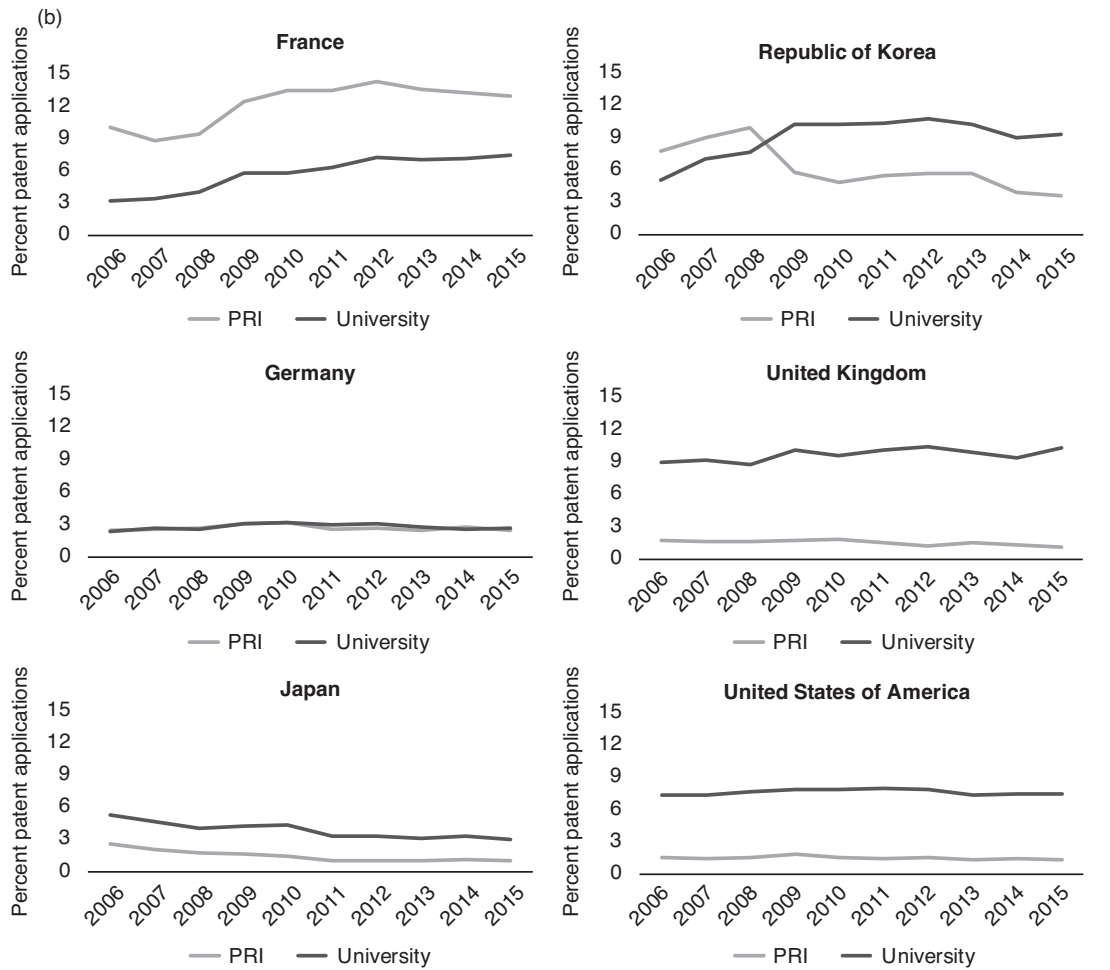

Figure 3.8 (cont.)

universities and public research institutes; in 2015 they filed 1,346 and 480 PCT filings, respectively.

The share of filings from universities in the Republic of Korea's PCT filings increased markedly during the period, from 5.1 percent in 2006 to 9.4 percent in 2015, with the number of PCT filings rising from 306 in 2006 to 1,364 in 2015. In contrast, public research institute PCT filings decreased as a share of the total from 7.8 percent in 2006 to 3.6 percent in 2015, mainly because the overall number of PCT filings from the Republic of Korea increased faster than the number of public research institute filings.

Figure 3.9 shows data for a selection of middle-income countries. Indian public research institutes accounted for 9.6 percent of total Indian PCT filings in 2015, with 135 filings. The share for universities peaked at 6.5 percent in 2010, having increased regularly over the 
previous decade. It stood at 1.8 percent in 2006 and 3.4 percent in 2015, with fifteen and forty-eight PCT filings, respectively.

The share of university PCT filings from South Africa has increased markedly over the past decade, from 5.4 percent in 2006 to 18.1 percent in 2015. This reflects an increase in the number of PCT filings from twenty-three in 2006 to fifty-six in 2015. In contrast, the shares and numbers of PCT filings from South African public research institutes have remained stable since 2006; in 2015 South African public research

(a)
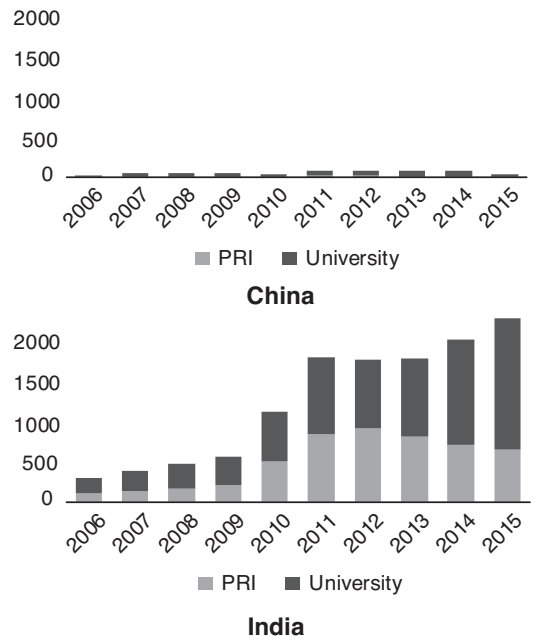

2000

1500

1000

500

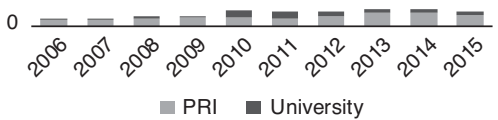

Malaysia

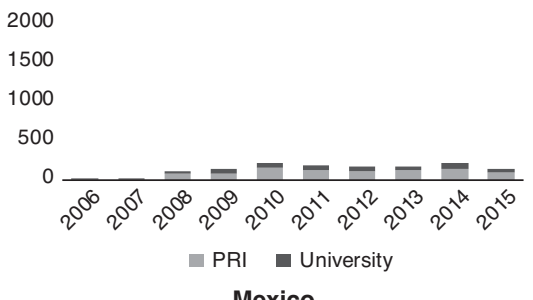

2000

1500

1000

500

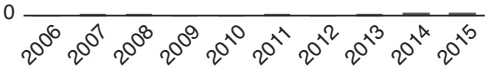

I PRI University

South Africa

2000

1500

1000

500

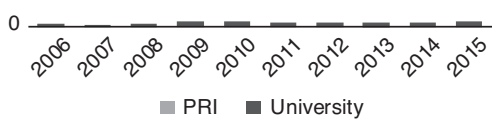

Figure 3.9 University and public research institute PCT filings in middle-income countries

3.9a Public research institute and university PCT applications from middle-income countries, absolute numbers, 2006-15

3.9b Share of public research institute and university PCT applications from middleincome countries, country shares (\%), 2006-15

Source: WIPO Statistics Database, April 2016 
(b)
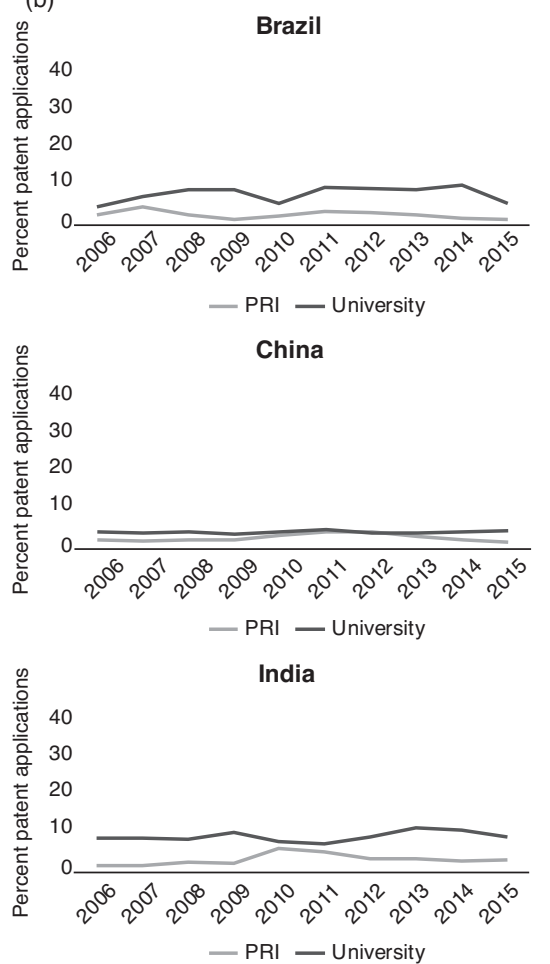

Figure 3.9 (cont.)
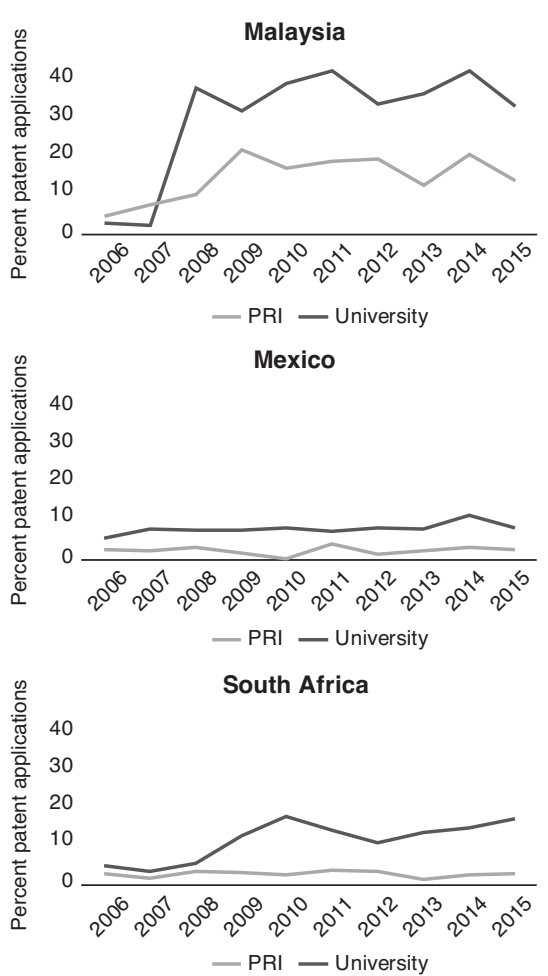

institutes filed ten PCT applications, representing 3.2 percent of the country's PCT filings.

As for Mexico, the numbers and shares of public research institute and university PCT filings remained small for the whole period. Mexican public research institutes and universities filed on average about twentyfive PCT applications per year each in most of the years reported, accounting for a maximum of 15.8 percent of total PCT filings from Mexico.

The share of public research institute PCT filings from Malaysia has increased sharply since 2006 and accounted for nearly half of total PCT filings originating from the country (44.0 percent). The number of public research institute filings increased from two in 2006 to ninety-two in 2015. Likewise, the share of university PCT filings increased, from 5.0 percent in 2006 to 14.5 percent in 2015, with numbers up from just three filings in 2006 to thirty-nine in 2015. University and public research 
institute PCT filings combined accounted for two-thirds (65.0 percent) of PCT filings from Malaysia in 2014.

Chinese university and public research institute PCT filings remained quite stable as a share of total Chinese PCT filings between 2006 and 2015 , with on average 4.7 percent and 3.1 percent respectively throughout this period. However, the numbers of PCT filings were six to eight times higher in 2015 than a decade earlier. The number of PCT filings for universities increased from 183 in 2006 to 1,547 in 2015, and from ninety-six to 607 for public research institutes.

(a)

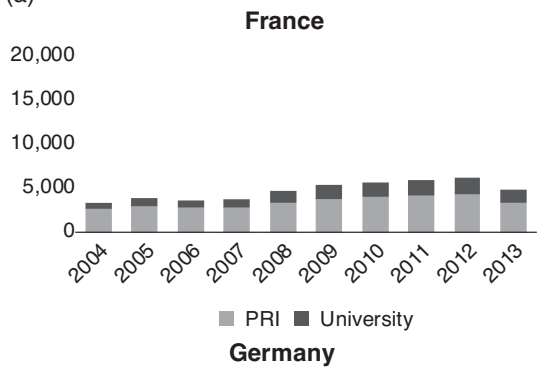

20,000

15,000

10,000

5,000

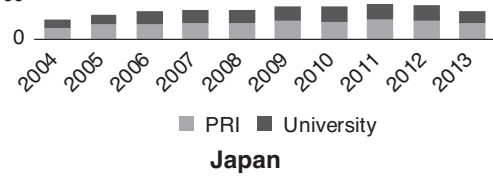

20,000

15,000

10,000

5,000

0

$2^{0^{\alpha}} 2^{0^{6}} 2^{0^{6}} 2^{0^{1}} 2^{0^{8}} 2^{0^{9}} 2^{0^{0}} 2^{0^{1}} 2^{0^{2}} 2^{0^{3}}$

I PRI — University

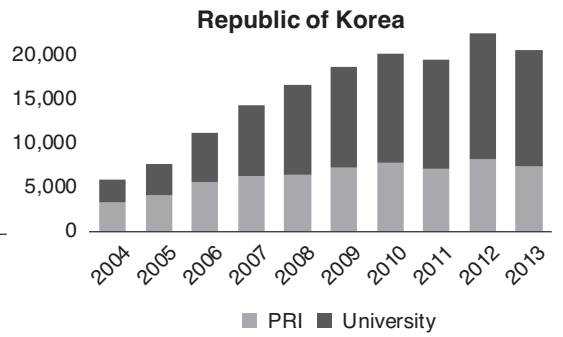

United Kingdom

20,000

15,000

10,000

5,000

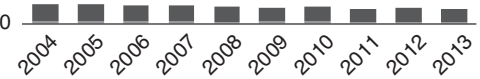

- PRI U University

United States of America

20,000

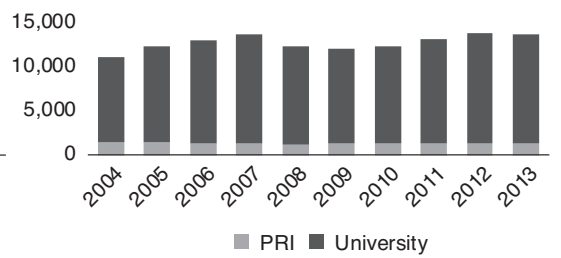

Figure 3.10 University and public research institute patent filings using PATSTAT data

3.10a Public research institute and university patent applications from high-income countries, absolute numbers, 2004-13

3.10b Public research institute and university patent applications from high-income countries, country shares (\%), 2004-13

Sources: WIPO Statistics Database and EPO PATSTAT database, April 2016 
(b)

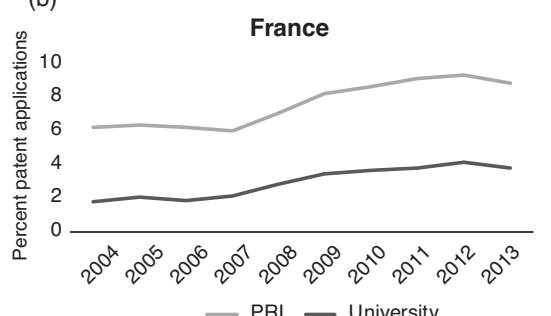

$$
\text { Germany }
$$
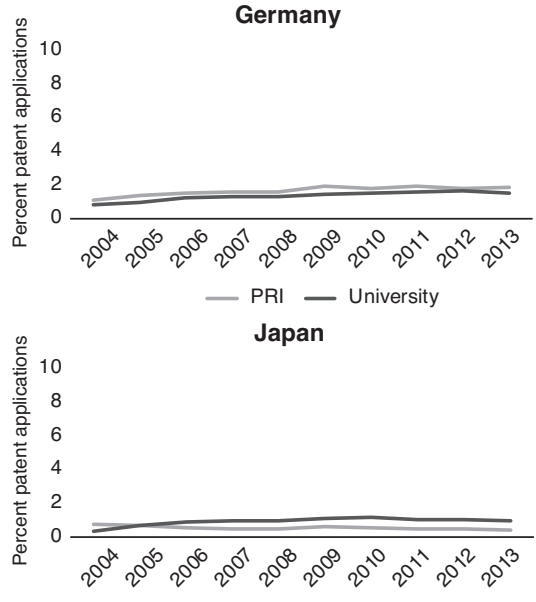

Figure 3.10 (cont.)

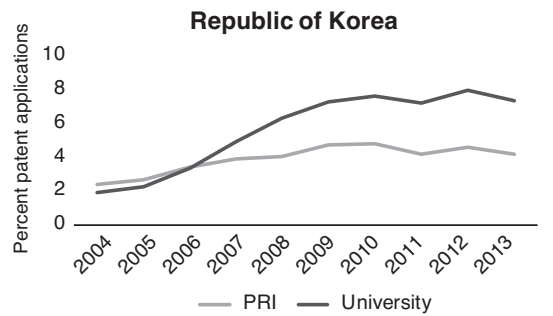

United Kingdom

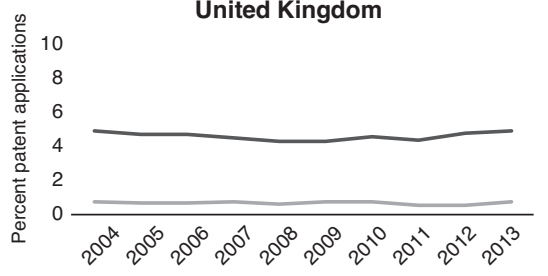

- PRI — University

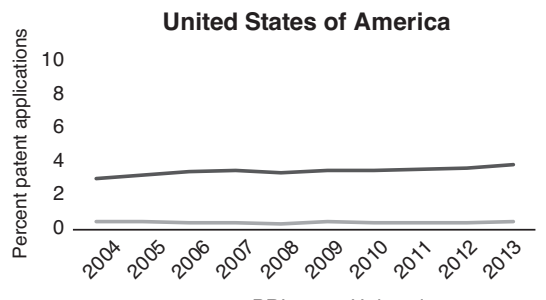

- PRI — University

According to PATSTAT data, university and public research institute patent filings in France increased by an average annual growth rate of 4.7 percent between 2004 and 2013, reaching 4,810 applications (Figures $3.10 \mathrm{a}$ and $3.10 \mathrm{~b}$ ). In Japan, the number of university and public research institute applications stood at 7,264 in 2010, but declined to 5,100 in 2013. In the Republic of Korea, 22,441 university and public research institute applications were filed in 2012, and the average annual growth rates is 15.9 percent in 2004-13.

Patents filed by US universities and public research institutes amounted to about 11,000 and 14,000 per year in the period 2004-13, with a decline to around 12,000 in 2005-10. US universities have been patenting their innovations for many years but because of the number of patents filed by the private sector, the university share stood at about 3.9 percent of total filings in 2013. 
In China, university and public research institute patent applications combined grew from 8,740 in 2004 to 111,397 in 2013, with an average annual growth rate of 33.2 percent since 2004 (Figures $3.11 \mathrm{a}$ and $3.11 \mathrm{~b}$ ). Chinese university patenting since 2004 shows a sharp increase in filing, making some Chinese universities among the most active in the world in terms of patent-filing activity. This can be explained in part by government grants to research institutes and universities that file a large number of patent applications, and related initiatives.

(a)
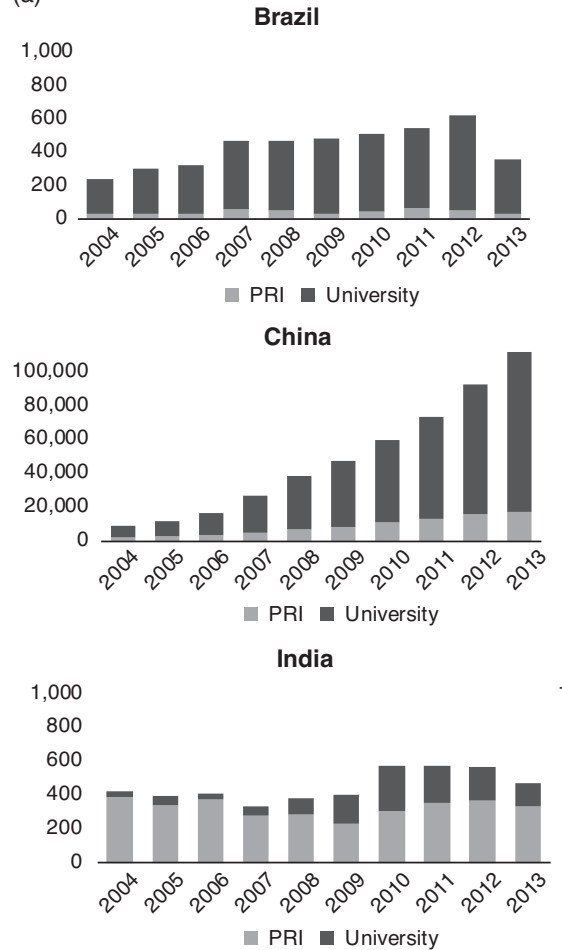

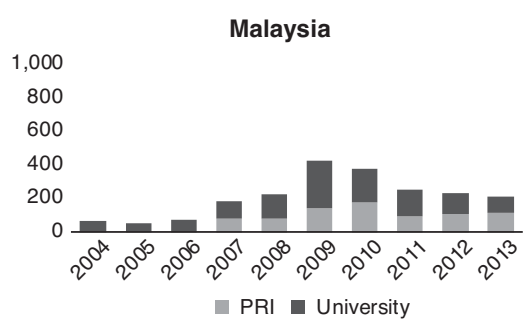

Mexico

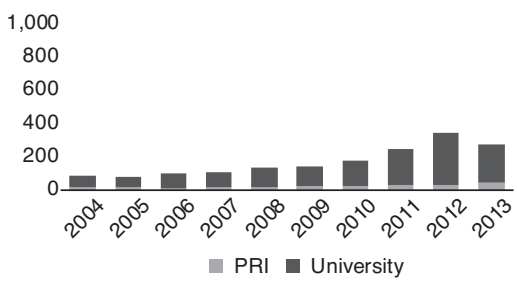

South Africa

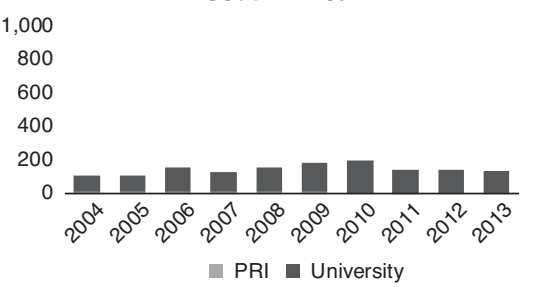

Figure 3.11 University and public research institute patent filings for middle-income countries

3.11a Public research institute and university patent applications from middle-income countries, absolute numbers, 2004-13

3.11b Public research institute and university patent applications from middle-income countries, country shares (\%), 2004-13

Sources: WIPO Statistics Database and EPO PATSTAT database, April 2016 

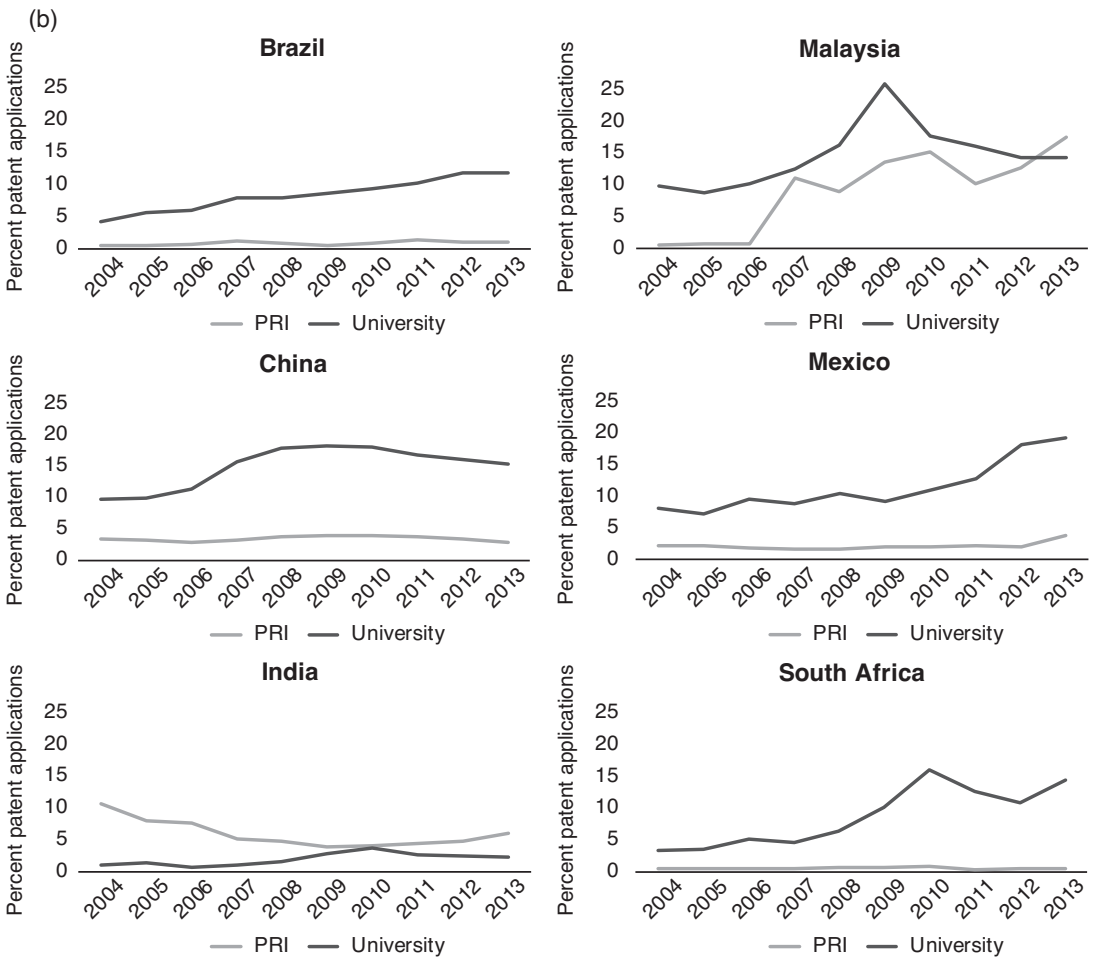

Figure 3.11 (cont.)

Two main points emerge from the above comparisons. First, the share of university and public research institute patent filings in all applications in high-income countries is more stable than their share in the middleincome group. Second, in terms of numbers of filings, middle-income countries are more heterogeneous than high-income countries.

Figure 3.12 shows the share of patent applications from universities and public research institutes in selected countries. The countries with the highest share of university filings in their total filings are China (14.8 percent), Malaysia (12.8 percent), Spain (6.9 percent), Israel (6.0 percent), Brazil (4.2 percent), and the Republic of Korea (4.2 percent). The countries with the highest share of public research institute applications are India (9.1 percent), France (5.7 percent), China (3.6 percent), the Republic of Korea (3.6 percent), and Spain (3.4 percent). 


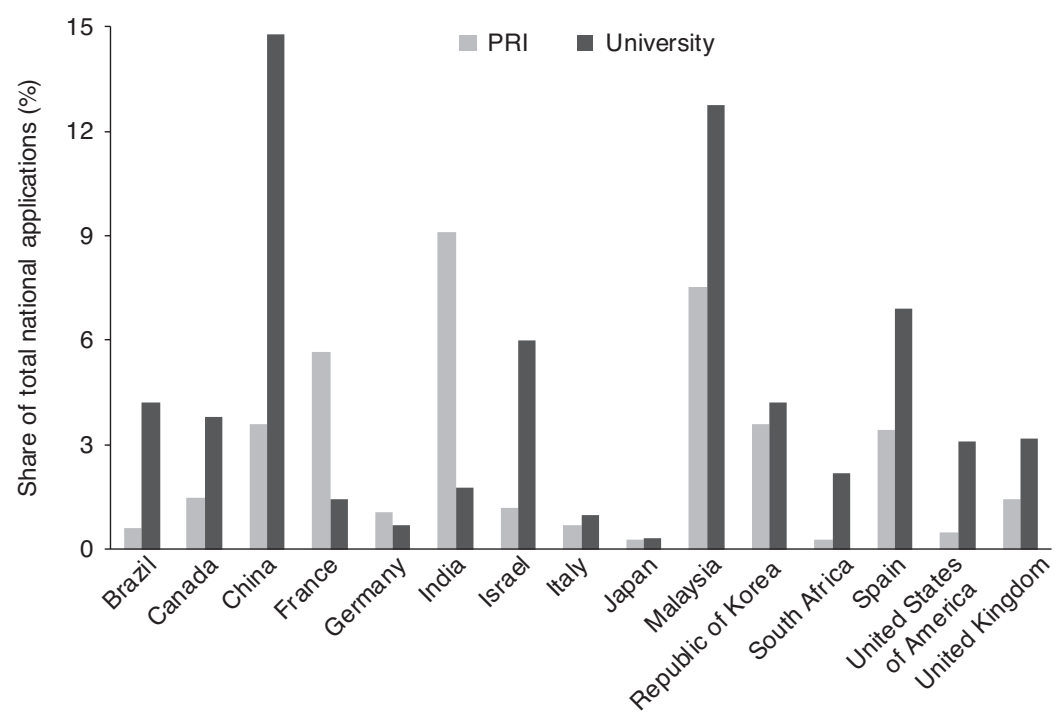

Figure 3.12 University and public research institute patent applications as a share of total applications for selected countries (\%), 1980-2013

Sources: WIPO Statistics Database and EPO PATSTAT database, April 2016

The shares of university and public research institute patent filings tend to be higher in the middle-income group than in the high-income group. It therefore seems particularly appropriate to encourage knowledge transfer in certain middle-income countries such as Brazil, China, India, Malaysia, and South Africa.

\subsubsection{By Technology Field}

Overall, university and public research institute patenting activity primarily concerns biomedical and pharmaceutical inventions, broadly defined. ${ }^{13}$ This is true of high-income countries and other economies alike. It is not surprising, as these industries are the most science-driven.

${ }^{13}$ WIPO's IPC technology concordance table was used in this section to convert IPC codes into corresponding fields of technology (see "Concept of a Technology Classification for Country Comparisons," Final Report to the World Intellectual Property Organization (WIPO), Ulrich Schmoch, June 2008). For an electronic version of the IPC technology concordance table, see www.wipo.int/ipstats. 


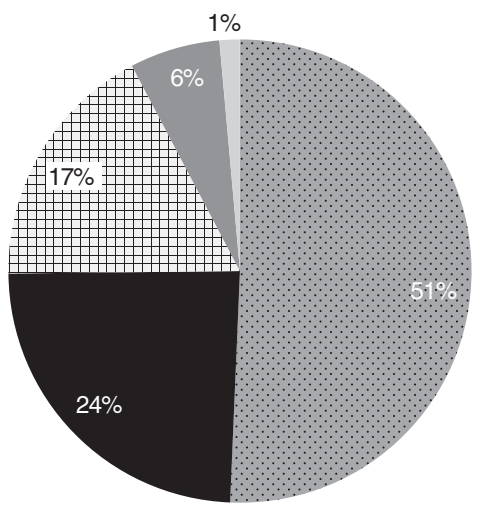

$\therefore$ Chemistry

Instruments

\# Electrical engineering

Mechanical engineering

Other fields

PCT applications from PRIs, 2007-16

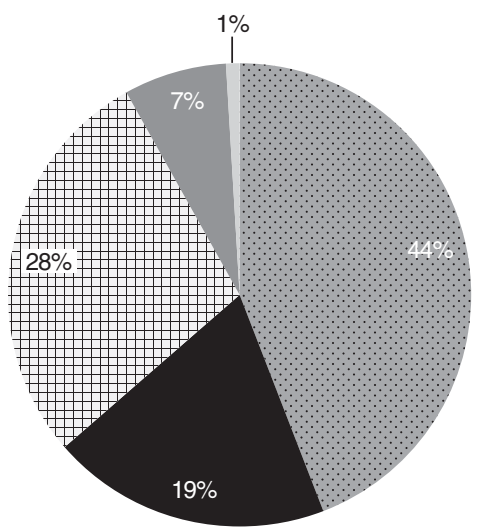

Chemistry

Instruments

\# Electrical engineering

Mechanical engineering

Other fields

Figure 3.13 Distribution of PCT applications by technology sector, 2007-16 Source: WIPO Statistics Database, July 2016

However, whether patenting in these technological fields is demand- or supply-driven is less clear.

On the basis of PCT data, it can be shown that for the period 2007-16, university filings mainly occurred in the chemistry sector (51 percent) (Figure 3.13), followed by instruments (24 percent), and electrical engineering (17 percent). The three sectors combined accounted for 92 percent of PCT applications filed by universities. 
Public research institutes also made their largest share of PCT applications in the chemistry sector (44 percent). Their share of PCT applications filed in the electrical engineering sector was relatively high, at 28 percent of their total filings. Together with instruments (20 percent), the top three sectors for public research institutes accounted for 92 percent of their total filings, precisely like the cumulative share of the top three sectors for universities.

In 2016, universities filed the largest number of PCT applications in the fields of pharmaceuticals (15 percent), biotechnology (13 percent), and medical technology (10 percent) (see Figure 3.14). These were also the top three fields for public research institutes. For public research institutes, pharmaceuticals accounted for 12 percent of total PCT filings, as did biotechnology. Medical technology represented 8 percent of public research institutes' total PCT filings.

Table 3.2 shows the share of patent applications filed worldwide by universities and public research institutes for selected technology fields in 2013-15, based on data from the PATSTAT database. Of the thirty-five technology fields, university applicants filed 40 percent of their applications in their top five fields: biotechnology (14.9 percent), pharmaceuticals ( 8.5 percent), measurement (5.7 percent), materials, metallurgy (5.5 percent), and organic fine chemistry ( 5.3 percent).

- University $\quad$ PRI

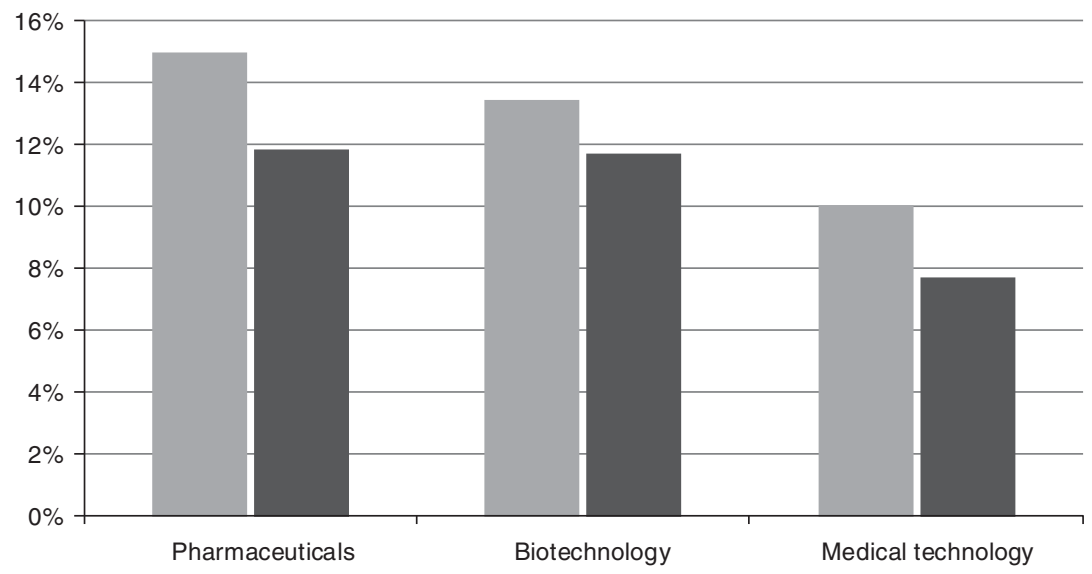

Figure 3.14 Share of PCT applications for the top three fields of technology, 2016 Source: WIPO Statistics Database, July 2016 
Table 3.2 Share of patent applications filed in selected technology fields by applicant type, 2013-15

\begin{tabular}{|c|c|c|c|}
\hline Technology field & Applicant type & Patent filings & $\begin{array}{l}\text { As a share of all } \\
\text { university/public } \\
\text { research institute } \\
\text { filings (\%) }\end{array}$ \\
\hline Biotechnology & University & 184,175 & 14.9 \\
\hline Pharmaceuticals & University & 183,509 & 8.5 \\
\hline Measurement & University & 143,493 & 5.7 \\
\hline Materials, metallurgy & University & 80,614 & 5.4 \\
\hline $\begin{array}{l}\text { Organic fine } \\
\text { chemistry }\end{array}$ & University & 114,147 & 5.3 \\
\hline Chemical engineering & University & 72,235 & 4.3 \\
\hline $\begin{array}{l}\text { Basic materials } \\
\text { chemistry }\end{array}$ & University & 66,177 & 3.6 \\
\hline $\begin{array}{l}\text { Other special } \\
\text { machines }\end{array}$ & University & 58,141 & 2.8 \\
\hline Computer technology & University & 91,807 & 2.7 \\
\hline $\begin{array}{l}\text { Electrical machinery, } \\
\text { apparatus, energy }\end{array}$ & University & 77,325 & 2.3 \\
\hline Biotechnology & $\begin{array}{l}\text { Public research } \\
\text { institute }\end{array}$ & 64,110 & 5.2 \\
\hline Measurement & $\begin{array}{l}\text { Public research } \\
\text { institute }\end{array}$ & 62,151 & 2.5 \\
\hline Pharmaceuticals & $\begin{array}{l}\text { Public research } \\
\text { institute }\end{array}$ & 48,923 & 2.3 \\
\hline Materials, metallurgy & $\begin{array}{l}\text { Public research } \\
\text { institute }\end{array}$ & 31,605 & 2.1 \\
\hline Chemical engineering & $\begin{array}{l}\text { Public research } \\
\text { institute }\end{array}$ & 33,323 & 2.0 \\
\hline $\begin{array}{l}\text { Organic fine } \\
\text { chemistry }\end{array}$ & $\begin{array}{l}\text { Public research } \\
\text { institute }\end{array}$ & 42,277 & 2.0 \\
\hline $\begin{array}{l}\text { Basic materials } \\
\text { chemistry }\end{array}$ & $\begin{array}{l}\text { Public research } \\
\text { institute }\end{array}$ & 31,323 & 1.7 \\
\hline $\begin{array}{l}\text { Other special } \\
\text { machines }\end{array}$ & $\begin{array}{l}\text { Public research } \\
\text { institute }\end{array}$ & 28,653 & 1.4 \\
\hline Computer technology & $\begin{array}{l}\text { Public research } \\
\text { institute }\end{array}$ & 37,728 & 1.1 \\
\hline $\begin{array}{c}\text { Electrical machinery, } \\
\text { apparatus, energy }\end{array}$ & $\begin{array}{l}\text { Public research } \\
\text { institute }\end{array}$ & 33,861 & 1.0 \\
\hline
\end{tabular}

Sources: WIPO Statistics Database and EPO PATSTAT database, April 2016 
Patent applications filed by public research institutes were not as concentrated among their top five (14.1 percent) as universities. These top five fields were: biotechnology (5.2 percent), measurement (2.5 percent), pharmaceuticals (2.3 percent), materials, metallurgy ( 2.1 percent), and chemical engineering ( 2 percent).

As described already, universities and public research institutes largely concentrate their filings - patent filings as well as PCT filings - in sciencebased technology fields, especially in pharmaceuticals and the biological fields.

The five universities that filed the largest number of PCT applications in 2016 were all in the U.S. (Figure 3.15). They mainly filed in pharmaceuticals and biotechnology. Pharmaceuticals accounted for the largest share of PCT filings by Johns Hopkins University and the University of Texas System, while biotechnology was the main field of technology for Harvard University, MIT, and the University of California.

The top five public research institutes in PCT filings were more diversified. Only ASTAR and INSERM had two of their three main technology fields belonging to the chemistry sector. China Academy of Telecommunication Technology filed the bulk of its applications in digital communications. The Commissariat à l'Energie Atomique et aux Energies Alternatives (CEA) and the Fraunhofer-Gesellschaft had each of their three main fields of technology within the electrical engineering sector.

Figure 3.16 shows the share of the top three fields of technology for selected universities and public research institutes in their total patent families created worldwide in 2010-13. All selected universities and public research institutes created a quarter or more of their patent families in their top three fields of technology. Precisely half the patent families created by the Korea Electronics Telecomm belonged to digital communications, telecommunications, and computer technology. The CEA is also highly concentrated in its top three fields of technology (electrical machinery, measurements, and semiconductors) as these three fields accounted for 41.3 percent of its total families.

Among this selection of ten universities and public research institutes, eight had measurement and six electrical machinery among their top three fields of technology. Pharmaceuticals and biotechnology - which are two popular fields of technology among universities and public research institutes - appears only among the top three fields of one public research institute (CNRS) and one university (Tokyo 

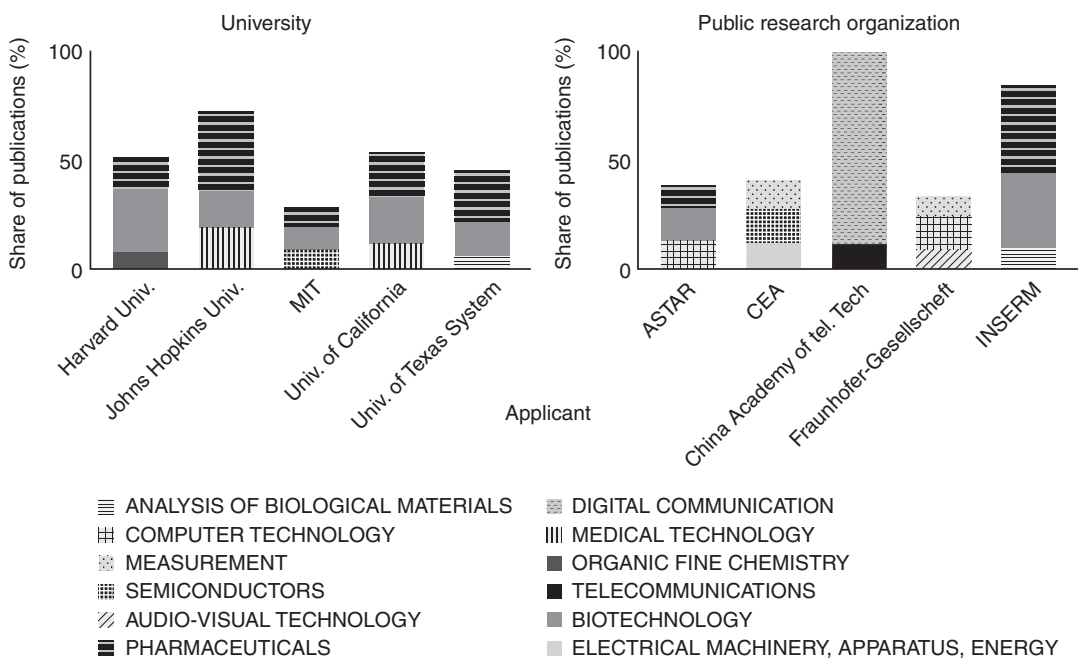

Figure 3.15 Shares of leading technology sectors in PCT applications filed by the top five universities

Source: WIPO Statistics Database, April 2017

Note: ASTAR is the Agency of Science, Technology and Research, CEA is the Commissariat à I'Énergie Atomique et aux Énergies Alternatives, INSERM is the Institut National de la Santé et de la Recherche Médicale, MIT is the Massachusetts Institute of Technology. Public research organizations include private organizations and hospitals. For confidentially reasons, data are based on publication date. WIPO's IPC technology concordance (available at: www.wipo.int/ipstats) was used to convert IPC symbols into thirty-five corresponding fields of technology.

University). This is due to the selection of universities and public research institutes, which shows that large organizations can be specialized in quite different fields of technologies.

\subsubsection{By University}

The University of California was the largest user of the PCT System in 2016, with 434 published PCT applications (Table 3.3). It has maintained that position since 1993. Massachusetts Institute of Technology (236) ranked second, followed by Harvard University (162), Johns Hopkins University (158), and the University of Texas System (152). Seven of the top ten universities were located in the U.S.; Seoul National University of the Republic of Korea (122) - in sixth position - was the highest-ranking non-US university, while Japan's University of Tokyo (108) ranked 
Electrical machinery $[\because \cdot$ Telecommunications

Digital communication $\square$ Measurement एणा Organic fine chemistry

Biotechnology

$\square$ Computer technology

ZIA Semiconductors
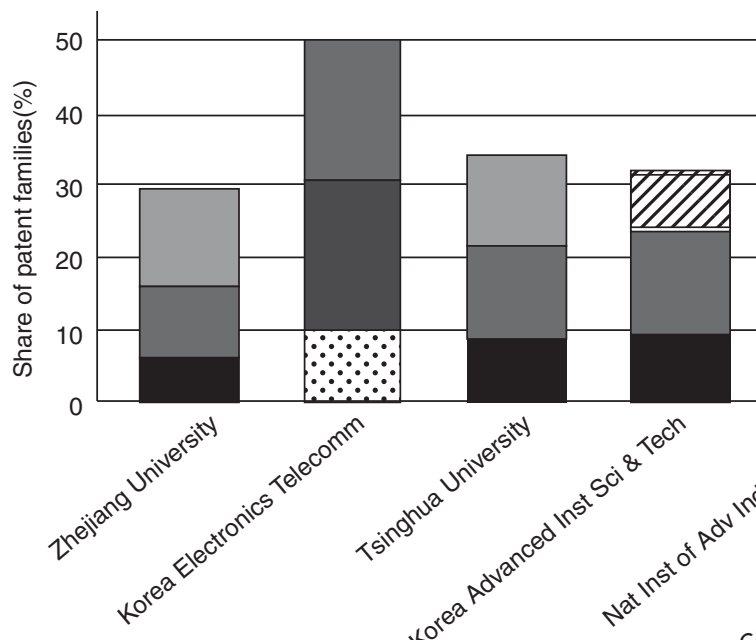

$\square$ Pharmaceuticals

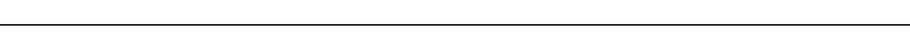

Figure 3.16 Top three technology fields for selected universities and public research institutes, 2010-13

Source: WIPO Statistics Database and EPO PATSTAT database, October 2016 
seventh. While the top ten was dominated by U.S.-based organizations, the top twenty list comprised ten US and ten Asian universities. China's Shenzhen University was in joint thirteenth position with eighty-seven published PCT applications, making it the highest-ranking Chinese university for PCT filings.

For the sixth consecutive year, the CEA of France was the top PCT applicant among public research institutes, with 329 published PCT applications (Table 3.4). It was followed by the FraunhoferGesellschaft zur Förderung der angewandten Forschung of Germany (252) and the Agency of Science, Technology and Research of Singapore (162).

Figure 3.17 shows the distribution of PCT applications for the top thirty origins, broken down by four types of applicant: businesses, individuals, universities, and government and research organizations. In 2016, 85.5 percent of all PCT applications belonged to business applicants, 7.5 percent to individuals, 5 percent to universities and 2 percent to public research institutes. Among the top thirty origins, universities accounted for a large share of applications in Morocco (42.9 percent), Colombia (33.7 percent), South Africa (16.2 percent), and Malaysia (14.4 percent). These five origins all belong to the middle-income category. They were followed by applicants from Singapore (14 percent), Spain (13.6 percent), Israel ( 9 percent), Australia ( 8.9 percent), and the United Kingdom (8.6 percent). In contrast, several countries - including Egypt, the Philippines and Sweden - had no PCT applications filed by universities in 2016.

Public research institutes represented a high share of applications originating in Malaysia (22.5 percent), Singapore (17.8 percent), the Philippines (11.8 percent), India (9.5 percent), and France ( 9.3 percent). Eleven of the top thirty origins had no PCT filing activity from public research institutes in 2016. For Colombia (33.7 percent), Malaysia (36.9 percent), and Morocco (42.9 percent), university and public research institute PCT filings combined accounted for more than onethird of their total PCT filings.

With 34,352 patent families worldwide, Panasonic of Japan was the top PCT applicant for the period 2010-13 (Table 3.5). It was followed by two other Japanese companies: Canon $(29,036)$ and Toyota Jidosha $(26,844)$. The top 100 list mainly comprises multinational companies. However, eleven Chinese universities and one Korean university as well as one Korean public research institute feature among the top 100 applicants. 
Table 3.3 Top PCT applicants for the university sector in 2016

\begin{tabular}{|c|c|c|c|c|}
\hline $\begin{array}{l}\text { Overall } \\
\text { rank }\end{array}$ & Change in position applicant's name from 2015 & Origin & $\begin{array}{l}\text { Published } \\
\text { applications }\end{array}$ & Change from 2015 \\
\hline 35 & 15 UNIVERSITY OF CALIFORNIA & USA & 434 & 73 \\
\hline 83 & $\begin{array}{l}8 \text { MASSACHUSETTS INSTITUTE OF } \\
\text { TECHNOLOGY }\end{array}$ & USA & 236 & 23 \\
\hline 119 & 10 HARVARD UNIVERISTY & USA & 162 & 4 \\
\hline 125 & 11 JOHNS HOPKINS UNIVERSITY & USA & 158 & -12 \\
\hline 133 & 12 UNIVERSITY OF TEXAS & USA & 152 & -11 \\
\hline 172 & 63 SEOUL NATIONAL UNIVERSTY & Republic of Korea & 122 & 27 \\
\hline 198 & 25 UNIVERSITY OF TOKYO & Japan & 108 & 7 \\
\hline 207 & 22 LEUAND STANFORD JUNIOR UNIVERSTY & USA & 104 & 5 \\
\hline 220 & 118 HANYANG UNIVERSITY & Republic of Korea & 101 & 33 \\
\hline 232 & 23 UNIVERSITY OF FLORIDA & USA & 97 & -11 \\
\hline 235 & 62 UNIVERSITY OF PENNSYLVANIA & USA & 96 & 20 \\
\hline 243 & 57 UNIVERSITY OF MICHIGAN & USA & 94 & -22 \\
\hline 262 & 42 KOREA UNIVERSITY & Republic of Korea & 87 & 12 \\
\hline 262 & 480 SHENZHEN UNIVERSITY & China & 87 & 58 \\
\hline 262 & $\begin{array}{l}120 \text { KOREA ADVANCED INSTITUTE OF SCIENCE } \\
\text { AND TECHNOLOGY }\end{array}$ & Republic of Korea & 87 & 30 \\
\hline 270 & 50 TSINGHUA UNIVERSITY & China & 84 & -18 \\
\hline
\end{tabular}


Table 3.3 (cont.)

\begin{tabular}{|c|c|c|c|c|}
\hline $\begin{array}{l}\text { Overall } \\
\text { rank }\end{array}$ & Change in position applicant's name from 2015 & Origin & $\begin{array}{l}\text { Published } \\
\text { applications }\end{array}$ & Change from 2015 \\
\hline 270 & $\begin{array}{l}228 \text { CHINA UNIVERSITY OF MINING AND } \\
\text { TECHNOLOGY }\end{array}$ & China & 84 & 41 \\
\hline 307 & 3 CALIFORNIA INSTITUTE OF TECHNOLOGY & USA & 73 & -1 \\
\hline 314 & $\begin{array}{l}222 \text { KING ABDULLAH UNIVERSITY OF SCIENCE } \\
\text { AND TECHNOLOGY }\end{array}$ & Saudi Arabia & 72 & 32 \\
\hline 314 & 17 KYOTO UNIVERSITY & Japan & 72 & -4 \\
\hline 321 & 421 NAGOYA UNIVERSITY & Japan & 69 & 40 \\
\hline 329 & 181 NORTHWESTERN UNIVERSITY & USA & 67 & 25 \\
\hline 329 & 43 COLUMBIA UNIVERSITY & USA & 67 & -13 \\
\hline 342 & 20 OSAKA UNIVERSITY & Japan & 65 & -7 \\
\hline 343 & 6 NANYANG TECHNOLOGICAL UNIVERSITY & Singapore & 64 & 1 \\
\hline 350 & 70 DUKE UNIVERSITY & USA & 62 & 10 \\
\hline 350 & 40 DANMARKS TEKNISKE UNIVERSITY & Denmark & 62 & -12 \\
\hline 361 & 116 UNIVERSITY OF NORTH CAROLINA & USA & 60 & 15 \\
\hline 361 & $\begin{array}{l}137 \text { ECOLE POLYTECHNIQUE FEDERALE DE } \\
\text { LAUSANNE }\end{array}$ & Switzerland & 60 & 17 \\
\hline 396 & 64 YONSE UNIVERSITY & Republic of Korea & 56 & -14 \\
\hline 396 & 14 KYUSHU UNIVERSITY & Japan & 56 & -1 \\
\hline 396 & 6 TOHOKU UNIVERSITY & Japan & 56 & 0 \\
\hline 411 & 127 PEKING UNIVERSITY & China & 54 & -27 \\
\hline
\end{tabular}



9 SOUTH CHINA UNIVERSITY OF TECHNOLOGY

China 45 UNIVERSITY OF WASHINGTON

USA

USA

166 ISIS INNOVATION LIMITED

UK

155 UNIVERSITY OF MARYLAND

USA

UK

Saudi Arabia

Israel

USA

USA

PO Statistics Database, April 2017

Source: WIPO Statistics Database, April 2017

Note: The university sector includes all types of educational organizations. For confidentiality reasons, data are based on publication date. 
Table 3.4 Top PCT applicants among governments and public research institutes in 2016

\begin{tabular}{|c|c|c|c|c|}
\hline $\begin{array}{l}\text { Overall } \\
\text { rank }\end{array}$ & Change in position applicant's name from 2015 & Origin & $\begin{array}{l}\text { Published } \\
\text { applications }\end{array}$ & $\begin{array}{l}\text { Change from } \\
2015\end{array}$ \\
\hline 52 & $\begin{array}{l}9 \text { COMMISSARIAT A L'ENERGIE ATOMIQUE ET } \\
\text { AUX ENERGIES ALTERNAT1VES }\end{array}$ & France & 329 & -80 \\
\hline 81 & $\begin{array}{l}22 \text { FRAUNHOFER-GESELLSCHAFT ZUR } \\
\text { FORDERUNG DER ANGEWANDTEN } \\
\text { FORSCHUNG EV. }\end{array}$ & Germany & 252 & -71 \\
\hline 119 & $\begin{array}{l}23 \text { AGENCY OF SCIENCE TECHNOLOGY AND } \\
\text { RESEARCH }\end{array}$ & Singapore & 162 & 14 \\
\hline 143 & $\begin{array}{l}12 \text { INSTITUT NATIONAL DE LA SANTE ET DE LA } \\
\text { RECHERCHE MEDICALE (INSERM) }\end{array}$ & France & 146 & 9 \\
\hline 146 & $\begin{array}{l}33 \text { CHINA ACADEMY OF } \\
\text { TELECOMMUNICATIONS TECHNOLCGY }\end{array}$ & India & 145 & 27 \\
\hline 156 & $\begin{array}{l}1 \text { CENTRE NATIONAL DE LA RECHERCE } \\
\text { SCIENTIFIQUE (CNRS) }\end{array}$ & France & 135 & -2 \\
\hline 172 & $\begin{array}{l}22 \text { NATIONAL INSTITUTE OF ADVANCED } \\
\text { INDUSTRIAL SCIENCE AND TECHNOLOGY }\end{array}$ & Japan & 122 & 10 \\
\hline 194 & $\begin{array}{l}7 \text { COUNCIL OF SCIENTIFIC AND INDUSTRIAL } \\
\text { RESEARCH }\end{array}$ & India & 109 & -1 \\
\hline 273 & $\begin{array}{l}56 \text { KOREA INSTITUTE OF INDUSTRAL } \\
\text { TECHNOLOGY }\end{array}$ & $\begin{array}{l}\text { Republic of } \\
\text { Korea }\end{array}$ & 83 & 12 \\
\hline 307 & $\begin{array}{l}83 \text { SLOAN-KETTTERNG INSTITUTE FOR } \\
\text { CANCER RESEARCH }\end{array}$ & USA & 73 & 17 \\
\hline
\end{tabular}


5 BATTELLE MEMORIAL INSTTUTE

USA

Japan

173 NEDERLANDSE ORGANISATIE VOOR TOEGEPAST NATUURWETENSCHAPPELIJK ONDERZOEK (TNO)

252 MAX-PLANCK GESELLSCHAFT ZUR FORDERUNG DER WISSENSCHAFTEN E.V 162 KOREA RESEARCH INSTITUTE OF SCIENCE AND BIOTECHNOLOGY

84 ELECTRONICS \& TELECOMMUNICATIONS RESEARCH INSTITUTE OF KOREA 197 JAPAN SCIENCE AND TECHNOLOGY AGENCY

Malaysia

Republic of

45

Korea

Australia

Netherlands

Germany

Republic of Korea

Republic of 
Table 3.4 (cont.)

\begin{tabular}{|c|c|c|c|c|}
\hline $\begin{array}{l}\text { Overall } \\
\text { rank }\end{array}$ & Change in position applicant's name from 2015 & Origin & $\begin{array}{l}\text { Published } \\
\text { applications }\end{array}$ & $\begin{array}{l}\text { Change from } \\
2015\end{array}$ \\
\hline 630 & $\begin{array}{l}523 \text { UNITED STATES OF AMERICA AS } \\
\text { REPRESENTED BY THE SECRETARY OF THE } \\
\text { NAVY }\end{array}$ & USA & 35 & 17 \\
\hline 669 & $\begin{array}{l}484 \text { KOREA INSTITUTE OF SCIENCE AND } \\
\text { TECHNOLOGY }\end{array}$ & $\begin{array}{l}\text { Republic of } \\
\text { Korea }\end{array}$ & 33 & 15 \\
\hline 688 & 251 KOREA INSTITUTE OF ENERGY RESEARCH & $\begin{array}{l}\text { Republic of } \\
\text { Korea }\end{array}$ & 32 & -18 \\
\hline 708 & $\begin{array}{l}94 \text { DALIAN INSTITUTE OF CHEMICAL PHYSICS } \\
\text { CHINESE ACADEMY OF SCIENCES }\end{array}$ & China & 31 & -5 \\
\hline 708 & $\begin{array}{l}445 \text { SHENZHEN INSTITUTE OF ADVANCED } \\
\text { TECHNOLOGY }\end{array}$ & China & 31 & 13 \\
\hline 727 & 43 CEDARS-SINAI MEDICAL CENTER & USA & 30 & 2 \\
\hline 727 & 32 CLEVELAND CLINIC FOUNDATION & USA & 30 & -1 \\
\hline 752 & $\begin{array}{l}341 \text { INSTITUTE AUTOMATION, CHINESE } \\
\text { ACADEMY OF SCIENCES }\end{array}$ & China & 29 & 10 \\
\hline 752 & $\begin{array}{l}213 \text { KOREA INSTITUTE OF MACHINERY \& } \\
\text { MATERIALS }\end{array}$ & $\begin{array}{l}\text { Republic of } \\
\text { Korea }\end{array}$ & 29 & 7 \\
\hline 752 & $\begin{array}{l}36 \text { KOREA RESEARCH INSTITUTE OF } \\
\text { STANDARDS AND SCIENCE }\end{array}$ & $\begin{array}{l}\text { Republic of } \\
\text { Korea }\end{array}$ & 29 & -1 \\
\hline
\end{tabular}

Source: WIPO Statistics Database, April 2017

Note: The government and public research institutes sector includes private nonprofit organizations and hospitals. For confidentiality reasons, data are based on publication date. 


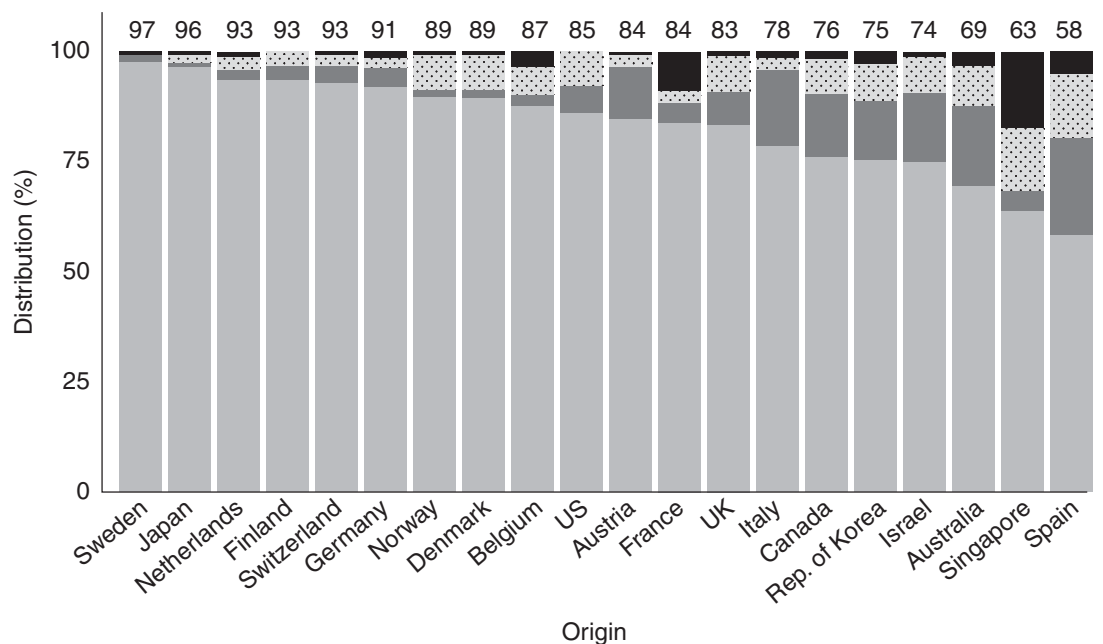

BUSINESS — INDIVIDUAL UNIVERSITY G GOVERNMENT/PRI

Middle-income group

BUSINESS SECTOR SHARE (\%)

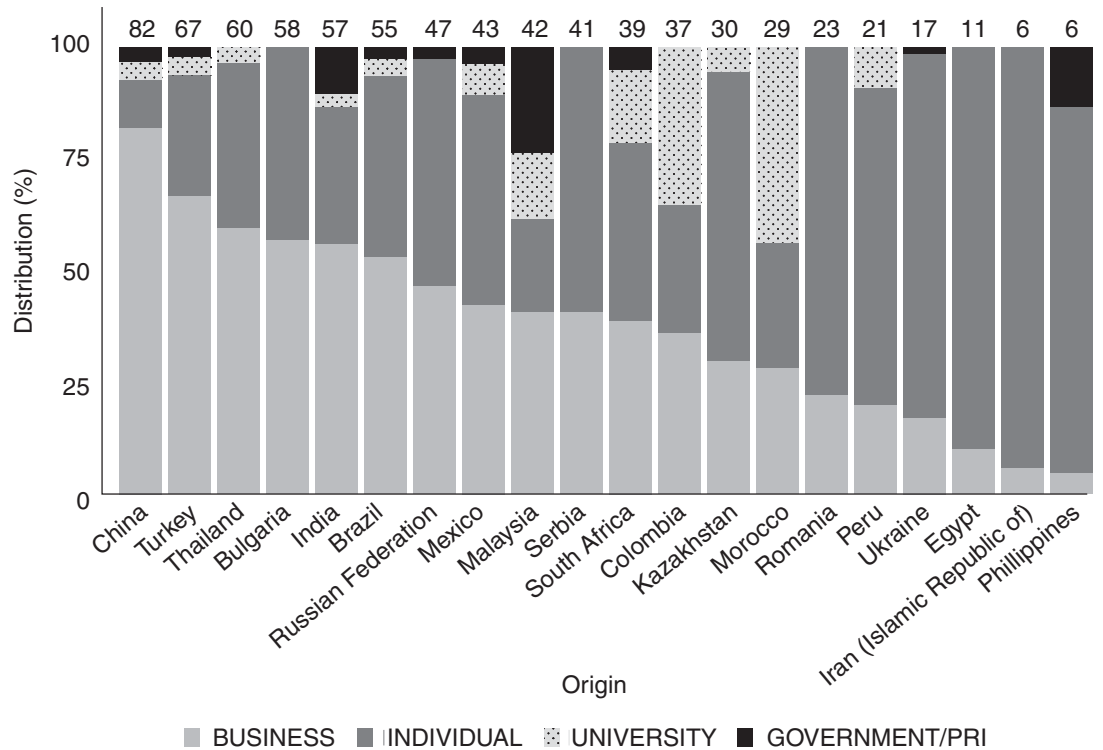

Figure 3.17 The share of the business sector in total PCT applications from selected origins

Source: WIPO Statistics Database, April 2017

Note: The government and public research organizations (PROs) sector includes private nonprofit organizations and hospitals. The university sector includes all educational institutions. For confidentiality reasons, data are based on the publication date. 
Table 3.5 Top fifty-five patent applicants worldwide, based on total number of patent families, 2010-13

\begin{tabular}{|c|c|c|c|c|c|c|}
\hline Applicant & Origin & 2010 & 2011 & 2012 & 2013 & $\begin{array}{l}\text { Total number } \\
\text { of patent fam- } \\
\text { ilies, 2010-13 }\end{array}$ \\
\hline Panasonic Corporation & Japan & 10,780 & 10,284 & 8,295 & 4,993 & 34,352 \\
\hline Canon Inc. & Japan & 6,686 & 7,132 & 7,507 & 7,711 & 29,036 \\
\hline Toyota Jidosha KK & Japan & 7,040 & 7,962 & 6,317 & 5,525 & 26,844 \\
\hline Samsung Electronics Co. Ltd & Republic of Korea & 5,873 & 5,865 & 6,666 & 8,243 & 26,647 \\
\hline Toshiba KK & Japan & 6,087 & 6,055 & 6,030 & 5,422 & 23,594 \\
\hline $\begin{array}{l}\text { Mitsubishi Electric } \\
\text { Corporation }\end{array}$ & Japan & 5,389 & 5,415 & 5,893 & 5,435 & 22,132 \\
\hline $\begin{array}{l}\text { Honghai Precision Industry } \\
\text { Co. Ltd }\end{array}$ & $\begin{array}{l}\text { Taiwan, Province of } \\
\text { China }\end{array}$ & 6,783 & 4,842 & 4,254 & 4,539 & 20,418 \\
\hline $\begin{array}{l}\text { International Business } \\
\text { Machines Corporation }\end{array}$ & USA & 4,463 & 4,419 & 5,108 & 5,298 & 19,288 \\
\hline $\begin{array}{l}\text { Ocean's King Lighting } \\
\text { Science \& Technology } \\
\text { Co. Ltd }\end{array}$ & China & 1,755 & 2,310 & 5,028 & 9,914 & 19,007 \\
\hline Sharp Corporation & Japan & 4,756 & 5,013 & 5,929 & 3,082 & 18,780 \\
\hline Seiko Epson Corporation & Japan & 5,531 & 5,374 & 3,833 & 3,715 & 18,453 \\
\hline Ricoh Co. Ltd & Japan & 4,402 & 4,397 & 4,155 & 4,781 & 17,735 \\
\hline Robert Bosch GmbH & Germany & 3,674 & 3,814 & 4,339 & 4,339 & 16,166 \\
\hline ZTE Corporation & China & 5,065 & 4,521 & 3,577 & 2,219 & 15,382 \\
\hline
\end{tabular}




垔

$\begin{array}{lrrrrr}\text { China } & 2,124 & 3,240 & 4,644 & 5,117 & 15,125 \\ \text { Japan } & & & & & \\ \text { Japan } & 3,488 & 3,768 & 3,663 & 3,562 & 14,481 \\ \text { China } & 3,337 & 3,435 & 3,460 & 3,694 & 13,926 \\ & 361 & 1,039 & 3,327 & 8,005 & 12,732 \\ \text { China } & & & & & \\ & 2,436 & 3,092 & 3,394 & 3,802 & 12,724 \\ \text { Japan } & & & & & \\ \text { Russian Federation } & 3,533 & 3,156 & 3,019 & 2,992 & 12,700 \\ \text { Republic of Korea } & 4,344 & 2,288 & 2,648 & 3,407 & 12,687 \\ \text { Japan } & 3,558 & 2,882 & 2,594 & 2,813 & 11,847 \\ \text { Germany } & 3,635 & 3,325 & 2,569 & 2,234 & 11,763 \\ \text { Japan } & 2,524 & 3,083 & 2,979 & 2,769 & 11,355 \\ \text { Japan } & 2,917 & 2,839 & 2,938 & 2,602 & 11,296 \\ \text { Japan } & 3,646 & 3,047 & 2,291 & 1,989 & 10,973 \\ \text { Republic of Korea } & 3,149 & 2,434 & 2,404 & 2,455 & 10,442 \\ \text { China } & 2,149 & 2,604 & 2,569 & 2,706 & 10,028 \\ & 2,799 & 2,840 & 2,475 & 1,754 & 9,868 \\ & & & & & \\ \text { China } & & & & & 9,488 \\ \text { USA } & 2,111 & 2,217 & 2,380 & 2,780 & 9,275\end{array}$


Table 3.5 (cont.)

\begin{tabular}{|c|c|c|c|c|c|c|}
\hline Applicant & Origin & 2010 & 2011 & 2012 & 2013 & $\begin{array}{l}\text { Total number } \\
\text { of patent fam- } \\
\text { ilies, } 2010-13\end{array}$ \\
\hline Korea Electronics Telecomm & Republic of Korea & 1,752 & 1,996 & 2,694 & 2,558 & 9,000 \\
\hline Dainippon Printing Co. Ltd & Japan & 1,908 & 2,105 & 2,366 & 2,175 & 8,554 \\
\hline $\begin{array}{l}\text { Nippon Telegraph \& } \\
\text { Telephone }\end{array}$ & Japan & 2,009 & 2,099 & 2,067 & 2,262 & 8,437 \\
\hline Daimler AG & Germany & 1,986 & 2,131 & 2,147 & 2,034 & 8,298 \\
\hline $\begin{array}{l}\text { Sumitomo Electric } \\
\text { Industries }\end{array}$ & Japan & 1,895 & 2,031 & 1,959 & 1,820 & 7,705 \\
\hline Tsinghua University & China & 1,643 & 1,779 & 2,125 & 2,060 & 7,607 \\
\hline LG Display Co. Ltd & Republic of Korea & 1,963 & 1,867 & 1,754 & 1,918 & 7,502 \\
\hline Brother Ind Ltd & Japan & 1,951 & 2,000 & 1,766 & 1,719 & 7,436 \\
\hline Mitsubishi Heavy Ind Ltd & Japan & 1,755 & 1,846 & 2,059 & 1,642 & 7,302 \\
\hline Samsung Electro Mech & Republic of Korea & 1,659 & 1,868 & 1,926 & 1,702 & 7,155 \\
\hline Kyocera Corporation & Japan & 1,923 & 1,956 & 1,798 & 1,461 & 7,138 \\
\hline LG Innotek Co. Ltd & Republic of Korea & 2,103 & 2,547 & 1,480 & 934 & 7,064 \\
\hline Microsoft Corporation & USA & 2,291 & 1,978 & 1,357 & 1,409 & 7,035 \\
\hline Posco & Republic of Korea & 1,314 & 1,723 & 1,973 & 1,798 & 6,808 \\
\hline Fuji Xerox Co. Ltd & Japan & 1,744 & 1,435 & 1,708 & 1,507 & 6,394 \\
\hline $\begin{array}{l}\text { GM Global Tech } \\
\text { Operations Inc. }\end{array}$ & USA & 1,597 & 1,742 & 1,546 & 1,236 & 6,121 \\
\hline $\begin{array}{l}\text { Schaeffler Technologies } \\
\text { GmbH \& Co. Kg }\end{array}$ & Germany & 1,193 & 1,538 & 1,556 & 1,743 & 6,030 \\
\hline Nippon Kogaku KK & Japan & 1,474 & 1,562 & 1,645 & 1,276 & 5,957 \\
\hline
\end{tabular}




\begin{tabular}{|c|c|c|c|c|c|}
\hline China & 1,168 & 1,146 & 1,574 & 2,065 & 5,953 \\
\hline China & 1,135 & 1,338 & 1,573 & 1,763 & 5,809 \\
\hline Japan & 963 & 1,238 & 1,673 & 1,825 & 5,699 \\
\hline China & 961 & 1,304 & 1,433 & 1,939 & 5,637 \\
\hline Republic of Korea & 747 & 1,393 & 1,946 & 1,437 & 5,523 \\
\hline Republic of Korea & 7 & 983 & 1,671 & 2,791 & 5,452 \\
\hline Japan & 2,033 & 1,887 & 931 & 510 & 5,361 \\
\hline Japan & 646 & 327 & 2,211 & 2,147 & 5,331 \\
\hline Japan & 1,596 & 1,708 & 1,304 & 662 & 5,270 \\
\hline Japan & 1,384 & 1,299 & 1,312 & 1,268 & 5,263 \\
\hline USA & 1,107 & 1,147 & 1,288 & 1,566 & 5,108 \\
\hline China & 453 & 829 & 1,889 & 1,905 & 5,076 \\
\hline Republic of Korea & 643 & 903 & 1,345 & 2,178 & 5,069 \\
\hline Japan & 1,137 & 1,494 & 1,260 & 1,010 & 4,901 \\
\hline Japan & 686 & 767 & 1,548 & 1,872 & 4,873 \\
\hline USA & 435 & 1,189 & 1,828 & 1,421 & 4,873 \\
\hline Japan & 1,567 & 1,446 & 1,150 & 612 & 4,775 \\
\hline Japan & 1,008 & 1,128 & 1,199 & 1,358 & 4,693 \\
\hline China & 749 & 1,015 & 1,294 & 1,572 & 4,630 \\
\hline
\end{tabular}


Table 3.5 (cont.)

\begin{tabular}{|c|c|c|c|c|c|c|}
\hline Applicant & Origin & 2010 & 2011 & 2012 & 2013 & $\begin{array}{l}\text { Total number } \\
\text { of patent fam- } \\
\text { ilies, } 2010-13\end{array}$ \\
\hline Bridgestone Corporation & Japan & 1,471 & 1,386 & 908 & 848 & 4,613 \\
\hline $\begin{array}{l}\text { Peugeot Citroen } \\
\text { Automobiles SA }\end{array}$ & France & 1,209 & 1,213 & 1,149 & 970 & 4,541 \\
\hline Samsung Heavy Ind & Republic of Korea & 1,039 & 1,050 & 1,314 & 1,131 & 4,534 \\
\hline Beihang University & China & 1,007 & 1,112 & 1,128 & 1,262 & 4,509 \\
\hline Lenovo (Beijing) Co. Ltd & China & 260 & 608 & 1,854 & 1,786 & 4,508 \\
\hline $\begin{array}{l}\text { South China University of } \\
\text { Technology }\end{array}$ & China & 773 & 955 & 1,231 & 1,450 & 4,409 \\
\hline Yazaki Corporation & Japan & 1,074 & 1,093 & 1,021 & 1,116 & 4,304 \\
\hline Peking University & China & 904 & 993 & 979 & 1,316 & 4,192 \\
\hline Olympus Corporation & Japan & 1,197 & 1,188 & 911 & 884 & 4,180 \\
\hline Intel Corporation & USA & 544 & 1,443 & 1,170 & 1,013 & 4,170 \\
\hline Jiangnan University & China & 678 & 992 & 1,281 & 1,219 & 4,170 \\
\hline Casio Computer Co. Ltd & Japan & 1,226 & 929 & 1,008 & 998 & 4,161 \\
\hline Murata Manufacturing Co. & Japan & 940 & 1,026 & 1,009 & 1,157 & 4,132 \\
\hline $\begin{array}{l}\text { Kyocera Document } \\
\text { Solutions Inc. }\end{array}$ & Japan & 148 & 1,100 & 1,235 & 1,603 & 4,086 \\
\hline $\begin{array}{l}\text { Telefonaktiebolaget LM } \\
\text { Ericsson (Publ) }\end{array}$ & Sweden & 831 & 1,009 & 1,121 & 1,058 & 4,019 \\
\hline $\begin{array}{l}\text { Korea Advanced Inst Sci \& } \\
\text { Tech }\end{array}$ & Republic of Korea & 1,015 & 1,006 & 1,101 & 856 & 3,978 \\
\hline Kao Corporation & Japan & 1,025 & 972 & 1,016 & 906 & 3,919 \\
\hline
\end{tabular}




\begin{tabular}{|c|c|c|c|c|c|c|}
\hline Daikin Ind Ltd & Japan & 838 & 1,008 & 1,140 & 856 & 3,842 \\
\hline Kyoraku Sangyo KK & Japan & 1,157 & 865 & 741 & 1,076 & 3,839 \\
\hline Hyundai Mobis Co. Ltd & Republic of Korea & 859 & 847 & 1,228 & 880 & 3,814 \\
\hline Ford Global Tech LLC & USA & 683 & 660 & 874 & 1,579 & 3,796 \\
\hline $\begin{array}{l}\text { Taiwan } \\
\text { Semiconductor MFG }\end{array}$ & $\begin{array}{l}\text { Taiwan, Province of } \\
\text { China }\end{array}$ & 567 & 787 & 1,054 & 1,358 & 3,766 \\
\hline SK Hynix Inc & Republic of Korea & 661 & 1,083 & 1,199 & 776 & 3,719 \\
\hline $\begin{array}{l}\text { BOE Technology Group } \\
\text { Co. Ltd }\end{array}$ & China & 139 & 474 & 1,233 & 1,863 & 3,709 \\
\hline JTEKT Corporation & Japan & 731 & 942 & 1,004 & 973 & 3,650 \\
\hline Hyundai Steel Co. & Republic of Korea & 1,044 & 986 & 1,014 & 601 & 3,645 \\
\hline Toray Industries & Japan & 810 & 898 & 959 & 970 & 3,637 \\
\hline $\begin{array}{l}\text { Konica Minolta Business } \\
\text { Tech }\end{array}$ & Japan & 1,856 & 1,713 & 32 & 2 & 3,603 \\
\hline Inventec Corporation & $\begin{array}{l}\text { Taiwan, Province of } \\
\text { China }\end{array}$ & 1,262 & 900 & 671 & 713 & 3,546 \\
\hline Nitto Denko Corporation & Japan & 793 & 887 & 921 & 888 & 3,489 \\
\hline Jiangsu University & China & 462 & 523 & 961 & 1,509 & 3,455 \\
\hline Toyota Ind Corporation & Japan & 464 & 730 & 1,236 & 1,022 & 3,452 \\
\hline
\end{tabular}

Sources: WIPO Statistics Database and EPO PATSTAT database, October 2016 
Combined, these thirteen applicants accounted for 8 percent of all patent families held by the top 100 applicants.

In 2010-13, the top three universities in patent families worldwide occupied positions thirty, thirty-seven, and fifty-one among the top applicants. These universities are Zhejiang University (9,488 patent families), Tsinghua University $(7,607)$ and Shanghai Jiao Tong University $(5,809)$. Two public research institutes took positions thirty-two and fifty: the Korea Electronics Telecomm $(9,000)$ and the Harbin Institute of Technology $(5,953)$.

Table 3.6 shows the top five university and public research institute applicants in patent families for selected origins in 2010-13. The top five university and public research institute applicants in China each created between 5,000 and 10,000 patent families during this four-year period. As shown in Table 3.5, all top five university and public research institute applicants from China are among the top 100 applicants in patent families worldwide.

Each of the top five university and public research institute applicants in the Republic of Korea had between about 2,000 and 9,000 patent families in 2010-13. Three university and public research institute applicants in Japan created more than a thousand patent families during 2010-13, while two public research institutes in France and one in Germany were also above the 1,000 mark.

The number of patent families created worldwide in 2013 was higher than that in 2010 for nineteen of the thirty university and public research institute applicants listed in Table 3.6, including all the top five for China and France. Compared to 2010, the number of patent families created in 2013 more than doubled for Southeast University of China, INSERM of France, and Northwestern University of the U.S.

\subsubsection{By IP Office}

In terms of the absolute number of nonresident university and public research institute patent applications, the top destinations over the past ten years have been the State Intellectual Property Office of China (SIPO), the United States Patent and Trademark Office (USPTO), the European Patent Office (EPO), the Japan Patent Office (JPO), the Canada Intellectual Property Office (CIPO), and the Korea Intellectual Property Office (KIPO) 
Table 3.6 Top five university and public research institute patent applicants worldwide by selected origins, 2010-13

\begin{tabular}{|c|c|c|c|c|c|c|}
\hline Applicant & Origin & 2010 & 2011 & 2012 & 2013 & $\begin{array}{l}\text { Total number } \\
\text { of patent fam- } \\
\text { ilies, } 2010-13\end{array}$ \\
\hline Zhejiang University & China & 2,111 & 2,217 & 2,380 & 2,780 & 9,488 \\
\hline Tsinghua University & China & 1,643 & 1,779 & 2,125 & 2,060 & 7,607 \\
\hline Harbin Institute of Technology & China & 1,168 & 1,146 & 1,574 & 2,065 & 5,953 \\
\hline Shanghai Jiao Tong University & China & 1,135 & 1,338 & 1,573 & 1,763 & 5,809 \\
\hline Southeast University & China & 961 & 1,304 & 1,433 & 1,939 & 5,637 \\
\hline CEA & France & 585 & 634 & 665 & 731 & 2,615 \\
\hline CNRS & France & 484 & 485 & 516 & 532 & 2,017 \\
\hline INSERM & France & 58 & 129 & 119 & 172 & 478 \\
\hline Univ Claude Bernard Lyon & France & 39 & 31 & 52 & 49 & 171 \\
\hline Centre Nat Etudes Spatiales & France & 34 & 41 & 45 & 38 & 158 \\
\hline Fraunhofer Ges Forschung & Germany & 434 & 441 & 491 & 523 & 1,889 \\
\hline $\begin{array}{l}\text { Deutsches Zentrum fur Luft } \\
\text { und Raumfahrt }\end{array}$ & Germany & 232 & 205 & 222 & 238 & 897 \\
\hline Univ Dresden Tech & Germany & 75 & 78 & 78 & 26 & 257 \\
\hline Max Planck Gesellschaft & Germany & 82 & 60 & 60 & 53 & 255 \\
\hline Karlsruhe Inst Technologie & Germany & 58 & 59 & 51 & 16 & 184 \\
\hline Nat Inst of Adv Ind \& Tech & Japan & 801 & 664 & 677 & 628 & 2,770 \\
\hline
\end{tabular}


Table 3.6 (cont.)

\begin{tabular}{|c|c|c|c|c|c|c|}
\hline Applicant & Origin & 2010 & 2011 & 2012 & 2013 & $\begin{array}{l}\text { Total number } \\
\text { of patent fam- } \\
\text { ilies, 2010-13 }\end{array}$ \\
\hline Tokyo University & Japan & 379 & 364 & 327 & 408 & 1,478 \\
\hline Tohcko University & Japan & 365 & 337 & 324 & 300 & 1,326 \\
\hline Osaka University & Japan & 243 & 226 & 272 & 256 & 997 \\
\hline Kyoto University & Japan & 212 & 210 & 224 & 235 & 881 \\
\hline Korea Electronics Telecomm & Republic of Korea & 1,752 & 1,996 & 2,694 & 2,558 & 9,000 \\
\hline $\begin{array}{l}\text { Korea Advanced Inst Sci \& } \\
\text { Tech }\end{array}$ & Republic of Korea & 1,015 & 1,006 & 1,101 & 856 & 3,978 \\
\hline SNU R\&DB Foundation & Republic of Korea & 621 & 550 & 609 & 599 & 2,379 \\
\hline Yonsei University & Republic of Korea & 535 & 552 & 577 & 611 & 2,275 \\
\hline Univ Korea Res \& Bus Found & Republic of Korea & 494 & 518 & 509 & 473 & 1,994 \\
\hline US Navy & USA & 231 & 204 & 92 & 65 & 592 \\
\hline Northwestern University & USA & 73 & 103 & 91 & 167 & 434 \\
\hline US Army & & 165 & 126 & 61 & 64 & 416 \\
\hline $\begin{array}{l}\text { Massachusetts Institute of } \\
\text { Technology }\end{array}$ & USA & 88 & 76 & 56 & 33 & 253 \\
\hline Wisconsin Alumni Res Found & USA & 40 & 52 & 54 & 98 & 244 \\
\hline
\end{tabular}

Sources: WIPO Statistics Database and EPO PATSTAT database, October 2016

Note: A patent family is defined as patent applications interlinked by one or more of: priority claim, PCT national phase entry, continuation, continuation-in-part, internal priority, and addition or division. Patent families include only those associated with patent applications for inventions and exclude patent families associated with utility model applications. 


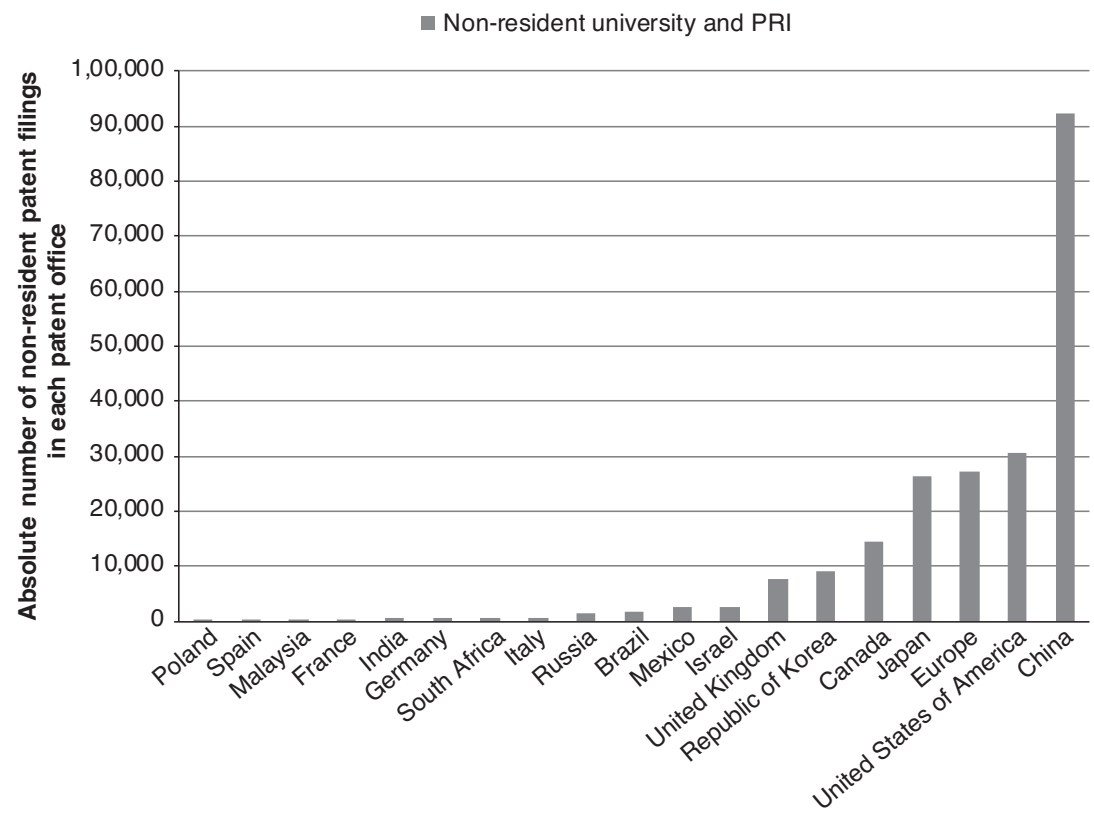

Figure 3.18 Nonresident university and public research institute patent applications for selected patent offices, 2006-15

Source: WIPO Statistics Database and EPO PATSTAT, January 2017

(Figure 3.18). ${ }^{14}$ Interestingly, the nonresident share of total university and public research institute patent applications is much higher at the JPO (58.6 percent), US PTO (54.0 percent), and EPO (49.5 percent) than at SIPO (13.1 percent) and KIPO (7.0 percent) (see Figure 3.19).

In the period 2006-15, the main sources of patent applications going outside a country were the U.S., France, Germany, the Republic of Korea, Japan, and China (Figure 3.20). However, the share of patent applications filed abroad by university and public research institute applicants was highest for the following countries of origin (Figure 3.21): Israel (90.9 percent), France (69.8 percent), the United Kingdom (66.1 percent), the U.S. (62.9 percent), Germany

${ }^{14}$ Data by office are broken down into resident applications (filed at the home office) and nonresident applications (filed by an applicant residing outside the jurisdiction of the office). 


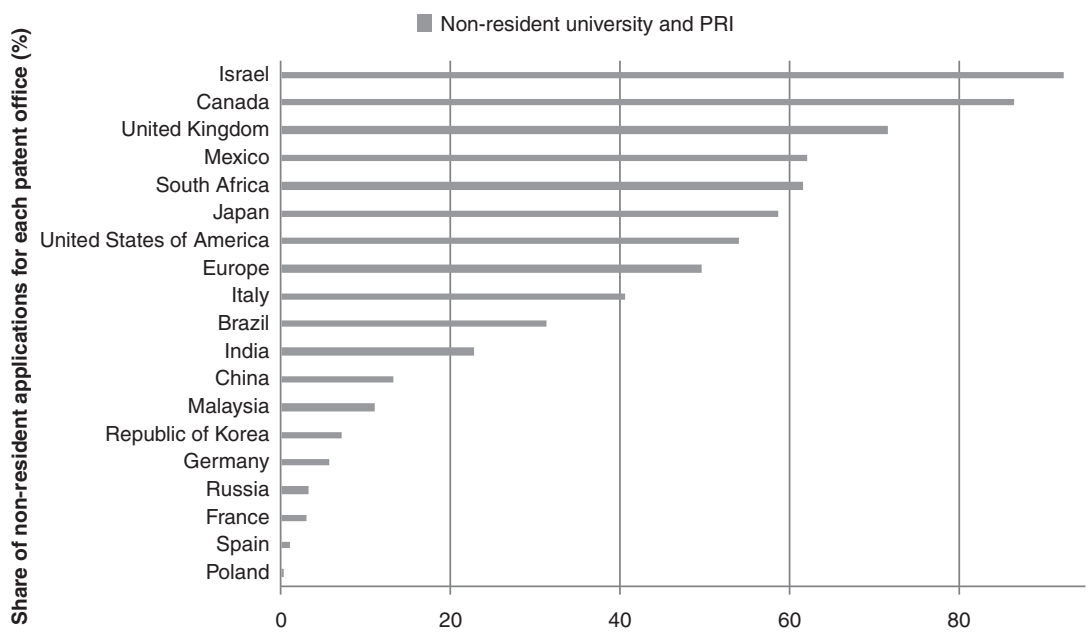

Figure 3.19 Share of nonresident university and public research institute patent applications for selected offices, 2006-15

Source: WIPO Statistics Database and EPO PATSTAT, January 2017

(61.7 percent), Canada (59.6 percent), Italy (57.5 percent), South Africa (56.3 percent), and India (46.1 percent).

\subsection{Conclusion}

In this chapter, we proposed a methodology for measuring academic patents. Using WIPO's PCT and the EPO's PATSTAT data, we provided a relatively comprehensive picture of global academic patenting data.

We showed that global patenting by public research institutes and universities has increased in the last thirty-five years and the map of the main actors has changed significantly. The main findings can be summarized as follows.

The main actors in global patenting are still private sector businesses, but university and public research institute applications are surging as important innovation drivers.

The biggest trend over the last thirty-five years has been a shift in university and public research institute patenting dominance from Europe and the U.S. to Asia. 


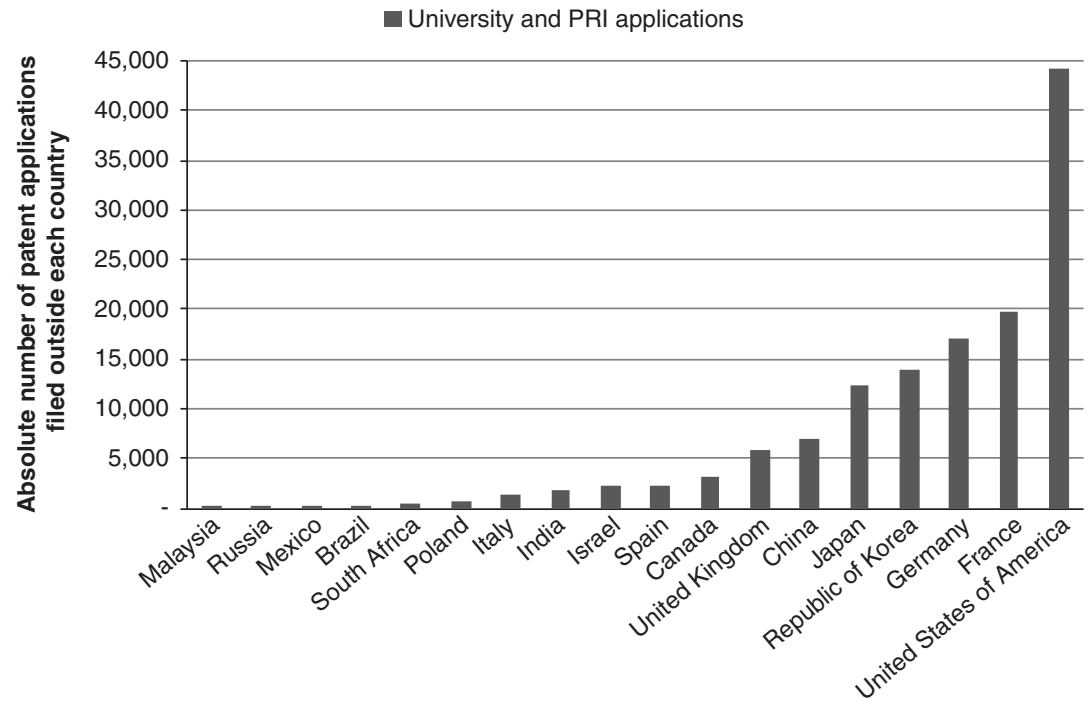

Figure 3.20 Patent applications filed abroad by universities and public research institutes for selected origins, 2006-15

Source: WIPO Statistics Database and EPO PATSTAT, January 2017

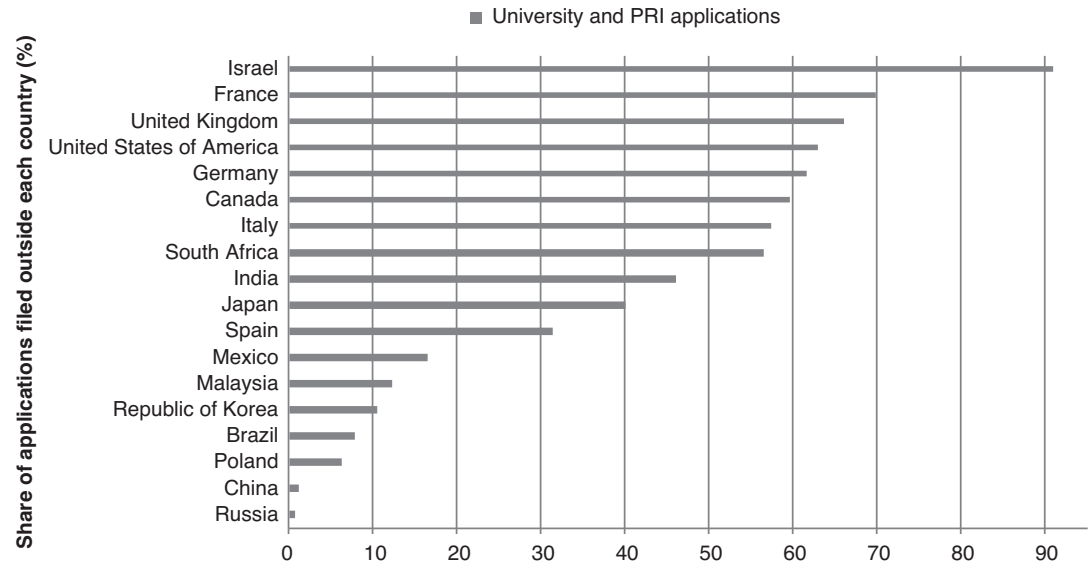

Figure 3.21 Share of patent applications filed abroad by type of applicant, selected origins, 2006-15

Source: WIPO Statistics Database and EPO PATSTAT, January 2017 
Applications by universities recorded in the PATSTAT and PCT databases were concentrated in science-based technology fields, especially pharmaceuticals and the biological sciences.

In the middle-income group of economies, universities hold more patents than public research institutes, while in the high-income group public research institutes tend to patent more than universities.

However, it is important to remember that there are numerous factors that can contribute to a university or public research institute's proclivity to patent. A strong focus on science, technology, engineering, and mathematics, public policies that govern IP ownership between university and industry, as well as other policies that enhance the use of patents are all likely to influence the patenting activities of universities and public research institutes across countries (Perkmann et al. 2013).

Nevertheless, while there are many limitations in using patent data and the extent to which it measures innovativeness, we contend that these data are useful in helping to identify potential weaknesses and highlight the strengths of universities and public research institutes.

\section{References}

Aldridge, T. T. and D. Audretsch (2011). "The Bayh-Dole Act and scientist entrepreneurship." Research Policy, 40(8), 1058-67.

Blumenthal, D., E. G. Campbell, M. S. Anderson, N. Causino, and K.S. Louis (1997). "Withholding research results in academic life science: Evidence from a national survey of faculty." Journal of the American Medical Association, 277(15), 1224-8.

Dernis, H. and M. Khan (2004). Triadic Patent Families Methodology. OECD Science, Technology and Industry Working Papers. Paris: Organisation for Economic Co-operation and Development.

Du Plessis, M., Van B. Looy, X. Song, and T. Magerman (2010). Data Production Methods for Harmonized Patent Statistics: Patentee Sector Allocation 2009. Brussels: Eurostat.

Geuna, A. (2001). "The changing rationale for university research funding: are there negative unintended consequences?" Journal of Economic Issues, 35, 607-32.

Geuna, A. and F. Rossi (2011). "Changes to university IPR regulations in Europe and the impact on academic patenting." Research Policy, 40(8), 1068-76.

Graff, G. D. (2007). "Echoes of Bayh-Dole? A survey of IP and technology transfer policies in emerging and developing economies." In A. Krattiger, R. T. Mahoney, L. Nelsen, J. A. Thomson, A. B. Bennett, K. Satyanarayana, G. D. Graff, C. Fernandez, and S. P. Kowalski, Intellectual Property Management 
in Health and Agricultural Innovation: A Handbook of Best Practices. Oxford: Oxford University Press.

Grimaldi, R., M. Kenney, D. S. Siegel, and M. Wright (2011). “30 years after Bayh-Dole: reassessing academic entrepreneurship." Research Policy, 40(8), 1045-57.

Guellec, D. and B. Van Pottelsberghe de la Potterie (2007). The Economics of the European Patent System: IP Policy for Innovation and Competition. Oxford: Oxford University Press.

Henderson, R., A. B. Jaffe, and M. Trajtenberg (1998). "Universities as a source of commercial technology: A detailed analysis of university patenting, 1965-1988." Review of Economics and Statistics, 80(1), 119-27.

Kelly, I. (2016). Patents for Technology Transfer: A Practical Guide. Seattle: CreateSpace Independent Publishing Platform.

Kenney, M. and D. Patton (2011). "Does inventor ownership encourage university research-derived entrepreneurship? A six university comparison.” Research Policy, 40(8), 1100-12.

Khan, M. and S. Wunsch-Vincent (2011). "Capturing innovation: The patent system.” In S. Dutta and I. Mia (eds.), The Global Information Technology Report 2010-2011. Geneva: World Economic Forum.

Martínez, C. (2011). "Patent families: When do different definitions really matter?" Scientometrics, 86, 39-63.

Mercelis, J., G. Galvez-Behar, and A. Guagnini (2017). “Commercializing science: Nineteenth- and twentieth-century academic scientists as consultants, patentees, and entrepreneurs." History and Technology, 33(1), 4-22.

Mowery, D. C., R. R. Nelson, B. N. Sampat, and A. Ziedonis (2004). Ivory Tower and Industrial Innovation: University-Industry Technology Transfer Before and After Bayh-Dole. Stanford: Stanford University Press.

Perkmann, M., V. Tartari, M. McKelvey et al. (2013). "Academic engagement and commercialisation: A review of the literature on university-industry relations." Research Policy, 42(2), 423-42.

Rosenberg, N. and E. Steinmueller (2013). "Engineering knowledge.” Industrial and Corporate Change, 22(5), 1129-58.

Rothaermel, F. T., S. D. Agung, and L. Jiang (2007). "University entrepreneurship: A taxonomy of the literature." Industrial and Corporate Change, 16(4), 691-791.

Schacht, W. H. (2006). The Bayh-Dole Act: Selected Issues in Patent Policy and the Commercialization of Technology. (CRS Reports RL32076). Washington: Congressional Research Service.

SCImago (2010). SIR World Report. SCIMAGO Institution Rankings. www .scimagoir.com.

So, A. D., B. N. Sampat, A. K. Rai et al. (2008). "Is Bayh-Dole good for developing countries? Lessons from the US experience.” PLoS Biol, 6(10), e262. 
Sterckx, S. (2011). "Patenting and licensing of university research: Promoting innovation or undermining academic values?" Science and Engineering Ethics, 17(1), 45-64.

Thursby, J. G., A. W. Fuller, and M. C. Thursby (2009). "US faculty patenting: Inside and outside the university." Research Policy, 38(1), 14-25.

Thursby, J. G. and M. C. Thursby (2011). "Has the Bayh-Dole act compromised basic research?" Research Policy, 40(8), 1077-83.

Van B. Looy, P. Landoni, J. Callaert, Van B. Pottelsberghe, E. Sapsalis, and K. Debackere (2011). "Entrepreneurial effectiveness of European universities: An empirical assessment of antecedents and trade-offs." Research Policy, 40(4), 553-64.

WIPO (2011). World Intellectual Property Report 2011: The Changing Face of Innovation and Intellectual Property. Geneva: World Intellectual Property Organization.

WIPO (2015). World Intellectual Property Report 2015: Breakthrough Innovation and Economic Growth. Geneva: World Intellectual Property Organization.

Wright, M., B. Clarysse, P. Mustar, and A. Lockett (2008). Academic Entrepreneurship in Europe. Cheltenham: Edward Elgar. 


\section{Annex: Verifying the Accuracy of WIPO University and Public Research Institute Applicant Names}

To verify the accuracy of our identification of university and public research institute patents, and going beyond the use of existing applicant information, our strategy involved a semi-automated process in two stages, web crawling and modeling.

Web crawlers, also known as spiders or robots, are programs that automatically download web pages. Different tools can be applied to the crawling method, such as SAS, R, and Python. The aim is to identify a series of category-related words for each applicant using the Baidu search and recommendation system. For universities, we used words such as "university," "college," and "universities" to identify organizations. For public research institutes, keywords used were "research" and "institute." For corporations, several synonyms were applied to the keywords.

The web-crawling stage involved four steps. First, according to the applicant's name, the programs generated a series of URLs to be sent to the Baidu search engine system. Second, the program inspected the source code of the result pages including a Baidu-generated recommendation list as a raw textual data set. Third, the program removed unwanted text, leaving a cleaner textual data set. Fourth, it extracted the keywords within the textual data set with Perl regular expression.

The modeling stage, in turn, involved a typical data-mining process with two steps. In the first step, also called the training phase, a learning algorithm used the training data to generate a classification model. In second step, that learned model was applied to the test samples to identify names that met the criteria and to increase the accuracy of our institutional classifications. An underlying assumption in that process was that the distribution of keywords for the training examples was identical to that for test examples.

All in all, this process helps to further fine-tune our patent categorizations and their corresponding institutional affiliations. This opens a new way of classifying organizations as compared to classical patent search strategies to identify university and public research institute patents in the literature.

Still, the approach does not necessarily generate perfect results: first, the classification algorithms may not be sufficiently sound and robust; second, the results generated are based on probability rather than on certain verifications. Given these risks, manual checking was undertaken to confirm the accuracy of the final results. 
Downloaded from https://www.cambridge.org/core. IP address: 86.30.88.132, on 14 Feb 2022 at 14:50:54, subject to the Cambridge Core terms of use, available at https://www.cambridge.org/core/terms. https://www.cambridge.org/core/product/979C0AAA92B1200DCE513DAAE4894BE7 


\section{P A R T I I}

\section{Selected Comparative Country Studies}


Downloaded from https://www.cambridge.org/core. IP address: 86.30.88.132, on 14 Feb 2022 at 14:50:54, subject to the Cambridge Core terms of use, available at https://www.cambridge.org/core/terms. https://www.cambridge.org/core/product/979C0AAA92B1200DCE513DAAE4894BE7 


\section{United Kingdom}

FEDERICA ROSSI AND SUMA ATHREYE

\subsection{Introduction}

The public research system in the United Kingdom is composed of many universities and a smaller number of public research institutes. Over time, knowledge transfer has been institutionalized as a key mission of public research performers, as important as their longstanding commitment to research (Lockett et al. 2014). As in other countries, the institutionalization of the knowledge transfer mission has largely been driven by policy incentives (Sánchez-Barrioluengo 2014; Pinheiro et al. 2015). The purpose of this chapter is to analyze, on the one hand, the United Kingdom's institutional setup (including the characteristics of the country's public research system and of the policies implemented therein), and, on the other hand, the variety of knowledge transfer activities undertaken and of governance models adopted in order to carry them out.

The United Kingdom provides an interesting case study for several reasons. First, the UK public sector research system has a variegated structure that can support a variety of models of knowledge transfer engagement. Indeed, the wide variety of knowledge transfer activities undertaken, and the diversity of approaches adopted, suggests that institutions pursue the strategy of knowledge transfer engagement that best suits their comparative advantages. This also leads to strong path dependency and a symbiotic relationship with the underlying socioeconomic structure of the country and its regions. Second, as UK universities have operational flexibility reminiscent of that of the United States of America (U.S.), but are also dependent on public funds very much like their European neighbors, this case can offer insights for countries with predominantly publicly-funded systems that intend to adopt an incentive-based approach to policy. The main policy tool used by the UK government to foster university-industry 
interaction and knowledge transfer has been the provision of performancebased funding in order to create a financial incentive for universities to engage in knowledge transfer activities and achieve measurable results that can be rewarded economically. Moreover, since knowledge transfer activities are income-producing in themselves, in a period of prolonged decline in public funding, universities have had strong incentives to engage in knowledge transfer activities irrespective of the presence of policy schemes. Consequently, there seems to have been a reorientation of the public science system toward more commercializable research. In turn, this raises the question whether the UK system is generating enough basic research on its own to keep it at the science frontier and make it possible to quickly absorb and exploit new technology. Investment in basic science - the original argument for public funding of education - could get lost in the thrust of policy to promote research commercialization.

This chapter is structured as follows. Section 4.2 provides a brief overview of the organization of the United Kingdom's public research system. Section 4.3 describes the historical evolution of policies in support of university-industry knowledge transfer in the United Kingdom, considering both the evolution of the institutional setup and of the supply- and demand-side policy instruments implemented. Section 4.4 examines the variety of knowledge transfer channels used by universities and public research institutes, with a particular focus on their performance in intellectual property (IP) commercialization, and compares the differential performance of universities and public research institutes in knowledge transfer, investigating some possible causes. It also considers the demand for university knowledge from the private sector. Section 4.5 delves into the institutional infrastructures that universities have set up to manage their knowledge transfer activities, and their practices. Finally, Section 4.6 concludes with some policy lessons.

\subsection{Universities and Public Research Institutes in the United Kingdom}

The earliest universities in Britain were founded in the Middle Ages, with Cambridge's charter dating back to 1209. Only a handful of institutions were created between then and the early nineteenth century, which saw the progressive establishment of many further education colleges that provided vocational training in a range of subjects, including teaching (teacher training colleges), various branches of engineering or agriculture (polytechnics), and the arts (arts colleges). These institutions (which were 
part of the public sector under the control of local education authorities, and sometimes religious foundations) contributed collectively to a binary higher education system, with universities educating the elite and colleges providing vocational education for the middle class.

This system began to change in the 1960s, with a shift toward mass university education thanks to the creation of twenty-five new universities. This trend received further impetus in 1992, as several existing polytechnics gained degree-awarding powers, ${ }^{1}$ and the process has continued since then with the transformation of teacher training colleges, art colleges, and other colleges into universities. Today, the UK university system includes 161 officially recognized degree-awarding higher education institutions. Figure 4.1 shows the cumulative number of universities founded since 1900. The 1960s, 1990s, and 2000s saw the largest increases in the number of institutions.

Eighty-three percent of institutions are based in England (of these, one-third are in London), 10 percent in Scotland, 5 percent in Wales, and

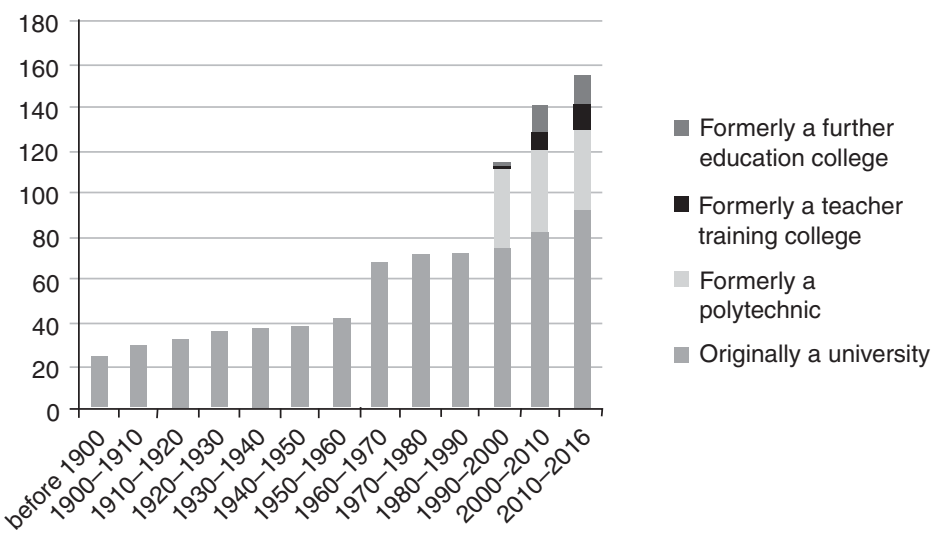

Figure 4.1 Cumulative number of degree-awarding institutions active since 1900 Source: Authors, based on data from the Higher Education Statistics Agency (HESA) and individual universities' websites

1 The Education Reform Act (ERA) of 1988 freed polytechnics and higher education colleges of local authority control and created a new national funding body, the Polytechnics and Colleges Funding Council (PCFC). In 1992, this was merged with the University Funding Council to create the Higher Education Funding Council (HEFC) with separate agencies for England, Scotland, and Wales, and thirty-nine polytechnics and colleges were given university status (Bathmaker 2003). 
the remaining 2 percent in Northern Ireland. Their nature is varied: some universities specialize in world-class research and others (particularly those that were previously focused on vocational education) in specialist training often closely linked to local industry. The UK university system is traditionally public, but particularly since the 2000s, a small but growing number of entirely private universities have emerged (the first of these, the University of Buckingham, was founded in 1973). Even those universities that receive most of their funding from the government are not formally part of the public sector as they are in some countries (such as in Germany, where academics are civil servants). Instead, UK public universities are regulated as nonprofit institutions governed by the Charities Act 2006, and, as such, enjoy considerable operational autonomy.

The United Kingdom's science, research, and higher education policy is the responsibility of the Department for Business, Energy, and Industrial Strategy (BEIS) and of the Department for Education (DfE). Funding allocation is devolved to the higher education agencies of the four countries of the UK: the Higher Education Funding Council for England (HEFCE), the Department for Employment and Learning Northern Ireland (DELNI), the Scottish Funding Council (SFC), and the Higher Education Funding Council for Wales (HEFCW). Each is responsible for funding universities' ordinary teaching and research activities as well as for implementing policy instruments in support of knowledge transfer engagement.

Research and teaching are funded through separate streams. Since the mid-1980s, recurrent research funding is distributed on a quality-related basis building on a periodic nationwide assessment of the quality of university research. Over time, the research assessment exercise has changed its name (from Research Selectivity Assessment to Research Assessment Exercise to Research Excellence Framework), its frequency (currently every six to seven years), the method of assessment (peer review of scientific output has been complemented by bibliometric measures and by an assessment of impact case studies), and the formula used for the funding distribution (Geuna, Piolatto and Sylos-Labini 2015). Research funds are also allocated to academics on a competitive basis by seven research councils. ${ }^{2}$

2 The research councils are divided into broad subject fields: Arts and Humanities (AHRC), Biotechnology and Biological Sciences (BBSRC), Engineering and Physical Sciences (EPSRC), Economic and Social Research (ESRC), Medical Research (MRC), Natural Environment (NERC), and Science and Technology Facilities (STFC). In 2018, these research councils were merged into a single agency called UK Research and Innovation (UKRI), which also includes the innovation funding agency Innovate UK. 
Until recently, recurrent funding for teaching was distributed to universities entirely according to a formula based on student numbers, weighted according to, among others factors, field, mode, and level of study (HEFCE 2015). In 2012/13, the government introduced a new system whereby universities receive a large share of their income directly from loan-backed tuition fees, while the amount of recurrent funding for teaching distributed by HEFCE has substantially decreased. A new teaching quality assessment system, the Teaching Excellence Framework (TEF), was introduced in 2017 with the objective of allowing institutions that gain a higher teaching quality score to increase their tuition fees in line with inflation.

Figure 4.2 shows how the sources of funding for universities have changed over the last ten years. Recurrent funding for teaching has been curtailed sharply since $2011 / 12$, only partly compensated by a temporary increase in research funding. Universities have compensated for this drop in public funding by increasing undergraduate tuition fees to up to $£ 9,000$ per year. Income from knowledge transfer activities consists of two categories: research grants and contracts, which includes income from collaborative research (competitively allocated grants from the research councils, government departments, and the European Commission as well as trusts and

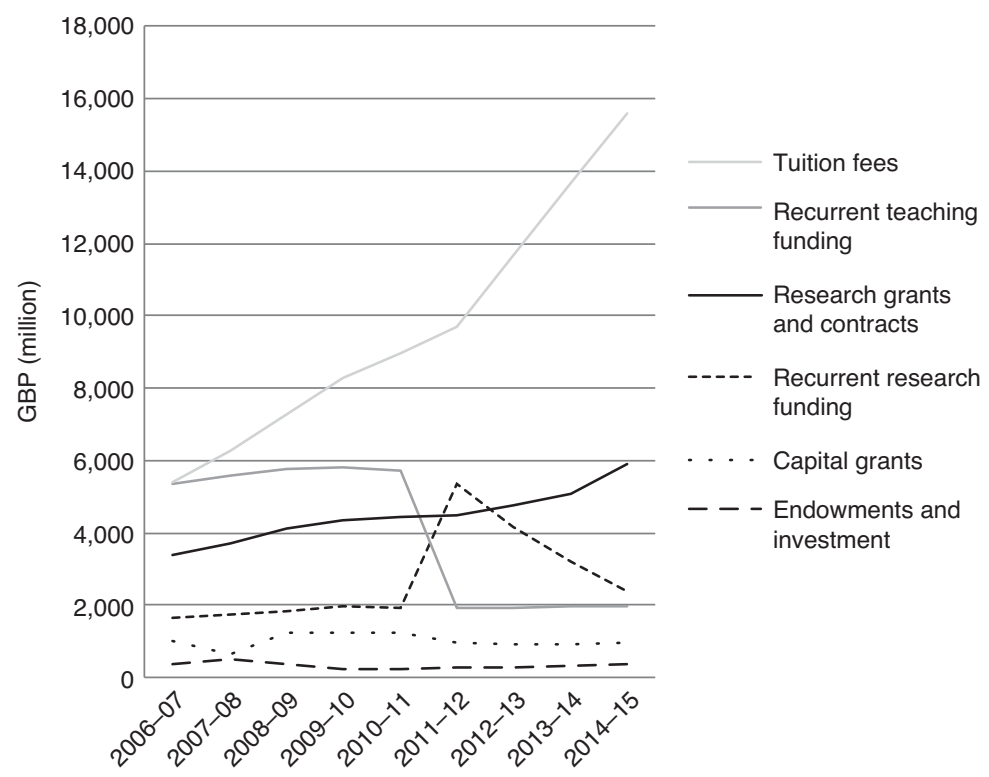

Figure 4.2 Universities' sources of income Source: Authors, based on data from HESA 
charities) and from research contracts with industry and the public sector; plus other income, which includes income from the sale and licensing of intellectual property (IP) (including sales of equity shares in spinoffs), consultancies, facilities and equipment, professional development (CPD) and continuing education (CE) courses, and regeneration programs. These sources of income have increased slowly but steadily and together currently amount to about $£ 12$ billion - about 36 percent of overall income. IP income is a small share, just 3-4 percent of the income from knowledge transfer activities (Geuna and Rossi 2011). A few universities (namely, Oxford and Cambridge colleges) benefit from considerable land endowments.

Public research institutes, funded by government departments or research councils, are collectively known as public sector research establishments (PSREs). They are important actors in the United Kingdom's research system. Unlike the university sector, the PSRE sector in the United Kingdom has shrunk due to mergers, closures, and numerous transfers to the private sector. There are currently thirty-five active PSREs (Smith 2015), each funded by a specific government department ${ }^{3}$ or research council. ${ }^{4}$ In addition, there are twenty-six research institutes that are part of the Medical Research Council (MRC) and twenty-four cultural institutions funded mainly by the Department of Culture, Media, and Sport and by the Welsh and Scottish governments (Smith 2015). ${ }^{5}$ The main difference between departmental PSREs and research council PSREs, besides their different sources of funding - the former are funded directly from the budgets of the departments they belong to, the latter are funded through the science budget - is that the former perform "responsive research" on topics directly mandated by the government, while the latter are more autonomous in setting their research priorities within their field. ${ }^{6}$ Figure 4.3 shows the cumulative number of PSREs over time. PSREs associated with government

3 These are: the Department for Business Innovation and Skills (4), the Department for Environment, Food and Rural Affairs (5), the Department for Energy and Climate Change (1), the Department of Health (1), the Health and Safety Executive (1), the Forestry Commission (1), the Ministry of Defence (3), the Scottish Government (3) and the Northern Ireland Government (1).

4 These are: the Natural Environment Research Council (6), the Medical Research Council (3), the Biotechnology and Biological Sciences Research Council (2), the Science and Technology Facilities Council (4).

${ }^{5}$ Cultural institutions mainly focus on the arts and humanities and rarely produce research that can be easily commercialized through, for example, patents and spinoffs. Other PSREs, by contrast, may be actively engaged in the production of commercializable IP.

${ }^{6}$ From an interview with a government economist working at the UK's Department of Business, Energy, and Industrial Strategy. 


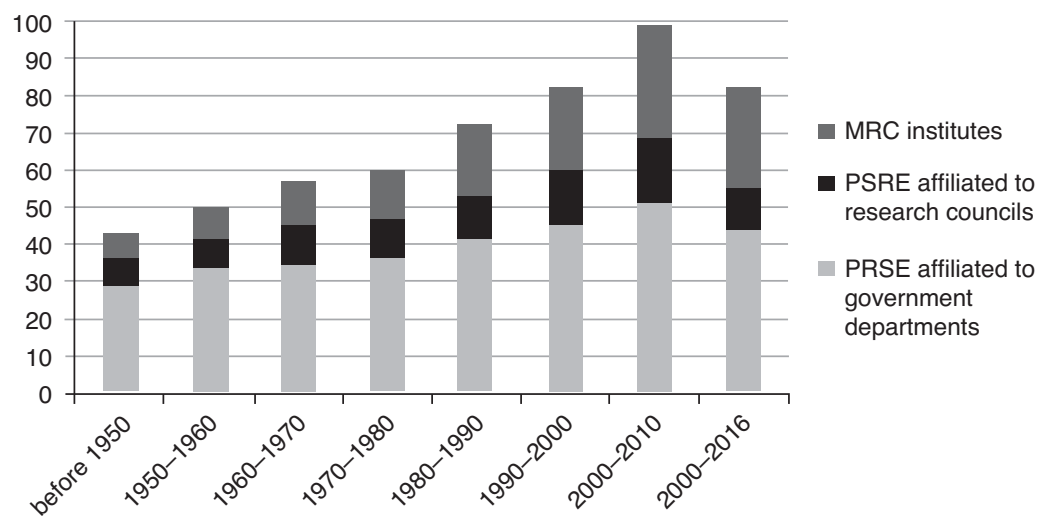

Figure 4.3 Cumulative number of public sector research establishments active since 1950

Source: Authors, based on data reported in BIS (2011a, 2014; Smith 2015); MaxwellJackson (2011); Government Office for Science (2013); NCUB (2016b)

departments have shown the largest decrease, in keeping with the idea of "lean government."

PSREs receive a much smaller amount of funding than the university sector. The Office for National Statistics (ONS 2016) reports that in 2014 the research councils spent $£ 819$ million on in-house $R \& D$ while government departments spent $£ 1,391$ million. Although reconstructing the amount of government funds that accrue to the PSRE sector is quite difficult, these approximate figures suggest that the sector currently receives about 30-35 percent of the recurrent funds allocated to universities. Interestingly, the ratio between the number of current PSREs (including cultural institutions but excluding MRC university-based units) and the number of university institutions is similar (about 36 percent), so we can estimate the size of the PSRE sector to be about one-third the size of the university sector.

Very limited information has been collected on the different sources of income of PSREs. A study of PSREs' knowledge transfer activities (BIS 2014) estimated that in $2012 / 13$, PSREs gained $£ 195$ million from intellectual property licensing, $£ 166$ million from consulting activities, and $\mathfrak{E 1 3 3}$ million from the use of facilities and equipment and training. ${ }^{7}$ Therefore, income from knowledge transfer is about 23 percent of the income that PSREs derive from government funding. In contrast to

7 The estimates presented in the BIS (2014) refer not only to the PSREs affiliated to government departments and research councils, but also to cultural institutions, MRC institutes, and research bodies that are part of the National Health Service. 
Table 4.1 Public funding of universities and PSREs

\begin{tabular}{lll}
\hline \hline & Universities & PSREs \\
\hline $2008 / 9$ & 8,819 & 2,128 \\
$2009 / 10$ & 9,043 & 2,216 \\
$2010 / 11$ & 8,878 & 2,287 \\
$2011 / 12$ & 8,271 & 2,199 \\
$2012 / 13$ & 7,032 & 2,045 \\
$2013 / 14$ & 6,080 & 2,153 \\
\hline \hline
\end{tabular}

Note: Values are in million GBP, current prices. Universities' public funding includes recurrent funding for teaching, recurrent funding for research, and capital grants (source: HESA). PSREs' public funding includes government expenditure for R\&D performed by UK government (civil departments and research councils only).

Source: ONS (2016)

universities, PSREs' IP income is a high share (about 65 percent) of their overall income from knowledge transfer activities.

PSREs operate under a variety of governance arrangements: they can be fully owned by a government department or research council, government-owned but contractor-operated (GOCO), registered charities, executive agencies, trading funds or nondepartmental public bodies. This variety of governance arrangements in the PSRE sector and the universities' status as charities have meant that both these institutions have greater operational autonomy in the United Kingdom than do similar institutions in Europe, and, in turn, this freedom has enabled them to be nimble and responsive to emerging market trends.

Table 4.1 compares public funding of universities and PSREs between 2008/9 and 2013/14. The table shows different trends, with public funding of PSREs remaining stable and public funding of universities declining - although the decline has occurred in relation to university teaching funding (a 67 percent drop in the period), while university research funding has increased.

\subsection{An Overview of Knowledge Transfer Policy in the United Kingdom}

\subsubsection{A Short History of Knowledge Transfer Policy in the United Kingdom}

The UK government's concern with supporting university-industry knowledge transfer began in the late 1970s, when a debate emerged on the United 
Kingdom's presumed failure to exploit research (Grady and Pratt 2000). Institutional and cultural barriers at the time had made cooperation between academic and industrial scientists difficult, and academia lacked incentives to engage with industry. The National Research Development Corporation (NRDC), a governmental body charged with facilitating the commercialization of research produced by public R\&D (particularly defense) laboratories, had been created in 1948, but it played a limited role. John Hendry's Innovating for Failure (1993), which recounts the early attempts to drive the creation of a computer industry in Manchester in the 1950s, is instructive. Despite having the new technology at the University of Manchester, an identified champion (Ferranti) and a government willing to provide funds for the enterprise, a technology industry based on computing failed to emerge, as the required interaction between the scientists and the managers at Ferranti did not take place. An industry based on computing technology did emerge in the 1980s, but at Cambridge, supported by the Cambridge colleges, and largely free from government influence (Athreye 2004). This early failure to seize the opportunity in a sector where the United Kingdom had numerous advantages may have contributed to policymakers moving away from directly supporting specific technologies. Instead, policy interventions increasingly involved promoting general framework conditions for innovation, including promoting universities' engagement with business.

Several initiatives to support university-industry interactions implemented since the mid-1970s exemplified such an indirect approach to technology policy. These included the Teaching Company Scheme, launched in 1975, which involved placing graduates in companies on projects jointly supervised by academics and company staff (Senker and Senker 1994) and the LINK scheme, launched in 1986, which aimed to support collaborative research partnerships between industry and the research base (Grimaldi and Von Tunzelmann 2002). In the early 1980s the government assigned the exclusive right to commercialize universitygenerated intellectual property to the British Technology Group (BTG, formed through the merger of the NRDC with the National Enterprise Board), and, a few years later, in 1985, universities were given the choice whether to commercialize academic inventions independently or to rely on the services provided by BTG. ${ }^{8}$

${ }^{8}$ In 1992, BTG was privatized and became a private supplier of IPR brokerage services; it is currently still operating but now focuses on acquiring, developing, and producing pharmaceutical drugs. 
Starting from the mid-1990s, government policy documents began to explicitly identify universities as the central focus for economic development, and to emphasize the importance of partnerships between industry, government, and the science base (OST 1993). With the move of the Office of Science and Technology (OST) from the Cabinet Office to the Department for Trade and Industry (DTI) in 1995, responsibilities for science and technology policy were centralized in a single department, which facilitated the emergence of a coordinated national policy on university knowledge transfer (Grady and Pratt 2000).

Rosli and Rossi (2016) argue that UK policymakers' views about how universities engage in knowledge transfer, and how policy should support them, have evolved over time. Until the early 2000s, policymakers envisioned a model of university engagement that borrowed heavily from the sciences and engineering (Kitagawa and Lightowler 2012): innovation was viewed as a linear process whereby universities would transfer technology to business, by selling patents and licenses, performing contract research (National Committee of Enquiry into Higher Education 1997; DTI 1998), or directly commercializing their technology through spinoff companies (Lockett, Wright, and Wild 2014).

During the 2000s, policy documents began to reflect a more nuanced view, supported by growing empirical evidence highlighting the diversity of channels through which universities engage with businesses and with other economic and social actors (D'Este and Patel 2007; Bekkers and Bodas Freitas 2008; Hughes and Martin 2012). Having identified the drawbacks of focusing too much on patenting and on the pursuit of narrow financial returns (Lambert Review: HM Treasury 2003; Gowers Review: HM Treasury 2006; Saraga report: DIUS 2007), universities were encouraged to realize the potential of their intellectual property beyond their patent portfolio, focusing on other areas such as copyright (Hargreaves Review: BIS 2011b). They were also encouraged to focus on their comparative strengths, since different universities had different contributions to make, some as world-class centers of research excellence and players in global markets, and others primarily as collaborators engaged with local businesses, communities, and regional bodies (DTI/ DFES 2005; DIUS 2008a, 2008b). It was argued that public funding should encourage such choice, by providing incentives for institutions to become more entrepreneurial, build closer links with business and the community, and have proper arrangements for exploiting the results of their work. The term "knowledge transfer" gained prominence (DES 
2003; HM Treasury 2003), suggesting that universities transfer more than just technology produced by science and engineering departments, and contribute through the whole spectrum of academic disciplines.

More recently, a broader view has emerged whereby universities are seen to be part of complex ecosystems of innovation characterized by collaboration and exchange among a variety of stakeholders, aimed at addressing complex social and economic challenges (Andersen, Brinkley, and Hutton 2011; BIS 2015). The bidirectional and collaborative nature of the interactions between universities and businesses (or other stakeholders), is reflected in the increasing use of the term "knowledge exchange" (DIUS 2008b; BIS 2012, 2013, 2015).

Another aspect of the evolution of knowledge transfer policy concerns the level of implementation. In the first decade of the 2000s, attention was paid to the regional dimension of universities' knowledge transfer engagement (Potts 2002; DES 2003; Lambert Review: HM Treasury 2003), and a new Regional Innovation Fund worth $£ 50$ million per year was set up to enable regional development agencies (RDAs) in England to support clusters, incubators and networking among scientists, entrepreneurs, managers, and financiers. However, all RDAs were closed in 2010, leading the government to abandon this regional focus (Cochrane and Williams 2013). In the absence of regional policy institutions, the implementation of regional policies for knowledge transfer has become more difficult, and universities' efforts to engage in knowledge transfer within their region are neither monitored nor encouraged. While numerous local enterprise partnerships (LEPs) between local authorities and businesses were established in 2011, covering all areas of England (BIS Committee 2014), how innovation and knowledge transfer policies can be implemented in the LEP context remains unclear. LEPs argue that their remit has expanded over time, and that their resources are insufficient (National Audit Office 2016). Although university representatives sit on the board of many LEPs, a recent review suggests that the relationship expected between LEPs and universities appears ill-defined and that engagement between them is patchy (BIS 2015), with LEPs lacking any firm obligation or support to help businesses connect with universities. In consequence, universities may have been discouraged from pursuing an agenda of contributing to regional development, focusing instead on different objectives (Kitagawa et al. 2016). However, little empirical evidence exists at the moment to show whether this has been the case. 


\subsubsection{Supply-Side Policy Instruments Supporting Knowledge Transfer}

Most of the policy instruments devised by the government in order to promote knowledge transfer have been targeted at universities (Science and Technology Committee 2017). The first comprehensive package, the Knowledge Exploitation Programme, was launched in 1999 and included three instruments (HEFCE 1999):

(i) The Higher Education Reach-out to Business and the Community (HEROBAC) Fund ( $\$ 60$ million allocated competitively in 1999-2004). Its aim was to help universities to build organizational capability and infrastructures to engage with business and the wider community.

(ii) The Science Enterprise Challenge (SEC) fund ( $£ 45$ million allocated competitively in 1999-2004). It aimed to support entrepreneurially oriented education and training within universities.

(iii) The University Challenge Seed Fund ( $£ 60$ million overall allocated via two competitions, in 1999 and 2001). It provided access to seed funds to exploit science and engineering research outcomes and support the creation of university spinouts.

The Higher Education Innovation Fund (HEIF), a permanent stream of funding to support universities' knowledge transfer activities, was announced in 2001/2 and implemented the following year. The activities originally funded by HEROBAC, the SEC and the University Challenge Seed Fund were progressively brought within HEIF's remit. After a marked increase between 2004 and 2008, the fund later stabilized at about $£ 130$ million per year, which is almost three times as much as it had been in 2001. The amount distributed through HEIF and parallel funding streams in Scotland, Wales, and Northern Ireland equates to approximately 2.4 percent of the recurrent government funding allocated to universities for teaching and research, and about 9 percent of the recurrent government funding allocated to research alone (Kitagawa and Lightowler 2013). Over time, HEIF has become a very important source of support for knowledge transfer activities, with about 34 percent of universities' knowledge transfer income resulting from HEIF-funded activities (Coates Ulrichsen 2014).

HEIF's allocation system has changed over time. Initially, funds were allocated to universities competitively on the basis of the project proposals that they presented, with the objective of helping them build capacity for knowledge transfer (Kitagawa and Lightowler 2012). Since 2006 this has 
been progressively replaced by a formula based on the income that universities accrue from knowledge transfer, so that money is channeled to the institutions that are already more commercially successful. The introduction of a minimum eligibility threshold of $£ 250,000$, an increase in the maximum award that can be received by each university ( $\$ 2.85$ million), and the allocation of additional funds to top performers ( $£ 6$ million to twelve institutions in 2012/13 and $£ 20$ million to twenty-seven institutions in 2014/15) have also contributed to greater funding concentration since 2011 (Coates Ulrichsen 2014; Day and Fernandez 2015), reversing the previous trend whereby smaller institutions used to have higher income growth $^{9}$ (Day and Fernandez 2015).

In addition to HEIF, several other instruments support universities' knowledge transfer activities. HEFCE runs the Catalyst Fund, which distributes funds competitively to projects aimed at driving innovation in higher education ( $£ 37.6$ million in $2013 / 14$ ) and the UK Research Partnership Investment Fund, which funds large-scale collaborative projects between universities and private partners ( $£ 136$ million in $2013 / 14$ ). Innovate UK also runs a number of schemes. The Knowledge Transfer Partnership (KTP) scheme, launched in 2003, is a revamped version of the Teaching Company Scheme. In 2013/14 it allocated $£ 16.9$ million. The Catapult Centres, launched in 2013, are research and technology innovation centers set up as collaborative ventures between universities and businesses, each focused on a specific area of research and technological development. The twelve "catapults" were allocated $£ 121.30$ million in $2013 / 14$. Innovate UK also funds collaborative R\&D projects and feasibility studies involving businesses and research organizations ( $£ 172.9$ million in 2013/14), collaborative research in biomedicine (Biomedical Catalyst, $£ 30$ million in 2013/14), Knowledge Transfer Networks ( $£ 15.2$ million in $2013 / 14$ ), and Innovation and Knowledge Centres ( $£ 1.9$ million in $2013 / 14$ ).

The overall set of government-supported knowledge transfer schemes allocated by HEFCE and Innovate UK amounted to approximately $£ 696$ million in 2013/14, which was about 37 percent of the recurrent government funding allocated to university research in the same period (NCUB 2016a). Small funding schemes supporting knowledge transfer activities, often restricted to specific academic fields, are also implemented by the devolved governments (Huggins and Kitagawa 2012), by

9 The introduction of a cap on the maximum and minimum annual changes in funding allocations - allocations may increase by 50 percent at most, and may not drop by more than 50 percent - was not sufficient to offset this concentration process. 
many of the research councils and by selected charities such as the Wellcome Trust and the Royal Society (Lockwood 2012, cited in Coates Ulrichsen 2014). ${ }^{10}$

Few policy instruments have been set up in support of the knowledge transfer activities of PSREs. In 2001, the government set up the Public Sector Research Exploitation Fund, awarding nineteen PSREs a total of $£ 10$ million of public venture capital to develop potential products to the point where they could be successfully marketed to the private sector. Two additional rounds of funding in 2004 and 2006 allocated a further $£ 40$ million. Since the demise of this instrument, there are no lines of funding specifically dedicated to supporting PSREs' knowledge transfer activities.

Not all policy instruments consist of the provision of funding. The Lambert Agreements are a set of decision tools and standard agreements created in 2005 to simplify contracting for business-university collaborations. Evidence on the success of these tools is mixed: most users report that they simplify processes and provide useful information and precedents (BIS 2015); however, their use is not widespread. While universities are generally aware of these tools and 63 percent use them to some extent (Tang et al. 2009), less than 10-15 percent by value of collaborative research between universities and business is based on a Lambert-type agreement (BIS 2015). For the most valuable agreements, companies are more likely to impose their preferred contractual forms. Scotland has mandated the use of template contracts for interactions funded by the Scottish Funding Council's innovation voucher and related schemes (BIS 2015).

A crucial nonfinancial policy instrument that affects knowledge transfer is the government regulation of IP rights. In the United Kingdom, there is no strong legislative framework regulating academic patenting, and, unlike other countries that have enacted specific laws on university IP, the assignment of IP rights over research outputs is governed by the general provisions on employee inventions contained in the Patent Law of 1977. The United Kingdom has a system of "automatic ownership," such that the university is the first owner of the IP, which usually cannot revert to the inventor. ${ }^{11}$ However, if research is sponsored fully or in part by external contractors, parties may negotiate a different agreement on

${ }^{10}$ PACEC (2012) found evidence that universities use a wide range of funding sources to support their knowledge transfer activities, with HEFCE, the RDAs, the research councils, the EU, and Innovate UK being the most frequently used.

${ }^{11}$ Other countries such as Austria, the Czech Republic, Denmark, Finland, Germany, Greece, Hungary, and Norway apply, fully or in part, the "pre-emption rights" principle, whereby the researcher is the first owner of the invention but the university has the right 
the allocation of IP rights. In some cases, the university may override existing regulations by developing internal IP rights regulations and procedures to enforce them. Issues such as the share of royalties to be assigned to the academic inventors, the rights of inventors who are $\mathrm{PhD}$ students, and the timing of patent filing procedures can vary widely among universities.

Mainly because of its fluidity, the policy framework around IP has not undergone radical changes over time. The main policy change, introduced in 1985, has been the possibility for universities to directly commercialize their intellectual property. This has encouraged an increase in the patenting activities of universities. In fact, UK universities tend to own a large share (over 50 percent) of patents invented by academics, similar to the U.S. (where the share is 69 percent) and unlike many other European countries, where the majority of academic-invented patents are owned by private companies; for example, Lissoni et al. (2008) show that university-owned patents constitute no more than 11 percent of all academic patents in France, Italy, and Sweden.

\subsubsection{Demand-Side Policies Supporting Knowledge Transfer}

Business also has a vital part to play in successful knowledge transfer. A number of policies exist to support business investment in R\&D, which in turn should increase businesses' commercial demand for university research. These include (BIS 2011a):

R\&D tax credits, which offer relief from corporation tax (equal to 22.5 percent of qualifying expenditure) with the objective of incentivizing companies in all sectors to undertake more $\mathrm{R} \& \mathrm{D}$. The government has also introduced a simplified tax regime for small companies and made it easier for them to claim the R\&D tax credit.

Open funding competitions (formerly Smart Programme) to support firms' R\&D projects that are "likely to lead to sustainable gains in productivity and/or access to new overseas markets through export led business growth."12

The Small Business Research Initiative (SBRI), which aims to enable innovative companies to solve challenges for government departments.

Support for venture capital funding, through government investment in the Enterprise Capital Funds program, in the Co-Investment Fund

to claim it within a specified period. In the event that the invention is not claimed within the specified period, the rights remain with the inventor (DLA Piper et al. 2007).

12

www.gov.uk/government/publications/innovate-uk-open-funding-competition/innov ate-uk-open-funding-competition-brief. 
(aimed at backing business angels), and in the UK Innovation Investment Fund (one of Europe's largest technology funds investing in life sciences, digital, advanced manufacturing and clean-tech companies). Additionally, several schemes provide tax relief to investors providing venture capital to qualifying seed companies (the Seed Enterprise Investment Scheme, SEIS), SMEs (the Enterprise Investment Scheme, EIS), or social enterprises (Social Investment Tax Relief, SITR). ${ }^{13}$

The recent Industrial Strategy White Paper (BEIS 2017) has outlined a more proactive role for the UK government in driving industrial policy in the wake of the United Kingdom's exit from the European Union and proposed several supply-side and demand-side interventions. On the supply side, the government has committed to increase investment in $\mathrm{R} \& \mathrm{D}$ by around 20 percent via an additional $£ 4.7$ billion of government R\&D funding by $2020-1$. Additional spending of $£ 100$ million has been committed to measures to incentivize universities to collaborate with businesses. These might include the expansion of existing mechanisms such as HEIF and KTPs, the introduction of new schemes aimed at funding industry placements for scientists, and supporting world-class clusters of research and innovation. A new Industrial Strategy Challenge Fund is planned to back technologies at all stages where the United Kingdom has the potential to take an industrial lead. This Fund will support a range of industrial $\mathrm{R} \& \mathrm{D}$ activities: joint research projects between business and academic researchers, graduate placements, setting up demonstrators to test near-to-market technologies in real-world environments and creating centers to bring together academic experts with entrepreneurs to promote commercialization (BEIS 2017).

On the demand side, a few measures aimed at driving up the level of business R\&D investment have also been announced. These include: a review of the tax environment for $R \& D$, a new challenge prize to support "everyday entrepreneurs" and a review of the IP system to stimulate collaborative innovation and licensing opportunities. The Science and Technology Committee (2017), while welcoming the government's renewed emphasis on knowledge transfer, remained concerned that its previous efforts had focused disproportionately on the "supply" of research by universities rather than the level of "demand" from businesses, and that the overall R\&D intensity and productivity of the UK business sector continue to be low compared to that in other OECD countries.

13 www.gov.uk/guidance/venture-capital-schemes-raise-money-by-offering-tax-reliefs-toinvestors. 


\subsection{Knowledge Transfer Activities of Universities and PSREs}

\subsubsection{The Variety of Knowledge Transfer Activities}

Knowledge transfer channels have been comprehensively classified in recent work by the National Centre for Universities and Business (NCUB 2016a, 2016b) into four categories: commercialization, problem-solving, peoplebased, and community-based activities. Commercialization activities include patenting, licensing research, consulting, and spinning out companies. Problem-solving activities include joint publications, joint research, consultancy services, prototyping and testing, research consortia, contract research, hosting personnel, providing informal advice, external secondment, and setting up physical facilities. People-based activities include standard-setting forums, participating in networks, attending conferences, student placements, giving invited lectures, curriculum development, sitting on advisory boards, employee training, and enterprise education. Community-based activities include social enterprises, museums and art galleries, public exhibitions, heritage and tourism, community-based sports, performing arts, school projects, and lectures for the community. While universities have been engaging in people-based and community-based activities for a long time, the literature has only relatively recently begun to acknowledge their importance in disseminating and sharing academic knowledge to the public (British Academy 2008, 2010; Olmos-Peñuela, Benneworth and Castro-Martínez 2014; Campaign for Social Science 2015).

Figure 4.4 shows the shares of academics and of PSRE staff who engage in each type of activity. Commercialization and problem-solving activities are relatively more important for PSRE staff than for academics, while the converse is true for people-based and community-based activities. This may be due, in part, to differences between fields of science, since commercialization and problem-solving are particularly important in engineering and materials science, while the arts and humanities and the social sciences, which are not represented in the set of PSREs considered in this study, lead in community-based and people-based activities respectively (NCUB 2016a). It is also apparent that both academics and PSRE staff engage far less in commercialization activities than in all other activities. In line with a large amount of evidence suggesting that IP-based activities are concentrated in a few fields, commercialization is particularly high among engineering and materials science academics, and among BBSRC-affiliated PSRE staff.

A more fine-grained analysis comparing the shares of academics (excluding those in the social sciences and the arts and humanities, for 


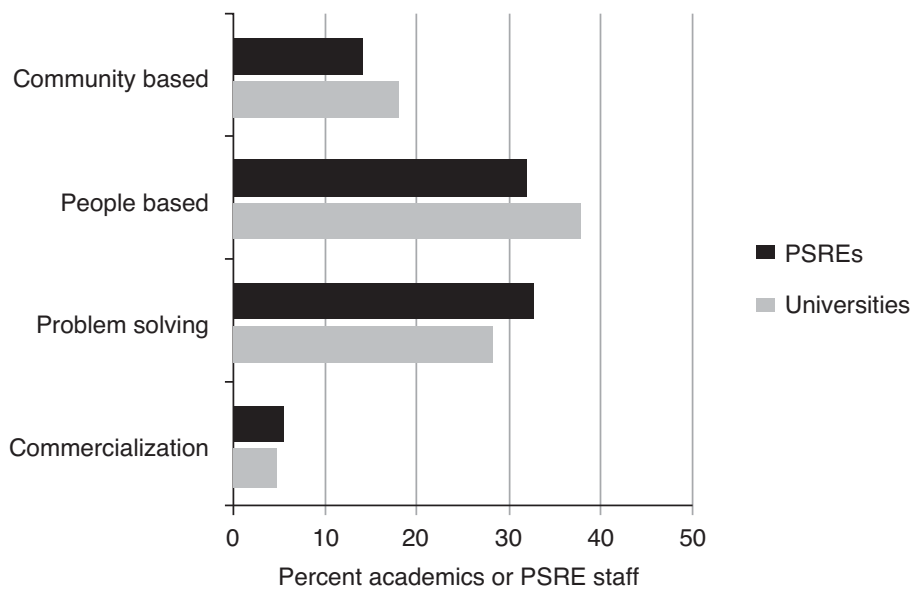

Figure 4.4 Shares of university and PSRE staff involved in different types of knowledge transfer activity

Source: Authors, based on data from NCUB (2016a, 2016b)

greater comparability) and the shares of PSRE staff who engage in each of the activities listed under the four main categories of commercialization, problem-solving, people-based, and community-based activities, suggests that the pattern of engagement is very similar. Academics are marginally more engaged in most activities, except for joint research, research consortia, giving informal advice, and attending conferences, while PSRE staff are marginally more active in several community-based activities. It appears that, in spite of the lack of specific policy schemes supporting PSREs' knowledge transfer activities, PSRE staff engage with external stakeholders through a variety of channels.

\subsubsection{Engagement in IP Commercialization}

While commercialization of IP has historically been considered an important avenue for university-industry knowledge transfer, in practice, it involves fewer academics and generates less income than all other knowledge transfer channels. There is a substantial amount of research investigating the patterns and determinants of university patenting, licensing, and spinouts in the United Kingdom. Table 4.2 presents the evolution of a subset of indicators of IP-related activities for the period from 2003-4 to 2014-15. IP income increased at about 11 percent per year, excluding the exceptionally good performance of 2008, which 
Table 4.2 Indicators of research commercialization activities in UK universities

\begin{tabular}{|c|c|c|c|c|c|c|c|c|c|c|c|c|}
\hline & $2003-4$ & $2004-5$ & $2005-6$ & $2006-7$ & $2007-8$ & $2008-9^{1}$ & 2009-10 & $2010-11$ & $2011-12$ & $2012-13$ & $2013-14$ & $2014-15$ \\
\hline $\begin{array}{l}\text { FTE staff employed in } \\
\text { commercialization } \\
\text { offices }\end{array}$ & 1,508 & 1,518 & 1,612 & 1,829 & 1,910 & 2,001 & 2,975 & 2,209 & 2,269 & 3,395 & 3,720 & 3,936 \\
\hline A) Patent applications & 1,308 & 1,648 & 1,536 & 1,913 & 1,898 & 2,097 & 1,994 & 2,256 & 2,274 & 1,936 & 2,076 & 2,156 \\
\hline B) Patents granted & 463 & 711 & 577 & 647 & 590 & 653 & 820 & 757 & 826 & 951 & 969 & 953 \\
\hline $\begin{array}{l}\text { C) Formal spinouts } \\
\text { established }\end{array}$ & 167 & 148 & 187 & 226 & 219 & 191 & 207 & 236 & 170 & 131 & 130 & 129 \\
\hline $\begin{array}{l}\text { D) Formal spinouts still } \\
\text { active after three years }\end{array}$ & 688 & 661 & 746 & 844 & 923 & 982 & 806 & 825 & 818 & 793 & 802 & 836 \\
\hline E) IP income ( $£$ million $)^{1}$ & 49 & 71 & 70 & 69 & 76 & 140 & 92 & 74 & 83 & 89 & 133 & 155 \\
\hline $\begin{array}{l}\text { F) Other knowledge } \\
\text { transfer income } \\
\text { ( } £ \text { million }){ }^{2} \text { of which: }\end{array}$ & 2,479 & 2,549 & 2,688 & 3,054 & 3,158 & 3,188 & 3,284 & 3,448 & 3,487 & 3,588 & 3,840 & 4,020 \\
\hline Collaborative research & 699 & 665 & 725 & 791 & 802 & 821 & 819 & 930 & 915 & 979 & 1,156 & 1,257 \\
\hline Consultancy & 272 & 281 & 294 & 340 & 385 & 372 & 397 & 395 & 418 & 412 & 446 & 442 \\
\hline Contract research & 745 & 773 & 792 & 925 & 960 & 1,052 & 1,075 & 1,123 & 1,148 & 1,201 & 1,205 & 1,210 \\
\hline $\mathrm{CPD}$ & 282 & 347 & 349 & 415 & 442 & 430 & 445 & 439 & 437 & 435 & 430 & 443 \\
\hline CPD and CE & 99 & 127 & 142 & 159 & 176 & 197 & 189 & 207 & 236 & 237 & 255 & 272 \\
\hline $\begin{array}{l}\text { Facilities and } \\
\text { equipment-related } \\
\text { services }\end{array}$ & 103 & 95 & 109 & 110 & 119 & 124 & 126 & 137 & 146 & 146 & 165 & 191 \\
\hline
\end{tabular}


Table 4.2 (cont.)

\begin{tabular}{|c|c|c|c|c|c|c|c|c|c|c|c|c|}
\hline & $2003-4$ & 2004-5 & $2005-6$ & $2006-7$ & $2007-8$ & $2008-9$ & 2009-10 & $2010-11$ & 2011-12 & $2012-13$ & 2013-14 & 2014-15 \\
\hline $\begin{array}{l}\text { Regeneration and } \\
\text { development } \\
\text { programs }\end{array}$ & 279 & 261 & 276 & 314 & 274 & 193 & 233 & 217 & 189 & 177 & 183 & 205 \\
\hline Ratio E/F (\%) & 2.0 & 2.8 & 2.6 & 2.3 & 2.4 & 4.4 & 2.8 & 2.1 & 2.4 & 2.5 & 3.5 & 3.9 \\
\hline
\end{tabular}

Source: Presented in Geuna and Rossi (2011), updated using HESA data

${ }^{1}$ Includes income from license agreements involving patents, copyright, design registrations, and trademarks.

${ }^{2}$ Includes income from collaborative research, research contracts, consultancies, facilities and equipment, CPD, CE courses, and regeneration programs. 
was largely due to one university selling its share of a well-established company (HEFCE 2010). Income from other knowledge transfer activities increased on average by 10.9 percent per year. However, these two types of income are very different in magnitude, with income from IP accounting on average for only 2.8 percent of total annual income from knowledge transfer. The number of patents applied for and granted (both national and international filings, but not counting multiple filings of the same patent in different countries) increased on average by 5.3 percent and 8.3 percent respectively each year. From the mid-2000s there appears to have been a leveling-off in the growth of university-owned patents. This matches the experience of the U.S., another country with a long tradition of institutional IP ownership (Mowery and Sampat 2005; Tang et al. 2009). Over time, knowledge transfer offices (KTOs) have gained experience in realistically assessing inventions' commercial and licensing potential, and have therefore become more selective in deciding whether patent applications should be made (Tang et al. 2009). As a consequence, the quality of university patents has improved, as suggested by several trends: an increase in the number of nonsoftware license agreements, an increase in the share of spinouts surviving for more than three years, and an increase in the share of patent applications that are eventually granted.

Despite the large number of universities that engage in patenting and spinning out (between 2009-10 and 2014-15, 122 universities filed at least one patent, generated income from IP, or created at least one spinout company), the bulk of these activities are concentrated in a subset of research-intensive universities with a substantial presence in engineering, materials science, biology, chemistry, and veterinary science (NCUB 2016a). In 2014-15, six institutions (3.7 percent) produced 40 percent of patent applications, and twenty-five institutions (16 percent) produced 80 percent of patent applications. The distribution of IP income is even more concentrated: just three institutions (1.8 percent) produced 41 percent of IP income, and seventeen institutions (11 percent) produced 80 percent of IP income. Twenty-seven institutions ( 17 percent) produced 80 percent of income from research contracts. The skewed distributions of patent income might suggest a skewed ability of institutions to produce high-quality patents, since evidence suggests that patents licensed to industry are of better quality than patents that are not licensed (Sterzi 2013).

Figure 4.5 summarizes some of the data from Table 4.2. The number of new spinouts established each year has been quite stable (although declining in recent years), but the number of spinouts surviving at least 


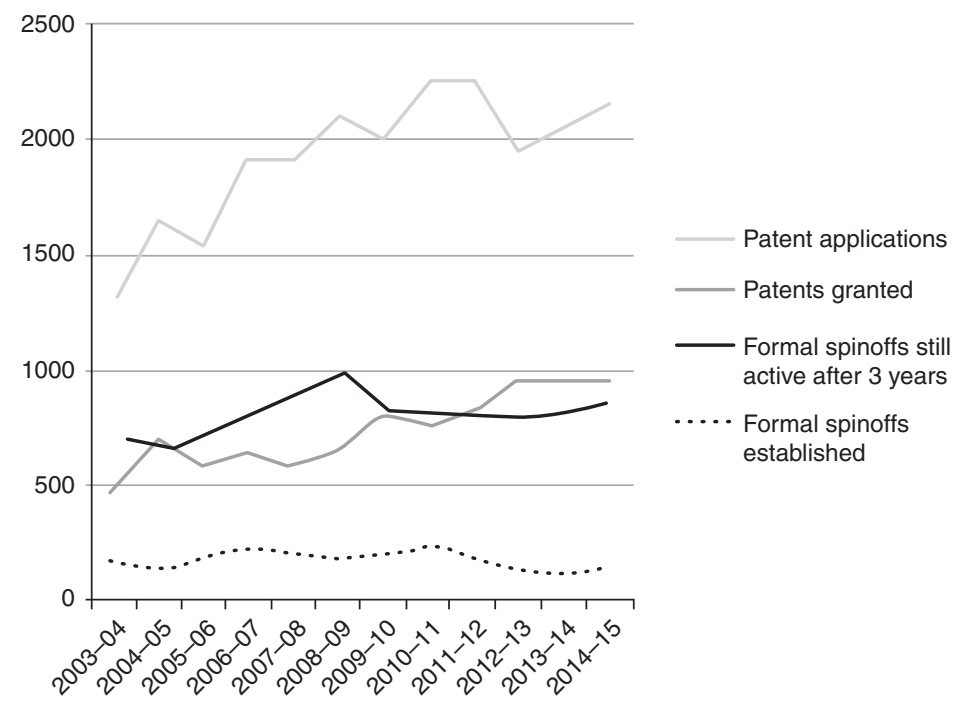

Figure 4.5 Patenting and spinout activities of universities Source: Authors, based on data from HESA

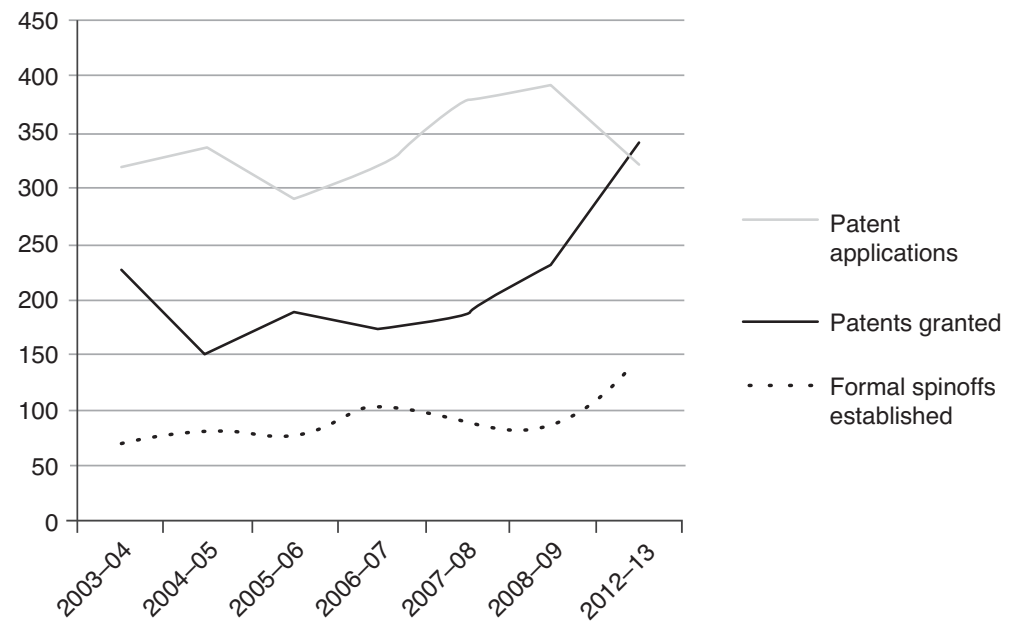

Figure 4.6 Patenting and spinout activities of PSREs Source: Authors, based on data from BIS (2014) 
three years has increased. While failure rates remain high and a great number of spinouts may still not survive in the long run (HM Treasury 2003), the survival rate ${ }^{14}$ of university spinouts in the United Kingdom is high by comparison with many other countries (Lawton Smith and Ho 2006).

One interesting aspect of Figure 4.5 is the close relationship between patents granted and spinout activity. It has been argued that patent licensing and spinning out companies are alternative modes of commercializing research results, and that one or the other will prevail depending on institutional and context conditions. International evidence suggests that those countries that have maintained an inventor-ownership model (such as Sweden and Italy) focus more on spinouts than countries that have a university-ownership model, which tend to focus on patent licensing. The University of Cambridge seems a case in point. Before its switch to the institutional-ownership model in 2005, the University of Cambridge had, for a long time, uniquely maintained a professor's privilege system similar to that implemented in Germany and the Nordic countries. Cambridge's historic success at spinout creation (Athreye 2004) might suggest that the lack of institutional ownership acted as an incentive to commercialize research results via spinout companies instead of relying on patent licensing.

However, the analysis of patenting and spinout data over time suggests that universities that make more income from technology licensing and file more patents may also create more successful spinouts. This relationship is consistent with the skew in the generation of new science noted earlier and suggests that universities have developed a range of competencies that allow them to engage in both licensing and spinouts. A growing literature on university KTOs appears to tell a similar story. Tang et al. (2009) reported that KTOs have improved their ability to explain the commercialization processes and options to academics, and to work with academics on defining appropriate IP ownership arrangements and financial incentives. Most KTOs continually review and restructure their strategies, and promote themselves as interface organizations between the academics (and university) and external parties, including venture capitalists (Chugh 2004). The number, experience, and knowledge of KTO staff have been found to be positively related to

${ }^{14}$ It must be noted, however, that survival is not a measure of profitability or even viability; many university spinouts, it has been shown, are able to survive with minimal business activity thanks to their ability to keep down costs by using university structures and personnel (Jelfs 2016). 
the number of spinouts (Lockett and Wright 2005; Powers and McDougall 2005) and to the quality of the advice and contacts they provide (Franklin, Wright, and Lockett 2001). The number of university spinouts is also positively correlated with university $R \& D$ spending, spending on IP disclosure, and the ability to develop new business (Lockett and Wright 2005) - but it is quite likely that these factors also determine how many patents the university can apply for. The ability to generate spinout companies also depends on university characteristics (such as institutional reputation, which makes it easier for academics to bring together resources to create spinouts, and the presence of cultures or norms that nurture entrepreneurial activity (DiGregorio and Shane 2003), and on external factors like the availability of local venture capital: the level of investment in firms located ten miles from a venture capital head office is double that of firms sited 100 miles away (Wright et al. 2004), and on individual attributes and experience (Clarysse, Tartari, and Salter 2011).

Information about the commercialization activities of PSREs is collected less systematically than information about universities' knowledge transfer activities. Between 2003 and 2004, the Department for Business, Innovation, and Skills (BIS 2011a, 2014) carried out seven surveys of knowledge transfer activities in all the PSREs funded by government departments and by the research councils, as well as in cultural institutions and regional NHS hospital trusts. Table 4.3, drawn from the latest available study (BIS 2014), shows grossed-up estimates for the whole sector. PSREs' commercialization activities have grown over time -the number of FTE staff in commercialization offices has grown by about 36 percent - as has business representation on their governing boards. As a group, PSREs outperform universities on a range of metrics. If we compare data from universities and PSREs in the last year for which they are available (2012-13), it is interesting to observe that while the number of patent applications by PSREs is much lower (322 versus 1,936 by universities), their probability of being granted is much higher (twothirds versus less than half) and so is their income from licensing ( $£ 195$ million versus $£ 61$ million). Consequently, the average licensing income per granted patent is much higher for PSREs $(£ 570,175)$ than for

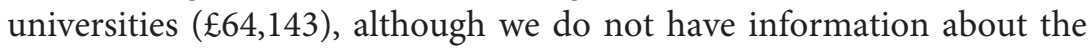
distributions: it is possible that a small number of blockbuster patents account for the largest share of income, for either or both PSREs and universities. 
Table 4.3 Summary indicators of research commercialization activities in UK PSREs

\begin{tabular}{|c|c|c|c|c|c|c|c|}
\hline & $2003-4$ & $2004-5$ & $2005-6$ & $2006-7$ & $2007-8$ & $2008-9$ & $2012-13$ \\
\hline Number of PSREs covered & 107 & 116 & 135 & 138 & 138 & 143 & $\begin{array}{l}\text { grossed-up } \\
\text { values }\end{array}$ \\
\hline $\begin{array}{l}\text { FTE staff employed } \\
\text { in commercialization } \\
\text { offices }\end{array}$ & 385 & 368 & 513 & 669 & 486 & 448 & 611 \\
\hline A) Patent applications & 316 & 335 & 290 & 316 & 379 & 392 & 322 \\
\hline B) Patents granted & 228 & 148 & 193 & 172 & 188 & 230 & 342 \\
\hline $\begin{array}{l}\text { C) Formal spinouts } \\
\text { established }\end{array}$ & 69 & 84 & 74 & 101 & 89 & 83 & 143 \\
\hline D) IP income ( $£$ million) & 33 & 46 & 186 & 116 & 146 & 198 & 195 \\
\hline $\begin{array}{l}\text { E) Income from } \\
\text { consultancy ( } \mathfrak{E} \text { million) }\end{array}$ & 36 & 31 & 26 & 43 & 37 & 100 & 166 \\
\hline $\begin{array}{l}\text { F) Income from use of } \\
\text { facilities and equipment } \\
\text { and training ( } \mathfrak{E} \text { million) }\end{array}$ & & & & & & & 133 \\
\hline Ratio $\mathrm{D} /(\mathrm{E}+\mathrm{F})(\%)$ & 91.7 & 148.4 & 715.4 & 269.8 & 394.6 & 198.0 & 65.2 \\
\hline
\end{tabular}

Source: BIS (2014) 
Table 4.3 also shows that PSREs' commercialization activities have been on the rise. Although patent applications have not increased much, the number of patents granted has increased. The number of spinouts doubled between 2008-9 and 2012-13, with PSREs owning some equity in 93 percent of these cases. Income from commercialization activities including business consultancy has also increased dramatically over time, and particularly since 2008-9. By way of contrast, a steady increase in licensing agreements (and corresponding income) in the early years has been followed by a decline in the last three years. Unlike universities, PSREs derive most of their knowledge transfer income from IP; for most of the period covered, income from IP was several times larger than income from consulting and other sources. Only in the most recent survey has the situation has changed: with IP income stable and rapid growth in other sources of knowledge transfer income, the former has dropped to only 65 percent of the latter. By contrast, universities' income from other knowledge transfer activities is much higher than that of PSREs ( $£ 2,269$ million versus $£ 299$ million), indicating that universities engage in a broader range of activities.

In comparing the commercialization activities of universities and PSREs, we may wonder whether we are comparing like with like. With 161 universities, the university sector is likely to be far more diverse than the thirty-five PSREs focused narrowly on a few subject areas. A narrow focus is more likely to generate economies of specialization in research, which are much harder for universities to achieve given their broader mandate.

Data collected from two surveys by NCUB, one of academic staff (NCUB 2016a) and one of PSRE staff (NCUB 2016b), allows us to perform some comparisons. It is apparent that PSRE staff can dedicate the majority of their time to research rather than teaching and administration, which instead take up a large part of university academics' time. Even though academics in the sciences spend on average a greater share of their time on research than academics in the social sciences and humanities, they still devote much less time to research than PSRE staff. However, while this might explain why a PSRE researcher produces more output than an academic, it still does not explain why their research enjoys greater commercial success.

PSREs' greater success in commercialization may be explained by their greater focus on more applied, mission-oriented research. However, whether PSREs' research is more applied than that conducted at universities is not clear. A comparison using NCUB data (2016a and 2016b) of 
the time allocated by academic and PSREs researchers between pure basic, user-inspired basic and applied research (as defined by the Frascati Manual, OECD 2003, pp. 77-9) suggests that the differences between research fields are greater than those between universities and PSREs: in both sectors, researchers in health and engineering spend relatively more time doing applied research, while researchers in biology, chemistry, and the natural sciences spend relatively more time doing basic research. Hence, categorizing research according to its objectives does not seem to reflect the commercialization potential of the resulting outcomes.

Another explanation might be that PSREs are more oriented to fields that are characterized by immediate commercial applicability, such as computer science and biotechnology. Data on the distribution of PSRE staff across fields of research are not collected systematically. By integrating information on the orientation of PSREs to various research fields (BIS 2015) with data on the number of staff employed in PSREs in 2012-13 (BIS 2014), we can estimate the share of PSRE staff in each field. These shares can be compared with the distribution of academics in each field in the same year. Considering only academics and PSRE staff employed in the sciences, we find that universities have greater shares of staff in medicine and in engineering and technology, while PSREs have greater shares of staff in the natural sciences (particularly biology, environmental, and sustainability studies) and in agriculture and veterinary science. While this shows different patterns of specialization in the two sectors, it is not immediately possible to deduce information about the ease of commercial applicability of the resulting research outcomes.

One reason why it is not so easy to explain the differential commercialization success of universities and PSREs is that the government is likely to have privatized, over time, exactly those PSREs whose research results could be commercialized more easily, since these would be more likely to survive without government funding. Therefore, the remaining PSREs are more likely to focus on the production of research outcomes that are less likely to generate large private returns, and which are thus more similar to the kind of research outcomes produced by universities. Academics and PSRE staff appear to have similar patterns of engagement in different channels of knowledge transfer, and to initiate interactions with external partners in similar ways. Further research in this area should adopt more fine-grained units of analysis. In particular, given that PSREs focus on narrow fields of research, their knowledge transfer performance should be compared with that of university departments or 
even research centers engaged in similar fields. Data at this level are currently not available systematically and would require ad hoc data collection.

\subsubsection{Industry Demand for Knowledge from Universities and PSREs}

Universities in the United Kingdom interact with a variety of industries. According to data from HESA, almost all universities work with organizations in the education, health and arts sectors, while three-quarters work with manufacturing. Almost every industrial sector draws on university knowledge: only five sectors approached fewer than eighty universities, and of these, only two sectors approached fewer than forty. However, when businesses are asked about their sources of knowledge for innovation, universities are not ranked highly: the most frequently cited sources of knowledge are the company itself, clients or customers, suppliers, and competitors in the same line of business (Hughes and Martin 2012). The fact that only 1 percent of the businesses report using the business sector alone, while 18 percent report using the business sector together with intermediaries, and over 80 percent report using some combination of sources from all three groupings, suggests that businesses use university knowledge in combination with other sources.

Data from the most recent Community Innovation Survey (BIS 2016) provide additional information about business engagement with universities. In the CIS sample of 15,091 companies, ${ }^{15}$ between January 1, 2012 and December 31, 2014, 7 percent of the companies collaborated on innovation activities with universities or other higher education institutions, and 5 percent collaborated on innovation activities with government or public research institutes. Table 4.4 shows a cross-tabulation of information on collaboration on innovation activities with universities and government or public research institutes. A total of 729 companies collaborated with the government, 1,068 with universities, 593 with both government and universities, 136 with the government but not with universities, and 475 with universities but not the government. The vast majority of firms $(13,887)$ collaborated with neither universities nor government.

Breaking down these data further, we find that of the CIS sample of 15,091 companies, 13 percent collaborated on innovation activities in the United Kingdom at the regional level, 19 percent collaborated at the

${ }^{15}$ In the sample, 44 percent of firms are small, 36 percent medium-sized, and 20 percent large. The median firm is medium-sized. 
Table 4.4 Collaboration with universities and governments

\begin{tabular}{|c|c|c|c|c|}
\hline & & \multicolumn{2}{|c|}{$\begin{array}{l}\text { Collaborated with } \\
\text { government? }\end{array}$} & \multirow[b]{2}{*}{ Total } \\
\hline & & No & Yes & \\
\hline \multirow{3}{*}{$\begin{array}{l}\text { Collaborated with } \\
\text { university? }\end{array}$} & No & 13,887 & 136 & 14,023 \\
\hline & Yes & 475 & 593 & 1,068 \\
\hline & Total & 14,362 & 729 & 15,091 \\
\hline
\end{tabular}

Source: Authors, based on data from BIS (2016)

national level, 9 percent collaborated with European countries, and 8 percent collaborated with non-European countries. However, relatively few companies collaborated with either universities or government, as can be seen from Table 4.5.

According to Abreu et al. (2008), who surveyed 1,449 UK firms, the channels most frequently used by firms to access university knowledge were the distribution of scientific knowledge through open science (publications and scientific conferences) and the appointment of graduate personnel. These far outstripped direct research collaborations between universities and firms (through research collaborations, research contracts and consultancies), while patents and licenses were used least of all. Data from HESA show differences between large firms and SMEs in the use of university IP: SMEs and non-commercial organizations generate 42 percent of universities' non-software licensing income, 64 percent of software licensing income, and 98 percent of other IP income (including income from copyright licensing).

\subsection{Organizational Practices in Knowledge Transfer}

Universities in the United Kingdom have very different knowledge transfer strategies (Hewitt-Dundas 2012) which tend to be aligned to their organizational goals and objectives (Buckland 2009) and to their tangible and intangible resources (research intensity, subject specialization, entrepreneurial culture, competencies within the KTO) (HewittDundas 2012; Kitagawa et al. 2016; Rossi 2017). Typically, knowledge transfer channels based on exploiting IP (patent licensing, spinouts) and research contracts are more prevalent in research-intensive institutions 
Table 4.5 Cooperation on innovation activities with universities and government at different geographical levels

\begin{tabular}{|c|c|c|c|c|c|}
\hline \multicolumn{6}{|c|}{ Cooperates on innovation activities with government or public research institutes } \\
\hline $\begin{array}{l}\text { Cooperation on } \\
\text { innovation } \\
\text { activities with } \\
\text { universities or } \\
\text { other higher } \\
\text { education } \\
\text { institutions }\end{array}$ & None & Nationally & Internationally & $\begin{array}{l}\text { Nationally and } \\
\text { internationally }\end{array}$ & Total \\
\hline None & 13,887 & 120 & 10 & 6 & 14,023 \\
\hline Nationally & 422 & 358 & 10 & 16 & 806 \\
\hline Internationally & 20 & 9 & 117 & 2 & 148 \\
\hline $\begin{array}{l}\text { Nationally and } \\
\text { internationally }\end{array}$ & 33 & 25 & 8 & 48 & 114 \\
\hline Total & 14,362 & 512 & 145 & 72 & 15,091 \\
\hline
\end{tabular}

Source: Authors, based on data from BIS (2016) 
and in those that include science, engineering, and medical subjects. In these institutions, the research and grants office may manage a larger share of university income than the KTO. By contrast, more teachingintensive institutions tend to focus on consultancy, the provision of CPD, and regeneration programs (Hewitt-Dundas 2012) aiming to provide skills and knowledge to their local communities (Jones and Craven 2001; Meagher, Lyall, and Nutley 2008; Wright et al. 2008). Universities specialized or oriented toward engineering, natural sciences, or information technology mainly interact with industry partners, while those specialized in the humanities, arts, and social sciences usually interact with public bodies, nonprofit organizations, and other community groups with lower purchasing power (Benneworth and Jongbloed 2010).

While different types of universities may prioritize different types of knowledge transfer activities, it is unclear which of these approaches bring the greatest economic returns: universities that are less researchintensive often receive more funds from industry than those that have a profile of research excellence (Geuna 1999). Compared with top universities, mid-range universities engage in a wider range of knowledge transfer activities (Wright et al. 2008) and serve a broader range of stakeholders (De La Torre, Rossi, and Sagarra 2017).

The knowledge transfer management practices adopted by universities are likely to play a role in their performance. Several studies have attempted to categorize different models for managing knowledge transfer activities. Rogers et al. (2009) identify four main models of research commercialization: the Cambridge Inventor-Ownership Model, based on academics' direct ownership of the IP originating from their research; the In-House Model, where the university manages the entire knowledge transfer process through an internal organization; the Stand-Alone Company Model, where the university establishes a dedicated, independent limited company to act as a conduit between university research and business; and finally the Hybrid Model, where the university signs a longterm partnership agreement that grants a private company a share in the university's IP (and income generated from its commercialization) in exchange for advice, funding, and expertise. A not-dissimilar classification was provided by Tang et al. (2009), who distinguished between having an internal organization wholly within the university structure, an organization operating outside of the university but reporting to it, an external nonprofit-making organization wholly owned by the university but operating autonomously and reporting to a board for all decisions, 
and an external profit-making commercial organization listed on the stock exchange.

Using survey data for 2006 and 2007, Rogers et al. (2009) showed that the share of universities using the services of external agents was increasing. Unsurprisingly, the universities that managed their IP licensing and filing internally tended to have larger KTOs. Even those universities that fully outsourced their IP activities and those that did not engage in IP at all still maintained an internal department for the management of other types of knowledge transfer activities. However, despite the variety of models, KTOs tended to centralize all university invention and commercialization activities and required all academic staff to notify them of their discoveries and to delegate all rights to negotiate licenses on their behalf. This prompted some (Rogers et al. 2009; Tang et al. 2009) to call for more varied approaches to knowledge transfer.

In a more recent study, Sengupta and Ray (2017) suggest that models of knowledge transfer governance have indeed grown more decentralized over time. By focusing on two dimensions - the extent to which knowledge transfer management is outsourced or performed in-house, and the extent to which knowledge transfer responsibilities are centralized or devolved to individual departments - their study identifies four models: coordinating KTO: most knowledge transfer functions are devolved to departments and performed in-house; absentee KTO: most knowledge transfer functions are devolved to departments and outsourced; traditional KTO: most knowledge transfer functions are controlled centrally and performed in-house; outward-facing KTO: most knowledge transfer functions are controlled centrally, with some outsourced. They also argue that: (1) universities whose strategy involves engagement with research users are more inclined to devolve a higher proportion of knowledge transfer responsibilities to departments, and (2) universities that exhibit relatively high volumes of application-oriented research outputs are more inclined to wholly or partly outsource key KTO functions to external organizations.

According to data from HESA, in 2013-14 only nineteen universities out of 161 (11.8 percent) did not have a formal KTO. The remaining 142 had an internal KTO or a subsidiary company (either majority or minority owned), or both. The functions of the KTO included providing support for SMEs (82 percent), drawing up contracts for various kinds of knowledge transfer interaction (66 percent), and providing indemnity insurance for staff (87 percent). 
Most universities had some infrastructure to manage the filing and commercialization of patents and other types of IP. As many as 146 universities (91 percent) had a formal structure (whether an internal office or external agency) in place to support the process of seeking protection for their IP. Eighty-four percent also had a formal structure (whether an internal office or external agency, or both) to support IP commercialization. Infrastructures to support academic and student entrepreneurship were also widespread: most universities provided business advice and entrepreneurship training services, followed by seedcorn investment and incubators, and finally by venture capital and science park accommodation. All these services were provided either directly by the university or by a partner organization, or both.

Most universities implemented incentives for academics to engage in knowledge transfer and to disclose their activities to the institution. Compulsory disclosure requirements were widespread. Furthermore, 80 percent of universities rewarded their staff individually (financially or by other means) for the IP they generated, and most universities (91 percent) believed that staff had medium or high incentives to engage in knowledge transfer. Academics' freedom to engage in private consulting activities presented a more mixed picture, since only 34 percent reported that they had a policy allowing them to do so; those that did allowed academics to spend, on average, twenty-eight days per year on private consulting.

Despite the vast improvement in KTOs' resources, competencies and strategies, a number of bottlenecks and barriers to knowledge transfer persist (Science and Technology Committee 2017). These include lack of access to finance to commercialize research, particularly early-stage funding and sustained funding for longer-term commercialization projects; difficulty in valuing IP assets and a lack of negotiating skills; the complexity of the policy support mechanisms for research and innovation; and the lack of a clear role for regional policymaking bodies in supporting knowledge transfer.

\subsection{Conclusion}

In the United Kingdom, as in many other countries, there has been a recurrent concern that university engagement with industry is not part of the institutional ecosystem for innovation in the way that such engagement is for US universities (Rosenberg and Nelson 1994). In order 
to promote knowledge transfer, the UK government, while concerned to make the academic sector accountable for the public science funding it receives, has always preferred a light-touch approach based on the creation of appropriate incentives rather than centralized management. This incentive-based approach to policy, combined with universities' extensive operational flexibility and autonomy (whereby they have extensive freedom to alter courses, compete for students and research with other universities, hire faculty and develop new revenue streams), makes the UK university system more similar to the U.S. one than to higher education systems in continental Europe. At the same time, the reliance on public funding has made it less similar to the U.S. and more similar to Europe. This halfway positioning of the UK model provides an interesting case study for those countries with predominantly publicly-funded systems that intend to adopt an incentive-based approach to policy.

The UK case study confirms that knowledge transfer as a phenomenon is characterized by strong path dependency and a symbiotic relationship with the underlying socioeconomic structure of the country and its regions. The United Kingdom's older, most research-intensive institutions have historically maintained strong relationships with industry, including with large industrial firms and the public sector, including defense. Policies directed at supporting knowledge transfer have allowed these universities to institutionalize knowledge transfer processes that were previously carried out by individual academics and research groups, and to increase the scale of their knowledge transfer engagement. Intensive engagement with industry via research contracts and patent commercialization remains typical of a small number of institutions. Other universities, particularly those that were previously vocational training colleges, also had historical relationships with industry, but these mainly revolved around training and problem-solving activities. For these universities, the institutionalization of knowledge transfer has mostly implied a scaling-up of their training and consultancy operations. Hence, universities' growing incentives to engage in knowledge transfer have led them to build on their preexisting networks, competencies and capabilities, and to develop models of engagement that are in harmony with the needs of the actors in their local social and economic context.

We can also draw some lessons from the specific kind of incentives that the UK system has generated. The main policy tool used by the UK government to foster university-industry interaction and knowledge transfer has been the provision of performance-based funding in order 
to create financial incentives for universities to engage in knowledge transfer activities and achieve measurable results that can be rewarded economically. This is different from the U.S. model, where individuals are rewarded for better performance by direct income-generating activities, often taxed very lightly. However, universities in the United Kingdom do reward their star scientists and researchers with better pay and promotion prospects, reflecting their reliance on such individuals' performance to attract research income. Moreover, since knowledge transfer activities are income-producing in themselves, in a period of prolonged decline in public funding, universities have had strong incentives to engage in knowledge transfer activities irrespective of the presence of policy schemes.

Universities' incentive to play to their strengths by engaging in those activities where they are more likely to be successful, and the government's lack of precise direction on what activities they should be engaging in, has led universities to adopt a varied range of modes of engagement, in terms both of the variety of knowledge transfer activities undertaken and of the organizational models they have adopted in order to carry them out. The variety of approaches shows a broad experimentation with a strategy that best suits the comparative advantages of the university.

At the same time, there are some risks inherent in having a system of incentives to engage in knowledge transfer that are primarily monetary in nature. First, they may encourage universities to refrain from engaging in activities that are beneficial for society while generating little or no income for the university (Rossi and Rosli 2015). Second, these incentives may encourage universities to focus predominantly on forms of research that are certain to bring economic rewards in the relatively short term, moving away from more uncertain and risky basic research. A reorientation of the system toward more commercializable research appears to have occurred in the PSRE sector, too. However, this raises the question whether the UK system is generating enough basic research on its own to keep it at the science frontier and make it possible to quickly absorb and exploit new technology - a question that is particularly pressing in the context of the present productivity stagnation in the UK economy (see, e.g., The Economist 2017). Evidence from the United Kingdom that high levels of engagement in patenting on the part of academics (in both applied and theoretical fields) reduces their scientific productivity (Crespi et al. 2011; Banal-Estanol, Jofre-Bonet, and Lawson 2015) suggests that a broader debate on the effects of strong incentives to 
engage in knowledge transfer on the amount and nature of basic research pursued in academia should be had.

Hence, policymakers should think very carefully about the consequence of performance-based funding on the performance of the overall system. Public funding of $R \& D$ rests on the argument that there is a market failure that leads to private underinvestment in basic research. Creating a system of monetary incentives for universities based on success at commercialization risks undermining this basic goal. If universities are to continue to engage in basic research, we have to accept that some universities may never do knowledge transfer - there must be slack in the system.

As in everything else, we have come full circle but the golden mean remains elusive.

\section{References}

Abreu, M., V. Grinevich, A. Hughes, M. Kitson, and P. Ternouth (2008). Universities, Business and Knowledge Exchange. London and Cambridge: Council for Industry and Higher Education and Centre for Business Research.

Andersen B., I. Brinkley, and W. Hutton (2011). Making the UK a Global Innovation Hub: How Business, Finance and an Enterprising State Can Transform the UK, Big Innovation Centre Working Paper, September 2011.

Athreye, S. (2004). "Agglomeration and growth: A study of the Cambridge hi-tech cluster." in T. Breshanan and A. Gambardella (eds.), Building High-Tech Clusters: Silicon Valley and Beyond. Cambridge: Cambridge University Press.

Banal-Estanol, A., M. Jofre-Bonet, and C. Lawson (2015). "The double-edged sword of industry collaboration: Evidence from engineering academics in the UK." Research Policy, 44, 1160-75.

Bathmaker, A. M. (2003). "The expansion of higher education: A consideration of control, funding and quality." In S. Bartlett and D. Burton (eds.), Education Studies: Essential Issues. London: Sage, 169-89.

BEIS (2017). Industrial Strategy: Building a Britain Fit for the Future. White Paper, HM Government.

Bekkers R. and L. Bodas Freitas (2008). "Analysing preferences for knowledge transfer channels between universities and industry: To what degree do sectors also matter?" Research Policy, 37, 1837-53.

Benneworth, P. and B. Jongbloed (2010). "Who matters to universities? A stakeholder perspective on humanities, arts and social science valorization." Higher Education, 59, 567-88. 
BIS (2011a) Sixth Annual Survey of Knowledge Transfer Activities in Public Sector Research Establishments and Research Councils, Department for Business Innovation and Skills, London: Stationery Office.

BIS (2011b) Digital Opportunity: A Review of Intellectual Property and Growth (Hargreaves Review). Department for Business Innovation and Skills, London: Stationery Office.

BIS (2012). A Review of Business-University Collaboration (Wilson Review). Department for Business Innovation and Skills, London: Stationery Office. BIS (2013). Growing Your Business: A Report on Growing Micro Businesses by Lord D. Young. Department for Business Innovation and Skills, London: Stationery Office.

BIS (2014). Seventh Annual Survey of Knowledge Transfer Activities in Public Sector Research Establishments and Research Councils. Department for Business Innovation and Skills, London: Stationery Office.

BIS (2015). The Dowling Review of Business-University Research Collaborations. Department for Business Innovation and Skills, London: Stationery Office. BIS (2016). UK Innovation Survey 2015. BIS July, https://assets.publishing.service. gov.uk/government/uploads/system/uploads/attachment_data/file/537016/ Innovation_Survey_Infographic_updated_for_Main_Report.pdf. Accessed 22 August 2019.

BIS Committee (2014). Local Enterprise Partnerships, Ninth Report of Session 2012-13. Business Innovation and Skills Committee, London: House of Commons.

British Academy (2008). Punching Our Weight: The Humanities and Social Sciences in Public Policy Making. London: British Academy.

British Academy (2010). Past, Present and Future: The Public Value of the Humanities and the Social Sciences. London: British Academy.

Buckland, R. (2009). "Private and public sector models for strategies in universities." British Journal of Management, 20(4), 524-36.

Campaign for Social Science (2015). The Business of People. The Significance of Social Science Over the Next Decade. Campaign for Social Science report.

Chugh, H. (2004). New Academic Venture Development: Exploring the Influence of the Technology Transfer Office on University Spinouts. Working Paper, Business School, Imperial College London.

Clarysse, B., V. Tartari, and A. Salter (2011). “The impact of entrepreneurial capacity, experience and organizational support on academic entrepreneurship." Research Policy, 40(8), 1084-93.

Coates Ulrichsen, T. (2014). Knowledge Exchange Performance and the Impact of HEIF in the English Higher Education Sector. HEFCE Report.

Cochrane, A. and R. Williams (2013). "Putting higher education in its place: The socio-political geographies of English universities." Policy and Politics, 41/1, 43-58. 
Crespi, G., P. D’Este, R. Fontana, and A. Geuna (2011). “The impact of academic patenting on university research and its transfer." Research Policy, 40, 55-68.

D'Este, P. and P. Patel (2007). "University-industry linkages in the UK: What are the factors underlying the variety of interactions with industry?" Research Policy, 36/9, 1295-313.

Day, A. and R. Fernandez (2015). Strategies for Sustaining Growth of Income from Knowledge Exchange Across Higher Education Institutions (HEIs) in the UK. London: National Centre for Universities and Business.

De LaTorre, E., F. Rossi, and M. Sagarra (2017). "Which Stakeholders Benefit from Third Mission Engagement? An Analysis of Priority Stakeholders and Third Mission Profiles of HEIs in the United Kingdom.” AEDE Conference, Murcia, 2017. DES (2003). The Future of Higher Education, Department for Education and Skills, London: Stationery Office.

DiGregorio, D. and S. Shane (2003). "Why do some universities generate more start-ups than others?" Research Policy, 32 (2), 209-27.

DIUS (2007). Streamlining University/Business Collaborative Research Negotiations, London: Stationery Office.

DIUS (2008a) Intellectual Property and Research Benefits, Department for Innovation, Universities and Skills, London: Stationery Office.

DIUS (2008b) Innovation Nation, Department for Innovation, Universities and Skills, London: Stationery Office.

DLA Piper and Mason Hayes \& Curran (2007). Monitoring and Analysis of Technology Transfer and Iprs and Their Use - Professor's Privilege. Report for the European Commission (DG research).

DTI (1998). Our Competitive Future: Building on Knowledge Driven Economy. Department for Trade and Industry, London: Stationery Office.

DTI/DFES (2005). Opportunity for All in a World of Change. Department for Trade and Industry/Department for Education and Employment, London: Stationery Office.

The Economist (2017). "Poor Productivity Leaves Britain's Public Finances Looking Shaky." October 12.

Franklin, S., M. Wright, and A. Lockett (2001). "Academic and surrogate entrepreneurs in university spinout companies." Journal of Technology Transfer, 26 (1/2), 127-41.

Geuna, A. (1999). The Economics of Knowledge Production. Cheltenham: Edward Elgar. Geuna, A., M. Piolatto, and M. Sylos-Labini (2015). "University funding and research assessment: An analysis of some British and Italian cases." In A. Geuna and F. Rossi, The University and the Economy: Pathways to Growth and Economic Development, Cheltenham: Edward Elgar.

Geuna, A. and F. Rossi (2011). "Changes to university IPR regulations in Europe and the impact on academic patenting." Research Policy, 40, 1068-76

Government Office for Science (2013). Current PSREs Affiliated with Government Departments and Research Councils. 
Grady, R. and J. Pratt (2000). "The UK technology transfer system: Calls for stronger links between higher education and industry." Journal of Technology Transfer, 25(2), 205-11.

Grimaldi, R. and N. von Tunzelmann (2002). "Assessing collaborative, precompetitive R\&D projects: The case of the UK LINK scheme.” R\&D Management, 32(2), 165-73.

HEFCE (1999). Higher Education Reach-out to Business and the Community Fund: Funding Proposals. Bristol: Higher Education Funding Council for England.

HEFCE (2010). Higher Education - Business and Community Interaction Survey 2008-09. Bristol: Higher Education Funding Council of England.

HEFCE (2015). Guide to Funding 2014-15: How HEFCE Allocates Its Funds. HEFCE, March; www.hefce.ac.uk/media/HEFCE,2014/Content/Pubs/2015/ 201504/2015_04.pdf. Accessed November 2016.

Hendry, J. (1993). Innovating for Failure. Cambridge: MIT Press.

Hewitt-Dundas, N. (2012). "Research intensity and knowledge transfer activity in UK universities." Research Policy, 41(2), 262-75.

HM Treasury (2003). Lambert Review of Business-University Collaboration.

HM Treasury (2006). Gowers Review of Intellectual Property.

Huggins, R. and F. Kitagawa (2012). "Regional policy and university knowledge transfer: Perspectives from devolved regions in the UK." Regional Studies, 46 (6), 817-32.

Hughes, A. and B. Martin (2012). Enhancing Impact: The Value of Public Sector R\&D. Cambridge: Centre for Business Research and UK IRC.

Jelfs, P. (2016). "Financial performance analysis of spin-off companies from a UK 'regional' university: A case study of the University of Birmingham." International Journal of Entrepreneurship and Small Business, 29(2), 271-86.

Jones, O. and M. Craven (2001). "Beyond the routine: innovation management and the Teaching Company Scheme.” Technovation, 21(5), 267-79.

Kitagawa, F. and C. Lightowler (2012). "Knowledge exchange: A comparison of policies, strategies, and funding incentives in English and Scottish higher education." Research Evaluation, 22(1), 1-14.

Kitagawa, F., M. Sanchez-Barrioluengo, and E. Uyarra (2016). "Third mission as institutional strategies: Between isomorphic forces and heterogeneous pathways." Science and Public Policy, doi: 10.1093/scipol/scw015.

Lawton Smith, H. and K. Ho (2006). "Measuring the performance of Oxford University, Oxford Brookes University and the government laboratories' spinoff companies." Research Policy, 35: 1554-68.

Lissoni F., P. Llerena, M. McKelvey, and B. Sanditov (2008). "Academic patenting in Europe: New evidence from the KEINS database." Research Evaluation, 17(2), 87-102.

Lockett, A. and M. Wright (2005). "Resources, capabilities, risk capital and the creation of university spinout companies." Research Policy, 34, 1043-57. 
Lockett, A., M. Wright, and A. Wild (2014). "The institutionalisation of third stream activities in UK higher education: The role of discourse and metrics." British Journal of Management, 26, 78-92.

Maxwell-Jackson, Q. (2011). Getting Better Value from Public Sector Research Establishments. London: CentreForum.

Meagher, L., C. Lyall, and S. Nutley (2008). "Flows of knowledge, expertise and influence: A method for assessing policy and practice impacts from social science research." Research Evaluation, 17, 163-73.

Mowery, D. and B. Sampat (2005). "Universities in national innovation systems." In J. Fagerberg, D. Mowery, and R. Nelson (eds.), The Oxford Handbook of Innovation. Oxford: Oxford University Press.

National Audit Office (2016). Local Enterprise Partnerships Census. London: NAO.

National Committee of Enquiry Into Higher Education (1997). Higher Education in the Learning Society. National Committee of Enquiry Into Higher Education, London: Stationery Office.

NCUB (2016a) The Changing State of Knowledge Exchange. UK Academic Interactions with External Organizations 2005-2015. National Centre for Universities and Business, February.

NCUB (2016b) Knowledge Exchange and Research Council Institutes; Interactions with External Organizations 2012-2015. National Centre for Universities and Business, October.

OECD (2003). Frascati Manual 2002: Proposed Standard Practice for Surveys on Research and Experimental Development. Paris: OECD.

Office for National Statistics (2016). UK Government Expenditure on Science, Engineering and Technology: 2014. London: ONS.

Olmos-Peñuela J., P. Benneworth, and E. Castro-Martínez (2014). “Are 'STEM from Mars and SSH from Venus'? Challenging disciplinary stereotypes of research's social value." Science and Public Policy, 41(3), 384-400.

OST (1993). Realising Our Potential: a Strategy for Science Engineering and Technology, Cm 2250. London: Office of Science and Technology.

PACEC (2012). Strengthening the Contribution of English Higher Education Institutions to the Innovation System: Knowledge Exchange and HEIF Funding, www.hefce.ac.uk/media/hefce/content/whatwedo/knowledgeexchangeands kills/heif/HEIF11\%9615-FullReport.pdf.

Pinheiro, R., P. Langav, and A. Pausits (2015). “The institutionalisation of universities' third mission: Introduction to the special issue." European Journal of Higher Education, 5(3), 227-32.

Potts, G. (2002). "Regional policy and the 'regionalization' of university-industry links: A view from the English regions.” European Planning Studies, 10(8), 987-1012.

Powers, J. B. and P. P. McDougall (2005). "Policy orientation effects on performance with licensing to start-ups and small companies." Research Policy, 34(7), $1028-42$. 
Rogers, M., C. Helmers, D. Baghurst, and T. Pollard (2009). A Literature Review on the Efficiency and Effectiveness of University Technology Transfer Offices and Hybrid Commercialization Models, Strategic Advisory Board for Intellectual Property, UK.

Rosenberg, N. and R. R. Nelson (1994). "American universities and technical advance in industry." Research Policy, 23(3), 323-48.

Rosli, A. and F. Rossi (2016). "Third Mission Policy Goals and Incentives from Performance-Based Funding: Are they Aligned?" Research Evaluation, doi: $10.1093 / \mathrm{reseval} / \mathrm{rvw0} 012$.

Rossi, F. (2017). "The drivers of efficient knowledge transfer performance: evidence from British universities." Cambridge Journal of Economics, https://doi .org/10.1093/cje/bex054.

Rossi, F. and A. Rosli (2015). "Indicators of university-industry knowledge transfer performance and their implications for universities: Evidence from the United Kingdom."Studies in Higher Education, 40(10), 1970-91.

Sánchez-Barrioluengo, M. (2014). “Articulating the 'three-missions' in Spanish universities." Research Policy, 43(10), 1760-73.

Science and Technology Committee (2017). Managing Intellectual Property and Technology Transfer. Tenth Report of Session 2016-17. London: House of Commons.

Sengupta, A. and A. S. Ray (2017) "Choice of structure, business model and portfolio: Organizational models of knowledge transfer offices in British universities." British Journal of Management, 28(4), 687-710.

Senker, P. and J. Senker (1994). "Transferring technology and expertise from universities to industry: Britain's Teaching Company Scheme." New Technology, Work and Employment, 9, 81-92.

Smith, K. (2015). Research and Innovation Organisations in the UK: Innovation Functions and Policy Issues, BIS Research Paper n. 226. Department for Business Innovation and Skills, London: Stationery Office.

Sterzi, V. (2013). "Patent quality and ownership: An analysis of UK faculty patenting." Research Policy, 42, 564-76.

Tang, P., D. Wecowska, A. Campos, and M. Hobday (2009). Managing Intellectual Property in Universities: Patents and the Protection Failure Problem, report prepared for the Gatsby Charitable Foundation.

Wright, M., B. Clarysse, A. Lockett, and M. Knockaert (2008). "Mid-range universities' linkages with industry: Knowledge types and the role of intermediaries." Research Policy, 37/8, 1205-23.

Wright, M, A. Vohora, and A. Lockett (2004). "The formation of high-tech university spinouts: The role of joint ventures and venture capital investors." Journal of Technology Transfer, 29(3/4), 287-310. 


\section{Germany}

DIRK CZARNITZKI AND GEORG LICHT

\subsection{Introduction}

The transfer of knowledge and technology is a key task of publicly financed research in Germany. This chapter analyzes the structures and processes for such transfer, based on a review of scholarly literature as well as original qualitative and quantitative research.

Germany is a federal republic, and some major governmental tasks, including science and education, are administered at the level of each state (Land; plural Länder). Germany's sixteen states thus administer their own education systems, including universities and other institutions of higher education (HE). As a result, the public science landscape in Germany is very diverse.

Universities and other HE colleges are not the only significant research organizations in Germany. In addition, the governments of the Länder and the federal government maintain a number of important public research institutes, some of which are much more focused on science and knowledge transfer than universities and other HE colleges are. The Fraunhofer Association in particular engages in highly industry-relevant research, and the Helmholtz Association, the Max Planck Association, and the Leibniz Association are also important players in public science. These institutions are supplemented by a number of public research institutes financed by the Länder.

Because the public science and education system is decentralized across the sixteen states, there is a dearth of centrally collected data about knowledge transfer. This chapter draws on several different sources but only a few official public statistics; most data were collected manually from the Internet, academic publications, and various policy reports, mostly published only in German. 
The chapter is structured as follows. In Section 5.2, we outline the German landscape of public scientific organizations. This is followed in Section 5.3 by a discussion of common channels of knowledge transfer. Section 5.4 discusses policies designed to enhance science and knowledge transfer, while Section 5.5 reviews the main findings of the scholarly literature concerning knowledge transfer in Germany. We then present our own research findings from interviews with selected university knowledge transfer offices (KTOs) and policymakers as well as results from a survey sent to all KTOs at German universities. A final section summarizes our conclusions.

\subsection{The Role of Universities and Public Research Institutes in Germany's National Innovation System}

According to the German Federal Statistical Office, ${ }^{1}$ the higher education system consisted of 427 institutions in 2014/2015, including 107 universities and 217 universities of applied sciences (Fachhochschulen). ${ }^{2}$ In addition, there were six pedagogical colleges, sixteen theological colleges, fifty-two colleges for arts and twenty-nine public administration colleges. Without question, the main knowledge transfer channel from these institutions to industry is the education of highly skilled labor. Figure 5.1 shows trends in numbers of students at different types of HE college. Between 1994 and 2015, the overall number of students increased from about 1.9 million to almost 2.8 million. While the share of colleges of arts, pedagogics, theology, and administration remained small at between 3 to 4 percent, the share of students at universities of applied sciences increased from 21 percent to 34 percent.

In addition to the HE colleges, Germany has several important research institutes: the Fraunhofer Association, the Helmholtz Association of German Research Centres, the Max Planck Association, the Leibniz Association, and several others with research missions that are financed either by the federal government or the Länder.

Figure 5.2 shows the distribution of R\&D expenditure in Germany in 2010. According to the Federal Ministry of Education and Research (BMBF), total R\&D expenditure amounted to about EUR 67 billion,

1 Source: German Federal Statistical Office, www.destatis.de/DE/ZahlenFakten/ GesellschaftStaat/BildungForschungKultur/Hochschulen/Tabellen/Hochschulen Hochschularten.html.

${ }^{2}$ Universities of applied sciences focus on applied aspects of higher education. They grant bachelor and master's degrees but are generally not entitled to grant doctorates. 


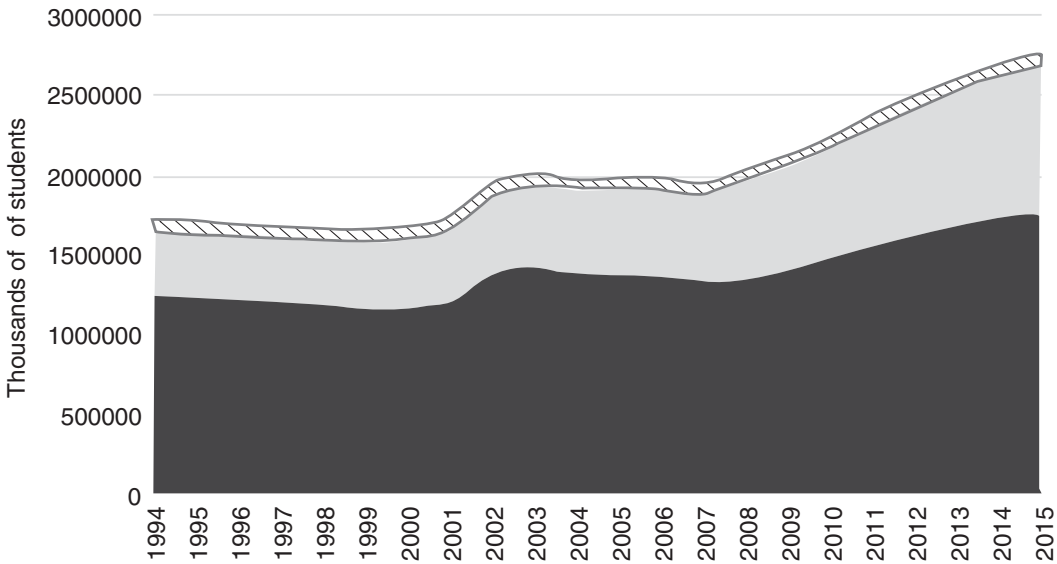

- Universities Universities of applied sciences $\triangle$ Other colleges

Figure 5.1 Number of students at different types of HE college in Germany Source: Statistisches Bundesamt (2016), Fachserie 11, Reihe 4.1.
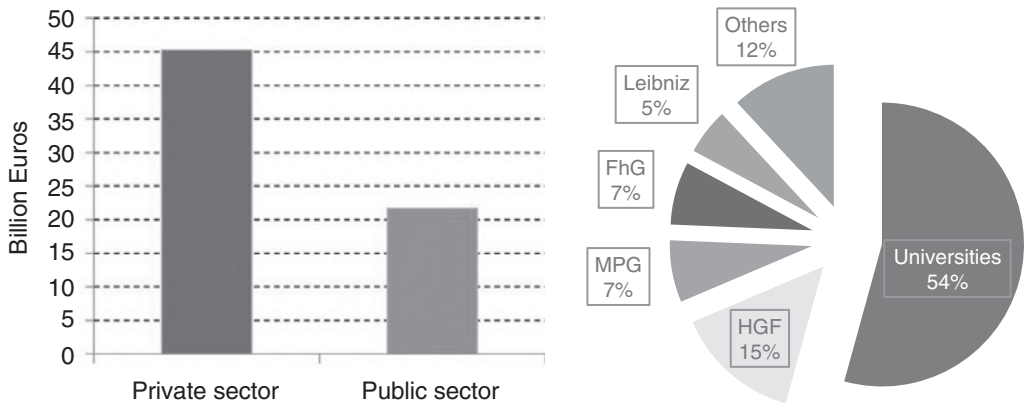

Figure 5.2 Distribution of R\&D expenditure in 2010

Source: BMBF (2012)

Note: FhG is the Fraunhofer Association, HGF is the Helmholtz Association and MPG is the Max Planck Association.

with about EUR 45 billion spent by the private sector, and EUR 22 billion by the public sector. Universities and other HE colleges spent about 54 percent of that EUR 22 billion. The rest was distributed among public research institutes, with the largest share of 15 percent being spent by the Helmholtz Association, followed by the Max Planck and Fraunhofer 
Associations with about 7 percent each, and the Leibniz Association with 5 percent. The other public research institutes spent about 12 percent of the total public research budget.

The Fraunhofer Association's research activities are conducted by sixty-nine institutes and research units at locations throughout Germany. It employs around 24,500 people, who work with an annual research budget totaling EUR 2.1 billion. Of this, EUR 1.9 billion is generated through contract research. More than 70 percent of its contract research revenue is derived from contracts with industry and from publicly financed research projects (Fraunhofer Association 2015).

The Helmholtz Association of German Research Centres was created in 1995 to formalize existing relationships between several independent research centers that are mainly engaged in "Big Science." It employed 38,237 people in 2015, and distributes core funding from the BMBF to its eighteen autonomous research centers. The 2015 budget amounted to EUR 4.45 billion, with roughly two-thirds coming from public sponsors (split 9:1 between federal and state authorities). The individual Helmholtz Centres attract more than 30 percent of funding themselves through contracts with public and private sector sponsors (Helmholtz Association 2016).

The Max Planck Association consists of eighty-three institutes (including five abroad) and mainly engages in basic research. As at January 2016, it had a total of 22,197 staff. The federal and state governments each provide half the institutional funding for its budget, which totaled around EUR 1.8 billion in 2016 (Max Planck Society for the Advancement of Science 2016).

The Leibniz Association is a conglomerate of research institutes that are members of the so-called Blue List - institutes that were originally founded by the Länder, but which are now regarded as being of federal importance and therefore cofinanced by the federal government. In 2015, Leibniz comprised eighty-nine institutes employing 18,476 people with a total budget of EUR 1.73 billion, of which around 21 percent came from third-party funding. ${ }^{3}$

Table 5.1 summarizes some key features of the major public research institutes.

\subsubsection{Knowledge Transfer Prior to the 2000s}

The knowledge and technology transfer (KTT) activities of German universities/HE colleges and public research institutes differ, reflecting

${ }^{3}$ Source www.leibniz-gemeinschaft.de/ueber-uns/organisation/leibniz-in-zahlen.html. 
Table 5.1 Selected key features of German public research institutes

\begin{tabular}{lllll}
\hline \hline & Fraunhofer & Helmholtz & Max Planck & Leibniz \\
\hline Orientation & Applied & Big Science & Basic & Diverse \\
Institutes & 69 & 18 & 83 & 89 \\
Staff & 24,500 & 38,237 & 22,197 & 18,476 \\
Budget & EUR & EUR & EUR & EUR \\
& 2.1 billion & 4.45 billion & 1.8 billion & 1.73 billion \\
& (EUR & $(2 / 3$ from & $(50: 50$ & (21 percent \\
& 1.9 billion & public & federal- & third-party \\
& from & sponsors; & state split $)$ & funding) \\
& contract & $9: 1$ federal- & & \\
& research $)$ & state split $)$ & & \\
\hline \hline
\end{tabular}

Sources: Various annual reports of the institutions

their differing missions. Based on a survey of professors at universities and Fachhochschulen plus heads of departments at public research institutes, Czarnitzki et al. (2000) assessed the extent to which different institutions met preconditions for KTT and how much KTT they actually carried out. This analysis was further developed by Edler and Schmoch (2001), and is shown in Figure 5.3.

Information on the preconditions for KTT was derived from institutions' mission statements supplemented by their size in terms of budgets and staff as well as their thematic orientations. These preconditions were then compared to the actual extent of KTT activities, as derived from the survey responses of almost 1,000 professors and heads of department. The extent of KTT takes into account the industry affinity of each institution's research, its interaction with industry, staff mobility between the institution and industry, and research funding obtained from industry.

Institutions are localized on the "KTT activity map" roughly according to their missions. The Fraunhofer Association had the highest predisposition for KTT to industry and also achieved the highest extent of KTT. It was followed by technical universities as a distinct subgroup of universities that are well suited to KTT because they generally focus on subjects that are highly relevant to industry. The Helmholtz Association seemed to meet many preconditions for KTT but was less active in practice than the technical universities. There were then significant variations among 


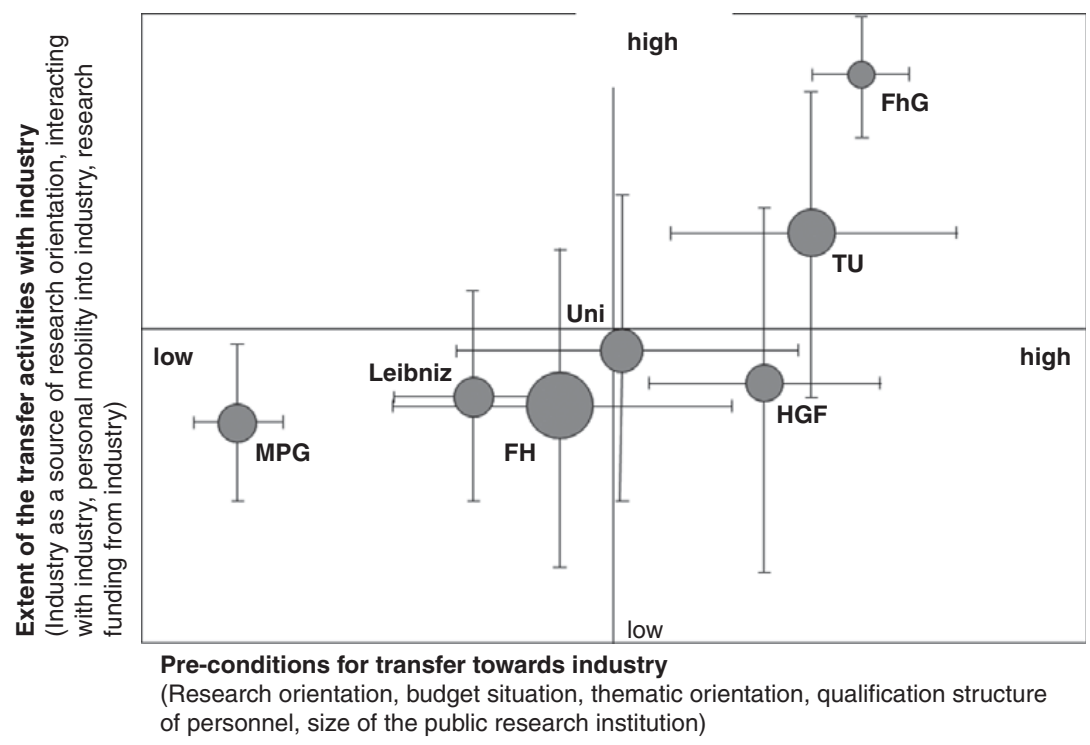

Figure 5.3 KTT missions and activities of different institutions in German public science

Note: Adapted from Rammer and Czarnitzki (2000) and Edler and Schmoch (2001). The size of the bubbles shows the extent of factors impeding KTT according to survey responses. FH is Fachhochschulen (universities of applied science), FhG is the Fraunhofer Association, HGF is the Helmholtz Association, MPG is the Max Planck Association, TU is the technical universities and Uni is other universities.

other universities and universities of applied sciences in terms of preconditions for KTT. Some faced significant barriers, such as understaffed KTOs and misaligned incentives. Of all the institutions, the Max Planck Association was least active in KTT, reflecting its basic research mission within the public science system.

\subsubsection{Knowledge Transfer at a Glance}

\section{Knowledge Transfer from Universities}

As the universities and Fachhochschulen are administered by the Länder, no comprehensive metrics on KTT exist centrally and we are obliged to use secondary data sources. The Munich Innovation Group (2013) published a study comparing patent applications by German universities with those by Chinese institutions, and analyzed the PATSTAT database 
of the European Patent Office, which contains data from many different national patent offices. ${ }^{4}$ The fifteen German universities with the highest patent activity between 1990 and 2009 are shown in Table 5.2. To compare this ranking with research activity, the table also includes the

Table 5.2 Top-ranking universities for patent applications, 1990-2009, and research

\begin{tabular}{|c|c|c|c|c|}
\hline University & $\begin{array}{l}\text { Rank: patent } \\
\text { applications }^{a}\end{array}$ & $\begin{array}{l}\text { Number of } \\
\text { patent } \\
\text { applications }^{a}\end{array}$ & $\begin{array}{l}\text { Rank: } \\
\text { citations per } \\
\text { faculty }^{b}\end{array}$ & $\begin{array}{l}\text { Rank: } \\
\text { academic }^{\text {reputation }^{c}}\end{array}$ \\
\hline $\begin{array}{l}\text { KIT, Karlsruhe } \\
\text { Institute of } \\
\text { Technology }^{d}\end{array}$ & 1 & 3,780 & 5 & 12 \\
\hline $\begin{array}{l}\text { Technische } \\
\text { Universität } \\
\text { Dresden }\end{array}$ & 2 & 1,495 & 3 & 16 \\
\hline $\begin{array}{l}\text { Albert-Ludwigs- } \\
\text { Universität } \\
\text { Freiburg }\end{array}$ & 3 & 1,103 & 6 & 7 \\
\hline $\begin{array}{l}\text { Freie Universität } \\
\text { Berlin }\end{array}$ & 4 & 1,038 & 9 & 4 \\
\hline $\begin{array}{l}\text { Eberhard Karls } \\
\text { Universität } \\
\text { Tübingen }\end{array}$ & 5 & 1,027 & 36 & 13 \\
\hline $\begin{array}{l}\text { Humboldt- } \\
\text { Universität zu } \\
\text { Berlin }\end{array}$ & 6 & 839 & 18 & 2 \\
\hline $\begin{array}{l}\text { Universität } \\
\text { Stuttgart }\end{array}$ & 7 & 770 & 19 & 18 \\
\hline Universität Jena & 8 & 769 & 33 & 28 \\
\hline $\begin{array}{l}\text { Friedrich- } \\
\text { Alexander- } \\
\text { Universität } \\
\text { Erlangen- } \\
\text { Nürnberg }\end{array}$ & 9 & 708 & 1 & 22 \\
\hline
\end{tabular}

${ }^{4}$ For more discussion of the strengths and weaknesses of PATSTAT as a data source, see Chapter 3 in this volume. 
Table 5.2 (cont.)

\begin{tabular}{|c|c|c|c|c|}
\hline University & $\begin{array}{l}\text { Rank: patent } \\
\text { applications }^{a}\end{array}$ & $\begin{array}{l}\text { Number of } \\
\text { patent } \\
\text { applications }^{a}\end{array}$ & $\begin{array}{l}\text { Rank: } \\
\text { citations per } \\
\text { faculty }^{b}\end{array}$ & $\begin{array}{l}\text { Rank: } \\
\text { academic } \\
\text { reputation }^{c}\end{array}$ \\
\hline $\begin{array}{l}\text { Technical } \\
\text { University of } \\
\text { Munich }\end{array}$ & 10 & 635 & 24 & 5 \\
\hline $\begin{array}{l}\text { Ruprecht-Karls- } \\
\text { Universität } \\
\text { Heidelberg }\end{array}$ & 11 & 598 & 16 & 3 \\
\hline $\begin{array}{l}\text { Ludwig- } \\
\text { Maximilians- } \\
\text { Universität } \\
\text { München }\end{array}$ & 12 & 536 & 10 & 1 \\
\hline $\begin{array}{l}\text { RWTH Aachen } \\
\text { University }\end{array}$ & 13 & 515 & 13 & 6 \\
\hline $\begin{array}{l}\text { Georg-August- } \\
\text { University } \\
\text { Goettingen }\end{array}$ & 14 & 389 & 27 & 8 \\
\hline $\begin{array}{l}\text { Technische } \\
\text { Universität } \\
\text { Berlin (TU } \\
\text { Berlin) }\end{array}$ & 15 & 381 & 22 & 9 \\
\hline $\begin{array}{l}\text { Leibniz } \\
\text { Universität } \\
\text { Hannover }\end{array}$ & $\mathrm{n} / \mathrm{a}$ & $\mathrm{n} / \mathrm{a}$ & 2 & 29 \\
\hline $\begin{array}{l}\text { Technische } \\
\text { Universität } \\
\text { Darmstadt }\end{array}$ & $\mathrm{n} / \mathrm{a}$ & $\mathrm{n} / \mathrm{a}$ & 4 & 23 \\
\hline $\begin{array}{l}\text { Julius- } \\
\text { Maximilians- } \\
\text { Universität } \\
\text { Würzburg }\end{array}$ & $\mathrm{n} / \mathrm{a}$ & $\mathrm{n} / \mathrm{a}$ & 7 & 24 \\
\hline University Ulm & $\mathrm{n} / \mathrm{a}$ & $\mathrm{n} / \mathrm{a}$ & 8 & 27 \\
\hline $\begin{array}{l}\text { Universität } \\
\text { Rostock }\end{array}$ & $\mathrm{n} / \mathrm{a}$ & $\mathrm{n} / \mathrm{a}$ & 11 & 43 \\
\hline
\end{tabular}


Table 5.2 (cont.)

\begin{tabular}{|c|c|c|c|c|}
\hline University & $\begin{array}{l}\text { Rank: patent } \\
\text { applications }^{a}\end{array}$ & $\begin{array}{l}\text { Number of } \\
\text { patent } \\
\text { applications }^{a}\end{array}$ & $\begin{array}{l}\text { Rank: } \\
\text { citations per } \\
\text { faculty }^{b}\end{array}$ & $\begin{array}{l}\text { Rank: } \\
\text { academic }^{\text {reputation }}\end{array}$ \\
\hline $\begin{array}{l}\text { WHU - Otto } \\
\text { Beisheim } \\
\text { School of } \\
\text { Management }\end{array}$ & $\mathrm{n} / \mathrm{a}$ & $\mathrm{n} / \mathrm{a}$ & 12 & 45 \\
\hline $\begin{array}{l}\text { Ruhr-Universität } \\
\text { Bochum }\end{array}$ & $\mathrm{n} / \mathrm{a}$ & $\mathrm{n} / \mathrm{a}$ & 14 & 25 \\
\hline $\begin{array}{l}\text { Justus-Liebig- } \\
\text { University } \\
\text { Giessen }\end{array}$ & $\mathrm{n} / \mathrm{a}$ & $\mathrm{n} / \mathrm{a}$ & 15 & 42 \\
\hline $\begin{array}{l}\text { Rheinische } \\
\text { Friedrich- } \\
\text { Wilhelms- } \\
\text { Universität } \\
\text { Bonn }\end{array}$ & $\mathrm{n} / \mathrm{a}$ & $\mathrm{n} / \mathrm{a}$ & 28 & 11 \\
\hline $\begin{array}{l}\text { Universität } \\
\text { Hamburg }\end{array}$ & $\mathrm{n} / \mathrm{a}$ & $\mathrm{n} / \mathrm{a}$ & 35 & 10 \\
\hline $\begin{array}{l}\text { Universität } \\
\text { Frankfurt am } \\
\text { Main }\end{array}$ & $\mathrm{n} / \mathrm{a}$ & $\mathrm{n} / \mathrm{a}$ & 37 & 14 \\
\hline $\begin{array}{c}\text { University of } \\
\text { Cologne }\end{array}$ & $\mathrm{n} / \mathrm{a}$ & $\mathrm{n} / \mathrm{a}$ & 38 & 15 \\
\hline
\end{tabular}

Notes:

a. Source: Munich Innovation Group (2013).

b. Source: QS World University Ranking 2016/2017; www.topuniversities.com/ university-rankings/world-university-rankings/2016. Ranks are within Germany and are based on a citation-to-paper ratio per faculty member in order to remove size effects. The publication and citation analysis is based on the Scopus database.

c. Source: QS World University Ranking 2016/2017; www.topuniversities.com/ university-rankings/world-university-rankings/2016. Ranks are within Germany and are based on a survey of scientists.

d. The Karlsruhe Institute of Technology is a merger between the former University of Karlsruhe and the Forschungszentrum Karlsruhe, an institute of the Helmholtz Association. 
fifteen top-scoring universities in terms of research publication citations based on the Scopus database as well as the highest ranking in terms of academic reputation according to the QS World Ranking of Universities. As can be seen, top patenting correlates with top research, but not as strongly as one might expect.

Unfortunately, patent applications are almost the only indicator of KTT from universities and Fachhochschulen that can be traced systematically with moderate effort. Other indicators such as licensing, spinoff activity, joint research projects with industry, and other more informal contacts are not collected on any systematic basis. Such data could only be gleaned from the annual reports of individual institutions (and even then comprehensive data are not available) or collected through surveys.

\section{Knowledge Transfer by Public Research Institutes}

A decade after the analysis by Rammer and Czarnitzki (2000) and Edler and Schmoch (2001), a survey of public research institutes conducted in 2009 by the Centre for European Economic Research (ZEW) offered an updated perspective. The heads of different public research institutes were asked whether various tasks featured in their institute's main mission. Public research institutes are often associations of many different institutes, and so there was scope for considerable variation among replies from heads within a single umbrella public research institute. Interestingly, the heads' subjective assessment in this survey generally chimes with the earlier findings reported in Figure 5.3.

Table 5.3 shows some key results of the 2009 survey. The most emphatic replies came from the Max Planck Association and the Fraunhofer Association. As expected, Max Planck views itself as provider of basic research insights: 100 percent of its heads view basic research as one of their main tasks. This is followed by providing $\mathrm{PhD}$ and other education (22 percent), which can be seen as an indirect channel of knowledge transfer (not necessarily to industry), and the provision of scientific information to the public (19 percent). Note the striking gap between basic research (100 percent) and the next most important task, $\mathrm{PhD}$ education (22 percent) - the most pronounced unimodal orientation among all public research institutes. Active knowledge transfer is not seen as one of the institute's main tasks.

This stands in stark contrast to the Fraunhofer Association, which has traditionally focused more on applied research. Here 91 percent of heads see applied research as a main task of their institute, followed by 
Table 5.3 Public research institute heads' assessment of their institutes' key tasks (\%)

\begin{tabular}{|c|c|c|c|c|c|c|}
\hline & Total & Max Planck & Fraunhofer & Helmholtz & Leibniz & PRO (Federal) \\
\hline Basic research & 44 & 100 & 9 & 46 & 62 & 7 \\
\hline Applied research & 57 & 3 & 91 & 57 & 48 & 74 \\
\hline Technical development & 18 & 3 & 46 & 26 & 6 & 7 \\
\hline $\begin{array}{l}\text { Testing, standardisation, and } \\
\text { certification }\end{array}$ & 11 & 0 & 17 & 6 & 6 & 26 \\
\hline $\begin{array}{l}\text { Information and } \\
\text { documentation }\end{array}$ & 11 & 3 & 3 & 3 & 23 & 22 \\
\hline $\begin{array}{l}\text { PhD education, Further } \\
\text { education }\end{array}$ & 16 & 22 & 3 & 34 & 19 & 7 \\
\hline $\begin{array}{l}\text { Providing scientific } \\
\quad \text { infrastructure }\end{array}$ & 15 & 6 & 11 & 37 & 13 & 15 \\
\hline Tech transfer to private sector & 26 & 3 & 57 & 31 & 12 & 7 \\
\hline Scientific information of public & 15 & 19 & 0 & 14 & 23 & 15 \\
\hline $\begin{array}{l}\text { Counseling services public } \\
\text { administration }\end{array}$ & 20 & 3 & 9 & 17 & 19 & 78 \\
\hline Fulfillment of regulatory tasks & 13 & 3 & 3 & 9 & 10 & 56 \\
\hline
\end{tabular}

Source: ZEW - Leibniz Centre for European Economic Research 2009 PRI Survey

Notes: Figures show the percentage of heads at each public research institute judging a specific task as a goal of their institute. 
knowledge transfer to industry (57 percent) and technical development (46 percent).

The Fraunhofer and Max Planck Associations take extreme positions in terms of basic versus applied research and development and active knowledge transfer. Other public research institutes have more balanced missions. For instance, the heads of the Helmholtz institutes regard basic and applied research as almost equally important (57 percent versus 46 percent). Helmholtz represents Big Science in Germany, and its heads see the provision of scientific infrastructure (which can also be accessed by non-Helmholtz researchers) as their third most important task. Direct knowledge transfer to industry is ranked fifth after providing $\mathrm{PhD}$ education. In sum, although Helmholtz still places more importance on basic and applied research, knowledge and technology transfer is on the agenda of its constituent institutes.

Like Helmholtz, the Leibniz Association is a hybrid between basic and applied research that does not see knowledge transfer as its main goal. Information, documentation, and the dissemination of scientific information to the public feature among its perceived missions.

The 2009 survey also provides interesting information about other public research institutes. These institutes have a strong focus on applied research (mentioned by 74 percent of their heads) and on monitoring and advising public administration (78 percent). A good example is the Robert Koch Institute, Germany's central institution for disease prevention and control, which operates under the Federal Ministry of Health and conducts research into vaccination and related fields. It has about 1,110 employees, including 450 scientists.

Another example is the German Meteorological Office (Deutscher Wetterdienst, DWD), which is attached to the Federal Ministry of Transport and Digital Infrastructure and whose principal tasks include warning against weather-related dangers and monitoring and rating the impact of climate change in Germany. The DWD runs atmospheric models on its supercomputer for precise weather forecasting as well as managing the national climate archive and one of the world's largest specialized libraries on weather and climate issues. While it does undertake climate research, its main tasks relate to information and documentation.

For more information about knowledge transfer from public research institutes to industry specifically, annual reports are a useful source. The main transfer channel is undoubtedly direct research collaboration with industry, but data on this are not readily available. Instead, Table 5.4 reports key figures on KTT based on annual reports. 
Table 5.4 KTT by leading German public research institutes at a glance

\begin{tabular}{|c|c|c|c|c|}
\hline & Patenting & Licensing & Spinoffs & Other \\
\hline Fraunhofer & $\begin{array}{l}563 \text { applications in } 2014 \\
506 \text { in } 2013\end{array}$ & Not available & Not available & $\begin{array}{l}\text { EUR } 641 \text { million } \\
\text { revenue from projects } \\
\text { with industry in } 2015\end{array}$ \\
\hline $\begin{array}{l}\text { Max } \\
\text { Planck }\end{array}$ & $\begin{array}{l}131 \text { applications in } 2014 \text {, } \\
127 \text { in } 2013\end{array}$ & $\begin{array}{l}80 \text { exploitation } \\
\text { agreements in } 2014 \\
\text { generating revenues } \\
\text { of EUR } 23.5 \text { million; } \\
93 \text { agreements in } 2013 \\
\text { and revenues of EUR } \\
22.5 \text { million }\end{array}$ & $\begin{array}{l}117 \text { spinoffs since } 1990, \\
83 \text { of them actively } \\
\text { managed by Max- } \\
\text { Planck Innovation; } \\
\text { c. } 3,000 \text { jobs created as } \\
\text { of } 2014\end{array}$ & $\begin{array}{l}\text { c.2,000 collaborative } \\
\text { projects with industry } \\
\text { per year generating } \\
\text { annual revenues of c. } \\
\text { EUR } 158 \text { million in } \\
2014\end{array}$ \\
\hline Helmholtz & c. 400 per year & $\begin{array}{l}\text { Revenues of EUR } \\
20 \text { million in } 2012 \text { and } \\
2013 \text {, and EUR } \\
11.7 \text { million in } 2015\end{array}$ & $\begin{array}{l}118 \text { spinoffs between } \\
2005 \text { and } 2014,21 \text { in } \\
2015\end{array}$ & $\begin{array}{l}\text { c.EUR } 150 \text { million } \\
\text { per year revenue from } \\
\text { industry partnerships }\end{array}$ \\
\hline Leibniz & $\begin{array}{l}\text { 2,605 between } 1990 \text { and } \\
2009\end{array}$ & $\mathrm{n} / \mathrm{a}$ & $\mathrm{n} / \mathrm{a}$ & $\begin{array}{l}\text { Third-party funding of } \\
\text { c.EUR } 363 \text { million in } \\
2014 \text { ( } 22.1 \text { percent of } \\
\text { all funding) }\end{array}$ \\
\hline
\end{tabular}

Sources: All data derived from annual reports of the public research institutes except for patent data for the Leibniz Association, which comes from Munich Innovation Group (2013) 
As expected, the Fraunhofer Association is very active in patenting due to the applied nature of its research, and secured EUR 641 million revenue from projects with industry in 2015. The Helmholtz Association is also very active in patenting - perhaps more than one might expect given its focus on Big Science - but earns much less than Fraunhofer from industry partnerships. The various Max Planck institutes patented only 131 inventions between them in 2014, in line with their basic research focus.

According to the Munich Innovation Group (2013), the Leibniz Association patented 2,605 inventions between 1990 and 2009, giving a similar annual total to that of Max Planck. Third-party funding amounted to about EUR 363 million, but it is unclear how much of this came from industry.

For Max Planck and Helmholtz, licensing income and spinoff numbers are also available, but these are difficult to compare across institutions. Max Planck reports that it has created 117 spinoff companies since 1990 , which in turn created about 3,000 jobs as of 2014, but it is unclear whether those jobs still existed in 2014, or whether the figure refers to employment in terms of "person-years" since 1990. Helmholtz outperformed Max Planck by creating 118 spinoffs between 2005 and 2014, but reported only EUR 20 million of research revenues compared with Max Planck's EUR 23.5 million. Furthermore, Helmholtz's revenues trended downward during the period of the study.

In summary, German universities and Fachhochschulen are not the only relevant institutions for knowledge and technology transfer from science to industry; public research institutes without teaching obligations play a crucial role in the public science landscape. Knowledge transfer seems to be actively supported by most universities and public research institutes.

\subsubsection{Leading Users of Commercially Valuable Knowledge}

In the Mannheim Innovation Panel (MIP), which constitutes the German part of the pan-European Community Innovation Surveys (CIS), firms are regularly asked about their innovation activities. The survey takes a representative sample of German manufacturers and selected services and its results can thus be extrapolated to all German firms in these sectors.

Among many other questions, firms are asked to report on their partners in innovation projects. As well as lead customers, suppliers, firms from the same industry and consultants, they also indicate whether 
they collaborate with universities, including universities of applied sciences, and public research institutes.

As can be seen in Table 5.5, of firms in the R\&D service sector, 66 percent collaborate with universities and 40 percent with other public research organizations. This is followed by the pharmaceutical sector, where 54 percent of firms report collaboration with universities and 30 percent with public research institutes. Other sectors that collaborate extensively with public science include ICT equipment, vehicles, machinery, chemicals, metal, and the ICT industry.

Interestingly, universities are generally reported more frequently than public research institutes. In part, this may simply be because they outnumber public research institutes, but it also shows that universities are frequently involved in knowledge transfer activities through joint research. These activities may well exceed the patenting of university inventions by the university KTOs themselves in terms of both frequency and importance.

For public research institutes, there is also survey data on the users of their research results. In the $2009 \mathrm{ZEW}$ public research institutes and universities survey, heads of institutes were asked to report on their most important user groups. Interestingly, their most important user group was universities, mentioned by 52 percent of respondents, followed by other public research institutes on 37 percent. Small and medium-sized firms and large firms were each mentioned by around one-third of respondents (see Table 5.6).

Once again, the biggest differences between public research institutes occur between Max Planck and Fraunhofer. While Max Planck heads almost exclusively report other scientific institutions as their main user group (universities and public research institutes with 84 percent and 40 percent, respectively), the Fraunhofer institutes focus unambiguously on industry, with large firms mentioned by 83 percent of heads and SMEs by 91 percent.

For the other institutions, the picture is again more mixed but public science as user dominates, except for other federal public research institutes that do not belong to one of the four major associations, where public administration is evidently the most important "client."

\subsubsection{Changes in the German Knowledge Transfer System}

In the period 1998-9, the BMBF commissioned a study of knowledge and technology transfer in Germany, the results of which were published (Schmoch et al. 2000). In response to the study, the BMBF launched 
Table 5.5 Leading collaboration partners by sector, 2008-10

\begin{tabular}{|c|c|c|c|c|}
\hline & \multicolumn{4}{|c|}{ Collaborations with: } \\
\hline & \multicolumn{2}{|c|}{ Universities and Fachhochschulen } & \multicolumn{2}{|c|}{ Other public research organizations } \\
\hline & Rank & $\begin{array}{l}\text { Share of innovators } \\
\text { (in percent) }\end{array}$ & Rank & $\begin{array}{l}\text { Share of innovators } \\
\text { (in percent) }\end{array}$ \\
\hline R\&D services & 1 & 66 & 1 & 40 \\
\hline Pharmaceuticals & 2 & 54 & 2 & 30 \\
\hline ICT equipment & 3 & 47 & 3 & 29 \\
\hline Vehicles & 4 & 43 & 4 & 26 \\
\hline Machinery & 5 & 38 & 6 & 19 \\
\hline Chemicals & 6 & 33 & 5 & 25 \\
\hline Metal & 7 & 32 & 7 & 15 \\
\hline ICT services & 8 & 32 & 8 & 14 \\
\hline
\end{tabular}

Source: Authors' calculations based on the Mannheim Innovation Panel (2011)

* Share of innovating firms reporting collaboration within the context of innovation projects. 
Table 5.6 Main users of public research institute research, as identified by public research institute heads

\begin{tabular}{lccccccc}
\hline \hline & Total & Max Planck & Fraunhofer & Helmholtz & Leibniz & PROs (Fed.) & Others \\
\hline Universities & 52 & 84 & 11 & 54 & 77 & 33 & 40 \\
PRIs & 37 & 40 & 3 & 34 & 64 & 33 & 33 \\
Public administration & 27 & 0 & 9 & 23 & 31 & 96 & 19 \\
Large firms & 30 & 0 & 83 & 37 & 15 & 11 & 31 \\
SMEs & 33 & 0 & 91 & 17 & 19 & 7 & 7 \\
Industry associations & 7 & 0 & 14 & 3 & 4 & 15 & 10 \\
Broader public & 12 & 3 & 0 & 9 & & 22 & 19 \\
\hline \hline
\end{tabular}

Source: ZEW 2009 public research institute and universities survey

Notes: Figures show the percentage of respondent public research institute heads who reported a specific user group as using their institution's research. 
a campaign called "Knowledge Creates Markets" in 2001 with four major objectives: (i) a valorization campaign to increase patenting by public research organizations; (ii) a spinoff campaign to encourage them to found companies; (iii) a collaboration campaign to foster bilateral research agreements between public research organizations and companies; and (iv) a competence campaign to increase awareness of the potential usefulness of public science among companies. In total, the four campaigns included twenty-six sub-schemes.

Major subsequent changes with respect to KTT in Germany included the abolition of professor's privilege and the establishment of regional "patent valorization agencies" (PVAs) intended to support university KTOs and researchers in commercializing their discoveries.

\section{The Abolition of Professor's Privilege}

The abolition of professor's privilege was a major change both legally and culturally. Under Clause 42 of the German employee invention law, university researchers owned inventions made in the course of their work. This was a unique legal privilege - ownership of all other inventions created in the course of employment are vested in the employerand reflected Article 5 of the German constitution, which protects the freedom of science and research.

Under the new law, introduced in 2000, German university researchers are now required to scrutinize their research findings and report any inventions to the university - unless they decide to keep their inventions secret by not publishing or patenting. The university has four months to consider patenting any inventions so submitted. If it does not claim the invention, rights to patent and commercialize it revert to the researcher. If it does claim it, the inventor is entitled to at least 30 percent of revenues from successful commercialization, but nothing otherwise. Furthermore, the university handles the patenting process and pays all related expenses such as processing fees, translation costs, and legal expenses. University researchers retain the right to disclose the invention through publication two months after submitting it to the university. Prior contractual agreements with third parties also remained valid during a prescribed transition period. ${ }^{5}$

A handful of studies have examined the effects of abolishing professor's privilege on patenting rates and ownership patterns in Germany. Schmoch (2007) found that the number of university-owned patents

${ }^{5}$ Contracts made before July 18, 2001 were treated under the old law until February 2003 (Gesetz über Arbeitnehmererfindungen, $₫ 43$ ArbnErfG). 
increased. Based on inventor lists, his data also suggest that the new law changed the propensity to invent among academics, discouraging those who had previously filed their own patents while encouraging nonpatenters. In a follow-up study, Cuntz et al. (2012) showed that the share of university-owned inventions increased after 2002 while the share of individually or industry-owned university inventions decreased. Von Proff et al. (2012) found that the policy change did not increase university-invented patents, but that ownership merely shifted from individual- and firm-owned patents to universities.

Czarnitzki et al. (2015c) analyzed the effects of the change in law through a more rigorous micro-econometric study using the differencein-difference methodology, comparing university-based patenting to the patenting activity of a control group of inventors before and after the change.

In essence, Czarnitzki et al. (2015c) argue that university patenting cannot be compared to general patenting activity in Germany, which is dominated by inventors employed in firms. As the reward systems in firms and public science are very different, they instead aim to compare patenting by university researchers with patenting by researchers employed by public research institutes.

Choosing a good control group of inventors is clearly crucial to evaluate the impact of policy changes. Figure 5.4 shows patenting activity in Germany, with the dotted line at the top showing the overall trend.

The underlying data are applications filed with the German Patent and Trademark Office (DPMA) and the European Patent Office (EPO) between 1978 and 2008 involving at least one German inventor. Data were collected from PATSTAT. Treating 1995 as the baseline (100 percent), patenting grew until the year 2000 and reached about 145 percent, then fell to about 140 percent in 2002, and then grew again to reach 160 percent in 2008 . However, academic patenting developed very differently. Patent filings based on university and public research institute inventions both grew from 100 percent in 1995 to roughly 110 percent in 1998 , but then both fell, to 70 percent and 80 percent respectively, in 2002 when the law changed. This pattern was found by prior researchers (Schmoch 2007; Cuntz et al. 2012; Von Proff et al. 2012). Analysts have speculated about the reasons for the decrease: suggestions include an increasing emphasis on publication in academic performance evaluations, decreased entry into academic jobs, the end of the New Economy boom and legal uncertainty surrounding patenting in the field of biotechnology (Schmoch 2007: 5-8; Cuntz et al. 2012: 21-2). 


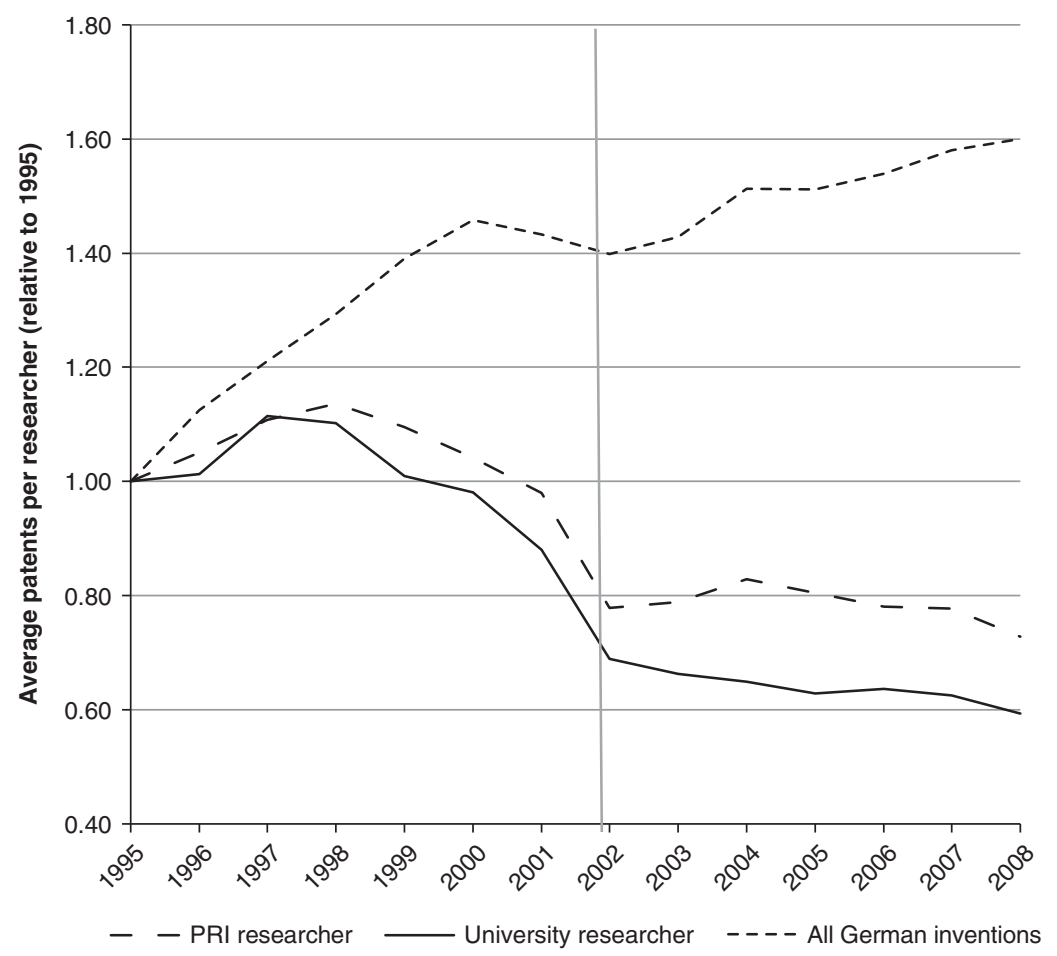

Figure 5.4 Patenting in Germany before and after the abolition of professor's privilege Source: Czarnitzki et al. (2015c)

Patenting by public research institutes did at first recover slightly after the change in law, but university patenting continued to decline.

For more rigorous analysis, Czarnitzki et al. (2015c) collected a panel of patent and publication data at the level of individual inventors at universities and public research institutes. The panel methodology allows one to control for individuals' ability to commercialize research, annual macroeconomic shocks, and each researcher's career age and publication record. Publications may serve as a control variable, reflecting potentially patentable new knowledge.

Figure 5.5 shows trends for the study group (university researchers) and the control group (public research institute researchers) as "within" demeaned average time series, that is, average patenting activity for each person over the whole panel time period is subtracted from their actual 


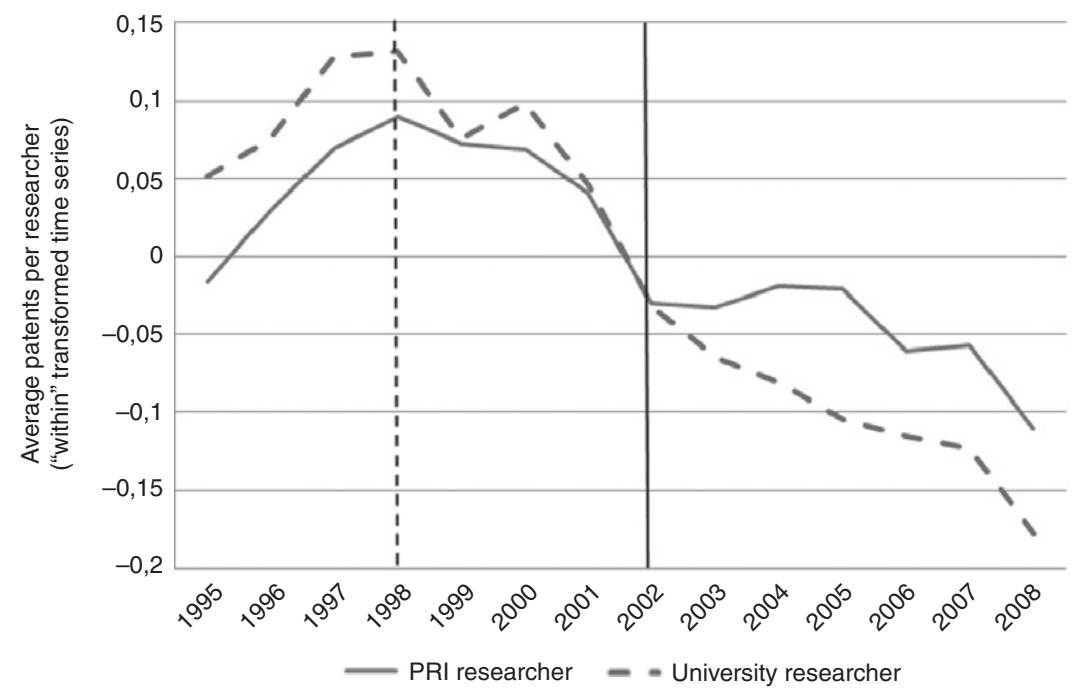

Figure 5.5 Trends in German patenting for university and public research institute researchers ("within" transformed), 1995-2008

Source: Czarnitzki et al. (2015c)

Note: The lines show "within" demeaned, averaged values for university and public research institute researchers. The 2002 vertical solid line marks the date of the actual policy change. The 1998 dashed vertical line shows the date on which the first public discussion took place, according to Internet searches.

observed patenting. This wipes out differences in levels of the time series which might be due to individuals' specific ability to patent. Here, we are more interested in changes over time rather than different levels of patenting activity among individuals. The figure shows that patenting by researchers at universities and public research institutes followed a similar trend before the law changed and diverged slightly between 1998 and 2001, when abolition of professor's privilege was under discussion, but that they diverged strongly after abolition. While public research institute patenting first stabilized in 2005, university patenting dropped steadily until 2008.

Having run micro-econometric fixed-effect panel regressions that also control for researchers' career ages and publication records, Czarnitzki et al. (2015c) conclude that the law change caused patenting by university researchers to fall by about 17 percent. Thus, the policy failed in its goal of 
Table 5.7 University researchers' patent activity by applicant type, 1995-2008

\begin{tabular}{|c|c|c|c|c|}
\hline \multirow[b]{2}{*}{$\begin{array}{l}\text { Applicant } \\
\text { type }\end{array}$} & \multicolumn{2}{|c|}{ Before 2002} & \multicolumn{2}{|c|}{ After 2002} \\
\hline & $\begin{array}{l}\text { Average } \\
\text { patents per } \\
\text { inventor } \\
\text { per year }\end{array}$ & $\begin{array}{l}\text { Relative fre- } \\
\text { quency } \\
\text { (in percent) }\end{array}$ & $\begin{array}{l}\text { Average } \\
\text { patents per } \\
\text { inventor } \\
\text { per year }\end{array}$ & $\begin{array}{l}\text { Relative fre- } \\
\text { quency } \\
\text { (in percent) }\end{array}$ \\
\hline Industry & 0.45 & 74 & 0.23 & 62 \\
\hline Individual & 0.14 & 23 & 0.04 & 11 \\
\hline University & 0.02 & 3 & 0.10 & 27 \\
\hline Sum & 0.61 & 100 & 0.37 & 100 \\
\hline Total $^{*}$ & 0.58 & & 0.34 & \\
\hline
\end{tabular}

Source: Czarnitzki et al. (2016)

* Note: In total, the average number of patent applications per identified university inventor per year amounted to 0.58 . However, a few patents are co-assigned to multiple types, e.g., a firm and a university file a joint patent application. These are counted for each type, so the total by type amount to 0.61 before 2002 instead of 0.58 .

increasing patenting. The authors argue that policymakers misperceived the incentives of university researchers. It was assumed that university researchers were mainly interested in publishing their work in academic journals and most were not interested in commercializing their research results. Instead, however, researchers who were interested in commercialization before the law changed maintained viable networks of industry contacts and often patented in collaboration with companies. These networks were disrupted by the law change, and university researchers instead had to involve university KTOs in negotiations about contract research, IP, and related collaborations.

Czarnitzki et al. (2015c) argue that the cost-and-benefit schedules for university inventors have shifted because of the change in IP ownership. On the one hand, KTOs now cover the cost of patent applications and associated fees, and are also supposed to look for industry partners for commercialization. Prior to the law change, researchers had to invest effort and their own money to realize commercial opportunities. On the other hand, researchers have lost the opportunity to appropriate all revenues from their patenting activity. Prior to the law change, they 
could theoretically enjoy 100 percent of potential revenues; now, they obtain a 30 percent royalty on all revenues, and the universities own the other 70 percent. In addition, bargaining has become more complex as now, in addition to the researchers, the university's KTO is involved in negotiations with the firm. The empirical results of Czarnitzki et al. (2015c) suggest that the negative incentives (forgone private benefits of commercialization) outweigh the positive incentives (lower private cost of commercialization).

Czarnitzki et al. (2016) separates patenting by university researchers by applicant type (see Table 5.7). Before 2002, total patenting per university inventor per year amounted to about 0.58 patent applications per year. After the law changed, this total dropped to 0.34 . However, the decline causally related to the law change is about 17 percent of the initial value of 0.58 only (according to the results from Czarnitzki et al. 2015c). More interestingly, Table 5.7 shows that a large chunk of the decline in patenting is due to a fall in patents where university researchers appear as inventors on corporate patent applications. These patents related to industry have declined by around 50 percent, from 0.45 before the law change to 0.23 .

In addition, patents may be filed by individuals, typically university inventors themselves, or by the university. Before 2002, an average of 0.14 patents were filed individually by each university inventor, and 0.02 by each university. As can be seen in Table 5.7, these numbers basically switched around, in line with the change in the law on IP ownership. After 2002, patents filed by individuals fell to 0.04 while university-filed patents increased from close to zero to 0.10 , amounting to 27 percent of total patent applications based on university inventions. Applications by individual researchers amount to just 11 percent. These are inventions where the KTO was not interested in claiming ownership or the university researcher did not report the invention to the university. Patent applications with industry are still the largest share with 62 percent. Note that universities are not required to claim ownership of the IP. They may well contract to transfer ownership to firms. The key change is that prior to 2002, the researcher was able to negotiate directly with industry, while now it is the university KTO that does so.

Patents filed along with industry applicants dropped dramatically from 0.45 to 0.23 per inventor per year. These most likely stem from direct research collaborations or contract research between industry and university researchers, strongly suggesting that the abolition of professor's 
privilege reduced actual knowledge and technology transfer. The loss of private income opportunities seems to have outweighed the possible benefits in terms of the reduced cost of commercialization for researchers.

\section{The Introduction of Patent Valorization Agencies}

As part of the Knowledge Creates Markets campaign, the BMBF established patent valorization agencies (PVAs). By 2012, twenty-nine PVAs had been created, with at least one in each state (Cuntz et al. 2012). Their primary mission is to help universities commercialize their research by providing advice on patenting, licensing and forming spinoffs. They also help to find business partners and licensees.

The main public funding for the PVAs is provided through the SIGNO program of the Federal German Ministry of Economics (BMWi). Funding is assigned to universities, which then use it to request services from the PVAs. The SIGNO budget amounted to EUR 29 million between 2001 and 2003, EUR 38 million between 2004 and 2007, and EUR 29 million between 2008 and 2010. Universities must top this up through co-payments. Cuntz et al. (2012) calculated that the PVAs' annual budgets totaled between EUR 9 and EUR 10 million in the period 2002-9.

Cuntz et al. (2012) also calculated that the revenues generated by the PVAs did not cover their cost: between 2002 and 2009, they never exceeded EUR 6 million.

It may be, however, that although the PVAs operate at a loss, their KTT activities bring indirect benefits. For instance, the foundation of more spinoff companies would not necessarily be reflected in higher PVA revenues. Researchers may be more likely to found their own companies, possibly in collaboration with a university KTO, after the establishment of PVAs and the abolition of professor's privilege, as KTOs may now be more actively pushing commercialization through spinoffs and this process may be strengthened by the presence of the PVAs. To test this hypothesis, Czarnitzki et al. (2016) investigated whether more or fewer spinoff companies have been founded since the abolition of professor's privilege and the establishment of PVAs. They collected data by searching for identified academic inventors among the population of firm founders in Germany. The Creditreform database (the German part of Bureau van Dijk's Orbis database) includes the names of all firm founders along with information on the foundation year, shareholdings, basic firm-level accounting, and supplemental data. Importantly, this captures 
not only spinoffs established by university or public research institute KTOs, but also those launched by researchers independently.

Table 5.8 summarizes their findings. Before 2002, university researchers were involved in about 46 startups per year and this number reduced to about 43 per year. The annual probability of a researcher founding a company remained constant at 4 percent. For public research institute researchers, the number of companies founded was lower and constant over time, with 29 spinoffs per year - 1 percent per researcher per year.

Annual within-demeaned spinoff probabilities at the researcher level are shown in Figure 5.6. As can be seen, while average annual spinoff probabilities fluctuate, they remain broadly constant over time and are unaffected by the law change. This is in line with micro-econometric findings by Czarnitzki et al. (2016). Using panel fixed-effects estimators in a difference-in-difference setup, they found no direct effect of the law change on university spinoffs. In summary, it seems that university KTOs and PVAs have not successfully pushed spinoff creation as the prime channel for commercializing academic inventions.

\section{Other Major Funding Schemes}

A major program involving KTT goals was the German University Excellence Initiative (www.dfg.de/en/research_funding/programmes/ excellence_initiative/index.html). This was intended to promote science and humanities to enhance Germany's international competitiveness and

Table 5.8 Academic entrepreneurship before and after the 2002 policy reform (annual mean values), 1995-2008

\begin{tabular}{clcc}
\hline \hline & & $\begin{array}{l}\text { Startups founded } \\
\text { per year }\end{array}$ & $\begin{array}{l}\text { Startups founded } \\
\text { per year per } \\
\text { inventor }\end{array}$ \\
\hline University & Before 2002 & 46.43 & 0.04 \\
researcher & After 2002 & 42.57 & 0.04 \\
PRI researcher & Before 2002 & 29.43 & 0.01 \\
& After 2002 & 28.71 & 0.01 \\
\hline \hline
\end{tabular}

Source: Czarnitzki et al. (2016)

Note: The sample included 1,946 patenting university researchers and 4,551 public research institute researchers. 


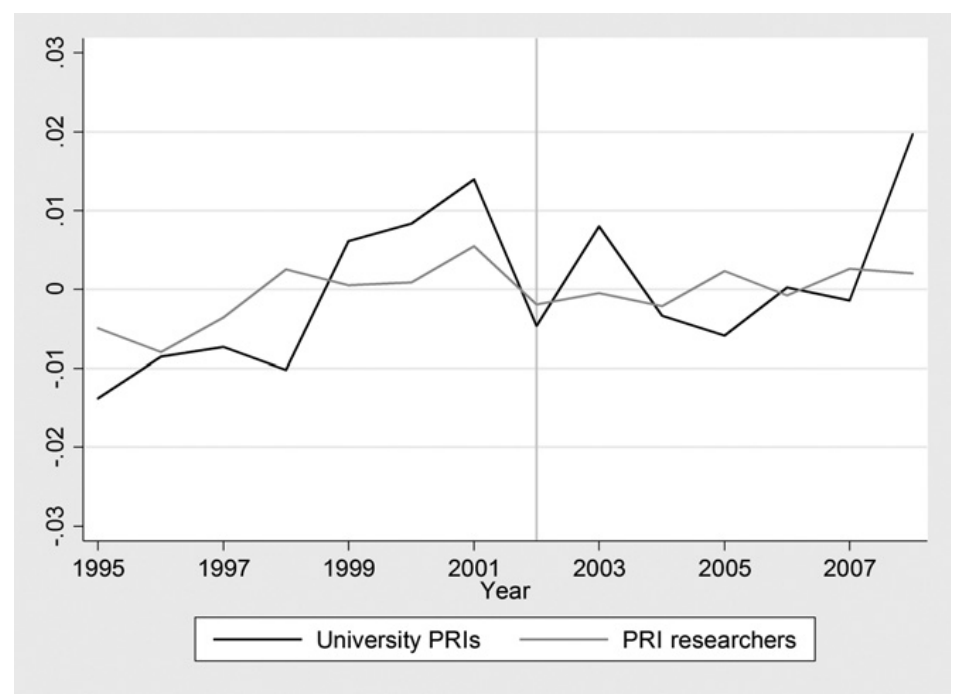

Figure 5.6 Average trends of spinoff activity (within demeaned)

Note: The vertical line in 2002 denotes the abolition of professor's privilege.

Source: Czarnitzki et al. (2016)

increase the visibility of top-level universities. It ran from 2005 to 2017 and comprised three funding lines:

- the establishment of graduate schools at universities to promote young researchers;

- funding "clusters of excellence" to promote top-level research; and

- institutional strategies to strengthen the institution "university" and its research setting as a whole.

In total, EUR 4.6 billion of funding was approved through the three funding lines, EUR 1.9 billion in the program's first phase (2006-12) and EUR 2.7 billion in its second phase (2012-17). While the program was not directly targeted at knowledge transfer, it helped universities strengthen their staffing and equipment, and some of these additional resources may have been used for business-relevant research and knowledge transfer.

Another relevant policy is the Spitzencluster ("top cluster") initiative (www.spitzencluster.de), in which universities, public research institutes, and firms team up to boost their research and innovation activities. Fifteen clusters were selected in three different program rounds, and each could obtain funding up to EUR 40 million over a five-year period. 


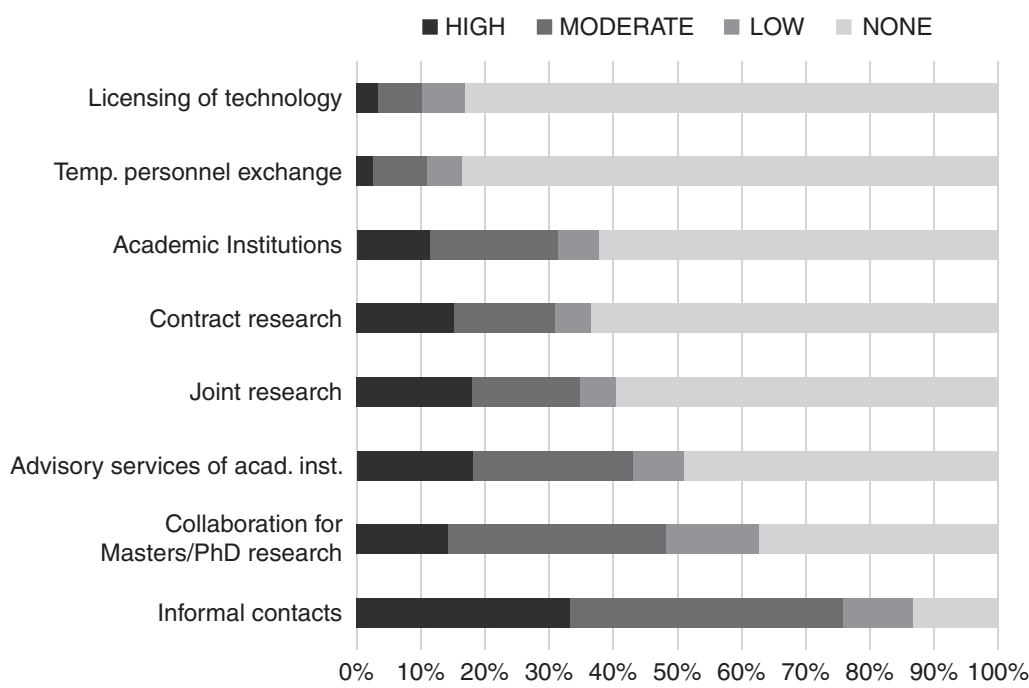

Figure 5.7 The firms' perspective on KTT channels

Source: ZEW Mannheim Innovation Panel (Survey 2003), authors' calculations

A very recent program launched in 2016 and directly targeted at KTT is the Innovative Hochschule scheme (www.bmbf.de/de/innovativehochschule-2866.html), which targets Fachhochschulen and small and medium-sized firms and has a budget of up to EUR 550 million to be disbursed in two five-year rounds until 2027. The main applicants are universities but firms can also be supported within project consortia. The goal is to strengthen universities' KTT activities, increase links within regional economies, and promote innovative forms of collaboration with business.

The EXIST program (www.exist.de) has supported academic entrepreneurship since 1998. It has three main pillars: (i) the "founder's fellowship" supports potential firm founders in academia to develop their business idea and create a business plan; (ii) the "research transfer" is intended to help develop applied research projects with commercial potential; and (iii) the "foundation culture" aims to help universities strengthen their infrastructure and enhance researchers' awareness of KTT. 


\subsection{Common Knowledge Transfer Channels}

To identify important channels of knowledge transfer in Germany and see how they have changed over time, we can use two surveys by ZEW.

The first survey was carried out in the year 2000 and included 856 responses from university professors and public research institute department heads (Czarnitzki et al. 2000).

Among many other questions, respondents evaluated the importance of different knowledge transfer channels on a four-item Likert scale $(0=$ no importance, $3=$ high importance). Table 5.9 shows the average values per type of institution, including general universities, technical universities, and universities of applied sciences. In the period 1997-9, general universities regarded publication in academic journals as the main knowledge transfer channel. Technical universities rated joint research projects with firms as important as publication and also emphasized the importance of contract research, collaborations on master's and $\mathrm{PhD}$ theses, and contacts from researchers' former occupation in the corporate sector. For universities of applied sciences, thesis collaboration was the most important channel, followed by former work contacts, and joint research projects, all of which ranked above academic publication.

Surprisingly, staff mobility was not rated as a major transfer channel for any type of university, but it was expected to gain importance in the future. All types of university also expected firm formation by academic researchers to become more important along with other KTT measures such as seminars and lectures for firms.

Overall, university respondents expected almost all KTT channels to become more important, indicating the growing importance of KTT generally as the third mission of the university system.

Responses from public research institutes reflected each institution's mission. Generally, respondents from the Fraunhofer institutes focused on direct knowledge transfer channels such as joint research projects, contract research, and presentations to firms. Respondents from Max Planck and Helmholtz tended to emphasize basic research and academic publication. For the Leibniz institutes, the results were more mixed but generally closer to Fraunhofer than to the other public research institutes.

In 2008, the ZEW conducted another survey among around 1,500 researchers (Grimpe et al. 2009). Although the questions in that survey are not fully comparable to the ones in Czarnitzki et al. (2000), some insights can be gained. 
Table 5.9 Importance of main knowledge transfer channels, by universities and public research institutes, 1997-9

\begin{tabular}{|c|c|c|c|c|c|c|c|}
\hline & UNI & TU & UAS & MPG & HGF & FhG & WGL \\
\hline \multirow{2}{*}{$\begin{array}{l}\text { Publication in academic } \\
\text { journals }\end{array}$} & 2.2 & 2.1 & 1.3 & 2.8 & 2.2 & 2.0 & 2.4 \\
\hline & $(-0.0)$ & $(+0.1)$ & $(+0.2)$ & $(+0.1)$ & $(+0.0)$ & $(+0.1)$ & $(+0.1)$ \\
\hline \multirow{2}{*}{$\begin{array}{l}\text { Joint research projects with } \\
\text { firms }\end{array}$} & 1.6 & 2.1 & 1.7 & 1.6 & 1.7 & 2.9 & 2.2 \\
\hline & $(+0.3)$ & $(+0.2)$ & $(+0.4)$ & $(+0.4)$ & $(+0.5)$ & $(+0.1)$ & $(+0.1)$ \\
\hline \multirow{2}{*}{$\begin{array}{l}\text { Presentations to firms or } \\
\text { related organizations }\end{array}$} & 1.4 & 1.6 & 1.5 & 1.5 & 1.5 & 2.6 & 1.7 \\
\hline & $(+0.2)$ & $(+0.1)$ & $(+0.3)$ & $(+0.2)$ & $(+0.3)$ & $(+0.1)$ & $(+0.3)$ \\
\hline $\begin{array}{l}\text { Publication of research } \\
\text { results in the press }\end{array}$ & 1.2 & 1.4 & 1.2 & 2.0 & 1.6 & 2.2 & 1.7 \\
\hline (newspapers, magazines) & $(+0.1)$ & $(+0.2)$ & $(+0.2)$ & $(+0.1)$ & $(+0.1)$ & $(+0.2)$ & $(+0.2)$ \\
\hline Contract research for firms & $\begin{array}{l}1.2 \\
(+0.3)\end{array}$ & $\begin{array}{l}1.8 \\
(+0.2)\end{array}$ & $\begin{array}{l}1.4 \\
(+0.5)\end{array}$ & $\begin{array}{l}0.3 \\
(+0.2)\end{array}$ & $\begin{array}{l}1.2 \\
(+0.5)\end{array}$ & $\begin{array}{l}2.9 \\
(0.0)\end{array}$ & $\begin{array}{l}1.3 \\
(+0.3)\end{array}$ \\
\hline
\end{tabular}




\begin{tabular}{|c|c|c|c|c|c|c|c|}
\hline $\begin{array}{l}\text { Master's and } \mathrm{PhD} \text { theses in } \\
\text { collaboration with }\end{array}$ & 1.3 & 1.8 & 2.5 & 0.9 & 0.9 & 1.6 & 1.0 \\
\hline firms & $(+0.3)$ & $(+0.2)$ & $(+0.0)$ & $(+0.2)$ & $(+0.4)$ & $(+0.2)$ & $(+0.3)$ \\
\hline \multirow{2}{*}{$\begin{array}{l}\text { Personnel mobility of } \\
\text { researchers between } \\
\text { research organizations } \\
\text { and firms }\end{array}$} & 1.4 & 1.6 & 0.9 & 1.6 & 1.3 & 2.0 & 1.2 \\
\hline & $(+0.4)$ & $(+0.4)$ & $(+0.4)$ & $(+0.3)$ & $(+0.4)$ & $(+0.2)$ & $(+0.5)$ \\
\hline $\begin{array}{l}\text { Contacts from academics' } \\
\text { former occupation }\end{array}$ & 1.0 & 1.7 & 2.1 & 1.2 & 1.0 & 2.0 & 0.9 \\
\hline in the corporate sector & $(+0.1)$ & $(+0.0)$ & $(+0.0)$ & $(0.0)$ & $(+0.1)$ & $(+0.2)$ & $(+0.3)$ \\
\hline $\begin{array}{l}\text { Joint publications and patent } \\
\text { applications }\end{array}$ & 0.8 & 1.0 & 0.8 & 1.1 & 1.0 & 1.9 & 1.3 \\
\hline with firms & $(+0.4)$ & $(+0.2)$ & $(+0.4)$ & $(+0.5)$ & $(+0.5)$ & $(+0.2)$ & $(+0.3)$ \\
\hline \multirow{2}{*}{$\begin{array}{l}\text { Seminars and lectures for } \\
\text { firms }\end{array}$} & 0.7 & 0.9 & 1.3 & 0.7 & 0.7 & 1.4 & 0.7 \\
\hline & $(+0.4)$ & $(+0.4)$ & $(+0.5)$ & $(+0.1)$ & $(+0.3)$ & $(+0.4)$ & $(+0.3)$ \\
\hline
\end{tabular}


Table 5.9 (cont.)

\begin{tabular}{llllllll}
\hline \hline & UNI & TU & UAS & MPG & HGF & FhG & WGL \\
\hline $\begin{array}{l}\text { Firm formation by academic } \\
\text { employees }\end{array}$ & 0.6 & 0.8 & 0.6 & 0.9 & 0.7 & 1.0 & 0.8 \\
& $(+0.5)$ & $(+0.5)$ & $(+0.5)$ & $(+0.6)$ & $(+0.6)$ & $(+1.0)$ & $(+0.6)$
\end{tabular}

Source: Czarnitzki and Rammer (2000)

Notes: The numbers are averages of the four response scores $(0=$ no importance, $1=$ minor importance, $2=$ moderate importance, $3=$ high importance) for the importance of the different channels in the years 1997-9. The expected change in importance of each channel in the future is given in the parentheses (calculated as positive or negative deviation from the mean of its current importance).Types of institutions: $\mathrm{UNI}=$ general universities, $\mathrm{TU}=$ technical universities, $\mathrm{UAS}=$ universities of applied sciences $($ Fachhochschule), $\mathrm{MPG}=$ Max Planck Association, HGF = Helmholtz Association, FhG = Fraunhofer Association, WGL = Leibniz Association (Wissenschaftsgemeinschaft Gottfried Wilhelm Leibniz). 
Table 5.10 External funding and channels of commercialization as reported by researchers in 2008

\begin{tabular}{|c|c|c|c|c|c|}
\hline & Uni & Fraunhofer & $\begin{array}{l}\text { Max } \\
\text { Planck }\end{array}$ & Helmholtz & Leibniz \\
\hline \multicolumn{6}{|l|}{ External funding: } \\
\hline Third-party funding & 88 & 88 & 73 & 79 & 81 \\
\hline Industry funding & 37 & 80 & 15 & 24 & 26 \\
\hline \multicolumn{6}{|l|}{$\begin{array}{l}\text { Channels of } \\
\text { knowledge } \\
\text { transfer: }\end{array}$} \\
\hline $\begin{array}{l}\text { Joint } \\
\text { commercialization } \\
\text { of technology }\end{array}$ & 43 & 87 & 21 & 39 & 44 \\
\hline Joint publications & 24 & 43 & 15 & 14 & 20 \\
\hline Consulting & 20 & 26 & 11 & 8 & 8 \\
\hline Company formation & 20 & 18 & 12 & 10 & 9 \\
\hline $\begin{array}{l}\text { Companies based on } \\
\text { research results }\end{array}$ & 12 & 16 & 8 & 7 & 6 \\
\hline
\end{tabular}

Source: ZEW survey of scientists 2008, authors' calculations

First, most academic researchers reported having used some external funding (see Table 5.10). At universities and Fraunhofer research units, 88 percent of respondents said they had sourced external funding, but whereas 80 percent of the Fraunhofer researchers said they had received funding from industry, only 37 percent of university researchers obtained industry funds. Max Planck, Helmholtz, and Leibniz researchers received third-party funding less frequently than those at universities and Fraunhofer, but the rates of receipt were still high: 81 percent of researchers at Leibniz, 79 percent at Helmholtz, and 73 percent of Max Plank researchers said they had benefited from external funds. However, only 26 percent of researchers at Leibniz, 24 percent at Helmholtz, and 15 percent at Max Planck reported having received funding from industry.

As regards knowledge transfer channels, 87 percent of Fraunhofer researchers said they had been involved in joint research and joint commercialization of technology with industry - far higher than the corresponding numbers of researchers at Leibniz (44 percent), universities (43 percent), Helmholtz (39 percent), and Max Planck 
(21 percent). Joint publications were generally the second most important channel. Private consulting activities and company formation were mentioned much less frequently. Interestingly, university researchers were more likely than other respondents to have been involved in founding an enterprise (20 percent), followed by those from Fraunhofer (18 percent). It is noteworthy, however, that in 40 percent of cases, university researchers' startups were not based on research results: while 20 percent reported involvement in establishing a firm, only 12 percent said it was based on research results. At Fraunhofer, 16 percent of respondents reported being involved in a startup based on research results. As expected, firm formation was less frequent among researchers at the other respondent public research institutes.

To investigate KTT channels at the firm level, we can use the Mannheim Innovation Panel Survey from 2003. Companies were asked to evaluate their contacts with research institutions according to their importance. Around 2,500 firms reported active contacts with public science between 2000 and 2002. The respondents were asked to rank every KTT channel according to its importance for the firm's access to knowhow on a scale between 0 and 3 (no to high importance).

Interestingly, informal contacts were the most important. More than 70 percent of firms with any active contact with science rated these as either highly or moderately important. This was followed by collaborations on master's and $\mathrm{PhD}$ theses, which almost 50 percent of firms ranked as highly or moderately important. Advisory services from academic institutions were highly or moderately important to 43 percent. Other formal channels such as joint research, contract research, training of employees in academic institutions, and temporary exchange of personnel as well as technology licensing played a less important role for most firms.

\subsection{Economic Literature on Knowledge Transfer in Germany}

The picture of KTT in Germany given above can be supplemented through a discussion of the scholarly literature. Here, we are particularly interested in two issues: the limits to and opportunity costs of KTT from science to industry, and its benefits downstream in the manufacturing and service sectors. 


\subsubsection{Limits to and Opportunity Cost of KTT}

Czarnitzki et al. (2007, 2009a) studied the growing importance of universities' unpublished technology-relevant research and cooperation with industry. As more and more scientific researchers became active in commercializing their discoveries, policymakers and academics debated whether patenting as a channel of entrepreneurial activity might significantly reduce scientific output in the economy, with potentially detrimental implications for long-term growth, competitiveness, and employment. Productivity in science can be measured in terms of the publication output and research quality of scientists engaging in commercialization. Czarnitzki et al. combined bibliometric and technometric indicators and econometric techniques to investigate the correlation between patenting and publication output and quality for a large data set of academics active in several research fields in Germany. Their 2007 study found no overall negative correlation between patenting and the scientific output of the academics in their sample, but more detailed analysis revealed heterogeneity in patenting behavior. Whereas some patent applications might result from purely intrinsically motivated research, others were the output of specially funded contract research, especially for industry. Czarnitzki et al. (2009a) classified academics' patent applications into corporate patents and academic patents using applicant data, distinguishing between patents where one or more academics featured as an inventor but the patent was filed by a company and those filed by another applicant (e.g., the academic themselves or a university or public research institute). Factoring this distinction into their multiple regression models, they found that academic-filed patents did not harm academics' scientific output, but company-owned patents were associated with (subsequent) lower publication output and also lower publication quality (as measured through subsequent citations by other academic papers). Czarnitzki et al. interpreted this as evidence that the researchers were likely to have engaged in company-relevant research for commercialization/knowledge transfer purposes and that such research could distract them from their own, original academic research.

If one accepts that company-relevant research is likely to be of a more applied nature than normal university research then intensified knowledge transfer efforts by universities may indeed partly crowd out the freely accessible knowledge produced in science in terms of (highquality) academic publications, potentially harming technological progress and economic development in the long run. 
The opportunity cost of knowledge transfer has also been documented. In general, academic patents are more basic than corporate patents, and patents by academic inventors filed along with corporations feature inventions that are based on more applied research than those academicinvention patents owned by universities, public research institutes, or academics personally (Czarnitzki et al. 2009b, 2012). Czarnitzki et al. (2011) revealed a steady decline in the quality of academic patents. They investigated forward citations received by patent applications a measure often employed as capturing the social value of an invention, as forward citations approximate how many subsequent inventions build on the patented technology. Czarnitzki et al. compared the forward citations received for patents by German university academics with a randomly chosen control group of patents filed by corporations in the same application year and technology field. They found that in the early 1980s, the average academic patent received significantly more forward citations than the control group of corporate patents, and they took this to indicate that academic patents were more fundamental and basic, and therefore more relevant to subsequent technological progress, than corporate patents. But as efforts to foster KTT from universities to industry grew in subsequent decades, differences between the quality or social value of academic and corporate patents, as measured by forward citations, diminished. By the beginning of the 2000s, there was no longer any statistically significant difference between forward citations of academic and corporate patents. This suggests that the move toward commercialization in academia has had a negative impact on the average social value of academic activities such as patenting. The boundary between not-for-profit academic and for-profit business $R \& D$ has become blurred.

Further studies have examined the impact of private industry funding of scientific activities on the publication of academic research results and the sharing of research materials. Czarnitzki et al. (2015a) showed that increased industry funding in Germany had hindered the dissemination of research in public science through disclosure restrictions. Arguing that the viability of modern open science norms and practices depends on public disclosure of new knowledge, methods, and materials, they sought to examine the relationship between industry sponsorship and restrictions on disclosure using individual-level data on German academic researchers. Their evidence, which controls for self-selection into extramural sponsorship, strongly supports the proposition that industry sponsorship jeopardizes the public disclosure of academic research. Academic 
scientists who adopt industry sponsorship are subject to more stringent contract terms that restrict the disclosure of academic research results through delay and secrecy. Controlling for scientist selection, the results show that the likelihood of such restrictions more than doubles with industry sponsorship, because firms expect proprietary benefits from their sponsorship relationships and realizing these benefits often requires disclosure restrictions that academic researchers would not otherwise impose.

These results are in line with those of Czarnitzki et al. (2015b) on access and sharing of research inputs among public scientists. The authors found that scientists who received industry funding were twice as likely to deny requests for research inputs as those who did not. Receiving external funding in general did not affect denying others access, but scientists who received external funding of any kind - from industry or elsewhere - were 50 percent more likely to be denied access to research materials by others.

In summary, active knowledge transfer does not come without opportunity cost. There is mounting evidence that the research output of public scientists is affected by their engagement in active knowledge transfer. Some may move toward more applied research, with potentially negative long-run impacts on the basic science that underpins future progress. In other cases, the dissemination of new academic knowledge may be directly impeded through disclosure restrictions imposed by private industry partners or sponsors.

\subsubsection{Benefits to Business of Knowledge Transfer}

While knowledge transfer can clearly have some negative impacts on the academic side, there are obvious potential benefits too. First and foremost, knowledge transfer may include private research sponsorship that enhances academic research capacities, allowing more doctoral students to be educated and so on. And even in the absence of major budget increases for public science, KTT may bring societal benefits.

The most extreme form of academic commercialization is academics' involvement in spinoff companies. In such cases, academic research is deemed valuable enough to warrant forming a company, transferring technology to the private sector and potentially adding social value by creating jobs and generating taxable revenues. Czarnitzki et al. (2014) investigated how far German academic startups grew in their first few years. They collected representative sample data from German firm 
foundation cohorts between 1996 and 2000 in knowledge-intensive and high-tech sectors. More than 57,000 new ventures were contacted by means of computer-aided telephone interviews, and about 20,000 interviews conducted. In their empirical analysis, Czarnitzki et al. estimated a model of company growth. They identified academic entrepreneurs among the sample of newly founded firms, and controlled for "firm survivor bias" by applying a sample selection model. ${ }^{6}$ They found that academic spinoffs grew by around 3 percent more per year on average than other startups.

In a companion paper based on similar data, Toole et al. (2015) examined how university research alliances and other cooperative links with universities contribute to startup employment growth. They argued that "scientific absorptive capacity" at the startup is critical to reap the benefits from university research alliances, but not necessarily for other university connections. They estimated the aggregate employment contribution of startup firms and attributed those employment gains to university research alliances and other university connections. They found significant contributions to employment growth from university research alliances and other university connections, but also found that scientific absorptive capacity was critical for university research alliances. Only 7 percent of startups maintained a university research alliance, but 3.4 percent of all jobs created by those firms were attributable to their alliances.

These numbers obtained from econometric regression analysis can be extrapolated to the population. For the period from 1996 to 2001, German National Account statistics show that total employment in the knowledge-intensive sectors increased by 701,000 jobs. Based on the results of Toole et al. (2015), 453,422 of these jobs were created by 171,833 companies founded between 1996 and 2000 that survived until the end of 2001. This is about 65 percent of total net jobs in the sectors covered. Among all the startups in this cohort, it can be estimated that 51,908 companies had some kind of university connection(s) in the postfoundation period and created 223,969 jobs. Using the Heckman regression model results, Toole et al. estimate that university connections (research alliances and all others) accounted for 9.2 percent (or 20,535) of these jobs. Turning to university research alliance relationships, they

${ }^{6}$ Several firms within the startup population could not be contacted for interviews as they had gone out of business by the time of the survey. The sample selection model takes into account this potential source of "survivor bias," which might otherwise have led to an overestimation of the growth potential of newly founded firms. 
calculate that a total of 11,896 startups within the population had such relationships and created a total of 72,857 jobs. The model results indicate that 3.4 percent (or 2,453) jobs can be attributed to university research alliances.

These results suggest that university connections are quite important for job growth, and university research alliances contributed substantially to job creation for those firms that had such alliances.

When it comes to innovation by established firms, studies have considered spillovers from public science in general and also benefits to companies from direct interaction with public science in the form of research collaborations.

Cappelli et al. (2014) focused on "essential knowledge spillovers" that companies received from public science. While some such spillovers may be obtained from simply reading academic publications, they may also result from direct interaction through contract research or joint research collaborations. In one wave of the Mannheim Innovation Panel, firms were asked about "essential inputs for innovation" that they had received from other actors in the economy including customers, suppliers, competitors, and public science. The term "essential" was defined in the survey to mean that an input had been indispensable for the development of a new product, service or process.

Cappelli et al. related firms' sales of market novelties to these reported spillover measures and found that essential information received from customers and public science was associated with higher sales of new products. On average, innovative firms in their sample achieved 9 percent of their sales from products that were novel in their main product market. Regression results showed that spillovers from public science pushed this share to about 13.2 percent.

In a very recent study, Comin et al. (2018) analyze the case of the Fraunhofer Association, the largest applied research public research institute in Germany. They investigate whether interacting with Fraunhofer institutes in research projects affects firms' performance and strategic orientation. To do this, they assembled a data set based on Fraunhofer's (confidential) internal project management system and merged it with the Mannheim Innovation Panel. They found that project interaction had a strong positive effect on firms' turnover and productivity growth. They also showed that a major driver of these positive effects is the firms' increased share of sales from new products and an increase in the share of their workers with tertiary education. More detailed analyses reveal, among other things, that performance effects 
become stronger the more often firms interact with Fraunhofer and that interactions aimed at generating technology have a stronger effect than those merely intended to implement existing technologies.

In summary, the literature has shown quite clearly that (active) knowledge transfer from public science to industry has positive effects on the business sector in Germany. The documented effects range from job creation to new product sales and productivity growth. These positive effects have been found in both startup companies (including academic startups) and established companies.

\subsection{Supporting Interviews}

To explore KTT in German universities in more depth, three supporting case studies including interviews were conducted for the research project on which this chapter draws - at the University of Heidelberg, FriedrichSchiller-University (FSU) Jena, and Ludwig-Maximilian University (LMU) Munich. Table 5.11 shows some key characteristics of these institutions.

The University of Heidelberg is located in the state of BadenWürttemberg in an area characterized by a strong science base, close to many other leading scientific organizations such as:

- the German Cancer Research Institute - a research institute of the Helmholtz Society with more than 3,000 employees;

- the National Center for Tumor Diseases Heidelberg - a joint venture between the German Cancer Research Institute and the University of Heidelberg;

- the European Molecular Biology Laboratory (EMBL) - one of the world's leading research institutions and Europe's flagship laboratory for the life sciences. This is an intergovernmental organization specializing in basic research in the life sciences, funded by public research monies from more than twenty member states, including much of Europe plus Israel and two associate members, Argentina and Australia;

- the Max Planck institute for Medical Research;

- a biotechnology science park and a growing number of local biotech startups;

- the BioMed X Innovation Center, a collaboration model at the interface between academia and industry where interdisciplinary project teams conduct biomedical research in an open-innovation lab facility on the campus of the University of Heidelberg. Each team is typically sponsored by a corporate pharmaceutical or biotech partner. At the end of a fully 
Table 5.11 Key characteristics of the three case study universities

\begin{tabular}{|c|c|c|c|}
\hline & Heidelberg & Jena & Munich \\
\hline $\begin{array}{l}\text { Number of } \\
\text { academics }\end{array}$ & 444 & 384 & 747 \\
\hline $\begin{array}{l}\text { Number of } \\
\text { students }\end{array}$ & $\begin{array}{l}\text { 30,300 (including } \\
\text { 1,300 PhDs } \\
\text { completed } \\
\text { per year) }\end{array}$ & 19,000 & 48,000 \\
\hline Fields of study & $\begin{array}{l}\text { Humanities, social } \\
\text { sciences, law, } \\
\text { economics, } \\
\text { mathematics, } \\
\text { physics, } \\
\text { biotechnology } \\
\text { and other } \\
\text { natural } \\
\text { sciences; two } \\
\text { faculties of } \\
\text { medicine and } \\
\text { two hospitals; } \\
\text { computer } \\
\text { science }\end{array}$ & $\begin{array}{l}\text { Humanities, social } \\
\text { sciences, law, } \\
\text { economics, } \\
\text { mathematics, } \\
\text { biology and } \\
\text { other natural } \\
\text { sciences, } \\
\text { medicine }\end{array}$ & $\begin{array}{l}\text { Humanities, social } \\
\text { sciences, law, } \\
\text { economics, } \\
\text { mathematics, } \\
\text { physics, } \\
\text { biology, } \\
\text { biotechnology } \\
\text { and other } \\
\text { natural } \\
\text { sciences, } \\
\text { medicine, } \\
\text { computer } \\
\text { science }\end{array}$ \\
\hline
\end{tabular}

Source: Authors

funded project term, successful projects are either internalized into the development pipeline of the respective pharmaceutical or biotech sponsor or spun off into an independent startup company.

Furthermore, several large companies are also located near Heidelberg, including BASF, SAP, Roche, AbbVie, Böhringer-Ingelheim, and Merck Serono.

FSU Jena is also located in a region with a strong science base, particularly in physics and optics. The Helmholtz institute at Jena hosts a particle accelerator, while the main optics company is Jenoptik.

LMU Munich is located near the Technical University of Munich and the Helmholtz Centre for Research on Environmental Health. Munich also hosts the headquarters of the Max Planck Association and the Fraunhofer Association plus a number of large companies such as BMW. 
The three universities' KTOs share more or less the same tasks and services, such as:

- information and support for researchers regarding funding opportunities;

- handling research contracts with other research organizations, research funding organizations and the private sector;

- implementation of the university's intellectual property policy and the management of IP rights;

- management of research-based spinoff processes;

- identification of transferable IP; and

- support for research conferences and research marketing.

Interviewees said they had benefited from major public funding programs such as the Excellence Initiative and the Spitzencluster program. As a result, their KTOs gained staff, at least temporarily, helping them achieve their goals.

Furthermore, some new forms of university-industry collaboration had been implemented, for example new types of startup such as InnovationLab and the CarLa Catalytics Research Lab - laboratories either run by industry with scientific support from universities or set up as joint ventures between a firm and a university, and ideally located within a technology park on campus. Also, more hybrid labs could be established whereby industrial researchers collaborate with university researchers and the latter are partly financed by industrial partners.

While the interviewees were happy to report success stories, it became apparent that a "cultural divide" between university and industry applies to the vast majority of both university and industrial researchers, and that the lion's share of university research is largely irrelevant to the needs of business. Interviewees also mentioned that sometimes national or local businesses lack the capability to use relevant research results, but said this is not necessarily the case at the global level.

Knowledge transfer officers reported that they have inefficient technology evaluation mechanisms and that their efforts to look for patentable inventions or other forms of IP to exploit were underdeveloped.

Interviewees felt that while recent German public funding initiatives had focused on excellence, support was also necessary at the average level to boost the volume of transfer activities. By definition, only a few research units can aspire to meet the standard of scientific excellence. Furthermore, the scientific excellence criterion leads to a focus on basic rather than applied research, producing researchers with absolutely no experience of working in the business sector. Examples mentioned 
included engineering faculties that were developing new fields of research with less evident industry relevance than Germany's traditionally strong engineering education.

Relationships with the recently established PVAs were said to be suboptimal, complicated by their for-profit nature. However, it was also reported that knowledge transfer officers sometimes found it difficult to engage with firms as they typically had to follow strict university IP policies. This was seen as negative political pressure - the imperative to maximize license income in the short term undermined the chance to develop long-run business relationships with company partners.

In summary, the interviews confirm that efforts have been made to foster systematic KTT from science to industry in the past decade. However, a longstanding cultural divide between science and industry still inhibits knowledge exchange between them. In addition, the relatively new phenomenon of rigorous IP management by universities may have complicated bilateral agreements between universities and firms.

\subsection{Conclusions}

The German public science landscape is complex, with many different actors undertaking diverse KTT activities. The different types of university and different public research institutes have different missions regarding knowledge transfer.

We described the German knowledge transfer system using large-scale survey evidence from both scientific institutions and for-profit firms. Primary data collection and the analysis of secondary data provide plenty of evidence of KTT from public research organizations, ranging from patenting and licensing of inventions through to joint research projects between science and industry, contract research, exchange of personnel, and more modern forms of public-private partnerships such as shared research laboratories.

We also noted some changes in the German KTT system and considered analyses of their impact in the scholarly literature. While there is evidence that some policy measures have improved conditions for KTT, the story is not uniformly positive. The abolition of professor's privilege in the early 2000s may well have reduced academics' incentives to commercialize their inventions while the success of patent valorization agencies is moot.

Case study evidence from interviews supports our overall conclusion that policy has been trying to systematically improve the conditions for 
KTT in Germany in the last two decades, and several improvements have been documented. However, policymakers need to balance the incentives for basic and applied research to ensure that Germany's science base is not hollowed out in the long run.

The challenge for universities and public research institutes is to deepen the understanding of IP and business-relevant research and applications within their institutions and to further improve communication between their researchers and industry.

\section{References}

BMBF (2012). Bundesbericht Forschung und Innovation. Bonn: BMBF.

Cappelli, R., D. Czarnitzki, and K. Kraft (2014). "Sources of spillovers for imitation and innovation." Research Policy, 43(1), 115-20.

Comin, D., G. Licht, M. Pellens, and T. Schubert (2018). Do Companies Benefit from Public Research Organizations? The Impact of the Fraunhofer Society in Germany. Papers in Innovation Studies No. 2018/07, Centre for Innovation, Research and Competence in the Learning Economy (CIRCLE), Lund.

Cuntz, A., H. Dauchert, P. Meurer, and A. Philipps (2012). Hochschulpatente zehn Jahre nach Abschaffung des Hochschullehrerprivilegs, Studien zum deutschen Innovationssystem 13-2012, Berlin.

Czarnitzki, D., T. Doherr, K. Hussinger, P. Schliessler, and A.A. Toole (2015c). Individual Versus Institutional Ownership of University-Discovered Inventions, ZEW Discussion Paper No. 15-007, Mannheim.

Czarnitzki, D., T. Doherr, K. Hussinger, P. Schliessler, and A.A. Toole (2016). "Knowledge creates markets: The influence of entrepreneurial support and patent rights on academic entrepreneurship." European Economic Review, 86: 131-46.

Czarnitzki, D., W. Glänzel, and K. Hussinger (2007). "Patent and publication activities of German professors: An empirical assessment of their co-activity." Research Evaluation, 16(4): 311-9.

Czarnitzki, D., W. Glänzel, and K. Hussinger (2009a). "Heterogeneity of patenting activity and its implications for scientific research." Research Policy, 38(1), 26-34.

Czarnitzki, D., C. Grimpe, and M. Pellens (2015a). "Access to research inputs: Open science versus the entrepreneurial university." Journal of Technology Transfer, 40: 1050-63.

Czarnitzki, D., C. Grimpe, and A.A. Toole (2015b). "Delay and secrecy: Does industry sponsorship jeopardize disclosure of academic research." Industrial and Corporate Change, 24(1): 251-79.

Czarnitzki, D., K. Hussinger, and C. Schneider (2009b). "Why challenge the ivory tower? New evidence on the basicness of academic patents." Kyklos: internationale Zeitschrift für Sozialwissenschaften, 62(4): 488-99. 
Czarnitzki, D., K. Hussinger, and C. Schneider (2011). "Commercializing academic research: The quality of faculty patenting." Industrial and Corporate Change, 20(5): 1403-37.

Czarnitzki, D., K. Hussinger, and C. Schneider (2012). "The nexus between science and industry: Evidence from faculty inventions." Journal of Technology Transfer, 37(5): 755-76.

Czarnitzki, D., C. Rammer, and A. Spielkamp (2000). Interaktion zwischen Wissenschaft und Wirtschaft in Deutschland - Ergebnisse einer Umfrage bei Hochschulen und öffentlichen Forschungseinrichtungen. (ZEW-Dokumentation Nr. 00-14). Mannheim, Zentrum für Europäische Wirtschaftsforschung.

Czarnitzki, D., C. Rammer, and A.A. Toole (2014). "University spinoffs and the 'performance premium'." Small Business Economics, 43(2): 309-32.

Edler, J. and U. Schmoch (2001). "Wissens- und Technologietransfer in öffentlichen Forschungseinrichtungen." ifo Schnelldienst, 2001(4): 18-27.

Fraunhofer Association (2015). Annual Report. Munich.

Grimpe, C., K. Cremers, T. Eckert, T. Doherr, G. Licht and M.O. Sellenthin (2009). Studie zur Beteiligung am 6. Forschungsrahmenprogramm der Europäischen Union. Bundesministerium für Bildung und Forschung (BMBF), Mannheim.

Helmholtz Association (2016). Annual Report. Bonn, Helmholtz Association of German Research Centres.

Max Planck Society for the Advancement of Science (2016). Annual Report. Munich.

Munich Innovation Group (2013), Benchmarking China and Germany - An Analysis of Patent Portfolios of Universities and Research Organizations. Munich, Munich Innovation Group.

Rammer, C. and D. Czarnitzki (2000). "Interacktion zwischen Wissenschaft und Wirtschaft - die Situation an den öffentlichen Forschungseinrichteungen in Deutschland." In U. Schmoch, G. Licht, and M. Reinhard (eds.). Wissens- und Technologietransfer in Deutschland.Stuttgart: Frauenhofer IRB Verlag, 38-73.

Schmoch, U. (2007), Patentanmeldungen aus deutschen Hochschulen-Analysen im Rahmen der Berichterstattung zur Technologischen Leistungsfähigkeit Deutschlands. Studien zum deutschen Innovationssystem Nr. 10-2007, Berlin.

Schmoch, U., G. Licht, and M. Reinhard (eds.) (2000). Wissens- und Technologietransfer in Deutschland. Stuttgart: Fraunhofer IRB Verlag.

Toole, A., D. Czarnitzki, and C. Rammer (2015). University research alliances, absorptive capacity, and the contribution of startups to employment growth." Economics of Innovation and New Technology, 24(5): 532-49.

Von Proff, S., G. Buenstorf, and M. Hummel (2012). "University patenting in Germany before and after 2002: What role did the professors' privilege play?" Industry \& Innovation, 19(1): 23-44. 


\title{
Republic of Korea
}

\author{
KEUN LEE AND HOCHUL ${ }^{*}$ SHIN
}

\subsection{Introduction}

With the arrival of the knowledge-based economy, universities and public research institutes have emerged as key components of the national innovation system (NIS). According to Freeman (1987), the NIS is "a network of institutions in the public and private sectors whose activities and interactions initiate, import, modify, and diffuse new technologies." In the NIS literature, one role of universities and public research institutes is to channel their knowledge into firms. Universities also diffuse knowledge by producing quality students and interacting with firms through cooperative programs.

One of the most important characteristics of the Republic of Korea's NIS is the "twin dominance" (Eom and Lee 2010) of big businesses (chaebols) and the government. This implies a relatively weak role for universities and small and medium-sized enterprises (SMEs) (Kim 1993; Lim 2006; Cho et al. 2007). For instance, universities and industry employ around 70 percent and 20 percent, respectively, of all doctorates in the Republic of Korea and yet, paradoxically, universities conduct only 10 percent of research activities in the country, while industry conducts 77 percent (OECD 2008). Additionally, as of 2005, 39.7 percent of researchers and 52.2 percent of $\mathrm{PhD}$ researchers were employed by the top twenty firms (Eom and Lee 2010).

While big business groups have dominated the Republic of Korea's NIS through their large in-house R\&D since the mid-1980s, the government and public research institutes and universities initially led the country's NIS during its early takeoff period in the 1960s and 1970s. In the 1970s, the Republic of Korea was in transition from light to heavy and chemical industries, but its national $\mathrm{R} \& \mathrm{D}$ base was weak. The 
government developed its national R\&D capacity by setting up public research institutes and universities. Several were established based on the Special Research Institute Promotion Law of 1973 in the fields of machinery, shipbuilding, chemical engineering, marine science, and electronics. From the mid-1970s, chaebol firms started to grow rapidly and enter heavy and chemical industry. Afterward, the government played a significant role by providing a selected number of big firms with privileges such as concessional bank loans and exclusive access to foreign exchange. Even in the 1980s and 1990s, big business groups were aided by government-led public-private research consortia in achieving key R\&D goals, with examples such as the development of TDX (a system of telephone switches), memory chips, and digital TV projects (Lee and Lim 2001; Lee et al. 2005). According to a study by the OECD (2003), the Republic of Korea is the only country in which public research institutes play a more important role in national $R \& D$ than do the universities themselves.

In contrast to public research institutes, universities have played a minor role in boosting the R\&D performance of the private sector in the Republic of Korea. Big private firms relied more on foreign knowledge sources than local sources and universities, as they wanted to hire quality scientists and engineers from abroad or acquire technology in collaboration with foreign partners. Kim (1993) argues that the lack of interaction between university and industry, due to the teaching-oriented nature of Korean universities, is one of the greatest weaknesses of the country's NIS. Research has received increasing priority in universities in the Republic of Korea only since the 1990s. For example, while Korea ranked nineteenth overall in terms of the number of Science Citation Index (SCI) papers in 1996, universities accounted for 83.0 percent of contributions (Lee 1998).

From the late 1990s, the policy agenda shifted to encourage the entrepreneurial role of universities in expanding national technological capability. The Technology Transfer Promotion Act 2000 symbolizes this growing interest in knowledge transfer from public science. The Act stipulates that public universities should establish units or institutions, such as knowledge transfer offices (KTOs), charged with knowledge transfer and training specialists. Promotion of university-industry cooperation gained further momentum with the Act on the Promotion of Industrial Education and Industry-University Collaboration 2003. While there were only seventeen KTOs in 2003, their number increased rapidly after that, especially in 2004, when 263 more were created 
(KRF 2016). By 2014, 356 universities - about 84 percent of the country's total - had established KTOs.

The main aim of this research is to explore the progress of the knowledge transfer system following these policy initiatives. Early assessments, such as that of Eom and Lee (2010), found that knowledge industrialization in the Republic of Korea remained at an early stage compared to advanced countries. Specifically, while government initiatives had had some nominal success (e.g., in generating more patents), such generated knowledge had not been successfully commercialized. Our research suggests that the situation has barely improved from the situation described in Eom and Lee (2010). Further, we argue that one source of the problem is the Republic of Korea's legacy of success with the twin dominance of big businesses and government dominating the process of economic catch-up, which has meant that both the manner and extent of knowledge commercialization have not fully accommodated or embraced the needs and specificities of SMEs and universities. Thus, SMEs tend to complain that organizations and university technologies are unsuitable for their conditions. Conversely, university KTO offices are very weak in terms of financial and human resources, leading to underutilization or under-commercialization of relatively good quality research outcomes from university professors.

The rest of this chapter is organized as follows. Section 6.2 reviews the policy changes since 2000 that were designed to improve knowledge transfer from public research institutes. Section 6.3 focuses on the overall performance of knowledge transfer activities in public research institutes. Section 6.4 identifies the important knowledge transfer channels in the Republic of Korea and presents some examples of them. Section 6.5 reviews the challenges that government policy and public research institutes face in achieving successful knowledge transfer. Section 6.6 provides conclusions.

\subsection{New Policies to Improve Knowledge Transfer from the Public Research Base}

The Technology Transfer Promotion Act 2000 was the first law to encourage knowledge transfer from the public sector research base. It required public research institutes and public universities to establish KTOs and allowed the government to financially support university KTOs. The Act specified that public research institutes and university researchers were eligible to obtain a portion of the income from 
knowledge transfer, providing researchers with an incentive for knowledge transfer and commercialization. This became possible because, as with the Bayh-Dole Act in the United States of America (U.S.), it allowed universities to retain ownership of IP from government-funded research.

In addition, Korea Technology Exchange was founded by the 2000 Act to manage the knowledge transfer market and mediate knowledge transfer. It also provided various services such as technology evaluation and support for technology transfer agents. The 2000 Act created a system of technology transfer agents: a person who satisfies standard qualifications, such as an experienced lawyer or a government official, can be authorized as a technology transfer agent by the government if he or she completes a specific curriculum.

The Act on the Promotion of Industrial Education and IndustryUniversity Collaboration 2003 deemed that most universities should have KTOs and could establish and run a for-profit "university company" using technology that they had developed, thus enabling direct commercialization.

The Technology Transfer and Commercialization Promotion Act 2006 focused more on commercialization than knowledge transfer. It required the government to include a budget for commercialization in $R \& D$ funding. Previous laws had provided that R\&D funding was to be mainly used for technology development rather than commercialization; the new Act changed that. Accordingly, part of the expenses of KTOs were to be provided by the government, equating to 29 percent in 2014. Public research institutes received more government funding than did universities: 38 percent of the expenses of public research institute KTOs came from government while the figure for universities amounted to only 14 percent.

The 2006 Act allowed public research institutes to establish technology holding companies if they developed cutting-edge technology. These holding companies were allowed, in turn, to establish subsidiaries using their technology; such subsidiaries include incubating, business consulting, and funding to improve technology commercialization. Researchers or staff could take leave to work at the technology holding companies. ${ }^{1}$

The law also specified that KTOs should receive more than 10 percent of total license income. Public research institutes were allowed to invest in forms of technology if authorized institutes such as the Korea Institute

${ }^{1}$ Conversely, it is not easy for Korean researchers to take leave to work at spinoffs or startups. 
for Advancement of Technology (KIAT) appraised and established the value of the technology. The government also promoted the securitization of technology assets by using technology as collateral for loans; this was designed to help SMEs borrow money using their technology.

To increase knowledge transfer from universities, the government also provided money through several initiatives. First, 150 billion Won (KRW) was spent on the Connect Korea project between 2006 and 2010 , the main goal being to invigorate the regional economy by improving KTOs' ability to support knowledge transfer and commercialization. Second, the Hub University for Industrial Collaboration (HUNIC) project from 2004 to 2011 saw a budget of KRW 31 billion per year split among seventeen to twenty-three universities and colleges chosen by the government, with each receiving between KRW 0.8 and 4 billion per year. Third, the Leaders in Industry-University Cooperation (LINC) project, from 2012 to 2016 increased the number of supported universities and colleges to eighty, while the project budget increased to approximately KRW 250 billion per year.

Yoon (2013) estimates that from 2004 to 2012, the government provided 473 university companies with KRW 119 billion in total. Accordingly, the number of university technology transfer contracts increased from 1,615 in 2010 to 3,247 in 2014. Universities' income from licensing also increased from KRW 37.6 billion in 2010 to KRW 57.6 billion in 2014 . The ratio of license income to $\mathrm{R} \& \mathrm{D}$ expenditure at universities increased from 0.94 percent in 2010 to 1.23 percent in 2014 (KRF 2016).

A new Market-Driven IP and Technology Transfer Promotion Plan, announced in April 2015, emphasized the maximization of market value from knowledge transfer. First, protection of intellectual property rights was strengthened. Previously, a specialized patent dispute court had been available only for first-instance legal disputes; this was extended to cover second-round disputes, meaning rulings at both levels would be based on more specialized expertise. The Plan also contemplated increasing the maximum punitive damages limit to three times the estimated damage amount, as was the case in US practice (Presidential Council on Intellectual Property 2015).

Second, the government relaxed some regulations that had resulted in low efficiency of knowledge transfer. To encourage patent quality in terms of commercialization, it changed the major performance evaluation yardstick to efficiency of knowledge transfer (calculated as license income divided by the cost of $\mathrm{R} \& \mathrm{D}$ ). However, the outcome of this 
change remains to be seen. Previously, knowledge transfer had focused exclusively on domestic SMEs, but this restriction has been relaxed to include large or foreign firms, which may now also benefit from obtaining technologies from public research institutes (Presidential Council on Intellectual Property 2015). Restrictions regarding exclusive licensing were also relaxed, and public research institutes were given greater autonomy in choosing between exclusive and nonexclusive licensing. Regarding co-owned patents, the Plan allowed third parties to practice such patents if firms with co-ownership were not practicing them.

The Plan encouraged technology transfer agents or KTOs to identify firms' technology needs, then help firms to connect with public research institutes capable of developing the required technology. It also encouraged KTO staff to participate in R\&D from the beginning so that $R \& D$ projects reflected firms' needs. To improve KTOs' capabilities, the government started to allow several public research institutes and universities to share one joint KTO, especially where a public research institute or university was unable to afford its own independent KTO. The government also gradually increased spending on KTOs as a share of total R\&D expenditure from 1.3 percent in 2010 to 3.3 percent in 2015. It provided fifty KTOs with KRW 9 billion per year between 2011 and 2015 (Presidential Council on Intellectual Property 2015). However, as we discuss later, the expected results of this have yet to be realized.

\subsection{The Extent of Knowledge Transfer from Public Research in the Republic of Korea}

Public R\&D expenditure increased from KRW 3.8 trillion (USD 3.37 billion) in 2000 to KRW 15.28 trillion (USD 14.5 billion) in 2014 . The ratio of public R\&D expenditure to GDP also increased, from 0.63 percent in 2000 to 1.03 percent in 2014. The number of public research institutes rose by 80 percent between 2000 and 2014. Table 6.1 shows the trend of public R\&D expenditure and the number of public research institutes and universities from 2000 to 2014. The R\&D activities of both universities and public research institutes are funded by the government - in 2014, 91.2 percent of public research institutes' R\&D expenditure and 86.6 percent of universities' $R \& D$ expenditure was government funded. ${ }^{2} \mathrm{R} \& \mathrm{D}$ expenditure and the number of research institutes has increased, as has R\&D output activity. Thus, the share of

${ }^{2}$ KIAT surveys. 
Table 6.1 Public R\&D expenditure and number of Korean public research institutes and universities, 2000-14

\begin{tabular}{|c|c|c|c|c|c|}
\hline Year & $\begin{array}{l}\text { Public R\&D } \\
\text { expenditure } \\
\text { (KRW million) }\end{array}$ & $\begin{array}{l}\text { Public R\&D } \\
\text { expenditure } \\
\text { (USD million) }\end{array}$ & $\begin{array}{l}\text { Public R\&D } \\
\text { expenditure as } \\
\text { a share of GDP (\%) }\end{array}$ & $\begin{array}{l}\text { Number of public } \\
\text { research institutes }\end{array}$ & $\begin{array}{l}\text { Number of } \\
\text { universities }\end{array}$ \\
\hline 2000 & $3,816,850$ & 3,375 & 0.63 & 164 & 368 \\
\hline 2001 & $4,361,534$ & 3,378 & 0.67 & 152 & 357 \\
\hline 2002 & $4,739,957$ & 3,789 & 0.66 & 141 & 389 \\
\hline 2003 & $4,876,225$ & 4,091 & 0.64 & 154 & 398 \\
\hline 2004 & $5,446,050$ & 4,756 & 0.66 & 159 & 403 \\
\hline 2005 & $5,877,167$ & 5,739 & 0.68 & 150 & 332 \\
\hline 2006 & $6,632,101$ & 6,945 & 0.73 & 151 & 294 \\
\hline 2007 & $8,177,479$ & 8,802 & 0.84 & 193 & 361 \\
\hline 2008 & $9,249,253$ & 8,393 & 0.9 & 202 & 376 \\
\hline 2009 & $10,888,944$ & 8,527 & 1.02 & 236 & 391 \\
\hline 2010 & $12,270,228$ & 10,614 & 1.05 & 237 & 385 \\
\hline 2011 & $13,003,277$ & 11,736 & 1.05 & 237 & 385 \\
\hline 2012 & $13,822,078$ & 12,275 & 1.09 & 245 & 378 \\
\hline 2013 & $14,241,744$ & 13,006 & 1.00 & 269 & 414 \\
\hline 2014 & $15,275,007$ & 14,506 & 1.03 & 296 & 411 \\
\hline
\end{tabular}

Source: Ministry of Science, ICT, and Future Planning, Survey of Research and Development in Korea, 2001-15

${ }^{*} \mathrm{R} \& D$ expenditure includes expenditure on all subjects, including social sciences and humanities. It also includes expenditure on administrative support staff. 
Korean-authored science and technology papers among world SCI papers increased from 1.74 percent in 2000 to 3.64 percent in 2013 while the Republic of Korea's share of granted patents among total US utility patents grew from 2.1 percent in 2000 to 6.01 percent in 2015 (USPTO).

The enactment of the Technology Transfer Promotion Act in 2000 encouraged IP commercialization and as a result, 54.6 percent of public research institutes and universities had KTOs by 2014. The rate of knowledge transfer reached 31.7 percent in 2014, which is similar to the rates in Europe (33.5 percent in 2008) and the U.S. (25.6 percent in 2008) (KIAT 2012). ${ }^{3}$ As shown in Table 6.2, there was a steep rise in the number of domestic patent applications by public research institutes, which increased thirteen-fold between 2000 and 2015. The number of domestic patent applications by universities increased even faster, by thirty-two times, during the same period.

Table 6.3 shows that other outputs of R\&D activity from universities and public research institutes also increased from 2007. ${ }^{4}$ The average number of newly developed technologies per institute increased from 70.4 in 2007 to 107.1 in 2014. The average number of transferred technologies per institute rose from 13.4 in 2007 to 30.2 in 2014 .

However, the efficiency of commercialization of research output from public research institutes and universities did not improve, even though outputs from R\&D activity increased. The ratio of license income to $R \& D$ expenditure in public research institutes and universities was 1.38 percent in 2009; it remained at 1.35 percent in 2014. Korean public research institutes and universities had over 190,000 technologies in 2012, but 154,000 of these were not commercialized (Lee and Kim 2015). One explanation could be the short history of IP commercialization by licensing. Korean public research institutes and universities previously provided the country's firms with many free new technologies and KTOs were only established after 2000. Thus, the KTOs of Korean public research institutes and universities have not acquired enough experience in, or developed enough capacity for, IP commercialization. The average number of KTO staff per institute was only 2.7 full-time equivalent in

3 The rate of technology transfer is defined as the ratio of the number of transferred technologies to the number of newly developed technologies.

${ }^{4}$ Relevant data are available since 2007, when the government of the Republic of Korea started conducting a survey of knowledge transfer by public research institutes and universities. 
Table 6.2 Number of domestic patent applications by public research institutes and universities 2000-15

\begin{tabular}{|c|c|c|c|c|c|c|c|c|c|}
\hline \multirow[b]{2}{*}{ Year } & \multicolumn{3}{|c|}{ Total } & \multicolumn{3}{|c|}{ Public research institutes } & \multicolumn{3}{|c|}{ Universities } \\
\hline & Number & $\begin{array}{l}\text { Per } 1,000 \\
\text { researchers }\end{array}$ & $\begin{array}{l}\text { Per USD } \\
1 \mathrm{~m} \text { R\&D } \\
\text { expenditure }\end{array}$ & Number & $\begin{array}{l}\text { Per } 1,000 \\
\text { researchers }\end{array}$ & $\begin{array}{l}\text { Per USD } \\
1 \mathrm{~m} \mathrm{R \& D} \\
\text { expenditure }\end{array}$ & Number & $\begin{array}{l}\text { Per } 1,000 \\
\text { researchers }\end{array}$ & $\begin{array}{l}\text { Per USD } \\
1 \mathrm{~m} \mathrm{R} \& \mathrm{D} \\
\text { expenditure }\end{array}$ \\
\hline 2000 & 2,302 & 35.1 & 0.72 & 1,675 & 120.4 & 0.93 & 627 & 12.1 & 0.45 \\
\hline 2001 & 2,735 & 40.4 & 0.92 & 2,024 & 145.4 & 1.21 & 711 & 13.2 & 0.55 \\
\hline 2002 & 3,613 & 50.4 & 1.04 & 2,656 & 188.4 & 1.30 & 957 & 16.6 & 0.67 \\
\hline 2003 & 4,877 & 64.4 & 1.28 & 3,185 & 202.6 & 1.45 & 1,692 & 28.2 & 1.04 \\
\hline 2004 & 5,441 & 71.9 & 1.21 & 3,479 & 221.3 & 1.34 & 1,962 & 32.7 & 1.02 \\
\hline 2005 & 6,862 & 85.4 & 1.26 & 4,292 & 276.9 & 1.38 & 2,570 & 39.6 & 1.10 \\
\hline 2006 & 11,612 & 140.4 & 1.78 & 6,051 & 360.8 & 1.65 & 5,561 & 84.4 & 1.95 \\
\hline 2007 & 14,936 & 145.0 & 1.87 & 6,857 & 327.3 & 1.55 & 8,079 & 98.4 & 2.25 \\
\hline 2008 & 16,704 & 162.1 & 2.17 & 6,892 & 329.0 & 1.63 & 9,812 & 119.5 & 2.81 \\
\hline 2009 & 19,490 & 172.7 & 2.55 & 8,334 & 342.7 & 1.91 & 11,156 & 126.0 & 3.39 \\
\hline 2010 & 21,057 & 175.9 & 2.20 & 9,109 & 347.2 & 1.67 & 11,948 & 127.8 & 2.91 \\
\hline 2011 & 23,781 & 190.9 & 2.25 & 10,220 & 354.9 & 1.70 & 13,561 & 141.6 & 2.98 \\
\hline 2012 & 25,906 & 206.0 & 2.39 & 11,211 & 389.0 & 1.82 & 14,695 & 151.6 & 3.14 \\
\hline 2013 & 27,395 & 213.3 & 2.35 & 11,356 & 364.7 & 1.71 & 16,039 & 164.8 & 3.20 \\
\hline 2014 & 28,408 & 214.2 & 2.16 & 10,398 & 312.0 & 1.35 & 18,010 & 181.3 & 3.29 \\
\hline 2015 & 29,991 & 221.5 & 2.38 & 10,078 & 283.5 & 1.38 & 19,913 & 199.4 & 3.75 \\
\hline
\end{tabular}

Source: Korean Intellectual Property Office (KIPO), White Papers on Korean Intellectual Property, 2006, 2011, 2016

${ }^{*}$ Domestic patent applications count unique patents applications at the Korean Intellectual Property Office.

* The figure for "researchers" includes those in all disciplines including social sciences and humanities. It also includes PhD students at universities. 
Table 6.3 Output of R\&D activities by Korean public research institutes and universities - new technologies and knowledge transfer, 2007-14

\begin{tabular}{|c|c|c|c|c|c|c|}
\hline \multirow[b]{2}{*}{ Year } & \multicolumn{3}{|c|}{ Number of new technologies } & \multicolumn{3}{|c|}{ Number of transferred technologies } \\
\hline & $\begin{array}{l}\text { Per } \\
\text { institute }\end{array}$ & $\begin{array}{l}\text { Per } 1,000 \\
\text { researchers }\end{array}$ & $\begin{array}{l}\text { Per USD } \\
1 \mathrm{~m} \text { R\&D } \\
\text { expenditure }\end{array}$ & $\begin{array}{l}\text { Per } \\
\text { institute }\end{array}$ & $\begin{array}{l}\text { Per } 1,000 \\
\text { researchers }\end{array}$ & $\begin{array}{l}\text { Per USD } \\
1 \mathrm{~m} \text { R\&D } \\
\text { expenditure }\end{array}$ \\
\hline 2007 & 70.4 & 139.89 & n.a. & 13.4 & 38.38 & n.a. \\
\hline 2008 & 59.8 & 152.12 & n.a. & 12.4 & 33.62 & n.a. \\
\hline 2009 & 80.7 & 140.78 & 2.65 & 14.0 & 32.02 & 0.60 \\
\hline 2010 & 88.2 & 180.48 & 2.54 & 16.8 & 41.69 & 0.59 \\
\hline 2011 & 81.3 & 155.08 & 2.32 & 20.6 & 40.28 & 0.60 \\
\hline 2012 & 94.9 & 205.21 & 2.47 & 25.5 & 55.55 & 0.67 \\
\hline 2013 & 88.4 & 258.83 & 2.65 & 27.6 & 80.64 & 0.83 \\
\hline 2014 & 107.1 & 256.97 & 2.72 & 30.2 & 81.51 & 0.86 \\
\hline
\end{tabular}

Source: Korea Institute for Advancement of Technology (KIAT), Survey of knowledge transfer by public research institutes and universities

2014 with an average work experience within the KTO of just 2.6 years (KIAT 2016). ${ }^{5}$

These average figures mask very different performance between the best and worst public research institutes and universities. Licensing incomes are highly concentrated among a small number of top public research institutes, but less concentrated in the case of universities. The five leading public research institutes received 64 percent of total public research institute license income in 2014, whereas the top five universities obtained 27.9 percent of total university license income in 2014. The leading public research institutes ${ }^{6}$ had a ratio of license income to R\&D expenditure of 2.11 percent in 2014. In contrast, university knowledge transfer was less efficient, with a ratio of license income to R\&D expenditure of 1.16 percent. Leading universities performed much worse than the average - the ratio of license income to R\&D expenditure of the five leading universities was only 0.93 percent. As Ok and Kim (2009) note, Korean universities focused on education rather than research until the

${ }^{5}$ Other possible reasons for this low efficiency are dealt with in Section 6.5.

${ }^{6}$ The top twenty-five public research institutes include ETRI and the Korea Institute of Science and Technology (KIST). 
1980s, so their research capability and commercialization ability was even lower than that of public research institutes.

The emphasis on knowledge transfer since 2000 has led public research institutes and universities to develop more transferrable technologies at the expense of technology quality. Further, universities and public research institutes may have split technologies into many small patents to help maximize their scores in performance evaluation. There are several indicators of this. The share of transferred technology among the total number of valid knowledge transfer contracts that resulted in increased sales was 14.1 percent in 2009, but had fallen to 12.4 percent in 2014. License-based incomes per institute from knowledge transfer did not increase. The average license income per institute was KRW 625.2 million (USD 0.67 million) in 2007, falling to KRW 561.3 million (USD 0.53 million) in 2014. Since the average number of transferred technologies per institute has increased since 2007 (see Table 6.3), we can infer that the average license income per transferred new technology has fallen. Average license income per transferred technology was KRW 40 million (USD 36,300) in 2008, but KRW 18 million (USD 16,440) in 2013. Table 6.4 presents these statistics.

If we compare leading Korean and US universities, the number of transferred technologies (license agreements) is similar. The total knowledge transfers per year by the Seoul National University (SNU) is seventy-nine, and the figure for Stanford University is 101. However, average license income per transferred technology shows a huge gap. Average license income per transferred technology for the SNU is KRW 58 million, but for Stanford it is KRW 734 million. One of the main reasons is that Stanford has several patents, such as a Google-licensed search patent, which earn lots of money. Three important patents earned 75 percent of Stanford's license income from 2000 to 2010.

Another possible reason for this low efficiency is that the focus of knowledge transfer in public research institutes in the Republic of Korea switched from big businesses to SMEs. SMEs cannot usually pay high license fees due to their limited financial resources. Large firms and foreign firms can pay higher license fees, but the government of the Republic of Korea made the country's public research institutes prioritize knowledge transfer to domestic SMEs over large or foreign firms in an attempt to reduce the huge productivity gap between large firms and SMEs. Fully 90.7 percent of knowledge transfer contracts from public research institutes were concluded with SMEs in 2014. License income 
Table 6.4 Output of R\&D activities by Korean public research institutes and universities - license income, 2007-14

\begin{tabular}{|c|c|c|c|c|c|}
\hline \multirow[b]{2}{*}{ Year } & \multicolumn{3}{|c|}{ License income } & \multirow[b]{2}{*}{$\begin{array}{l}\text { License income } \\
\text { as a share of } \\
\text { R\&D expend- } \\
\text { iture (\%) }\end{array}$} & \multirow[b]{2}{*}{$\begin{array}{l}\text { Knowledge transfers resulting } \\
\text { in sales as a share of the total } \\
\text { number of valid knowledge } \\
\text { transfer contracts (\%) }\end{array}$} \\
\hline & $\begin{array}{l}\text { Per institute } \\
\text { (USD } \\
\text { million) }\end{array}$ & $\begin{array}{l}\text { Per } 1,000 \\
\text { researchers } \\
\text { (USD million) }\end{array}$ & $\begin{array}{l}\text { Per transferred } \\
\text { technology } \\
\text { (USD } \\
\text { thousand) }\end{array}$ & & \\
\hline 2007 & 0.67 & 1.24 & n.a. & n.a. & n.a. \\
\hline 2008 & 0.45 & 1.22 & 36.30 & n.a. & n.a. \\
\hline 2009 & 0.33 & 0.74 & 22.71 & 1.38 & 14.1 \\
\hline 2010 & 0.49 & 1.05 & 25.09 & 1.48 & 18.3 \\
\hline 2011 & 0.59 & 0.88 & 21.66 & 1.32 & 23.6 \\
\hline 2012 & 0.74 & 1.22 & 22.20 & 1.47 & 33.6 \\
\hline 2013 & 0.45 & 1.33 & 16.44 & 1.36 & 15.9 \\
\hline 2014 & 0.53 & 1.27 & n.a. & 1.35 & 12.4 \\
\hline
\end{tabular}

Source: KIAT, Survey of knowledge transfer by public research institutes and universities, 2008-15

${ }^{*}$ License incomes include both lump-sum payments and running royalties. 
per transferred technology was KRW 15.39 million from SMEs and KRW 52.51 million from large firms in 2014.

As regards the sectoral distribution of transfer activity from universities, Kwon et al. (2014) analyzed 5,249 knowledge transfer contracts between universities and firms from 2011 to 2013 to identify the number of contracts by industry. Table 6.5 shows the top seven industries by the number of knowledge transfer contracts. The electronic parts, video, sound, and communication equipment industry accounted for the largest share in terms of both the number of knowledge transfer contracts and license income, which is reasonable given that this is the major industry in the Republic of Korea. The IT services and software industry also had a large number of knowledge transfer contracts. The textile and food industries had a relatively large number of contracts, but their license income was small. Thus, the size of knowledge transfer contracts is small in these industries.

The Science and Technology Policy Institute (STEPI) conducts a survey every two or three years to reveal the sources of innovation for Korean firms' innovation activities. In this survey, STEPI asks firms about the major sources of information/knowledge for their R\&D activities. In their answers, firms identify universities, research institutes (public or private) or other sources such as in-house, suppliers and customers as their main source of information. Table 6.6 summarizes the main findings in this regard.

Research institutes are used more in the electronic and chemical industries, perhaps because these have been the major industries in the Republic of Korea since the 1970s and have a long history of collaboration with public research institutes. Universities are used more in the other machinery and medical and optical instruments industries. The medical and optical instruments industry is science-based and depends more on universities than other industries. The food and textiles industries depend on both universities and research institutes.

Korean universities interact with both local and foreign firms, but the share of foreign firms is small. According to Kwon et al. (2014), only 1.4 percent of knowledge transfer contracts from Korean universities in 2012 were with foreign firms and they accounted for only 0.68 percent of total license income. Most of the interaction occurs between universities and local firms.

\subsection{Knowledge Transfer Channels in the Republic of Korea}

There are various knowledge transfer channels from public research institutes to the private sector, including reading papers, attending 
Table 6.5 University knowledge transfer contracts by industry, 2011-13

\begin{tabular}{lcccc}
\hline \hline Industry & $\begin{array}{l}\text { Number of knowledge } \\
\text { transfer contracts }\end{array}$ & $\begin{array}{l}\text { Share of knowledge } \\
\text { transfer contracts (\%) }\end{array}$ & $\begin{array}{l}\text { License income } \\
\text { (KRW million) }\end{array}$ & $\begin{array}{c}\text { Share of license } \\
\text { income (\%) }\end{array}$ \\
\hline $\begin{array}{l}\text { Electronic parts, video, sound, } \\
\quad \text { and communication equipment }\end{array}$ & 526 & 13 & 12,748 & 13 \\
$\begin{array}{l}\text { IT services and software } \\
\text { Other machinery and equipment }\end{array}$ & 397 & 10 & 7,291 & 7 \\
Chemicals and chemical products & 290 & 9 & 7,765 & 8 \\
Textiles (excluding clothing) & 274 & 7 & 12,731 & 13 \\
Medical and optical instruments & 261 & 7 & 969 & 1 \\
$\quad$ and watches & 232 & 6 & 12,654 & 13 \\
Food and beverages & & 6 & 2,319 & 2 \\
\hline \hline
\end{tabular}

Source: Kwon et al. (2014) 
Table 6.6 Firms reporting universities or research institutes as sources of innovation information, 2011-13

\begin{tabular}{lcc}
\hline & \multicolumn{2}{c}{ Source of information for innovation activity } \\
\cline { 2 - 3 } & $\begin{array}{l}\text { Universities or other } \\
\text { higher education institu- } \\
\text { tions (\%) }\end{array}$ & $\begin{array}{c}\text { Public or private research } \\
\text { institutes (\%) }\end{array}$ \\
Industry & 15.4 & 20.0 \\
\hline $\begin{array}{l}\text { Electronic parts, video, } \\
\text { sound, and } \\
\text { communication } \\
\text { equipment }\end{array}$ & & \\
$\begin{array}{l}\text { IT services and software } \\
\text { Other machinery and } \\
\text { equipment }\end{array}$ & 14.8 & 10.8 \\
$\begin{array}{l}\text { Chemicals and chemical } \\
\text { products }\end{array}$ & 21.9 & 27.0 \\
$\begin{array}{l}\text { Textiles (excluding } \\
\text { clothing) }\end{array}$ & 14.4 & 15.6 \\
$\begin{array}{l}\text { Medical and optical } \\
\text { instruments and } \\
\text { watches }\end{array}$ & 15.9 & 8.8 \\
\begin{tabular}{l} 
Food and beverages \\
\hline \hline
\end{tabular} & & \\
\hline
\end{tabular}

Source: Science and Technology Policy Institute (STEPI), Korean Innovation Survey, 2014

conferences, IP licensing, employing researchers and graduate students, startups, consulting by researchers, using public research institutes' research facilities, collaborative $\mathrm{R} \& \mathrm{D}$, and informal discussion between firms and public research institutes. These can be classified into formal and informal transfer channels, with formal channels being those based on contracts.

Cho et al. (2007) surveyed 600 Korean firms to study how they cooperate with public research organizations to transfer knowledge. Table 6.7 summarizes their main results. The most common channel of knowledge transfer in the Republic of Korea is collaborative R\&D commissioned by firms. About 60 percent of the firms that cooperate with public research organizations used this channel as the primary cooperation type. Cho et al. (2009) argue that this is because government 
Table 6.7 Primary types of cooperation with public research organizations among surveyed firms

\begin{tabular}{|c|c|c|}
\hline Object of cooperation & $\begin{array}{l}\text { University (percentage } \\
\text { share of each type of } \\
\text { cooperation) }\end{array}$ & $\begin{array}{l}\text { Public research institute } \\
\text { (percentage share of each } \\
\text { type of cooperation) }\end{array}$ \\
\hline $\begin{array}{l}\text { Collaborative R\&D or } \\
\text { commissioned research by } \\
\text { firms }\end{array}$ & 62.9 & 58.0 \\
\hline IP licensing & 2.9 & 4.8 \\
\hline $\begin{array}{l}\text { Using public research } \\
\text { facilities }\end{array}$ & 16.1 & 22.7 \\
\hline $\begin{array}{l}\text { Dispatch of staff between } \\
\text { firms and public research } \\
\text { organizations }\end{array}$ & 3.4 & 1.2 \\
\hline $\begin{array}{l}\text { Startup or joint venture } \\
\text { between firms and public } \\
\text { research organizations }\end{array}$ & 0.3 & 2.7 \\
\hline $\begin{array}{l}\text { Commissioned education of } \\
\text { firms'staff }\end{array}$ & 2.1 & 0.0 \\
\hline $\begin{array}{l}\text { Consulting or lectures by } \\
\text { public research } \\
\text { organization researchers }\end{array}$ & 8.8 & 8.2 \\
\hline $\begin{array}{l}\text { Activities of public research } \\
\text { organization researchers } \\
\text { as official consultants for } \\
\text { firms }\end{array}$ & 3.6 & 2.4 \\
\hline
\end{tabular}

Source: Cho et al. (2007)

supports collaboration between industry and public research organizations in the Republic of Korea. The second most common channel in their survey was use of public research facilities. Twenty percent of firms reported this channel as their primary method. There is no similar category in the equivalent US survey (the 1994 Carnegie Mellon Survey), so direct comparison between the U.S. and the Republic of Korea is difficult, but it is clear that using research facilities are more important to Korean firms than IP licensing or establishing startups. About 10 percent of Korean firms reported consulting and lectures by 
researchers in public research institutes as the primary channel, which makes it less important than consulting in the US survey. Other types of transfer, such as hiring, licensing, education of staff members, and startups are not very significant in the Republic of Korea.

Table 6.7 also shows some differences between public research institutes and universities in the Republic of Korea. Interaction between universities and firms is mostly consulting and training-based while that between public research institutes and firms tends to involve IP licensing, joint ventures, and laboratory infrastructure, seemingly reflecting the fact that universities are education-oriented whereas public research institutes have better research capabilities and facilities.

\subsubsection{Formal Channels in Public Research Institute and University Knowledge Transfer Contracts}

Drawing on the results of the various KIAT surveys of public research organizations in the Republic of Korea (see Appendix for details), Table 6.8 shows the total number of knowledge transfer contracts in public research organizations and the share of each knowledge transfer channel. IP licensing is a more common (formal) knowledge transfer practice than sales of technologies. The share of license contracts among the total number of knowledge transfer contracts was 68.5 percent in 2014 whereas the share of technology sales was only 12 percent. However, freeof-charge licensing also accounts for a significant share of knowledge transfer contracts - 10.7 percent in 2014 - because one of the main goals of Korean public research institutes and universities is to support SMEs by providing them with free technology. As there is a large technology gap between large firms and SMEs, the government has used public research institutes and universities to improve the technological competitiveness of SMEs.

Within IP licensing, lump-sum payment dominates. While there are presently no statistics to prove this, most of the respondents in this study confirm it anecdotally. In contrast, most IP licensing in leading US universities involves running royalties. The low efficiency of the knowledge transfer market involving public research organizations in the Republic of Korea, in the sense that there is a low level of trust on both sides, makes negotiating long-term contracts involving running royalties difficult. This is bad for research organizations as running royalties, proportional to increased sales, may generate a more stable income. 
Table 6.8 Knowledge transfer contracts and share of different types of knowledge transfer, 2007-14

\begin{tabular}{llllc}
\hline \hline & $\begin{array}{l}\text { Number of } \\
\text { knowledge } \\
\text { transfer } \\
\text { contracts }\end{array}$ & $\begin{array}{l}\text { Share of } \\
\text { technology } \\
\text { sales (\%) }\end{array}$ & $\begin{array}{l}\text { Share of } \\
\text { licensing (\%) }\end{array}$ & $\begin{array}{l}\text { Share of free } \\
\text { licensing (\%) }\end{array}$ \\
Year & 2,593 & 22.6 & 65.0 & 6.7 \\
\hline 2007 & 2,641 & 10.8 & 74.2 & 10.0 \\
2008 & 2,918 & 7.7 & 75.7 & 14.8 \\
2009 & 2,940 & 5.9 & 86.3 & 6.1 \\
2010 & 3,420 & 9.6 & 80.7 & 5.2 \\
2011 & 4,312 & 8.9 & 82.5 & 6.5 \\
2012 & 4,358 & 12.3 & 79.3 & 6.0 \\
2013 & 5,981 & 12.0 & 68.5 & 10.7 \\
2014 & 20.3 & & \\
\hline \hline
\end{tabular}

Source: KIAT, Survey of technology transfer by public research institutes and universities, 2008-15

Conversely, no firm was willing to pay a large lump sum because of the uncertain sales potential of the transferred technology.

The total number of startups in 2014 created using technologies from public research institutes and universities was 136; the number of startups by staff (spinoffs) was 108; the number of startups by other people using public research IP was twenty-eight; and the average number of startups per institute was 0.54 , which is relatively small compared to rates in the U.S. and other countries. However, several leading public research institutes created more startups: twenty-four leading public research institutes under the auspices of the National Research Council of Science \& Technology (NST) created forty-one startups, and the average number per institute was 1.7 (KIAT 2016).

One special type of startup from public research institutes is the "laboratory company," which is defined in the Special R\&D Zone Promotion Act 2005. If a startup from a public research institute is located in a special $R \& D$ zone and the institute invests more than 20 percent of the capital, then it can be authorized as a laboratory company and exempt from tax for three to seven years. The technology of public research institutes can be regarded as the startup's 
Table 6.9 Laboratory companies - sales and employment, 2009-15

\begin{tabular}{lcc}
\hline \hline Year & Sales (KRW billion) & Employment \\
\hline 2009 & 28.3 & 237 \\
2010 & 43.0 & 272 \\
2011 & 72.4 & 310 \\
2012 & 120.8 & 524 \\
2013 & 164.3 & 639 \\
2014 & 236.5 & 850 \\
2015 & 288.1 & 1,194 \\
\hline \hline
\end{tabular}

Source: INNOPOLIS Foundation (www.innopolis.or.kr/sub0303)

capital, so it is not difficult for such startups to be authorized as laboratory companies.

In 2016, there were 219 laboratory companies in the five special $R \& D$ zones (Daedeok, Daegu, Busan, Gwangju, and Jeonubuk). Due to government support and advanced technologies from public research organizations, their sales increased tenfold and their employment increased fivefold between 2009 and 2015, as shown in Table 6.9. The five-year survival rate of laboratory companies was about 64.9 percent, more than double the survival rate of normal startups (29.6 percent) (Ministry of Science, ICT, and Future Planning 2014).

\subsubsection{Qualitative Evidence of Successful Knowledge Transfer}

IP licensing by ETRI represents a case study of successful licensing. ETRI is the largest public research institute in terms of both R\&D expenditure and license income. It earned KRW 34.6 billion from licensing in $2014-$ about a quarter (24.7 percent) of the total license income of all Korean public research organizations. Its ratio of license income to total $R \& D$ expenditure is 8.4 percent - the highest ratio among Korean public research organizations.

One example of successful IP licensing at ETRI involved a company called Initech, an IT security system company that started in 1997 with two employees. Its core technology is a user authentication solution based on public-key infrastructure (PKI) which ETRI transferred to it through IP licensing in December 1999. In the late 1990s, the number of 
users of Internet and e-commerce increased rapidly, and so IT security in e-commerce became important. ETRI started research into authentication servers and systems in 1995, as a project for the Korean Ministry of Information and Communication. At an early stage of R\&D, ETRI identified potential users of the technology, such as public financial institutions (e.g., the Korea Financial Telecommunications \& Clearing Institute). Within four years, ETRI had developed an "authentication processing protocol and verification technology," and transferred this technology to Initech.

Public-key infrastructure is the system relating to the generation, authentication, distribution and management of public-key encryption, a method of data encryption that uses different keys for encryption and decryption. It is a more secure method than its predecessor, secret-key encryption, and became widely adopted as demand from e-commerce and Internet banking increased. Even after knowledge transfer, researchers in ETRI frequently helped Initech to further develop its own system and service.

Apart from the favorable demand conditions, government policy also contributed to the success of Initech. The government recognized the PKI-based technology as the industry standard in 1999, encouraging more domestic users to adopt it. In turn, this helped the rapid growth of Internet banking and e-commerce.

Although several hundreds of technology startups existed in 2014, most remained small and did not develop a stable growth path. One of the most successful cases of a startup from a public research institute comes from the Korea Atomic Energy Research Institute (KAERI). KAERI is the third-largest public research institute in the Republic of Korea. It started to develop health-promoting functional foods focusing on boosting immunity in 1997. Researchers at KAERI recombined medicinal herbs such as dong quai, cnidium, and white woodland peony using radiation technology. It took six years to develop the original technology ${ }^{7}$ and cost KRW 1.2 billion in R\&D. Researchers at KAERI were confident of the quality of their product and decided to establish a company, reaching an agreement with a private company, Kolmar Korea, in 2001. KAERI had transferred other technologies to Kolmar Korea before 2001, and so Kolmar Korea was interested in its new technology.

\footnotetext{
7 The Korean Economic Daily, "10 Billion Won in Royalties for Research," May 23, 2015, www.hankyung.com/news/app/newsview.php?aid=2015032265091.
} 
However, KAERI faced a difficulty as government-appointed directors on its board opposed the agreement, arguing that public research institutes should not engage in income-generating businesses and that there was no precedent for a public research institute providing funds to establish a company. ${ }^{8}$ This is interesting because the government of the Republic of Korea had already enacted the Technology Transfer Promotion Act 2000 and mandated public research institutes to establish KTOs.

No company was established for three years. However, finally KAERI changed its strategy and chose technology investment, which meant that the value of KAERI's technology was regarded as capital and so it did not have to invest any cash. This plan persuaded the government, so KAERI and Kolmar Korea co-established a company, Sunbiotech, in 2004. Sunbiotech can be classified as a joint venture, as the value of KAERI's technology was approved as KRW 378 million and Kolmar Korea invested KRW 622 million as capital.

Sunbiotech's sales were poor at first because the product did not obtain approval from the government as a functional health food. The company achieved total sales of between KRW 0.8 and 1.2 billion between 2004 and 2006. Finally, in 2006, it obtained approval for the product as a functional food from the Ministry of Food and Drug Safety. This was one of the first approvals in the Republic of Korea for a functional food that improves immunity. It also obtained authorization from the government as the first laboratory company under the Special R\&D Zone Promotion Act 2006. Using that governmental authorization, it was able to sell its products as health-promoting, functional foods that improve immunity. It grew rapidly, with sales increasing from KRW 3.8 billion in 2007 to KRW 9.9 billion in 2008 and KRW 20.1 billion in 2009 (Ham 2015). By 2013, sales reached KRW 121.5 billion and the company's name was changed to Kolmar BNH. It was floated on the KOSDAQ stock market in 2015.

The sales and operating profit of Kolmar BNH reached KRW 236.2 billion and KRW 34.4 billion respectively in 2015, by which time the company had 156 employees. By July 2016, its market value stood at around KRW 1 trillion. KAERI held 16.1 percent of Kolmar BNH's stock at the time of the IPO, and earned over USD 100 million, a sum greater than the total license income of all Korean public research institutes in 2014. The case of Kolmar BNH thus shows the potential of startups and

8 In-soon Jang (former president of KAERI), EconomyTalk (Korean Press), September 2015, www.econotalking.kr/news/articleView.html?idxno=129290. 
joint ventures in knowledge transfer and commercialization. Following the success of Kolmar BNH, the government of the Republic of Korea changed its attitude and started to actively support public research organization startups.

The KAERI KTO played an important role in the success of Kolmar $\mathrm{BNH}$ as it started to apply for Korean and international patents on the core ingredients of the product between 2000 and 2003, just three years after the start of its $\mathrm{R} \& \mathrm{D}$ activities. It applied for the trademark "HEMOHIM" in relation to its products in 2002.

Another factor in Kolmar BNH's success was reputation. KAERI has a fifty-year history and is well known as the third-largest Korean public research institute, so Korean consumers trusted the product more than products from other startups. The stability and safety of the product are very important factors to consumers in the functional health food market, so the reputation of KAERI helped Kolmar BNH to survive in its early stages.

As in the case of Initech, demand also helped Kolmar BNH to succeed. As income levels in the Republic of Korea rose, people started to pay more attention to their health and the market size for functional health foods increased rapidly. Production of functional health foods in the Republic of Korea increased from KRW 700.8 billion in 2006 to KRW 1.48 trillion in 2013, and the annual growth rate was 11.5 percent during this period (Ham 2015).

A further factor explaining the company's success was the management skill available from a private firm. A typical problem in public research organization startups is the lack of sound management skills. However, Kolmar BNH was a joint venture with the private sector, and the managers and employees of Kolmar BNH had the benefit of the management knowhow of Kolmar Korea.

\subsubsection{Informal Knowledge Transfer Channels}

As seen in Table 6.7, the proportion of firms that actually use formal channels is small. To detail other knowledge transfer channels, Cho et al. (2009) cite examples that do not use IP licensing or startups. We summarize those examples here.

Company $S^{9}$ is a leading Korean ICT firm that actively cooperates with public research organizations, but it does not use IP licensing or startup

9 The discussion here is based on Cho et al. (2009). 
channels to transfer knowledge from them. Instead, its main knowledge transfer channel is the participation of its staff in seminars or education programs provided by public research organizations. For example, it began research into optical materials in the early 2000s, attracted by the thriving optical industry, but since it lacked basic knowledge about optical materials, it sent researchers to participate in relevant university seminars.

It also uses researchers from public research organizations as consultants. Company $S$ has built a network of specialists, and consults them about technology trends and information in their specialized fields. To do this, it undertakes an annual program of twenty-thirty technology seminars with them. In addition, the CEO of the company holds periodic meetings with key experts. It usually consults researchers in public research organizations about the market or technology situation for emerging technology. For instance, it consulted researchers at the Korea Institute of Energy Research about the market prospects and technology when solid oxide fuel cell technology was regarded as promising.

A third knowledge transfer channel is collaborative R\&D. As technological convergence/fusion has deepened, Company $S$ has needed collaborative $R \& D$ because it does not have research capability in some technology fields. For example, it needed film-coloring technology for PDP (plasma display panel) filters, but did not have research capability in that field. It therefore collaborated with SNU to develop the technology. It obtained basic knowledge about the technology through a year of collaborative research.

However, Company S has not used IP licensing for knowledge transfer. There has been no case of licensing or joint venture with public research institutes. It has previously concluded license contracts with firms in an advanced country, but has not licensed technology from domestic public research organizations. The main reason seems to be that as Company $S$ has recently become a leading ICT firm in the global market, it needs world-class technology to compete, but domestic public research organizations do not offer research capability at a sufficiently high level.

Using research facilities is the second most used knowledge transfer channel in the Republic of Korea, as shown in Table 6.7. However, Company $\mathrm{S}$ has not used research facilities in public research organizations, presumably because it is a big firm and has most of the research facilities that public research organizations have and so does not need to use external facilities. 
Company $\mathrm{S}$ has barely used basic research outputs from public research organizations such as reports, papers, and patents because basic research is not relevant to the company's technology roadmap.

In sum, leading companies such as Company $S$ primarily use public research organizations as consultants, trainers of their staff, and partners in collaborative research. However, they barely use research outputs such as papers, patents, and technologies produced by public research organizations, which might reflect the relatively low level of research capability of such organizations.

Another example of knowledge transfer channels that shows the importance of informal channels is ViroMed Inc. ViroMed was established by Professor Sun-Young Kim from SNU in 1996. Its main products include DNA, protein, and cell-based biotherapeutics that can treat incurable diseases such as diabetic peripheral neuropathy, peripheral artery disease, amyotrophic lateral sclerosis (Lou Gehrig's disease), and thrombocytopenia.

Professor Kim received KRW 150 million in government funding as part of a leading technology development project in 1994. It was a joint project with a firm. Professor Kim's team achieved positive results concerning DNA-based biotherapeutics in 1996. They published their results in Science in 1996 and applied for patents in 1997. After these results, Professor Kim suggested that a firm participating in the project invest and commercialize the product, but the firm refused due to the high risk in the biotherapeutics sector. Following a presentation by Professor Kim at an international conference, a UK venture capital company indicated its intention to invest in his research. Using that investment, Professor Kim established ViroMed in 1996.

ViroMed agreed to a technology export contract with Oxford Biomedica, a UK firm, in 1997, and Takara Shuzo, a Japanese firm, in 1999. On the basis of this export agreement, ViroMed was able to attract both domestic and foreign investment. It was floated on the KOSDAQ stock market in 2005. Its market value reached KRW 1.64 trillion in October 2016, following sales of KRW 7.7 billion and operating income of KRW 1.1 billion in 2015. Its market value is high compared to its sales and operating income because clinical trials of its major products have yet to be completed, even though those products are regarded as high quality. As of October 2017, some of its biotherapeutics are in phase III clinical trials (the final step before coming to market) and some are in phase II in the U.S., China, and the Republic of Korea. 
Informal channels of knowledge transfer are important, as shown in the ViroMed case, which was established because a UK venture capital firm was interested in its work after learning about it at an international conference.

Another important informal channel is the use of research facilities at public research organizations. The initial capital of ViroMed was only KRW 200 million and, as such, it did not have enough money to buy research facilities. To solve this problem, SNU allowed Professor Kim and ViroMed to use its research facilities. Without such support, ViroMed would not have been able to continue its research.

A third informal knowledge transfer channel involves hiring graduate students. ViroMed started in the form of a "university company," so Professor Kim could work with graduate students in his laboratory at SNU, thus providing ViroMed with high-quality personnel.

One distinctive feature in ViroMed's case is that knowledge transfer to domestic firms is very hard. Unlike Korean ICT firms, Korean pharmaceutical firms have been very reluctant to invest in high-risk projects. They have been used to licensing-in foreign technology. This case shows that domestic industrial capability can affect knowledge transfer from public research organizations. Low industrial capability means that domestic firms have insufficient knowledge and are unable to properly evaluate the potential and risks of new technology. Professor Kim indicated that the most serious problem during the growth process of ViroMed was technology evaluation (Cho et al. 2009).

\subsubsection{The Government-Funded Nonpracticing Entity}

One distinctive feature of knowledge transfer in the Republic of Korea is the existence of a government-funded IP nonpracticing entity (NPE). This approach began in 2010 to protect domestic firms against patent infringement lawsuits by global NPEs or patent trolls. At that time, US private NPEs started buying many Korean patents from public research organizations, sparking public concern that they might use them to file IP lawsuits against domestic firms, taking advantage of the fact that most Korean firms did not seriously consider IP issues at that time. To prevent this possibility, the government decided to set up an entity serving as a pool of patents owned by Korean agents. Thus, the government and big businesses invested about KRW 58 billion and established an IP NPE with the name of Intellectual Discovery (ID), one of the first 
government-funded IP NPEs in the world; other countries such as Japan, China, and France have since followed suit.

Intellectual Discovery, ranked sixth globally, buys domestic and foreign patents, and had a portfolio of about 5,000 patents by 2016. Its first objective is to protect domestic firms from patent infringement lawsuits. Big firms that funded it initially and have paid license fees can use the patents that it owns. SMEs can obtain membership and license patents by paying a relatively small fee. If foreign firms or NPEs file a lawsuit against domestic member firms, ID provides them with professional help and even some patents which can be used defensively for cross-licensing. If foreign firms or NPEs violate patents that ID holds, ID can charge them with patent infringement and, on behalf of any domestic firm, negotiate for settlement and for legal process.

\subsubsection{Important Factors in Knowledge Transfer}

The cases cited earlier show the important factors in each type of knowledge transfer channel. The cases of Initech and Kolmar BNH show the importance of follow-on/adaptive R\&D by public research institutes after initial knowledge transfer, which is consistent with the results of the qualitative analyses of Kim (2012) and Lee et al. (2015). Furthermore, the case of Kolmar BNH shows the benefits of having a joint venture with existing firms, allowing it to draw on the management skills of the parent companies. Nevertheless, the fact that both were supported by favorable demand conditions suggests it might not be easy to obtain successful results by IP licensing or through a startup if demand conditions are poor.

The cases of Company S and ViroMed show the importance of contract/collaborative research and using facilities in the public sector for knowledge transfer from the public science base. Company $S$ relies on collaborative $\mathrm{R} \& \mathrm{D}$ and consulting, whereas ViroMed relies on using research facilities in public research institutes. The Company $S$ case suggests that the level of research capability of public research institutes may be an important success factor for knowledge transfer, as we argued in Section 6.2. The ViroMed case shows the importance of informal transfer channels such as conferences, even though firm survey data usually rank these as unimportant. It also shows that knowledge transfer from public research institutes can be more difficult in sectors where the country has relatively weak industrial capacity. This may be related to knowledge transfer from ETRI in the ICT sector being more efficient than that of public research institutes in other sectors. 
Last, the establishment of ID is an institutional innovation, driven by the government of the Republic of Korea to protect domestic firms against patent infringement by hostile foreign actors.

\subsection{Public Policies and Knowledge Transfer Challenges}

The government of the Republic of Korea started focusing on knowledge transfer in 2000 and tried to "create" knowledge transfer markets using various policies and projects. In other words, the major player in the knowledge transfer system was the government itself rather than private agents. However, the country's institutional system for knowledge transfer remains immature, and some of the legacy of the developmental state of the past hinders the realization of a knowledge transfer market. This section will discuss important institutional challenges encountered in the Republic of Korea.

\subsubsection{Institutional Challenges}

One of the first and fundamental challenges is that legal protection of IPR remains weak in the Republic of Korea. Although the country was ranked twenty-ninth among 128 countries for IPR protection in 2016 in the International Property Rights Index (IPRI), actual protection by the courts is weak compared to advanced countries. For example, the probability of the plaintiff winning a patent infringement lawsuit was 20 percent in 2011, far lower than that in the U.S. (60 percent). Furthermore, when the plaintiff did win, average damages from 2009 to 2011 were just KRW 78 million - a mere 0.77 percent of the US figure (Presidential Council on Intellectual Property 2015). The expected payout to the plaintiff was only KRW 15.6 million compared to legal costs of approximately KRW 200 million, severely decreasing the incentive to file a patent infringement lawsuit. In consequence, firms have little incentive to buy licenses or patents from public research institutes if they can obtain technology in other ways, reducing the efficiency of knowledge transfer from public research institutes and depressing the knowledge transfer market.

Weak IPR protection is a legacy of the developmental state during the catch-up period. The major knowledge transfer channel in this period was copying technology from firms in advanced countries. Korean firms did not hesitate to copy good domestic or foreign technology. Furthermore, patent lawsuits were dealt with by the ordinary courts, 
where judges lacked the technological expertise to analyze the issues at stake. While dozens of private knowledge transfer agents exist, their IP business is mainly geared to foreign countries; they do not usually file domestic lawsuits for patent infringement even when the IPRs of their domestic clients are violated.

\subsubsection{Immature Capabilities of Government and the SMEs Sector}

A second set of challenges relate to the government's immature policies for knowledge transfer. One of the clearest examples is co-ownership of patents from publicly funded research. It is often difficult for co-owners to reach consensus about whether to license and, if so, to whom, and as a result co-owned patents tend to be underutilized or under-licensed. Thus, while co-owned patents accounted for around 10 percent of total patents in the Republic of Korea in 2013, only 2.8 percent of patent transactions involved co-owned patents. This problem is especially severe when public research institutes and private firms share a patent. As public research institutes do not have production facilities, they cannot make money directly using shared patents.

A second or related problem concerns types of license. The government has tended to encourage nonexclusive licensing to promote more and wider uses of technologies developed by public research institutes. However, this can undermine the interests of licensee firms, which will generally want to use the technology exclusively to increase their potential profits, and it also fails to offer any extra reward to first-licensee firms, which take a bigger commercial risk than follow-on firms in acquiring technology before its value has been proved in the market. Firms have therefore avoided nonexclusive licensing, reducing licensing income for the public research institutes.

The preferred form of licensing payment is a lump sum. This contrasts with the situation in the U.S., where running royalties make up around 70-80 percent of total license income for the leading universities. And even when a running royalty clause is included in the contract, firms do not usually reveal their true sales from the technology to public research institutes - a serious implementation issue and a possible case of market failure.

Other challenges for knowledge transfer in the Republic of Korea stem from the short history of its knowledge transfer system and the primary role of the government in developing that system. The R\&D process in public research organizations does not fit the needs of SMEs. Until the 
1990s, the major partners of public research institutes included big firms such as Samsung and LG, because their R\&D capability remained weak. However, as their R\&D capability has improved due to large in-house $\mathrm{R} \& \mathrm{D}$ investment, big firms can conduct their own $\mathrm{R} \& \mathrm{D}$ without the support of public research institutes. As a result, SMEs have become the major partners of public research institutes, accounting for 90.7 percent of knowledge transfer contracts with public research institutes in 2014 (KIAT 2016).

As the R\&D capability of SMEs is weak, public research institutes have to develop technology to an advanced stage, until it is ready for commercialization. However, many government-supported $R \& D$ projects do not consider this issue. The normal $\mathrm{R} \& \mathrm{D}$ project duration is two to three years, and public research institutes usually have only completed laboratory-stage development within this period. In terms of technology readiness level (TRL), ${ }^{10}$ SMEs need at least TRL level 7 technologies (technology demonstrated by prototypes in operational environments), but public research organizations usually tend to provide only TRL level 4 technologies (technology validated in labs). Thus, there is a serious gap in of the technology level demanded and supplied, which hinders effective commercialization of $\mathrm{R} \& \mathrm{D}$ conducted in public laboratories.

SMEs cannot successfully commercialize the transferred technology due to their weak R\&D capability. As a result, the technology is not utilized successfully and public research organizations and SMEs tend to blame one another for this failure. It also decreases future private demand for technology from public research organizations. Government therefore needs to provide public research organizations with enough time and funds to complete the technology to a sufficient level. Otherwise, a short-termist reluctance to commit to extra spending decreases the efficiency of public R\&D projects. An interviewee from ETRI said that this is a major barrier in knowledge transfer, which is consistent with the findings of several qualitative studies and case studies that emphasize the importance of follow-on/adaptive (or after-transfer)

10 TRL is an indicator of the completeness of technology development. It has nine levels; the higher the level, the readier the technology is to be implemented in factories. The TRL scale was developed by NASA in the 1970s and is widely used in many fields. The European Commission (2014) describes each level as follows: TRL1 - basic principles observed; TRL2 - technology concept formulated; TRL3 - experimental proof of concept; TRL4 - technology validated in laboratory; TRL5 - technology validated in industrially relevant environment; TRL6 - technology demonstrated in relevant industrial environment; TRL7 - system prototype demonstration in operational environment; TRL8 system complete and qualified; TRL9 - actual system proved in operational environment. 
$\mathrm{R} \& \mathrm{D}$ being provided by public research organizations to ensure successful knowledge transfer.

\subsubsection{Issues with Public Research Institutes and Universities}

One problem is due in part to the specific nature of the project imposed on public research institutes in the Republic of Korea. In the projectbased system, the government allocates R\&D expenses, including the researchers' salaries and overhead costs for each R\&D project. The main goal of the project-based system is to increase the cost efficiency of $\mathrm{R} \& \mathrm{D}$, but it generates some side effects. Researchers at public research institutes have to undertake as many $R \& D$ projects as possible to generate their own income, because the majority of $\mathrm{R} \& \mathrm{D}$ funding is determined by the number of $R \& D$ projects executed and the researchers' salaries are part of the acquired $R \& D$ budget. Furthermore, given that each public research institute's budgetary resources are proportional to the size of the $\mathrm{R} \& \mathrm{D}$ funding it receives, public research institutes incentivize researchers who obtain more $\mathrm{R} \& \mathrm{D}$ projects. Such a system induces researchers to try to obtain as many public $R \& D$ projects as possible. Thus, the average number of $\mathrm{R} \& \mathrm{D}$ projects per researcher per year reached as high as 4.8 in 2011 (Kim and Shim 2013), reducing the amount of time that researchers could spend on each project and diminishing the quality and TRL of $\mathrm{R} \& \mathrm{D}$ results.

Public research organizations also face problems relating to the low capability of KTOs. Despite support from various government laws and projects, KTOs employ small numbers of staff and lack many important skills for successful commercialization. Furthermore, many KTOs implement a staff rotation system, making it difficult for them to accumulate the necessary skills. Incentives for KTO staff to commercialize technologies are weak -61.8 percent of public research organizations gave no license income to any KTO staff in 2014 even if they played a role in the commercialization of technologies (KIAT 2016). The average share of license income going to KTO staff that played a role in successful commercialization in 2014 was just 3.8 percent, discouraging highperforming staff from working in KTOs. The average annual wage of KTO staff in 2014 was about KRW 34 million (less than USD 30,000), close to the national average wage and clearly insufficient to attract highquality workers. Only 20 percent of KTOs hire professional staff such as patent lawyers. 
Weak incentives for staff at KTOs are related to strong incentives for researchers. The Technology Transfer and Commercialization Promotion Act requires a minimum share of license income for researchers of 50 percent. The actual average share of license income going to researchers across public research institutes was 40.8 percent in 2014 (KIAT 2016), but this is greater than in advanced countries such as the U.S. and Germany. It seems that the government is trying to compensate researchers generously because the system for knowledge transfer remains immature, but one consequence is that little or no license income is available for KTO staff and so they have few incentives to conclude licensing deals.

The problem of weak KTO capability is exacerbated by the fact that few public research organizations are willing to provide the knowledge transfer market with high-quality technologies. Instead they prefer to commercialize their best technologies directly using their KTOs. Nevertheless, the capability of most KTOs at public research organizations is weak, except at ETRI and some leading public research institutes. Thus, public research organizations are not in a good position to fully utilize or commercialize high-quality technologies generated in-house, which decreases the efficiency of the knowledge transfer market. One private knowledge transfer agent identified this as a major problem in the Republic of Korea. ${ }^{11}$

The weak capability of KTOs is mainly due to the Republic of Korea's short history ${ }^{12}$ of knowledge transfer and commercialization. The government mandated many public research organizations to establish KTOs in the early 2000s, but it takes time for these KTOs to build capability. During this period, the government should have set up systems whereby private agents could use and commercialize high-quality technologies developed by public research organizations, but these policies are yet to be realized. Thus, this problem is one side effect of the government-driven character of the knowledge transfer system.

Weak KTO capability is related to a third challenge, which concerns the quality of patents. As KTO capability is weak, it is difficult to generate high-quality patents even when high-quality technologies exist. In particular, professionals such as patent lawyers make up only a small

11 This information is based on interviews conducted for the research project report that preceded this chapter.

12 Friedman and Silberman (2003) argue that there is a strong relationship between the age of a KTO and its performance in technology transfer because developing a high-quality portfolio of inventions takes time. 
proportion of KTO staff, so public research organizations cannot obtain high-quality services during the patent application process. Even when public research organizations sign contracts with external professional staff for patent applications, their budget is very small compared to R\&D expenses and, as such, it is difficult to obtain good services. Most interviewees said the budget per patent draft has stagnated - it has remained at about KRW 0.5-1 million (less than USD 1,000) per patent for the last twenty years. This is a very small budget compared to that in the leading global firms, which is about KRW 10 million. One interviewee argued that the budget for drafting each patent application should increase to as much as KRW 5 million - five to ten times the current level. ${ }^{13}$

\subsection{Summary and Concluding Remarks}

Public research institutes played a significant role in economic catch-up in the Republic of Korea by importing and assimilating foreign technologies and knowledge in the 1970s and early 1980s, and by initiating public-private joint $R \& D$ since the late 1980s and 1990s. Universities remained less active in this catch-up process until the 2000s. One of the reasons the Republic of Korea was late in enacting its own version of the Bayh-Dole Act, in comparison to South Africa or Brazil, was the dominance of businesses possessing higher levels of technological capabilities and thus demanding and expecting less from universities. Moreover, these big firms used to collaborate more with government research institutes than with universities.

Since the 2000s, knowledge transfer from universities and public research institutes and its commercialization have become a top policy issue in the Republic of Korea, as the country's technology level converges with that of advanced countries and its economy tries to switch to more science-based or long-cycle-based technology fields (Lee 2013). The Technology Transfer Promotion Act 2000 led to an increase in some quantitative measures of knowledge transfer such as patent applications, and the number of knowledge transfer contracts with public research institutes increased markedly. However, other measures such as the ratio of license income to R\&D expenses did not increase, and average license income per transferred technology fell. The government's emphasis, until recently, on quantitative measures such as patent

13 This point was noted in interviews with private agents. 
applications led to a rapid increase in patent applications by public research organizations, but also caused the quality of patents to fall.

The main channels for knowledge transfer in the Republic of Korea still show some differences from those in advanced countries. The major channels are collaborative/contract-based R\&D between firms and public research organizations funded by firms, which implies no change from the situation in the 1990s as described in Eom and Lee (2010). Informal channels, IP licensing and startups are all minor channels. Our research identifies as one of the most serious problems the fact that the research outputs of public research organizations do not meet the needs of firms, especially SMEs, which have low levels of absorptive capacity. Furthermore, the typical Korean firm still prefers in-house R\&D to licensing from public research organizations. When firms work with public research organizations, they prefer joint/collaborative R\&D to IP licensing.

Since 2000, the government has tried to "create" a knowledge transfer market and initiated various polices and projects. The government forced many public research organizations to have their own KTOs in the early 2000s, but their capability remains weak and the incentive system for them is not strong. In particular, the fees paid to patent attorneys for writing and preparing patent application documents have generally been too low at just KRW $0.5-1$ million per patent for the last two decades, making it very difficult to produce high-quality patents. This problem means that even high-quality inventions and technologies tend to be either undersold or not sold at all in IP markets. As such, and given the abundance of low-quality patents from universities, the typical perception of private firms is that patents and technologies from universities are of low quality and not easily commercialized. Thus, domestic firms have little interest in obtaining licenses or patents from universities and public research institutes. A low level of domestic IPR protection is another reason for this attitude; damages in IP disputes tend to be far lower than in advanced countries. The knowledge transfer system remains immature and some of the legacies from the early "developmental state regime" hinders further development of the knowledge transfer market.

Government policy mandating all public research organizations to have a KTO had several adverse effects. The KTOs ended up being small and lacking sufficient resources. Although they had initial monopoly rights in the research outcomes of their organization, these were often underutilized. This problem of monopoly and related underutilization is more serious in universities than in research institutes. If the patenting 
and marketing activities for university research outcomes were more open to capable private agents, rather than being monopolized by university KTOs, there could have been more successful knowledge transfer. Instead, the KTOs' monopoly has depressed the private knowledge transfer market. The government responded by giving higher shares of license-related income to individual researchers, to strengthen their incentives to commercialize their work, but this reduced the incentives available to KTO staff.

In sum, it can be said that the national innovation system in the Republic of Korea has found it difficult to change from the old catchup mode characterized by the twin dominance of big businesses and the government. Several important factors for successful knowledge transfer from public research organizations, as identified in the literature, are undeveloped in the Republic of Korea: the importance of demandoriented research, monetary incentives for researchers in terms of license income, sufficient weight on knowledge transfer outcomes in the performance evaluation of researchers, and high-quality personnel for KTOs. These are all areas where the Korean system should try to improve to move beyond the catch-up stage. 


\section{Appendix: Data Sources Used in this Chapter}

\section{Nature of the Survey}

We conducted an email survey of thirty-one KTO managers at public research organizations, thirteen at public research institutes and eighteen at universities (five of which are technical universities). Ten organizations are located in Seoul and seven in Daejeon, the two main innovation centers in Korea. Most leading universities are located in Seoul, while most leading public research institutes are located in Daedeok special R\&D zone (part of Daejeon). Other locations include Chungcheong province, Gyeongsang province, Gyeonggi province, Gangwon province, and Jeju island. We divided the thirty-one organizations into fifteen leading and sixteen other organizations according to $\mathrm{R} \& \mathrm{D}$ expenditure in 2014. The average R\&D expense was KRW 170,961 million at the leading organizations and KRW 22,117 million at the others in 2014. The average number of full-time researchers was 868 at the leading organizations and 249 at the others. Full details of the responses to our survey are available at www.keunlee.com.

\section{In-Depth Interviews}

We also conducted seven interviews between August and October 2016: three with staff from public research organizations, two with government officials, and two with knowledge transfer experts in the private sector. These interviews were used to detail the typical knowledge transfer channels.

\section{KIAT Surveys}

Another source of data utilized in this paper is the annual national survey of public research organizations conducted by KIAT (Korea Institute for Advancement of Technology). Most Korean public research organizations are included in the survey, which had a response rate of 94 percent in 2014. The survey was first conducted in 2007 and focuses on a limited number of channels for knowledge transfer (technology contracts, startups, and license income), but not the number of research agreements and use of research facilities of public research organizations by firms. In addition, it only covers knowledge transfer to domestic firms. 


\section{References}

Cho, H.-D., Y.-S. Hwang, W.-D. Kim et al. (2007). The Evolution of Public Research Systems of Major Countries and Policy Recommendation for Korea. Sejong: Science and Technology Policy Institute (in Korean).

Cho, H.-D., C.-G. Min, J.-O. Lee et al. (2009). An Analysis of Impacts and Channels of Public Research on Industrial Innovation in Korea and Policy Recommendations. Sejong: Science and Technology Policy Institute (in Korean).

Eom, B.-Y. and K. Lee (2010). "Determinants of industry-academy linkages and their impact on firm performance: The case of Korea as a latecomer in knowledge industrialization." Research Policy, 39(5): 625-39.

European Commission (2014). Horizon 2020 Work Programme 2014-15. (European Commission Decision C (4995 of 22 July, 2014).

Freeman, C. (1987). Technology Policy and Economic Performance: The Theory and an Application to the Semiconductor Industry. London: Macmillan.

Friedman, J. and A. Silberman (2003). "University technology transfer: Do incentives, management, and location matter?” Journal of Technology Transfer, 28(1): 17-30.

Ham, H.-U. (2015). “A Case Study of Spin-off by a Public Research Institute Kolmar BNH Co. Ltd.” Master's thesis presented to the Department of MOT, Graduate School of Hannam University, Daejon (in Korean).

INNOPOLIS Foundation website: www.innopolis.or.kr/sub0303.

Kim, C.H. (2012). "Case Studies of the Successes and Failures of Commercialization of Technology." Doctoral thesis presented to Hannam University, Daejon (in Korean).

Kim, H.-S. and Y.-B. Shim (2013). "An exploratory study on the interaction model of institutional change of government-funded research institutes: focused on R\&D funding systems." Journal of Digital Policy \& Management, 11(9): 29-43 (in Korean).

Kim, L.-S. (1993). "National system of industrial innovation: dynamics of capability building in Korea." In Nelson, R.R. (ed.), National Innovation Systems: A Comparative Analysis. Oxford: Oxford University Press.

KIAT (Korea Institute for Advancement of Technology) (various editions) Survey of Technology Transfer of PROs and Universities. Seoul: Korea Institute for Advancement of Technology (in Korean).

KIPO (Korean Intellectual Property Office) (2006, 2011, 2016). A White Paper on Korean Intellectual Property. Daejeon, Korean Intellectual Property Office (in Korean).

Korean Council for University Education, Higher Education in Korea website: www.academyinfo.go.kr (in Korean).

KRF (Korea Research Foundation) (2016). A White Paper on University-Industry Cooperation. Seoul: Korea Research Foundation (in Korean).

Kwon, K.-S., I.-W. Seo, H.-G. Kim, S.-H. Kim, and T.-S. Park (2014). The Analysis of Korean Industry-University Collaboration Network. (KRF Issue Report 2014(3)). Seoul: Korea Research Foundation (in Korean). 
Lee, J.-J. (1998). "University research and industry-university cooperation.” In Lee, et al. (eds.), National Innovation System in Korea. Sejong: Science and Technology Policy Institute.

Lee, K. (2013). Schumpeterian Analysis of Economic Catch-Up: Knowledge, Path Creation, and the Middle-Income Trap. Cambridge: Cambridge University Press. Lee, K. and C. Lim (2001). "Technological regimes, catch-up and leapfrogging: Findings from the Korean industries," Research Policy, 30(3): 459-83.

Lee, K., C. Lim, and W. Song (2005). "Emerging digital technology as a window of opportunity and technological leapfrogging: Catch-up in digital TV by the Korean firms." Industrial Journal of Technology Management, 29(1/2): 40-63.

Lee, K.-B., K.-W. Kim, and H.-K. Park (2015). "A study of the success factors for start-ups through technology transfer by public research institutes." Productivity Review, 29(1): 115-42 (in Korean).

Lee, S.-J. and T.-Y. Kim (2015). “A study of determinants of national R\&D projects.” Journal of Korea Technology Innovation Society, 18(4): 590-620 (in Korean).

Lim, C. (2006). Research Issues Derived from the Study of National Systems of Innovation (NI) of Small Advanced National. Sejong: Science and Technology Policy Institute.

Ministry of Science, ICT, and Future Planning (various editions) Survey of Research and Development in Korea. Gwacheon: Ministry of Science, ICT, and Future Planning (in Korean).

Ministry of Science, ICT, and Future Planning (2014). The Performance of INNOPOLIS Research Spin-Offs. Gwacheon: Ministry of Science, ICT, and Future Planning (in Korean).

Ministry of Strategy and Finance, All Public Information In-one System (ALIO) website: www.alio.go.kr (in Korean).

OECD (2003). Turning Science into Business: Patenting and Licensing at Public Research Organizations. Paris: Organisation for Economic Co-operation and Development.

OECD (2008). OECD Review of Korea's Innovation Policy. Interim report presented in Seoul.

Ok, J.-Y. and B.-K. Kim (2009). "Measuring the performance of technology transfer activities of the public research institutes in Korea." Journal of Technology Innovation, 17(2): 131-158 (in Korean).

Presidential Council on Intellectual Property (2015). Market-Driven IP and Technology Transfer Promotion Plan (in Korean).

Property Rights Alliance (2016). The International Property Rights Index 2016. http://internationalpropertyrightsindex.org/ipri2016.

Science and Technology Policy Institute (various editions). Korean Innovation Survey. Sejong: Science and Technology Policy Institute (in Korean).

Yoon, C.-M. (2013). "A study of the management system of special organizations for university technology transfer and commercialization," Journal of Korea Technology Innovation Society, 16(4): 1055-89 (in Korean). 


\section{Brazil}

FERNANDA DE NEGRI AND CRISTIANE VIANNA RAUEN

\subsection{Introduction}

It is widely recognized that the knowledge production of universities and research institutions is one of the foundations of economic development. The experiences of countries such as Japan, the Republic of Korea, the United States of America (U.S.), and, more recently, China have shown that successful development results from a combination of good policies, a sound research and education infrastructure, and productive interaction between that infrastructure and enterprises.

Brazil does not have a strong tradition of interaction between universities/public research institutes and businesses, but the situation has changed greatly in recent years. The lack of interaction used to be one of the most frequently noted characteristics of the Brazilian innovation system. Sutz (2000), for instance, observed a very low level of contact between the country's universities and companies. Data consolidated by De Negri et al. (2009) show that only 14 percent of all research projects supported by the main source of public funding for science and technology (S\&T) in Brazil, the so-called Sectoral Funds, counted companies among the beneficiaries. Although these projects represent around 35 percent of the resources invested by the Sectoral Funds, that is probably not enough since the aim of the Funds is to support innovation.

However, there has been a notable increase in efforts to support innovation and facilitate interaction among universities, researchers, research institutions, and companies in Brazil in recent years. The 2000s witnessed the creation of several policies that transformed the scenario for innovation in Brazil. From new policies to support R\&D investments by companies to a new regulatory framework for universityindustry interaction, several initiatives were implemented during this 
period. And several new pieces of evidence suggest that these policies probably did increase the level of interaction between universities and companies.

This chapter aims to analyze the conditions and policies framing the interaction between public research institutes and universities and the business sector in Brazil. Our analysis is based on: (1) a review of the scholarly literature and Brazilian legislation regarding innovation policies and university-industry interactions; (2) data on IP and related indicators in official Brazilian government reports; (3) information gathered through questionnaires sent to eighteen Brazilian universities and research institutions; and (4) in-depth interviews with four selected Brazilian knowledge transfer offices (KTOs).

The chapter is composed of five sections including this introduction. The second section briefly reviews the key literature on knowledge transfer in Brazil. The third section gives an overview of the historical role of universities and public research institutes in the Brazilian innovation system as well as the main policy instruments and mechanisms in relation to science, technology, and innovation. Section 7.4 analyzes the main policies and practices adopted by institutions and companies for knowledge transfer in the country, while the fifth and final section presents our concluding remarks.

\subsection{The Literature on University-Industry Relations in Brazil}

University-industry interactions are considered an important element of any national innovation system (NIS) as they are one of the engines of technological progress and of competence building at the regional and national levels (Chaves et al. 2015). In Brazil, the view is often advanced that academia is too remote from the needs of industry.

Albuquerque (1999), for instance, argues that the channels of knowledge transfer are weak in Brazil, impairing the frequency and quality of university-industry interactions in the country. A combination of two main factors may explain the weakness of knowledge transfer mechanisms in Brazil: the historical backwardness of Brazilian industrialization and the relatively late creation of universities and research institutes in comparison with developed countries (Suzigan and Albuquerque 2011).

Several authors have sought to explain the low level of interaction between universities/public research institutes and business. Rapini et al. (2009) argue that it reflects a poor pattern of demand from industry. Indeed, Britto et al. (2015) show that, in comparison with other 
countries, the majority of Brazilian companies - especially the internationalized ones - still do not look to universities to establish any kind of knowledge transfer in order to promote their innovative activities.

Dutrénit and Arza (2015) argue that although linkages between universities and firms in Brazil are fragile, there have been successful cases of knowledge transfer, including in the steel, petrochemicals, aircraft, and agro-industry sectors. But despite these success stories, Brazilian NIS is lagging behind other countries, since there remains a mismatch between the scientific side of the system and its productive structure.

Recently, several authors have argued that the level of universityindustry partnership has increased, based on new data from several sources. Brito Cruz (2015), for instance, found that the volume of research revenues flowing from companies to some universities in São Paulo was similar to the average for US universities (around 5 percent of their research revenues). De Negri and Squeff (2016) also found that around 43 percent of Brazilian laboratories and research facilities among a sample of almost 2,000 said they provided some sort of services to companies.

Several studies have focused on other aspects of university-industry interactions, such as the main channels and kinds of knowledge transfer, the main technology areas of transfer, patent statistics, firm profiles, and the overall incentives and barriers to cooperation.

Póvoa (2008) identified that the vast majority of Brazilian knowledge transfer occurs in areas related to engineering and agrarian sciences (70 percent), and that the companies that received most of the technology generated by universities and public research institutes belong to what he called the "processing industry" sector (47.1 percent) - mainly the manufacturing of food products, chemical products, and machinery and equipment.

A survey by Chaves et al. (2015) of 1,005 research group leaders at Brazilian universities showed that firms do not usually seek interactions with these institutions in order to obtain high-level research and experimental development. According to them, the most common channels of knowledge transfer from universities to firms are training of human resources, consulting activities, and the provision of routine services such as measuring, testing, and quality control. Patents and other institutional knowledge exchange channels such as incubators and technology parks still seem to feature rarely in knowledge exchange between universities/public research institutes and firms. 
In fact, as observed by Livesey (2014), the belief that patenting is the best way to transfer new knowledge from universities to companies is no longer dominant in Brazil, since other routes including spinouts and consultancy are also now highly regarded.

Based on a survey of 178 leaders of research groups affiliated to Brazilian universities and public research institutes, Póvoa (2008) also established that the main channels for knowledge transfer in Brazil are informal. In fact, more than 70 percent of knowledge transfers are based on "publications and reports," 46.5 percent are based on "informal exchange of information," 43.5 percent on "training and consulting," and only 13.7 percent on "patents and licensing." This emphasis on informal channels has also been observed in many developed countries (Mowery et al. 2004).

The same results were reached by de Castro et al. (2014) through a survey applied to 314 Brazilian firms that had already established channels for knowledge transfer with universities and public research institutes. The majority of respondent firms said that the most important knowledge transfer channels for their innovation activities were informal, including publications and reports (68.9 percent), informal information exchanges (62.4 percent), and conferences and seminars (61.1 percent). Fewer companies (33 percent) considered licensing an important channel to foster innovation.

Póvoa and Rapini (2010) have shown that, as might be expected, the type of transfer channel varies according to the type of knowledge transferred. Patents showed a high correlation with the transfer of knowledge aimed at obtaining new products, equipment, prototypes, and materials. However, mechanisms such as consulting and hiring of personnel were more correlated with new processes and techniques. This analysis corroborates the conclusions of Póvoa (2008), who found that the main kinds of technology transferred by universities and public research institutes to companies were new processes (44.6 percent), new techniques (43.5 percent), and new products (28.4 percent).

The results of the studies presented here confirm that, in Brazil, patenting is not the most relevant type of knowledge transfer between universities/public research institutes and enterprises, and that informal channels as well as the regular forms of "open science" are more important than formal ones. Póvoa (2008) showed that the only enterprises able to manage formal mechanisms of knowledge transfer such as patents were those with a pre-established capacity to absorb these technologies, 
for example R\&D departments and well-trained personnel, and most Brazilian companies lack such capacity.

De Castro et al. (2014) also argue that patenting is not an important knowledge transfer channel in Brazil due to firms' low capacity to absorb this kind of knowledge. They believe that firms prefer to access cheaper kinds of knowledge such as knowledge in the public domain (e.g., seminars and reports) as well as forms of collaborative research that could complement their relatively weak R\&D.

By way of contrast, Dos Santos et al. (2009) emphasize the importance of KTOs associated with universities and public research institute in guaranteeing the professionalization and success of the transfer of knowledge and technologies between these organizations and interested companies.

The Brazilian literature on knowledge transfer also emphasizes the importance of implementing policies to encourage a strong patenting culture in universities and public research institutes. Póvoa (2008), for instance, showed that between 1999 and 2003, the top fifty patent applicants in Brazil included eight Brazilian universities and four Brazilian public research institutes - accounting for nearly one-quarter of those top applicants. The main technological domains in which universities and public research institutes patented during this period were measurement and control (14.2 percent), organic chemistry (9.3 percent), and biotechnology (7.5 percent), which Póvoa saw as demonstrating a significant contribution of universities to "science-based" sectors.

Póvoa also showed that between 1996 and 2004, the total number of university patent applications increased by about 700 percent. He thinks this rise is in large part attributable to the introduction of the Industrial Property Law in 1996 (Brasil 1996), which brought significant changes to patenting activities in Brazil. In addition to expanding the range of patentable inventions, the Law allowed researchers to share in the economic gains derived from the exploitation of university patents.

Some scholars believe that the Brazilian Innovation Act 2004 (Brasil 2004) also spurred the increase in patenting activities by universities and public research institutes, especially by formalizing the KTOs associated with these institutions, charged, among other things, with managing patenting activities. According to Pereira and Mello (2015), the main reason for the increase in the number of patenting activities by universities in recent decades is the professionalization of the industrial property management carried out by the KTOs. 
On the other hand, a survey of thirty-three Brazilian KTOs by Livesey (2014) revealed that they tended to be small structures with just seven staff on average, only two of whom have advanced degrees and one of whom is an IP specialist. Less than one-third ( 29 percent) of the KTOs surveyed believed they had the technical skills required to manage knowledge transfer, compared to nearly half (45 percent) who did not. The largest deficit was found in commercial skills, with only 13 percent of respondents saying they had the necessary skills in this area to be effective.

Livesey (2014) considers that KTOs should be more integrated into universities in order to better perform knowledge transfer to enterprises. In fact, his study showed that KTOs felt marginalized and disconnected from the organizations they were trying to serve. Over half of respondents (54 percent) did not believe they had the necessary support and funding, and nearly two-thirds (63 percent) did not believe that knowledge transfer was an established part of their university's strategy.

The confidence of KTOs that they had the skills required to manage technology varied by region. Livesey's survey revealed that, while only 20 percent of KTOs in the northeast of the country believed they had the necessary legal skills, this figure reached 60 percent among KTOs in the southeast and almost 40 percent among those in the south. In relation to technical skills, none of the northeastern respondents thought they had the necessary skills to manage knowledge transfer, whereas almost 40 percent of their southern counterparts and 20 percent of those in the southeast expressed confidence. Finally, regarding commercial skills, KTOs from the southeast showed the lowest level of confidence (10 percent), followed by those from the south (over 10 percent), and the northeast (20 percent).

Regional differences are also noticeable as regards KTOs' preferred knowledge transfer routes. Broadening the discussion on knowledge transfer from licensing and consulting, Livesey (2014) found that half the KTOs in the south agreed that spinouts were the best way to transfer a technology, whereas those from the northeast and southeast were less likely to endorse this view ( 20 percent and 30 percent, respectively). Livesey noted that his survey showed that the south was also the region with the largest number of links to venture capital.

Regarding patenting activity, Pinheiro-Machado and Oliveira (2004) revealed that patenting by Brazilian universities increased twice as quickly as in US universities in the period 1990-2001. However, they argued that the performance of Brazil's universities was impaired by poor 
performance on the part of the KTOs: "[A] significant fraction of Brazilian academic patent applications remains abandoned due to the lack of specialized staff to help in writing and to shepherd the application through the patenting process in universities."

Along with the launch of the Industrial Property Law (1996) and the Innovation Act (2004), Chaves et al. (2015) consider that the Brazilian government has implemented other important measures to stimulate university-industry interactions since the mid-1990s, including the establishment of new lines of S\&T funding such as the abovementioned Sectoral Funds and the use of tax breaks for firms that propose joint $R \& D$ projects with universities and public research institutes.

Undeniably, these institutional changes have become important mechanisms to encourage patenting activities by Brazilian universities, as observed in statistics for recent decades and in the results of the interviews presented in Section 7.4. But while the performance of universities and public research institutes in recent years represents a remarkable achievement of Brazilian S\&T and industrial policies, Albuquerque (2003) argues that the relative strength of these institutions in patenting activities exposes the comparative fragility of Brazil's industrial structure, especially as regards business investment in R\&D activities.

According to Póvoa (2008), patents owned jointly by universities and companies represented around 6 percent of patent applications by universities in the period 1979-2004. While this proportion may seem small, it is close to that observed in several European countries in the period 1978-2002: 11.5 percent in the case of German universities, 10.2 percent in the case of French universities, and 9.4 percent in the case of UK universities (Ruiz 2005, cited in Póvoa 2008).

Póvoa (2008) also showed that most of the patents jointly owned by Brazilian universities in this period were deposited by three universities based in São Paulo State: USP (thirteen joint-ownership patents), Unicamp (twelve), and Universidade Federal de São Carlos (UFSCar) (eleven). The main technological fields for joint patenting were optical technologies and telecommunications. Petrobrás was the company with the largest number of patent applications made jointly with universities in the period.

An analysis of patent filings by public universities in São Paulo State from 1995 to 2006 by Amadei and Torkomian (2009) confirms that the number of joint filings was not significant. According to them, during this period the universities were the sole patent holders of more than 
80 percent of their total filings. They argue that given the considerable contribution made by the patent indicators in the construction of national innovation policy, there is a need for a more user-friendly national patent database with the possibility to consult more up-to-date indicators integrated with existing ones to help interested firms identify the technologies available at universities.

These statistics represent the evolution of an important formal channel of knowledge transfer in the last decades, but as noted earlier, not all kinds of knowledge transfer from universities to companies result in an attempt to obtain a new invention. According to Rapini (2007), such formal transfers represent only a small portion of the possible university-industry interaction: "[N]ot every invention is patentable or patented."

Curiously, in spite of what is traditionally expected from this kind of interaction, Póvoa (2008) showed that in Brazil, a significant number of the knowledge transfers analyzed (slightly more than one-third) were motivated by the leaders of universities' research groups interested in private funding opportunities for new lines of research.

Póvoa (2008) also showed that universities, as opposed to public research institutes, were responsible for 88.1 percent of the total number of technologies transferred to enterprises. The only area in which the public research institutes stood out was agronomy, which accounted for 24 percent of all knowledge transfers, especially due to the prominent role of Embrapa in national agronomy research.

Telles (2011) identified that public research institutes were responsible for presenting new applied research to companies. In the cases he analyzed, it was public research institutes that proposed new technological projects to companies as well as financing many project expenses using their own resources. Public research institutes thus also emerge as institutions inducing knowledge transfer in Brazil. Telles attributes the proactivity of the public research institutes in their interactions with firms to the fact that governments usually use these institutes as an instrument to promote the development of specific national sectors.

But while universities and public research institutes are responsible for determining the research agenda for cooperation with companies, according to Porto et al. (2011), most university-business interaction in Brazil is focused on short- and medium-term technological development aimed at solving firms' technological problems.

In fact, university and industry partners express divergent interests and perceptions about their interaction and relationship. Bearing this 
in mind, Closs and Ferreira (2012) aimed to identify the factors that facilitate university-industry interactions in Brazil and those that jeopardize them. From a review of the literature on knowledge transfer in Brazil from 2005 to 2009, they concluded that among the motivations for university-industry cooperation, the ones related to financial resources stand out. On the one hand, universities increasingly need private resources to finance new areas of research in the face of a reduction of public resources in recent decades. On the other hand, firms want to save costs in implementing new technologies by accessing infrastructure and professional consultancy provided by universities.

The importance of cost concerns in motivating university-industry cooperation is also corroborated by Porto et al. (2011), who analyzed information from 2,623 Brazilian companies and 1,663 research groups distributed in 193 research organizations (universities and public research institutes) - that carried out joint technology projects in 2003 and 2004. According to the authors: "[T]he increase in R\&D spending by companies and research institutes leads to the search for cost dilution instruments and, consequently, encourages cooperation between companies and universities."

Rauen and Turchi (2017) found that access to public funding is important to stimulate companies to look for university cooperation. As will be discussed in Section 7.4, they found that there is a seasonal component in the companies' demand for support from public research organizations which correlates with the periods in which development agencies publish funding notices.

As regards barriers to the promotion of university-industry interactions, Rapini et al. (2009) emphasize some noted above, such as excessive bureaucracy and legal uncertainty, difficulties in establishing contractual agreements with firms, and a lack of staff with specialized knowledge transfer skills.

The studies analyzed by Closs and Ferreira (2012) highlighted a range of problem factors from the firms' point of view, such as legal uncertainty and excessive bureaucracy, noncompliance with project deadlines, a lack of information security, and a lack of project management skills. From the universities' point of view, challenges included the need to establish reward mechanisms for researchers and teachers to engage in projects with firms, excessive university bureaucracy, backwardness in the execution of contracts or the registration of patents, and the fact that the evaluation of researchers and teachers is still based on their record of 
scientific publication, not on patents or any other kind of knowledge transfer to firms.

\subsection{The Role of Universities and Public Research Institutes in the Brazilian Innovation System}

As noted earlier, Brazil has undertaken several actions and introduced new policies to reinforce its scientific and innovative capacity over the last two decades. One of the most important policies was the creation of the Sectoral Funds in 1999, to be operated and managed by the innovation agency Finep. The Sectoral Funds were designed to have several different revenue sources in order to ensure stable long-term public funding for S\&T. These revenues included a share of royalties from the oil sector, a special levy on gas and other sector-specific taxes. At the time they were introduced, instability was considered one of the most serious problems in S\&T funding in Brazil, and the creation of the Sectoral Funds was seen as a promising attempt to overcome this challenge.

Besides assuring stable S\&T funding, the Funds were also intended to foster innovation in the Brazilian economy, focusing on research projects related to technological challenges in specific sectors. This objective was prompted by the low level of interaction between universities, research institutions, and the country's productive industry. The revenues of each fund were intended to support R\&D related to the sector for which that fund was created. These sectors include oil, mining, health, infrastructure, agriculture, aeronautics, biotechnology, information, and communication, and there are also funds designed to foster cross-sectional projects and research facilities.

In the early 2000s, growing recognition of the economic importance of innovation resulted in a series of new policies intended to create incentives for R\&D investments and a more up-to-date framework for S\&T and innovation. The Innovation Act (Law no. 10,973 of 2004) was introduced to improve the innovation system and empower linkages between different actors. One of the major breakthroughs of the Act was the possibility for the government to provide grants ${ }^{1}$ to companies for investments in innovation, which was not previously allowed under Brazilian law. The Act also established a clear regulatory framework for

${ }^{1}$ Grants are nonrepayable money given by the government to a recipient to perform a specific research project. The recipient may be a nonprofit entity, an educational institution, a business, or an individual. To receive a grant, it is often necessary to submit a proposal or application in a competitive process. 
the interaction between universities/public research institutes and companies, and for the IP rights arising from such interaction.

Finally, in 2005 the so-called Good Law (Lei do Bem, Law no. 11.196, of 2005) implemented tax breaks for firms that invest in $R \& D$ in the country. Such tax incentives could reach up to half the total amount invested in $\mathrm{R} \& \mathrm{D}$ by companies.

Both the Innovation Act and the Good Law were implemented in the context of the first industrial policy of President Lula's government in 2003: the PITCE (Industrial, Technological, and Foreign Trade Policy). After the PITCE, two new editions of this industrial policy were launched: the Productive Development Policy in 2008 and the Greater Brazil Plan in 2010, right after the global financial crisis. In these two last versions, the main measure adopted to encourage innovation was the Innovate Company Program (Programa Inova Empresa), introduced within the Greater Brazil Plan (Plano Brasil Maior), taking advantage of a small share of the resources meant for the Investment Maintenance Program (PSI).

These various new policies together created a relatively comprehensive framework of innovation policies in terms of the diversity of instruments (see Table 7.1). Currently, the country can count on many of the instruments used in most of the developed world to foster innovation, such as subsidized credit/loans, ${ }^{2}$ tax incentives, grants for companies, and grants for research projects and individuals at universities and research centers, among others.

Regarding direct public investments in S\&T, according to the Brazilian Ministry of Science, Technology, and Innovation, ${ }^{3}$ in 2012 the Brazilian public sector (federal and subnational governments) spent around BRL 40 billion (around USD 20 billion) on science and technology. About 40 percent of the S\&T public investment is attached at maintaining postgraduate courses and institutions at federal and state levels. Of the remaining BRL 25 billion (USD 13 billion), about BRL 18 billion (or USD 9.4 billion) was invested by the federal government.

An important share of public S\&T investment is devoted to building and maintaining the country's research infrastructure and facilities. In the last few years, Brazil's S\&T infrastructure has received substantial resources from several sources, notably the Infrastructure Sectoral Fund,

${ }^{2}$ Loans for innovation at below market interest rates are provided by both the National Development Bank (BNDES) and by the Brazilian Innovation Agency (Finep).

${ }^{3}$ Indicators available at www.mctic.gov.br/mctic/opencms/indicadores/indicadores_cti .html (only in Portuguese). 
Table 7.1 Main policies and instruments for S\&T funding in Brazil in 2012

\begin{tabular}{|c|c|c|c|}
\hline & $\begin{array}{l}\text { Policies and } \\
\text { instruments }\end{array}$ & $\begin{array}{l}\text { Value in } 2012 \\
\text { (current BRL) }\end{array}$ & $\begin{array}{l}\text { Current USD } \\
\text { (USD } 1=\mathrm{R} \$ 1.95 \text { ) }\end{array}$ \\
\hline $\begin{array}{l}\text { Tax incentives for } \\
\text { innovation }\end{array}$ & & 6,423 & 3,294 \\
\hline \multirow{5}{*}{$\begin{array}{l}\text { Public credit/loans for } \\
\text { innovation } \\
\text { (disbursements in } \\
\text { the year) }\end{array}$} & Finep & 1,800 & 923 \\
\hline & BNDES & 2,200 & 1,128 \\
\hline & $\begin{array}{l}\text { Total (public } \\
\text { credit) }\end{array}$ & 4,000 & 2,051 \\
\hline & $\begin{array}{c}\text { States (excluding } \\
\text { postgraduate } \\
\text { programs) }\end{array}$ & 7,034 & 3,607 \\
\hline & $\begin{array}{l}\text { Federal } \\
\text { government } \\
\text { (excluding }\end{array}$ & 18,388 & 9,430 \\
\hline \multirow[t]{3}{*}{$\begin{array}{l}\text { Public investments } \\
\quad \text { in S\&T }\end{array}$} & $\begin{array}{l}\text { postgraduate } \\
\text { programs) }\end{array}$ & & \\
\hline & $\begin{array}{l}\text { Total (excluding } \\
\text { postgraduate } \\
\text { programs) }\end{array}$ & 25,422 & 13,037 \\
\hline & $\begin{array}{l}\text { Total (with } \\
\text { postgraduate } \\
\text { programs) }\end{array}$ & 40,045 & 20,536 \\
\hline
\end{tabular}

Sources: Ministry of Science, Technology and Innovation (MCTI) - www .mctic.gov.br/mctic/opencms/indicadores/indicadores_cti.html; National Bank for Social and Economic Development (BNDES) - Annual Report/2013; Brazilian Innovation Agency (Finep); Electricity Regulatory Agency (ANEEL); National Petroleum Agency (ANP) - Statistical Yearbook/2013. Extracted and adapted from Zuniga et al. (2016)

also known as CT-Infra. ${ }^{4}$ Significant resources have also been provided under the Coordination for the Improvement of Higher Education Personnel (Capes) program of the Ministry of Education (MEC), by

${ }^{4}$ CT-Infra was created to enable the modernization and expansion of the infrastructure and support services of all the Brazilian higher education and research institutions. Its resources are earmarked for the construction and renovation of laboratories, and the purchase of equipment, among other actions. 
Table 7.2 Number of research infrastructures in Brazil by launch period

\begin{tabular}{lcc}
\hline \hline & $\begin{array}{l}\text { Number of infrastruc- } \\
\text { tures launched }\end{array}$ & $\begin{array}{l}\text { Number of infrastruc- } \\
\text { tures launched as a share } \\
\text { of all infrastructures }(\%)\end{array}$ \\
\hline Pre-1970 & 50 & 2.8 \\
$1970-9$ & 110 & 6.3 \\
$1980-9$ & 193 & 11.0 \\
$1990-9$ & 410 & 23.3 \\
$2000-9$ & 654 & 37.2 \\
$2010-12$ & 343 & 19.5 \\
Total & 1,760 & 100 \\
\hline \hline
\end{tabular}

Source: IPEA/CNPq/MCTI - Research Infrastructure Mapping in Brazil (2013). Extracted from De Negri and Squeff (2016)

state foundations that support research, and by companies such as Petrobrás (De Negri, Cavalcante, and Alves 2015).

In fact, it is safe to say that the country's research infrastructure ${ }^{5}$ is now much more up to date than it was few years ago. De Negri and Squeff (2016) show that most laboratories and research facilities (56.7 percent) began operation since 2000 (Table 7.2) and argue that this fact could be related to an increase in investments in science, technology, and innovation from the middle of the 2000s until 2014. ${ }^{6}$ The authors conducted a survey with around 2,000 researchers in charge of research laboratories at Brazilian universities and research institutions in 2012. More than 70 percent of respondents said they had received significant investments in the five years preceding the survey, and many reported significant investment within the past year.

However, according to De Negri and Squeff (2016), most of the research facilities in Brazil are small laboratories scattered across the

${ }^{5}$ For the purposes of this chapter, the concept of research "infrastructure" refers to "the set of physical facilities and material conditions of support (equipment and resources) used by researchers to carry out R\&D activities." The term thus covers everything from laboratories to biotools, high-performance computer networks, specialized libraries, observatories, telescopes, research vessels, experimental stations, and so on (De Negri and Squeff 2016: 17).

${ }^{6}$ De Negri and Squeff (2016) is based on a pioneering survey carried out in 2013 by Ipea, $\mathrm{CNPq}$, and the MCTI which collected information about 2,000 research facilities in more than 130 universities and research institutions in Brazil. 
Table 7.3 Number of universities, research universities, and federal technological institutions in Brazil in 2015

\begin{tabular}{lcclr}
\hline \hline & $\begin{array}{l}\text { Research } \\
\text { universities }\end{array}$ & $\begin{array}{l}\text { Universities } \\
\text { (university } \\
\text { centers) }\end{array}$ & $\begin{array}{l}\text { Federal } \\
\text { technological } \\
\text { institutions }\end{array}$ & Total \\
\hline Federal institutions & 63 & & 40 & 103 \\
$\begin{array}{l}\text { State institutions } \\
\text { Municipal }\end{array} \quad 38$ & 6 & 8 & & 39 \\
$\quad$ institutions & 88 & 140 & & 14 \\
Private institutions & 195 & 149 & 40 & 228 \\
Total & & & & 384 \\
\hline \hline
\end{tabular}

Source: National Institute for Educational Studies and Research - INEP (2016)

* Research universities are universities obliged to perform research and some sort of social activities as well as teaching. The universities (in Portuguese, "university centers") are not obliged to perform research, and there are also 1,980 colleges in Brazil (not listed in the table) which teach but do not research. The federal technological institutions focus on professional and technological education.

departments of the big Brazilian universities. Although the country has some important research institutions, they are few and most of them are small when compared to the national laboratories or similar large scientific facilities of some other countries. There are 7,090 researchers working in Brazil's 1,760 research infrastructures, an average of just four per laboratory.

Brazil has more than 2,300 higher education institutions, including universities, schools, and federal institutes, as well as several research centers. While there are roughly as many private education institutes as public ones, the importance of the latter in science and technology production is much greater than that of the former.

The number of higher education institutions has grown sharply over the last decade, from fewer than 1,400 in 2000. Between 2000 and 2013, the Brazilian federal government and the states created eighty-nine new higher education institutions, mostly research or technical universities growth of more than 150 percent in the number of public institutions within fifteen years.

It is widely recognized in Brazil that the most relevant research universities in the country are public, although the number of good private 
universities is believed to have grown in recent decades. Among the country's higher education institutions, 193 can be considered research universities, most of which are federal or state ones. The private sector is mostly present in colleges and in so-called university centers, where there is no obligation to perform scientific research.

To identify the biggest public research universities in the country, Table 7.4 shows the amount of R\&D investments performed by these institutions. The three biggest universities in São Paulo are responsible alone for more than half of all R\&D investment by the country's fifteen biggest public research universities. The University of São Paulo, besides being Brazil's biggest university in terms of budget, is also its main university in terms of academic publications as well as the best placed in several national and world rankings.

Public research institutes also play a very important role in the Brazilian S\&T system and the biggest ones, based on their budget information in 2014, are shown in Table 7.5. The two biggest are also the most important public research institutes in the country. The Oswaldo Cruz Foundation is a public research institution attached to the Ministry of Health and is responsible for a range of activities such as $R \& D$, production of vaccines and drugs, education and training, hospital care services, and quality control of products and services. The institution was created in 1900 and today has over 11,000 employees and health professionals.

The Brazilian Agriculture Research Corporation (Embrapa) is also very important within the Brazilian innovation system. Embrapa is a public company created in 1973 under the stewardship of the Ministry of Agriculture with the objective of developing science and technology applied to the Brazilian farming sector. Today, it has more than 9,000 employees and about 2,400 researchers working in more than sixty units around the country.

The Butantan Institute (Instituto Butantan), created in 1901, is linked to the State of São Paulo. Today, the Institute is the main producer of immunobiologicals in Brazil and responsible for a big share of the national production of vaccines and hyperimmune serums used by the Brazilian Ministry of Health. Besides producing immunobiologicals, the Butantan Institute also maintains zoological scientific collections and performs basic and applied research on venomous animals and pathogenic agents, and the production and control of immunobiological products. The Institute is currently involved in the research and development 
Table 7.4 ReD investment by the main public universities in Brazil in 2012

\begin{tabular}{|c|c|c|c|c|}
\hline & Name & $\begin{array}{l}\text { R\&D invest- } \\
\text { ments (USD } \\
\text { million) }\end{array}$ & Ownership & State \\
\hline USP & Universidade de São Paulo & $1,715.71$ & State & SP \\
\hline UNICAMP & $\begin{array}{l}\text { Universidade Estadual de } \\
\text { Campinas }\end{array}$ & 634.59 & State & SP \\
\hline UNESP & $\begin{array}{l}\text { Universidade Estadual } \\
\text { Paulista "Júlio de } \\
\text { Mesquita Filho" }\end{array}$ & 415.31 & State & SP \\
\hline UFRJ & $\begin{array}{l}\text { Universidade Federal do } \\
\text { Rio de Janeiro }\end{array}$ & 371.48 & Federal & RJ \\
\hline UFMG & $\begin{array}{l}\text { Universidade Federal de } \\
\text { Minas Gerais }\end{array}$ & 251.58 & Federal & MG \\
\hline UNB & Universidade de Brasília & 235.89 & Federal & DF \\
\hline UFRGS & $\begin{array}{l}\text { Universidade Federal do } \\
\text { Rio Grande do Sul }\end{array}$ & 224.63 & Federal & RS \\
\hline UFSC & $\begin{array}{l}\text { Universidade Federal de } \\
\text { Santa Catarina }\end{array}$ & 191.23 & Federal & SC \\
\hline UNIFESP & $\begin{array}{l}\text { Universidade Federal de } \\
\text { São Paulo }\end{array}$ & 177.42 & Federal & SP \\
\hline UFC & $\begin{array}{l}\text { Universidade Federal do } \\
\text { Ceará }\end{array}$ & 136.05 & Federal & CE \\
\hline UFPE & $\begin{array}{l}\text { Universidade Federal de } \\
\text { Pernambuco }\end{array}$ & 126.79 & Federal & $\mathrm{PE}$ \\
\hline UERJ & $\begin{array}{l}\text { Universidade do Estado do } \\
\text { Rio de Janeiro }\end{array}$ & 125.97 & State & RJ \\
\hline UFPR & $\begin{array}{l}\text { Universidade Federal do } \\
\text { Paraná }\end{array}$ & 125.30 & Federal & PR \\
\hline UFF & $\begin{array}{l}\text { Universidade Federal } \\
\text { Fluminense }\end{array}$ & 116.93 & Federal & RJ \\
\hline UFBA & $\begin{array}{l}\text { Universidade Federal da } \\
\text { Bahia }\end{array}$ & 103.27 & Federal & BA \\
\hline
\end{tabular}

Source: Ministry of Science, Technology, Innovation and Communications www .mctic.gov.br/mctic/opencms/indicadores/indicadores_cti.html, accessed September 2016

${ }^{*}$ Exchange rate: $\mathrm{R} \$ / \mathrm{USD}=2.04,31 / 12 / 2012$. 
Table 7.5 Budget or revenues of the main public research institutes in Brazil in 2014

\begin{tabular}{|c|c|}
\hline Public research institute & Budget/revenues (USD thousands) \\
\hline Oswaldo Cruz Foundation (Fiocruz) ${ }^{(1)}$ & $1,609,803$ \\
\hline $\begin{array}{l}\text { Brazilian Agriculture Research } \\
\text { Corporation (Embrapa) }\end{array}$ & $1,076,427$ \\
\hline Butantan Institute & 411,370 \\
\hline $\begin{array}{l}\text { Brazilian Center for Research in Energy } \\
\text { and Materials (CNPEM })^{(2)}\end{array}$ & 78,631 \\
\hline $\begin{array}{l}\text { IPT - Institute for Technological } \\
\quad \text { Research }^{(3)}\end{array}$ & 63,712 \\
\hline $\begin{array}{l}\text { National Institute for Pure and Applied } \\
\text { Mathematics (IMPA) }\end{array}$ & 42,580 \\
\hline $\begin{array}{l}\text { National Institute for Space Research } \\
\text { (INPE) }\end{array}$ & 40,909 \\
\hline $\begin{array}{l}\text { Center for Natural Disaster Monitoring } \\
\text { and Alert (CEMADEN) }\end{array}$ & 31,420 \\
\hline $\begin{array}{l}\text { National Institute for Amazonian } \\
\text { Research (INPA) }\end{array}$ & 13,989 \\
\hline
\end{tabular}

Source: http://odimpact.org/case-brazils-open-budget-transparency-portal.html Brazil's Open Budget Transparency Portal (www.portaltransparencia.gov.br/) and Ministry of Science, Technology, Innovation and Communications (MCTIC), accessed September 2016

About half this budget is not spent on R\&D.

${ }^{(1)}$ Includes not only research but also teaching and manufacturing of medicines.

(2) Data from 2015 (exchange rate $\mathrm{BRL} / \mathrm{USD}=2.65$ ). Includes the budget for investment in a new synchrotron light source (around USD 31 million in 2015) and other special projects. The normal budget for the institution is around USD 30 million.

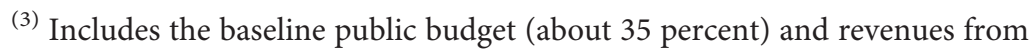
technological services (65 percent).

of a vaccine for Dengue fever and the Zika virus. Last, it offers graduate courses in its areas of expertise.

The Brazilian Center for Research in Energy and Materials (CNPEM) is a quasi-public organization, very similar to the federally owned and privately operated National Laboratories in the U.S. It is linked to the Ministry of 
Science, Technology, Innovation, and Communications ${ }^{7}$ (MCTIC) and has seventy-five in-house researchers. The facilities of CNPEM were used by almost 2,000 researchers in 2014. Probably the most used facility is the synchrotron light source, which is used by researchers from all over the country as well as other countries. MCTIC has other quasi-public research organizations attached to it, for instance the National Institute for Pure and Applied Mathematics (IMPA) and the National Education and Research Network (RNP).

The organizations mentioned above - universities and public research institutes - are the most important research institutions in the country and are responsible for a large share of Brazilian scientific publications, as one can see in the Scimago ranking of Brazilian universities and research institutions.

The public universities and research institutions are also very relevant in terms of patenting. By way of context, in Brazil, as in other middleincome countries, most patent applications come from non-residents (80 percent). ${ }^{8}$ Applications from residents are distributed almost equally among private individuals - independent inventors, university researchers, and professors, and so on - and institutions, comprising companies including foreign-owned subsidiaries, universities, public and private research institutions, nonprofit organizations, and so on.

The institutions account for around 10 percent of total patent applications, of which around 30 percent are filed by the public sector or by teaching or research institutions. Indeed, Brazilian universities and research institutions have increased their share of patent applications to the National Institute of Industrial Property (INPI) sharply, from 0.6 percent in 2000 to 2.7 percent in 2012 (Table 7.6).

As we noted earlier, some authors argue that this growth was encouraged by the Industrial Property Law in 1996 (Póvoa 2008), particularly the possibilities it offered for researchers to share in the economic gains from patents. Others believe that the Innovation Act of 2004 is mainly responsible. Most likely, both laws as well as other, more minor

7 Since May 2016, when the Ministry of Science, Technology, and Innovation was merged with the Ministry of Communications.

8 The concept of non-resident and resident application is as used by the World Intellectual Property Organization (WIPO) and available at www.wipo.int/ipstats/en/statistics/gloss ary.html. According to WIPO, a resident application is "an application filed with an IP office by an applicant residing in the country/region in which that office has jurisdiction." In that sense, an application to the Brazilian patent office by a foreign subsidiary installed in Brazil would be considered a resident application and an application from its headquarters would be a nonresident one. 
Table 7.6 Number of patents filed by Brazilian universities and research institutions at the National Institute of Industrial Property, 2000-12

\begin{tabular}{|c|c|c|c|c|c|c|c|}
\hline University/institution & 2000 & 2002 & 2004 & 2006 & 2008 & 2010 & 2012 \\
\hline Universidade Estadual de Campinas - UNICAMP & 36 & 55 & 49 & 53 & 48 & 45 & 67 \\
\hline Universidade de São Paulo - USP & 6 & 11 & 15 & 26 & 53 & 47 & 58 \\
\hline Universidade Federal de Minas Gerais - UFMG & 6 & 21 & 18 & 30 & 38 & 59 & 64 \\
\hline Universidade Federal do Rio de Janeiro - UFRJ & 2 & 23 & 24 & 14 & 29 & 27 & 16 \\
\hline Universidade Federal do Paraná - UFPR & 1 & 1 & 7 & 12 & 17 & 21 & 68 \\
\hline Universidade Federal do Rio Grande do Sul - UFRGS & 5 & 11 & 10 & 4 & 9 & 23 & 30 \\
\hline Serviço Nacional de Aprendizagem Industrial - SENAI & 1 & 0 & 2 & 1 & 3 & 20 & 20 \\
\hline Fundação Universidade de Brasília - UNB & 2 & 0 & 4 & 4 & 7 & 6 & 21 \\
\hline Universidade Federal da Bahia - UFBA & 0 & 0 & 0 & 0 & 4 & 16 & 22 \\
\hline Universidade Federal de Pelotas - UFPEL & 0 & 0 & 1 & 1 & 1 & 0 & 17 \\
\hline $\begin{array}{l}\text { Total patent applications by universities and research } \\
\text { institutions (A) }\end{array}$ & 115 & 219 & 264 & 318 & 440 & 590 & 904 \\
\hline Total patents filed at INPI by residents (B) & 6,449 & 7,052 & 7,701 & 7,194 & 7,711 & 7,244 & 7808 \\
\hline Total patents filed at INPI (C) & 20,854 & 20,334 & 20,431 & 23,152 & 26,641 & 28,099 & 33,569 \\
\hline $\begin{array}{l}\text { Universities and public research institute filings as a share of } \\
\text { total filings }(\mathrm{A} / \mathrm{C})(\%)\end{array}$ & 0.6 & 1.1 & 1.3 & 1.4 & 1.7 & 2.1 & 2.7 \\
\hline Resident filings as a share of total fiings (B/C) (\%) & 31 & 35 & 38 & 31 & 29 & 26 & 23 \\
\hline $\begin{array}{l}\text { Universities and public research institute filings as a share of } \\
\text { resident filings }(\mathrm{A} / \mathrm{B})(\%)\end{array}$ & 2 & 3 & 3 & 4 & 6 & 8 & 12 \\
\hline
\end{tabular}

Source: National Institute of Industrial Property (INPI): http://www.inpi.gov.br/estatisticas/anuario-estatistico-de-propriedadeindustrial-2000-2012-patente1\#patente 
institutional improvements are important in explaining the increasing role of universities and public research institutes in patenting.

In any case, one of the consequences of this growth is that the list of the twenty leading patent applicants in Brazil in 2015 featured fifteen public universities, only four companies, and one private research institution: the Telecom Research and Development Center $(\mathrm{CPqD}$ in the Portuguese acronym).

This once again highlights the importance of public institutions in the Brazilian innovation system. Indeed, in Table 7.6 one can see that among the ten leading universities and research institutions applying for patents in Brazil between 2000 and 2012, there is only one private research institution. The Brazilian National Service for Industrial Training (SENAI) is a nonprofit organization funded by industry organizations that originally aimed to train workers for industry. In recent years, it has become increasingly concerned with innovation, having established several research institutions across the country. As a result, it increased its number of patents filings from around two per year to around twenty per year between 2010 and 2012. According to Table 7.6, the most prominent universities in terms of patent filings are UNICAMP, USP, UFMG, UFRJ, and, more recently, UFPR. Pereira and Mello (2015), analyzing the period from 1979 to 2011, reached the same conclusions.

However, a large number of patents registered by universities and research institutions does not in itself prove the market value or relevance of the knowledge they produce. Many of the patents filed and registered by universities may never be transferred to companies. For instance, although Unicamp is one of the country's major patent applicants, it has licensed only eighty-seven of its $1,000+$ patents in the past two decades. At MIT, by contrast, around 40 percent of the patents obtained are licensed every year (Reynolds and De Negri, 2017).

The latest Brazilian Innovation Survey (PINTEC/IBGE 2014) reveals that only 2.3 percent of innovative firms consider interaction with universities and public research institutes, and, in particular, the existence of cooperation agreements with them, to be highly important for innovation (Table 7.7). ${ }^{9}$ The industries that are the leading users of knowledge produced by universities and research institutions according to the Survey are: research and development (44 percent), electricity and gas services (33 percent),

${ }^{9}$ Wunsch-Vincent (2012: Figure 3) provides data on collaboration between private companies and universities or public research institutes in several countries. Brazil emerges as one of the countries with the lowest rates of collaboration. 
Table 7.7 Firms that innovated using a cooperation agreement with a university or public research institute in 2014

\begin{tabular}{|c|c|c|c|c|}
\hline \multirow{2}{*}{$\frac{\text { Sector }}{\text { Total }}$} & \multirow{2}{*}{$\begin{array}{l}\text { Innovative } \\
\text { firms } \\
47,693\end{array}$} & \multirow{2}{*}{$\begin{array}{l}\text { Firms with } \\
\text { cooperation } \\
\text { agreements } \\
\text { with other } \\
\text { organizations } \\
7,300\end{array}$} & \multicolumn{2}{|c|}{$\begin{array}{l}\text { Firms that rate cooperation } \\
\text { with universities/PROs as } \\
\text { highly important }\end{array}$} \\
\hline & & & 1,098 & 2.3 percent \\
\hline $\begin{array}{l}\text { Research and } \\
\text { development }\end{array}$ & 18 & 15 & 8 & 44 percent \\
\hline $\begin{array}{l}\text { Electricity and gas } \\
\text { services }\end{array}$ & 137 & 75 & 45 & 33 percent \\
\hline $\begin{array}{l}\text { Manufacture of } \\
\text { computer } \\
\text { equipment }\end{array}$ & 156 & 72 & 38 & 24 percent \\
\hline $\begin{array}{l}\text { Manufacture of } \\
\text { chemical } \\
\text { products }\end{array}$ & 196 & 80 & 37 & 19 percent \\
\hline $\begin{array}{l}\text { Manufacture of } \\
\text { pharmaceutical } \\
\text { products }\end{array}$ & 204 & 91 & 36 & 18 percent \\
\hline $\begin{array}{l}\text { Manufacture of } \\
\text { computer, } \\
\text { electronic and } \\
\text { optical } \\
\text { products }\end{array}$ & 1,053 & 317 & 117 & 11 percent \\
\hline
\end{tabular}

Source: Brazilian Innovation Survey (PINTEC - 2014). Brazilian Institute of Geography and Statistics (IBGE)

manufacture of computer equipment (24 percent), manufacture of chemical products (19 percent), manufacture of pharmaceutical products (18 percent), and manufacture of computer, electronic, and optical products (11 percent). Importantly, most firms that consider interaction with universities and public research institutes to be highly important belong to sectors with a medium or high technology intensity. In addition, firms from regulated sectors such as electricity and gas services must comply with rules established in the concession agreements, for example contractual 
$\mathrm{R} \& \mathrm{D}$ clauses, ${ }^{10}$ which oblige them to invest a percentage of their revenues in R\&D activities in partnership with universities and research institutes in Brazil.

\subsection{Policies and Institutional Practices for Knowledge Transfer in Brazil}

This section is based on several interviews with researchers and KTOs and on questionnaires sent to more than ten KTOs in Brazil. The interviews and questionnaires were intended to collect information in order to identify the types of procedure and practice used by the institutions and KTOs to transfer knowledge.

\subsubsection{Legal Framework}

The main regulation regarding the relationship between public research institutes, universities and companies in Brazil is provided by the Innovation Act (Law no. 10,973 of 2004). This law aims to promote partnerships between such institutions and companies in order to foster innovation in the country. As regards IP rights specifically, prior to the Innovation Act, the Brazilian Intellectual Property Law approved in 1996 guaranteed that universities and public research institutes would own patents generated inside the institution.

However, the Innovation Act goes much further in regulating and fostering knowledge transfer between universities, public research institutes, and companies. For the first time in Brazil, this law allowed public institutions - public research institutes or universities - to sign knowledge transfer contracts with companies, and established some basic rules for such contracts. These include rules regarding exclusive licenses, which the original version of the Act required be preceded by an open call. Recently, the Science and Technology Act (Law no. 13.243 of 2016) has changed some of the requirements for public research institutes and universities signing exclusive agreements with companies. Exclusive agreements originating from a prior partnership with a specific company

${ }^{10}$ By way of example, the Resolution of the Oil National Agency (ANP 2005) establishes that oil and gas concessionaires must invest in Brazil the equivalent of 1 percent of their gross revenue in carrying out $\mathrm{R} \& \mathrm{D}$, and at least half this amount must be expenses incurred in $\mathrm{R} \& D$ partnerships with universities and research institutes previously accredited by the ANP for this purpose. A similar Resolution established by the National Electric Energy Agency (Aneel) applies to concessionaires of the electrical sector. 
have been simplified. However, this law has also introduced a series of new requirements that reduce the autonomy of a public research institute or university in negotiating such contracts.

The emphasis of the Innovation Act on fostering knowledge transfer is revealed by seven chapters dedicated to promoting the so-called "cooperative environments of innovation." A special role is accorded to public-based research organizations - universities and public research institutes - in the cooperative production of new technologies with firms.

To ensure such engagement, the Act sets out the specific formal channels through which universities and public research institutes are expected to support firms in the production of new technologies:

- Article 4 provides for (a) sharing university and public research institute laboratories and facilities with SMEs in incubation activities, and (b) granting private companies access to laboratories, equipment and facilities for R\&D activities.

- Article 6 allows universities and public research institutes to sign knowledge transfer and IP licensing contracts based on technologies developed by the institution or in partnership and establishes the basic rules for those contracts.

- Article 8 foresees the provision of technical services by universities and public research institutes to private firms engaged in R\&D activities, such as tests, trials and calibrations, as well as technical reports.

- Article 9 allows universities and public research institutes to enter into partnership agreements with firms aimed at developing new technologies together.

To encourage university and public research institute staff (mostly government researchers) to engage in such interactions, the Innovation Act states that these institutions may be financially compensated by firms for such activities, and any of their staff involved may also be financially compensated through an additional variable payment or an "innovation stimulus scholarship."

The Act also stipulates that each research organization should establish its own knowledge transfer and innovation policies creating guidelines for entrepreneurship, innovation, knowledge transfer, and so on. Indeed, the existence of a KTO in each public research institute or university is a requirement of the Act and it sets out the basic competences of a KTO. This was controversial, since even universities with a low technology focus were obliged to establish a KTO. The requirement was relaxed 
recently and the law was modified to allow KTOs to be created in association with other universities or public research institutes.

The Innovation Act represented a major change in the Brazilian landscape for innovation. However, there are still a lot of improvements to be made and a lot of uncertainty regarding its application. Prompted by concerns about uncertainty, excessive bureaucracy and overlapping laws in the Brazilian legal framework for innovation, the New Science and Technology Act (Law no. 13.243 of 2016) was recently enacted to consolidate several different pieces of legislation affecting innovation. This new act aimed to promote the modernization of the legal framework as well as reducing constraints on the implementation of universityindustry partnerships.

The possibilities and stimulus mechanisms established by the Innovation Act in 2004 notwithstanding, university-industry interaction remains low in Brazil. One oft-cited barrier is the legal uncertainty that surrounds the Brazilian innovation legal framework (Rapini et al. 2009; Closs and Ferreira 2012; Rauen 2016). Three particular aspects of legal uncertainty in the Innovation Act should be highlighted: (1) the management of private resources received by universities and public research institutes as compensation for their involvement in innovation activities (since they are part of central government administration, universities and public research institutes do not enjoy autonomy in managing private resources); (2) the difficulty of implementing financial compensation for university and public research institute researchers involved in innovation activities, since the law does not clearly state how such benefits should be granted; and (3) the still-limited role of KTOs - a situation that undermines their capacity to generate and implement new university and public research institute partnerships.

Recognizing the legal uncertainty in these areas, the 2016 Science and Technology Act introduced significant reforms to the Innovation Act. As regards university/public research institute-enterprise interaction, it aimed to strengthen and empower KTOs and establish clearer processes for managing private resources to reward institutions engaging in innovation activities. However, it has not clarified the law on compensation for public researchers, and so it seems unlikely to succeed in reducing the difficulties faced by universities and public research institutes in managing rewards for researchers involved in such activities.

In sum, there is still scope to improve the Brazilian Innovation Act and complementary laws and practices in order to further reduce legal uncertainty within the Brazilian innovation legal framework as regards 
university-industry interaction. But in any case, fostering public-private partnerships in Brazil requires changes that go beyond the modernization of innovation legislation. The solutions needed are many, but all of them are connected - at least in some way - with the creation, diffusion, and application of protocols, internal processes, and rules of conduct in government organizations, and with the capacity of government agencies to deal with conflicts of interest and risk.

\subsubsection{The Main Channels of Knowledge Transfer}

The most common channels for knowledge transfer are probably informal ones such as technology fairs, workshops, conferences, and seminars. Based on informal networks and contacts, these channels play an important role in the innovation landscape in many countries, not only Brazil. However, our analysis here focuses mainly on formal mechanisms for knowledge transfer, even though these are likely to be preceded by an informal approach.

The Innovation Act established the formal channels for knowledge transfer. One of the obligations of universities and public research institutes in this context is to inform the Ministry of Science, Technology, and Innovation about licensing contracts and the overall intellectual property policies of the institution. This information is collected by the Ministry every year and published in a report that contains basic information about knowledge transfer in Brazilian public research institutes and universities - the so-called FORMICT ${ }^{11}$ reports. For instance, these reports contain the number and type of knowledge transfer contracts undertaken by public organizations in the country.

Based on this information, Table 7.8 shows the most common formal channels for knowledge transfer used by the 264 public research institutes and public universities that responded to the MCTIC survey in 2014. Licensing contracts seem to be the most common knowledge transfer channel among the sample, representing more than 42 percent of total contracts signed by respondent institutions, followed by R\&D agreements ( 25 percent) and know-how contracts ( 9 percent).

According to the MCTIC data, most of the licensing contracts were made with companies from Brazilian manufacturing, which represented around 30 percent of total contracts. Within manufacturing, the

11 Acronym for "Form for Information on the Intellectual Property Policy of the Brazilian Scientific, Technological and Innovation Institutions." 
Table 7.8 Knowledge transfer contracts undertaken by Brazilian public research institutes and public universities by type of contract in 2014

\begin{tabular}{|c|c|c|c|c|c|}
\hline $\begin{array}{l}\text { Type of contract for knowledge } \\
\text { transfer }\end{array}$ & $\begin{array}{l}\text { Number of universities } \\
\text { and public research } \\
\text { institutes that reported } \\
\text { having this kind of } \\
\text { contract }\end{array}$ & $\begin{array}{l}\text { Number of } \\
\text { contracts }\end{array}$ & $\begin{array}{l}\text { Contracts as a share of } \\
\text { all knowledge transfer } \\
\text { contracts }(\%)\end{array}$ & $\begin{array}{l}\text { Total amount } \\
\text { (BRL million) }\end{array}$ & $\begin{array}{l}\text { Total amount } \\
\text { (USD million) }\end{array}$ \\
\hline Licensing contract & 30 & 823 & 42 & 34.40 & 10.62 \\
\hline $\begin{array}{l}\text { R\&D collaboration agreement / } \\
\text { collaborative } R \& D\end{array}$ & 34 & 485 & 25 & 221.70 & 68.43 \\
\hline $\begin{array}{l}\text { Contracts for knowhow, technical } \\
\text { assistance and other services }\end{array}$ & 15 & 159 & 8 & 108.00 & 33.33 \\
\hline Confidentiality agreement & 12 & 133 & 7 & - & - \\
\hline Co-ownership agreement & 13 & 84 & 4 & 2.60 & 0.80 \\
\hline $\begin{array}{l}\text { Contract or agreement for access } \\
\text { to research facilities }\end{array}$ & 4 & 76 & 4 & 2.10 & 0.65 \\
\hline $\begin{array}{l}\text { Contract or agreement for the use } \\
\text { of intellectual human capital in } \\
\text { R\&D projects }\end{array}$ & 5 & 45 & 2 & 58.00 & 17.90 \\
\hline
\end{tabular}




\begin{tabular}{|c|c|c|c|c|c|}
\hline $\begin{array}{l}\text { Contract or agreement to share } \\
\text { research facilities with small } \\
\text { companies in incubation } \\
\text { activities }\end{array}$ & 5 & 27 & 1 & 6.90 & 2.13 \\
\hline $\begin{array}{l}\text { Biological material transfer } \\
\text { agreement }\end{array}$ & 6 & 19 & 1 & - & - \\
\hline Contract to assign IP rights & 2 & 2 & 0 & - & - \\
\hline Other & 13 & 104 & 5 & 3.90 & 1.20 \\
\hline Total & & 1,957 & 100 & 437.60 & 135.06 \\
\hline
\end{tabular}

Source: FORMICT Report 2016 (MCTIC 2017)

Note: Data from 2016 (exchange rate USD/BRL $=3.24$ ). 
pharmaceutical and chemical industries were the sectors with the largest number of knowledge transfer contracts.

It is important to note, however, that the figures are distorted by the fact that the information comes from KTOs. KTOs are most likely only reporting on those contracts and agreements for which they are responsible. Since the involvement of a KTO is only mandatory in the case of licensing contracts, this channel is probably overestimated in the official data.

For the same reason, our own interview data from KTOs also probably overstate the importance of licensing. Four interviews were undertaken with major KTOs in Brazil as part of the research project for this book. We identified three main formal channels of knowledge transfer: licensing and commercialization of IP, software, and knowhow; non-disclosure agreements; and technological partnership agreements. Of these, licensing emerged as the KTOs' main activity.

This contrasts with the results of the interviews we conducted with researchers, which identified consultancy performed by academics personally rather than agreements on the part of their universities as the main knowledge transfer channel, followed by research agreements (sponsored research) between universities and companies. The literature on knowledge transfer also emphasizes the importance of academic consultancy.

All the interviewees - KTOs and individual researchers - agreed that data management was crucial to control and improve KTOs' activities and knowledge transfer processes. They also noted the importance of data management in enabling KTOs to comply with their obligations under the Brazilian Innovation Act, which requires them to "monitor the processing of applications and the maintenance of the institution's intellectual property rights" and "promote and monitor the University/PRI relationship with companies."

Despite the importance of their data management function, KTOs may hold incomplete information about universities' knowledge transfer activities. For instance, at Unicamp the KTO (called Inova) may support the process of signing a new sponsored research contract with a company, but this is not necessary or mandatory. In fact, the internal regulations on this process do not foresee a role for the office. As a result, in 2016 Inova had information about fewer than thirty research contracts with companies undertaken by Unicamp, according its annual report.

The same thing happens in several other universities, explaining why licensing contracts appear in the official statistics as the main formal channel for knowledge transfer. But all the other evidence suggests that 
consultancy and research contracts are the most important channels, although there are no consolidated data to confirm this.

\subsubsection{Institutional Knowledge Transfer Practices}

In general, the knowledge transfer activities of the institutions whose personnel were interviewed are based on: (1) the innovation policy of the universities to which they are linked, (2) their university's internal regulations on research and graduate activities, (3) the Brazilian Innovation Act and related regulations, (4) federal law on supporting agencies, (5) laws on academic employment, and (6) implicit policies of innovation (the "culture") adopted by researchers and university academics.

In order to stimulate university/public research institute-enterprise interactions, the Brazilian Innovation Act obliged all public research institutes and public universities to establish their own innovation policies covering, among other things: (1) strategic objectives and guidelines for innovation; (2) entrepreneurship; (3) technological services; (4) laboratory-sharing procedures; and (5) IP rights and knowledge transfer. The Act also stipulated that universities and public research institutes should have their own KTOs fulfilling the role of intermediate agents responsible for managing the institution's innovation policies (Brasil 2004: art. 16).

All the institutions answering our research questionnaire said they had an IP policy. The requirements of the Innovation Act are probably responsible for that in many cases, but some institutions had already established their IP policies or created KTOs before the Act. For instance, Inova, the KTO at Unicamp, was created in 2003, and UFMG has had an IP policy since 1998.

While every public university and public research institute in the country is required to have a KTO, the Innovation Act allowed institutions to share a KTO. This is probably a unique feature of the Brazilian KTOs: several of them serve more than one research organization. ${ }^{12}$

It is rare for Brazilian universities and public research institutes to use other kinds of agency to support knowledge transfer or entrepreneurship. For example, liaison offices to promote partnerships with companies are not common in Brazilian institutions, and neither are funds or specific agencies geared to supporting entrepreneurship. Therefore, the KTOs

${ }^{12}$ NIT Mantiqueira and NIT Rio are examples. 
sometimes take on these kinds of responsibility. For instance, some interviewees mentioned actions taken to stimulate faculty and graduate students to get involved in technology partnerships with companies and entrepreneurship, and at Unicamp the incubator and technology park come under the umbrella of Inova.

However, several authors argue that the role of Brazilian KTOs is still very limited, and, in certain cases, research institutions do not include them in the management of innovation activities (Pinheiro-Machado and Oliveira 2004; Dos Santos et al. 2009; Closs and Ferreira 2012; Pereira and Mello 2015; Rauen and Turchi 2017).

The explanation for the limited role of Brazilian KTOs may in part lie in their staff profile. According to the MCTI (2017), more than 50 percent of KTO staff are public servants with no previous experience in the private sector, which might be of great help in evaluating the commercial potential of or market interest in a given technology. The others are fellows, students or support employees (interns constitute almost 10 percent of all KTO staff).

Regarding KTOs' intended role as a contact point for companies at public research institutes, this is also not so relevant since companies' approaches to public research institutes tend to be informal or motivated by other concerns. Rauen and Turchi (2017) consulted thirteen public research institutes and over sixty public specialists in the management of public-private R\&D interaction to identify, among other things, common business practices in accessing public research institutes' knowledge transfer channels. Their interviewees reported that companies tend to approach public research institutes in four different ways to seek their R\&D support:

- spontaneous demand (motivated by previous informal contacts with public research institutes' technicians and researchers);

- response to public funding notices (especially those notices that prioritize research activities and technological development through public-private partnerships);

- contact with public research institute alumni; and

- response to support advertised by public research institutes themselves, which occurs mainly in the case of institutions that provide open-access laboratories for many different users.

In fact, several studies (Porto et al. 2011; Closs and Ferreira 2012; Rauen and Turchi 2017) have shown that public funding announcements aimed at building partnerships between business and universities/public 
research institutes are very important in fostering interest among companies in formalizing partnership agreements.

Nevertheless, KTOs undertake several activities to promote university-industry interaction. All the KTOs at larger universities, for instance, release a list of their institution's technologies that are available for licensing so that companies can find the most suitable ones for their interests.

Other activities, such as pricing technical services, agreeing the number of public research organization staff who will consult on $\mathrm{R} \& \mathrm{D}$ projects or the number of hours of private access to laboratories, tend to be led by public research organization researchers and technicians themselves. The role of the KTO at this negotiation stage is minimal or nonexistent.

While KTOs have limited participation in most of the public research institutes' innovation management activities, they do make an important contribution to managing IP activities, especially drafting, registering, and filing patents. Rauen and Turchi (2017) reached this conclusion from interviews with specialists in knowledge transfer and researchers at several public research institutes in Brazil in which they asked about the role of KTOs, among other things. The identified two main reasons why KTOs have little participation in and limited influence over public research institutes' innovation management activities. First, KTOs have limited managerial and budgetary autonomy, as they depend largely on fund transfers from and strategic decisions by public research institutes. Second, they suffer from high staff turnover and a dearth of qualified or specialized staff, because their link to government institutions obliges them to rely on public tenders in hiring new staff and they do not offer competitive salaries.

In sum, although the KTOs were expected to play an important role in mediating innovation activities with the private sector, they lack the recognition and operational flexibility necessary to carry out their tasks.

As regards incentives, the Innovation Act and subsequent legislation did provide financial incentives for universities and academics to work with companies, and, in consequence, it is now very common for both institution and individual staff to receive financial and nonfinancial compensation for their participation in innovation activities.

All the institutions we surveyed reported that professors and researchers can undertake consultancy activities for companies and can also receive additional remuneration for participating in research contracts between universities and companies. Finally, they can also receive 
one-third of any royalties received from licensing technologies that they helped to develop. ${ }^{13}$

Regarding nonfinancial compensations, interviewees affirm that, in collaborative projects, the standard procedure is that any remaining research assets such as equipment tend to be donated to the university.

In spite of all the difficulties faced, in particular by public universities, the institutions were unanimous in reporting that these compensation mechanisms are important in stimulating engagement among teachers and researchers in developing technologies in partnership with companies. Interviewees believe that KTOs helped to empower researchers to seek new innovation projects with companies, because they felt there was a support structure in place for identifying, negotiating and managing projects.

\subsection{Final Remarks}

There has been increasing concern among researchers, specialists, and policymakers about the need to narrow the gap between the scientific knowledge production in universities and the requirements of the business sector. To some extent, such concern lay behind the development of a brand-new framework of public policies fostering university-industry interaction in Brazil in the last fifteen years.

Thanks to these new policies, a lack of interaction between companies and universities is no longer the main bottleneck in the Brazilian innovation system. Today, most of Brazil's major universities and research institutes have a knowledge transfer office to support knowledge transfer to the business sector. Furthermore, there are financial incentives for universities and for academics personally to work in partnership with companies, through sponsored research at the university or consultancy.

Brazilian legislation is now much more akin to the rules in place in several developed countries in terms of managing intellectual property rights. The KTOs have primary responsibility for filing patents on behalf of Brazilian universities, and universities are now the main institutional applicants at the National Institute of Industrial Property.

However, some problems clearly remain unsolved. Excessive bureaucracy is always mentioned as a concern when it comes to the

${ }^{13}$ One-third of the royalties goes to the university and the remaining third covers laboratory costs. 
relationship between universities and research institutes and the business sector. Bureaucracy is a big issue in the public sector, and most of Brazil's universities and public research institutes are part of the public sector.

When it comes to patenting, although the share of universities and research institutes in Brazilian patenting activity has increased, few of the patents they own are, in fact, licensed to companies. This underlines the importance of informal knowledge transfer channels in universityindustry interaction in Brazil. So one of the main conclusions in terms of future policy is that it should aim to reinforce such channels.

Of course, it is also necessary to look at the demand side. The overall business environment is also important in explaining why universityindustry interaction is not stronger in Brazil. This chapter has not examined the private sector as such in detail, but a lack of competition should be acknowledged as an important reason why Brazilian companies show little interest in the knowledge produced by the country's universities. Brazil is one of the most closed economies in the world, and so the motivation to innovate is low.

\section{References}

Agência Nacional do Petróleo (ANP) (2005). Resoluça o ANP no 33, de 24 de novembro de 2005. Rio de Janeiro: ANP.

Albuquerque, E. (1999). "National systems of innovation and non-OECD countries: Notes about a rudimentary and tentative 'typology'." Brazilian Journal of Political Economy, 19(4): 35-52.

Albuquerque, E. (2003). "Patentes e atividades inovativas: uma avaliaça o preliminar do caso brasileiro." In E.B. Viotti and M.M. Macedo (eds.), Indicadores de ciencia, tecnologia e inovaça o no Brasil. Campinas: UNICAMP.

Amadei, J.R.P. and A.L.V. Torkomian (2009). "As patentes nas universidades: Análise dos depósitos das universidades públicas paulistas." Ciência da Informação, 38(2): 9-18.

Brasil. Lei n. 9.279, de 14 de maio de 1996;www.planalto.gov.br/ccivil_03/leis/ L9279.htm.

Brasil. Lei n. 10.973, de 2 de dezembro de 2004; www.planalto.gov.br/ccivil_03/ _ato2004-2006/2004/lei/l10.973.htm.

Brito Cruz, C.H. (2015). Ciência e tecnologia em São Paulo, 2015. Mimeo.

Britto, G., U.P. Dos Santos, G. Kruss, and E. Albuquerque (2015). "Global innovation networks and university-firm interactions: An exploratory survey analysis." Revista Brasileira de Inovação, 14(1): 163-92. 
de Castro, P.G., A.L. da Silva Teixeira, and J. E. de Lima (2014). “A relação entre os canais de transferência de conhecimento das Universidades/IPPS e o desempenho inovativo das firmas no Brasil." Revista Brasileira de Inovação, 13(2): 345-70.

Chaves, C.V., M.S. Rapini, W. Suzigan, A.C. de A. Fernandes, E. Domingues, and S. S. Martins Carvalho (2015). "The contribution of universities and research institutes to Brazilian innovation system." Innovation and Development, 6(1): $31-50$.

Closs, L.Q. and G.C. Ferreira (2012). “A transferência de tecnologia universidadeempresa no contexto brasileiro: Uma revisão de estudos científicos publicados entre os anos 2005 e 2009." Gestão \& Produção, 19(2): 419-32.

De Negri, F. et al. (2009). Perfil das empresas integradas ao sistema federal de CT\&I no Brasil e aos fundos setoriais: uma análise exploratória. Brasília: MCT, FINEP, IPEA; Belo Horizonte: UFMG.

De Negri, F., L.R. Cavalcante, and P.F. Alves (2015). University-Enterprise Interaction in Brazil: The Role of the Public Research Infrastructure. (IPEA Discussion Paper Series n. 206). Brasilia: IPEA.

De Negri, F. and F.H.S. Squeff (2016). Sistemas setoriais de inovação e infraestrutura de pesquisa no Brasil. Brasília: IPEA.

Dos Santos, M.E.R., P.T.M. Toledo, and R.A. Lotufo (eds.) (2009). Transferência de tecnologia: Estratégias para a estruturação e gestão de núcleos de inovação tecnológica. Campinas: SPL Komedi.

Dutrénit, G. and V. Arza (2015). "Features of interactions between public research organizations and industry in Latin America: The perspective of researchers and firms." In E. Albuquerque, W. Suzigan, G. Kruss, and K. Lee (eds.), Developing National Systems of Innovation: University-Industry Interactions in the Global South. Cheltenham: Edward Elgar.

Instituto Brasileiro de Geografia e Estatística (IBGE) (2016). Pesquisa de Inovação (PINTEC) 2014. Rio de Janeiro: IBGE.

Instituto Nacional de Estudos e Pesquisas Educacionais Anisio Teixeira (Inep) (2016). Sinopse Estatística da Educação Superior 2015. Brasília: Inep. Available http://portal .inep.gov.br/web/guest/sinopses-estatisticas-da-educacao-superior.

Livesey, F. (2014). Report on Survey of Brazilian Technology Transfer Offices (TTOs). Cambridge: University of Cambridge.

Ministério da Ciência, Tecnologia, Inovações e Comunicações (MCTIC) (2017). Política de Propriedade Intelectual das Instituições Científicas e Tecnológicas do Brasil - Relatório FORMICT 2016. Brasilia: MCTIC; www.mctic.gov.br/mctic/ export/sites/institucional/tecnologia/propriedade_intelectual/arquivos/ Relatorio-Formict-Ano-Base-2016.pdf.

Mowery, D.C., R.R. Nelson, B.N. Sampat, and A.A. Ziedonis (2004). Ivory Tower and Industrial Innovation: University - Industry Technology Transfer Before and After Bayh-Dole. Stanford: Stanford University Press. 
Pereira, F.C. and J.M.C. Mello (2015). "Depósitos de patentes de universidades brasileiras na base do INPI." XXXV Encontro Nacional de Engenharia de Produção. Rio de Janeiro: Associação Brasileira de Engenharia de Produção (ABEPRO).

Pinheiro-Machado, R. and P. Oliveira (2004). "A comparative study of patenting activity in US and Brazilian scientific institutions." Scientometrics, 61(3): 323-38.

Porto, G.S., Kannebley Júnior, S., Selan, B., and Baroni, J.P.M.T. (2011). "Rede de interações universidade-empresa no Brasil: Uma análise de redes sociais.” Revista de Economia, 37(special issue): 51-84.

Póvoa, L.M.C. (2008). “Patentes de Universidades e Institutos Públicos de Pesquisa e a Transferência de Tecnologia para Empresas no Brasil." Doctoral thesis presented to the Federal University of Minas Gerais, Belo Horizonte.

Póvoa, L.M.C. and M.S. Rapini (2010). “Technology transfer from universities and public research institutes to firms in Brazil: What is transferred and how the transfer is made." Science and Public Policy, 37(2): 147-59.

Rapini, M.S. (2007). "Interaça o universidade-empresa no Brasil: Evidências do Diretório dos Grupos de Pesquisa do CNPq." Estudos Econômicos, 37(1): 211-33.

Rapini, M.S., E. Albuquerque, C. Chaves, L. Silva, S. Souza, H. Righi, and W. Cruz (2009). "University-industry interactions in an immature system of innovation: Evidence from Minas Gerais, Brazil.” Science and Public Policy, 36(5): 373-86.

Rauen, C.V. (2016). “O Novo Marco Legal da Inovação no Brasil: O Que Muda na Relação ICT-Empresa?” Radar: Tecnologia, Produção e Comércio Exterior, 43: 21-35.

Rauen, C.V. and L.M. Turchi (2017). “Apoio à Inovação por Institutos Públicos de Pesquisa: Limites e Possibilidades Legais da Interação ICT-Empresa.” In L. M. Turchi (ed.), Políticas de Inovação Tecnológica: Avanços recentes e desafios futuros. Brasília: IPEA.

Reynolds, E. and F. De Negri (2017). The University as an Engine of Innovation: Critical Case Studies from Brazil and the U.S. (MIT-IPC Working Paper 17-006). Cambridge: MIT Press.

Sutz, J. (2000). “The university-industry-government relations in Latin America.” Research Policy, 29(2): 279-90.

Suzigan, W. and E.M. Albuquerque (2011). “A interação universidades e empresas em perspectiva histórica no Brasil.” In W. Suzigan, E.M. Albuquerque, and S.A. F. Cario (eds.), Em busca da inovação: interação universidade-empresa no Brasil. Belo Horizonte: Autêntica.

Telles, L.O. (2011). "O Papel dos Institutos Públicos de Pesquisa no Desenvolvimento Tecnológico e na Cooperação Universidade-Empresa.” Doctoral thesis presented to the University of São Paulo. 
Wunsch-Vincent, S. (2012). "Accounting for science-industry collaboration in innovation: existing metrics and related challenges." In Global Innovation Index 2012: Stronger Innovation Linkages for Global Growth. Fontainebleau: INSEAD/World Intellectual Property Organization.

Zuniga, P., F. De Negri, M.A. Dutz, D. Pilat, and A. Rauen (2016). Conditions for Innovation in Brazil: A Review of Key Issues and Policy Challenges (Discussion Paper n. 0218). Brasilia: IPEA. 


\section{China}

B AOMINGCHEN, CAN HUANG, CHUNYAN PENG, MINGLEI DING, NING HUANG, XIA LIU, AND JUAN YANG

\subsection{Introduction}

China is an emerging economy with a rapidly growing technology market. Both the central and provincial governments have supported knowledge transfer activities and directed technology development, initiating regional innovation collaboration and promoting entrepreneurship, innovation, and economic growth. As in other countries, many of these activities are geographically concentrated. For example, five provinces (Beijing, Guangdong, Shanghai, Shandong, and Jiangsu) accounted for half of total R\&D expenditure in China in 2011, while the top ten provinces accounted for 70 percent of total R\&D expenditure that year (Wang et al. 2015a).

In recent decades, Chinese universities and public research institutes have made tremendous progress in the fields of research and education. This progress is reflected in the increasing number of scientific publications and patent applications originating in the country. The technology market, spinoff companies from universities and public research institutes, cooperation between academy and industry, and patent transfer and licensing have all developed rapidly in China. Yet several issues have resulted in lower than possible rates of knowledge transfer from universities and public research institutes to firms, resulting in substantial amendments in 2015 to the Law on Promoting the Transformation of Scientific and Technological Achievements (PTSTA). These amendments removed legal barriers to knowledge transfer and provided incentives for universities and public research institutes to engage more actively in knowledge transfer activities.

Can Huang and Xia Liu acknowledge the financial support provided by the National Natural Science Foundation of China through grant nos. 71874152, 71732008 and 71402161, the Soft Science Research Program of Zhejiang Province through grant no. 2019C25038, and the Fundamental Research Funds for the Central Universities. 
However, several factors are likely to continue to hinder the growth of knowledge transfer from universities and public research institutes to firms. Challenges include the immaturity of technology markets, the inadequate $\mathrm{R} \& \mathrm{D}$ capabilities and investments of Chinese companies, the historical legacy of past policies that failed to provide sufficient incentives for patenting and transfer activities, ambiguous corporate governance and regulations, and underdeveloped intermediary agencies such as knowledge transfer offices.

This chapter looks at these issues in detail. Section 8.2 describes how the role of Chinese universities and public research institutes has evolved in recent decades with the transition to a market economy. Section 8.3 outlines changes in the main laws and policies governing knowledge transfer activities. Section 8.4 examines the knowledge transfer activities of Chinese universities and public research institutes, while Section 8.5 analyzes ongoing barriers to knowledge transfer. Last, a short concluding section summarizes our main findings.

\subsection{The Role of Universities and Public Research Institutes in China}

Since the 1980s, China's universities and public research institutes have undergone fundamental changes as part of the country's economic transformation from a centrally planned system to a market-based economy.

In March 1985, the Central Committee of the Communist Party of China issued a Decision on Reforming the Science and Technology System (CCCPC 1985), which emphasized the economic orientation of the science and technology (S\&T) system by introducing elements of competition and market discipline. Research institutions formally under the administration of central or local governments were encouraged to join large and medium-sized enterprises and become responsible for their own profits and losses (Baark 2001; Huang et al. 2004; OECD 2008).

$\mathrm{R} \& \mathrm{D}$ investment made up approximately one-third of total S\&T expenditures in the 1990s. Government $R \& D$ expenditures have increased steadily since then (Baark 2001). However, as Huang et al. (2004) note, compared to the European Union member states and other Organisation for Economic Co-operation and Development (OECD) countries, China's innovation system was underdeveloped in the 1990s, partly as a consequence of insufficient support from legislative actions, inadequate policies to support innovation, human resources and finance, and low levels of business innovation. 
In 1993, the State Council promulgated the National Outline for Educational Reform and Development (CCCPC 1993), with the goal of raising the quality of teaching and research at Chinese universities to among the world's best through funding to create an elite group of universities and to support key disciplines. Subsequently, the Ministry of Education launched the "211 Project" to support the development of 100 leading universities. In 1995, China announced the Strategy of Invigorating China through Science and Education, emphasizing the role of science and education in economic and social development. The country's higher education sector developed rapidly thereafter. The 1998 Law of Higher Education established three basic functions for Chinese universities: cultivating talent, scientific research, and social services.

In 1999, the Ministry of Education initiated the "985 Project" supporting the development of world-class research universities. By 2015, China had 2,852 universities, 1.57 million faculty members, 9.75 million undergraduate students and 6.45 million graduate students, of whom 74,000 were $\mathrm{PhD}$ students. Today, China has 112 universities supported by the 211 Project and thirty-seven supported by the 985 Project.

In 2006, the government issued its National Plan for Medium and Long-Term S\&T Development (CCCPC 2006), which further defined the functions of universities and public research institutes in the national innovation system. The Plan states that universities are "important bases for cultivating high-level innovation talents," "one of the most important forces for basic research and high-technology innovations," and "an emerging force for solving important science and technology problems, promoting technology transfer." The roles of public research institutes were to conduct basic research, cutting-edge technological research and social science research.

Due to recent efforts, China's innovation activities have intensified substantially and attracted the return of highly skilled workers from overseas. Combined with a growth in $\mathrm{R} \& \mathrm{D}$ investments, this has led to increased scientific publications and patent applications, as shown in the following section.

\subsubsection{Investment, Scientific Publications and Patent Applications}

$\mathrm{R} \& \mathrm{D}$ Investment

China has become a powerhouse in R\&D spending since the 2000s. In 2012, its gross expenditure on R\&D (GERD) passed 1 trillion renminbi 


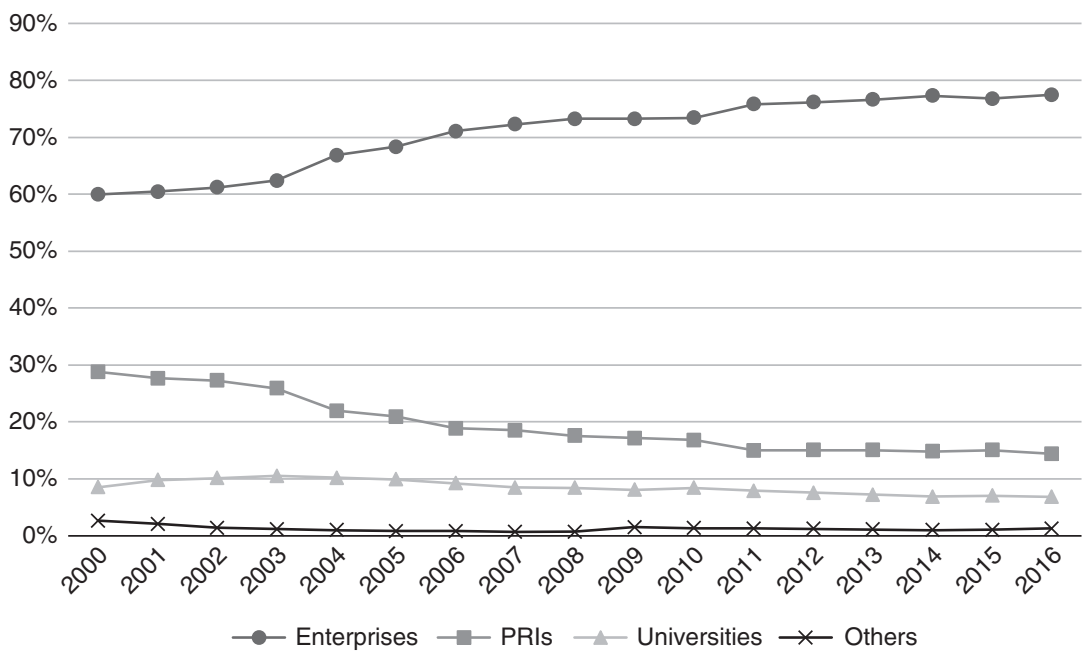

Figure 8.1 Share of total R\&D expenditures by enterprises, public research institutes, and universities in China, 2000-16

Source: China Statistical Yearbook on Science and Technology (2017)

(CNY) (USD 163 billion), third behind only the U.S. and the European Union. In 2017, this number rose to a record CNY 1.76 trillion (USD 254 billion), ranking China as second in the world in terms of R\&D spending after the U.S. (National Bureau of Statistics 2018). R\&D intensity, the ratio of R\&D expenditure divided by gross domestic product (GDP), hit a record high of 2.12 percent - a rise of 0.01 percentage points compared to 2016.

As Figure 8.1 demonstrates, the share of business R\&D spending out of total $\mathrm{R} \& \mathrm{D}$ expenditures has kept increasing throughout the past twenty years, rising from 60 percent in 2000 to 77 percent in 2016 (China Statistical Yearbook on Science and Technology 2017).

All types of organizations devote most of their R\&D investment to experimental development or applied research (Figure 8.2), but universities are the primary performer of basic research, accounting for 49.3 percent of total basic research expenditures of $\mathrm{CNY}$ 82.3 billion. ${ }^{1}$

${ }^{1} \mathrm{R} \& \mathrm{D}$ includes basic research, applied research and experimental development. Basic research is experimental or theoretical work undertaken primarily to acquire new knowledge of the underlying foundation of phenomena and observable facts, without any particular application or use in view. Applied research is also original investigation 


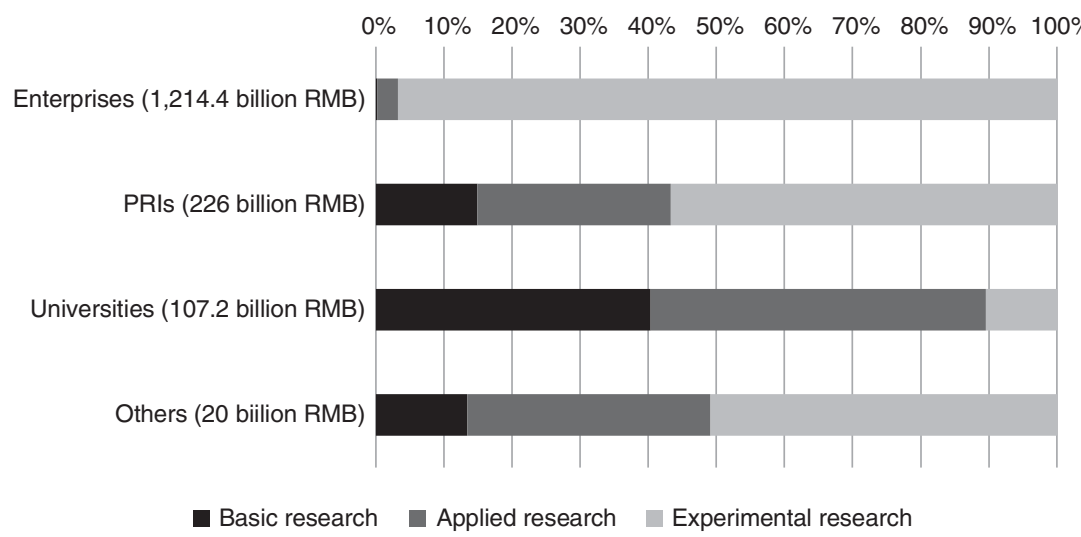

Figure 8.2 Share of 2016 R\&D expenditures in China by application Source: China Statistical Yearbook on Science and Technology (2017)

\section{Scientific Publications}

China has become the world's second largest producer of scientific publications (Institute of Scientific and Technical Information of China 2018). In 1989, the number of Science Citation Index (SCI) papers by Chinese authors was only 3 percent of the number of papers written by US authors. By 2008, this proportion had risen to 30 percent. Based on the data in Table 8.1, universities and public research institutes accounted for 85.9 percent and 10.2 percent respectively of all SCIindexed papers published by Chinese researchers in 2017 .

\section{Patent Applications}

Since the 2000s, China has experienced a surge of patent applications. The total number of invention patent applications ${ }^{2}$ filed with China's State Intellectual Property Office (SIPO) increased from 51,747 in 2000 to

undertaken to acquire new knowledge, but directed primarily toward a specific practical aim or objective. Experimental development is systematic work, drawing on existing knowledge gained from research and/or practical experience, which is directed toward producing new materials, products or devices, performing new processes, systems and services, or substantially improving those already produced or installed.

2 An invention patent is granted for new technical solutions for a product, process or the improvement thereof, provided that the technical solutions have a practical applicability. A utility model patent is granted for new and practical technical solutions relating to the shape and/or structure of a product. In general, the inventive step required for a utility model patent is less than that required for invention patents. On average, invention patents can require three to five years from application to grant, while utility patents require one year. 
Table 8.1 Number of SCI-indexed papers by different organizations in China, 2003-17

\begin{tabular}{lrrrrr}
\hline \hline Quantity/year & \multicolumn{1}{c}{2003} & \multicolumn{1}{c}{2005} & \multicolumn{1}{c}{2010} & \multicolumn{1}{c}{2015} & \multicolumn{1}{c}{2017} \\
\hline Universities & 63,672 & 125,814 & 100,772 & 219,957 & 273,337 \\
PRIs & 15,840 & 25,010 & 18,941 & 29,749 & 32,370 \\
Medical institutions & 455 & 1250 & 342 & 8,973 & 11,208 \\
Enterprises & 550 & 756 & 1,340 & 744 & 1,149 \\
Total & 80,517 & 152,830 & 121,395 & 259,423 & 318,064 \\
\hline \hline
\end{tabular}

Source: Various issues of Statistical Data of Chinese S\&T Papers Compiled by the Institute of Scientific and Technical Information of China

$1,338,503$ in 2016. In 2017, more patent applications were filed with SIPO than the filings for the United States of America (U.S.), Japan, Republic of Korea, and Europe combined. Figure 8.3 shows domestic invention patent applications by type of entity. Enterprises have the most rapid growth in patent filings. The share of university and public research institutes in total invention patent applications increased from 14.4 percent in 1995 to 22.9 percent in 2005 , before declining to approximately 19 percent from 2014. Zhang and Wan (2008) analyzed the ownership of Chinese patents and found that public research institutes have a higher efficiency (measured by the number of patents per unit of R\&D expenditure) in generating invention patents, while enterprises have higher efficiency in generating utility model patents.

\subsection{Laws and Policies Relevant to Knowledge Transfer}

\subsubsection{The Legal Framework for Knowledge Transfer in China}

One of the most important laws governing knowledge transfer activities in China is the 2007 Science and Technology Progress Law, which provides the legal framework for the management of scientific and technological achievements. According to Article 20 of the Science and Technology Progress Law, intellectual property rights (IPRs) that are generated from government funding by a university or public research institute belong to the institution, except when the IP rights involve national security, the national interest, or other major social and public interests. IPRs include patents, copyrighted software, integrated circuit designs, and new plant variety rights. 


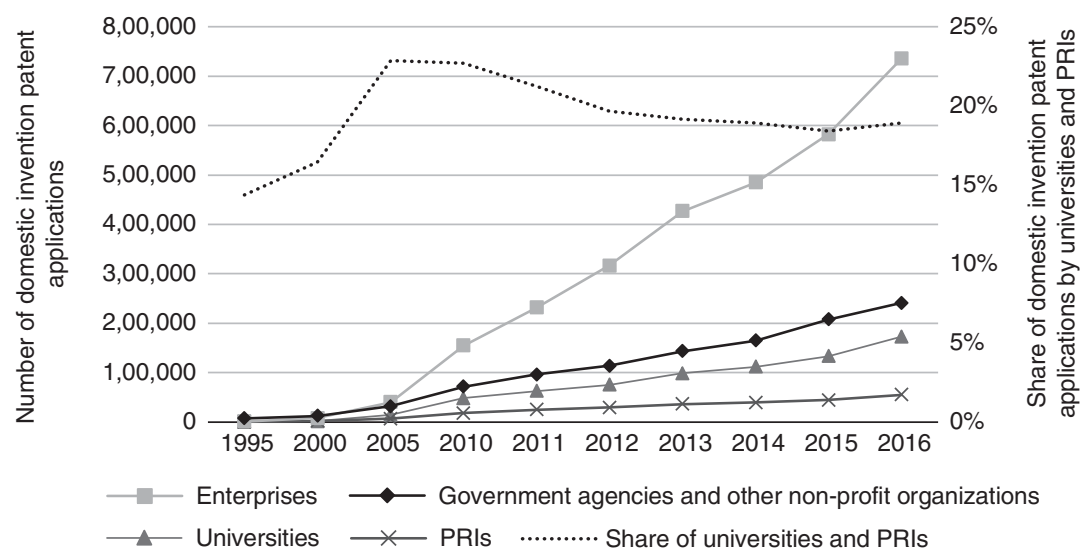

Figure 8.3 Domestic invention patent applications by different types of organization, 1995-2016

Source: China Statistical Yearbook on Science and Technology (2017)

While the concept of patents dates to the fifteenth century in Europe, the introduction of a system of intellectual property laws in China is very recent (Kafouros et al. 2015). China joined the World Intellectual Property Organization in 1980, paving the way for the creation of an IP system that complies with international standards (Bosworth and Yang 2000). Five years later, in 1985, China signed the Paris Convention for the Protection of Industrial Property and established a Patent Office, the predecessor of the current SIPO. The Chinese Patent Law was enacted in 1984 and is the governing legislation for the protection of technological inventions in China. The Patent Law came into effect in 1985 and has been amended three times, in 1993, 2001, and 2009.

Article 6 of the 2009 Patent Law regulates the ownership of inventions created by academics and researchers at universities and public research institutes during their work, or when they use materials, facilities, or equipment provided by a university or public research institute. According to the Patent Law, the inventor of inventions created as part of their work or using workplace assets has the right to be acknowledged on the patent document and receive a reward or compensation from their employer, but the employer owns the invention.

Another essential law governing knowledge transfer in China is the Law on Promoting the Transformation of Scientific and Technological Achievements (PTSTA), promulgated in 1996 and amended in 2015. The 
Law covers rights to scientific and technological achievements, rewards for R\&D and knowledge transfer personnel, and requires universities and public research institutes to establish or obtain access to knowledge transfer agencies.

Contract law and company law also regulate knowledge transfer in China, as the relationship between the parties to a knowledge transfer agreement reflects basic contractual relations and knowledge transfer often involves enterprises as technology buyers or collaborating partners.

\subsubsection{Amendments to the PTSTA Law in 2015}

The PTSTA Law of 1996 was amended in 2015 for three reasons. First, several articles of the Law were outdated as a result of significant changes in the Chinese economy. Second, many provinces had experimented with various policies to stimulate knowledge transfer and the amendments were designed to enact the most effective policies into law. Third, universities and public research institutes in China lacked adequate incentives to transfer technology because of the institutional setting and rules defined in the 1996 Law.

Under the 1996 Law, a university or public research institute was required to report to and obtain approval from the Ministry of Finance or the State-Owned Asset Supervision and Administration Commission in order to license or otherwise dispose of IP. Universities and public research institutes did not have full owner's rights, and consequently were less motivated to promote knowledge transfer. Furthermore, after they transferred IP assets, any revenue they earned from the transfer had to be paid to the Ministry of Finance.

The amendment dealt with these issues. Under Article 18 of the amended PTSTA Law, universities and public research institutes established by the state have the right to dispose of their scientific and technological achievements, including the right to transfer technologies. However, the price agreed on by both parties in negotiation or auction and the name of the scientific and technological achievements must be disclosed to the public. Furthermore, universities and public research institutes can keep the revenue from knowledge transfer and are not required to pay it to the Ministry of Finance.

Before the amendment, knowledge transfer was not used as a performance measure for universities and public research institutes. In contrast, the amendment has made knowledge transfer a legal 
obligation for Chinese universities and public research institutes. Article 17 of the amended Law stipulates that public research institutes and universities established by the state are required to strengthen the management, organization and coordination of the transformation of scientific and technological achievements, prepare an annual report on their achievements in transforming science and technology, and set up a knowledge transfer organization and process.

In May 2016, the State Council announced implementation details for the PTSTA Law in a Program on Promoting Scientific and Technological Achievements, Transfer and Transformation to promote the disclosure and exchange of information on scientific and technological achievements. Specific actions under this program included:

- Setting up a coordination mechanism for industry, universities and public research institutes so they can cooperate fully to promote knowledge transfer.

- Creating a commercialization base for scientific and technological achievements.

- Strengthening the transfer of scientific and technological achievements into market-oriented services, including building a national technology trading network platform and offering knowledge transfer services at the regional level.

- Promoting scientific and technological innovation and entrepreneurship through the development of "maker spaces" to open up the scientific and technological resources of universities and public research institutes to the public.

- Training professional knowledge transfer personnel.

Almost every provincial government has enacted regulations to implement the provisions of the amended PTSTA Law. For example, several provinces increased the proportion of knowledge transfer revenue that can be used to reward R\&D and knowledge transfer or set up special scientific and technological achievement funds. In Jiangsu Province the fund was valued at CNY 2 billion in 2014. Provincial governments were often bolder than the central government in promoting knowledge transfer because they considered knowledge transfer to be an important driver of local economic growth.

To fulfill the legal obligations stipulated in the amended PTSTA Law, China's universities and public research institutes adopted up to seven actions to facilitate knowledge transfer, although some universities and public research institutes implemented some of these actions before the 
amended Law, for instance, to reflect provincial policies or known best practice.

1. Increasing rewards and compensation for inventors and knowledge transfer contributors. Article 45 of the amended Law requires that no less than 50 percent of the net profit from knowledge transfer should be given as a reward or compensation by universities and public research institutes to the inventors and others who made significant contributions to the transfer, including knowledge transfer officers. This provision greatly incentivized knowledge transfer by universities and public research institutes. Nearly all universities and public research institutes have reformed their reward regulations since 2015. Many now give up to 70 percent of net profits from successful transfer to the inventors and related contributors. In 2015, the Drug Research Institution of the Chinese Science Academy paid nearly CNY 12 million to inventors and knowledge transfer contributors.

2. Setting up knowledge transfer organizations. China's public research institutes have set up knowledge transfer organizations that are either associated with several national-level organizations, such as the National Technology Transfer Center or the National Technology Transfer Demonstration Institution, or cofounded with local governments or enterprises. Successful examples include the Hunan University of Chinese Medicine, which transferred its newly developed Chinese traditional medicine to pharmaceutical enterprises and earned revenue of CNY 68 million. The transfer eventually resulted in the development of enterprises with annual revenues of several hundred million renminbi and created several leading brands of biomedical products in Hunan Province. Another example is the Central South University of Forestry and Technology. The University provided a feasibility study of bamboo plywood production, factory planning, process design for workshops, technical training, preproduction technical guidance and many other technical services to more than 400 bamboo plywood enterprises which together achieved total output valued at more than CNY 20 billion. A third example is Changzhou University, which signed twenty-two knowledge transfer agreements with twenty major manufacturers of phosphorus chemical products and obtained a total income of over CNY 20 million.

3. Implementing performance evaluation systems. Many universities and public research institutes have established performance 
evaluation systems to motivate knowledge transfer staff. By contributing to knowledge transfer, staff can be promoted to senior management positions and have the opportunity to pursue a promising career path.

4. Marketing of information on scientific and technological achievements. Universities and public research institutes participate in exhibitions organized by governments and other commercial organizations to exchange information with enterprises and investors, introduce their scientific and technological achievements, negotiate with potential buyers, and disseminate information about their scientific and technological achievements on their websites to attract potential partners.

5. Permission for academics to take a leave of absence to start a business. Before the 2015 amendment to the PTSTA Law, universities and public research institutes did not encourage academics to work parttime to assist a firm to transfer licensed university technology or take a leave of absence to start their own businesses. However, the 2016 implementation details to the PTSTA Law allow academics to do so. The policy requires universities and public research institutes to establish their own systems to manage academics while they are on leave, and should keep the faculty position of academics for up to three years for those who take a leave of absence to create new businesses.

6. Policies on spinoffs. Many universities and public research institutes have introduced new initiatives to permit and encourage students to start their own businesses. On-the-job and off-the-job entrepreneurship by professionals and technicians in universities and public research institutes are also encouraged. For example, according to the Knowledge Transfer Regulation of Zhejiang University, faculty and students can invest in companies, using their scientific and technological achievements and proprietary technology.

7. Strengthening cooperation between universities, public research institutes and local industry. In addition to the policies identified above to provide incentives for academics to engage in knowledge transfer, policy has also encouraged knowledge transfer via university-industry collaboration. A common channel is to establish a joint research institute that offers technology services to local industries. In this collaborative model, local governments offer land, funds, and buildings while universities and public research institutes offer their scientific and technological achievements, R\&D capabilities, management teams, and 
equipment. Local governments are eager to support this model due to expectations that collaboration will promote local economic growth.

China has formulated four other types of policy to promote university-industry research linkages. One consists of policies to establish strategic alliances for industrial technology innovation. The first fiftysix alliances were set up in 2010 and focused primarily on promoting industrial technology innovation. Many were led by universities and public research institutes. Once scientific and technological progress was made, new technologies could be transferred smoothly from universities and public research institutes to industry through the alliances.

The second policy type relates to the reform of the National Science and Technology Plan. Industrial development projects that are funded under the Plan are required to include enterprises in the research and in the development of research agendas. Currently, enterprises participate in nearly 90 percent of projects under the Plan and lead nearly 50 percent of science and technology projects.

The third policy category establishes national technology innovation platforms or Innovation Centers to promote university-industry research cooperation on nationally strategic industrial technologies. The first center, the National High-Speed Train Technology Innovation Center, located at Qingdao City in Shandong Province, was established in September 2016. In the same year, the Ministry of Industry and Information began creating other National Manufacturing Innovation Centers to advance industrial innovation capacity. Nearly fifteen such centers were planned to be established by 2020 .

The fourth policy category consists of science parks, which are an important tool for Chinese innovation policy (Lai and Shyu 2005; Jongwanich et al. 2014). In 1991, the State Council established the Torch Program, which accelerated the establishment of science and industry parks across China. The number of university science parks increased from forty-two in 2004 to 115 in 2014 (Torch Report 2016). These science parks offer various incentives to encourage investment and the formation of new firms:

- New firms are exempt from corporate income tax for two years.

- Licenses are waived for the importation of materials and parts used in producing products for export.

- Revenue from knowledge transfer is only taxable after the first CNY 300,000 . 
- Intangible assets such as intellectual property can be factored into a company's registered capital.

- The science parks can provide professional intermediary services such as legal services, human resource management services, and marketing support.

Several studies have confirmed the contribution of university-industry research cooperation in China to universities' revenue, firms' innovative capacity and regional economic development (Liu and Shi 2009; Ng and Li 2009; Yang and Ling 2009; Li et al. 2010; Kafouros et al. 2015; Fu and Li 2016; Hao et al. 2016).

Quan (2010) surveyed R\&D laboratories in companies that interact with universities in Beijing. His results show that firms have different motivations that prompt different collaboration activities. The most frequently cited incentive for firms to collaborate with universities is to build a positive public image. In addition, companies sponsor research projects as a costeffective way of keeping abreast of relevant new discoveries in China. Companies will outsource R\&D to a university to reduce costs. But the most attractive factor for cooperation, according to the survey, is access to high-quality graduates. A large proportion of employees and interns in corporate R\&D laboratories are graduates of partner universities. Wang et al. (2015a) conducted a survey on the factors that affect the success of academic-industry collaborations. They found that collaboration output was affected by not only the university's reputation and research capability, but also by the breadth and depth of the collaboration.

\subsection{Data and Research on Knowledge Transfer from Universities and Public Research Institutes}

Other than making new knowledge publicly available at no cost, universities and public research institutes can transfer technology through cooperative arrangements, including contract research and collaboration, licensing, and establishing spinoff enterprises. Many of these transfers occur through the technology market.

\subsubsection{The Technology Market}

Recently, China has made great progress in developing its technology market. Based on information from the technology trading information service platform and Innovation Relay Center networks, China has 
Table 8.2 Share of transaction value of knowledge transfer contracts by seller types, 2009-16 (\%)

\begin{tabular}{lrrrrrrrr}
\hline \hline & 2009 & 2010 & 2011 & 2012 & 2013 & 2014 & 2015 & 2016 \\
\hline PRIs & 6.3 & 5.1 & 5.5 & 6.3 & 6.7 & 5.3 & 5.7 & 6.2 \\
Universities & 4.4 & 5.0 & 5.2 & 4.6 & 4.4 & 3.7 & 3.2 & 3.2 \\
Enterprises & 86.4 & 85.5 & 86.5 & 86.5 & 86.2 & 87.6 & 86.2 & 86.6 \\
Others & 2.8 & 4.3 & 2.8 & 2.6 & 2.7 & 3.3 & 4.9 & 4.0 \\
\hline \hline
\end{tabular}

Source: China Statistical Yearbook on Science and Technology (2017)

PRI = public research institute.

established a unified and open platform to publish information about resources for knowledge transfer. In 2016, universities and public research institutes signed 90,573 contracts for knowledge transfer and research cooperation. The total value of these contracts was CNY 106.52 billion. Between 2009 and 2016, universities and public research institutes combined accounted for approximately 10 percent of the total value of knowledge transfer contracts (see Table 8.2).

There are several successful examples of the development of technology markets. The Xi'an S\&T Market opened in 2011 and has facilitated knowledge transfer transactions worth more than CNY 110 billion, organized information exchange activities, and served more than 25,000 enterprises. The Zhejiang Online Technology Market, opened in 2002, uses network information technology and e-commerce technology to disseminate information on the supply of and demand for technologies. By the end of November 2013, Zhejiang Online Technology Market had 94,319 members, including enterprises, universities, and public research institutes; listed 63,944 technical problems from enterprises, and published 153,771 scientific and technological achievements. The number of signed contracts from the period of 2002-2013 amounted to 28,929, worth CNY 25.245 billion. The Online Technology Market has become an important platform for technology trading in Zhejiang Province.

\subsubsection{University-Industry Research Cooperation}

Brehm and Lundin (2012) explored university-industry collaboration activities and innovation outputs in China between 1998 and 2004 involving 20,000 large and medium-sized companies. They found that 
Chinese universities' revenue from knowledge commercialization activities has increased over time.

Lan (2006) categorizes research contracts between universities and public research institutes and companies in China into four types: contracts for technology development, knowledge transfer, technology consulting, and technology services. Among the four types of contract, technology development was the most common, accounting for more than 30 percent of the total contract value. Liu and Jiang (2001) discuss the methods obtained by Tsinghua University to pursue knowledge transfer since 1995, which include establishing a university-industry cooperation committee to provide services for member companies, setting up funding for collaborative research, and building an online information system to update research findings and enterprise requests. Wang and Ma (2007) researched how Tsinghua University dealt with the IPRs created through collaborative R\&D projects with multinational companies. They describe four types of contract: (1) commissioned projects, in which an enterprise provides the research funding and the university conducts the research using its own equipment and manpower; (2) joint research projects, in which senior researchers from the university participate in the research and the enterprise provides research funding, equipment and engineers; (3) joint development projects, in which the university provides researchers and an enterprise provides equipment and engineers, with development funding coming from a third party; and (4) joint research organizations, in which both parties provide funds, equipment, and researchers.

The most recent data for 2015 show that universities and enterprises in China jointly performed more than $88,000 \mathrm{R} \& \mathrm{D}$ projects for a total value of CNY 66.65 billion (Ministry of Science and Technology 2017). The universities and enterprises established 2,276 post-doctoral fellowships and 10,191 joint research institutions between them. According to the Ministry of Commerce (2015), by 2015, foreign firms had established more than 2,400 $R \& D$ laboratories in China. Many foreign firms established joint R\&D programs, laboratories, training centers, technical innovation alliances, and so on with universities and public research institutes. These institutions play an increasingly important role in the Chinese innovation system, and an indispensable role in knowledge transfer.

\subsubsection{Patent Transfer and Licensing}

Scholarly studies have identified a positive correlation between government expenditures on science and technology at the provincial level and 
the number of patent licensing contracts held by local universities in the same region (Rao et al. 2013). This supports the efforts of provincial governments to fund local research capabilities and suggests that proximity may influence knowledge transfer in China, as found in the U.S. and Europe.

Wang et al. (2015b) argue that licensing universities' technologies can contribute substantially to the subsequent innovation performance of licensee firms. The more licensing activities a licensee firm performs, the greater its subsequent innovative performance.

The sale (assignment) and licensing of patents owned by Chinese universities has increased steadily. The number of patent ownership transfers and licenses grew from 1,810 in 2010 to 4,839 in 2016 (Figure 8.4), with a notable increase between 2014 and 2016 that could be due to the implementation of the 2015 PTSTA Law. The total value of transactions increased from CNY 359 million in 2010 to CNY 1215.43 million in 2016 (Figure 8.5), and the average transaction value increased from CNY 198,000 to CNY 251,000.

The total number of knowledge transfer agreements (including the sale or assignment of patents, patent licensing, and other non-patent-related knowledge transfer activities) showed a similar upward trend (Figures 8.6 and 8.7). The total number of knowledge transfer agreements by universities increased from 8,408 in 2008 to 10,517 in 2014 and the total annual value of transactions in the same period grew from CNY 3.05 billion to CNY 4.01 billion, with the average transaction value increasing from CNY 3.63 million to CNY 3.82 million (Figure 8.7). A comparison between Figures 8.4 and 8.6 suggests that non-patented knowledge transfer accounts for the majority of the agreements, which include contract research and consulting services. In addition, a comparison of Figures 8.5 and 8.7 indicates that non-patent-related knowledge transfer is a considerably larger income source for universities than patent-related knowledge transfer.

Table 8.3 shows the patenting activities of the most important 1,497 universities in China in 2015. These universities applied for 109,445 invention patents, were granted 54,868 invention patents and signed 2,695 contracts involving patent transfer with a total value of CNY 2.77 billion. Over the period 2011-15, the total value of all types of knowledge transfer transactions exceeded CNY 19.6 billion.

Although universities and public research institutes have made tremendous progress in terms of knowledge transfer, they are still challenged by relatively low efficiency in terms of the amount of knowledge 


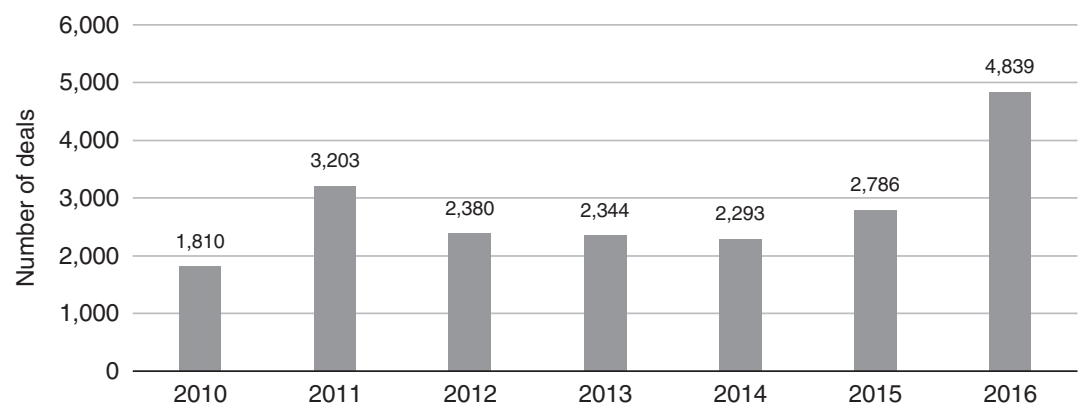

Figure 8.4 Number of patent transfers and licenses by universities, 2010-16 Source: China Statistical Yearbook on Science and Technology (2017)

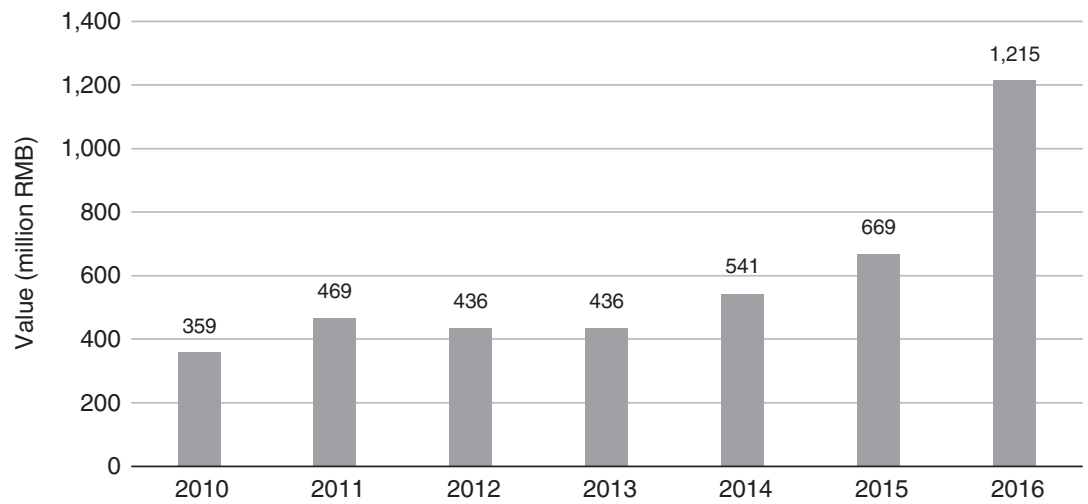

Figure 8.5 Value of patent ownership transfers and licenses by universities, 2010-16 (million CNY)

Source: China Statistical Yearbook on Science and Technology (2017)

transferred per unit of R\&D expenditure, understaffing and a lack of knowledge transfer professionals. The Patent Investigation Report (2015) surveyed 7,424 enterprises, 436 universities and 455 public research institutes in China. More than half of the surveyed universities and public research institutes categorized themselves as "carrying out basic research, obtaining a few patents" and that "patent licensing is limited" (Table 8.4). Approximately 25.4 percent of universities and 32.4 percent of public research institutes surveyed responded that they "carry out applied 


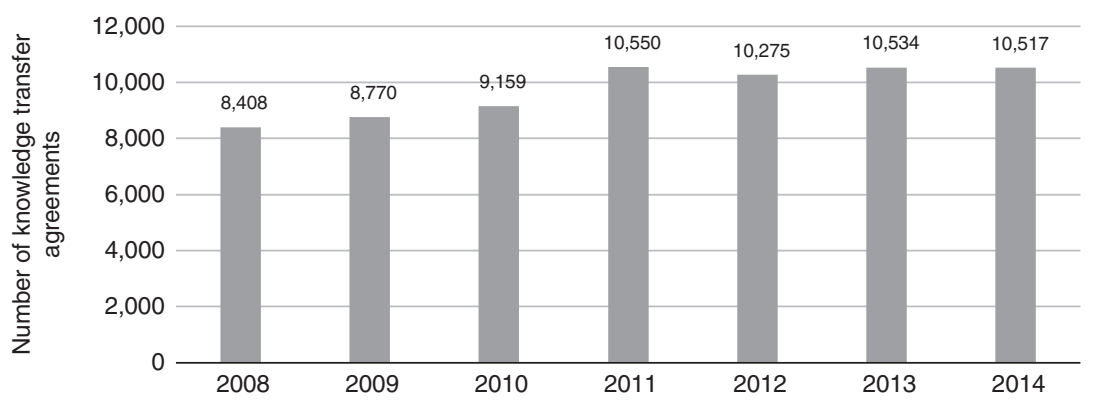

Figure 8.6 Total annual knowledge transfer agreements by universities, 2008-14 Source: Statistical Data of Science and Technology Activities in Colleges and Universities

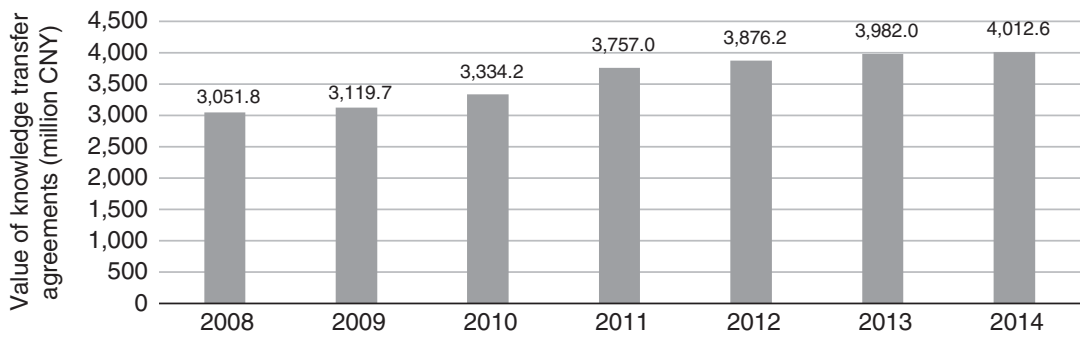

Figure 8.7 Total annual value of knowledge transfer agreements by universities, 2008-14 (million CNY)

Source: Statistical Data of Science and Technology Activities in Colleges and Universities

research, obtain many patents, and obtain revenue from patent licensing."

Table 8.5 gives the "exploitation rate" for patents owned by enterprises, universities, public research institutes, and individuals, which is defined as the number of patents used to make, use, offer to sell, sell, or import patented innovations or being sold to others divided by the total number of patents. Table 8.5 shows a clear difference between universities, public research institutes, and enterprises. In 2014, the average exploitation rate of patents in force was 57.9 percent, but the rate among enterprises exceeded that average by approximately 10 percentage points. The exploitation rate of public research institutes was 16 percentage 
Table 8.3 Patent applications, grants, and transfers by 1,497 universities in 2015

\begin{tabular}{|c|c|c|c|c|c|c|c|}
\hline \multirow[b]{2}{*}{ University type } & \multicolumn{2}{|c|}{ Patent applications } & \multicolumn{2}{|c|}{ Patents granted } & \multicolumn{2}{|c|}{ Patents transferred ${ }^{1}$} & \multirow{2}{*}{$\begin{array}{l}\text { Number of } \\
\text { other types of } \\
\text { IP rights }\end{array}$} \\
\hline & All & Invention & All & Invention & $\begin{array}{l}\text { Contract } \\
\text { (item) }\end{array}$ & $\begin{array}{l}\text { Amount } \\
(\mathrm{CNY} 1,000)\end{array}$ & \\
\hline Comprehensive & 54,977 & 34,530 & 35,723 & 17,302 & 858 & 627,056 & 4,143 \\
\hline Engineering & 99,185 & 59,802 & 65,272 & 30,701 & 1,410 & $1,911,766$ & 5,682 \\
\hline Agricultural and forestry & 11,071 & 6,248 & 7,800 & 3,079 & 252 & 61,363 & 1,045 \\
\hline Medicine & 5,202 & 2,683 & 3,625 & 1,249 & 46 & 147,108 & 75 \\
\hline Normal & 11,737 & 5,182 & 7,971 & 2,011 & 102 & 21,176 & 799 \\
\hline Others & 2,231 & 1,000 & 1,590 & 526 & 27 & 6,270 & 208 \\
\hline Total & 184,423 & 109,445 & 121,981 & 54,868 & 2,695 & $2,774,739$ & 11,952 \\
\hline
\end{tabular}

Source: Statistical Data of Science and Technology Activities in Colleges and Universities (2016)

${ }^{1}$ Includes sales (assignments) and licenses.

${ }^{2}$ Other IP rights include new plant varieties, software copyright, and layout design of integrated circuits. 
points lower than the average at 41.6 percent, while the rate for universities was only 9.9 percent. The low exploitation rate by universities (which includes patents that are only offered for sale) may be due to the low quality of patents, a lack of professionals specialized in knowledge transfer, and/or the lack of incentives to transfer technology before the 2015 amendments to the PTSTA Law.

The same study also provides data on the rate of patent sales and licensing (Tables 8.6 and 8.7), defined respectively as the number of patents sold or licensed divided by the total number of patents. This may be a better indicator of the use of university patents because it excludes patents that are only offered for sale and possibly never taken up. The results demonstrate the relatively low efficiency of knowledge transfer through patents by universities and public research institutes. In 2014 , the average rate of patent sales was 5.5 percent. The rate of patent sales by enterprises and individuals exceeded 5 percent, while the rate of sales was 3.5 percent for public research institutes and 1.5 percent for universities. The average rate of patent licensing was 9.9 percent. The rates of licensing by enterprises and individuals were equal to or slightly higher than the national average, compared to 5.9 percent for public research institutes and just 2.1 percent for universities. The total of patent sales and licensing rates is only 3.5 percent for universities (suggesting

Table 8.4 R\&D and licensing modes of universities and public research institutes (\%)

\begin{tabular}{lcc}
\hline \hline & Universities & PRIs \\
\hline $\begin{array}{l}\text { Develop better technical solutions in scientific research } \\
\text { projects, obtain patents and set up new enterprises. }\end{array}$ & 31.1 & 38.8 \\
$\begin{array}{l}\text { Cooperate actively with enterprises, commissioned by } \\
\text { enterprises to carry out specific research, cooperate } \\
\text { with enterprises to produce products. }\end{array}$ & 60.9 & 34.4 \\
$\begin{array}{l}\text { Carry out applied research, obtain a lot of patents, } \\
\text { obtain revenues from patent licensing }\end{array}$ & 25.4 & 32.4 \\
$\begin{array}{l}\text { Carry out basic research, obtain a few patents, patent } \\
\text { licensing is limited }\end{array}$ & 58.2 & 50.4 \\
\hline \hline
\end{tabular}

Source: Patent Investigation Report of China (2015)

Note: Multiple responses were possible so the percentages sum to more than 100 percent. 
Table 8.5 Patent exploitation rates in 2014 (\%)

\begin{tabular}{lccccc}
\hline \hline & Enterprises & Universities & PRIs & Individuals & Total \\
\hline $\begin{array}{l}\text { Invention patents in } \\
\text { force }\end{array}$ & 67.5 & 13.5 & 28.2 & 40.0 & 50.9 \\
$\begin{array}{l}\text { Utility model patents } \\
\text { in force }\end{array}$ & 68.2 & 9.3 & 43.3 & 36.5 & 59.0 \\
$\begin{array}{l}\text { Design patents in } \\
\text { force }\end{array}$ & 70.3 & 9.0 & 46.7 & 47.4 & 60.1 \\
\begin{tabular}{l} 
Total \\
\hline \hline
\end{tabular} & 68.6 & 9.9 & 41.6 & 40.0 & 57.9 \\
\hline
\end{tabular}

Source: Patent Investigation Report of China (2015)

Table 8.6 Patent sales (assignments) rates in 2014 (\%)

\begin{tabular}{lccccc}
\hline \hline Type of patent & Enterprises & Universities & PRIs & Individuals & Total \\
\hline $\begin{array}{l}\text { Invention } \\
\quad \text { patents }\end{array}$ & 6.7 & 1.9 & 3.2 & 4.8 & 5.2 \\
$\begin{array}{l}\text { Utility model } \\
\quad \text { patents }\end{array}$ & 5.6 & 1.4 & 3.4 & 4.7 & 5.2 \\
$\begin{array}{l}\text { Design patents } \\
\text { Total (all }\end{array}$ & 5.8 & 1.2 & 3.8 & 7.5 & 6.4 \\
$\quad$ patents) & 5.9 & 1.5 & 3.5 & 5.4 & 5.5 \\
\hline \hline
\end{tabular}

Source: Patent Investigation Report of China (2015)

${ }^{1}$ Limited to valid patent rights in force in 2014.

that only 3.5 percent of university patents were taken up by companies), but considerably higher for public research institutes, at 9.4 percent.

Tan et al. (2013) studied patent licensing contracts signed by Chinese universities in 2011. There were 1,359 licensing contracts involving 1,352 university patents, of which 1,202 (88.4 percent) were invention patents. Most licensing contracts were exclusive, and licensed patents were mostly for inventions in the field of chemistry (organic chemistry, polymers), physics and instruments. Additionally, only 10 percent of Chinese universities had licensing activities, and most were affiliated with the 211 Project. Other universities, which received less government financing and support, cannot be compared to 211 Project universities in terms of patenting 
Table 8.7 Patent licensing rates in 2014 (\%)

\begin{tabular}{|c|c|c|c|c|c|}
\hline Type of patent ${ }^{1}$ & Enterprises & Universities & PRIs & Individuals & Total \\
\hline Invention patents & 9.6 & 3.3 & 5.5 & 13.0 & 8.2 \\
\hline Utility model patents & 9.7 & 1.9 & 5.4 & 10.3 & 9.3 \\
\hline Design patents & 10.7 & 2.0 & 7.2 & 14.7 & 12.1 \\
\hline Total (all patents) & 9.9 & 2.1 & 5.9 & 11.9 & 9.9 \\
\hline
\end{tabular}

Source: Patent Investigation Report of China (2015)

${ }^{1}$ Limited to valid patent rights in force in 2014.

activities. Most licensees were enterprises and were located in the eastern regions, including Shanghai, Jiangsu, and Guangdong provinces.

\subsubsection{Science Parks}

In 1988, the first Chinese national-level science park was established in Beijing, which is the predecessor of the Zhongguancun Science Park. After thirty years' development, the number of national-level science parks had increased to 168 by the end of 2018. By the end of 2017, the gross domestic product produced within the national-level science parks amounted to CNY 9.52 trillion, accounting for 11.5 percent of the Chinese total GDP. In 2017, there were 52,000 high-tech companies operating in the 168 national-level science parks, 38.2 percent of the national total. Half of the incubators and "maker spaces" are located in national-level science parks (Zhang 2018).

Zou and Zhao (2014) discuss a typical university science park in China, TusPark, which is tied to the top university in China, Tsinghua University. TusPark is considered to be part of the Zhongguancun High-Tech Science Park (the first and largest cluster of semiconductor, computer, and telecommunications firms in China) and therefore enjoys many preferential policies thanks to the established relationship between Zhongguancun High-Tech Science Park and the government. However, TusPark has its own strategy and preferences. For example, bolstered by the university's reputation and research capacity, TusPark is home to joint R\&D laboratories between Tsinghua University and world-renowned enterprises.

Tan (2006) and Todo et al. (2011) studied the evolution and achievements of Zhongguancun Science Park. Tan (2006) argues that the Zhongguancun Science Park has been an example of innovation driven 
by knowledge transfer from leading research institutions to companies. Groups of professionals acted as risk takers and were involved in an early experiment to establish non-state-owned firms in the region. Todo et al. (2011) emphasize the role of science parks as an efficient channel to promote technology diffusion from multinational enterprises to domestic firms in China. As Todo et al. (2011) note, Zhongguancun Science Park has become a cluster of R\&D centers for multinational enterprises. By the end of 2005, forty-three of the top 500 corporations worldwide had located their R\&D centers in the Zhongguancun Science Park, and most of them had a collaborative R\&D laboratory with local universities.

Cai and Liu (2015) discuss another successful university science park, Tongji University Creative Cluster. It is separate from Zhangjiang HiTech Park in Shanghai, which is the state-level high-tech park in Shanghai, hosting many high-tech manufacturing firms just as Zhongguancun Science Park does in Beijing. Playing to the advantages of Tongji University and the characteristics of the enterprises in the cluster, Tongji Creative Cluster targets startups active in knowledgeintensive services. Once these startups become larger and mature, they may be integrated into the Zhangjiang Hi-Tech Park.

A few studies provide evidence regarding the contribution of science parks to knowledge flow and regional innovation capacity. For example, Jongwanich et al. (2014) used a provincial-level panel data set over the 1997-2009 period to study links among firms, public research institutes, and science parks. They found that science parks had a significantly positive impact on regional innovation capacity in terms of various measures, including a positive innovation-enhancing effect from $R \& D$ cooperation between industries and universities.

\subsection{Barriers to Knowledge Transfer from Universities and Public Research Institutes to Firms}

Four barriers to the technology and transfer activities of universities and public research institutes in China have been identified in the scholarly literature.

First, on the demand side, the technology market is not mature, so there have been few licensing opportunities for leading technologies. Most licensing contracts have involved traditional industries, with only a few involving emerging industries such as new energy and biological technologies (Wang et al. 2015a; Zhang 2016). Additionally, experienced licensees have been limited in number. Most state-owned enterprises 
were required to complete a complicated approval process before signing a licensing agreement. Even if they licensed a patent, they lacked the research capabilities to effectively use a patent and realize its market value quickly. A representative example is the licensing agreement between Fudan University and Huya Bioscience International regarding IDO (indoleamine 2,3-dioxygenase) inhibitors. Since domestic drug firms had little incentive to innovate due to high risk, a long development cycle, and the complex approval processes for new medicines, Fudan University licensed its patents to a US bioscience company using international capital (Zhang 2016), earning USD 65 million. Since many Chinese firms lack research capabilities to effectively use patents, more than half of all university patent licenses in China have been granted to foreign investors (Tan et al. 2013).

The limited R\&D capacity of Chinese domestic enterprises is a significant barrier for knowledge transfer to domestic firms. Many industries in China are still at the middle or low end of global value chains, and the R\&D intensity of Chinese enterprises is low, with an average of only 0.9 percent for industrial enterprises with annual revenue over CNY 20 million. In several provinces in the central and western regions, approximately 90 percent of industrial enterprises with revenue more than CNY 20 million have no R\&D activities. Without R\&D, these enterprises lack the ability to create and absorb the scientific and technological achievements generated by universities and public research institutes.

The second barrier is a lack of long-term financial support. As Tan et al. (2013) observe, most government patent subsidy programs provide funding to patent owners for under five years, which is not long enough to develop and commercialize an invention. Thus, many patents owned by universities, even potentially valuable ones, expire quickly after being granted. Additionally, although many university spinoffs have sufficient initial capital, they lack sustained investment for continuing operations.

The third barrier is ambiguous corporate governance and regulations. Kroll and Liefner (2008) studied knowledge transfer activities in three major research universities in China: Tsinghua University, Zhejiang University, and Wuhan University. They found that universities were only moderately oriented toward the needs of the market. In much of China, the absorptive capacity of spinoff enterprises was low.

Although the 2015 amendment to the PTSTA Law has removed the major legal barriers to knowledge transfer, implementation of the Law has not been without challenges. If academics and researchers from 
universities and public research institutes receive a share of a newly founded company in return for contributing their technologies, this knowledge transfer is subject to additional approvals because the technology would be considered as state-owned assets. Another challenge is that the calculation of "net profit" in the transformation of scientific and technological achievements is not clearly defined in the Law, and this hinders the provision of rewards and remuneration to inventors and knowledge transfer contributors.

The final barrier is that an underdeveloped intermediary agency sector results in high transaction costs. Zhang (2016) found that many university professors do not license their technology because they do not have the time and experience necessary to conduct business negotiations and perform marketing tasks. There are a limited number of intermediary agencies capable of providing such services to academics.

\subsection{Conclusion}

Since the 1980s, Chinese universities and public research institutes have been dramatically transformed in order to meet government policy goals of producing cutting-edge scientific and technological developments to support economic and social advancement. In 1985, the Chinese government emphasized the economic orientation of the S\&T system by introducing competition and market discipline. In the 1990s, investment in $\mathrm{R} \& \mathrm{D}$ was made a priority in the central and local government budget appropriation and outlays. In 1993, the Chinese government announced a plan to build and develop approximately 100 world-class universities and key academic disciplines through the 211 Project. In 1998, the Chinese government intensified the development of world-class universities by starting the 985 Project. With continuous and strengthened funding, Chinese universities and public research institutes were able to make progress in knowledge and technology production, reflected in an increasing number of scientific publications and patent applications.

The basic legal framework governing knowledge transfer from universities and public research institutes to industry in China includes the Science and Technology Progress Law, Patent Law, the PTSTA Law, Contract Law, and Company Law. The PTSTA Law was enacted in 1996 and substantially amended in 2015. The amendment is seen as an important development of the legal system governing knowledge transfer in China. It has made knowledge transfer a legal obligation for Chinese universities and public research institutes. Additionally, it 
gives universities and public research institutes established by the state the right to dispose of their scientific and technological achievements, including transferring technologies, as long as the price agreed on by both parties in negotiation or auction and the name of the scientific and technological achievements are disclosed to the public. The Law states that no less than 50 percent of the net profit from the knowledge transfer should be given as a reward or compensation to the university or public research institutes inventors and knowledge transfer contributors. These new regulations remove the legal barrier to knowledge transfer in China and provide incentives for inventors within universities and public research institutes to engage more actively in knowledge transfer activities. The full impact of the amendment will be seen in years to come and will deserve further evaluation and study.

With several reforms since the 1980s, the technology market, cooperation between universities and public research institutes with industry, patent transfer and licensing, and spinoff companies from universities and public research institutes have developed rapidly in China. This rapid development was aided by government funding of and support for knowledge transfer and policy measures, such as establishing science parks. However, remaining challenges lie in areas such as the immaturity of technology markets, inadequate research capabilities and R\&D investment by Chinese companies, a lack of longterm financial support for patenting and transfer activities, ambiguous corporate governance and regulations, and underdeveloped intermediary agencies.

\section{References}

Baark, E. (2001). "The making of science and technology policy in China." International Journal of Technology Management, 21(2): 1-21.

Bosworth, D.Y. and D. Yang (2000). "Intellectual property law, technology flow and licensing opportunities in the People's Republic of China." International Business Review, 9(4): 453-77.

Brehm, S. and N. Lundin (2012). "University-industry linkages and absorptive capacity: An empirical analysis of China's manufacturing industry." Economics of Innovation and New Technology, 21(8): 837-52.

Cai, Y.Z. and C. Liu (2015). "The roles of universities in fostering knowledge-intensive clusters in Chinese regional innovation systems." Science and Public Policy, 42(1): 15-29. 
CCCPC (1985). Decision on Reforming the Science and Technology System, 中共中 央关于科学技术体制改革的决定. Central Committee of the CPC.

CCCPC (1993). The National Outline for Educational Reform and Development, 《中国教育改革和发展纲要》Central Committee of the CPC.

CCCPC (2006). The National Plan for Medium and Long-Term S\&T Development, 国家中长期科学和技术发展规划纲要(2006-2020年). Central Committee of the CPC.

China Statistical Yearbook on Science and Technology (2017). 中国科技统计年 鉴. China Statistics Press.

Fu, X. and J. Li (2016). "Collaboration with foreign universities for innovation: Evidence from Chinese manufacturing firms.” International Journal of Technology Management, 70(2-3): 193-217.

Hao, Y., J. Pan and F. Zhao (2016). "Effects of cooperative knowledge transfer on high-tech enterprise independent innovation ability." Science and Technology Management Research, 36(16): 17-21. 郝英杰,潘杰义,赵飞;产学 合作知识转移对高新技术企业自主创新能力影响; 《科技管理研究》2016, 36(16): 17-21.

Huang, C., C. Amorim, M. Spinoglio, B. Gouveia, and A. Medina (2004). "Organization, programme and structure: An analysis of the Chinese innovation policy framework." R\&D Management, 34(4): 367-87.

ISTIC (2018). 《2018年中国科技论文统计结果》. Institute of Scientific and Technical Information of China.中国科学技术信息研究所.

Jongwanich, J., A. Kohpaiboon, and C. H. Yang (2014). “Science park, triple helix, and regional innovative capacity: Province-level evidence from China." Journal of the Asia Pacific Economy, 19(2): 333-52.

Kafouros, M., C.Q. Wang, P. Piperopoulos, and M.S. Zhang (2015). “Academic collaborations and firm innovation performance in China: The role of region-specific institutions." Research Policy, 44(3): 803-17.

Kroll, H. and I. Liefner (2008). "Spinoff enterprises as a means of technology commercialisation in a transforming economy: Evidence from three universities in China." Technovation, 28(5): 298-313.

Lai, H.C. and J.Z. Shyu (2005). "A comparison of innovation capacity at science parks across the Taiwan strait: The case of Zhangjiang High-Tech Park and Hsinchu Science-based Industrial Park." Technovation, 25(7): 805-13.

Lan, X. (2006). "Universities in China's national innovation system.” Paper presented at the UNESCO Forum on Higher Education, Research and Knowledge, November 27-30, 2006, Paris, United Nations Educational, Scientific and Cultural Organization.

Li, J., L. Ren, and C. Wu (2010). "Research on R\&D expenditure and patent output of scientific research institutions, universities and enterprises." Science \& Technology Progress and Policy, 2010(10): 103-8. 李娟,任利成,吴 
翠花. 科研机构、高校、企业R\&D支出与专利产出的关系研究. 《科技进步 与对, 2010(10): 103-8.

Liu, H. and Y. Jiang (2001). “Technology transfer from higher education institutions to industry in China: Nature and implications." Technovation, 21(3): $175-88$.

Liu, H. and J. Shi (2009). "An empirical study of the relationship between university technology transfer and China's economic growth." Science and Technology Management Research, 29(8): 244-6. 刘和东, 施建军. 大学技术转移与中国经 济增长关系的实证研究. 《科技管理研究, 29(8): 244-6.

Ministry of Commerce (2015). Director of the Foreign Investment Department of Ministry of Commerce Introduces the Foreign Investment in China in 2015. Available at http://bgt.mofcom.gov.cn/article/c/e/201601/20160101234256 .shtml. Accessed March 6, 2019.

Ministry of Science and Technology (2017). R\&D Statistics, unpublished document.

National Bureau of Statistics (2018). China's R\&D Intensity Is 2.12 Percent in 2017. Available at www.stats.gov.cn/tjsj/zxfb/201802/t20180213_1583420.html. Accessed December 31, 2018.

Ng, Y.C. and S.K. Li (2009). "Efficiency and productivity growth in Chinese universities during the post-reform period." China Economic Review, 20(2): 183-92.

OECD (2008). OECD Reviews of Innovation Policy: China. Paris, Organisation for Economic Co-operation and Development.

Patent Investigation Report of China (2015). 《中国专利调查数据报告》 State Intellectual Property Office of the People's Republic of China (SIPO).

Quan, X.H. (2010). "Knowledge diffusion from MNC R\&D Labs in developing countries: Evidence from interaction between MNC R\&D Labs and local universities in Beijing." International Journal of Technology Management, 51 (2/3/4): 364-86.

Rao, K., X. Meng, and L. Xu (2013). “The impact of R\&D investment on patent technology transfer in local universities: An empirical analysis based on provincial panel data.” Business Review, 25(5): 144-54. 饶凯,孟宪飞,徐亮,Andrea Piccaluga. 研发投入对地方高校专利技术转移活动的影响——基于省级面 板数据的实证分析. 《管理评论, 25(5): 144-54.

Statistical Data of Science and Technology Activities in Colleges and Universities (2016). Ministry of Education. www.moe.edu.cn/s78/A16/A16_tjdc/201703/ t20170303_298076.html. 《2016年高等学校科技统计资料汇编》.

Tan, J. (2006). "Growth of industry clusters and innovation: Lessons from Beijing Zhongguancun Science Park." Journal of Business Venturing, 21(6): 827-50.

Tan, L., Y. Liu, and Y.Y. Hou (2013). "Empirical analysis on Chinese universities' patent licensing and its inspiration.” R\&D Management, 25. 
Todo, Y., W. Y. Zhang, and L.A. Zhou (2011). “Intra-industry knowledge spillovers from foreign direct investment in research and development: Evidence from China's 'Silicon Valley'." Review of Development Economics, 15(3): 569-85.

Torch Report (2016). Main Economic Indicators of National University Science Parks. www.chinatorch.gov.cn/kjb/tjnb/201603/261a95cb17f54 2f1a2ec 89486709c150.shtml.

Wang, B. and J. Ma. (2007). "Collaborative R\&D: Intellectual property rights between Tsinghua University and multinational companies." Journal of Technology Transfer, 32(4): 457-74.

Wang, Y.D., D. Hu, W.P. Li, Y.W. Li, and Q. Li (2015a). "Collaboration strategies and effects on university research: Evidence from Chinese universities." Scientometrics, 103(2): 725-49.

Wang, Y.D., M.J. Liu, Q.W. Ma, and J. Chen (2015b). “Analysis on strategic emerging industries' patent licensing of Chinese universities." R\&D Management, 27.

Yang, T. and W. Ling (2009). "Granger causality analysis of technology transfer in universities and economic growth in Guangdong Province." Science and Technology Management Research, 29(11): 215-17. 杨廷钫,凌文轻;广东省高 校技术转移与经济增长的协整和Granger因果关系分析; 《科技管理研究》 2009 29(11): 215-17.

Zhang, C. and X. Wan (2008). "A comparative study of the efficiency of patent output between public R\&D institutions and enterprises in China." Science Research Management, 29(5): 167-72. 张传杰,万小丽;我国企业与公共研发 机构专利产出效率的比较研究, 《科研管理》29(5): 167-72.

Zhang, M.X. (2016). "University-industry collaboration in the biological medicine industry - based on Fudan University academic research.” Science \& Technology Industry of China, 2016(4): 76-7. 从复旦大学药物专利授权看生 物医药产业的产学研合作, 《中国科技产业》.

Zhang, W. (2018). The Meeting on the 30 Years' Development of National Science Parks Held in Beijing. 国家高新区建设30周年座谈会在北京召开。Available at www.chinatorch.gov.cn/gxq30/gxyw/201812/b56174a275e6419281f818 356e897b91.shtml.

Zou, Y.H. and W.X. Zhao (2014). "Anatomy of Tsinghua University Science Park in China: Institutional evolution and assessment.” Journal of Technology Transfer, 39(5): 663-74. 


\title{
South Africa
}

\author{
MICHAEL KAHN
}

\subsection{Introduction}

South Africa is the thirty-fifth largest economy in the world with a population of 57 million and an estimated per capita income in 2016 of USD 13,500 in purchasing power parity (PPP). It is rich in natural resources and has well-established industries, including mining, manufacturing, and agriculture with a strong financial, transport, and communication infrastructure. However, it faces substantial economic challenges, including a low rate of economic growth, one of the world's highest levels of income inequality, deep structural unemployment, and high mortality rates during the 2000s among the working-age population due to epidemic HIV and tuberculosis.

South Africa's unique history of apartheid between 1948 and the early 1990s influenced the structure of the public science system and consequently knowledge transfer. During the apartheid period, individuals who were classified as "African," "Indian," or "Coloured" (essentially those regarded as being of mixed ethnicity) had limited access to tertiary education and were restricted to attending higher education institutions (HEIs) in predetermined disciplines such as technical training, healthcare, education, administration, and teaching. Only one institution offered medical training. In contrast, the HEIs for the white population, including a network of public research institutions with advanced research capabilities, enabled the early careers of four Nobel Laureates in science and medicine, and supported innovation to circumvent sanctions (Van Vuuren 2017).

Sanctions during the apartheid years drove a need for self-sufficiency, which was met through government-owned enterprises in key sectors, including water, energy, transport, iron and steel, and timber, and major 
public research institutes known as science councils (Basson 1996). The apartheid-era public research system of HEIs and public research institutes operated according to an implicit social contract of "walking on two legs" (Kahn 2013): one leg encouraged "own" science, where research programs were determined by academics and resulted in internationally recognized research papers, while the other provided science and technology for the state, including military equipment and nuclear weapons (Kahn 2006; Maharajh 2011). Sanctions-induced innovation pressure was met through a mixture of adaptation and reverse engineering involving close collaboration between government, public research, and industry. In this period, the ratio of gross expenditure on R\&D (GERD) to GDP reached a peak of 1.04 percent in 1992.

After the adoption of constitutional democracy in 1994, the public research system entered a period of transition in which existing universities were desegregated and new universities established, while research priorities shifted due to the end of economic sanctions. However, the distinction in research capabilities between the historically white institutions (referred to as "traditional universities") and the historically disadvantaged institutions continues, although efforts are underway to remedy this disparity. This context remains relevant for knowledge transfer in South Africa.

After 1994, there were both new opportunities and challenges. On the plus side, South African services firms were able to take advantage of new opportunities in neighboring African countries. Among the challenges was a decline in domestic manufacturing and mining, a rise in ruralurban migration, a large influx of foreign economic and political migrants, and strains on infrastructure. Various interventions have failed to significantly increase economic growth (Hausmann 2017).

South Africa's National Development Plan (NDP; Vision for 2030) was developed over the period 2009-11 to tackle the three challenges of unemployment, inequality, and poverty. The plan recognizes science, technology, and innovation as a means of economic development and the necessity for "public funding to help finance research and development in critical areas." To date, its implementation has been inconsistent.

\subsection{The National Innovation System}

Over the period of South Africa's industrialization, a modest-sized, effective national innovation system with sectoral subsystems emerged, notably in viticulture, fruits, cereals, mining and metallurgy, forestry, 
chemicals, military equipment, health, and telemetry. These sectoral innovation systems survive into the present and have been joined by sectoral systems for automobiles and financial services.

Prior to 1994, the public science system consisted of thirty-six HEIs, including universities and technikons (polytechnic institutes), and several public research institutes, including seven science council research institutes, four national research facilities, over twenty departmental research institutes, and R\&D divisions in state-owned enterprises. The technikons had close ties with industry, reflecting their origins in technical and vocational education and training colleges. In addition to public research, the national innovation system was supplemented with private sector research, regulatory bodies, industry associations, and the South African Patent Office (SAPO).

After 1994 the higher education system restructured and merged into a unitary system of twenty-six institutions comprising twelve "traditional" universities, six comprehensive universities, and eight universities of technology (Nongxa and Carelse 2014). One medical school and two of the comprehensive universities were founded after 2009. For ease of reference, the term "university" is used in this chapter for all of these higher education institutes.

Five of the universities are research intensive, while another seven are emerging research universities. The higher education system is the strongest in Africa, with two universities among the top 200 in the Times Higher Education World University Rankings 2016-17. ${ }^{1}$ All five researchintensive universities (the University of Cape Town, the University of the Witwatersrand, Stellenbosch University, the University of Johannesburg, and the University of KwaZulu-Natal) are listed in the ARWU top 500 rankings. ${ }^{2}$ However, the changes to the higher education system weakened the previous linkages between the technikons and industry (Kruss et al. 2015). Institutes that had focused on teaching during the apartheid era largely retained this focus, except when merged with institutes that had prior research competences.

Government is the main source of research funding to the public science sector, via budget allocations from the Ministry of Higher Education and Training and the National Research Foundation. The public research institutes (science councils) include the Medical

${ }^{1}$ www.timeshighereducation.com/world-university-rankings/2017/world-ranking\#!/page/ 0/length/25/sort_by/rank/sort_order/asc/cols/stats.

2 www.shanghairanking.com/World-University-Rankings/Shanghai-Jiao-Tong-

University.html. 
Research Council, the Council for Scientific and Industrial Research (CSIR), the Agricultural Research Council (ARC), the Council for Geosciences, the Human Sciences Research Council, the Council for Mineral Technology, and the South Africa Bureau of Standards (SABS). Most public research institutes are sector-specific, with the exceptions of the CSIR and SABS.

State-owned enterprises are an important component of the innovation system and include Eskom (power), Transnet (communications), Telkom (telecommunications), Denel (defense industries), Armscor (defense industries), NECSA (nuclear engineering and products), and Onderstepoort Biological Products (veterinary medicines).

The $R \& D$ expenditures of the leading research universities, science councils, and state-owned enterprises are given in Table 9.1. In 2013-14 the "big five" research universities accounted for 70 percent of total higher education R\&D expenditure, of which 52 percent was for basic research. The two leading science councils accounted for 65 percent of R\&D expenditure, of which 23 percent was for basic research, 49 percent for applied research, and the balance for experimental development. This ranking, led as it is by the older institutions, has barely changed in the last fifteen years. Such historic path dependence is true of many other innovation systems.

In addition to the universities, public research institutes, and stateowned enterprises, the government research and innovation infrastructure includes national facilities (nuclear research, optical, and radio astronomy) managed by the National Research Foundation and research units in environmental science, geomagnetism, and seismology, military R\&D, metrology, forensics, biotechnology, and public health.

A unique characteristic of the South African innovation system is that SAPO was and remains a non-examining patent authority that does not assess the novelty of patent applications. Although the cost of obtaining a patent is low, the patent system leads to a proliferation of low-value domestic patents, provides protection to foreign intellectual property, and creates extra costs for firms that need to monitor non-novel patents (Pouris and Pouris 2011). The system is also likely to reduce the domestic use of formal knowledge transfer based on patents.

The potential economic value of South African patents is therefore best assessed through patents granted in foreign jurisdictions with a patent examination system. Unless otherwise specified, this chapter limits all evaluations of patents to patents filed through the Patent Cooperation 
Table 9.1 R\&D expenditure of leading universities, public research institutes, and state-owned enterprises, 2013-14

\begin{tabular}{|c|c|c|}
\hline Universities & ZAR ’000s & USD '000s ${ }^{*}$ \\
\hline \multicolumn{3}{|c|}{ Science Councils (public research institutes) } \\
\hline University of Cape Town & $1,178,888$ & 111,122 \\
\hline $\begin{array}{l}\text { University of } \\
\text { Witwatersrand }\end{array}$ & 896,566 & 84,510 \\
\hline $\begin{array}{l}\text { University of } \\
\text { Stellenbosch }\end{array}$ & 827,137 & 77,966 \\
\hline $\begin{array}{l}\text { University of Kwazulu- } \\
\text { Natal }\end{array}$ & 648,942 & 61,169 \\
\hline University of Pretoria & 644,215 & 60,724 \\
\hline $\begin{array}{l}\text { University of South } \\
\text { Africa }\end{array}$ & 605,001 & 57,027 \\
\hline North West University & 585,124 & 55,154 \\
\hline Free State University & 330,182 & 31,123 \\
\hline $\begin{array}{l}\text { University of } \\
\text { Johannesburg }\end{array}$ & 252,049 & 23,758 \\
\hline $\begin{array}{c}\text { Nelson Mandela } \\
\text { Metropolitan } \\
\text { University }\end{array}$ & 216,191 & 20,378 \\
\hline Rhodes University & 211,956 & 19,979 \\
\hline $\begin{array}{l}\text { University of the Western } \\
\text { Cape }\end{array}$ & 171,979 & 16,211 \\
\hline \multicolumn{3}{|c|}{ State-owned enterprises (SoEs) } \\
\hline CSIR & $2,095,576$ & 197,529 \\
\hline $\begin{array}{l}\text { Agricultural Research } \\
\text { Council }\end{array}$ & $1,008,401$ & 95,052 \\
\hline National laboratories $^{\dagger}$ & 480,000 & 45,245 \\
\hline $\begin{array}{l}\text { Medical Research } \\
\text { Council }\end{array}$ & 390,820 & 36,839 \\
\hline $\begin{array}{l}\text { Council for Mineral } \\
\text { Technology (Mintek) }\end{array}$ & 281,883 & 26,570 \\
\hline $\begin{array}{l}\text { Human Science Research } \\
\text { Council }\end{array}$ & 244,938 & 23,088 \\
\hline Council for Geoscience & 109,577 & 10,329 \\
\hline Denel & 507,000 & 47,790 \\
\hline Eskom & 130,200 & 12,273 \\
\hline Transnet & 83,200 & 7,842 \\
\hline
\end{tabular}


Table 9.1 (cont.)

\begin{tabular}{lcc}
\hline \hline Universities & ZAR '000s & USD ’000s \\
\hline NECSA $^{*}$ & 74,800 & 7,051 \\
Onderstepoort Biological & 32,000 & 3,016 \\
$\quad$ Products & & \\
\hline \hline
\end{tabular}

Sources: Universities and public research institutes (DST 2015a); SoEs (annual reports)

* Exchange rate as at 29 June, 2014 of 1 ZAR = USD 0.9426.

${ }^{\dagger}$ Author estimate.

Treaty (PCT) system or other foreign registries such as the US Patent and Trademark Office (USPTO).

Financing for innovation in the private sector comes primarily from cash reserves, but also through equity and loan financing from the market, the modest-sized venture capital sector, the state Industrial Development Corporation, and the Public Investment Corporation. More risky innovation activities may be funded from the incentive programs of the Department of Trade and Industry. An estimate of total private sector expenditure on innovation (including $\mathrm{R} \& \mathrm{D}$ and other innovation activities) can be obtained from the Innovation Survey 2005-7 (DST 2011). Adjusted forward, the value would be approximately 100 billion South African rand (ZAR) (USD 8.1 billion) in 2017, with most expenditure on purchases of equipment, technology, and software.

\subsection{Post-1994 Science, Technology, and Innovation Policy}

Policy on science and technology is vested in the Department of Science and Technology (DST), while industrial policy resides with the Department of Trade and Industry (DTI).

The 1996 White Paper on Science and Technology (DACST 1996) introduced innovation system thinking to shape and manage science and technology policy for economic, sociopolitical, and intellectual benefit. Subsequent policy acts or programs included the National R\&D Strategy (DST 2002), the Innovation Fund, the Ten-Year Innovation Plan (DST 2008), an enhanced R\&D Tax Incentive (RSA 2008a), and the Intellectual 


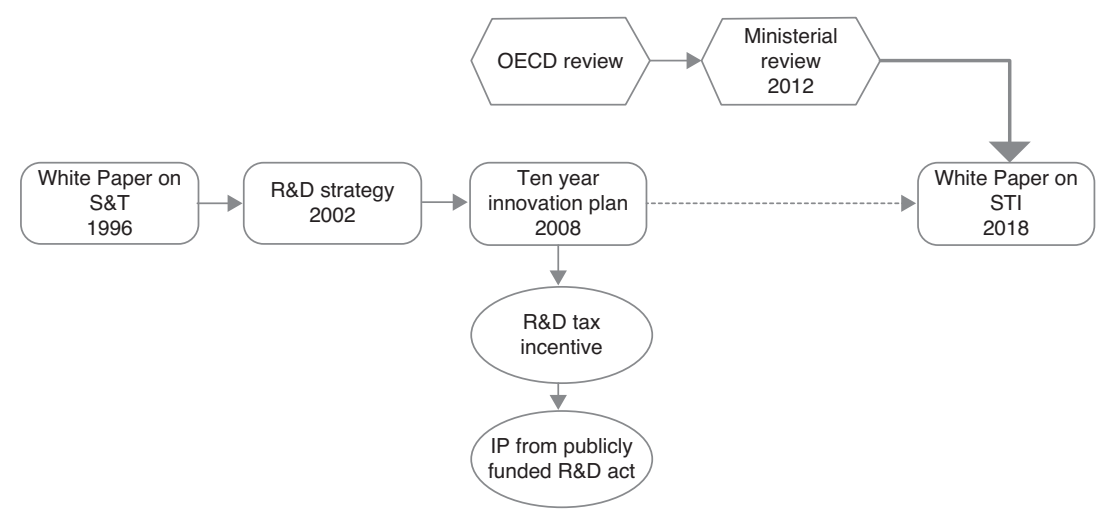

Figure 9.1 Major STI policy documents or acts

Source: Authors

Property Rights from Publicly Funded Research and Development Act (hereafter "the Public Research IP Act") (RSA 2008b) (see Figure 9.1). New organizations that were established as a result of policy changes included the National Research Foundation as the major grant funder, the National Advisory Council on Innovation, the Technology Innovation Agency (TIA), and the National Intellectual Property Management Office (NIPMO).

The R\&D Strategy and its successor, the Ten-Year Innovation Plan, outlined objectives and targets that were taken up in other government policy statements, notably the New Growth Path (EDD 2010) and the seminal National Development Plan (Presidency 2012). Constrained by shortfalls of funding, skilled labor and coordination, the goals achieved varying degrees of success. They continue to inform policy, but are not highly directed, with the exception of megascience astronomy projects.

The R\&D Strategy shifted from the innovation systems approach advocated in the White Paper to that of a linear, research-led system, whereby investment in $\mathrm{R} \& \mathrm{D}$ was understood to be a precursor to socioeconomic development. This emphasis on R\&D influenced the Ten-Year Innovation Plan, the strategy of the National Advisory Council on Innovation, the TIA, and NIPMO.

The next three sections describe South African policies to support the supply of public research, consisting of the outputs of universities and public research institutes, policies to support the innovative capabilities of firms, and policies to support linkages and knowledge transfer between public research and firms. 


\subsubsection{Policies for Public Research}

The public research sector in all countries has multiple goals, commonly consisting of training individuals in useful skills, including the ability to absorb, understand and replicate leading-edge knowledge produced abroad, providing assistance to industry, and producing new discoveries, some of which may have commercial applications.

The DST is not directly responsible for higher education, but has developed mechanisms to boost university research capacity, including the Researcher Rating Scheme, the 200-strong SA Research Chair Initiative, sixteen Centres of Excellence and five Centres of Competence. These receive generous funding and entail a mix of open and directed selection. The National Research Foundation implements these programs, and, in the case of the last three, requires beneficiaries to report on industry and community impacts. In addition, there are a large number of industryendowed professorial positions (chairs) in mining, engineering, and agricultural sciences as well as chairs funded by state-owned enterprises in roads, water, and telecommunications.

To provide necessary skills, the DST invested heavily in the universities, as well as in the CSIR, the National Facilities and the National Research Foundation. Between 2010-11 and 2014-15, the number of researchers at universities increased by 36.5 percent, from 32,571 to 44,457 , compared to a small decline at public research institutes. ${ }^{3}$

The CSIR had a history of "knowledge transfer" through organizational development and transfer (Basson 1996), but its effectiveness declined in the 1980s, leading to a restructuring during the 1990s around strategic business units.

The Higher Education National Funding Formula allocates baseline funding to universities and includes a "publication output" variable that supports science (essential for understanding advances in knowledge) through funding for approved types of publication. This provided funding of ZAR 3 billion (approximately USD 250 million) in 2016.

The Innovation Fund provided competitive funding for research with commercial applications. It initially allocated three-year grants for predefined research areas and encouraged knowledge sharing by prioritizing awards to consortia of universities, science councils, and industry. This restriction was subsequently eased so that any research proposal with

${ }^{3}$ National Survey of Research and Experimental Development, 2010/11-2014/15. In comparison, the number of researchers in the business sector increased 25.6 percent, from 14,933 to 18,743 . 
commercial applications could be supported. As of 2009, the Innovation Fund was merged into the new Technology Innovation Agency.

Innovation Fund projects that resulted in successful commercialization include microwave technology for egg sterilization and the Smartbolt ${ }^{\mathrm{TM}}$ rock stress detection device. A costly but unsuccessful project was the Joule electric vehicle, abandoned after the prototype failed to elicit funds for production.

Other publicly funded ventures included four Biotechnology Regional Innovation Centres, structured as single-purpose not-for-profit companies. The combined funding for the Innovation Fund and the Biotechnology Research Centres was approximately ZAR 300 million ( \pm USD 30 million) per year. No evaluative study is available on the contribution of the Innovation Fund or the Biotechnology Research Centres to measures of potential commercial outputs such as IP, startups, or job creation.

The South African Research Chairs Initiative was established in 2006 by the DST and the National Research Foundation with the goal of expanding the research and innovation capabilities of South African universities by attracting and retaining high-quality researchers and increasing the output of master's and doctoral graduates. The initiative has been successful in fostering cutting-edge research, retaining skills in the country and contributing to the stock of doctoral graduates (Fedderke and Velez 2013).

\subsubsection{Policies for the Business Sector}

From a systems perspective, policy should improve the innovative capabilities of firms. This often takes the form of subsides to encourage firms to invest in capability-building activities such as $\mathrm{R} \& \mathrm{D}$ or to provide skills that would otherwise not be provided by the market. To support firm capabilities, the South African government provides an R\&D tax incentive that is designed to boost private sector R\&D spending (DST 2015b). Firms initially filed a post hoc claim that would be verified by the DST, but this system was open to misuse. After four rounds, it was replaced with a preapproval model that required detailed submission of the intentions and expected outcomes of corporate R\&D. This process appears to have deterred many would-be applicants, particularly SMMEs (small, medium, and micro-enterprises), reflecting a tension between a user-friendly incentive regime and company willingness or capacity to engage in a detailed submission process. 
The government has used industrial policy to correct market failure, such as the National Foundry Technology Network to provide skills training, knowledge transfer, and diffusion of state-of-the-art technologies. The 2015-17 iteration of the industrial policy aims to strengthen "linkages between knowledge production, utilisation and innovation and industrial growth" (DTI 2015: 69). The Industrial Policy Action Plan supports R\&D-led industry development programs for titanium metal powder manufacturing, fuel cell development, and additive manufacturing. All three are focal areas of the Ten-Year Innovation Plan (DST 2008).

An agency of the DTI, the South Africa Bureau of Standards Design Institute, seeks to use "the broad nature and bridging capacity of design to address the existing innovation chasm by linking R\&D with the user, the market, the social environment for the benefit of the country's socioeconomic growth." To this end, support is given to SMMEs and individuals to move from idea to prototype. The Institute has set up the Transnet Design, Innovation, and Research Centre for SMMEs to research and develop innovative and commercially viable ideas. This is largely a private-to-private knowledge development channel that partially involves universities and public research institutes, for instance, for micro-satellite development.

\subsubsection{Policies to Support Linkages between Public Research and Businesses}

A common assumption is that the public research sector in South Africa is failing to transfer knowledge with commercial value to the business sector. For example, the annual surveys of the Global Entrepreneurship Monitor (GEMS 2016) find that South African experts believe that universities are not playing a sufficiently constructive role in facilitating knowledge transfer and stimulating innovation. This next section examines the possible causes of low rates of knowledge transfer from the public research sector to firms and then describes policies aimed at addressing those causes.

\section{Failures in Knowledge Transfer}

There are two main potential causes of failure. First, the public research sector could be producing very few discoveries with commercial applications. This could occur as a result of a failure in the design of the public research sector, for instance, if there are few incentives for academics to 
conduct research of potential commercial value (Zhang et al. 2011) or to take part in knowledge transfer activities. Sibanda (2009) identified an absence of an entrepreneurial culture among researchers at public research institutes, while Goldberg and Kuriakose (2011) found that insufficient attention was given to the needs of startups, especially business services and IP management. In a study of university research centers, Cooper (2011) argued that knowledge transfer was problematic as long as universities focus on "own" research, rather than committing to use-inspired basic research, even though there was strong evidence that research group survival and use-inspired research (on the MIT and Stanford models) went hand in hand. In other words, the nature of the research was a strong determinant of its future commercial value, resonating with similar results in studies by Fedderke and Velez (2013) and the National Research Foundation (2016) . Kruss et al. (2015) claim that a policy emphasis on "Big Science, knowledge transfer and the growth of niche competences and capabilities" has created "islands of innovation," but prevented the widespread diffusion of public research knowledge to industry. The consequence is large variation by sector in the relevance of public research to industry.

Second, the public sector could be producing commercially valuable outputs that are not taken up by firms for a number of reasons: lack of communication between the public and private sectors (network failure), a shortage of funding to support the activities of firms to develop discoveries into commercial products or processes (finance failure), or public research discoveries not meeting the requirements of firms, particularly if firms lack the internal capabilities to exploit them (demand failure).

Kruss (2008a) found very few new knowledge networks in evidence in South Africa's research-oriented universities. The capacity and desire on the part of industry to forge research and innovation partnerships were generally limited. In a subsequent study, Kruss (2008b) argues that the lack of commercialization of research arises from a combination of network failure and a lack of "interactive capability" with industry.

Kahn $(2006,2013,2016)$ identified the influence of the linear innovation model on policy (instead of an innovation system model) as underlying poor performance in knowledge transfer. Ideographic research based on case studies in South Africa found that poor performance is partly due to a lack of two-way communication between public research and firms. Instead, there is implicit adherence to a linear model of innovation whereby scientists follow their own research interests, often 
in basic research such as the Square Kilometre Array radio telescope. This is reflected in the high proportion of South African gross expenditures on R\&D (GERD) for basic research, currently standing at 26.7 percent. Although "blue sky" research can, over time, result in commercial products or processes, such research is rarely of short-term value to firms. Zhang et al. (2011: 14) noted that the influence of the linear model was made worse by the fact that the DST was a science-driven organization whose staff had little knowledge of industrial practice.

De Wet (2001) introduced the idea of the "technology colony" to explain low rates of knowledge transfer in South Africa. This idea became known as the "innovation chasm" due to a lack of funding (finance failure) for earlystage commercialization. Zhang et al. (2011) question the reality and utility of the construct of an innovation chasm and suggest that the problem could be due to demand failure, arguing that policy gave insufficient attention to strengthening the absorptive capacity of firms. Kaplan (2011) used patent data to show that mining equipment was the only industry where local expertise was at the technology frontier. Phaho and Pouris (2008), in a study of original equipment manufacturers (OEMs) in the automotive sector, determined that most OEMs failed to take steps to improve their capabilities. They did not conduct in-house $\mathrm{R} \& \mathrm{D}$, did not engage in innovation activities that were new to the market, and did not use government incentives to improve their competitiveness through technology diffusion or intelligence. Fongwa and Marais (2016) studied knowledge transfer in a developing region of South Africa and found that the rate at which knowledge was transferred through the available channels was strongly influenced by the absorptive capacity of firms.

\section{Policies to Address Design, Network, Finance, and Demand Failures}

The South African government has implemented policies to address all of these factors affecting knowledge transfer, although their execution has been fragmented and is focused on a linear model of innovation that emphasizes the role of public research in supplying new knowledge.

The Ten-Year Plan for Innovation declared bridging the "innovation chasm" (addressing finance failure) as a key goal, alongside the need to support human resource development, $\mathrm{R} \& \mathrm{D}$, and knowledge infrastructure (DST 2008: 23).

The Department of Science and Technology's Sector Innovation Fund and Sector Innovation Programme are responses to a Ministerial Review (DST 2012) to promote networking between researchers, innovators, 
businesses, and business associations. The Sector Innovation Programme brings together public ministries, industry, industry associations, and public research institutions around common innovation needs. The Programme has been extended to nine sectors, including forestry, sugar, aquaculture, and boatbuilding (DST 2015c: 11).

Both networking and demand failure are targeted through the longstanding Technology and Human Resources for Industry Programme (THRIP) of the DTI. THRIP supports partnerships between industry and public research on a cost-sharing basis. It promotes use-oriented R\&D and offers associated high-level training and education for technology development. THRIP supports the mobility of researchers and students between universities, public research institutes, and industry, and improves the competitiveness of the participating business organizations. External evaluation (DPME 2015) found it to be cost-efficient in terms of technology development, with an estimated average commercial revenue of ZAR 24 million (USD 2.4 million) five years after the conclusion of projects.

Other programs to address network and demand failure include the DST's regional innovation forums, four of which remain functional, and the Bio-economy Strategy. Several regional innovation strategies to promote knowledge transfer and commercialization were also developed. These moves reflect a shift in thinking toward "innovation-enabling ecosystems." The Bio-economy Strategy seeks to harmonize R\&D among various actors in agriculture, health, industry, and environment (DST 2013). In comparison to the earlier linear Biotechnology Strategy (DACST 2001), the new strategy argues for a demand-led, incentive-based approach to build absorptive capacity and stimulate knowledge transfer.

Design failure is partly addressed through changes to the management of IP produced in the public research sector. The 1996 White Paper proposed harmonizing South Africa's IP regime with international good practice. The 2002 R\&D Strategy argued that a version of the US Bayh-Dole Act could promote patent activity in the public sector (DST 2002: 67; DNSH 2017). The subsequent Public Research IP Act instituted benefit-sharing obligations for license income earned by specified public research institutions ${ }^{4}$ and other policies of relevance to the generation, disclosure, exploitation, and transfer of IP toward small enterprises and $\mathrm{BBBEE}^{5}$ entities. The Act required universities and public research institutes to establish knowledge transfer offices, with part of the costs funded by the NIPMO. The Southern

\footnotetext{
4 Public universities, Science Councils, the Water Research Commission, and NECSA.

5 Broad-Based Black Economic Empowerment.
} 
African Research and Innovation Managers Association (SARIMA) supports the training of innovation managers and the establishment of KTOs, and works with NIPMO and regional equivalents to advance the commercialization of research discoveries.

\subsection{Literature on Knowledge Transfer Channels}

How knowledge transfer occurs in South Africa has been examined in a number of studies (Kaplan 2004, 2008, 2011; Goldberg and Kuriakose 2011; Kuriakose et al. 2011; Morris et al. 2011; Zhang et al. 2011). Most of this research is based on case studies, in part due to a lack of representative data on knowledge transfer activities.

\subsubsection{Informal and Contractual Knowledge Transfer}

South African automotive OEMs mainly rely on universities as providers, where needed, of highly qualified personnel, rather than as partners in use-oriented research collaboration that could upgrade their technological capabilities (Kruss 2008b).

In the "low" technology wine sector, Cusmano et al. (2010) found that the relationships between industry and public research were based on a mix of informal contacts and industry-commissioned research. Kruss et al. (2012) reported that most academics interact with the outside community through traditional mechanisms such as training and capacity development, conferences and workshops, action research, contract research, demonstration projects, and services. Consultancy and entrepreneurial engagement was less common, informal, indirect, and not knowledge-intensive. From the industry side, there was low demand for knowledge from, or direct cooperation with, universities on the part of larger innovating firms, but stronger demand from a smaller number of R\&D-performing firms.

\subsubsection{IP-Mediated Knowledge Transfer}

In the six years prior to the promulgation of the Public Research IP Act in 2008, Kaplan (2009) found that there was a dearth of economic studies on the IP system and low awareness of the value of knowledge transfer to the resource industries. IP activity between 2001 and 2007 was low, with only twenty-one patent-based startups produced by the public research sector. 
Alessandrini et al. (2013) note that formalized knowledge transfer is still emerging in local universities and public research institutes.

A case study of three firms active in the southern node of the telemetry sectoral system of innovation (Kahn 2014) found that two firms made extensive use of government innovation incentives, while one maintained independence. The case studies show the initial importance of mentorship and academic research to the startup pioneers. As the companies matured they shifted their search for knowledge exchange toward their own value chains. This autonomous behavior accords with the international pattern revealed through innovation surveys.

In a study of the patenting activity of academics, Lubango and Pouris (2007) concluded that most academic inventors or co-inventors had prior experience with firms or state-owned enterprises. Rorwana and Tengeh (2015) surveyed thirty-six academics with research projects with industry and employed at a single university of technology to identify the effect of different factors on their participation in commercialization activities. They report that the personal interest of the academics in innovation had the largest effect on their participation in commercialization activities. No results were reported on the use of IP.

\subsubsection{Case Studies}

Four case studies (see Box 9.1) of sectoral innovation systems show that the main channels for knowledge transfer in South Africa are informal methods and research agreements. The case studies are based on desk research and interviews.

The four case studies fall into two groups. The first two, on oil and gas and platinum group metals, display similar hub-and-spoke models with universities, with the main companies (Sasol and Anglo-American Platinum) forming the hubs. Interviews revealed that neither company relied on the flow of research information from universities for its core business. The other two cases, for pulp and paper and viticulture, resemble triple helixes, with universities, companies, and government contributing to research of commercial value. None of the cases exhibits demand-led characteristics; all are supply-side driven, although capacity development is an important goal.

Breschi and Malerba (2005) stress the importance of networking and other forms of knowledge exchange in sectoral innovation systems. They note that these systems evolve organically and cannot easily be developed through government fiat. Sasol was a state initiative, although its evolution into a research-led organization was driven internally. Including the 
BOX 9.1 CASE STUDIES OF SECTORAL INNOVATION SYSTEMS

Oil and Gas The South African government established Sasol in 1950 to address uncertainty in fuel supplies. Sasol developed proprietary technologies and is currently a world leader in hydrocarbon synthesis and the largest private sector R\&D performer in South Africa. Working with the CSIR, the University of Witwatersrand, and other universities, Sasol developed a gas-to-liquid process that has been implemented internationally. Sasol has a portfolio of 200 product lines. It had 262 copublications with universities in the period 2011-015. Knowledge transfer to Sasol occurs through formal research projects, the THRIP channel, staff and student mobility, conferences, and seminars. Sasol sees itself as a coordinator of activities across universities to develop expertise rather than specific technologies (Morgan 2006). Its technical success is a demonstration of the importance of early-stage government support.

Pulp and Paper The two main firms in this sector are Sappi and Mondi. Sappi is the largest South African R\&D performer in pulp and paper and the biggest producer of fine paper in the world. Sappi is part of the Gauteng Province Innovation Hub, where it has a pulp R\&D laboratory. Its research center in Kwazulu-Natal specializes in genetically improved planting stock. Sappi and Mondi sponsor chairs in forest genomics and tree pathology at Pretoria University. The Tree Protection Cooperative Programme brings together all forestry companies, Forestry South Africa and the Ministry of Agriculture, Forestry, and Fisheries. Sappi collaborates on genetically modified breeding with the Forest Molecular Genetics Programme of the University of Pretoria. The independent, "quasi-public" Institute for Commercial Forestry Research is supported by contributions from its members and hosts its own forty-five-person R\&D lab.

Platinum Group Metals This sectoral system is among the oldest in the country. The leading producer and researcher is Anglo Platinum, followed by Impala Platinum. To boost demand for platinum metal, Anglo-American Platinum constructed a hydrogen fuel cell technology demonstrator for off-grid electricity generation using platinum catalyst fuel cells from the Canadian firm Ballard. The hydrogen Centre of Competence developed local fuel cell technology including the necessary catalysts, membrane technology, casings, and control systems, and has collaborated with Impala Platinum to trial the fuel cell prototype in a forklift vehicle. A Web of Science search shows fifteen co-publications with AngloAmerican Platinum, one public research institute, and South African universities. Knowledge transfer occurs through formal research projects, the THRIP channel, staff and student mobility, conferencing, and seminars.

Viticulture Centers of viticulture research include Stellenbosch University, the Distell Group, the Agricultural Research Council, and the Elsenburg Agricultural Training Institute. Distell is among the top ten producers of wine worldwide. Its in-house R\&D is supported by science and technology service firms, specialist manufacturing, yeast providers, and irrigation firms. Cusmano et al. (2010) 
BOX 9.1 (cont.)

identify post-1994 deregulation and engagement with world markets as the driver of wine quality improvement. Industry players founded the South African Wine and Brandy Company with both industry and public research participants to provide open-access generic research. Stellenbosch University works closely with industry players and makes ongoing use of the THRIP channel. Informal contacts and industry-commissioned research are an important part of this sectoral innovation system (Cusmano et al. 2010).

Centres of Competence within a sectoral system seems to be left to an evolutionary process.

\subsection{Evidence and Metrics of Knowledge Transfer}

A major challenge in evaluating knowledge transfer in South Africa is a lack of metrics. Basic metrics are available for innovation activities in South Africa (see Table 9.2) and show a modest level of foreign patents and a low level of high-technology exports. Some metrics are available on the IP-mediated knowledge transfer activities of universities and public research institutes, but there are little comparable data over time. However, the main drawback is a lack of data on informal and contractual forms of knowledge transfer.

South Africa has sought to develop a regular series of innovation surveys similar to the EU Community Innovation Survey (CIS). The best quality data are from the 2005 survey, which achieved a satisfactory response rate. The question on knowledge sources in that survey is relevant to knowledge transfer. The most widely cited important sources of information for innovation are suppliers and customers, cited by 43.9 percent of industrial firms and 26.2 percent of firms in the services sectors (see Table 9.3). Universities and public research institutes are less commonly cited as important sources, with only 9.9 percent of industrial firms citing higher education institutes and 6.1 percent citing public research institutes. Within industry, a higher share of manufacturing than mining firms give a rating of high importance to higher education and public research institutes, while firms in transport and communications and scientific and technological services (STS) are more likely to report linkages with public research than firms in trade or financial services.

The results in Table 9.3 indicate that the South African public research sector is less important than several other sources of information for 


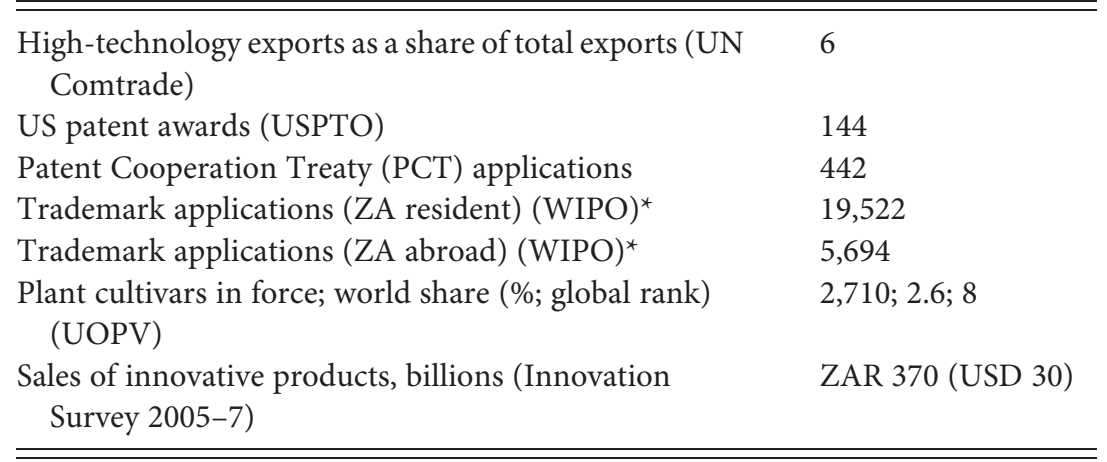

Sources: http://data.worldbank.org/indicator/TX.VAL.TECH.MF.ZS?page=4

innovation, but this is a common pattern in many countries. Comparable data are available from Eurostat for the CIS 2008 survey, covering the three years from 2006 to $2008 .{ }^{6}$ Limited to innovative manufacturing firms in six high-income countries (Belgium, Finland, France, Germany, Italy, and the Netherlands), an average of 22 percent of firms gave high importance to suppliers and 29 percent to customers as sources of knowledge for innovation. The comparable share of innovative European manufacturing firms that gave high importance to universities and public research institutes is much lower, at 2.7 percent and 1.6 percent. Note that this is considerably lower than the percentages for South African manufacturing firms of 10.2 percent for universities and 6.3 percent for public research institutes, indicating that the public research sector plays a greater role in private sector innovation in South Africa than in high-income European countries. ${ }^{7}$ One explanation could be a continuing tradition in South Africa of greater state involvement in economic activity.

The results in Table 9.3 indicate that there are ample linkages between the public and business sectors in South Africa compared to Europe. The common assumption that this is not the case could be due to the lack of

${ }^{6}$ Eurostat, Innovation Statistics, "Highly important source of information for innovation during 2006-2008” [inn_cis6_sou]. Results for the 2006 survey covering years 2004-6 are comparable, but data are available for fewer high-income countries.

7 The average share of innovative manufacturing firms in ten lower-income European countries that accorded high importance to knowledge sourced from universities was slightly higher than in the high-income countries, at 3.5 percent for universities and 2.5 percent for PROs. 
Table 9.3 Share of innovative firms rating sources of information for innovation as "highly important"

\begin{tabular}{|c|c|c|c|c|c|c|c|c|}
\hline & $\begin{array}{l}\text { All } \\
\text { industry }\end{array}$ & Mining & Manuf & $\begin{array}{l}\text { All } \\
\text { services }\end{array}$ & Trade & $\begin{array}{l}\text { Transport } \\
\text { and comms }\end{array}$ & $\begin{array}{l}\text { Financial } \\
\text { services }\end{array}$ & STS $^{*}$ \\
\hline Within the firm & 54.3 & 56.1 & 54.3 & 44.9 & 44.8 & 41.2 & 75.0 & 47.8 \\
\hline Suppliers & 25.7 & 14.0 & 25.9 & 23.1 & 23.0 & 18.9 & 12.5 & 29.3 \\
\hline Clients/customers & 43.9 & 45.2 & 43.7 & 26.2 & 27.3 & 18.0 & 8.3 & 26.4 \\
\hline Competitors & 15.9 & 33.0 & 15.5 & 9.7 & 9.8 & 9.3 & 4.2 & 9.5 \\
\hline $\begin{array}{l}\text { Consultants, labs or } \\
\text { private } R \& D\end{array}$ & 6.2 & 10.2 & 6.1 & 1.8 & 0.7 & 6.4 & 4.2 & 7.2 \\
\hline Higher education & 9.9 & 0.0 & 10.2 & 1.1 & 0.1 & 4.5 & 0.0 & 6.2 \\
\hline $\begin{array}{l}\text { Govt. and public research } \\
\text { institutes }\end{array}$ & 6.1 & 0.8 & 6.3 & 0.9 & 0.1 & 4.3 & 0.0 & 4.8 \\
\hline $\begin{array}{l}\text { Conferences, trade fairs, } \\
\text { exhibitions }\end{array}$ & 3.5 & 0.0 & 3.6 & 1.1 & 0.8 & 2.3 & 0.0 & 2.6 \\
\hline $\begin{array}{l}\text { Journals/trade } \\
\text { publications }\end{array}$ & 5.7 & 1.4 & 5.8 & 2.2 & 0.5 & 9.6 & 0.0 & 9.4 \\
\hline Professional assoc. & 0.8 & 2.0 & 0.8 & 15.5 & 16.1 & 12.2 & 0.0 & 14.8 \\
\hline
\end{tabular}

Source: Innovation Survey 2005

* STS = scientific and technological services. 
representative metrics on informal and contract-based knowledge flows, with the available data on IP-mediated knowledge transfer not capturing the main knowledge flow channels in South Africa.

There are several other sources of data on knowledge transfer from public research to firms, including bibliometric data on co-publications between public research and industry partners, $R \& D$ survey data, data published by universities and public research institutes, and a recent survey of KTOs on IP-mediated knowledge transfer.

The major research universities publish annual reports that include the number of research contracts, rated researchers, research chair holders, publication units, invention disclosures, patent applications, patent grants, and outbound transfer agreements. Even so, these reports do not follow a standard format, so comparable data are not readily available. In addition, some financial data are provided for total research income, the value of research contracts, equity held in spinout companies, and income from the exploitation of IP.

In general, the universities provide little information on their formal involvement in promoting new businesses and jobs. One exception is the University of Cape Town (2015), whose annual research report provides details of earnings, licensing, patent activity, and spinouts. Table 9.4 provides results for four research-intensive universities. Little is known about the performance of the various private companies established by universities, since private companies are not required to place such information in the public domain.

Three of the public research institutes, Mintek, the ARC, and the CSIR, use sector-specific metrics to demonstrate socioeconomic impacts, knowledge transfer, and commercialization success. The ARC collects data on the number of registrations for plant breeders' rights for plant cultivars. The CSIR provides metrics on "demonstrator" implementation such as the Technology Readiness Level, characterized by protocols for rolling out a demonstration project. These "metrics" of knowledge transfer are certified for validity and reliability through the Office of the Auditor General prior to their submission to Parliament.

\subsubsection{Metrics of Non-IP-Mediated Knowledge Transfer}

Non-IP-mediated knowledge transfer includes informal methods such as hiring university graduates and contacts with university staff that are not based on a payment to the university, plus formal methods such as collaborative research, consulting, and contracting. 
Table 9.4 R\&D expenditure and knowledge transfer metrics for four leading universities in 2014

\begin{tabular}{|c|c|c|c|c|c|c|c|}
\hline & $\begin{array}{l}\text { Total R\&D expend- } \\
\text { itures (ZAR billion) }\end{array}$ & $\begin{array}{l}\text { IP cost } \\
\text { (ZAR } \\
\text { million) }\end{array}$ & $\begin{array}{l}\text { KTO cost } \\
\text { (ZAR } \\
\text { million) }\end{array}$ & $\begin{array}{l}\text { Number of } \\
\text { invention } \\
\text { disclosures }\end{array}$ & $\begin{array}{l}\text { Number of } \\
\text { technolo- } \\
\text { gies }^{*}\end{array}$ & $\begin{array}{l}\text { Number of } \\
\text { licenses }\end{array}$ & $\begin{array}{l}\text { Number of } \\
\text { patent } \\
\text { families }\end{array}$ \\
\hline $\begin{array}{l}\text { University of Cape } \\
\text { Town }\end{array}$ & 1.18 & 4.8 & 3.3 & 41 & 108 & 17 & 104 \\
\hline Witwatersrand & 0.89 & 9.2 & 4.6 & 37 & 126 & & 111 \\
\hline $\begin{array}{l}\text { University of } \\
\text { Kwazulu-Natal }\end{array}$ & 0.65 & 0.5 & 1.0 & 10 & 18 & & 7 \\
\hline $\begin{array}{l}\text { University of } \\
\text { Johannesburg }\end{array}$ & 0.25 & 0.8 & 4.2 & 14 & 8 & & \\
\hline
\end{tabular}

Source: Author's enquiry to NIPMO

* A technology is the embodiment of a single innovative idea. Multiple technologies can arise from a single invention disclosure or a single technology can result from a combination of disclosures. 
South Africa's total publication output rose from 0.39 percent of world publications between 1996 and 2000 to 0.63 percent between 2011 and 2015 (NACI 2016). There is also extensive co-authorship between South African and foreign academics, creating opportunities for inward knowledge transfer. However, a search on the Web of Science for the period 2005-15 did not find any co-publications between the major foreign patentee firms active in South Africa and South African universities.

The South African R\&D Surveys record a greater number of R\&D collaborations between local firms and universities than with public research institutes, supporting the results of the innovation survey. The flow of funds from firms to universities amounts to 8 percent of higher education R\&D (HERD), while that to public research institutes is 10 percent of their expenditure on R\&D (DST 2015a). Given that universities use some of these funds for studentships, this suggests more extensive R\&D collaboration with public research institutes. In addition, industry R\&D collaboration with public research is highly concentrated, with only onesixth of 600 firms that received an R\&D tax incentive reporting collaboration with either universities or public research institutes.

\subsubsection{Metrics of IP-Mediated Knowledge Transfer}

The 2008 Public Research IP Act gave incentives to public sector researchers to patent and commercialize their inventions, while funding to defray patent application costs was also provided. The preferred patenting route is the Patent Cooperation Treaty (PCT), to which South Africa acceded in 1999. The output of commercially valuable knowledge from universities and public research institutes can be tracked via PCT filings and USPTO assignments. South African patent applications via the PCT nearly tripled between 2000 and 2013 in three stages - up to 2004, from 2005 to 2012, and from 2013 onward. The post-2004 increase could be due to the support of the Innovation Fund for IP activity and subsidization of the costs of PCT filing. The distribution of PCT filings over the period 2009-15 shows a shift from the private sector and public research institutes toward universities, with Stellenbosch University the most prolific, followed by industry giant Sasol and the University of Cape Town. The five universities with the most patents are Stellenbosch, Cape Town, Witwatersrand, North West, and Pretoria. The top two public research institutes are the CSIR and the ARC.

The number of USPTO patent awards by South African organizations has increased slightly from 2011 onward, with Sasol in first place followed 
by the CSIR and United States of America (U.S.)'s company Amazon. There has been a significant shift away from the mineral resources sector hardly surprising in that gold production has declined by 83 percent from its 1970s' peak, while platinum exports have remained static. Gold and PGM miners have restructured and in some cases moved their primary listings abroad. Eskom, Denel, and Mintek (previously important patentees) recorded no USPTO patents in the period 2011-15. Another significant change in the identity of assignees is the participation of local universities, namely Witwatersrand, Cape Town, and Northwest.

A survey by the DST, NIPMO, SARIMA and HSRC (DNSH 2017) (the inaugural South African National Survey of Intellectual Property and Technology Transfer at Publicly Funded Research Institutions) collected data on formal knowledge transfer activities of up to twenty-five universities and eleven public research institutes for fiscal year 2013-14. The questionnaire followed that of the Association of University Technology Managers (AUTM) in the U.S. Most of the questions collected data on inputs (research expenditures) or outputs (invention disclosures, patents, startups, etc.).

The results, given in Table 9.5, identified fifteen startups in the 2013-14 fiscal year and 315 international patent applications, which is almost 50 percent higher than the number of domestic patent applications. The survey also found that there were twenty-eight licenses in 2013-14. License revenues totaled ZAR 35.6 million (USD 3.4 million) compared with aggregate expenditures of ZAR 86 million (USD 8.1 million) for knowledge transfer costs such as maintaining a KTO. Based on the experience in Europe and the U.S., some institutions are likely to have earned revenues that more than covered their costs while the majority were likely to have revenues below costs.

Of particular interest is the finding that 79 percent of licenses were given to foreign-owned firms, suggesting that there is very little IPmediated knowledge transfer to domestic firms. This could also explain the higher number of international patents. With data for only one year, it is not known whether the large role of foreign-owned firms as recipients of formal knowledge transfer is a one-year anomaly or a long-term characteristic of the South African innovation system.

With greater experience, it is likely that knowledge transfer outcomes will increase in the future. During 2013-14, 52 percent of the 100 staff employed by KTOs had under four years' experience. Many are on contract, with their salaries paid by NIPMO. This intervention has been critical to establish capacity and build experience, which is mostly obtained on the job. 
Table 9.5 Metrics of the knowledge transfer activities of South African universities and public research institutes, fiscal year 2013-14

\begin{tabular}{|c|c|c|}
\hline & $\mathrm{N}$ & Metric \\
\hline \multicolumn{3}{|l|}{ KTOs } \\
\hline Share of universities/PROs with a KTO & 36 & 92 percent \\
\hline KTO budget (ZAR) for all reporting KTOs (ZAR)* & 24 & 86 million \\
\hline Total expenditure on patent applications (ZAR) & 24 & 36 million \\
\hline \multicolumn{3}{|l|}{ Non-patent IP metrics } \\
\hline Number of invention disclosures & 22 & 306 \\
\hline Plant cultivars filed & 21 & 19 \\
\hline Designs filed & 22 & 10 \\
\hline Number of startups established & 22 & 15 \\
\hline \multicolumn{3}{|l|}{ Patenting } \\
\hline Number of international patent applications & 22 & 315 \\
\hline Number of domestic patent applications & 22 & 216 \\
\hline Number of international patent grants & 21 & 76 \\
\hline Number of domestic patent grants & 21 & 32 \\
\hline \multicolumn{3}{|l|}{ Licensing } \\
\hline Number of licenses with firms (including startups) & 22 & 28 \\
\hline Share of licenses with internationally owned firms & 22 & 79 percent \\
\hline Percentage of licenses based on a patent & 20 & 69 percent \\
\hline Percentage of licenses earning revenue & 19 & 35 percent \\
\hline Total license income earned (ZAR) & 22 & 35.6 million \\
\hline Share of license agreements with startups or SMEs & 21 & 88 percent \\
\hline Share of exclusive license agreements & 23 & 54 percent \\
\hline $\begin{array}{l}\text { Amount of research funding provided by } \\
\text { businesses (ZAR) }\end{array}$ & - & 1.08 billion \\
\hline $\begin{array}{l}\text { Share of license revenue in total business research } \\
\text { funding }\end{array}$ & - & 3.3 percent \\
\hline
\end{tabular}

Sources: NIPMO

$\mathrm{N}$ : number of reporting universities and public research institutes.

* Excludes expenditures for patent applications.

Unfortunately, the study did not collect data on non-mediated forms of knowledge transfer such as through research agreements, but it did collect data from twenty-four KTOs on the level of impact (high, moderate, or no impact) of four obstacles to knowledge transfer: (1) inadequate awareness on the part of research staff of the need to disclose and manage IP, (2) inadequate funding for the KTO, 
(3) inadequate funding for IP registration costs, and, (4) a lack of specialist resources. Two obstacles were given a high impact rating by 42 percent of respondents: inadequate KTO funding and a lack of specialist resources, while the other two (inadequate awareness and lack of funds for IP registration) were given a high impact rating by 25 percent of respondents. In addition, 75 percent of respondents cited a lack of awareness among research staff of the need to disclose their inventions as a medium-impact obstacle. This indicates that formal methods of knowledge transfer are in a state of infancy.

\subsubsection{Impacts of Knowledge Transfer}

The Technology Innovation Agency commissioned an Economic Impact Assessment for the period 2011-16 (Urban-Econ 2016) which estimated that expenditures of ZAR 6.0 billion (USD 600 million) contributed to ZAR 1.7 billion (USD 170 million) of economic activity with an aggregate employment multiplier of 4.66. Specific cases of knowledge transfer were not studied in this evaluation.

The largest science council, the CSIR, has not provided an impact assessment of all its activities, although individual CSIR divisions have published occasional impact studies.

In contrast, the ARC publishes impact assessments of a range of its activities. ${ }^{8}$ For example, an assessment of grain crop activities (involving the ARC, Grain SA, the University of Pretoria, seed companies and its parent government department) reports that the knowledge transferred through new cultivars between 1997 and 2012 resulted in a massive 3,700 percent return on investment to maize production. ARC research on peach and nectarine cultivars released to local producers demonstrated a rate of return of 56 percent, while that for plums was lower at 14 percent.

Until recently, there was a poor track record of independent evaluations of public research institution activities, let alone use of their findings. The establishment of the Department for Planning, Monitoring and Evaluation (DPME) and a Centre of Excellence in Scientometrics and Science Policy at Stellenbosch University signal new capabilities for conducting evaluations to advance policy learning.

The above discussion points to significant gaps regarding knowledge transfer from universities and public research institutes to businesses that may lead to economic or social impact. There appear to be no studies of

${ }^{8}$ See www.arc.agric.za/Pages/Economic-Analysis.aspx. 
the links between university/public research institute activity and the formation of new enterprises and job creation. Impact assessment post hoc - let alone ex ante - is also thin on the ground. The fact that a compliance culture is in place may serve as the starting point to engender more routine impact assessment with associated data collection. An evaluation culture is emerging, although organizations tend to prioritize compliance with Auditor General reporting requirements over engaging in evaluation to serve as corrective and learning devices.

\subsection{Conclusions}

A number of factors have limited the flow of knowledge from public research to businesses in South Africa. These include high levels of basic R\&D that support the "own science" agenda of skilled researchers. Without top-down steering toward national imperatives, a shift toward use-inspired basic research, built on close interactions between public research and businesses, will not occur in the foreseeable future. In any case, a change toward use-inspired research will also require actions to improve the demand for university research, which requires greater capabilities on the part of a broad spectrum of South African firms. Otherwise, the national innovation system will continue to consist of "islands" of expertise in research and innovation through which researchers advance their professional and commercial interests.

South African universities have adjusted to the requirements of the 2008 Public Research IP Act by establishing KTOs and implementing practices to support knowledge transfer. All universities had already set up or were in the process of setting up a trading entity to house startups or IP, and to put a stop to academics acting as commercial service providers. This was balanced with a range of staff incentive schemes to promote commercialization.

Those universities that had experience in IP management before the Public Research IP Act were well-equipped to adapt to its introduction. Some universities developed full-cost business models to encourage firms to contract R\&D while retaining full IP rights. This would appear to have induced some new contracts, yet there were concerns that the substantial business funding of university research would decline. Interviews found that universities were generally positive as to the role of NIPMO and financial support for the cost of patenting, although in one case it was argued that serving the broad community should trump the acquisition of IP rights, which was considered to be "a prestige activity." 
All research universities and public research institutes currently have internal IP management policies. In many instances, these predate the Public Research IP Act. Moreover, "getting close to customers/communities" has been part of the general ethos of universities and public research institutes over the last two decades, in part because of the widespread adoption of "value for money" thinking, but also because of postapartheid development imperatives. University interviewees noted that pressure to address public and commercial needs comes from institutional boards, communities, and public representatives. This does not mean that public institutions have abandoned their traditional mandates of teaching and research. Actual promotion of the generation of IPR varies considerably. Detecting latent IP does not come easily, and, to this end, some organizations have brought in IP scouts who work with researchers to identify potential invention disclosures. In some cases, staff with commercially valuable IP are allowed to place their students in a business incubator and are given time out to support commercialization.

In contrast, interviews with managers from public research institutes showed that they were less enthusiastic about the Public Research IP Act, arguing that the requirements to share benefits with inventors would put further stress on their bottom line in an already constrained operating environment. This stress is evidenced through a comparison of government funding for R\&D. From 2005 to 2014, funding to public research institutes (unadjusted for inflation) rose 3.4 times compared to a 3.8-fold increase for universities. Yet not all public research institutes were concerned about benefit sharing in all circumstances. A major public research institute experimented with giving equity stakes to its researchers and introduced the idea of the "entrepreneur in residence" to promote practical approaches to commercialization.

The interviewees from public research institutes and government also expressed concerns over a lack of policy coherence between the DTI and the DST and believed that differences in mandates hindered knowledge transfer rather than helping it. Policy confusion and mandate creep also limited the effectiveness of incentive schemes that often failed to attract high-quality proposals supported by well-crafted business cases.

More broadly, the underlying and continuing "two legs" social contract characterizes the innovation system and ensures the persistence of supply-side thinking. This in turn creates barriers to knowledge transfer outside the islands of excellence, since the needs of clients or users are of little immediate concern. 
The present period in South Africa may be characterized as transitional, as the old order yields to new interests. To support this transition, considerable policy experimentation has taken place since the 1996 White Paper. One of the overarching goals of the government's National Development Plan was to deploy science, technology, and innovation for economic development. This would necessarily demand effective knowledge transfer. Subsequent policies such as the Innovation Fund, the R\&D Tax Incentive, the Public Research IP Act, the Technology Innovation Agency, and the Sectoral Innovation Programmes were designed to support this goal.

The current Presidency of Cyril Ramaphosa is actively soliciting foreign direct investment to modernize and expand infrastructure and equipment in South Africa. The long-term benefits of new investment and modernization will in turn depend on domestic capability to absorb and learn how to use the associated technologies. This is another form of knowledge transfer in which the public research system can play an important role.

\section{References}

Alessandrini, M., K. Klose, and M.S. Pepper (2013). "University entrepreneurship in South Africa: Developments in technology transfer practices." Innovation: Organization \& Management, 15(2): 205-14.

ARC (2015). Annual Report 2014/15. Pretoria: Agricultural Research Council.

Basson, N. (1996). Passage to Progress. The CSIR's Journey of Change, 1945-1995. Johannesburg: Jonathan Ball Publishers.

Breschi, S. and F. Malerba (2005). "Clusters, networks, and innovation: Research results and new directions." In S. Breschi, and F. Malerba (eds.), Clusters, Networks and Innovation. Oxford: Oxford University Press.

Cooper, D. (2011). The University in Development. Cape Town: HSRC Press.

CSIR (2015). Annual Report 2014/15. Pretoria: CSIR.

Cusmano, L., A. Morrison, and R. Rabelotti (2010). "Catching-up trajectories in the wine sector: A comparative study of Chile, Italy, and South Africa." World Development, 38(11): 1588-1602.

DACST (1996). White Paper on Science and Technology of 1996. Pretoria: Department of Arts, Culture, Science, and Technology.

DACST (2001). National Biotechnology Strategy. Pretoria: Department of Arts, Culture, Science, and Technology.

De Wet, G. (2001). "Emerging from the technology colony: A view from the South." University of Pretoria.

DNSH (2017). South African National Survey of Intellectual Property and Technology Transfer at Publicly Funded Research Institutions. Inaugural Baseline Study, 2008-2014. Pretoria: Department of Science and Technology, 
National IP Management Office, Southern African Research and Innovation Management Association and Human Science Research Council.

DPME (2015). Evaluation of the Technological Human Resources for Industry

Programme. Pretoria: Department of Planning, Monitoring, and Evaluation.

DST (2002). National R\&D Strategy. Pretoria: Department of Science and Technology.

DST (2008). Ten-Year Innovation Plan 2008-2018. Pretoria: Department of Science and Technology.

DST (2011). Innovation Survey 2005/07. Pretoria: Department of Science and Technology.

DST (2012). Report of the Ministerial Review of the STI Landscape. Pretoria: Department of Science and Technology.

DST (2013). Bio-economy Strategy. Pretoria: Department of Science and Technology. DST (2015a). RÆD Survey 2013/14. Pretoria: Department of Science and Technology. DST (2015b). Report on the R\&D Tax Incentive to Parliament. Pretoria: Department of Science and Technology.

DST (2015c). Strategic Plan 2016-20. Pretoria: Department of Science and Technology.

DTI (2015). Industrial Policy Action Plan 2015-2017. Pretoria: Department of Trade and Industry.

EDD (2010). New Growth Path. Pretoria: Economic Development Department.

Fedderke, J.W. and M. Velez (2013). Does Massive Funding Support of Researchers

Work? Evaluating the Impact of the South African Research Chair Funding Initiative. ERSA Working Paper 389 November 2013. Pretoria: The Treasury.

Fongwa, N.S. and L. Marais (2016). "University knowledge and regional development: Factors affecting knowledge transfer in a developing region." Africa Education Review, 13(3-4): 191-210.

GEMS (2016). Global Entrepreneurship Monitor. South African Report 2015/16. Cape Town: Development Unit for New Enterprise, University of Cape Town. Goldberg, I. and S. Kuriakose (eds.) (2011). Fostering Technology Absorption in Southern African Enterprises. Washington, DC: World Bank.

Hausmann, R. (2017). "Is South Africa about to make an historic mistake?" CDE Insight, June 2017. Johannesburg: Centre for Development and Enterprise.

HSRC (2007). Innovation Survey 2005. Pretoria: Human Sciences Research Council. Kahn, M.J. (2006). "The South African national system of innovation after Apartheid: From constructed crisis to constructed advantage?" Science and Public Policy, 33(2): 125-36.

Kahn, M.J. (2013) "Rhetoric and change in South Africa's innovation policy." Science, Technology and Society, 18(2): 189-211.

Kahn, M.J. (2014). "SMEs and the telemetry system of innovation." Paper presented to the International Conference for the Management of Technology (IAMOT) Conference 2014, Washington, May 22-6, 2014. 
Kahn, M.J. (2016). "Evolution of science policy in South Africa: plus ça change ....” Plenary address to the IDRC/IRD/IFRIS International Conference on The Transformation of Research in the South: Policies and Outcomes. Paris, Organisation for Economic Co-operation and Development.

Kaplan, D. (2004). "South Africa's national research and development strategy: A review." Science, Technology \& Society, 9(2): 273-94.

Kaplan, D. (2008). Science and Technology Policy in South Africa: A Critical Assessment of Past Performance and Proposed Future Directions. Working Paper 1/2008. Geneva: United Nations Industrial Development Organization.

Kaplan, D. (2011). South African Mining Equipment and Specialist Services: Technological Capacity, Export Performance and Policy. MMCP Discussion Paper No. 5. Cape Town/Milton Keynes, Making the Most of Commodities Programme.

Kaplan, D. (ed.) (2009). The Economics of Intellectual Property in South Africa. Geneva: World Intellectual Property Organization.

Kruss, G. (2008a) "Balancing old and new organisational forms: Changing dynamics of government, industry and university interaction in South Africa." Technology Analysis \& Strategic Management, 20(6): 667-82.

Kruss, G. (2008b) "Knowledge-intensive university spinoff firms in South Africa: Fragile network alignment?" Industry and Higher Education, 22(4): 233-43.

Kruss, G., M. Visser, M. Aphane, and G. Haupt (2012). Academic Interaction with Social Partners. Cape Town: HSRC Press.

Kruss, G., S. McGrath, I. Petersen, and M. Gastrow (2015). "Higher education and economic development: The importance of building technological capabilities." International Journal of Educational Development, 43: 22-31.

Kuriakose, S., D. Kaplan, and K. Tuomi (2011). "Channels of and constraints to technology absorption.” In I. Goldberg and S. Kuriakose (eds.), Fostering Technology Absorption in Southern African Enterprises. Washington, DC: World Bank.

Lubango, L.M. and A. Pouris (2007). "Industry work experience and inventive capacity of South African academic researchers.” Technovation, 27(12): 788-96.

Maharajh, R. (2011). "Innovating beyond Racial Capitalism. A Contribution towards the Analysis of the Political Economy of Post-Apartheid South Africa." Doctoral dissertation presented to Lund University.

Morgan, P. (2006). "Human Capital Development: A contribution from industry" Sasol R\&D presentation to the South Africa Day at the Royal Society, London.

Morris, M., R. Kaplinsky, and D. Kaplan (2011). Commodities and Linkages: Industrialisation in Sub-Saharan Africa. Milton Keynes: Open University Press.

NACI (2016). STI Indicators 2015. Pretoria: National Advisory Council on Innovation.

Nongxa, L. and E. Carelse (2014). Moving Forward: Trends in Annual Reporting by South African Public Universities - A Review of Annual Reporting by South 
African Public Higher Education Institutions 2010-2012. Cape Town: PricewaterhouseCoopers. www.pwc.co.za.

National Research Foundation (2008). THRIP Impact 2008. Pretoria: National Research Foundation.

National Research Foundation (2012). THRIP Impact 2012. Pretoria: National Research Foundation.

National Research Foundation (2016). Socio-economic Impact Evaluation of the RISA Programme. Pretoria: National Research Foundation.

NSF (2015). Science and Engineering Indicators. Washington, DC: National Science Foundation.

Phaho, D. and A. Pouris (2008). "Impact of technology diffusion on the innovation capacity and competitiveness of automotive components SMEs in South Africa." Management Review: An International Journal, 3(2): 61-93.

Pouris, A. and A. Pouris (2011). "Patents and economic development in South Africa: Managing intellectual property rights." South African Journal of Science, 107(11/12).

Presidency (2012). National Development Plan. Pretoria: The Presidency.

Rorwana, A. and R.K. Tengeh (2015). "The role of academic entrepreneurs in the process of technology transfer and commercialization: The case of a University of Technology in South Africa." Environmental Economics, 6(4): 25-37.

RSA (2008a) Amendment to Section 11D of the Income Tax Act 1962. Pretoria: Government Printer.

RSA (2008b) Intellectual Property Rights from Publicly Funded Research and Development Act. Pretoria: Government Printer.

Sibanda, M. (2009). "Intellectual property, commercialization and institutional arrangements at South African publicly financed research institutions." In D. Kaplan (ed.), The Economics of Intellectual Property in South Africa. Geneva: World Intellectual Property Organization.

University of Cape Town (2015). Research 2014-15. Cape Town: University of Cape Town.

Urban-Econ (2016). Technological Innovation Agency Economic Impact Assessment 2010/11-2015/16 Financial Year. Pretoria: Urban-Econ. https://www.tia.org.za /files/2017/12/201617-TIA-Economic-Impact-Assessment-Report.pdf.

Van Vuuren, H. (2017). Apartheid, Guns and Money. Johannesburg: Jacana Press. WIPO (2011). World Intellectual Property Report 2011: The Changing Face of Innovation. Geneva: World Intellectual Property Organization (WIPO).

Zhang, C., I. Goldberg, D. Kaplan, and S. Kuriakose (2011). "Policy options for greater technology absorption.” In I. Goldberg and S. Kuriakose (eds.), Fostering Technology Absorption in Southern African Enterprises. Washington, DC: World Bank. 


\section{The Way Forward}


Downloaded from https://www.cambridge.org/core. IP address: 86.30.88.132, on 14 Feb 2022 at 14:50:54, subject to the Cambridge Core terms of use, available at https://www.cambridge.org/core/terms. https://www.cambridge.org/core/product/979C0AAA92B1200DCE513DAAE4894BE7 


\section{Policies and Practices for Supporting Successful Knowledge Transfer from Public Research to Firms}

ANTHONY ARUNDEL

\subsection{Introduction}

In the last decades, governments in many countries have added a third goal of community engagement to the university goals of teaching and research. Although there are many types of engagement, a primary focus is to encourage universities to support the commercialization of university-produced knowledge by private sector firms, with the expectation that this will improve competitiveness, living standards, and employment. This also requires universities to adopt some of the goals of public research institutes such as the Fraunhofer Institutes in Germany, which were established to fulfill this role. The combination of universities and publicly funded research institutes are referred to in this chapter as "public research" or "public research organizations."

Multiple types of policy and practice are involved in successful knowledge transfer and commercialization. Successful transfer results in products or processes, derived in part on discoveries or inventions made by researchers in the public research sector, that are either introduced onto the market and acquired by users or implemented in the business processes or functions of firms or government organizations. Successful transfer is difficult to identify (see Chapter 12) and consequently many pre-commercial metrics are used as a proxy, such as the licensing of public research inventions or the establishment of startups.

The discussion of policies and practices in this chapter draws on the published literature and six national case studies, three of which are for high-income countries (Germany, the Republic of Korea, and the United Kingdom) and three from middle-income countries (Brazil, China, and 
South Africa). These six countries show a range of policies and practices for knowledge transfer and a variety of contextual conditions that influence success, including different industrial structures and levels of technological competence within the public research sector and the business sector. In the last few decades, all six countries have undergone major changes in national policies with the goal of improving rates of knowledge transfer and commercialization.

Section 10.2 evaluates the context for successful knowledge transfer and commercialization, exploring the effects of linear and nonlinear models of innovation and how these models influence our understanding of the demand-side requirements for knowledge transfer. Section 10.3 draws on the literature and the case studies to identify "what works" and uses the case studies to illuminate the contextual factors that influence outcomes. Section 10.4 provides brief descriptions of changes in knowledge transfer policy practices in each of the six case countries and an evaluation of the causes of the changes. Section 10.5 draws conclusions and recommendations for supporting knowledge transfer.

\subsection{Models of Knowledge Transfer}

Knowledge transfer can occur via multiple channels, as discussed in Chapter 2. Different methods for knowledge transfer can result in equally successful results, indicating equifinality, in which multiple causal paths can lead to the same desired outcome (Ordanini et al., 2014). The probability of a successful outcome is affected by many contextual factors that are not the direct target of knowledge transfer practices, such as the national industrial structure, the firm's main sector of activity, the national or regional level of economic development, the type of research conducted by public research organizations, and the technological and innovation capabilities of both the public research sector and private sector firms.

The type of research varies by the domain or field of science, but also between basic and applied research. Basic research is expected to have long time lags between discovery and commercialization, whereas applied research is closer to the market and therefore has shorter time lags. The widely disparaged but still powerful "linear model" of innovation assumes that basic research, conducted by universities and some public research institutes, is followed by applied research, either by public research organizations or firms, that results in commercial products and processes. The linear model, or the "mode 1" conception of knowledge 
transfer (Gibbons et al. 1994), underpins the American Bayh-Dole Act of 1980.

The linear model has two assumptions. First, it views knowledge flows as unidirectional, flowing from public research organizations to firms. Second, it assumes that there is an ample supply of firms that are capable of taking university discoveries and further developing them into commercial products and processes, but unwilling to invest in further research because of a lack of patent protection on inventions. The BayhDole Act permits universities to provide the necessary patent protection.

The assumption of an ample supply of firms with the absorptive capacity to develop university inventions into products and processes probably reaches its closest approximation to reality in the United States of America (U.S.), where there is a larger pool of firms that are close to the technological frontier than in many other countries. Firms in sciencebased industries are also more likely to successfully use university inventions within a mode 1 linear model because they have the necessary capabilities to work within this model. However, this model does not hold in many countries and is also unlikely to be true in some regions of the U.S., in sectors where innovation is not based on science, or among specific types of firm, such as SMEs that lack advanced technological or scientific capabilities.

The mode 1 linear model of innovation assumes that there is always sufficient demand from national firms that are capable of using knowledge produced by universities. This has led to national policy reports in almost every developed country lamenting that excellent research results produced by national universities fail to be picked up and developed by national firms, with the blame placed on the universities or on the lack of programs to transfer knowledge from universities to capable firms. An example is a South African White Paper that states:

Whilst South Africa has many examples of good R\&D work, it has only managed to commercialise and exploit the research results in a few instances. Part of the problem is undoubtedly the absence of mechanisms to ensure that industry benefits maximally from the [output of public research] and other basic and/or applied research performers. (cited in Kahn 2017: 12).

The "mode 2" model (Gibbons et al. 1994) revises the original linear model based on technology push by introducing the need for universities to conduct applied research and consequently provide firms with inventions that are closer to the market. Market proximity has been measured 
through "technology readiness levels" or "proof of concept" (Heder 2017; Munari et al. 2017). Yet the mode 2 model is still insufficient because it fails to integrate the other half of the knowledge transfer process: the absorptive capacity of firms. Caryannis and Campbell (2009) and Miller et al. (2016) extend the mode 2 model by recognizing the need for demand pull from firms to the public research system, such that public research scientists are aware of industry needs and are able to act on this knowledge by altering their research programs. In the South African case, Kaplan (2008) argues that this occurs infrequently because there are few incentives for researchers to change or adjust their research programs to meet domestic needs. Furthermore, government officials in South Africa have understood a failure to transfer knowledge as a network failure, where there is a lack of bilateral communication between university academics and the managers of firms, or as a financial problem, with insufficient early-stage funding for startups or incentives for university researchers, instead of a possible "mismatch between demand and supply" (Kahn 2017: 28).

This is not only a problem for South Africa - in many countries, academics are comfortable within a technology-push model because it requires less involvement and provides more independence, permitting academics to conduct the type of research that they want to do and in the way they want to do it. This model does not require academics to conduct research that meets the needs of industry. This goes deeper than arguments over the "different cultures" of academics and firms, which often revolve around deadlines and confidentiality and arise when academics are involved in a collaborative research project with industry. The greater issue is the willingness of public researchers to engage with industry in the first place. O'Shea et al. (2008) note that there are large differences among academic researchers in their interest in engaging with a variety of stakeholders, while Arque-Castells et al. (2016) find that approximately one-third of Spanish and Portuguese academics that hold a patent for an invention are not interested in working with firms, even with financial incentives from a possible share of future royalty income.

The "mode 3" model for knowledge transfer assumes that effective transfer requires a pool of firms with sufficient absorptive capabilities (Hallam et al., 2014) and that there is a reverse knowledge flow whereby firms provide public research scientists with information on their needs and that this information influences the research projects of public research scientists. Miller et al. (2016) argue that this "demand pull" is the dominant factor in the process of effective knowledge transfer. It is 
likely to be of critical importance to collaborative research between the public research sector and firms. Mode 3 therefore follows a nonlinear model that is aligned with theories of national innovation systems (Lundvall 1992; Hallam et al. 2014).

In many countries, an awareness of demand pull has existed for decades and was met through public research institutes that conducted applied research for local industries, but universities were often outside this system. An example is Germany, which maintains a clearly defined basic research infrastructure, including universities, the Max Planck Institutes, and, to a certain extent, the Helmholtz Institute. Researchers at Max Planck do not see knowledge transfer as part of their role and have been largely unaffected by the trend, in many countries, to introduce third-pillar "community engagement" into public research organizations (see Chapter 5). Conversely, other public research institutes such as the Fraunhofer Institutes and the Leibnitz Institute view knowledge transfer as an important part of their role.

Out of the six country case studies, the United Kingdom has probably experimented the most with policies to encourage demand pull. Since the early 2000s, UK policy identified the disadvantages of too much focus on IP as part of a technology-push model and encouraged universities to become active players within a complex ecosystem of innovation characterized by collaboration and knowledge exchange (see Chapter 4). This was supported by financial incentives that allocated 9 percent of total government research funding on the basis of the income universities obtained from knowledge transfer activities, along with research subsidies to firms to participate in collaborative research with universities.

A "mode 3" model based on an understanding of national innovation systems recognizes the roles of both technology push and demand pull, with a focus on both public research and the capabilities and needs of national firms. Both public science and the private sector play strong roles, such that the failure to transfer knowledge could be due to a range of deficiencies on each side. Furthermore, mode 3 includes knowledge transfer intermediaries, such as university "technology transfer" and "knowledge transfer" offices, that play a greater role than simply preparing patent applications and licensing contracts. Instead, effective knowledge intermediaries need to actively find firms that could benefit from public research and encourage informal and formal contacts and collaborations between public research scientists and firms (Garengo 2019).

The terminology for knowledge intermediaries reflects the different conceptions of how knowledge flows. The original concept of 
a "technology transfer" office is based on the linear model, whereby knowledge flows in one direction from public research to firms. The update to "knowledge transfer" offices remains within this paradigm, with the exception that "knowledge" includes nontechnical knowledge such as works protected by copyright. The most recent term, although still rarely used for practical purposes, is "knowledge exchange," which views the process as involving a bidirectional flow of knowledge. This also includes cocreation as part of "open innovation" (Chesbrough 2003; Miller et al. 2016), where researchers from firms and public research organizations jointly develop inventions, often through collaborative research projects.

\subsubsection{The Knowledge Capabilities Gap}

While the linear model assumes that there is a pool of capable firms that can make use of results flowing out of a "public research pipeline," mode 3 models assume that a pool of capable firms may not exist: national firms might lack the absorptive capacity to use the outputs of the public research sector. This can be captured through the concept of a knowledge (or technological) capability gap between firms and public research.

The effect of a knowledge capability gap has been identified in several contexts. Haas et al. (2015), in an analysis of 952 problems posted on an online forum, find that knowledge providers are more likely to allocate time to solving a posted problem if the problem matches their expertise. In addition, they find an inverse " $U$ " relationship between the novelty of a problem and the probability that solution providers will respond. Chan et al. (2018) examine the adoption of novel ideas obtained from a firm's customers through crowdsourcing and find that the adoption of the idea by the firm declines with the novelty of the idea, as measured through newness, distinctiveness, and originality. Criscuolo et al. (2017) also find an inverse "U" relationship between the novelty of 556 research proposals for R\&D funding and the share of requested funding received.

A study by Kotha et al. (2013) provides an empirical example of the effect of a knowledge gap on the licensing of invention disclosures from an unidentified American university between 2001 and 2006. Out of 3,776 invention disclosures, 874 inventions were patented, of which 38 percent (339) were licensed, while 14 percent (416) of the nonpatented inventions were also licensed, giving a total of 755 licensed inventions. Of note, more licenses were given to non-patented inventions 
than to patented inventions. The authors calculate the scientific "distance" or technological complexity of each invention disclosure, measured by the number of knowledge domains used for the invention and the prevalence of cross-disciplinary research between the domains. Inventions with low technological complexity are likely to provide minor increments to existing knowledge, while very technologically complex inventions are likely to represent major inventions. The authors use survival analysis to determine the probability of each invention being licensed. Similar to Criscuolo et al. (2017) and Chan et al. (2018), Kotha et al. (2013) find an inverse " $U$ "-shaped relationship between the probability of licensing and scientific distance. Inventions of medium complexity are more likely to be licensed than inventions of both low and high complexity. This effect is mediated by the inventor team's experience with licensing. Greater experience increases the probability of licensing all types of invention, while low experience decreases the probability of licensing more technologically complex inventions.

The implication of this research is that a large gap between the technological complexity or novelty of an invention or idea and the capabilities of potential users decreases the probability that an invention or idea will be taken up, probably because potential users lack the absorptive capacity to understand and adapt an invention or idea for their own uses. Conversely, inventions or ideas with low complexity or novelty are also less likely to be taken up, possibly because firms are capable of developing similar solutions. In the Kotha et al. study, university inventions with low complexity may be less likely to be licensed because firms can work around the patent, saving the cost of taking out a license. The positive effect of the previous licensing experience of the inventors could increase the probability of licensing complex inventions because it signals to firms that the inventors are willing to assist firms in understanding and further developing complex inventions into commercially useful products or processes.

The gap in capabilities between university inventors and a firm is likely to vary between countries. For instance, the average absorptive capacity of the potential pool of licensees in a technologically leading economy such as the U.S. is likely to be greater than in a middle-income economy such as Brazil. In addition, inventions by universities in middle-income economies are also likely to be less novel or complex than they are in the U.S. Nevertheless, the literature suggests that what matters is the gap in technological capabilities between university academics and domestic firms, rather than the absolute level of complexity of the 
university invention. The gap needs to be sufficiently large to provide inventions that firms could not develop themselves, but not so large that firms are unable to understand and commercialize them. Of course, there may be islands of competence where the technological gap between public research and firms is within a "sweet spot" for licensing, as shown by the high technological capabilities and close linkages with public research of aircraft manufacturers in Brazil (De Negri and Rauen 2017) or petrochemical firms such as Sasol in South Africa (Kahn 2017).

The technological gap can also occur in the other direction, with universities operating at a lower level of technological competence than firms. In this case, firms have little interest in licensing inventions from universities. One example is large firms in the Republic of Korea, which benefited from public research from the 1970s until the 1990s. However, after the late 1990s, the capabilities of large firms in the Republic of Korea exceeded the capabilities of the public research sector (see Chapter 6), with one consequence being a shift in policy to encourage public research institutions to support technologically lagging SMEs.

The concept of a knowledge gap applies not only to licensing IP, but also to involvement in collaborative research. When the knowledge is gap is high, firms might resort instead to contracting out research to public research organizations.

Out of the six country case studies, four identify barriers to knowledge transfer as a result of a knowledge gap where the capacities of universities exceed those of firms (Brazil, China, South Africa, and the United Kingdom), and the Republic of Korea identifies a knowledge gap where the capacities of firms gradually exceeded those of universities. Germany is the only case study where a knowledge gap does not appear to be a significant issue, either because of the well-developed infrastructure of public research institutes that serves the requirement for applied research by German firms, or because of a lack of comprehensive data for Germany on knowledge transfer channels other than those based on patents (see Chapter 5).

The technological gap between universities and firms can be imagined as a situation where knowledge must be "pumped uphill" to overcome the deficit in the absorptive capacities of firms. The "pump" can consist of demand-side activities such as investments by firms in absorptive capacity, the active assistance of academics in helping firms to understand their inventions, or closer collaboration between firms and academics so that the last are more knowledgeable about the problems that firms face. 
Policy can contribute to the pump by subsidizing the R\&D activities of firms, providing subsidies for collaborative research between firms and universities, or supporting university practices that encourage inventors to assist firms, for instance, by taking up short-term contracts with firms to assist with knowledge transfer.

\subsection{Appropriate Policies and Practices}

Successful knowledge transfer from public research depends on context: the technological and related capabilities of firms and public research organizations, the gap between these capabilities, and the industrial structure of a country, among other factors.

From the perspective of the mode 3 model, there are three main actors in knowledge transfer: the public research organization (a university or public research institute), intermediaries, particularly knowledge transfer offices, and firms. Figure 10.1 charts the relationships between these three nodes and identifies the main factors for each actor that can influence successful knowledge transfer.

The set of factors that promote knowledge transfer are likely to differ depending on the knowledge transfer channel (startups, contract research, collaboration, or IP licensing), interactions between policies, and interactions with other knowledge transfer channels. The systems perspective underlying the mode 3 model of knowledge transfer emphasizes the need for policies and practices to bridge the knowledge gap

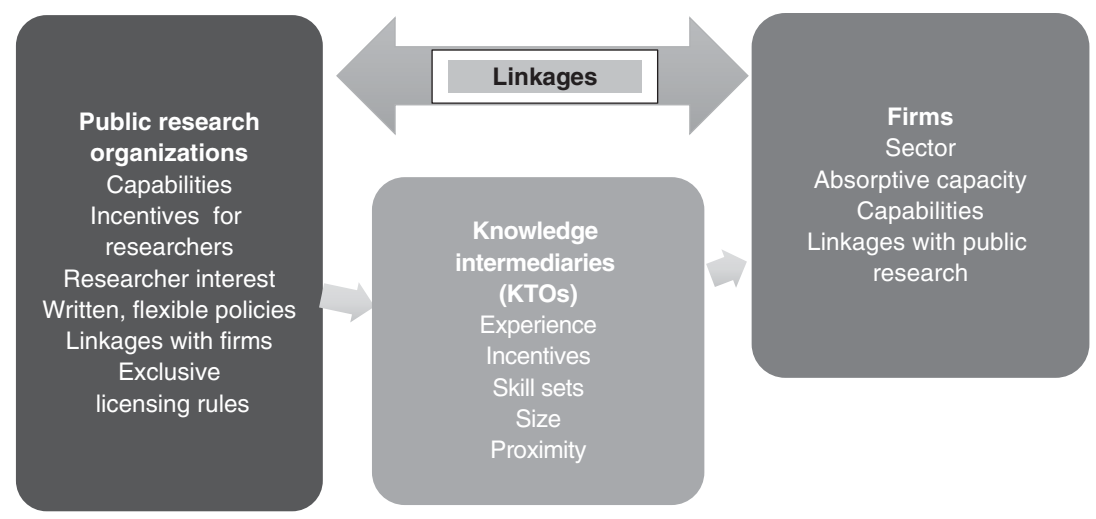

Figure 10.1 Factors that influence knowledge transfer Source: Authors 
between public research and firms and to support knowledge exchange in addition to knowledge flows from academia to firms.

The question for policy is which factors need to be further developed and which factors are functioning adequately? Table 10.1 provides a basic framework for answering this question, based on the concept of a knowledge gap between public research and firms. Table 10.1 should be interpreted in respect to specific knowledge domains, for instance it could refer to knowledge on food manufacturing (safety, shelf life, processing, packaging, etc.) or to pharmaceutical manufacturing.

Successful knowledge flows require motivating all three partners (researchers, KTO intermediaries, and firms) to participate in knowledge

Table 10.1 Policies to support knowledge transfer for differing capabilities of public research organizations and firms

\begin{tabular}{|c|c|c|c|}
\hline & & \multicolumn{2}{|c|}{ Level of firm capabilities } \\
\hline & & High & Low \\
\hline \multirow[t]{2}{*}{$\begin{array}{l}\text { Level of public } \\
\text { research } \\
\text { capabilities }\end{array}$} & High & $\begin{array}{l}\text { A Ensure } \\
\text { knowledge } \\
\text { flows through } \\
\text { flexible } \\
\text { licensing and } \\
\text { contracting } \\
\text { rules; incentives } \\
\text { for public } \\
\text { research } \\
\text { scientists to } \\
\text { disclose } \\
\text { inventions and } \\
\text { assist firms }\end{array}$ & $\begin{array}{l}\text { B Bridge the gap } \\
\text { through polices } \\
\text { to build firm } \\
\text { capabilities and } \\
\text { incentives for } \\
\text { the public } \\
\text { research sector } \\
\text { to interact with } \\
\text { firms }\end{array}$ \\
\hline & Low & $\begin{array}{l}\text { C Bridge the gap } \\
\text { through } \\
\text { policies to build } \\
\text { public research } \\
\text { capabilities and } \\
\text { incentives for } \\
\text { firms to interact } \\
\text { with the public } \\
\text { research sector }\end{array}$ & $\begin{array}{l}\text { D Improve public } \\
\text { research } \\
\text { capabilities } \\
\text { (supply), firm } \\
\text { capabilities } \\
\text { (demand), and } \\
\text { knowledge } \\
\text { exchange } \\
\text { between them }\end{array}$ \\
\hline
\end{tabular}

Source: Authors 
transfer. In cell A of Table 10.1, where the capabilities of both public research and firms are high (and with a suitable knowledge gap somewhere near the top of the inverse " $U$ " distribution), the role of policy is to ensure that there are appropriate incentives for interactions and capabilities in place for the three main actors in knowledge transfer. For cells B, C, and D, additional policies to either build supply capabilities in the public research sector or demand capabilities in firms are likely to be required in addition to the policies identified in cell A. For example, when public research capabilities are high but firm capabilities are low (cell B), incentives are required to encourage public research academics to interact with firms, in addition to $\mathrm{R} \& \mathrm{D}$ or other types of subsidy to build firm capabilities. Cell C provides the opposite case where firm capabilities are high but public research capabilities are low. Here, incentives could be required to encourage firms to interact with the public research sector, in addition to supply-side policies to improve the capabilities of public research academics.

Policies and practices can be usefully divided into two groups: those that directly address knowledge transfer, such as incentives, funding for KTOs, etc., and those that affect contextual factors such as the technical capabilities of firms or the industrial structure. Most of the existing literature on policies and practices to support knowledge transfer is relevant to cell A in Table 10.1 and concerns direct methods to improve knowledge transfer. Nevertheless, this literature is of use to all other conditions because it identifies practices that support interactions between public research and firms. These direct policies and practices are discussed below for each of the three main actors: public research organizations, knowledge intermediaries, and firms.

\subsubsection{Policies, Practices, and Characteristics of Public Research Organizations}

A history of previous linkages between a public research organization and firms increases the interest of researchers in knowledge transfer activities and consequently the probability of knowledge transfer (D'Este and Patel 2007; Libaers 2012; Padilla-Meléndez and GarridoMoreno 2012; Grimpe and Hussinger 2013; Agiar-Diaz et al. 2016). In addition, academics can be motivated to collaborate with firms by previous involvement in applied research and the importance of applied research to career advancement (Abreu and Grinevich 2013; Abreu et al. 2016; Zhang et al. 2016). In contrast, practices such as a requirement to disclose inventions with commercial potential have 
only a small effect on the involvement of academics in knowledge transfer (Abreu et al. 2016).

Combining informal and formal knowledge transfer channels can have a positive effect on the innovation activities of firms (Siegel et al. 2003; Grimpe and Hussinger 2013). Informal channels build up relationships and trust between academic researchers and firms that can lead, over time, to research relationships that produce IP (Weckowska 2015). The use of both informal and formal channels could be especially important to spinoffs (Hayer 2016).

Another type of linkage is when public research organizations and firms coinvent through a collaborative research agreement. This can result in corporate patents that include university inventors as a contributor through formal or informal channels. Walsh (2016) reports that 4 percent of corporate triad patents held by American firms between 2001 and 2004 included formal or informal input from universities.

An important factor for encouraging knowledge transfer via IP-mediated methods is financial incentives for academic staff to disclose inventions and participate in the knowledge transfer process (Walter et al. 2013). The size of the financial reward has a positive effect, either through a one-off lump sum or a share of ongoing royalties (Friedman and Silberman 2003; Siegel et al. 2003; Lach and Schankerman 2004; Debackere and Veugelers 2005; Walter et al. 2013), although in Brazil an increase in status and recognition has also been a driver for increased academic interest in knowledge transfer activities (Closs et al. 2013).

Studies of academics find that their interest in participating in knowledge transfer can also be increased by including knowledge transfer activities in performance measures (Siegel et al. 2003; Closs et al. 2013; Ranga et al. 2016) and permitting academics to take time off to work with a firm.

Barriers to researcher interest in knowledge transfer include personal characteristics that create a lack of interest in knowledge transfer or in financial incentives, teaching and other responsibilities that reduce the time available for academics to engage in knowledge transfer (Closs et al. 2013), concern over delays in publishing knowledge linked to IP, a lack of financial support (for instance, when the academic must cover the patenting costs, which can be an issue in middle-income countries), a lack of research ideas with commercial potential, limited experience with interactions with firms (D'Este and Patel 2007), and differences between academic and business cultures, although this may be less important than commonly believed. In a UK survey of both businesses and academics, less than 7 percent of both groups cited cultural differences as an important barrier 
to interactions. In comparison, the most commonly cited barrier was "insufficient internal resources," cited by 42 percent of businesses and 28 percent of academics (Hughes and Kitson 2012).

Bureaucratic and inflexible rules for knowledge transfer activities can act as a barrier to the participation of both academics and firms in knowledge transfer (Muscio et al. 2016). Knowledge transfer via licensing is supported by clear IP regulations that provide guidance to staff (Baldini et al. 2006) and a flexible approach on the part of the public research organization to licensing (Lerner 2005; Okamuro and Nishimura 2013; Barjak et al. 2015; Shen 2016).

Policies that contribute to knowledge transfer via the establishment of startups include dedicated programs (support for developing business plans, etc.) and facilities (such as an incubator) (Berbegal-Mirabent et al. 2015; Muscio et al. 2016) and employment conditions that permit academics to take leave to work with startups. High licensing income for inventors has been found to reduce the number of startups, possibly because it provides a less demanding source of income (Markman et al. 2004; Barjak et al. 2015). However, a European study that evaluated the effect of multiple policies on the establishment of startups found that the share of license income retained by inventors had a positive effect on the number of startups (Barjak et al. 2015).

\subsubsection{Policies, Practices, and Characteristics of KTOs}

The experience of the KTO, often estimated by the number of years that the KTO has been active, has a significant positive effect on many knowledge transfer outcomes (Friedman and Silberman 2003; Conti and Gaule 2011; WIPO 2011; Berbegal-Mirabent and Sabate 2015). The effect is due to a positive relationship between KTO age and institutional experience with knowledge transfer activities.

To be effective at knowledge transfer tasks, KTOs require highly skilled staff. Relatively low salaries, as noted in the case studies for Brazil and the Republic of Korea, can result in a failure to attract skilled employees. In addition, policies that do not permit KTOs to retain a percentage of license revenues can limit the ability of KTOs to offer benefits to staff.

Several of the case study countries provide regional or national KTOs or technology exchanges that can serve multiple public research organizations (China, Brazil, Germany). However, the preference of larger public research organizations is to retain their own KTO instead of using the services of a regional KTO. This suggests that proximity 
between a KTO and its institution is a strong advantage (see Chapter 4). This could be due to the ability of proximate KTOs to develop close working relationships with researchers and local firms.

\subsubsection{Policies, Practices, and Characteristics of Firms}

Two consistent results from the literature are that firms dislike rigid rules over IP and firm involvement in knowledge transfer from public research organizations increases with the firm's R\&D intensity (an indicator of technological capabilities) (Okamuro and Nishimura 2013; Maria et al. 2014; Kafouros et al. 2015). Okamuro and Nishimura (2013) also find that firm involvement with universities increases with the number of universities in a region, possibly because it improves the probability of a good match between the needs of firms and what universities can offer, or because greater competition between universities increases the flexibility of academic and KTO staff.

A major policy challenge is to create demand pull from firms, which requires firms with sufficient absorptive capacity to take an interest in public research inventions. Demand pull can be created through subsidies for R\&D and innovation activities within firms, subsidies to permit firms to hire trained graduates from public research organizations and to thereby interact with these institutes, such as the THRIPS program in South Africa, or subsidies for consulting, contract research, or collaboration with universities or public research institutes.

A second issue related to demand is ensuring that firms are aware of research projects and inventions developed in the public research sector. Several countries have established national technology exchanges for this purpose (e.g., China and Brazil), but the effectiveness of these exchanges appears to be limited. This could be because firms have many other methods of identifying interesting projects or capabilities, such as reading the scientific literature or searching patent databases. Alternatively, KTOs can publish relevant information that is oriented to the needs of local firms. Due to the importance of proximity in firm-university contacts, this could be an important complement to other sources of information used by firms.

\subsubsection{National versus Institutional Policies and Practices}

Knowledge transfer programs can be supported at the national level and at the institutional level. Munari et al. (2016), in an analysis of European 
programs at 125 KTOs to fund the gap between invention and the development of a commercially viable prototype, report a shift over time in national centralized programs to decentralized activities at the level of the institution or region, which then shifts back again to a centralized program. The authors suggest that centralization is high at the start of policies to initiate and encourage knowledge transfer activities, which are then replaced by local experimentation that builds on in-depth knowledge of the needs of local firms. Over time this is then replaced by further centralization to "refine and complement local initiatives with measures promoting critical mass and selectivity."

A similar pattern appears to have occurred in the United Kingdom (see Chapter 4). The 2009 UK survey of university academics found that academics in regional areas were more intensively involved in university-industry linkages than academics in the metropolitan regions and that teaching-oriented universities were also very active in these linkages (Zhang et al. 2016). However, a policy of using knowledge transfer for local economic development (supported by regional development authorities) was abandoned in 2010. This was followed by a shift to finding the highest bidder for university IP, no matter where located.

In many countries there is an unavoidable tension between a national goal to maximize income from IP and goals to use knowledge transfer to improve the competitiveness of domestic or regional firms (Kassicieh 2012; Rosli and Rossi. 2014). Until recently, the Republic of Korea explicitly followed a policy of encouraging universities to support the local economic development of SMEs, at the cost of reduced IP income (Lee and Shin 2017). SMART specialization platforms can help to overcome these problems by focusing on promoting regional strengths and providing mechanisms whereby firms can influence public sector research through demand pull. This can require an open knowledge exchange environment to assist in building effective relationships and for KTOs to actively support cocreation (Miller et al. 2016).

\subsection{Policies and Practices for Knowledge Transfer: Case Study Results}

Several of the case studies identify a common pattern: direct policies to support knowledge transfer were implemented to address one of the players in the knowledge transfer system without sufficient steps to ensure that all players could participate, including a failure to adequately address 
a knowledge gap between public research and firms. As a result, direct policies that increased the output of patented inventions in Brazil, the Republic of Korea, China, and South Africa were not matched by an equivalent increase in patent licensing. Over time, the mix of policies and practices were changed to address inadequacies in existing policies (China, Brazil, South Africa, and the United Kingdom), changing circumstances (Republic of Korea) and changes in political goals (United Kingdom).

\subsubsection{Brazil (Chapter 7)}

The Innovation Act of 2004 addressed the knowledge gap, a lack of incentives for public researchers to work with firms, and the need for knowledge intermediaries. It allowed the government to provide grants to firms to invest in innovation (thereby building capabilities) and created a framework for university-firm interactions, including the right for universities to sign exclusive licensing agreements with firms and provide staff with financial compensation. The Act also required all universities and public research organizations to have a KTO or use the services of a shared KTO. The Act appears to have increased university patenting. Between 2000 and 2012, Brazilian universities increased their share of total patents tenfold, from 0.38 percent to 3 percent. However, the Act had several flaws: it failed to provide sufficient funding to KTOs, required KTO staff to be public servants, and did not specify the specific mechanisms by which researchers could receive a share of license income for their patents. In 2016 the Act was replaced by a new Act that addressed many of the shortcomings of the 2004 Act, but it did not resolve the issue of financial incentives for university researchers.

\subsubsection{Republic of Korea (Chapter 6)}

The Government of the Republic of Korea established public research institutes in 1973. Since then, public research institutes have played a greater role than universities in public $\mathrm{R} \& \mathrm{D}$ and knowledge transfer. In the late 1990s, policies were introduced to improve the role of universities in knowledge transfer, culminating in the Technology Promotion Act of 2000, which required universities to have KTOs and shifted ownership of IP from the government or individual professors to KTOs. The number of KTOs increased from seventeen in 2003 to 263 by the mid-2010s. This generated a large increase in university patents, but little additional commercialization. The government has also tried to 
engineer a shift in the role of universities and public research institutes from supporting large firms to supporting knowledge transfer to SMEs. Large firms no longer required public research support because their own internal capabilities exceeded those of public research institutes.

The shift in the role of public research institutes to support SMEs and regional economic development has not succeeded due to the funding model for salaries of researchers. Financing is linked to the number of projects, which compels researchers to conduct many projects within a short period of time. The result is that projects are completed before a discovery reaches a level of development that is appropriate for SMEs. Given a large knowledge gap between public research institutes and SMEs, there is a need to make sure that new technologies are developed to the level of demonstrated prototypes in operational environments (technology readiness level 7).

In the late 2000s, the government made several further changes to the knowledge transfer system, by providing funding for universities to revitalize regional economies and by relaxing restrictions on exclusive licensing and permitting universities to license to foreign firms. KTOs were also instructed to obtain more information on the needs of firms in order to create demand pull. The government also increased the rate of funding for KTOs from 1.3 percent of research expenditures in 2010 to 3.3 percent in 2015, with the expectation of improving the skills and quality of KTO staff. To date there is little evidence that the policy revisions have paid off in an increase in commercialization via licensing. The share of total license income out of total R\&D expenditures for public research institutes and universities combined was 1.38 percent in 2009 and 1.35 percent in 2014 .

The example of the Republic of Korea suggests that government policy has lagged behind the needs of industry (public research institutes failed to maintain an optimal knowledge gap with both large firms and SMEs). Policy also appears to have dropped the focus on domestic industry in favor of increasing the amount of license income earned by public research institutes. This is an imperfect measure of successful knowledge transfer in a country where most licenses are based on lump sum payments instead of running royalties on the actual sales of products based on licensed inventions.

\subsubsection{China (Chapter 8)}

The patenting activity of Chinese public research organizations has increased substantially, but both patent applications and licensing are 
concentrated in a small number of research universities. The main barrier to licensing is low demand from domestic firms, suggesting a continuing knowledge capability gap. Half of licenses go to foreign-owned firms.

To address these issues, the 1996 law on knowledge transfer for universities and public research institutes was amended in 2015 to support the knowledge transfer capabilities of public research organizations and the technological capabilities of firms. Before 2015 the transfer of university IP had to obtain the approval of the Ministry of Finance, and income from knowledge transfer also went to the Ministry of Finance. The 2015 amendment gave full control of IP and related income to universities and public research institutes and allowed these organizations to give much larger financial incentives to researchers and KTO personnel. Other Chinese policies supported demand pull by involving firms in research cooperation with universities. Firms participate in 90 percent of national R\&D projects and lead approximately half of science and technology projects.

\subsubsection{South Africa (Chapter 9)}

South Africa has world-class universities that focus on leading-edge research. A substantial share of all research expenditures (24.5 percent) is for basic research as part of "Big Science." Research programs are primarily driven by academic interest. With the important exception of several industry-focused public research institutes that serve the petrochemical, pulp and paper, wine, and mining sectors and excellent linkages between university agricultural research and the agricultural sector, the South African research system is not designed to produce applied research of relevance to the majority of South African firms. A major challenge for knowledge transfer in South Africa is to improve the technological capabilities of South African firms outside of several sectors of excellence. Other challenges include shifting from a mode 1 to a mode 3 model for knowledge exchange on the part of public research organizations, for instance, by building closer relationships between firms and academics so that demand-pull influences are incorporated into research programs.

\subsubsection{United Kingdom (Chapter 4)}

The public research sector in the United Kingdom is dominated by universities, with 80 percent of research expenditures conducted by 
universities compared to a 20 percent share for public research institutes. Policies and practices for knowledge transfer in the United Kingdom have tracked academic research on how knowledge transfer occurs. Up until the early 2000s, practices followed the mode 1 model of a linear flow of knowledge from public research organizations to firms, with an emphasis on IP-mediated licensing. Currently, knowledge transfer is viewed as part of a "complex ecosystem of innovation characterized by collaboration and knowledge exchange among many actors" (Chapter 4). The importance of flexibility in negotiations between firms and universities is also recognized, with flexible policies on IP licensing, including the amount received by the inventor.

Policy for universities recognizes four types of knowledge transfer activities: commercialization (patenting, licensing, consulting, spinoffs), problem solving (collaborative research, contractual research, access to university facilities), people-based (conferences, invited lectures, enterprise education, etc.) and community-based (social enterprises, museums, public exhibits, open lectures, etc.). With the possible exception of community-based activities, all are relevant to the economic activities of firms. Universities vary in the depth of their activities in each of the four knowledge transfer activities, with teaching and regional universities more active in people-based and community-based activities and research-intensive universities more active in commercialization. This partly explains the high concentration of IP licensing. In fiscal year 2014-15, twenty-five universities produced 80 percent of university patent applications and twenty-seven universities earned 80 percent of contract income. In the late 2000s, IP income was approximately 3-4 percent of total income from all knowledge transfer activities.

KTO experience and learning over time has improved efficiency, with a decline in the number of patent applications since the mid-2000s to patents with a higher commercial potential. The quality of spinoffs has also improved, with an increase in the share that survive for three or more years. Demand-side policies include R\&D tax credits, Smart Programme grants to firms, the Small Business Research Initiative (SBRI) and support for venture capital.

\subsubsection{Germany (Chapter 5)}

Germany has a well-developed knowledge transfer system with clear delineations between public research institutes that specialize in basic research and public research institutes and universities of applied 
sciences that specialize in applied research of commercial interest to firms. Surveys of researchers from institutes that conduct applied research show that they give a high level of importance to knowledge transfer activities.

The German case emphasizes how knowledge transfer can form a functioning innovation system that can be difficult to change, due to the many actors and networks involved. Ownership of IP was changed in 2002 from the inventor to the inventor's institution to emulate the U.S. Bayh-Dole model. The switch was expected to increase the number of startups and patent applications by academics. Instead, up to 2008 the change in policy reduced the number of patents by university academics by 17 percent and had no effect on the number of startups (Czarnitzki and Licht 2017). These poor outcomes could be temporary effects that may dissipate after sufficient time to adjust to the new model. ${ }^{1}$

\subsection{Conclusions}

Over time, the conceptual model behind policies to support knowledge transfer has shifted from a mode 1 linear pipeline model to a mode 3 model that involves multiple actors in an innovation system, including different types of public research organization, knowledge intermediaries such as knowledge transfer offices, and private businesses. The mode 3 model recognizes the role of both supply-side activities on the part of public research and demand-side activities on the part of firms. A knowledge capability gap between public research and firms is required for public research results to be useful to firms, but too much of a gap will prevent firms from being able to acquire public research results, closing off demand. Current best practice recognizes that all actors in the system must have sufficient capabilities and incentives to participate in knowledge transfer activities including consulting, contractual research, collaborative research, and IP licensing.

Research finds that activities that create demand for knowledge produced by public research organizations, including both informal contacts and the participation of firms in contractual relationships with public research organizations, increases the probability of knowledge transfer and IP licensing. In addition, IP licensing can occur without any previous linkages

1 The inventor-owner model produced more spinoffs at Cambridge University, with a decline noted in spinoffs after Cambridge switched to university ownership of IP in 2005 (Chapter 4). 
between public research and firms. Nevertheless, knowledge transfer systems can benefit considerably from incorporating demand pull, for instance, by building close relationships between firms and research institutes to ensure that the needs of firms are included in applied research.

Best practice for public research organizations includes providing sufficient financial incentives and time for researchers to participate in knowledge transfer and to include knowledge transfer activities in career evaluations. Successful knowledge transfer can require researchers to expend considerable time on the process, from developing a patent application to working with firms or spinoffs to ensure follow-on development of an invention. KTOs need adequate financing to ensure that they develop sufficient expertise, the ability to hire and retain staff with a variety of necessary skills, incentives for successful transfer, and freedom to pursue a range of knowledge transfer activities, in addition to IP licensing. Firms must have the absorptive capacity to adapt and use knowledge and inventions to create product and process innovations. Best practice includes policy support for $R \& D$ and other innovationrelated activities and incentives for firms to work closely with public sector researchers for problem solving and commercialization.

A significant barrier to knowledge transfer in middle-income countries is the knowledge gap between the public research sector and firms. Overcoming this gap can require public research organizations to take inventions to the prototype stage or for public sector researchers to work closely with firms to assist follow-on development.

IP licensing is a minor but not unimportant part of knowledge exchange between public research and firms that facilitates knowledge transfer by protecting investments in follow-on research from imitation. It can also provide an additional funding stream for public research organizations, although this is likely to be a small share of total research expenditures. Best practice for IP licensing includes flexibility in drawing up IP contracts, negotiating skills on the part of KTO staff, and outreach activities to identify potential licensees. However, in many contexts, successful IP licensing is dependent on other good practices that support demand pull and research outputs that are relevant to the needs of firms.

\section{References}

Abreu, M., P. Demirel, V. Grinevich, and M. Karatas-Ozkan (2016). "Entrepreneurial practices in research-intensive and teaching led universities." Small Business Economics, 47: 695-717. 
Abreu, M. and V. Grinevich (2013). "The nature of academic entrepreneurship in the UK: Widening the focus on entrepreneurial activities." Research Policy, 42: 408-22.

Agiar-Díaz, I., N.L. Díaz-Díaz, J.L. Ballesteros-Rodríguez, and P. De Sáa-Pérez (2016). "University-industry relations and research group productions: Is there a bidirectional relationship?” Industrial and Corporate Change, 25: 611-32.

Arque-Castells, P., R.M. Cartaxo, J. Garcia-Quevdo, and M.M. Godinho (2016). "Royalty sharing, effort and invention in universities: Evidence from Portugal and Spain.” Research Policy, 45: 1858-72.

Baldini, N., R. Grimaldi, and M. Sobrero (2006). "Institutional changes and the commercialization of academic knowledge: A study of Italian universities' patenting activities between 1965 and 2002." Research Policy, 35: 518-32.

Barjak, F., N. Es-Sadki, and A. Arundel (2015). "The effectiveness of policies for formal knowledge transfer from European universities and public research institutes to firms." Research Evaluation, 24: 4-18.

Berbegal-Mirabent, J., D.E. Ribeiro-Soriano, and J.L.S. Garcia (2015). “Can a magic recipe foster university spin-off creation?” Journal of Business Research, 68: 2272-8.

Berbegal-Mirabent, J. and F. Sabate (2015). "Balancing basic and applied research outputs: A study of the trade-offs between publishing and patenting." Technology Analysis \& Strategic Management, 27: 1143-58.

Carayannis, E.G. and D.F.G. Campbell (2009). "'Mode 3' and 'Quadruple Helix': Toward a 21st-century fractal innovation ecosystem.” International Journal of Technology Management, 46: 201-34.

Chan, K.W., S.Y. Li, and J.J. Zhu (2018). "Good to be novel? Understanding how idea feasibility affects idea adoption and decision making on crowdsourcing." Journal of Interactive Marketing, 43: 52-68.

Chesbrough, H. (2003). Open Innovation: The New Imperative for Creating and Profiting from Technology. Cambridge, MA: Harvard Business School Press.

Closs, L., G. Ferreira, V. Brasil, C. Sampaio, and M. Perin (2013). "What motivates Brazilian academic researchers to transfer technology?" Journal of Technology Management and Innovation, 8: 79-90.

Conti, A. and P. Gaule (2011). "Is the US out-performing Europe in university technology licensing? A new perspective on the European Paradox." Research Policy, 40: 123-35.

Criscuolo P., L. Dahlander, T. Grohsjean, and A. Salter (2017). "Evaluating novelty: The role of panels in the selection of R\&D projects." Academy of Management Journal, 60: 433-60.

Czarnitzki, D. and G. Licht (2107)., Leveraging Public Research for Innovation and Growth: Germany. WIPO project report.

De Negri, F. and C.V. Rauen (2017). Leveraging Public Research for Innovation and Growth: Brazil. WIPO project report. 
Debackere, K. and R. Veugelers (2005). "The role of academic technology transfer organizations in improving industry science links." Research Policy, 34: $21-342$.

D'Este, P. and P. Patel (2007). "University-industry linkages in the UK: What are the factors underlying the variety of interactions with industry?" Research Policy, 36: 1295-313.

Friedman, J. and J. Silberman (2003). "University technology transfer: Do incentives, management, and location matter?" Journal of Technology Transfer, 28: 17-30.

Garengo. P. (2019). "How bridging organisations manage technology transfer in SMEs and empirical investigation." Technology Analysis and Strategic Management, 31: $477-91$.

Gibbons, M., C. Limoges, H. Nowotny, S. Schwartzman, P. Scott, and M. Trow (1994). The New Production of Knowledge: The Dynamics of Science and Research in Contemporary Societies. London: Sage.

Grimpe, C. and K. Hussinger (2013). "Formal and informal knowledge and technology transfer from academia to industry: Complementarity effects and innovation performance." Industry and Innovation, 20: 683-700.

Haas, M.R., P. Criscuolo, and G. George (2015). "Which problems to solve? Online knowledge sharing and attention allocation in organizations." Academy of Management Journal, 58: 680-711.

Hallam, C., B. Wurth, and R. Mancha (2014). "University-industry technology transfer: A systems approach with policy implications." International Journal of Technology Transfer and Commercialisation, 13: 57-79.

Hayer, C.S. (2016). "A trajectory of early-stage spinoff success: The role of knowledge intermediaries within an entrepreneurial university ecosystem." Small Business Economics, 47: 633-56.

Heder, M. (2017). "From NASA to EU: The evolution of the TRL scale in public sector innovation." Innovation Journal: The Public Sector Innovation Journal, 22: article 3.

Hughes, A. and M. Kitson (2012). "Pathways to impact and the strategic role of universities: New evidence on the breadth and depth of university knowledge exchange in the UK and the factors constraining its development." Cambridge Journal of Economics, 36: 723-50.

Kafouros, M., C. Wang., P. Piperopoulos, and M. Zhang (2015). "Academic collaborations and firm innovation performance in China: The role of region-specific institutions." Research Policy, 44: 803-17.

Kahn M. (2017). Leveraging Public Research for Innovation and Growth: South Africa. WIPO project report.

Kaplan, D. (2008). "South Africa's national research and development strategy: A review." Science, Technology and Society, 9: 273-94.

Kassicieh, S. (2012). "The case for a difference public sector intellectual property policy." Proceedings of PICMET '12: Technology Management for Emerging Technologies, IEEE. 
Kotha, R., G. George, and K. Srikanth (2013). "Bridging the mutual knowledge gap: Coordination and the commercialization of university science." Academy of Management Journal, 52: 498-524.

Lach, S. and M. Schankerman (2004). "Royalty sharing and technology licensing in universities." Journal of the European Economic Association, 2: 252-64.

Lee, K. and H. Shin (2017). Commercializing Knowledge from the Public Sector in Korea: Current Situation and Future Challenges. WIPO project report.

Lerner, J. (2005). "The university and the start-up: Lessons from the past two decades." Journal of Technology Transfer, 30: 49-56.

Libaers, D. (2012). "Time allocation decisions of academic scientists and their impact on technology commercialization.” IEEE Transactions on Engineering Management, 59: 705-716.

Lundvall, B.A. (1992). National Systems of Innovation: Towards a Theory of Innovation and Interactive Learning. London: Pinter.

Maria, B.F.I., F. Rossi, and A. Geuna (2014). "Collaboration objectives and the location of the university partner: Evidence from the Piedmont region in Italy." Papers in Regional Science, 93: S203-S206.

Markman, G.D., P.T. Gianiodis, P.H. Phan, and D.B. Balkin (2004). "Entrepreneurship from the ivory tower: Do incentive systems matter?" Journal of Technology Transfer, 29: 353-64.

Miller, K., R. McAdam and M. McAdam (2016). "A systematic literature review of university technology transfer from a quadruple helix perspective: Toward a research agenda." R\&D Management, $48: 1-17$.

Munari F., E. Rasmussen, L. Toschi, and E. Villani (2016). "Determinants of the university technology transfer policy mix: A cross-national analysis of gap-funding instruments." Journal of Technology Transfer, 41:1377-405.

Munari, F., M. Sobrero, and L. Toschi (2017). "Financing technology transfer: Assessment of university-oriented proof-of-concept programmes.” Technology Analysis and Strategic Management, 29: 233-46.

Muscio, A., D. Quaglione, and L. Ramaciotti (2016). “The effects of university rules on spinoff creation: The case of academia in Italy." Research Policy, 45: 1386-96.

Okamuro, H. and J. Nishimura (2013). "Impact of university intellectual property policy on the performance of university-industry research collaboration." Journal of Technology Transfer, 38: 273-301.

Ordanini, A., A. Parasuraman, and G. Rubera (2014). "When the recipe is more important than the ingredients: A qualitative comparative analysis (QCA) of service innovation configurations." Journal of Service Research, 17: 134-49.

O'Shea, R.P., H. Chugh, and T.J. Allen (2008). “Determinants and consequences of university spinoff activity: A conceptual framework.” Journal of Technology Transfer, 33: 653-66. 
Padilla-Meléndez, A. and A. Garrido-Moreno (2012). "Open innovation in universities: What motivates researchers to engage in knowledge transfer exchanges?" International Journal of Entrepreneurial Behaviour \& Research, 18: 417-39.

Ranga, M., S. Temel, I.M. Ar, R.B. Yesilay, and F.V Sukan (2016). "Building technology transfer capacity in Turkish universities: A critical analysis." European Journal of Education, 51: 90-106.

Rosli, A. and F. Rossi (2014). Explaining the Gap between Policy Aspirations and Implementation: The Case of University Knowledge Transfer Policy in the United Kingdom. CIMR Research Working Paper Series, Working Paper No. 20, Birbeck, University of London.

Shen, Y.-C. (2016). Identifying the Key Barriers of University-Industry Linkage in Taiwan. Paper presented at ISPIM Innovation Forum, Boston, March 13-16, 2016.

Siegel, D.S., D. Waldman D., and A. Link (2003). "Assessing the impact of organizational practices on the relative productivity of university technology transfer offices: An exploratory study." Research Policy, 32: 27-48.

Walsh, J.P. (2016). "Openness and innovation in the US: Collaboration form, idea generation and implementation." Research Policy, 45: 1660-71.

Walter, T., C. Ihl, R. Mauer, and M. Brettel (2013). "Grace, gold, or glory? Exploring incentives for invention disclosure in the university context." Journal of Technology Transfer, 38: 1-35.

Weckowska, D.M. (2015). "Learning in university technology transfer offices: Transactions-focused and relations-focused approaches to commercialization of academic research." Technovation, 41-42: 62-74.

WIPO (2011). "Harnessing public research for innovation - the role of intellectual property." In World Intellectual Property Report 2011: The Changing Face of Innovation. Geneva: World Intellectual Property Organization (WIPO). www.wipo.int/edocs/pubdocs/en/wipo_pub_944_2011-chapter4.pdf.

Zhang, Q., N.G. MacKenzie, D. Jones-Evans, and R. Huggins (2016). "Leveraging knowledge as a competitive asset? The intensity, performance and structure of universities entrepreneurial knowledge activities at a regional level." Small Business Economics, 47: 657-75. 


\section{Comment 10.1}

HENRI J.M. THEUN IS S EN

The current chapter studies how to successfully transfer knowledge from public research organizations to companies. Clearly, this depends, among other things, on the technological and related capabilities of firms and public research organizations, the gap between these capabilities, and the industrial structure of a country.

In this commentary I would like to provide some insight on the basis of my experience in the past in science, business and valorization at the University of Maastricht and the Brightlands Maastricht Health Campus.

Valorization is a term that is used in the Netherlands and some other countries to indicate the process through which knowledge from academic institutions is made available and relevant to society. In our practice, we attempt to translate this knowledge in the form of licenses, spinoffs and alliances with companies, or a combination of these. In fact, a license is always provided to the company, be it a spinoff of the university itself or a third party (i.e., a company not affiliated to the university). In this respect, licensing is crucial to the knowledge transfer process. It may be given either as a "standalone" asset in the form of a licensing agreement or in the context of a broader collaboration agreement.

The decision whether to grant a license to an already existing company or to a yet-to-be-established spinoff of the university is taken based on many factors, such as the mere availability of a licensee, bargaining power, match between the parties, preferences of stakeholders at the university and the valorization office, the nature and maturity of the technology, etc. The overriding argument is, however, the estimated overall probability of success that the technology will actually get to market in favor of customers or - in our case - patients. Hence, in principle, we would prefer to license our IP to firmly established companies that would develop the technology to maturity and bring it to 
market, while we receive a reasonable return on our investment in the research and the IP ensuing from it.

However, the chance of finding such a perfect licensee is slim, and, in practice, we have seen only a few such examples. This may be related to the subject of the science and the licensing opportunities that emerge from our knowledge institution. Indeed, we have in the past generated relatively few technology platforms, let alone ones that are able to generate products, such as monoclonal antibodies for therapy. That situation is gradually changing and hence may result in more straightforward licensing deals. Instead, the most frequent form of valorization of IP occurs via licensing to our own spinoff companies.

Having said this, we would very much like to increase our performance in terms of licensing to companies. There are many activities one might undertake to enhance the probability that companies would license our IP, such as putting even more effort into showcasing our opportunities, e.g., via websites, portals, and other marketing tools.

One aspect that makes straightforward licensing difficult is tacit knowledge. It often occurs that there is a long scientific and maybe even business history behind an emerging licensing opportunity. The moment the company is asked to have a look at the opportunity there is a huge lack in knowledge, understanding, and experience with the matter at hand. This seriously hampers the closing of a deal based on just one piece of information (i.e., the IP or the patent). In my daily practice at the company I worked for, I never licensed any isolated piece of IP from an academic partner outside the realm of an established collaboration. Also, besides the tacit knowledge issue there is yet another very practical problem: if a company scientist tells management that the IP at hand is interesting and should be licensed, it implies a risk that external technology may be better than their own and that the latter may be abandoned!

Based on my previous experience in the pharma industry, I believe that establishing an alliance with an industrial partner is the preferred route toward effective IP licensing. This would then be a separate paragraph in the collaboration agreement in which the company has an option to license or even acquire IP emerging from the collaboration. This would enable the company to develop and sell products covered by that IP. This should give the company sufficient comfort to use the results from the collaboration for their benefit.

It goes without saying that such an arrangement would require a reasonable return for the knowledge institution. Depending on the nature and value of the IP and the preference of the partners, this could 
be in the form of (additional) sponsored research or upfront, milestone, or royalty payments. In practice, it turns out that royalties are sometimes a no-go for companies. This is the most cumbersome part of the negotiation, as it directly affects product margins. However, it is reasonable as well as realistic to address this issue during negotiations. Both parties should make an effort to discuss this matter in good faith. Also, they should keep in mind that IP is a means, not a goal, and therefore should be treated with proportionate priority, especially when it comes to early IP emerging from an academic collaboration.

It is important that the inventor of the IP and their department gets a fair share of the return made on IP revenues. In our institution we split any revenues from IP in three equal parts, i.e., a third each for the inventor(s), department(s) and the valorization organization itself. Such an incentive is important to motivate scientists to go the extra mile, often after daily work or at the weekend. At the same time, it is a great deal for the department as well, as revenues are spent on new research that, once again, could generate novel IP.

Even though I have described the experiences and practices that we have at our institution in the Netherlands, I believe that the main issues that I have mentioned are similar in many other developed countries. The operational implementation of these issues and policies will, however, be different from one country to another. In any case, the overall guiding principle is that IP is a major driving force for valorization, knowledge transfer, and innovation across the globe! 


\title{
Comment 10.2
}

\author{
KERRY FA UL
}

South Africa (the "Rainbow Nation") is a vibrant dynamic country of 57 million people speaking at least one of the eleven official languages, spread across nine provinces. It is a country rich in natural resources with a number of well-established industries, including mining, manufacturing, and agriculture, with strong financial, transport, and communication infrastructure but with significant weaknesses in areas of labor, health, and primary education. South Africa is strongly characterized in our National Development Plan (NDP; Vision for 2030) by the three permeating challenges of unemployment, inequality, and poverty. The NDP acknowledges that science and technology, and, indeed, innovation are a means to "fundamentally alter the way people live, connect, communicate, and transact, with profound effects on economic development," with "the ability to innovate and learn by doing by investing public funding to help finance research and development in critical areas" being required. Public research institutes and universities are integral in the approach to address a number of the challenges experienced, not just as a third stream of income for the public research institute or university but also as a combination of commercialization and utilization of research results for societal benefit. South Africa experienced the same global trend in that it required a policy intervention to shift the focus at our public research institutes and universities from pure academia and teaching to knowledge transfer. In South Africa, it was the impetus of the Intellectual Property Rights from Publicly Financed Research and Development Act (IPR Act; No. 51 of 2008) that mandated the shift from "publications" to "innovations."

There is no doubt that a critical intervention that can be classified as a direct means of facilitating knowledge transfer was the legislative provision for support, including in financial terms, for the establishment of Offices of Technology Transfer. Through the "Office of Technology 
Transfer (OTT) Support Fund" the salaries of individuals within the offices are paid for by the South African government, through the National Intellectual Property Management Office, for a three-year period, giving the institution an opportunity to motivate staff for these positions to be included on their payroll thereafter. Should they not succeed, the government steps in again to ensure that capacity is not lost and provides funding for a further three-year period, but this time on a sliding scale. The funding under the OTT Support Fund also provides a ring-fenced budget for training such as licensing, technology evaluation, and later valuation, as well as marketing techniques and tips, and most recently has been expanded to now support knowledge transfer-related activities, such as IP audits, business case development, techno-economic feasibility analyses, etc. A survey conducted in 2014 and to be run every five years revealed that the South African system has just over 100 full-time equivalents and that the level of outcomes from each OTT was directly proportional to the experience of the individuals within the office.

The growing capacity at institutions has, however, been overshadowed by the "pushback" received from both academia and, in particular, industry, due to the fundamental changes the legislation brought about. For the first time, academics are now being held, to some extent, accountable for the outputs of publicly financed research and development. The impact of new legislative framework on formal knowledge transfer between academia and industry was significant as the IPR Act prescribes who owns the intellectual property. As such, industry is no longer able to instruct an institution and pay a portion of the costs and walk away with the intellectual property. The so-called default position is "s/he who creates shall own" as opposed to having the option to contractually own all IP created. This shift necessitated an effective changemanagement strategy as industry balked at instructing institutions to do research on their behalf amid the uncertainty of who would own and have access to the resulting intellectual property, and worries over whether industry would be held to "ransom," so to speak. Informal communications have revealed that the more experienced the knowledge transfer professionals, the more willing researchers are to work with them and the more productive the relationships with industry partners are. In addition, these relationships are often made or broken depending on how nimble the institution is in processing disclosures and concluding research collaboration agreements, for example. A reputation for "doing the deal" versus "making as much money as possible" also appears 
to strongly impact on the success of an OTT and the strength of the relationships built with the industry partner. This is evident in that one might put all the right direct support into the system, but if the indirect knowledge transfer channels are not operational or optimal, the ability to move the technology into the market or public space is negatively impacted.

Nine years later, the implementing office, NIPMO, continues to "demystify" the IPR Act to players across the triple helix as a critical intervention to assisting everyone to understand the clear framework that the IPR Act establishes.

In spite of these challenges, which are typically anecdotal, hence subjective, and can only be measured qualitatively, a quantitative analysis of the inputs, outputs, outcomes, and early impacts of the publicly financed research and development system in South Africa, a subset of the National System of Innovation, shows some positive upward trends. Over the period 2008 to 2014 there has been an increase in the outputs in the form of the number of disclosures received by knowledge transfer offices at institutions and an increase in the number of patent applications filed. When normalized against research and development expenditure, the increase in the outputs outstrips the growth in the inputs, namely, research and development funding. Furthermore, the conversion of these outputs into outcomes, namely, licensing arrangements or spinoff companies also increased over the period, albeit from a low base. In line with the vision of the NDP, employment is being realized with a doubling in the number of full-time equivalents employed by these SMMEs between 2008 and 2014.

As with any partnership or collaboration (or any other synonym), the core determinant of the success and longevity of the relationship depends, almost solely, on trust and a sound almost watertight contract. It is clear that over time, increases are observed in a number of formal knowledge transfer metrics, but it is the informal knowledge transfer metrics that are at the core. What is encouraging is the increase observed in the level of awareness and understanding about intellectual property and the associated rights among academia, industry, and within government. As we are enveloped by the so-called fourth industrial revolution, the role of government to fund highly risky technologies in our public research organizations will come to the fore again, providing the platform for, when they are ready, industry partners to step in and, in the words of Professor Mariana Mazzucato, "roar"! With 
the baseline now established in South Africa, time will tell whether we are indeed able to achieve critical mass in the system and thereby harness the public research system to bring innovation solutions to local problems in an emerging economy sitting at the end of the African continent. 


\title{
Policy Recommendations
}

\author{
Aiming for Effective Knowledge Transfer Policies \\ in High- and Middle-Income Countries
}

SUMA ATHREYE AND FEDERICA ROSSI

\subsection{Introduction}

Policy interventions supporting the transfer of knowledge from public research organizations, including universities and public research institutes, to industry, have been adopted in many countries around the world since the 1980s. This has led to a marked convergence in policies supporting knowledge transfer from the public science base in different countries. However, implementing similar policies in different innovation systems is full of pitfalls. Drawing on the six case studies in this book, which range from high- (United Kingdom, Germany, Republic of Korea) to middle-income countries (China, Brazil, South Africa), we show that, because the innovation systems in these countries were different, the implementation of similar knowledge transfer policies was supported by different sets of complementary polices. In fact, many middleincome countries were forced to compensate for institutional deficiencies with supporting policies that differed from those adopted by highincome countries.

In this chapter, we identify the different sets of complementary knowledge transfer policies implemented in high- and middle-income countries, evaluate their implications for the success of knowledge transfer processes, and develop policy recommendations. Briefly, we show that in high-income countries with mature national innovation systems, patterns of interaction between university and industry already existed, and the policy convergence merely incentivized the rearrangement of outcomes in the vector of possible outcomes that was outlined in Chapter 2. Thus, commercialization through patent licensing in Germany and the 
United Kingdom often replaced other established knowledge transfer channels. The policy challenge in these economies is to ensure all channels of knowledge transfer are appropriately nurtured. In middle-income economies, where patterns of interaction with industry are still developing, policy convergence needs a different set of complementary measures to succeed, which include incentives to researchers, changing the legal structure of university incomes to allow academics to earn income from consultancy and the use of public research institutes. These measures compensate for structural differences/deficiencies in national innovation systems. Identifying the appropriate complementary measures is therefore crucial for the success of knowledge transfer policy in both high- and middle-income economies.

As the international convergence of policies in support of university patenting and licensing through the allocation of intellectual property (IP) rights to universities was strongly inspired by US policy, we first revisit the case of the United States of America (U.S.) We then use the six case studies in this book to describe the process of convergence of knowledge transfer policies and the reasons for the substantial differences between the paths followed by the high- and middle-income countries. We highlight the different innovation systems in which these interventions were implemented, the different shapes that these interventions took, and why convergence in policy outcomes and in the overall knowledge transfer systems of these countries has not yet been reached. Finally, we conclude with implications for policy and further research.

\subsection{New Policies in Support of Knowledge Transfer from Public Science}

\subsubsection{The U.S. as a Model for Policy}

One of the most visible policy interventions in support of knowledge transfer to industry was the US Federal Government's implementation of the Bayh-Dole Act in 1980 (Mowery and Sampat 2005). As noted in Chapter 1, although this piece of legislation was not the first attempt by governments to regulate university IP - Israel had introduced university IP policies in the 1960s and the US government had already experimented with giving seventy universities the right to patent federal government-funded inventions since 1968 - the Bayh-Dole Act of 1980 was the most influential. The Act granted universities ownership of the IP emerging from their staff s federally funded research, which previously 
used to lie with the US Federal Government. The rationale for this move was to improve the commercialization of research findings by moving the ownership of the IP closer to the researchers and institutions involved and away from distant government offices. Sampat (2009) notes that the most commonly cited justification by proponents of Bayh-Dole-type legislation worldwide is that very few government-owned inventions were commercialized in the U.S. before 1981. For example, in a letter to the prime minister, arguing for an Indian Bayh-Dole act, the National Knowledge Commission noted:

In the United States, before the Bayh-Dole Act was enacted, the country's federal agencies owned about 28,000 patents, out of which only $5 \%$ were licensed to industry to develop commercial products (Pitroda 2007, as cited in Sampat 2009)

Policymakers were also concerned that unpatented university discoveries at an early stage of development would not be taken up by industry unless a patent provided firms with an incentive to invest in additional research for their commercialization (Berman 2008; Kenney and Patton 2009). Hence, Bayh-Dole was designed to encourage commercialization, particularly through permitting exclusive licensing and preferential access to public science for SMEs (Schacht 2005). However, the requirement to give preference to small businesses does not seem to have had much of an effect and may have been revised at a later date.

The years following the implementation of the Bayh-Dole Act saw the emergence of several blockbuster patents bringing very high economic returns to the institutions that owned them. One of these was the CohenBoyer patent (1980-97) for recombinant DNA, which during its seventeen-year term earned Stanford University USD 254 million (90 percent of which came from royalties on product sales), was licensed to 468 companies and used in 2,400 products (Feldman et al. 2005). Another example was the Axel patent for rDNA in mammalian cells, which earned Columbia University and its inventors USD 790 million (Colaianni and Cook Degan 2009). Yet another was the exclusive license for the drug Taxol given by the National Institutes of Health (NIH) and Florida State University to Bristol-Myers-Squibb (BMS). Florida State University earned more than USD 200 million in royalties from BMS (Powers 2006).

It is very likely that these very high-profile examples, combined with the general perception of the US national innovation system as being particularly successful in the development of advanced technology, inspired policymakers in other countries to implement similar policies. 
Graff (2007) notes that several countries, including India, Brazil, South Africa, Malaysia, and Jordan, debated or passed legislation modeled on the US Bayh-Dole Act.

The success of the Bayh-Dole legislation in the U.S. masks the fact that Bayh-Dole did not happen in isolation but was nested in a broader policy mix that aimed to transfer knowledge from the science base to industry. Block (2008) argues that the U.S. has been engaged since the 1970s in the creation of a "developmental network state" whose aim is to facilitate the translation of fundamental research into cutting-edge technologies. It has done so through the deployment of a broad range of interventions supporting the transfer of knowledge between university and industry, both on the "supply side" and also, very importantly, on the "demand side" (see also Bozeman 1994). Supply-side policies encouraged federal laboratories to engage with state and local government, universities, and private industry (Stevenson-Wydler Technology Innovation Act, 1980; Federal Technology Transfer Act, 1988). These policies also supported the formation of university research centers focused on translational research (Engineering Research Centers, 1985) as well as centers diffusing technologies developed by the Department of Defense to small firms (Defense Industrial and Technology Base Initiative, 1991). Complementary demand-side policies, by contrast, provided matching grants to firms investing in the commercialization of new technologies (Advanced Technology Program, 1988), earmarked a share of the budget of federal laboratories to support the research efforts of small firms (Small Business Innovation Development Act, 1982), encouraged collaborations between small firms and universities (Small Business Research and Development Enhancement Act, 1982), and incentivized firms' adoption of advanced technologies (Manufacturing Extension Program, 1988). Nevertheless, these additional interventions have not figured prominently in the mainstream policy discourse (Block 2008).

Equally important to note is the lack of any consensus on what created successful knowledge transfer in areas such as Silicon Valley. Along with the importance of particular universities, attention has also focused on other aspects of the innovation system, namely, the presence of superstar scientists who drew firms into their regions (Zucker et al. 1998), the presence of knowledge networks and conducive regional systems of innovation (Storper and Walker 1983; Saxenian 1994), and the role of diasporic labor and their transnational links (Saxenian 2007) that allowed nascent small-scale technological experiments in multiple locations and 
the smooth scale-up of successful innovations without running into labor and material shortages. These factors lurk in the background of the explanations of US Bayh-Dole successes, but are notable by their absence in other parts of the world.

\subsubsection{Convergence of Knowledge Transfer Policies}

Bayh-Dole-inspired legislation has been progressively implemented around the world since the early 1990s and particularly during the 2000s. In continental Europe - where there was a diversity of ownership arrangements for public sector science - most countries switched to university ownership between the mid-1990s and 2010 (Geuna and Rossi 2011). Early adopters of the university ownership system, such as Switzerland, the United Kingdom, France, and Spain, began to enforce it stringently from the 1990s. In other countries - Germany, Austria, and most of Scandinavia - the switch in university ownership was from a previous system of "professor's privilege," where academics owned the IP rights to their inventions and were able to dispose of them freely. Cambridge University, which had maintained a professor's privilege system, finally switched to university ownership in 2005. Currently, in Europe, only a few cases of inventor ownership systems remain - Sweden being the clearest example. Italy has a system combining aspects of both. Countries in the former Eastern bloc - Hungary, the Czech Republic, Slovakia, Slovenia, Poland - also switched to university ownership from a previous system of government ownership. The Republic of Korea, having broken into the group of high-income countries in the 1990s, has implemented Bayh-Dole-type policies since 2000.

Despite the overarching convergence to Bayh-Dole, university ownership systems have been implemented in different ways. For example, there are differences in the vesting of IP rights in the university: in some countries, the university is the first owner of the IP, while, in others, the IP is owned by the inventor, and the university has the right to claim it if it is not used within a certain period, or vice versa, the university has a time limit within which it has the right to claim ownership of IP, after which it reverts to the inventor. The scope of the policy also differs: in some countries, all inventions produced by academics fall under university ownership, while, in others, there are distinctions depending on whether the invention was developed in the course of their normal employment or outside it (see DLA Piper 2007, for a detailed analysis of the different systems).

The three middle-income countries considered in this book also followed the pattern of convergence to Bayh-Dole popular in Europe. 
However, as shown in Table 11.1, policy changes were implemented beyond the vesting of IP ownership rights in the university. Laws were passed to allow universities to license IP and to profit from it by allowing them to receive incomes from royalties. Universities were also obliged to compensate the inventor with a share of royalties. Brazil, China, and South Africa, which had previously limited the extent to which universities and public research institutes were permitted to engage with industry, began to relax these rules to allow universities much greater freedom of action. Laws were also passed so that public universities were given greater freedom to contract with industry, to establish spinoffs, and to allow academics to take leave of absence in order to engage in commercialization activities in their own or another firm.

More detail on the regulations that underpinned these changes in other middle-income countries is presented in WIPO (2011: Chapter 4) and in Zuniga (2011). This shows that the Bayh-Dole-inspired legislative reforms implemented in each country were usually a distinct package (e.g., in terms of the specific rules on the scope of university patenting, invention disclosure, incentives for researchers, and whether certain safeguards were instituted to counteract the potentially negative effects of patenting). Therefore, as argued in Chapter 1, what we term convergence to BayhDole was never a process of countries making simple binary choices with respect to institutional or individual patent ownership, but one with significant differences in the features of the whole package of policies.

Yet, in all cases, this new policy framework was justified by a "lack of commercialization of public research" argument: the idea that national universities in all countries produced good-quality research, which stayed locked up in ivory towers and which they failed to commercialize sufficiently. In other words, the problem was framed as one of lack of interaction between university and industry, which needed to be corrected by implementing changes in legal ownership rights and in incentives to encourage interaction between the actors in the system. As Arundel points out in Chapter 10, an absence of interactions between university and industry could also be caused by the failure of industry to "demand" knowledge from universities.

\subsection{Different Innovation Systems and Different Policy Mixes}

Chapter 2 detailed six different types of knowledge transfer channel from the public science base to industry. These ranged through research publications; conferences seminars and meetings with industry; 
Table 11.1 Convergence of knowledge transfer policies

\begin{tabular}{|c|c|c|c|c|c|c|c|}
\hline & $\begin{array}{l}\text { University } \\
\text { can own IP }\end{array}$ & $\begin{array}{l}\text { University } \\
\text { has right to } \\
\text { license IP }\end{array}$ & $\begin{array}{l}\text { University } \\
\text { can retain } \\
\text { royalties } \\
\text { from IP }\end{array}$ & $\begin{array}{l}\text { University } \\
\text { must com- } \\
\text { pensate } \\
\text { inventor } \\
\text { for IP }\end{array}$ & $\begin{array}{l}\text { Universities } \\
\text { can contract } \\
\text { with industry }\end{array}$ & $\begin{array}{l}\text { University } \\
\text { can establish } \\
\text { spinoffs }\end{array}$ & $\begin{array}{l}\text { Academics } \\
\text { can take leave } \\
\text { of absence to } \\
\text { work in } \\
\text { spinoffs }\end{array}$ \\
\hline UK & Yes (1948) & Yes & Yes & Yes & Yes & Yes & Yes \\
\hline Germany & Yes (2000) & Yes & Yes & Yes & Yes & Yes & Yes \\
\hline $\begin{array}{l}\text { Republic of } \\
\text { Korea }\end{array}$ & Yes (2000) & Yes (2000) & Yes (2000) & Yes (2000) & Yes & Yes (2003) & Yes \\
\hline China & Yes (2002) & Yes (2015) & Yes (2015) & Yes (2002) & Yes & Yes & Yes (2016) \\
\hline Brazil & Yes (1996) & Yes (1996) & Yes (2004) & Yes (1996) & Yes (2004) & Yes & Yes \\
\hline South Africa & Yes (2008) & Yes (2008) & Yes (2008) & Yes (2008) & Yes & Yes & Yes \\
\hline
\end{tabular}

Source: Authors

Note: In parenthesis, we report the year in which the law allowing the activity above was enacted (in cases without a date, this means that there was no previous prohibition against the activity). 
education and training of students/researchers recruited by the private sector; consultancies and contract innovation research (including university-industry joint research projects, joint research centers, and $\mathrm{PhD}$ projects); creation of IP for licensing; and creation of spinoff companies. A striking feature of knowledge transfer from the science base in middleincome countries lies in the fact that the last two forms of knowledge transfer are negligible and occur very rarely. This is clear from the country studies. One could, of course, argue that IP licensing and spinoff companies account for very small shares of overall university incomes even in high-income economies (see, for example, Chapter 4 and the evidence in WIPO 2011). This suggests in turn that the proportion of formal to informal knowledge transfer may not be the main indicator that sets high- and middle-income countries apart.

It is, of course, apparent that the institutional frameworks within the six country case studies (where Bayh-Dole-type measures were implemented) were very different. Further, none of these contexts (and set of packages) was similar to that of the U.S., the model that they appeared to be inspired by and aspired to. Some of the key differences between the six countries' innovation systems are summarized in Table 11.2, based on the country chapters and data in Chapter 1 . The first key difference is that firms' R\&D engagement is higher in high-income countries than in middle-income countries, as noted in Chapter 10. Interactions between public research and industry, and universities' research intensity, are also higher in high-income countries than in middle-income countries. The importance of public research institutes versus universities is variable. The Republic of Korea is a fascinating case as it presents some features that are intermediate between the two groups. Here, collaborative R\&D between public research institutes and private firms has been the most important and effective form of breaking into the higher-end segment of the industry (Lee et al. 2005; Lee 2013), whereas interactions between universities and industry have been low, although this has been changing since the 1990s.

The detailed case studies in this book, situated in a historical perspective, help us to appreciate the often overlooked point that what sets highand middle-income countries apart are that their innovation systems, and, more particularly, the system of production and transfer of knowledge between university and industry are quite different. In wellfunctioning high-income economies there are two-way flows of ideas and people between the university and industrial sectors. In middleincome economies, there is a healthy flow of people between universities 
Table 11.2 Differences between the national systems of innovation of six high-and middle-income countries

\begin{tabular}{|c|c|c|c|c|}
\hline & $\begin{array}{l}\text { Firms' R\&D } \\
\text { engagement }\end{array}$ & $\begin{array}{l}\text { Interactions } \\
\text { between pub- } \\
\text { lic research } \\
\text { and industry }\end{array}$ & $\begin{array}{l}\text { Importance of } \\
\text { research from } \\
\text { public } \\
\text { research insti- } \\
\text { tutes vs } \\
\text { universities }\end{array}$ & $\begin{array}{l}\text { Universities' } \\
\text { research } \\
\text { intensity }\end{array}$ \\
\hline UK & High & High & Low & High \\
\hline Germany & High & High & Medium & High \\
\hline $\begin{array}{c}\text { Republic of } \\
\text { Korea }\end{array}$ & High & High & High & Medium \\
\hline China & Low & Low & High & Low \\
\hline Brazil & Low & Low & Medium & Low \\
\hline South Africa & Low & Low & High & Low \\
\hline
\end{tabular}

Source: Authors

Note: The table builds on information provided in Chapter 1 and in the six country studies presented in this book and refers to the period considered in them. In most cases, firms' $\mathrm{R} \& \mathrm{D}$ engagement is measured in terms of $\mathrm{R} \& \mathrm{D}$ expenditure or $\mathrm{R} \& \mathrm{D}$ and patenting intensity of domestic firms. Interactions between public research and industry are measured in terms of firms' licensing of university patents and business funding of university research. Publications per academic are the most commonly used indicator of a university's research intensity.

and industry, but channels to establish a flow of ideas are very underdeveloped, and public research institutes are prominent as they bridge the gap between frontier science and its application to domestic industrial conditions. Thus, the success of Bayh-Dole-type policies in these economies needs to be judged not only by the vector of knowledge transfer outputs but also by the impetus that the legislation provided for establishing channels through which new ideas, emerging in universities, could find direct application in the industrial sector, without necessarily involving public research institutes in an intermediate role.

The stress in this chapter on links for people and ideas is thus complementary to the discussion of formal and informal channels of knowledge exchange outlined in Chapter 2. Formal methods of knowledge transfer and commercialization identified in that chapter are likely to require the institution of legal arrangements that favor the movement of ideas, while 
the movement of people is likely to favor more informal methods of knowledge exchange.

\subsubsection{High-Income Countries}

As noted in Chapter 1, high-income countries are characterized by high private expenditure in $\mathrm{R} \& \mathrm{D}$, with numerous large firms that employ R\&D staff and possess a high absorptive capacity for new technological knowledge and thus are able to interact with universities. In these countries, the university system is also highly developed, with many research-intensive universities. Although public research institutes are more (e.g., Germany, Republic of Korea) or less (e.g., United Kingdom) present in the system, in all cases, they are not the only source of research in the country: universities also play a prominent role. The Republic of Korea is slightly different from Germany, as public research institutes, although highly research-intensive, deal exclusively with large domestic firms and have struggled to establish links with smaller companies.

When the knowledge ecosystem is well developed we see two-way links between public research institutes, universities, and firms, as shown in Figure 11.1. The first link is through the movement of people, shown by the solid lines. Students may move to placements in firms and continue to collaborate with their former professors. Equally, managers of firms may draw on expertise in their alma mater to solve technical problems in the firms they are employed in. Similarly, public research institutes may invite secondments, allow the use of their R\&D labs, and develop joint R\&D projects. These people links, based on both institutionalized and interpersonal links, are distinct from arms' length transactions in technology and ideas through formal knowledge transfer.

The formal links, shown by the dashed lines in Figure 11.1, are likely to be based on the issue of patents, technology contracts, or equity investments. Patents are likely to be preferred in the case of mature, codifiable technologies, where licensing is a viable option because buyers can understand the technology quite readily (although evidence suggests that very often scientists who develop patented inventions continue to collaborate with licensing firms through consulting contracts, in order to support the implementation of the licensed technology; Thursby et al. 2001). Equity investment in spinoffs may make sense in the context of early-stage technologies, which cannot be easily codified and may need joint development with firms. 


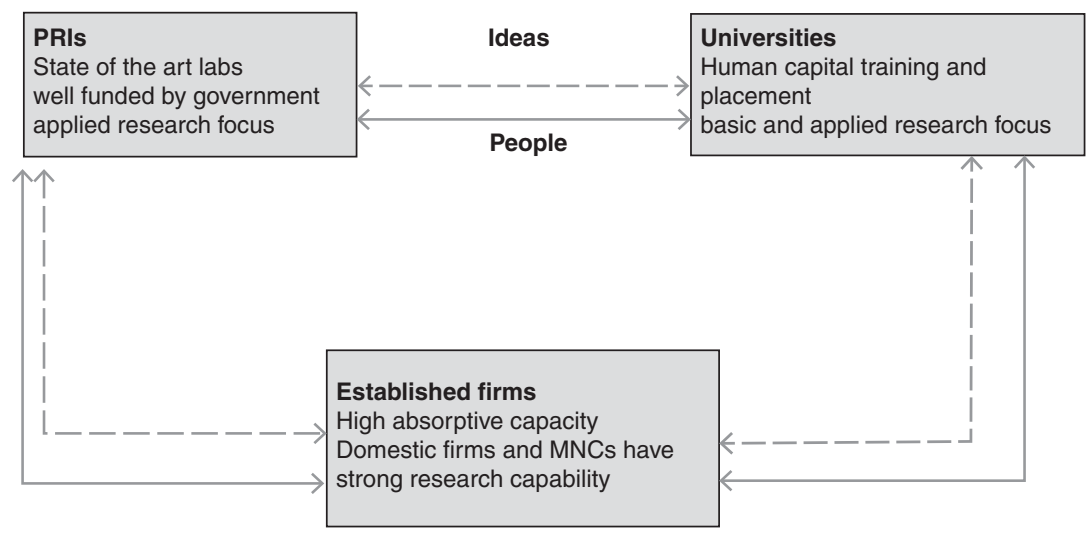

Figure 11.1 The knowledge ecosystem in high-income economies

In high-income economies, due to the presence of $\mathrm{R} \& \mathrm{D}$-intensive domestic firms and multinational corporations (MNCs) and of researchintensive universities and public research institutes (see also Chapter 10), both people and ideas circulate relatively frequently, through both institutionalized channels and well-established interpersonal relations. Indeed, for these countries, the assumption that a lack of interactions required new institutions was probably misleading. Certainly in Germany (see Chapter 5), there was not a lot of university patenting, and universities were not generating income from IP licensing, but a lot of knowledge transfer was happening without requiring university patents. Professors often collaborated directly with industry, either informally or through research contracts, and ceded their IP rights to their collaborating firms, which then patented the resulting inventions. Hence, although German universities owned few patents, professors often figured as inventors of industrially owned patents, a pattern that was present in most of continental Europe (Lissoni et al. 2008; Geuna and Rossi 2011).

The United Kingdom was an intermediate case, since it never had the professor's privilege and the IP rights to academic inventions belonged to the university, which initially ceded them to a central agency tasked with research commercialization, the British Technology Group. In spite of some successes (e.g., successful commercialization of the technology behind hovercrafts and magnetic resonance imaging), this approach did not lead to a large amount of commercialization: outside the medical sector, academics' interactions with industry were mostly either informal 
or focused on research contracting. Cambridge, which maintained a system of professor's privilege until 2005, saw intense involvement of professors in the development of spinoff companies, some of which spawned very large firms, particularly in ICT, which eventually generated a local high-technology cluster (Athreye 2004).

In the Republic of Korea, large firms were strong investors in $R \& D$ and had a very strong relationship with the government (chaebol system). Public research institutes played a greater role than universities in public $\mathrm{R} \& \mathrm{D}$ and knowledge transfer in the process of catch-up.

In these countries, characterized by preexisting strong interactions between universities, public research institutes, and firms, the introduction of Bayh-Dole-type legislation could disrupt as well as enhance interactions. In German-speaking and Scandinavian countries, as well as in Cambridge pre-2005, patents were owned by inventors, so the introduction of BayhDole-type legislation brought the patenting process further away from inventors; exactly the opposite of what had happened in the U.S., where patents were already owned by the Federal Government so the change brought the patenting process closer to inventors (Mowery and Sampat 2005). As a result, this process could disrupt existing relationships - which had developed in harmony with a system where inventors held IP rights rather than enhance them. Indeed, Chapter 5 argues that this is what happened in Germany, where, up to 2008, the change in policy reduced the number of patents by university academics by 17 percent and had no effect on the number of startups.

In the United Kingdom, which already had a system of university ownership for many universities, universities' obligation to commercialize their patents through the British Technology Group was removed in 1985. Since then, most universities have set up internal knowledge transfer offices (KTOs) dealing with commercialization activities. Given that in the United Kingdom individual academics could not dispose of their IP freely, most collaborations with industry already occurred with some involvement of the university institution, and there is little evidence of displacement effects. However, there is evidence that the increase in university patenting did not lead to the expected increase in licensing income, with licensing income concentrated in a few universities (see Chapter 4). ${ }^{1}$ There are signs of a decline in university patenting in recent years as universities are becoming more selective in which patents they pursue (Tang et al. 2010).

${ }^{1}$ Cross-country evidence in WIPO (2011) shows that in many countries only a handful of universities accounted for the bulk of the commercialization activities. 


\subsubsection{Middle-Income Countries}

In contrast to high-income countries, middle-income countries are characterized by a low number of R\&D-intensive firms, with the majority of domestic companies performing very little research and possessing low absorptive capacity, as discussed in Chapter 1. The few companies that perform R\&D tend to be MNCs, or companies that are partly government owned (e.g., the Brazil country study noted that 80 percent of patents generated in the country have nonresident applicants). These countries also tend to have a strong division of labor in knowledge production, with universities concentrating on basic research and the training of students, while public research institutes are tasked with adapting frontier research to the needs of industry and government. The data in Chapter 1 also show that in middle-income countries most research is performed in public research institutes funded by and responding to the government.

Figure 11.2 sketches the knowledge ecosystem in middle-income countries. The people links work well, and there are institutionalized links between public research institutes and firms. However, public research institutes tend to be strongly specialized by sector (very often, agriculture, engineering, and health), therefore interactions with firms are concentrated in particular industries and involve large firms. Furthermore, as the country studies of China, Brazil, and South Africa note, the links between public research institutes and industry are still limited outside of particular sectors or technology areas. One reason for this limitation may be the small size of many public research laboratories, which, with a few exceptions, do not produce world-leading research. This limited interaction may also be due to contractual laws that limit the employment of university researchers by other employers: for example, public research institutes in Brazil have only been allowed to sign knowledge transfer contracts with companies since 2004. The cultural chasm between scientists working in labs and industry staff may also be a factor. In many countries, pursuit of science and learning may be seen as a "pure" goal and one that should not be contaminated by commercial considerations. $^{2}$

Our case studies suggest that in middle-income countries, the main difference when compared to Figure 11.1 for high-income countries is

${ }^{2}$ In India, for example, Saraswati (the goddess of learning) is said to leave the room when Lakshmi (the goddess of wealth) enters it. See https://devdutt.com/articles/battle-oflakshmi-and-sarawati.html. 


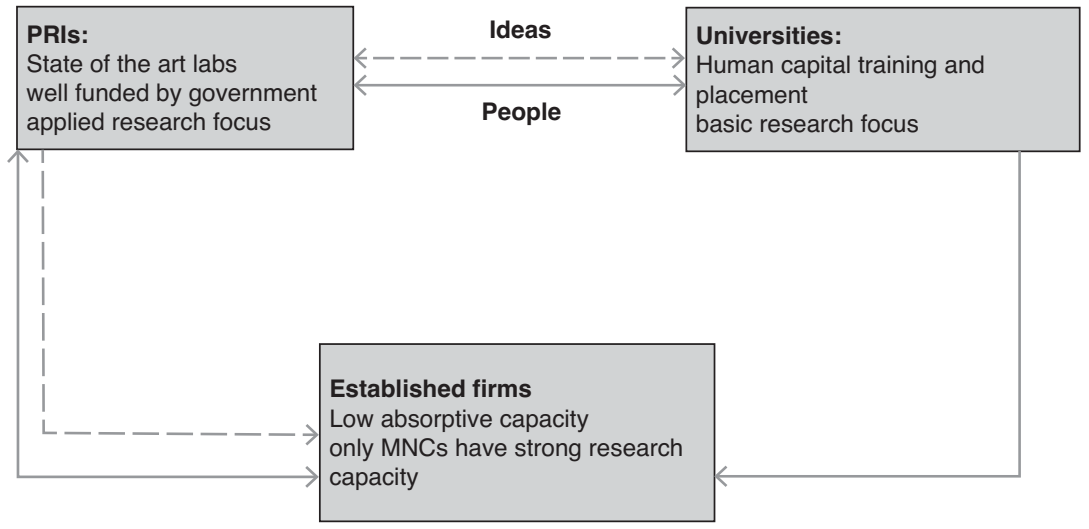

Figure 11.2 The public research ecosystem in middle-income economies

the presence of only weak linkages (and sometimes their complete absence) for transferring research ideas, knowledge, and technology from the university science base to industry. Universities in middleincome countries mainly engage in training and provide the human capital for both industry and public research institutes. These training links have resulted in informal people-mediated channels of knowledge transfer, but formal channels are largely limited - where present, they usually take the form of contract research and consulting. Interestingly, the Republic of Korea shows these features as well, despite being a highincome country.

The absence of linkages between university and industry poses two challenges for the implementation of knowledge transfer policies. As already noted in Chapter 10, universities have not yet developed a way to bridge the gap between the basic scientific research they produce and the prototype level of development of an innovative idea. Many firms require the latter to readily absorb and use to scale up production. The second challenge comes from the legal and contractual obligations surrounding university researchers, which are often not conducive to engagement with industry on research issues. Our case studies provide evidence of the full range of such challenges.

In all the middle-income countries studied in this book, the implementation of Bayh-Dole-inspired knowledge transfer policies encountered problems created by the missing (ideas) links between universities and industry and further rounds of policy changes were required to overcome the problems. Thus each of our country chapters also outlines a policy-induced process of adaptation of institutional frameworks that 
share some important similarities, but that also differ in several details. While the general policy discourse around the implementation of BayhDole-type legislation seemed to suggest that these changes in formal rules would, in themselves, be sufficient to achieve the hoped-for increases in commercialization activities, in practice, most countries have also implemented a range of supporting measures aimed at stimulating the creation of the infrastructures and competences that are required to connect university actors to industry. This includes rules to support exploiting the new IP rights framework, as well as measures to stimulate firms' demand for university IP (e.g., funds for joint research projects).

\subsubsection{Policy Mixes Adopted}

Analysis of the policy interventions enacted in the six country case studies can be subsumed under two major categories and related subcategories. The first category of complementary interventions aims to introduce supply-side incentives for universities to supply technology more readily and frequently to industry. These include institutional-level incentives for universities to patent and license IP and to interact with industry in different ways, for example, by establishing KTOs and other intermediaries encouraging interactions between universities and industry. These intermediaries manage research contracts, the creation of spinoffs, the establishment of joint research centers, and other related activities. In some cases, KTOs were established at local, regional or national levels, with or without the involvement of universities, and several universities "shared" KTO services.

As technology transactions are plagued by asymmetric information about the nature of technology and potential applications, individual researchers are in the best position to alleviate these concerns. In addition, the interpersonal networks of researchers can often be used to kickstart links with industry when none exists. Therefore, in all cases, supplyside measures also included incentives for individual academics to engage in knowledge transfer. Examples include monetary incentives that allow academics to receive income from royalties and consulting activities in addition to their salaries; career development incentives that include knowledge transfer performance as a criterion for academic promotion; incentives for academics to engage in entrepreneurial and other business activities, including permissions to take leave of absence in order to work for university spinoffs or for other companies, and to earn income from these activities. 
The second category of interventions consists of demand-side incentives for firms to engage with industry. These incentives range from general incentives for firms to invest in R\&D (such as R\&D tax credits, grants, innovation vouchers) and more specific incentives for firms to collaborate with universities and public research institutes (such as joint project grants, subsidies for the establishment of joint research centers, and mandatory investment in university research). All these incentives can be created purely through legal requirements, or they can involve the use of government funds, either in the form of government subsidies for certain activities or in the form of rewards for universities' good performance in certain activities.

Table 11.3 summarizes the extent to which the six countries implemented supply-side and demand-side incentives of the kinds just described. As can be seen, most countries implemented a combination of incentives. All of them focused on supply-side incentives, consistent with the argument that they saw the problem primarily as one of getting universities to reach out to industry.

Middle-income countries have mainly issued legal requirements for universities to engage with industry (although individual universities can enact their own internal policies providing academics with monetary incentives, for example, to develop spinoff companies or engage in consulting activities), while high-income countries have also dedicated government funds to supporting universities in these activities. All countries have invested public funds in the setup of KTOs (either within universities, or at local, regional, or national levels). In Brazil, while every public university and public research institute in the country is required to have a KTO, the Innovation Act allowed institutions to share a KTO, so that several of them serve more than one research institution.

On the demand side, all countries enacted specific monetary incentives for companies to interact with public research, mainly in the form of $\mathrm{R} \& \mathrm{D}$ tax breaks and opportunities to bid for joint R\&D projects. In Brazil, companies in some sectors such as energy are required to invest a share of their revenue in $R \& D$ in partnership with universities and public research institutes. This has been successful in stimulating university-industry interactions. However, this requirement applies to companies that are large, often multinationals headquartered outside Brazil, and benefits only a few research-intensive universities and public research institutes. The majority of public research institutes in Brazil continue to be too small and insufficiently research-intensive to benefit from these incentives. 
Table 11.3 Differences in range of supporting policies

\begin{tabular}{|c|c|c|c|c|c|c|}
\hline & \multicolumn{4}{|c|}{ Supply-side incentives } & \multicolumn{2}{|c|}{ Demand-side incentives } \\
\hline & $\begin{array}{l}\text { Incentives for } \\
\text { formation of } \\
\text { KTOs }\end{array}$ & $\begin{array}{l}\text { Incentives for } \\
\text { universities to } \\
\text { patent and } \\
\text { license IP }\end{array}$ & $\begin{array}{l}\text { Incentives for } \\
\text { universities to } \\
\text { engage with } \\
\text { industry } \\
\text { through con- } \\
\text { tracts, spin- } \\
\text { offs etc. }\end{array}$ & $\begin{array}{l}\text { Incentives for } \\
\text { individual aca- } \\
\text { demics to } \\
\text { engage with } \\
\text { industry }\end{array}$ & $\begin{array}{l}\text { Incentives for } \\
\text { industry to } \\
\text { invest in } R \& D\end{array}$ & $\begin{array}{l}\text { Incentives for } \\
\text { industry to } \\
\text { engage with } \\
\text { universities }\end{array}$ \\
\hline UK & M & $\mathrm{E}$ & $\mathrm{M} / \mathrm{E}$ & $\mathrm{L}$ & M & M \\
\hline Germany & $\mathrm{M}$ & $\mathrm{L}$ & $\mathrm{M}$ & M & M & M \\
\hline Republic of Korea & $\mathrm{L} / \mathrm{M}$ & $\mathrm{L}$ & $\mathrm{L}$ & $\mathrm{L}$ & M & M \\
\hline China & $\mathrm{L} / \mathrm{M}$ & $\mathrm{L} / \mathrm{E}$ & $\mathrm{L} / \mathrm{E}$ & $\mathrm{L}$ & & $\mathrm{M}$ \\
\hline Brazil & $\mathrm{L} / \mathrm{M}$ & $\mathrm{L}$ & $\mathrm{L}$ & $\mathrm{L}$ & $\mathrm{L} / \mathrm{M}$ & $\mathrm{L} / \mathrm{M}$ \\
\hline South Africa & $\mathrm{M}$ & $\mathrm{L}$ & & $\mathrm{L}$ & $\mathrm{M}$ & $\mathrm{M}$ \\
\hline
\end{tabular}

Source: Authors.

Note: $\mathrm{L}=$ legal requirement to implement the activity; $\mathrm{E}=$ the activity is part of performance evaluation; $\mathrm{M}=$ direct government support provided to the activity, including tax breaks. 
In addition, the case studies provide interesting insights into the timing and sequence of the policy changes. Almost all countries started by implementing legal changes but had to follow them up with a mixture of carrot (monetary incentives) and stick (performance evaluation) policies, to encourage take-up of these activities.

In Brazil, policy interventions implemented in 1996 allowed universities to own and license IP as well as compensating individual inventors. In 2004, the policy changed to allow universities to retain some income from licensing and to contract with industry. Universities and public research institutes were also required to have a KTO or use the services of a shared KTO, and were provided with some funding for this. ${ }^{3}$

Despite some increases in university patenting and licensing activities in Brazil, these supply-side incentives have had limited effectiveness in stimulating universities' interactions with industry, due to several problems, including lack of clarity, insufficient financial incentives for individual researchers, and limited resources and competences of KTOs, whose staff consist entirely of public servants. KTOs suffer from high staff turnover and a dearth of qualified or specialized staff, because their link to government institutions obliges them to rely on public tenders in hiring new staff and they do not offer competitive salaries. According to the MCTIC (2017), more than 50 percent of KTO staff had no previous experience in the private sector.

China started in 2002 by enacting laws that allowed university ownership of IP and compensation of inventors for their IP. More than a decade later (2015-16), it enacted a raft of measures allowing universities to profit from their IP (retain royalties, set up spinoff firms), and permitting academics to work for companies by taking leave of absence. One way of interpreting this lag is that the early experiments with researchers initiating links were ready to be institutionalized only a decade later. A remarkable feature of the Chinese case is the combination of monetary incentives and performance monitoring to achieve the objective of knowledge exchange. In this respect, the country's overall policy is similar to the case of the United Kingdom.

South Africa is the most recent country in our sample to have enacted knowledge transfer policies, and, in contrast to the other countries, they immediately allowed both individuals and universities to retain profits

3 There were a few open calls to grant fellowships for hiring people to work in KTOs in Brazilian universities in recent years. In 2006, there was a funding program from CNPq and FINEP to support the creation and implementation of KTOs. 
from their IP. In South Africa, the Council for Scientific and Industrial Research (CSIR) dominates the public research institute landscape and has highly specialized labs in the area of petrochemicals. CSIR also has extensive links with universities. The government has not provided direct funding to support universities' engagement with industry, but it has enacted some demand-side measures in the form of monetary incentives, which include the provision of funding for companies' R\&D, often in partnership with universities or public research institutes.

In the Republic of Korea, the government's promotion efforts were focused on encouraging interactions between domestic public research institutes and universities and firms, particularly SMEs, whose role in the economy the government intended to strengthen. They did so through incentives for commercialization but particularly through strengthening the KTO system through numerous measures. So far, efforts have not been as successful as was hoped (see Chapter 6). Large firms do interact with universities by establishing R\&D centers on the campuses of major universities, ${ }^{4}$ although they have tended to invite and hire star professors (mostly Korean) from universities located abroad. SMEs lack absorptive capacity and consequently need technologies to be provided at a higher level of technological readiness. This has been stymied by a research funding model that provides funds on a project basis, with funding often terminated before a discovery is developed sufficiently.

\subsection{An Ideal Policy Mix?}

If one form of legislation cannot fit all circumstances, how should policymakers decide which polices to adopt? Clearly the objectives of policies to support knowledge transfer from universities will be different in high- and middle-income countries and may even differ among universities within the country.

In high-income countries, the main challenge facing knowledge transfer policies is the need to avoid displacement. As patent-mediated commercialization processes can produce very high financial rewards, it may be important to ensure that financial constraints do not push universities to prefer any one kind of commercialization. Thus, first, funding to universities should be increased so that different channels of commercialization are not substituted for one another. Second, universities should try to

${ }^{4}$ For instance, Samsung Electronics and Hyundai Motors have R\&D centers on the campus of Seoul National University. 
promote a broad range of interactions outside formal channels, such as through the involvement of alumni active in research - often in other countries. In recent years, the United Kingdom has sought to redress the imbalance in perceptions of value by inclusion of research impact as an important evaluation criterion on a par with patents and publications in research-active universities. Last, the policy focus on rewarding IP ownership should subtly shift to encourage and reward IP use by universities or firms rather than ownership per se. This could take the form of recognizing impact (as in United Kingdom universities) or take the form of a subsidy that could be used by the department or inventor as income for further research.

In middle-income countries, interactions between university and industry face greater challenges and may need more policy intervention. In these countries, the knowledge ecosystem is relatively immature and research interactions between universities and industries are generally lacking (except for a few interactions involving large, multinational firms and a few highly research-intensive universities and public research institutes) due to weaknesses on both sides.

A first problem confronting middle-income country governments is the overall limited research intensity of their universities due to a traditional focus on teaching. Several additional factors reinforce this low research intensity. Universities have traditional incentive structures that reward teaching over commercialization and industry engagement. Additionally, universities find it difficult to retain their brightest and their best. Policies to correct these problems include allowing the university and inventor to profit from knowledge transfer and research, in part, by ensuring that extra profits are not taxed away as higher income - that is, ensuring that there is a financial incentive to use scientific knowledge and plow back the investments from it.

A second problem confronting policymakers in middle-income countries is the small volume of (or nonexistent) industry interactions. When such interactions are nonexistent because the contractual obligations of university researchers do not allow self-employment or employment by others (e.g., through research contracts), then legal changes may be needed to permit such interactions to take place. If there are no legal barriers, then establishing contacts may require the active involvement of the researcher and direction by knowledge transfer specialists with knowledge of industry needs and an understanding of university researcher contexts. In high-income economies such roles are usually played by KTOs, which is warranted when there is a large volume of 
technology transactions. In middle-income economies, the small volume of transactions may not warrant a specialist centralized intermediary to aid and advise the university. In the short term, universities may also gain by interacting more closely with public research institutes, which were historically set up to translate frontier technology into applicable technology for local industries. There is some evidence that South African and Indian CSIR laboratories are doing this for particular sectors, and utilizing existing public research institutes may offer a more resourceefficient method of knowledge exchange than establishing new KTOs.

The third problem facing middle-income countries is the lack of a culture of interaction with industry and lack of awareness of commercialization possibilities. KTO staff are usually career civil servants, governed by civil service rules and promotion policies. Staffing KTOs with scientists familiar with industrial R\&D is extremely important to changing the culture of interaction between university and industry. Policies that target the recruitment into management positions of scientists who had some training abroad could also help to change the research culture in universities. This has been done extremely successfully in China and Singapore.

Chapter 10 has offered a number of suggestions for improving firms' uptake of technology produced in universities and we will not repeat them here except to note that offering joint funds for exploitation with university partners may both alleviate the low research intensity of existing firms and encourage them to search for the best university partners and so make it mutually beneficial for universities and firms to establish links around research and the commercialization of research.

We summarize our arguments in Figure 11.3, which outlines five questions that governments and universities must ask themselves before deciding on the appropriate policy mix.

\subsection{Summary}

Our concern in this chapter has been to look more closely at the policyinduced convergence of the knowledge ecosystem that the Bayh-Doletype legislation in various countries attempted, drawing on the extensive material of the country case studies. Our analysis suggests that in highincome countries, such as the United Kingdom and Germany, where the knowledge ecosystems were already well developed and mature, the adoption of Bayh-Dole-type legislation while simultaneously cutting back on government funding of research in universities and public 


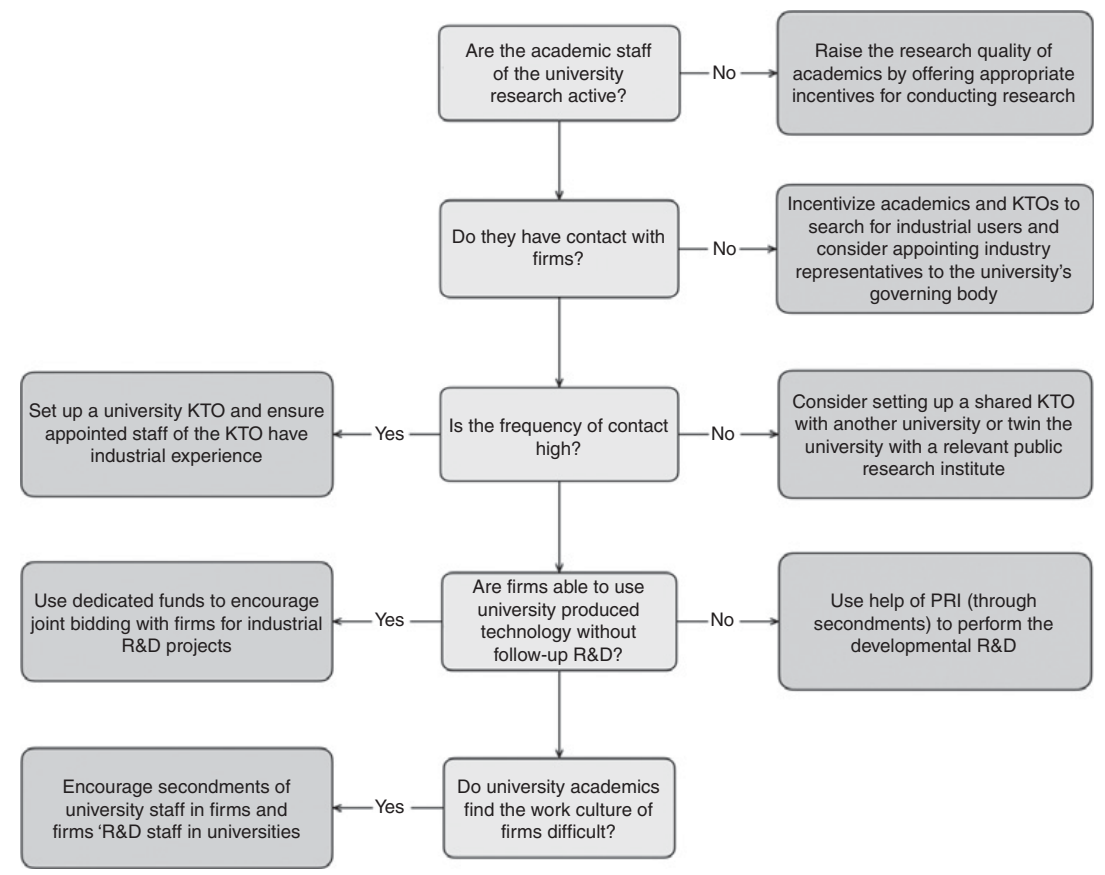

Figure 11.3 Five questions to guide policy toward knowledge exchange from universities

research institutes created the risk of "displacement effects." By displacement effects, we mean research expected to produce patents being incentivized and preferred (due to its higher expected value) over other types of commercialization, such as more informal and risky codeveloped research (in spinoff firms or with domestic firms). Despite this, the data show that non-IP methods such as contract research are a much bigger income earner, even in the United Kingdom, than research-producing patents for licensing, while overall income from knowledge transfer has remained steady as a proportion of university incomes. This could be because patent use was harder to achieve than patent ownership and/or in many research fields, contract research, or the development of applications in spinoff firms were simply better avenues of commercialization.

In middle-income economies, where knowledge ecosystems were less mature, with missing links in the knowledge ecosystem, the Bayh-Dole legislation kick-started a process of institutional reform. Middle-income 
countries often needed to adopt a complementary set of policies (in stages) in addition to permitting university ownership of IP. In most countries in our study, the requirement that universities undertake research that benefits industry was supported by a generous allocation of financial resources to enable such a transformation. The role that policy played in plugging institutional gaps is interesting (although it differs from country to country) and may, in time, deliver the desired outcome of an increase in the value of university research for the innovation activities of national firms.

The chapter concludes by noting that there cannot be a one-size-fits-all policy and enumerates a number of university-level factors that should be taken account of in middle- and low-income economies in order to deliver an effective knowledge transfer policy.

\section{References}

Athreye, S. (2004). "Agglomeration and growth: A study of the Cambridge high tech cluster." In T. Breshanan and A. Gambardella (eds.), Building HighTech Clusters: Silicon Valley and Beyond. Cambridge: Cambridge University Press.

Berman, E.P. (2008). "Why did universities start patenting? Institution-building and the road to the Bayh-Dole Act." Social Studies of Science, 38: 835-71.

Block, F. (2008). "Swimming against the current: The rise of a hidden developmental state in the United States." Politics and Society, 36(2): 169-206.

Bozeman, B. (1994). "Evaluating government technology transfer: Early impacts of the "cooperative technology paradigm." Policy Studies Journal, 22(2): 322-7.

Colaianni, A. and R. Cook Degan (2009). "Columbia University's Axel patents: Technology transfer and implications for the Bayh-Dole Act." Millbank Quarterly, 87(3): 683-715.

DLA PIPER, Mason Hayes+Currant (2007). Monitoring and Analysis of Technology 842 Transfer and IPRs and Their Use - Professor's Privilege. Report for the European 843 Commission (DG research).

Feldman, M., A. Colaianni, and K. Liu (2005). Commercializing Cohen-Boyer 1980-1997. DRUID Working Paper 05-21.

Geuna, A. and F. Rossi (2011). "Changes to university IPR regulations in Europe and the impact on academic patenting." Research Policy, 40(8): 1068-76.

Graff, G.D. (2007). "Echoes of Bayh-Dole: A survey of intellectual property and technology transfer policies in emerging and developing economies." In R. Mahoney, A. Krattiger, L. Nelsen et al. (eds.), Intellectual Property Management in Health and Agricultural Innovation: A Handbook of Best Practices. Davis: CAL MIHR-USA. 
Kenney, M. and D. Patton (2009). "Reconsidering the Bayh-Dole Act and the current university invention ownership model." Research Policy, 38 (9): $1407-22$.

Lee (2013). "Capability failure and industrial policy to move beyond the middleincome trap: From trade-based to technology-based specialization." In J.E. Stiglitz and J.Y. Lin (eds.), The Industrial Policy Revolution I. International Economic Association Series. London: Palgrave Macmillan.

Lee, K., L. Chaisung, and W. Song (2005). "Emerging digital technology as a window of opportunity and technological leapfrogging: Catch-up in digital TV by the Korean firms." Industrial Journal of Technology Management, 29(1/2): 40-63.

Lissoni, F., P. Llerena, M. McKelvey, and B. Sanditov (2008). "Academic patenting in Europe: New evidence from the KEINS database." Research Evaluation, 17(2): 87-102.

Ministério da Ciência, Tecnologia, Inovações e Comunicações (MCTIC) (2017). Política de Propriedade Intelectual das Instituições Científicas e Tecnológicas do Brasil - Relatório FORMICT 2017. Brasilia: MCTIC. Available at www .mctic.gov.br/mctic/export/sites/institucional/tecnologia/propriedade_intelec tual/arquivos/Relatorio-Formict-Ano-Base-2016.pdf. Accessed January 2018.

Mowery, D.C. and B. Sampat (2005). “The Bayh-Dole Act of 1980 and universityindustry technology transfer: A model for other OECD governments?" Journal of Technology Transfer, 30(1-2): 115-27.

Powers, J. (2006). "Patents and royalties." In D.M. Priest and E.P. St John (eds.), Privatization and Public Universities in Priest. Bloomington, IN: Indiana University Press.

Sampat, B. (2009). "Patenting and US academic research in the 20th Century: The world before and after Bayh-Dole." Research Policy, 35(6): 772-89.

Saxenian, A. (1994). Regional Advantage: Culture and Competition in Silicon Valley and Route 128. Cambridge, MA: Harvard University Press.

Saxenian, A. (2007). The New Argonauts: Regional Advantage in a Global Economy. Cambridge, MA: Harvard University Press.

Schacht, W.H. (2005). The Bayh-Dole Act: Selected Issues in Patent Policy and the Commercialization of Technology. Congressional Research Service Report for US Congress.

Storper, M. and R. Walker (1983). "The theory of labour and the theory of location." International Journal of Urban and Regional Research, 7(1): 1-43.

Tang, P., D. Weckowska, A. Campos, and M. Hobday (2010). Managing Intellectual Property in Universities: Patents and the Protection Failure Problem. Final Report prepared for the Gatsby Charitable Foundation. (SPRU Working Paper Series 188). Brighton: Science and Technology Policy Research, University of Sussex. 
Thursby J., R. Jensen, and M. Thursby (2001). "Objectives, characteristics and outcomes of university licensing: A survey of major U.S. universities." Journal of Technology Transfer, 26: 59-72.

WIPO (2011). "Harnessing public research for innovation - the role of intellectual property." In World Intellectual Property Report 2011: The Changing Face of Innovation. Geneva: World Intellectual Property Organization (WIPO). www.wipo.int/edocs/pubdocs/en/wipo_pub_944_2011-chapter4.pdf.

Zucker, L.G., M.R. Darby, and M.B. Brewer (1998). "Intellectual human capital and the birth of US biotechnology enterprises." American Economic Review, 88(1): 290-306.

Zuñiga, P. (2011). The State of Patenting at Research Institutions in Developing Countries: Policy Approaches and Practices, WIPO Economics Research Working Papers No. 4, Geneva: WIPO, http://www.wipo.int/edocs/pubdocs/ en/wipo_pub_econstat_wp_4.pdf. 


\title{
Comment 11.1
}

\author{
ANTENOR CESAR VANDERLEI CORRÊ AND FERNANDA \\ MAGALH Ã E
}

The chapter put into perspective the implementation of policies to support the transfer of knowledge from public research organizations to industry in high- and middle-income countries, drawing on the experience of six countries (Germany, Republic of Korea, the United Kingdom, Brazil, China, and South Africa). Some common traits are identified, although it is made clear that each country requires an individualized analysis of what is needed to build effective knowledge transfer channels between universities and public research institutes and industry.

Our experience in dealing with these issues in Brazil suggests that a set of measures aimed at increasing the "two-way flow" of ideas and people, as identified by the authors, between universities and public research institutes and industry should address three different layers of the problem: cultural, institutional, and financial.

The cultural layer is the most crucial because it deals with the foundation of the system. The limited interaction between the aforementioned actors in middle-income countries is somewhat difficult to overcome. Publishing papers and contributing to the dissemination of knowledge are the main tasks that have been historically associated with universities. Commercial considerations are often seen as a deviation from the purpose of academia. In this context, the relationship with industry is often neglected and sometimes seen as undesirable. One of the problems of not being used to dealing with the industry is related to the protection of knowledge. It is not uncommon for professors involved in applied research to be so keen to show the results of their work that they end up revealing secrets that should be protected. Another element that can add difficulty is the financial incentives normally associated with industry collaboration. Sectors of the university that do not benefit from these incentives in a situation of scarce public funding can produce an environment that is not conducive to commercial dealings. Timing and excessive bureaucracy are other 
issues often mentioned by industry when identifying difficulties in dealing with public research organizations.

The second layer, institutional, is addressed in depth by the authors when they mention the impact of the Bayh-Dole-type legislation on worldwide policies to support the transfer of knowledge from public science. Indeed, the Bayh-Dole Act strongly influenced Brazilian legislation on the matter. The Brazilian Innovation Act from 2004 was the first step toward establishing institutional and legal frameworks to facilitate the process of change in the interplay between universities and public research institutes and industry. Some of the key aspects of this initiative were: (i) it consolidated the legislation in order to provide a more coherent and unambiguous basis on which this interaction could happen, thus helping to positively affect the first layer mentioned in the previous paragraph; (ii) the ownership rights attributed to universities and public research institutes placed greater emphasis on the results of research conducted within these institutions; and (iii) the incentives provided to the institution and researchers involved in projects with industry were important in assisting the establishment of a new pattern of relationships. The Innovation Act has been fully revised and a revamped version was approved in 2016. In fact, there was a thorough and overall revision of all aspects of the national science, technology, and innovation policy in the country, even involving changes in the Brazilian National Constitution, which is referred to as the New Science, Technology, and Innovation Legal Framework. The key aspect of the new legislation in regard to the process of knowledge transfer discussed here is the mandatory requirement for all public research organizations to establish their own innovation policies, whose main focus is exactly knowledge transfer to industry.

The third layer, financial, refers to the lack of funding, not only by the government but mainly by the private sector, to support engagement of universities and public research institutes with industry in $\mathrm{R} \& \mathrm{D}$ projects. This layer is considerably influenced by the previous ones, particularly in middle-income countries where the national innovation systems are less mature. For example, in Brazil, most of the investment in $R \& D$ is made by the public sector (56 percent, according to data from the Brazilian Ministry of Science, Technology, Innovations, and Communications), which emphasizes the need for stronger cooperation between public research organizations and industry in order to accrue more economic benefits for society as whole from this type of investment. Due to the lack of 
tradition of investing in high-risk technology-based ventures, such as startup and spinoff companies, there is a low flow of financial resources between industries and universities and public research institutes. It is also worth mentioning that regulations related to the attribution of responsibilities in case of business failure are harsh in relation to all parties involved, including the investors, which is not particularly encouraging for venture capitalists.

These factors, added to budget constraints, do not create a motivating environment for strong partnerships between industry and public research organizations. One measure that could be taken to foster collaboration would be the provision of additional monetary incentives for companies to interact with public research organizations on top of those that provide general incentives for firms to invest in $R \& D$.

During the analysis, the authors explore the policy interventions adopted by countries to promote an effective knowledge exchange policy. They divide policy interventions into two categories: the supply side, which includes incentives for universities to provide technology to industry, and the demand side, which includes incentives for firms to engage with industry. Regarding these incentives, it is interesting to note in Table 11.3, which shows the types of supporting policy among the selected countries, a trend in high-income countries to provide direct government support and a tendency in middle-income countries to enact legal requirements to implement the activity. In Brazil, both legal measures and governmental funding were used to support the interaction.

Although the current institutional framework in Brazil has evolved significantly in order to bridge the gap between public science and industry, there are still considerable challenges to be overcome. The report produced by the Brazilian government with data from universities and research institutes on the implementation of the Innovation Act shows that some progress has been achieved. Over the years, there has been an increase in knowledge transfer offices, protection of intellectual assets, contracts with industry, and revenue from these contracts. Nevertheless, it is difficult to say that it is a harmonized movement, because the country is vast and full of particularities. Most contracts and revenues from these contracts are concentrated within a small number of institutions. Some factors can be mentioned that favor these institutions: location, type of research developed, tradition in the relationship with industry, good laboratory infrastructure, and open-minded researchers to relate to industry. 
From the institutional point of view, we believe that Brazil has established a comprehensive legal framework on innovation policy. But is that enough? As we have tried to point out, there are barriers that can only be overcome with continuous assessment and adjustment of the policies in place. In this context, the authors provide a good guide to assist in these tasks. 


\title{
Comment 11.2
}

\author{
SI KYONG SUNG
}

In 2000, Korea established the Technology Transfer and Commercialization Promotion Act, a Korean Bayh-Dole Act, and the ownership of public research results became able to be transferred to universities and public research institutes. The next year, the ownership of public research results was transferred to universities and public research institutes in compliance with the new regulation on the management of government-funded $R \& D$ projects.

In the last five years, there have been three major blockbuster public knowledge transfers in Korea. In this chapter, these cases are introduced, along with the detailed concerns of the Korean Intellectual Property Office.

The first was the case in which a startup established by a public research organization grew successfully and a large amount of inventor compensation (more than USD 10 million) was awarded to each of two researchers. The Korean Bayh-Dole Act and the regulation on the management of government-funded $\mathrm{R} \& \mathrm{D}$ projects both stipulate that public researchers must be compensated for more than 50 percent of the royalty income of their research products. This case gave rise to the argument to alleviate the compensation gap between researchers. As a result, the government introduced a regulation to reduce the percentage of inventor compensation for the royalty gradually if the compensation exceeds USD 2 million a year.

The second case is one in which a university gave up filing a patent application for an invention (Bulk fin-FET), where the professor filed a patent application in United States of America (U.S.) in his own name and with his own money, and, ten to fifteen years later, received USD 10 million and USD 400 million royalty from foreign and Korean companies, respectively. In Korea, the market size is about one-tenth smaller than that of the U.S., and the compensation for patent infringement is as low as one-hundredth of the U.S compensation. Therefore, inventions that only 
have a Korean patent cannot make a good license contract. Unlike the BayhDole Act and the German employee invention law, the Korean Act did not stipulate the return of ownership to the inventor when the university gave up filing or sustaining a patent application. Therefore, academic inventions are often left idle unless the university applies for overseas patents. For reference, Korean universities file patent applications in foreign countries for only 4.5 percent of their domestic patent applications.

The third case is where a professor transferred his invention (CRISPR genetic scissors) to his own startup three days after disclosing it to his university, using a cheap upfront payment (about USD 20,000) and appropriate running royalty rate, and the company grew to about USD $\$ 800$ million in value last year. Since public technology in Korea can be transferred exclusively only when there is no demand for a nonexclusive license, the professor and the KTO are being accused of concealing the valuable patent and selling it off to the company concerned at a low price.

The reason for these problems is that ownership of public research results has been transferred institutionally to universities and public enterprises, but they are still regarded as public goods rather than private property. The purpose of ownership transfer in the Bayh-Dole Act is to ensure that the patents are widely used while public research organizations maximize their own profits. By the same token, the Korean BayhDole Act aims for public research results to be widely used but disapproves of a public research organization maximizing its profits. During the last fifty years of rapid economic growth, the purpose of public research in Korea was to help domestic companies to catch up quickly, and the research results were to be shared rather than be owned exclusively. Even after the establishment of the Korean Bayh-Dole Act, this perception has not changed, and Koreans still consider it unfair for someone to monopolize the profits from the results of tax-based research. It is clear that they do not want the invention to be returned to the inventor even if it is not going to be filed, and they consider it to be monopolization for a patent to be assigned to a startup and make a success.

We would like to add a few more details to the institutional incentives suggested by the authors of this chapter.

First, a patent should be recognized as the private property of the university and the public research institute. This means that the public research institute should be able to decide autonomously on the selection criteria for the company to transfer its results, the license type (exclusive/ nonexclusive), and the royalty distribution so that the public research 
institute can actively maximize its profits. When knowledge transfer can make money, universities and public research institutes, as well as researchers, will make efforts to get valuable patents and transfer technologies.

Second, the purpose of the knowledge transfer policy should be that the invention is used more rather than making the invention used by more companies. The ultimate goal of the patent system is to make more utilization of inventions in the long run, even if transitory monopolies are allowed. In fact, this is consistent with the public interest of public research policy, and is consistent with why researchers prefer knowledge sharing rather than knowledge transfer.

According to the second objective, it is better to choose a company that has the ability and willingness to commercialize the patent rather than the company that pays the highest upfront lump sum fee. Unfortunately, the running royalty income of Korean universities was only 8 percent of their total royalty incomes in 2017 , while that of the U.S. was as high as 55 percent. If universities and public research institutes are pushed to raise the immediate financial achievements with $R \& D$, they cannot but license their knowledge focusing on the upfront fee, regardless of commercialization.

There's no need to worry that SMEs and startups may have no opportunities if technologies are transferred institutionally to the companies that will utilize them more. Technologies transferred to large companies often go to the warehouse and lie dormant until a patent dispute arises. Rather, SMEs and startups are often eager to commercialize the patent for their survival. In particular, a company founded by the inventor him(her)self is very competitive in terms of technical expertise. If full authority over the profits is given to universities and public research institutes, they will make reasonable choices.

Although the purpose of public research policy may vary from country to country, the purpose behind granting ownership of research results to public research organizations must be the promotion of utilization of the results. For patent utilization, public research organizations pursuing profits are much better than bureaucracy. Policies that are applied to the knowledge transfer process should limit the private property rights of institutes only if they are clearly against the public interest. In the future, Korea intends to improve the system in this direction. 


\title{
Toward a Comprehensive Set of Metrics for Knowledge Transfer
}

\author{
ANTHONY ARUNDEL AND NORDINE ES-SADKI
}

\subsection{Introduction}

The commercialization of knowledge produced by public research organizations, consisting of universities and public research institutes, requires the transfer of knowledge to firms, government entities, or nonprofit organizations and the application of this knowledge to products and processes. This transfer process occurs through a number of channels, but, as noted in Chapter 2, most research on knowledge transfer from public research organizations to other organizations uses metrics for IP-mediated forms of knowledge transfer, for instance, licenses for codified intellectual property such as patents. This is partly because research on IP-mediated knowledge transfer is facilitated by the electronic "trail" left by IP. This ensures that the activities and outputs of IP are easier to identify than other methods of knowledge transfer.

Six metrics for IP-mediated knowledge transfer are often collected by private or public sector organizations in high-income countries from surveys of knowledge transfer offices (KTOs): the number of invention disclosures, patent applications, patent grants, licenses, and startups established, plus the total amount of license revenue earned by the public research organization. In addition, many of these surveys also collect data on the number of research agreements with firms, which can result in knowledge transferred by IP or through other channels.

Table 12.1 identifies the collection of data on these knowledge transfer metrics by each of the six case study countries covered in this book. The only metrics that have been collected for a large sample of public research organizations in all six countries are the number of patent applications and patent grants. In most countries, the collection of data for other metrics has been sporadic, with only the United Kingdom collecting 
Table 12.1 Data collected for IP-mediated knowledge transfer plus research agreements at the institutional level (results for six countries)

\begin{tabular}{|c|c|c|c|c|c|c|}
\hline & China & Brazil & $\begin{array}{l}\text { South } \\
\text { Africa }\end{array}$ & UK & Korea & Germany 1 \\
\hline $\begin{array}{l}\text { Number of invention } \\
\text { disclosures }\end{array}$ & & & $\checkmark$ & $\checkmark$ & $\checkmark$ & \\
\hline $\begin{array}{l}\text { Number of patent } \\
\text { applications }\end{array}$ & $\checkmark$ & $\checkmark$ & $\checkmark$ & $\checkmark$ & $\checkmark$ & $\checkmark$ \\
\hline $\begin{array}{l}\text { Number of patent } \\
\text { grants }\end{array}$ & $\checkmark$ & $\checkmark$ & $\checkmark$ & $\checkmark$ & $\checkmark$ & $\checkmark$ \\
\hline $\begin{array}{l}\text { Number of licenses with } \\
\text { firms }\end{array}$ & & $\checkmark$ & $\checkmark$ & $\checkmark$ & $\checkmark$ & \\
\hline $\begin{array}{l}\text { Total license income } \\
\text { earned }\end{array}$ & & $\checkmark$ & $\checkmark$ & $\checkmark$ & $\checkmark$ & \\
\hline $\begin{array}{l}\text { Number of startups } \\
\text { using institutional IP }\end{array}$ & & & $\checkmark$ & $\checkmark$ & $\checkmark$ & $\checkmark$ \\
\hline $\begin{array}{l}\text { Number of research } \\
\text { agreements with } \\
\text { firms }\end{array}$ & & $\checkmark$ & & $\checkmark$ & & \\
\hline
\end{tabular}

Source: National experts responding to a WIPO survey on data collection

${ }^{1}$ Data have been collected by private-sector organizations for all seven metrics for a selected number of leading public research organizations.

these data for all universities over the long term. ${ }^{1}$ Additionally, privatesector organizations that represent knowledge transfer professionals such as RedOTRI (Spain), NetVal (Italy), and the umbrella organization ASTP (formerly ASTP-ProTon) collect relevant data for these metrics in Germany and other high-income countries, but with the exception of Spain and Italy, less than 50 percent of universities and public research institutes are covered (Finne et al. 2009). Since these metrics are of high value for benchmarking outcome performance and monitoring the use of IP to transfer knowledge, all countries should ideally collect these metrics on a regular basis for all public research organizations, or at the

1 The Danish Agency for Science, Technology and Innovation (DASTI), currently part of the Ministry of Higher Education in Science in Denmark, collected knowledge transfer data for all Danish universities between 2000 and 2013. Réseau SATT in France, an umbrella organization of regional networks that provide support on knowledge transfer for universities in their region, has collected relevant data, but not consistently. 
minimum for research-intensive public research organizations, as done by the Association of University Technology Managers (AUTM) in the United States of America (U.S.) and in Canada (AUTM 2016, 2017).

A major issue is the international comparability of knowledge transfer metrics. Comparable metrics are of value for benchmarking performance and for policy learning through the use of econometric analysis to evaluate the effects of inputs and outputs on knowledge transfer. For instance, policymakers in one country or region can learn from evaluations of the effects of knowledge transfer activities on outcomes in countries or regions with similar levels of economic development or similar industrial structures. As discussed in Chapter 2, the de facto definitions of IP-mediated knowledge transfer have been set by the AUTM. China collects data on activities such as "knowledge transfer" and university enterprises that are not fully comparable with the AUTM definitions. As some of these metrics are useful for Chinese policy, international comparability would require China to collect additional metrics using the AUTM definitions.

A reliance on metrics for IP-mediated knowledge transfer creates two substantial issues. First, measurement implies that the measured activity is of high value, while unmeasured activities are of low value. Consequently, the act of measuring IP sends a strong signal to university managers (and policymakers) that more university IP is desirable, while other activities to transfer knowledge are erroneously viewed as unimportant. One consequence is that the types of metrics that are collected can affect the distribution of public funding and the ranking of universities. In the United Kingdom this resulted in a dispute over the types of knowledge transfer metrics to be collected between the Russel Group of research universities, which benefited from a narrow focus on IP metrics, and a group of younger universities, established after 1992, that wanted knowledge transfer metrics to cover a broader number of activities (Lockett et al. 2015).

Second, policies and practices to promote knowledge transfer must ensure that all aspects of a knowledge transfer system are functioning. There is a large and diverse variety of channels for transferring knowledge that are not covered by the seven commonly used metrics and which have been identified as important conduits for knowledge transfer in Chapter 11 and other research (Walshok and Shapiro 2014). Bekkers et al. (2008) identify twenty-one channels, ranging from publications to personal contacts. In particular, metrics for IP-mediated knowledge transfer do not capture the transfer of tacit knowledge, which requires 
direct, personal contact between the provider and the recipient of the knowledge. These personal contacts, for instance, through staff exchanges between firms and public research organizations, play a vital role in the transfer of knowledge for breakthrough discoveries (Bekkers et al. 2008). One concern is that a policy focus on supporting IP-mediated channels can unintentionally interfere with the use of other knowledge transfer channels (Rosli and Rossi 2014; Czarnitzki et al. 2016; Veugelers 2016). The combination of informal and formal channels has been found to have a positive effect on innovation outcomes (Link et al. 2007; Siegel et al. 2003; Grimpe and Hussinger 2013) and could be especially important to the performance of spinoffs (Hayer 2016).

The economic relevance of a broader set of knowledge transfer metrics is well established, with research from both the United Kingdom and China (see Chapters 4 and 8), showing that non-IP-mediated knowledge transfer activities are considerably more important than IP-mediated channels, as proxied by the amount of income earned by public research organizations from IP versus other knowledge transfer methods. For example, in 2015-16 all universities in the United Kingdom combined earned $£ 4.2$ billion from all knowledge transfer activities, of which only $£ 176$ million (4.2 percent) was due to IP licensing (HEFCE 2017).

These limitations with metrics for IP-mediated knowledge transfer have been recognized for some time (Holi et al. 2008; Jensen et al. 2009; Lockett et al. 2015). They may be particularly important for middle-income countries that have enacted policies to replicate the American Bayh-Dole Act for IP (see Chapter 11), while neglecting policies to support other forms of knowledge transfer. Based on the country case studies and other research, Chapter 10 argues that middle-income countries would benefit from knowledge transfer policies to increase incentives for public research organizations to interact with firms and policies to increase the absorptive capacities of firms to use and apply knowledge produced by public research organizations. Both of these goals can be enhanced by policies that support the full range of knowledge transfer channels, based on evidence showing that the optimal channel varies by firm capabilities and the characteristics of the knowledge to be transferred (Bekkers et al. 2008; Belitski et al. 2019).

In addition to data on IP-mediated knowledge transfer, surveys of KTOs or other administrative units within a public research organization can collect data on other formal channels such as contract and collaborative research with firms or government organizations. However, other knowledge transfer metrics need to be collected from academics and 
firms in order to overcome a lack of knowledge on the part of KTO staff. Large-scale surveys in Europe show that KTO managers are not always able to report research agreements with firms, as some of these are managed outside KTO administration (Barjak et al. 2015). Furthermore, KTO staff can be unaware of important knowledge transfer activities via publications or through informal channels. Freitas et al. (2013) estimates that approximately 50 percent of knowledge transfer from public research organizations in a province of Northern Italy occurred through personal interactions.

There can also be large differences in the perceptions of KTO managers, academics, and firm managers on the factors that support or act as barriers to knowledge transfer. Siegel et al. (2003) surveyed KTO managers, academics, and firm managers to obtain their opinions on barriers to knowledge transfer. They found large and statistically significant differences among these three groups that were often self-serving. For example, KTO managers did not find university bureaucracy and inflexibility to be important barriers, but both academics and firm managers did. Relying on the perceptions of only one of these three key actors could result in misleading recommendations for how to improve knowledge transfer.

This chapter discusses and identifies data for measuring non-IPmediated methods of knowledge transfer, as well as metrics for the use of policies and practices to support knowledge transfer. The latter are required to be able to assess policy effectiveness. The purpose is to provide data for all major channels of knowledge transfer in addition to IP-mediated channels, as covered in Chapter 2. Many of the types of data discussed in this chapter also meet statistical requirements to be specific, measurable, reliable, timely, and cost-effective (Jensen et al. 2009). In addition, the chapter discusses a limited number of metrics that can be used to assess the systemic impacts of knowledge transfer, including impacts from IP licensing. Metrics for impacts are, unfortunately, considerably more difficult and costly to obtain than metrics for activities.

In addition to collecting data from KTOs (or university administrations responsible for knowledge transfer), data on knowledge transfer activities need to be collected through surveys of scientists and other academics employed by public research organizations that create knowledge, and the firms that are the intended recipient of knowledge. Surveys of academics and firms are the best method for collecting data on informal knowledge transfer channels (Sigurdson et al. 2015). A fourth method is to use publicly available data, for instance, on patenting or publications or through web-scraping techniques. The types of data that can be collected through each of these 
methods and their limitations are discussed below. Of note, this chapter follows the Oslo Manual (OECD/Eurostat 2018) by identifying lists of topics to be covered by data collection instead of providing specific questions for surveys, with the exception of questions for policies and practices to promote knowledge transfer. ${ }^{2}$

\subsection{Data from KTOs and University Administrations}

The AUTM licensing activity surveys have served as the baseline model for data collection from KTOs, but the questions are largely limited to IPmediated knowledge transfer outcomes and activities. ${ }^{3}$ The British Higher Education-Business and Community Interaction (HE-BCI) survey, sent to KTOs or other responsible administrative units within British universities, covers a broader range of formal knowledge transfer activities that are not always part of IP licensing, although some of these activities can contribute to IP licensing (Holi et al. 2008; Rossi and Rosli 2015). Part A of the survey collects data on policies and practices for knowledge transfer, including the strategic goals for these activities, priorities by region, staff incentives, in-house capabilities for managing IP, and practices for supporting spinoffs and startups. Part B of the survey collects financial data on income earned by universities for five formal knowledge transfer activities: collaborative research, contract research, consultancies, facilities and equipment-related services, and professional development and continuing education. ${ }^{4}$ Income data are obtained by the source of funding: government, businesses, and third-sector organizations. In addition, business funding is separated into SMEs and large businesses for all activities other than collaborative research. ${ }^{5}$ KTO data are useful for benchmarking and monitoring formal knowledge transfer

${ }^{2}$ Specific questions are not provided because questions need to be carefully developed following agreed international definitions and to undergo cognitive testing through faceto-face interviews with potential survey respondents. First drafts of questions usually go through substantial changes before they are ready for use. The examples of questions for policy practice should not be used without further testing.

${ }^{3}$ See https://autm.net/surveys-and-tools.

4 The questions used in Part A are available at www.hesa.ac.uk/collection/c18032/heb ci_a_questions. The questions for Part B are available as downloadable templates for individual years, with the templates for the 2017-18 survey available here: www .hesa.ac.uk/collection/c17032.

5 A sixth category of regeneration and development programs is not included here because it is not relevant to many countries. 
outcomes such as different forms of income earned by universities and public research institutes and for policy evaluation.

The HE-BCI survey is a useful model for collecting data on a full range of formal knowledge activities for all countries and was proposed for implementation by Australia (Jensen et al. 2009). To succeed, public research organizations need to invest in accounting systems to collect financial data for specific income sources. As this can be costly, a governmental authority may need to provide an incentive to compel universities to collect these data. The United Kingdom is able to collect these data for almost all universities because compliance with the HE-BCI reporting requirements is necessary for eligibility for one of the UK government's funding programs. A similar approach could be useful in other countries that provide publicly funded research grants to public research organizations.

\subsubsection{Measuring the Benefits of Knowledge Transfer to Public Research Organizations}

The financial benefit to public research organizations is usually measured through license revenue from IP licensing and income from industryfunded research, including contracts, research collaboration, consultancy, renting of equipment and facilities, and professional development and education programs (HEFCE 2017). Other benefits that are difficult to measure in financial terms have not been measured on a consistent basis, although they have been examined in the academic literature (Perkman et al. 2011). They include knowledge flows from firms to universities, information on interesting opportunities for research, including research of value for commercial applications, and job placements for graduates and $\mathrm{PhD}$ candidates. Potential costs include the costs of funding KTO activities, such as marketing and managing IP, evaluating the commercial potential of inventions, and patenting and other legal costs. Nonfinancial costs include disruptions to the research function of universities, such as delays in publication, a decline in academic involvement in basic research, or the diversion of academic time to patenting and licensing activities (Thursby and Thursby 2007).

\subsubsection{Data on Policies and Practices to Support Knowledge Transfer}

Data on the policies and practices that public research organizations use to support knowledge transfer can be used to evaluate and identify 
the factors that support or hamper knowledge transfer activities. These include both policies at the national level and policies and practices that are implemented at the institutional level for each university or public research institute. Useful data on policies and practices implemented by national or regional governments or the institution itself can be obtained from surveying KTOs. International comparability in data for policies and practices is required for multicountry analyses of the factors that influence knowledge transfer performance.

Many countries have introduced legislation on the ownership of IP produced by public research organizations, the establishment of KTOs, whether or not researchers should be provided financial incentives if a discovery is licensed, and, in some countries, the percentage of license income that researchers should receive; and whether or not academics at universities must file invention disclosure reports. For Europe, Geuna and Rossi (2011) found that it is difficult to disentangle the effects of changes in IP ownership on academic patenting activities from the effects of concurrent transformations in the institutional, cultural, and organization landscape surrounding knowledge transfer. National policies that are directed toward businesses can also encourage knowledge transfer, such as subsidies for firms to collaborate on innovation with university or public research institute partners, or government reimbursement "vouchers" that firms can give to researchers in return for assistance with practical problems. Information on national policies is valuable for understanding the factors that shape national knowledge transfer activities.

Practices are often based on written regulations or guidelines, but are either not legally required (in the case of a guideline), or, if based on regulation, not enforced. For example, policies on the ownership of IP are usually established at the national level and universities are legally required to follow them. In contrast, a national or institutional regulation requiring academics to file an invention disclosure report for a discovery with potential commercial value is often closer to a practice, with few or any penalties for academics that fail to file.

Data collection for policies and practices is less developed than for knowledge transfer activities, as shown in Table 12.2 for the six case study countries. China only provides data on national regulations on the assumption that these are implemented by all public research organizations. Neither Brazil nor Germany collects data on policies and practices for large samples of public research organizations. 
Table 12.2 Data collected for IP policies at the national $(\checkmark)$ or institutional $(\checkmark \checkmark)$ level (results for six countries)

\begin{tabular}{|c|c|c|c|c|c|c|}
\hline & China & Brazil & $\begin{array}{l}\text { South } \\
\text { Africa }\end{array}$ & UK & Korea & Germany $^{1}$ \\
\hline $\begin{array}{l}\text { Incentives for } \\
\text { academics to disclose } \\
\text { inventions to support } \\
\text { knowledge transfer }\end{array}$ & $\checkmark$ & & & $\checkmark \checkmark$ & $\checkmark \checkmark$ & \\
\hline $\begin{array}{l}\text { Promotion of } \\
\text { knowledge transfer } \\
\text { opportunities to the } \\
\text { business sector }\end{array}$ & $\checkmark$ & & & & & \\
\hline $\begin{array}{l}\text { Written rules or } \\
\text { guidelines for } \\
\text { knowledge transfer }\end{array}$ & $\checkmark$ & & $\checkmark$ & & $\checkmark \checkmark$ & \\
\hline $\begin{array}{l}\text { Written rules or } \\
\text { guidelines made } \\
\text { publicly available }\end{array}$ & $\checkmark$ & & $\checkmark$ & & & \\
\hline $\begin{array}{l}\text { Rules for publication } \\
\text { delays to support IP } \\
\text { licensing }\end{array}$ & & & $\checkmark \checkmark$ & & & \\
\hline $\begin{array}{l}\text { Academics permitted to } \\
\text { take leave to work at } \\
\text { a firm or startup }\end{array}$ & $\checkmark$ & & & $\checkmark \checkmark$ & & \\
\hline $\begin{array}{l}\text { Goals of KTOs for } \\
\text { knowledge transfer }\end{array}$ & $\checkmark$ & & $\checkmark \checkmark$ & $\checkmark \checkmark$ & $\checkmark \checkmark$ & \\
\hline
\end{tabular}

Source: National experts responding to a WIPO survey on data collection ${ }^{1}$ Some data have been collected on a sporadic basis by private-sector organizations or academics for a selected number of leading public research organizations.

Most of the research on policies and practices has primarily focused on IP-mediated knowledge transfer, although some has also evaluated research contracts and consulting. Knowledge transfer via licensing is influenced by IP regulations (Baldini et al. 2006), rules for exclusive licensing, licensing practices (Okamuro and Nishimura 2013; Shen 2016), the involvement of academics in contract or consulting research (Weckowska 2015), and financial and nonfinancial incentives (Chatterjee and Sankaran 2015) for academics to participate in knowledge transfer. 
Policies that contribute to the establishment of startups include dedicated programs (support for developing business plans, etc.) and facilities (such as an incubator) to support startups (Berbegal-Mirabent et al. 2015; Muscio et al. 2016), and employment conditions that permit academics to take leave to work with startups. The share of license revenue allotted to inventors acts as an alternative source of income for startups and can reduce the interest of academics in participating in them (Markman et al. 2004; Barjak et al. 2015).

Table 12.3 summarizes useful metrics on policies and practices for data collection at the level of the university or public research institute. The

Table 12.3 Metrics at the institutional level for policies and practices to support knowledge transfer

\begin{tabular}{|c|c|c|}
\hline \multirow[b]{2}{*}{ Metric } & \multicolumn{2}{|c|}{ Measurement level } \\
\hline & Nominal & Ordinal/interval \\
\hline \multicolumn{3}{|l|}{ Key policy metrics } \\
\hline $\begin{array}{l}\text { Importance of goals for knowledge } \\
\text { transfer (earn income, support } \\
\text { regional development, marketing } \\
\text { university capabilities, etc.) }\end{array}$ & & $\checkmark$ \\
\hline $\begin{array}{l}\text { Ownership rules for IP developed by } \\
\text { public research organizations, } \\
\text { including ownership of IP resulting } \\
\text { from public research organization- } \\
\text { firm research agreements }\end{array}$ & $\checkmark$ & \\
\hline $\begin{array}{l}\text { Financial incentives for researchers to } \\
\text { support knowledge transfer: } \\
\text { (incentives for invention disclosure, } \\
\text { share of revenue from licenses, } \\
\text { research contracts, etc.) }\end{array}$ & $\checkmark$ & $\checkmark$ \\
\hline $\begin{array}{l}\text { Rules for consulting (time limits on } \\
\text { consulting, how income is } \\
\text { distributed between the academic, } \\
\text { research group, etc.) }\end{array}$ & $\checkmark$ & $\checkmark$ \\
\hline $\begin{array}{l}\text { Nonfinancial incentives for researchers } \\
\text { for different types of knowledge } \\
\text { transfer (reputation, job } \\
\text { promotion, etc.) }\end{array}$ & $\checkmark$ & \\
\hline
\end{tabular}




\begin{tabular}{|c|c|c|}
\hline \multirow[b]{2}{*}{ Metric } & \multicolumn{2}{|c|}{ Measurement level } \\
\hline & Nominal & Ordinal/interval \\
\hline $\begin{array}{l}\text { Researcher permitted to temporarily } \\
\text { work with a licensee/spinoff, firm } \\
\text { involved in collaborative research } \\
\text { (including maximum length) }\end{array}$ & $\checkmark$ & $\checkmark$ \\
\hline $\begin{array}{l}\text { Presence and amount of supporting } \\
\text { infrastructure for startups and } \\
\text { spinoffs (incubator, science } \\
\text { park, etc.) }\end{array}$ & $\checkmark$ & $\checkmark$ \\
\hline $\begin{array}{l}\text { Presence of different types of financial } \\
\text { support (funding for KTOs, seed } \\
\text { funding, etc.) }\end{array}$ & $\checkmark$ & $\checkmark$ \\
\hline \multicolumn{3}{|l|}{ Supplementary policy metrics } \\
\hline $\begin{array}{l}\text { Requirement or incentives for } \\
\text { researchers to assist } \\
\text { commercialization (i.e., work with } \\
\text { a licensee, research contract partner) }\end{array}$ & $\checkmark$ & \\
\hline $\begin{array}{l}\text { Requirement for researchers to report } \\
\text { invention disclosures }\end{array}$ & $\checkmark$ & \\
\hline $\begin{array}{l}\text { Presence of written rules or guidelines } \\
\text { for licensing, including publicly } \\
\text { available model contracts }\end{array}$ & $\checkmark$ & \\
\hline Presence of flexible rules for licensing & $\checkmark$ & \\
\hline $\begin{array}{l}\text { Presence of written rules for the } \\
\text { conditions for an exclusive or } \\
\text { nonexclusive license }\end{array}$ & $\checkmark$ & \\
\hline $\begin{array}{l}\text { Policy for publication delays (including } \\
\text { maximum length) to support } \\
\text { patenting, licensing, or collaborative } \\
\text { research }\end{array}$ & $\checkmark$ & $\checkmark$ \\
\hline $\begin{array}{l}\text { KTO or other public research } \\
\text { organization activities to promote IP } \\
\text { or staff capabilities to the business } \\
\text { sector }\end{array}$ & $\checkmark$ & \\
\hline
\end{tabular}

Source: Authors 
main purpose of these metrics is for monitoring and policy evaluation. Some of the data need only be collected at the nominal level (yes or no), whereas other data can be collected on an interval level (percent of royalties provided to inventors or length of academic leave to work with a firm) or ordinal level (importance of different goals for knowledge transfer). The table is divided into key and supplementary metrics, based on the importance, as identified in the literature, of each policy or practice. Sample questions for measuring many of these policies, derived from a 2016 WIPO survey, are provided in the Technical Annex.

\subsection{Surveys of Academics (Researchers) at Public Research Organizations}

Surveys of academics can provide several types of data that cannot be obtained through surveys of KTOs or university administrations: the use and importance of informal knowledge channels compared to other channels and the influence on knowledge transfer activities and outcomes of the personal characteristics of academics and organizational factors at the departmental or research group level. The main purpose of collecting data from academics is for monitoring and policy evaluation.

Compared to research using data obtained from KTOs, there are considerably fewer empirical studies on the engagement of academics in activities to transfer knowledge to firms. A 2013 systematic literature review of studies on academic engagement published between 1980 and 2011 identified twenty-five separate surveys of academics in thirteen countries: ten surveys in the U.S., four in the United Kingdom, two surveys in each of the Netherlands and Germany, and one survey in each of Spain, Chile, South Africa, Italy, Norway, Ireland, Sweden, Belgium, and Japan (Perkman et al. 2013). In addition, the study reported on two studies with over thirty interviews. The studies focused on engagement through contractual, collaborative, and consulting agreements and collected data on four types of factor, as summarized in Table 12.4. The first three factors influence knowledge transfer activities while the fourth measures the effects of knowledge transfer.

Relevant data to collect in surveys of academics include the number or percentage of different types of academic staff involved in knowledge transfer through informal, contractual, and IP-mediated channels; barriers to interactions, including "cost" factors such as secrecy and concern over academic freedom (see Table 12.5); and the goals for participation in each type of channel. In addition, academic surveys can provide relevant 
Table 12.4 Data collected in previous surveys of academic engagement

\begin{tabular}{|c|c|}
\hline Factor & Data \\
\hline Characteristics of academics & $\begin{array}{l}\text { Gender, age, seniority, previous } \\
\text { commercialization experience, } \\
\text { government grants awarded, and } \\
\text { scientific productivity }\end{array}$ \\
\hline Organizational factors & $\begin{array}{l}\text { Quality of the university or department, } \\
\text { organizational support, incentives, } \\
\text { organizational experience with } \\
\text { commercialization, peer effects }\end{array}$ \\
\hline Institutional factors & $\begin{array}{l}\text { Discipline or field, national regulations/ } \\
\text { policies }\end{array}$ \\
\hline Outcomes & $\begin{array}{l}\text { Scientific productivity (publications, } \\
\text { patents), commercial productivity, } \\
\text { shift to applied research, secrecy, } \\
\text { collaborative behavior, teaching }\end{array}$ \\
\hline
\end{tabular}

Source: Based on Perkman et al. 2013

information on the types of partner, such as firms, government organizations, and nonprofits. An example of good practice is the large 2008-9 survey of 22,556 UK academics active in teaching or research (Abreu and Grenevich 2013; Abreu et al. 2016; Zhang et al. 2016). ${ }^{6}$ Due to the use of a representative sample, this study was able to determine that more academics interact with government organizations (53 percent) than with firms (41 percent) (Hughes and Kitson 2012), that academics in regional areas are more intensively involved in university-industry linkages than academics in the metropolitan regions, and that teaching-oriented universities are also very active in these linkages (Zhang et al. 2016).

The main challenge for surveying academics is to reduce the costs of surveying. A common method is to construct a sample that excludes academics who are unlikely to develop knowledge with commercial potential and consequently have little or no experience with knowledge transfer. A solution is to focus surveys on academics in applied science

6 The survey questionnaire does not appear to be available online, but the questions can be reconstructed using the tables in the following URL: https://eprints.soton.ac.uk/357117/1/ AcademicSurveyReport.pdf. 
Table 12.5 Knowledge transfer metrics from surveys of academics and firms

Academics

Firms

Incentives for participation in knowledge transfer

Financial

Promotion

Previous experience with knowledge transfer

Informal (personal contacts, conferences/

meetings)

Training

Use of advanced equipment/facilities

Research contracts or consultancy

Collaborative research

Licensing IP

Barriers/reasons not to participate

University rules for knowledge transfer

Lack of time (teaching responsibilities etc.)

Research of little interest

Concern over publication/delays

Underdeveloped technology

Difficulties in find right licensee

Costs to evaluate commercial potential

Costs to prepare legal matters involving IP rights

Potential loss of technological/competitive edge

Prices charged by licensor too high

Goals for participation

Acquire leading-edge research results

Freedom-to-operate

Close technological gaps

Funding from businesses for research, $\mathrm{PhD}$ candidates etc.

Better insight to commercialization opportunities

Economic effects

New knowledge from public research

organizations incorporated in products and

processes

Sales share/imputed savings due to knowledge

from public research organizations

Source: Authors 
departments, or on research-intensive universities who are likely to have experience in developing commercially valuable knowledge (Perkmann et al. 2013), or by selecting the departmental heads for technology disciplines, principal investigators on research projects, the heads of research groups (Van Dierdonck et al. 1990), academics who have been granted a patent, or academics who have founded a firm (Agiar-Díaz et al. 2016; Czarnitzki et al. 2016).

The disadvantage of these methods for selecting academics for surveys on knowledge transfer is that they can undervalue the opportunities for knowledge transfer from teaching-oriented universities or from the social sciences and result in inaccurate measures of the disadvantages of different types of knowledge transfer activity. For example, the possible disadvantages of close university-industry linkages include a loss of academic freedom (ability to choose to conduct basic research or research of low commercial interest) and restrictions or delays on publication due to the interest in commercial partners in secrecy (Van Looy et al. 2004; Tartari and Breschi 2012; Muscio and Pozzali 2013). The importance of publication delays is likely to be greatest for early career researchers such as $\mathrm{PhD}$ candidates and post-doctorates that need to rapidly build up a list of publications. Yet this possible effect will be missed entirely in studies that focus on the heads of research groups or departments. This could be one reason why a study of departmental heads finds that publication delays are given a low importance ranking as a barrier to collaboration with industry, whereas impacts on the choice of research is given a much higher importance ranking (Muscio and Pozzali 2013).

\subsection{Surveys of Firms}

Surveys of firms can complement surveys of academics. Both types of survey can include similar questions and thereby identify differences in the perspectives of academics and firm managers on knowledge transfer activities. Data from firms can be used for benchmarking performance (if data are collected on economic effects), monitoring and policy evaluation.

Survey research on firms consistently points to the importance of open science methods of knowledge transfer in high-, medium-, and lowincome countries, although in middle-income countries in Asia contractual methods are often more commonly cited than open science (Siegel et al. 2003; De Fuentes and Dutrénit 2012; Frietas et al. 2013; Grimpe and 
Hussinger 2013; Okamuro and Nishimura 2013; Dutrénit and Arza 2015; Kafouros et al. 2015; Kruss et al. 2015; Schiller and Lee 2015). A possible explanation is the importance of contractual relationships to building innovative capacity and problem-solving abilities among firms.

Firms in low- and middle-income countries in Africa, Asia, and Latin America were surveyed on their use of knowledge channels in an internationally coordinated study that used the same questionnaire (Albuquerque et al. 2015). In two low-income countries (Uganda and Nigeria) informal methods dominate (Kruss et al. 2015), whereas in middle-income countries in Asia (Malaysia, Thailand, and China) the most common methods are consultancy and research contracts (Schiller and Lee 2015). In four middle-income Latin American countries (Argentina, Brazil, Mexico, and Costa Rica) both contracts and informal methods are more frequently used than IP-mediated methods (Dutrénit and Arza 2015). These results indicate that surveys of firms are of value to identifying the relative importance of different knowledge channels.

Surveys of firms face similar issues to those of surveys of academics: to reduce costs, the 80-90 percent of firms that are unlikely to source knowledge from public research organizations in a defined time period are usually excluded. Targeting can be improved by limiting surveys to firms in specific sectors where the use of knowledge produced by public research organizations is more likely (Bekkers et al. 2008), such as life science firms, or excluding firms with few employees.

Surveys that follow the Oslo Manual guidelines (OECD/Eurostat 2018) for measuring innovation in the business sector, such as the European Community Innovation Survey (CIS), often collect relevant data on university-firm linkages. For example, the CIS includes a question on the importance of information obtained from universities to the firm's innovation activities and a question on collaboration with universities. These surveys consistently find that universities are an important source of information to less than 10 percent of firms, but their importance is higher for large firms and for firms in sectors such as pharmaceuticals that draw extensively on science. R\&D surveys, although limited to R\&D-performing firms that account for less than half of innovative firms, can also include relevant questions, such as business expenditures for $\mathrm{R} \& \mathrm{D}$ that is contracted out to universities or government laboratories.

Table 12.5 identifies useful indicators that can be obtained from surveys of academics and firms. Many of the indicators are applicable to both academics and firms, although some of the questions may need to 
be adapted to the type of respondent. For instance, questions on financial incentives for firms to source knowledge from public research organizations could list specific policy instruments, such as vouchers, subsidies for collaboration, etc. To improve recall quality, these surveys need to be limited to a defined period of time of between one and three years (OECD/Eurostat 2018) or refer to specific research outputs or inventions.

The benefits of knowledge transfer for firms consist of solutions for known problems (mostly relevant to contractual or collaborative research) (Perkman et al. 2011), improvements in innovative capabilities (De Fuentes and Dutrénit 2012), innovative products and processes, and earned income or cost savings from these innovations. Knowledge transfer activities can increase costs for firms when licenses are required for types of knowledge that were previously available at no cost or as part of open science. Otherwise, most of the costs incurred by firms are opportunity costs.

Several additional details to the questions listed in Table 12.5 for economic effects would assist research on the economic benefits for businesses. Relevant questions include (1) whether new knowledge obtained through public research organization research contracts, public research organization licensing, or informal public research organization contacts was implemented in products and processes, (2) the total sales revenue from these products and the imputed savings from these processes, (3) the fraction of sales revenue/cost savings attributed to knowledge obtained from public research organizations, (4) the sector of application for products and processes, (5) expectations for the next two years for a change in sales/cost savings for these products and processes, and (6) total sales revenues from all products (required to estimate the share of sales from products containing knowledge obtained from public research organizations).

\subsection{Publicly Available (Big) Data}

Big data are collected automatically and available in electronic form. Patent records, Google citations, and administrative data collected by governments for taxation and other purposes are all examples of big data. Another form that is attracting increasing attention is the use of Internet data, such as web-scraping to identify innovation activities within firms or university startups (NESTA 2018).

Big data such as patent databases can be used to directly produce knowledge transfer metrics or combined with data from KTOs or 
academic surveys. For example, patent data can be used to identify the share of patents produced by academics that are owned by firms or by universities (Geuna and Rossi 2011). Big data on publications, patents, or administrative data can also be linked to university-level data on a range of knowledge transfer activities and outcomes (Van Looy et al. 2011; Berbegal-Mirabent and Sabate 2015). An example is to evaluate the relationship between regional firm capabilities and knowledge transfer activities. Firm-level capabilities can be estimated from regional administrative data on $\mathrm{R} \& \mathrm{D}$ expenditures, business sector $\mathrm{R} \& \mathrm{D}$ intensities, and industrial structure (for instance, the share of private-sector output in low-, medium-, and high-technology sectors).

The use of web-scraping to produce metrics for innovation, including knowledge transfer, is in its infancy, but experimentation in this area is expected to produce useful results in the future. Woltmann (2018) used web-scraping methods to try to identify knowledge transfer from the Technical University of Denmark to firms via publications and university-owned patents. Text mining was used to identify similarities in the text of business websites and university patents and publications. The assumption is that firms that benefit from these two types of university output will replicate relevant text on their corporate webpages. The method identified a small number of matches with business websites, with matching better for publications than for patents.

\subsection{Metrics for the Systemic Benefits of Knowledge Transfer}

The main policy goal for knowledge transfer is to support the systemic economic and social benefits of knowledge transferred to firms, individuals, and governments and the subsequent effects at the municipal (Felsenstein 1996), regional, or national level (Cheah 2016). A review of academic research on the economic contribution of publicly funded basic research concludes that it is positive and substantial (Salter and Martin 2001), but it is a challenge to link specific knowledge transfer channels to systemic outcomes. Research using patent citation data has found positive benefits from academic research on the number of corporate patents in technology-based sectors (Verspagen 1999), which could result in an increase in innovative products and processes, but, in other sectors, knowledge transfer via patents is likely to be less important since the majority of innovations are not patented (Arundel and Kabla 1998). For a region or country, the greatest contributor to systemic benefits could be via non-IP-mediated channels such as research contracts, open science, 
and the employment of individuals with university qualifications (Roessner et al. 2013).

Collaboration between government, academia, and industry is considered to be of critical importance in enhancing regional economic and social development (Etzkowitz and Leydesdorff 2000; Klofsten et al. 2010; Urbano and Guerrero 2013). The effectiveness of tripartite collaboration has, however, been questioned, as many regions have failed to obtain expected benefits from knowledge transfer in terms of innovation, GDP, and employment (Asheim and Coenen 2005; McAdam et al. 2012). In order to address this challenge, recent policy initiatives identify the need for a more open science approach that includes social innovators involved at various stages throughout the knowledge transfer process (Wilson 2012). The inclusion of social innovators (Leydesdorff 2011) reflects the increasing importance placed on knowledge transfer to meet societal needs (Bozeman et al. 2015). It also emphasizes that knowledge transfer occurs not only between public research organizations and firms but also between public research organizations, governments, and nonprofit organizations.

Estimates of systemic financial benefits require data from surveys of firms, nonprofits, and government organizations on the uptake, application, and economic value of knowledge produced by public research organizations. This is very difficult to estimate because many innovations are built on multiple sources of knowledge. For all knowledge transfer channels, estimates need to obtain data from surveys of managers, but managers are unlikely to be able to estimate the diffuse effects of open science on their organization and often may not know or recognize the role of open science on key products (Mazzucato 2015).

A more feasible approach is to focus on formal knowledge transfer channels. Data on the economic impacts of knowledge transfer on government organizations or firms (using the data described in Section 12.5) from a random sample could be extrapolated to specific sectors. For contracts, this would require data on which contracts led to commercialized products or processes, the sector of application, and the sales revenue earned by the firm (or the value of services provided by governments) for products or imputed savings from processes. The reliability of this approach depends on the willingness of managers to volunteer information that could be commercially confidential and their ability to provide accurate retrospective information over a number of years.

Estimates of financial benefits are perhaps easiest to obtain for public research organization spinoffs on the heroic assumption that all future 
sales derive from the initial development of knowledge obtained from the public research organization at the time of establishment (Vincett 2010).

Other researchers have estimated the effect of public research organization research on GDP by combining data on running royalties (percentage of total sales) from licensed IP with estimates of the running royalty rate and the value-added components of sales from sectoral input-output models. For example, a study for the U.S. uses AUTM licensing data to estimate output from 1996 to 2010 for assumed royalty rates of 2, 5, and 10 percent. The estimated contribution to GDP in 2009 from licensing varied from USD 70.4 billion at a 2 percent royalty rate to USD 16.4 billion for a 10 percent royalty rate (Roessner et al. 2013). Although the former estimate exceeds total university R\&D expenditures in 2009 of USD 55 billion, it is important to note that the estimated contribution is based on IP developed over multiple years before 2009. The disadvantage of this method is that it is only likely to account for a small percentage of the benefits from all knowledge transfer channels.

A regular survey aimed at universities and public research organizations conducted by the State Intellectual Property Office (SIPO) of the People's Republic of China asks patent applicants about the knowledge transfer process and commercialization method and, for patented products, the total income earned from product sales. ${ }^{7}$ This information is potentially of great interest, but patent applicants may not always know the answers to questions on commercialization or income earned from product sales.

Nonfinancial systemic benefits are diverse and include improved quality of life from new therapeutic treatments for diseases, new business opportunities, and social benefits such as new educational and entertainment platforms on the Internet. These types of benefit are rarely measured, in part due to the difficulty in attaching a financial value to social outcomes. The default is to use case studies to highlight the social benefits of university research (Kearnes and Wienroth 2011). The AUTM, as part of its "better world project," includes case-study examples in its annual licensing reports of the social and economic impacts of licensed university inventions. In many cases, this is a practical solution to illustrating the range of different types of both financial and nonfinancial benefit for

7 See, for the first public release, http://english.sipo.gov.cn/news/official/201608/ t20160802_1284168.html. 
specific inventions based on knowledge produced by public research organizations.

Systemic costs are difficult to identify and estimate since they are based on "what if" situations involving unmeasurable counterfactuals. For example, a theoretical social cost would occur if academics neglect basic research with high benefits over the long term in order to pursue applied research that meets short-term industry needs.

\subsection{Conclusions}

Knowledge transfer metrics are required for benchmarking changes in performance over time and for econometric analysis to evaluate the effectiveness of policies and practices. In both high- and middleincome countries most of the existing metrics focus on IP-mediated knowledge transfer, such as the number of patents produced by universities and the amount of license income earned. The premise of this chapter is that this is insufficient - both because it sends an erroneous signal to policymakers and administrators in universities and public research institutes that IP-mediated knowledge transfer is the optimum form, resulting in distortions in incentives, and also because it is not fit for purpose, with most knowledge transferred by means of other formal and informal channels. Consequently, a comprehensive set of knowledge transfer metrics to guide policy requires collecting metrics for a diverse range of knowledge transfer channels.

In addition to the basic metrics for IP-mediated knowledge transfer (see Chapter 2), this chapter recommends collecting metrics for other formal channels (collaboration, contracts, consultancy, etc.) from universities and public research institutes (for instance, by surveying KTOs) and metrics for informal knowledge transfer methods from surveys of academics and firms. Such surveys as these can also collect useful data on the goals of academics and firms in participating in knowledge transfer and the barriers that they face. Surveys of firms in middle-income countries should also include metrics to identify differences in the use of and need for knowledge transfer by firm capabilities (see also Chapter 11 ) and the types of financial incentive that they receive from government, such as vouchers. The main topics to be covered through data collection are identified through several tables in this chapter.

Another feature of a comprehensive set of metrics is the need to collect institutional data on policies and practices for use in policy evaluation and monitoring. This is essential for determining which factors best 
promote knowledge transfer and support the absorptive capacity of firms under different conditions. For example, the set of factors that promote knowledge transfer are likely to differ depending on the outcome (startup establishments versus adoption by existing firms), interactions with other policies, firm capabilities, and the industrial structure of a country or region.

Data for all types of formal knowledge channel should be collected on an annual basis from universities and public research institutes in order to encourage them to establish rigorous administrative records for these types of knowledge transfer activity. The marginal cost of annual data collection is also likely to be very low compared to the cost of biennial or less frequent surveys. In contrast, surveys of academics and firms are expensive and consequently these surveys only need to be conducted every three to five years, possibly by contracting out surveys to academics with expertise in knowledge transfer. Data on policies and practices tend to change slowly and therefore could be collected every three to five years from KTO surveys, although an open question could be included in annual surveys of KTOs to identify recent changes.

\section{References}

Abreu, M., P. Demirel, V. Grenevich, and M. Karatas-Ozkan (2016). "Entrepreneurial practices in research-intensive and teaching led universities." Small Business Economics, 47: 695-717.

Abreu, M. and V. Grenevich (2013). "The nature of academic entrepreneurship in the UK: Widening the focus on E activities." Research Policy, 42: 408-22.

Agiar-Díaz, I., N.L. Díaz-Díaz, J.L. Ballesteros-Rodríguez, and P. De Sáa-Pérez (2016). "University-industry relations and research group productions: Is there a bidirectional relationship?” Industrial and Corporate Change, 25: 611-32.

Albuquerque, E., W. Suzigan, G. Kruss, and K. Lee (eds.) (2015). Developing National Systems of Innovation: University-Industry Interactions in the Global South. Cheltenham: Edward Elgar.

Arundel. A. and I. Kabla (1998). "What percentage of innovations are patented? Empirical estimates for European firms." Research Policy, 27: 127-41.

Asheim, B.T. and L. Coenen (2005). "Knowledge bases and regional innovation systems: Comparing Nordic clusters.” Research Policy, 34: 1173-90.

AUTM (Association of University Technology Managers) (2016). Highlights of AUTM"s Canadian Licensing Survey FY2015, Oakbrook Terrace.

AUTM (Association of University Technology Managers) (2017). AUTM U.S. Licensing Activity Survey: FY2016, A Survey Report of Technology Licensing 
(and Related) Activity for U.S. Academic and Nonprofit Institutions and Technology Investment Firms, Oakbrook Terrace.

Baldini, N., R. Grimaldi, and M. Sobrero (2006). "Institutional changes and the commercialization of academic knowledge: A study of Italian universities' patenting activities between 1965 and 2002.” Research Policy, 35: 518-32.

Barjak, F., N. Es-Sadki, and A. Arundel (2015). "The effectiveness of policies for formal knowledge transfer from European universities and public research institutes to firms." Research Evaluation, 24: 4-18.

Bekkers, R. and I.M. Bodas-Freitas (2008). “Analysing knowledge transfer channels between universities and industry: To what degree to sectors also matter?"Research Policy, 37: 1837-53.

Belitski, M., A. Aginskaja, and R. Marozau (2019). "Commercializing university research in transition economies: Technology transfer offices or direct industrial funding?" Research Policy, 48: 601-15.

Berbegal-Mirabent, J., D.E. Ribeiro-Soriano, and J.L.S. Garcia (2015). “Can a magic recipe foster university spin-off creation?” Journal of Business Research, 68: 2272-8.

Berbegal-Mirabent, J. and F. Sabate (2015). "Balancing basic and applied research outputs: A study of the trade-offs between publishing and patenting." Technology Analysis \& Strategic Management, 27: 1143-58.

Bozeman, B., H. Rimes, and J. Youtie (2015). "The evolving state-of-the-art in technology transfer research: Revisiting the contingent effectiveness model." Research Policy, 44: 34-49.

Chatterjee, D. and B. Sankaran (2015). "Commercializing academic research in emerging economies: Do organizational identities matter?” Science and Public Policy, 42: 599-613.

Cheah, S. "Framework for measuring research and innovation impact." Innovation: Management, Policy \& Practice, 18: 212-32.

Czarnitzki, D., T. Doherr, K. Hussinger, P. Schliessler, and A.A. Toole (2016). "Knowledge creates markets: The influence of entrepreneurial support and patent rights on academic entrepreneurship." European Economic Review, 86: 131-46.

De Fuentes, C. and G. Dutrénit (2012). "Best channels of academia-industry interaction for long-term benefit." Research Policy, 41: 1666-82.

Dutrénit, G. and V. Arza (2015). "Features of interactions between public research organizations and industry in Latin America: The perspective of researchers and firms." In E. Albuquerque, W. Suzigan, G. Kruss, and L. Lee K (eds.), Developing National Systems of Innovation. Cheltenham: Edward Elgar.

Etzkowitz, H. and L. Leydesdorff (2000). "The dynamics of innovation: from national systems and 'mode 2' to a triple helix of university-industrygovernment relations.” Research Policy, 29: 109-23. 
Felsenstein, D. (1996). “The university in the metropolitan arena: Impacts and public policy implications." Urban Studies, 33: 1565-80.

Finne, H., A. Arundel, G. Balling, P. Brisson, and J. Erselius (2009). Metrics for Knowledge Transfer from Public Research Organisations in Europe. Report from the European Commission's expert group on knowledge transfer metrics. Luxembourg: Office for Official Publications of the European Communities.

Freitas, I.M.B., A. Geuna, and F. Rossi (2013). "Finding the right partners: Institutional and personal modes of governance of university-industry interactions." Research Policy, 42: 50-62.

Geuna, A. and F. Rossi (2011). "Changes to university IPR regulations in Europe and the impact on academic patenting." Research Policy, 40: 1068-76.

Grimpe, C. and K. Hussinger (2013). "Formal and informal knowledge and technology transfer from academia to industry: Complementarity effects and innovation performance." Industry and innovation, 20: 683-700.

Hayer, C.S. (2016). "A trajectory of early-stage spinoff success: The role of knowledge intermediaries within an entrepreneurial university ecosystem.” Small Business Economics, 47: 633-56.

HEFCE (Higher Education Funding Council for England) (2017). Higher Education - Business and Community Interaction Survey 2015-16. London: HEFCE.

Holi. M., R. Wickramasinghe, and M. van Leeuwen (2008). Metrics for the Evaluation of Knowledge Transfer Activities at Universities. Cambridge: Library House.

Hughes, A. and M. Kitson (2012). "Pathways to impact and the strategic role of universities: New evidence on the breadth and depth of university knowledge exchange in the UK and the factors constraining its development." Cambridge Journal of Economics, 36: 723-50.

Jensen, P.H., A. Palangkaraya, and E. Webster (2009). "A guide to metrics on knowledge transfer from universities to businesses and industry in Australia." Knowledge Commercialisation Australasia, September.

Kafouros, M., C. Wang, P. Piperopoulis, and M. Zhang (2015). “Academic collaborations and firm innovation performance in China: The role of region-specific institutions." Research Policy, 44: 803-17.

Kearnes, M. and M. Wienroth (2011). "Tools of the trade: UK research intermediaries and the politics of impacts.” Minerva, 49: 153-74.

Klofsten, M., P. Heydebreck, and D. Jones-Evans (2010). “Transferring good practice beyond organizational borders: Lessons from transferring an entrepreneurship programme." Regional Studies, 44: 791-9.

Kruss, G., J.O. Adeoti, and D. Nabudere (2015). "Bracing for change: Making universities and firms partners for innovation in sub-Saharan Africa." In 
E. Albuquerque, W. Suzigan, G. Kruss, and K. Lee (eds.), Developing National Systems of Innovation. Cheltenham: Edward Elgar.

Leydesdorff, L. (2011). “The triple helix, quadruple helix, and an N-tuple of helices: Explanatory models for analyzing the knowledge-based economy?"Journal of the Knowledge Economy, 3: 25-35.

Link, A.N., D.S. Siegel, and B. Bozeman (2007). "An empirical analysis of the propensity of academics to engage in informal university technology transfer." Industrial and Corporate Change, 16: 641-55.

Lockett, A., M. Wright, and A. Wild (2015). "The institutionalization of third stream activities in UK higher education: The role of discourse and metrics." British Journal of Management, 26: 78-92.

Markman, G.D., P.T Gianiodis, P.H. Phan, and D.B. Balkin (2004). "Entrepreneurship from the Ivory tower: Do incentive systems matter?" Journal of Technology Transfer, 29: 353-64.

Mazzucato, M. (2015). The Entrepreneurial State, US ed. New York: Public Affairs.

McAdam, R., K. Miller, M. McAdam, and S. Teague (2012). “The development of university technology transfer stakeholder relationships at a regional level: Lessons for the future." Technovation, 32: 57-67.

Muscio, A., D. Quaglione, and L. Ramaciotti (2016). "The effects of university rules on spinoff creation: The case of academia in Italy.” Research Policy, 45: 1386-96.

Muscio, A. and A. Pozzali (2013). "The effects of cognitive distance in university-industry collaborations: Some evidence from Italian universities." Journal of Technology Transfer, 38: 486-508.

NESTA (2018). European Innovation Scoreboard 2018: Exploratory Report B: Toward the Incorporation of Big Data in the European Innovation Scoreboard. Luxembourg: European Commission.

OECD/Eurostat (2018). Oslo Manual: Guidelines for Collecting, Reporting and Using Data on Innovation, 4th edn. Luxembourg: OECD Publishing Paris/Eurostat.

Okamuro, H. and J. Nishimura (2013). "Impact of university intellectual property policy on the performance of university-industry research collaboration." Journal of Technology Transfer, 38: 273-301.

Perkman, M., A. Neely, and K. Walsh (2011). "How should firms evaluate success in university-industry alliances? A performance measurement system." R\&D Management, 41: 202-16.

Perkman, M., V. Tartari, and M. McKelvey (2013). "Academic engagement and commercialisation: A review of the literature on university-industry relations." Research Policy, 42: 423-42.

Roessner, D., J. Bond, S. Okubo, and M. Planting (2013). “The economic impact of licensed commercialized inventions originating in university research." Research Policy, 42: 23-34.

Rosli, A. and F. Rossi (2014). Explaining the Gap between Policy Aspirations and Implementation: The Case of University Knowledge Transfer Policy in the 
United Kingdom. Working Paper no. 20. CIMR Research Working Paper Series. London: Birkbeck College.

Rossi, F. and R.A. Rosli (2015). "Indicators of university-industry knowledge transfer performance and their implications for universities: Evidence from the United Kingdom." Studies in Higher Education, 40: 1970-91.

Salter, A.J. and B.R. Martin (2001). "The economic benefits of publicly-funded basic research: A critical review." Research Policy, 30: 509-32.

Schiller, D. and K. Lee (2015). "Are university-industry links meaningful for catch up? A comparative analysis of five Asian countries." In E. Albuquerque, W. Suzigan, G. Kruss, and K. Lee (eds.), Developing National Systems of Innovation. Cheltenham: Edward Elgar.

Shen, Y.-C. (2003). "Identifying the Key Barriers of University-Industry Linkage in Taiwan.” Paper presented at ISPIM Innovation Forum, Boston, March 13-16, 2016. Siegel, D.S., D. Waldman, and A. Link (2003). "Assessing the impact of organizational practices on the relative productivity of university technology transfer offices: An exploratory study." Research Policy, 32: 27-48.

Sigurdson, K., C.M. Sa, and A. Kretz (2015). "Looking for the street light: Limitations of mainstream technology transfer indicators." Science and Public Policy, 42: 632-45.

Tartari, V. and S. Breschi (2012). "Set them free: Scientists' evaluations of the benefits and costs of university-industry research collaboration." Industrial and Corporate Change, 21: 1117-47.

Thursby, G. and M.C. Thursby (2007). "University licensing." Oxford Review of Economic Policy, 23: 620-39.

Urbano, D. and N. Guerrero (2013). "Entrepreneurial universities: Socioeconomic impacts of academic entrepreneurship in a European context." Economic Development Quarterly, 27: 40-55.

Van Dierdonck, R., K. Debackere, and B. Engelen (1990). "University-industry relationships: How does the Belgian academic community feel about it?" Research Policy, 19: 551-66.

Van Looy, B., P. Landoni, J. Callaert, B. Van Pottelsberghe, E. Sapsalis, and K. Debackere (2011). "Entrepreneurial effectiveness of European universities: An empirical assessment of antecedents and trade-offs." Research Policy, 40: 553-64.

Van Looy, B., Ranga, M., Callaert, J., K. Debackere, and E. Zimmermann (2004). "Combining entrepreneurial and scientific performance in academia: Towards a compounded and reciprocal Matthew-effect?" Research Policy, 33: 425-41.

Verspagen, B. (1999). "Large firms and knowledge flows in the Dutch R\&D System: A case study of Philips Electronics." Technology Analysis \& Strategic Management, 11: 211-33.

Veugelers, R. (2016). "The embodiment of knowledge: Universities as engines of growth." Oxford Review of Economic Policy, 32: 615-31. 
Vincett, P.S. (2010). "The economic impacts of academic spin-off companies and their implications." Research Policy, 39: 736-47.

Walshok, M.L. and J.D. Shapiro (2014). "Beyond tech transfer: A more comprehensive approach to measuring the entrepreneurial university." Advances in Entrepreneurship, Firm Emergence and Growth, 16: 1-36.

Weckowska, D.M. (2015) "Learning in university technology transfer offices: Transactions-focused and relations-focused approaches to commercialization of academic research." Technovation, 41-42: 62-74.

Wilson, T. (2012). A Review of Business-Industry Collaboration. London: Department for Business, Innovation, and Skills.

Woltmann, S. (2018). “Traces of Knowledge: Benchmarking Novel Text Mining Based Measurements." Proceedings of the DRUID Academy.

Zhang, Q., N.G. MacKenzie, D. Jones-Evans, and R. Huggins (2016). "Leveraging knowledge as a competitive asset? The intensity, performance and structure of universities entrepreneurial knowledge activities at a regional level." Small Business Economics, 47: 657-75. 


\section{Comment 12.1}

PHILIPPE KUHUTAMA MAWOKO

Africa has become an investment magnet thanks to its general economic performance as measured by a continuous improvement of its gross domestic product (GDP) and its population dynamics. Africa's GDP increased by 3.5 percent in 2018, about the same as in 2017 and up from 2.1 percent in 2016. This growth is projected to accelerate to 4.0 percent by the end of 2019 and 4.1 percent in 2020. ${ }^{1}$ Projections of population growth predict that the African population is likely to reach 1.7 billion by $2030 .^{2}$ These prospects have created an environment in which foreign firms and development partners are bound to interact with local firms and institutions. This has led to a complex and crowded policy environment that, if properly managed, will lead to good business outlooks, employment, and well-being for the African population.

In this space, technology and knowledge transfer will undoubtedly play a pivotal role in sustaining these undertakings. Consequently, relevant metrics will be required to produce evidence on which better policy can be made. Metrics will also facilitate better understanding and management of the complex patterns and interrelationships that will likely emerge. So, knowledge needs to be acquired, stored, created, disseminated, and improved on or added into existing knowledge. To that end, we welcome the chapter by Anthony Arundel and Nordine Es-Sadki, on which we are pleased to comment from an African perspective.

\section{STISA's Call for Knowledge Transfer Metrics}

The African Union adopted its current Strategy for Science, Technology, and Innovation (STISA-24) in 2014. Its implementation is going through a Monitoring and Evaluation (M\&E) phase which requires, among other

1 African Economic Outlook (2019), www.afdb.org/fileadmin/uploads/afdb/Documents/ Publications/2019AEO/AEO_2019-EN.pdf.

2 www.un.org/en/development/desa/population/publications/pdf/trends/Population2030.pdf. 
things, an inclusive set of metrics that gauge the transfer of knowledge between various actors in order to reinforce the M\&E relevance for facilitating evidence-based, transparent, and accountable decision making (Chux et al. 2018). This chapter discusses themes that are undoubtedly of use to the STISA M\&E processes. These are the basic metrics for non-IP-mediated knowledge transfer, metrics for policy and practices related to knowledge transfer activities, and metrics to gauge the costs and benefits of knowledge transfer.

However, STISA has embraced a broader concept of knowledge that includes formal or codified tacit knowledge as well as traditional or indigenous knowledge. Tacit knowledge needs to be understood well especially for service industries, which are becoming a vital source of income and employment in Africa. Yes, tacit knowledge is difficult to write down, visualize, or transfer from one person to another but it underpins several innovations in the service sector, as shown by the Community Innovation Survey (CIS) ${ }^{3}$ conducted in about thirty African countries. The compilation and sharing of lessons learnt and other experiences and stories could be used alongside the CIS questionnaire to capture tacit knowledge. However, traditional knowledge transfer will need its own family of metrics to measure its dynamics.

STISA was designed in a way that responds to the demand of STI from socioeconomic sectors by embedding STI in those sectors. It outlines the key priorities that countries in Africa should collectively address through a series of innovative programs and projects. In that manner, the strategy aims to position STI to contribute toward Africa's transition to a knowledge-based economy. This strategy requires buy-in from, and collaboration between, state and nonstate actors at various level of implementation. These include continental, regional, and national public institutions, the private sector, research institutions, and actors operating in the formal and informal sectors, as well as a significant cluster of multinational and development partners operating on the continent. In this complex environment, the set of metrics for knowledge transfer highlighted in the Arundel and Es-Sadki chapter will play a critical role if STISA seeks societal-led knowledge transfer in extending Africa's development toward a knowledge-based economy.

The metrics for non-IP-mediated knowledge transfer need to be expanded and adapted to collate relevant data that will feed the analysis of the critical factors that underpin tacit knowledge. The CIS referred to

3 African Innovation Outlook Series I (2014) \& II, 2014. 
above indicates that innovation is a connected activity. Innovative firms in Africa collaborate and their first choice of collaborator is the client or customer. Thus, knowledge transfer happens and needs to be measured. This is a link that needs to be expanded for additional data collection regarding tacit knowledge. Finally, there is a need to establish a consensus on a framework to connect the informal economy, innovation, and intellectual property to round up the measurement agenda for STISA as far as "moving the continent towards a knowledge-based economy" is concerned. As a matter of fact, the informal sector plays a major role in the national economies, as measured by the share of its contribution to GDP. This is estimated to be between 25 and 45 percent, and its contribution to employment ranges from 3 percent to 90 percent. In this context, both African Innovation Outlook series pointed to several areas that need further research, including the definition of comparable indicators for policy purposes, understanding how innovation takes place in the informal economy, and how knowledge is passed between generations, and the barriers, incentives, and linkages between the informal and formal sector dynamics.

\section{Measurement Challenges for New Data Dynamics in Africa}

New technologies can help African countries harness new sources of data and indicators by exploring knowledge transfer mechanisms between socioeconomic actors operating at the time of the Fourth Industrial Revolution (4IR).

The advent of the African Continental Free Trade Agreement (AfCFTA) would, in its optimal operational phase, transform the continent into a single market of a billion people with a combined GDP estimated to reach USD 2.5 trillion. ${ }^{4}$ The AfCFTA was signed in 2018 by the African countries. In this context, public policies, especially those related to the digital divide, trade regulations, and tariffs, ought to be amended or transformed to support free movement of capital and to sustain the single continental market for goods and services.

Other interesting advances to note concern the regional and continental dialogues that are taking place in the areas related to the 4IR. For instance, at their meeting in September 2017, ministers responsible for information and communication technology (ICT) of the Southern

4 www.un.org/africarenewal/magazine/august-november-2018/africa-set-massive-freetrade-area. 
African Development Community (SADC) noted that their region is on the brink of a technological revolution that will fundamentally alter the way people live, work, and relate to one another, and, in this regard, they signed the Declaration on the Fourth Industrial Revolution to guide the development of regional programs and projects. ${ }^{5}$ The Declaration is a commitment to preparing SADC for the Fourth Industrial Revolution through the use of ICT. The Declaration also calls for harmonization of enabling digital policies and universal access to critical broadband infrastructure.

The continent has also been home to several innovations, including the digital payment system (M-PESA), made in Kenya - which is gradually boosting many services ranging from e-commerce to healthcare and transportation. Blockchain technology has been trialed in areas of microlending. The Africa blockchain conference, which was due to be held in March 2020, offers an opportunity for African researchers to explore how this technology might simplify and streamline systems and processes across various industries. The question that begs for an answer remains: How to measure? What are the appropriate and relevant metrics to measure knowledge transfer?

Measuring knowledge transfer in this new era will require defining new sources of data. As pointed out by Arundel and Es-Sadki, big data and web-scraping would be the technologies for continental institutions like AOSTI to explore and invest in by continental institutions like the African Observatory for Science, Technology, and Innovation (AOSTI).

\section{Conclusion}

The production of the African Innovation Outlook Series, including the bibliometrics series produced by AOSTI, shows the importance of better understanding the transfer and application of knowledge between firms, policymaking institutions, research institutions, and the public. Yet the African measurement community needs to invest in metrics related to knowledge activities, especially knowledge transfer. The chapter by Arundel and Es-Sadki is an important step that needs to be extended by collecting more African examples. It is also important to gain knowledge on big data, blockchain, artificial intelligence, and the Internet of Things through case studies across impact sectors in the African contexts highlightedhere.

5 www.sadc.int/files/6315/6115/1098/Statement_ET-STI_21_June_2019_final.pdf. 


\section{References}

African Union (2014). Science, Technology and Innovation Strategy for Africa (STISA2024). 2014. https://au.int/sites/default/files/newsevents/workingdocuments/ 33178-wd-stisa-english_-_final.pdf.

Chux, C., K.P. Mawoko, and A. Konte (2018). Evaluating Science, Technology and Innovation Policies in Africa: Insights from the Science, Technology, and Innovation Strategy for Africa 2024 (STISA-2024). African Observatory for Science, Technology and Innovation (AOSTI) policy brief. 


\title{
Comment 12.2
}

\author{
GI A N CARLO CARATTI I
}

A consensus exists that the EU's excellence in the realm of scientific research does not translate into a correspondingly high level of performance in terms of technological innovation. The perceived failure of European countries to turn scientific advances into marketable innovations is often termed the "European paradox." The innovation landscape is undergoing profound changes due to the accelerating pace of technological development, the globalization of markets, and the shortening economic life of products and processes. Hence, support frameworks for innovation and knowledge transfer are foreseen to play a highly significant role in the forthcoming EU Multiannual Financial Framework (MFF).

Although some scholars doubt the validity of this paradox, claiming that it is also a question of lower scientific quality and weak industry (Dosi et al. 2006), it is undisputable that Europe is lagging behind in terms of exploitation of its research and this is also matter of culture, for example, risk aversion, inertia, and resistance to change in universities, limited financial availability connected to an incomplete internal market, and delays in enacting legislation encouraging the exploitation of R\&D such as the Bayh-Dole Act of 1980 in the United States of America (U.S.).

Knowledge transfer offices (KTOs) play a strategic role in innovation in Europe. The adoption of standard metrics and standardized performance measurements is crucial to monitor and measure the KTOs' annual activities, and to compare and combine their results so as to get a global view of the European situation.

Many KTOs have established specialized staff and services for assessing knowledge transfer in terms of disclosed inventions, patenting, research agreements, licensing and developing, and funding spinoffs and startups. The European Commission recognizes the need for

1 The opinions expressed are those of the author only and do not necessarily reflect the position or opinion of the European Commission. 
comparable and consistent metrics across Europe regarding knowledge transfer (KT) activities in public research organizations.

A European Commission Expert Group on KT Metrics was established in 2008 in order "to identify indicators used in several existing recurrent surveys and nominate a small selection of these as core indicators, and agree on a harmonised set of definitions for them" (European Commission 2009).

Over time, the need for coherent KT metrics at the European level is still felt, and the results of the 2008 Expert Group need to be updated to take into account the specific evolving priorities, such as artificial intelligence, the Internet of Things, climate change, and the greater attention consumers are paying to the social and environmental impacts of industrial products.

In this context, a new Expert Group on Metrics for Knowledge Transfer was set up in 2019 by the European Commission's Competence Centre on Technology Transfer (CC TT), in partnership with ASTP (pan-European association for professionals involved in knowledge transfer between universities and industry) and its network of National Associations Advisory Committee (NAAC), in order to review the past work toward a key set of harmonized KT indicators that would be accepted by most in Europe. Therefore, the input provided from the authors in this chapter is both timely and useful.

The CC TT is a new service of the Joint Research Centre, which was established in 2018, and its core mission is to provide expert services to European Commission Directorates-General, regional and local authorities, and relevant stakeholders in three key areas: knowledge transfer operational support, financial instrument conception and design, and support for innovation ecosystems and clusters.

The new expert group on metrics for knowledge transfer will take into account the indicators from the European Commission report "Metrics for Knowledge Transfer from Public Research Organisations in Europe" (European Commission 2009) recent literature, current transnational and national surveys, and interviews and recommendations from national KT associations, gathered in the ASTP NAAC.

The expert group will adopt a broad concept in which knowledge transfer incorporates all functions that can lead to improved use of knowledge developed and held in the research sector for the benefit of society and its individuals. The main objectives of this expert group are the implementation of a core set of harmonized indicators, including identified risk mitigation, and the setting up of recommendations on IT 
infrastructures able to manage pan-European KT metrics data (database, security). The deliverables will be published in 2020. The expert group gathers experienced practitioners of technology and knowledge transfer with experience in $\mathrm{KT}$ activities and output measurement at a regional, national, or transnational level.

Anthony Arundel and Nordine Es-Sadki's chapter correctly points out that the indicators collected by KTOs are not capturing a significant part of knowledge transfer, which is transferred via tacit channels and, increasingly, via open science. Therefore putting emphasis only on codified knowledge may provide a distorted analysis of the ability of a research organization to transfer its knowledge. The authors propose additional indicators using specific surveys of academics or firms to complement the data from KTOs. In my view, this is an interesting proposal from a theoretical point of view but it is also very challenging to put into practice. Besides the high organizational costs of consulting a large number of academics and industries (and their survey fatigue), ASTP already finds it challenging to consult the existing KTOs in Europe, with the result that their statistical data have a skewed geographic coverage. One of the reasons is that the current set of indicators is probably too large, and many small KTOs cannot regularly monitor all of them. One of our recommendations to the experts undertaking the review of the KT metrics would therefore be to develop as simple as possible a system of indicators and to specify other potentially important factors, in most cases nonmeasurable, that contribute to the success of the knowledge transfer process. Some expert readers will be aware of "Goodhart's Law": "when a measure becomes a target, it ceases to be a good measure."

\section{References}

Dosi, G., P. Llerena, and M. Sylos Labini (2006). The Relationships Between Science, Technologies and Their Industrial Exploitation: An Illustration Through the Myths and Realities of the So-Called "European Paradox." Amsterdam: Elsevier.

European Commission (2009). Metrics for Knowledge Transfer from Public Research Organisations in Europe. Report from the European Commission's Expert Group on Knowledge Transfer Metrics. ec.europa.eu/invest-in-research /pdf/download_en/knowledge_transfer_web.pdf. 


\section{Comment 12.3}

AMIT SHOVON RAY

This chapter makes an important contribution to the literature on knowledge transfer from public research organizations by expanding its scope well beyond the conventional IP-driven channel. After the enactment of the Bayh-Dole Act of 1980 in the United States of America (U.S.), academic and policy attention centered on streamlining the "clumsy" IPR frameworks prevalent in public research organizations across the world. Enthused by the US legislation, many countries, both developed and emerging (France, Denmark, Japan, Brazil, China, and South Africa, among others), started enacting their own Bayh-Dole-type legislations from the late 1990s onward. There prevailed a sense of faith in such legislation as though it would act as a magic formula to energize public-funded research for knowledge transfer in different countries. However, the subsequent academic literature on the US post-Bayh-Dole experience suggests that the evidence in this regard is far from unambiguous (Ray and Saha 2011). This has not only raised questions about the effectiveness of IP as a vehicle of knowledge transfer from public research organizations but also redirected policy focus in many countries toward other (perhaps more) important channels of knowledge transfer, hitherto underemphasized.

The need to expand the scope of knowledge transfer from public research organizations to other formal and informal channels, like collaborations, contracts, consultancies, use of public research organization facilities and infrastructure, training, student placements, and so on, is now fairly well established in academic and policy circles, and many of these channels are now frequently used for knowledge transfer in both developed and emerging nations. However, there is still a lack of comprehensive information metrics for the non-IP channels, the United Kingdom being a noted exception in this regard, as highlighted by the authors in the chapter. The British Higher Education-Business and Community Interaction (HE-BCI) survey collects data on knowledge transfer activities of British universities through multiple channels. In 
fact, using these data, Sengupta and Ray (2017) showed that among the various channels of knowledge transfer in British universities, it is only the academic exchange channel (contracts and collaborations) that brings about a virtuous cycle. They showed that a large research base leads to greater knowledge transfer through this channel, some of which, in turn, further augments the research base, thus completing the virtuous cycle. Studies on other countries have relied primarily on sample surveys or case studies of knowledge transfer offices (KTO) and academic researchers (in some cases). One of the few studies for India on the subject is by Ray and Saha (2012) - a study commissioned by the Department of Science and Technology, Government of India. It highlighted the importance of non-IP channels for selected Indian publicfunded institutions. Based on case studies of six public research organizations in India, Ray and Saha (2012) found that while success stories of effective knowledge transfer through the IP-driven channel in many of these institutions are limited in number, many of these Indian public research organizations do engage in knowledge transfers significantly and effectively through various non-IP channels.

Despite such compelling evidence on the importance of non-IP channels of knowledge transfer in different countries, there has unfortunately been very little attempt until now to construct comprehensive metrics of knowledge transfer activities, including the various facets of non-IP channels. The chapter by Arundel and Es-Sadki fills this very important gap in the knowledge transfer literature. Without such a comprehensive database, knowledge transfer activities can never be fully captured and understood for appropriate policy interventions. Informational bias toward the IP-mediated channels may lead to distortion of policy prioritization, resulting in suboptimal knowledge transfer through the other important channels. In drawing up these comprehensive metrics of knowledge transfer activities, the authors have correctly distinguished between three different methods of data collection from three distinct sources: (1) KTOs and the public research organization administration, (2) surveys of academics and researchers at public research organizations, and (3) firm-level surveys. The importance of combining all three sources stems from the fact that the conventional source, that is, the KTOs, may not have information on all channels of knowledge transfer, particularly the informal ones. Moreover, perceptions about the relative importance of different channels of knowledge transfer and their determinants and barriers may diverge widely among the three sets of stakeholders. The paper contains an elaborate and useful discussion of the 
types of data that can be collected through each of these modes of data collection and their limitations.

While reiterating the importance of collecting data through multiple modes to create comprehensive metrics, I would like to add a word of caution and a suggestion. First, if one ends up collecting information on the same variable from all three sources, there is a possibility of ending up with data discrepancies. For instance, the number of cases of knowledge transfer through licensing reported by the KTO may or may not exactly tally with the total number of these cases reported in the survey of academics. One must, therefore, have a well-designed strategy to tackle such data discrepancies. Second, academics are often survey fatigued, as they are regularly bombarded with questionnaires asking for the same factual information along with some questions on their perceptions. As a result, academics are often reluctant to respond to survey questionnaires. This is highly avoidable if the public research organization administration mandates that all researchers submit a comprehensive annual report of their academic activities undertaken in the preceding academic year, including an extensive set of information pertaining to their knowledge transfer activities through multiple channels. This could form a database of factual information that would be compiled by the public research organization and made available in the public domain. Such databases could be used for numerous purposes by multiple agencies and stakeholders. The public research organization will use this information to prepare its annual reports. Funding agencies (government and nongovernment) may use this information to assess the performance and accountability of public research organizations. National and international ranking agencies may use it for ranking and accreditation purposes. And, most importantly, this database would go a long way in constructing comprehensive metrics for knowledge transfer activities. The survey of academics could then be restricted to a much smaller set of questions only about their perceptions of the knowledge transfer policies and practices. A smaller questionnaire would allow a larger sample to be surveyed with little or no escalation of the survey costs, a challenge highlighted by the authors. Enlarging the sample size could potentially mitigate the sample selection bias of small sample surveys that tend to ignore academics and departments with little or no knowledge transfer experience.

The final section of the chapter highlights another very important aspect of knowledge transfer, namely, the metrics of costs and benefits. This is a complex issue as both costs and benefits include a large number 
of elements that cannot be adequately captured purely in financial terms. The authors present a detailed discussion of the systemic benefits and costs as well as the benefits and costs to the public research organizations and to the firms, focusing on both financial and nonfinancial elements. The authors do acknowledge that nonfinancial benefits and costs are more difficult to measure, especially in a format that is amenable to comparisons over time, both nationally and internationally. But, unfortunately, we fail to find much in the chapter by way of clear directions in this regard. Likewise, the authors also highlight the difficulties of identifying and estimating the systemic benefits and costs. But again, we do not find any concrete guidelines here to overcome this difficulty in order to come up with comparable measures of systemic costs and benefits. Of course, neither of these limitations has a simple solution. It could be a matter of another extensive research study just to explore possible solutions to the highlighted problems of measuring the costs and benefits of knowledge transfer. Nevertheless, one must acknowledge that the chapter makes a good beginning by flagging the issues and concerns pertaining to the creation of comparable metrics of benefits and costs.

Overall, the chapter makes a significant value addition to the scholarship by putting forward a concrete pathway for generating comprehensive metrics of knowledge transfer activities - facts, policies, and practices. If the framework proposed by the authors, along with the suggestions given here, were to be implemented judiciously, it could go a long way in providing incisive insights on various facets of knowledge transfer activities and their determinants and obstacles in different contexts, regions and time periods.

\section{References}

Ray, A.S. and S. Saha (2011). "Patenting public-funded research for knowledge transfer: A conceptual-empirical synthesis of U.S. evidence and lessons for India." Journal of World Intellectual Property, 14 (1): 75-101.

Ray, A.S. and S. Saha (2012). Commercialisation of Inventions from Public Funded Research in India - Case Studies of Selected Institutions. Project Report submitted to the Department of Science \& Technology, Government of India, June 2012.

Sengupta, A. and A.S. Ray (2017). "University research and knowledge transfer: A dynamic view of ambidexterity in British universities." Research Policy, 46 (5): 881-97. 


\section{Survey on Policies and Practices for IP-Mediated Knowledge Transfer ${ }^{1}$}

\section{General Information about the Institution}

1. Number of academic and other research-active employees:

Full-time (35 hours per week or more):

Part-time (less than 35 hours per week):

2. Number of $\mathrm{PhD}$ students:

3. In which of the following technical fields does your university/PRO conduct research?

More than one answer is possible.

$\square$ Agriculture

Biotechnology

Chemistry

Medical Sciences*

$\square$ Operation and

Transportation

$\square$ Mechanical Engineering

$\square$ Electrical Engineering

Other $\square$ Computer Engineering

$\square$ Chemical Engineering

$\square$ Industrial Engineering

$\square$ Civil Engineering

$\square$ Environmental

Engineering

$\square$ Physics

Electronics and

Telecommunications

${ }^{*}$ Include pharmaceuticals, medical instruments and technologies, etc.

1 This questionnaire is a modified version of the WIPO Assessment Questionnaire for Stakeholders from Academic and Research Institutions developed by the Intellectual Property Policies for Universities Focus Group. It is meant as a template only for policies and practices to support IP and IP mediated knowledge transfer. Questions for specific types of IP, such as copyright, or trademarks, can be added as needed. 
4. What are the primary roles/missions of your institution? More than one answer is possible.

$\square$ Teaching/education

Social sciences research (humanities, business, economics, etc.)

$\square$ STEM research (science, technology, engineering, mathematics)

$\square$ Medical and health sciences research

$\square$ Visual and performing arts (painting, sculpture, dance, theatre, film, etc.)

$\square$ Other (please explain)

5. Does your institution have any IP policies (including IP regulations, guidelines, rules, etc.) relevant to the creation, ownership and protection of IP, knowledge transfer, or commercialization activities?

Yes

No

Don't know/Not relevant

\section{Ownership of IPRs Created at Your Institution \\ Questions 7-10 only need to be answered if your institution has an IP policy}

6. Does your institution's IP policy regulate ownership of the following IPRs that are created within the institution? More than one answer is possible.

$\square$ Patents

$\square$ Copyright

$\square$ Industrial designs

$\square$ Utility models

$\square$ Trademarks

$\square$ Plant varieties

$\square$ Trade secrets/confidential business information

$\square$ No, it does not regulate ownership of any IPRs

$\square$ Don't know/Not relevant

7. Does your institution's IP policy follow national regulations on the ownership of IPRs?

$\square$ Yes, the institution's policies follow the national regulations

$\square$ Yes, but the institution's policies include areas not covered by the national regulations 
No, because there are no relevant national regulations

No, the IP policy alters the national regulations

Don't know/Not relevant

8. Who owns the IP when research is funded by public or private sources?*

More than one answer is possible.

\begin{tabular}{|l|l|l|}
\hline IP owner & $\begin{array}{l}\text { Funded by public } \\
\text { sources }\end{array}$ & $\begin{array}{l}\text { Funded by private } \\
\text { (business) sources }\end{array}$ \\
\hline University/PRO & $\square$ & $\square$ \\
\hline Funding organization/business & $\square$ & $\square$ \\
\hline Inventor(s) & $\square$ & $\square$ \\
\hline Other & $\square$ & $\square$ \\
\hline Don't know/Not relevant & $\square$ & $\square$ \\
\hline
\end{tabular}

If other, please explain.

*Include both research funded under contract, for instance for a private business or government department, and research funded through research grants.

9. If the inventor/creator may own the IP: Which of the following types of inventor or creator can become owners of IPRs (excluding copyright) at your institution? More than one answer is possible.

Students

PhD students

Researcher-employees

Professors

Visiting researchers (include researchers on exchange from other organizations and honorary appointees).

$\square$ Don't know/Not relevant 


\section{IP and Technology Management in the Institution}

\section{IP Disclosure Form}

10. Are academics and/or researchers required to report inventions with possible commercial applications?

$\square$ Yes
$\square$ No
$\square$ Don't know/Not relevant

11. Is there a well-defined procedure for evaluating the potential commercial value of research produced by your institution?

$\square$ Yes

$\square$ No

Don't know/Not relevant

12. If yes to question 12: Who is responsible for reviewing research results for their potential commercial application and/or possible protection by IPRs? More than one answer is possible.

Administration officer/office

$\square$ University/PRO department where the invention was made

Inventor/creator

Knowledge transfer officer/office owned by or affiliated with the university/PRO

$\square$ Private company (not part of or owned by the University/PRO)

Other (please explain)

Don't know/Not relevant

\section{IP Protection and Protection Against Infringement}

13. Does your institution have policies or guidelines on confidentiality to protect IP?

Yes

No

Don't know/Not relevant 


\section{Commercialization}

14. Does your institution have regulations, guidelines or an IP policy for the commercialization of IP created at your institution?

$\square$ Yes

No

$\square$ Don't know/Not relevant

15. Who manages IP for your institution, including the negotiation of licenses? More than one answer is possible.

$\square$ Administration officer/office

$\square$ University/PRO department where the invention was made

$\square$ Inventor/creator

$\square$ Knowledge transfer officer/office owned by or affiliated with the University/PRO

$\square$ Private company (not part of or owned by the University/PRO)

$\square$ Other (please explain)

$\square$ Don't know/Not relevant

16. Does your institution have a budget for filing, defending and/or maintaining IPRs?

$\square$ Yes

No

$\square$ Don't know/Not relevant

17. Who shares in the financial benefits resulting from the exploitation of IP?

More than one answer is possible.

$\square$ Institution

$\square$ University/PRO department where invention was conceived

$\square$ Inventor/creator

$\square$ Government or other public funding body

$\square$ Other (please explain)

$\square$ Don’t know/Not relevant 
18. Does your institution provide any of the following types of support for its spin-off companies? More than one answer is possible.

Startup capital

$\square$ Releasing researchers/academics to (partially) work in the spinoff company

Incubator units

Management and/or administrative support from the institution Other (please explain)

\section{Don't know/Not relevant}

\section{Incentives}

19. Does your institution provide any of the following incentives or assistance to encourage staff to actively assist in implementing the IP policy? More than one answer is possible.

\begin{tabular}{|l|l|l|l|}
\hline & Yes & No & $\begin{array}{l}\text { Don't know/ } \\
\text { Not relevant }\end{array}$ \\
\hline $\begin{array}{l}\text { 1. Funding of research projects to further } \\
\text { develop the IP }\end{array}$ & $\square$ & $\square$ & $\square$ \\
\hline 2. Training on IP/technology management & $\square$ & $\square$ & $\square$ \\
\hline $\begin{array}{l}\text { 3. Nonfinancial rewards to inventors (e.g., } \\
\text { promotion scheme, public } \\
\text { acknowledgement or invention } \\
\text { certificates, etc.) }\end{array}$ & $\square$ & $\square$ & $\square$ \\
\hline $\begin{array}{l}\text { 4. Academic recognition/reward } \\
\text { 5. Financial rewards to inventors (e.g.. } \\
\text { participation in licensing income) }\end{array}$ & $\square$ & $\square$ & $\square$ \\
\hline $\begin{array}{l}\text { 6. Assistance in IP management (e.g., human } \\
\text { resources, patent information search, }\end{array}$ & $\square$ & $\square$ & $\square$ \\
\hline
\end{tabular}




\begin{tabular}{|l|l|l|l|}
\hline & & & $\begin{array}{l}\text { Don't know/ } \\
\text { Not relevant }\end{array}$ \\
\hline $\begin{array}{l}\text { marketing research, patentability } \\
\text { evaluation, commercialization, etc.) }\end{array}$ & No & & \\
\hline $\begin{array}{l}\text { 7. Grants for IP protection costs (e.g., patent } \\
\text { filing fees, prototype creation and/or legal } \\
\text { fees) }\end{array}$ & $\square$ & $\square$ & $\square$ \\
\hline $\begin{array}{l}\text { 8. Assistance with a startup/spinoff (e.g., help } \\
\text { for developing a business plan, market } \\
\text { research, finance, identifying business } \\
\text { partners, etc.) }\end{array}$ & $\square$ & $\square$ & $\square$ \\
\hline \begin{tabular}{l} 
9. Other (please explain): \\
\hline
\end{tabular} & $\square$ & $\square$ & $\square$ \\
\hline
\end{tabular}

\section{Engagement with Third Parties}

20. How are contacts established between potential commercialization partners and your institution? More than one answer is possible.

$\square$ Knowledge transfer officer/office identifies contacts

$\square$ Inventor(s)/researchers identify contacts

$\square$ Advertising or technology databases

$\square$ Scientific conferences/seminars

$\square$ Other (please explain)

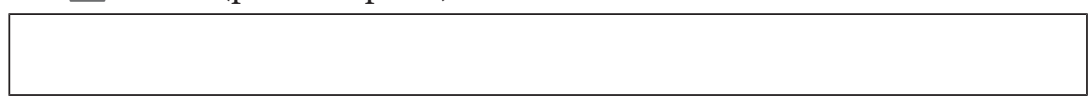

\section{Don't know/Not relevant}

21. Are there written rules or guidelines for licensing, including model contracts?

Yes (please explain)

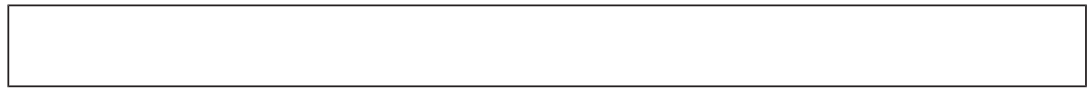

No

Don't know/Not relevant 
22. Are the rules for licensing flexible?

Yes (please explain)

\section{No}

Don't know/Not relevant

23. Are there rules or guidelines for exclusive versus nonexclusive licenses?

Yes (please explain)

\section{$\square$ No}

Don't know/Not relevant

\section{Funding Sources for Research and Development (R\&D)}

24. Approximately what percent of your institution's total research expenditures are funded by the following types of organization? Estimates are acceptable.

$\square$ National governments* $\%$

Private sector (businesses)

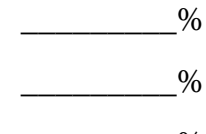

International funding agencies ${ }^{* *}$ $\%$

Other (please explain)

Don't know/Not relevant

* Government includes all national sources of public funding, including national, regional and local governments, plus funding by your university/PRO or other universities/PROs.

** Include government and nonprofit agencies such as the UN, World Bank, European Commission, etc. 


\section{Publication/Dissemination Policy}

25. Are there are any initiatives to promote the broad dissemination of R\&D results or copyrighted materials, such as Public Domain, Open Search, Open Access, Open Source, Open Course Ware ${ }^{2}$ ?

Yes (please explain)

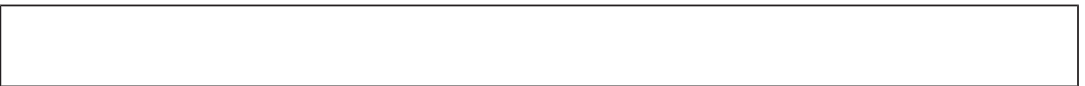

No

Don't know/Not relevant

26. Are there are any initiatives, regulations or policies that regulate the policies for publication delays (such as maximum length) for licensed IP? $\square$ Yes (please explain)

\section{No}

Don't know/Not relevant

\section{IP Policy Awareness Raising}

27. How are your institution's policies on IP distributed to its employees and other stakeholders?

Through the institution website, URL

Paper copy

Training actions for students and staff

Other (please explain)

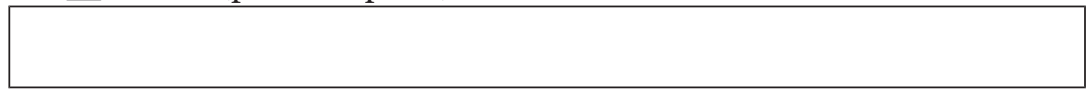

No distribution or not relevant (if no IP policy)

${ }^{2}$ Open Search is a collection of technologies that allow publishing of search results in a standard and accessible format. Open Source refers to access to software or source code. Open Access is associated with journal literature and other scholarly content. Open Course Ware (OCW) offers course materials free to anyone with online access. 
28. Does your institution have a web page dedicated to IP matters?

$\square$ Yes, URL:

$\square$ No

Don't know/Not relevant

\section{Problems, Challenges and Strategic Issues}

29. Does your institution face any of the following challenges and obstacles for the commercialization of IPRs? If yes, please indicate the three most important ones.

For relevant column, tick all that apply.

\begin{tabular}{|c|c|c|}
\hline Challenges and obstacles & Relevant & $\begin{array}{l}\text { Three most } \\
\text { important ones }\end{array}$ \\
\hline Weak scientific innovation capacity & $\square$ & $\square$ \\
\hline $\begin{array}{l}\text { Research not relevant to the needs of } \\
\text { businesses in your country }\end{array}$ & $\square$ & $\square$ \\
\hline $\begin{array}{l}\text { National or local businesses lack the } \\
\text { capability to use relevant research results }\end{array}$ & $\square$ & $\square$ \\
\hline Lack of funds to file for patents & $\square$ & $\square$ \\
\hline $\begin{array}{l}\text { Lack of technical skills for patent information } \\
\text { searches or drafting patents }\end{array}$ & $\square$ & $\square$ \\
\hline $\begin{array}{l}\text { Inefficient technology evaluation mechanisms } \\
\text { (e.g., invention disclosure procedures not } \\
\text { in place, inefficient technology } \\
\text { evaluation, etc.) }\end{array}$ & $\square$ & $\square$ \\
\hline $\begin{array}{l}\text { Lack of appropriate institutional IP } \\
\text { guidelines/policies }\end{array}$ & $\square$ & $\square$ \\
\hline Cultural gap between university and industry & $\square$ & $\square$ \\
\hline $\begin{array}{l}\text { Inadequate national legal framework } \\
\text { (e.g., laws, policies, regulations) }\end{array}$ & $\square$ & $\square$ \\
\hline
\end{tabular}




\begin{tabular}{|c|c|c|}
\hline Challenges and obstacles & Relevant & $\begin{array}{l}\text { Three most } \\
\text { important ones }\end{array}$ \\
\hline Lack of support from university management & $\square$ & $\square$ \\
\hline Lack of incentives for researchers/inventors & $\square$ & $\square$ \\
\hline $\begin{array}{l}\text { Conflicts of interest (e.g., what kind of } \\
\text { research to undertake; which third parties } \\
\text { to cooperate with; whether to put IP into } \\
\text { the public domain or whether to seek } \\
\text { exclusive commercialization deals, etc.) }\end{array}$ & $\square$ & $\square$ \\
\hline
\end{tabular}

30. What are the main goals of your institution in supporting the commercialization of IP? More than one answer is possible.

$\square$ Earn income

$\square$ Support economic development in the region where your institute is located

Market the scientific and technical expertise of your institution

$\square$ Identify research collaboration partners for academic research

$\square$ Promote entrepreneurial attitudes among students and academics

Attract and retain academics

$\square$ Identify job opportunities for students

31. Please comment on any additional issues concerning institutional IP policies you consider relevant to this Needs Assessment Questionnaire. 


\section{INDEX}

AbbVie, 221

Abreu, M., 169

Absorptive capacity of firms

commercialization of IP and, 11

knowledge transfer and, 38, 267

in mode 1 conception of knowledge transfer, 363

Academics

professor's privilege, abolition of, 7 , $41,69,163,199-205,397,403$

surveys of, 429-430, 436-439, 461-462

Africa. See also specific country

blockchain technology in, 455

measurement challenges in, 454-455

metrics of knowledge transfer in, 440, 452, 455

Strategy for Science, Technology and Innovation (STISA-24), 452-454

university knowledge transfer policies in, 8-9

African Continental Free Trade Agreement (AfCFTA), 454

African Innovation Outlook series, 454, 455

African Observatory for Science, Technology and Innovation (AOSTI), 455

Albuquerque, E., 38, 264, 269

Alessandrini, M., 342

Algeria, university knowledge transfer policy in, 8-9

Amadei, J.R.P., 269-270

Amazon, 349-350

Anglo Platinum (South Africa), 343

Annual reports, 462

Argentina

channels of knowledge transfer in, 38 government funding of $\mathrm{R} \& \mathrm{D}$ in, 13

industry financing of R\&D in, 48

structural challenges for public R\&D in, 16

Arque-Castells, P., 364

Arundel, Anthony, 59, 398, 452, 453, $455,459,461-462$

Arza, V., 265

Asia. See also specific country metrics of knowledge transfer in, 440 university knowledge transfer policies in, 7,8

Association of University Technology Managers (AUTM)

Better World Project, 75, 444-445

IP licensing model, metrics for, 53, 56,59

Licensing Activity Survey, 73

metrics of knowledge transfer and, 426-427, 444

questionnaire, 350

surveys of KTOs, 73

ASTP, 426, 458, 459

Australia surveys of KTOs in, 53 university, patent filings by, 114

Austria

pre-emption rights principle in, 154-155

professor's privilege, abolition of, 7, 397

Axel patent, 395

Ballard (Canada), 343

Bangladesh, university knowledge

BASF, 221 transfer policy in, 8

Belgium, metrics of knowledge transfer in, 436 
"Big data," 441-442

BioMed X Innovation Center, 220-221

Biotechnology, patent filings in, 109-112

Block, F., 396

Blockchain technology, 455

Böhringer-Ingelheim, 221

Bolivia, government funding of $R \& D$ in, 13

Bordoy, C., 59

Brazil

Brazilian Agriculture Research Corporation (Embrapa), 270, 277

Brazilian Centre for Research in Energy and Materials (CNPEM), 279-280

Brazilian Innovation Survey, 282

Brazilian National Service for Industrial Training

(SENAI), 282

Butantan Institute, 277-279

channels of knowledge transfer in, 38 collaborative research in, 267

Constitution, 419

consultancies in, 290-291, 293-294

Coordination for the Improvement of Higher Education Personnel (Capes) program, 273-275

CT-Infra, 273-275

education and training in, 265

Finep, 272

Good Law, 273

government funding of $\mathrm{R} \& \mathrm{D}$ in, 13

Greater Brazil Plan, 273

growth of public R\&D in, 263-264

income level, patent filings by, 93, 106-107

Industrial, Technological and Foreign Trade Policy (PITCE), 273

Industrial Property Law 1996, 267, 269, 280

Innovate Company Program, 273

Innovation Act 2004, 267, 269, 272-273, 280-282, 284-287, 291, 293, 376, 408, 419, 420

Intellectual Property Law 1996, 284
Investment Maintenance Program (PSI), 273

ITec platform, 33

knowledge capabilities gap in, 368

knowledge transfer in

absorptive capacity of firms and, 267

bureaucratic issues, 271-272, 294-295

case study, 376

challenges of, 420-421

channels of, 287-291

consultancies and, 290-291, 293-294

cooperative agreements and, 282-284

demand-side incentives supporting, 408, 420

financial factors, 419-420

formal channels of, 287-290

funding and, 270-271

high level R\&D, lack of, 265

incentives, 293

informal channels of, 266-267, 287

institutional factors, 419

institutional practices, 291-294

instruments, 274

legal framework of, 284-287

legislation patterned on Bayh-

Dole Act in, 406-407

non-disclosure agreements and, 290

"open science" and, 266-267

overview, 22, 263-264, 294-295

patent licensing and, 287-290, 375-376

policies and practices, 274, 376

in "processing industry," 265

by public research institutes, 270 , 277-280

research agreements and, 290-291

spin-offs and, 266

supply-side incentives supporting, 410, 420

technological partnership

agreements and, 290 
type of knowledge, correlation with, 266

by universities, 270

university knowledge transfer policy, 8

weakness of channels, 264

KTOs in, 373

legislation patterned on Bayh-Dole Act in, 396, 419

metrics of knowledge transfer in, 426, 432-433

Ministry of Agriculture, 277

Ministry of Education, 273-275

Ministry of Health, 277-279

Ministry of Science, Technology, Innovation and Communication, 33, 273, 287-290

National Education and Research Network (RNP), 280

National Electric Energy Agency, 284

National Institute for Pure and Applied Mathematics (IMPA), 280

National Institute of Industrial Property (INPI), 280, 294

New Science, Technology and Innovation Legal

Framework, 419

Oil National Agency, 284

Oswaldo Cruz Foundation, 277

patent licensing in, 287-290, 375-376

patent metrics in, 86

Productive Development Policy, 273

public investment in science and technology in, 273-275

public research institutes collaboration with industry, 405 consultancies and, 293-294 cooperative agreements and, 282-284

innovation and, 282-284

knowledge transfer by, 270, 277-280

KTOs in, 267, 285-286, 291-293, 294

non-financial compensation, 294 number of, 276

patent filings by, 280-282

revenues of, 279

rationale for inclusion in study, $18-21$

$\mathrm{R} \& \mathrm{D} / \mathrm{GDP}$ ratio in, $25-26$

research infrastructure in, 273-276

research publications in, 266, 287

Science and Technology Act 2016, 284-285, 286

Sectoral Funds, 263, 269, 272

seminars in, 266

specialization of innovation in, 27

Telecom Research and Development Center, 282

"two-way flow" of ideas in, 418

universities

bureaucratic issues, 271-272, 294-295

collaboration with industry, 398, 405-406

consultancies and, 290-291, 293-294

cooperative agreements and, 282-284

fragility of linkages with industry, 265, 269

funding and, 270-271

increase in interaction with industry, 265

innovation and, 282-284

knowledge transfer by, 270

knowledge transfer policy, 8

KTOs in, 267, 268, 285-286, 291-293, 294, 408

low level of interaction with industry, 264-265

non-financial compensation, 294

number of, 276

patent filings by, 267, 268-270, 280-282, 295

patent licensing and, 410

public research universities, 276-277

research agreements and, 290-291

technological problems and, 270

Brehm, S., 312-313

Breschi, S., 342-344 
Bristol-Meyers-Squibb, 395

Brito Cruz, C.H., 265

Britto, G., 264-265

Burkina Faso, government funding of R\&D in, 13

Cai, Y.Z., 321

Cambridge Inventor-Ownership Model, 171

Cambridge University, 142, 149, 163, 397, 404

Cameron, William Bruce, 78

Campbell, D.F.G., 364

Canada

Canada Intellectual Property Office (CIPO), 128-131

IP office, patent filings by, 131-132 metrics of knowledge transfer in, 426-427

national and institutional policies and practices supporting knowledge transfer in, 40 surveys of KTOs in, 53, 56

Canon, 114-128

Cappelli, R.D., 219

Caryannis, E.G., 364

Central South University of Forestry and Technology (China), 308

Centre for European Economic Research (ZEW), 191, 209

Chan, K.W., 366, 367

Changzhou University, 308

Channels of knowledge transfer, 36-39 collaborative research, 364-365, $368-369,380,460$

consultancies, 38, 290-291, 293-294, $341,380,398-400,460$

contracts, $38,50-52,380$, 439-440, 460

education and training, 398-400, 460

formal channels, 36-37, 38-39, 50-52, 76, 372, 443, 445, 446

hiring of university graduates, 36 informal channels, 36-37, 38-39, $50-52,76,372,445$

“open science," 50-52, 169, 266-267, 439-440

patent licensing, 398-400 research publications, 303, 398-400

seminars, 209, 266, 267, 287, 398-400

spin-offs as, 217-218, 243, 266, 309, 398-400

Chaves, C.V., 265, 269

Chemical engineering, patent filings in, 111

Chemistry, patent filings in, 108, 109

Chile, metrics of knowledge transfer in, 436

China

Central Committee of Communist Party of China, 300

channels of knowledge transfer in, 38

China Academy of Telecommunication

Technology, 111

Chinese Patent Office, 26-27

Chinese Science Academy, 308

collaborative research in, 313

Company Law, 306, 323

Contract Law, 306, 323

Decision on Reforming the Science and Technology System, 300

Drug Research Institution, 308

European Union compared, 300 government funding of R\&D in, 13 income level, patent filings by, 93, 95, $97,103,105,106-107$

industry financing of R\&D in, 48

Innovation Centers, 310

innovation in, 300

investment in $\mathrm{R} \& \mathrm{D}, 301-302$

IP office, patent filings by, 131-132

ITC, 26-27

knowledge capabilities gap in, 368

knowledge transfer in ambiguous corporate governance and regulation as barrier to, 322-323

barriers to, 299-300, 321-323

case study, 377-378

immaturity of technology market as barrier to, 321-322

increased rewards and compensation, 308

Innovation Centers and, 310 
KTOs, 308

lack of financial support as barrier to, 322

legal framework, 304-306

legislation patterned on Bayh-

Dole Act in, 406-407

marketing of information, 309

overview, 22, 299-300, 323-324

performance evaluation

systems, 308

policies and practices, $377-378$

policies promoting, 307-311

in provinces, 307

by public research institutes, 306-307

science parks and, 310-311, 320-321

spin-offs and, 309

strategic alliances for innovation and, 310

transaction costs as barrier to, 323

by universities, 306-307

Law of Higher Education 1998, 301

Law on Promoting the Transformation of Scientific and Technological Achievements (PTSTA), 299, 305-306, 323-324, 378

2015 amendments, 306-311, 322,378

metrics of knowledge transfer in, $426,427,428,432-433$

Ministry of Commerce, 313

Ministry of Education, 301

Ministry of Finance, 306, 378

Ministry of Industry and Information, 310

National High-Speed Train Technology Innovation Center, 310

National Outline for Educational Reform and Development, 301

National Plan for Medium and Long-Term S\&T

Development, 301

National Science and Technology Plan, 310
National Technology Transfer Center, 308

National Technology Transfer Demonstration Institution, 308

985 Project, 301, 323

OECD countries compared, 300 patent applications in, 303-304

Patent Law 1984, 305, 323

patent licensing in, 313-320

patent metrics in, 86

Patent Office, 305

patent sales or assignments in, 313-320

Program on Promoting Scientific and Technological Achievements, Transfer and Transformation, 307

public R\&D, 300

public research institutes collaboration with industry, 309-310, 405

IP and, 306

knowledge transfer by, 306-307

KTOs in, 308

patent exploitation rates, $316-318$

patent filings by, 128

patent licensing by, 314-316, 320

patent sales or assignments by, 318-319

role in $\mathrm{R} \& \mathrm{D}, 300-301$

rationale for inclusion in study, $18-21$

$\mathrm{R} \& \mathrm{D} / \mathrm{GDP}$ ratio in, $25-26$

recruitment policies of KTOs, 413

research publications in, 303

Science and Technology Progress Law 2007, 304, 323

science parks in, 310-311, 320-321

State Intellectual Property Office of China (SIPO), 128-131, 303-304, 444

State-Owned Asset Supervision and Administration Commission, 306

strategic alliances for innovation, 310

Strategy of Invigorating China through Science and Education, 301 
China (cont.)

technology market in, 311-312

Tongji University Creative

Cluster, 321

Torch Program, 310

TusPark, 320

211 Project, 301, 323

universities

collaboration with industry, 309-310, 311, 312-313, 398,

405-406

IP and, 306

knowledge transfer by, 306-307

knowledge transfer policy, 8

KTOs in, 308

leaves of absence in, 309

ownership of patents, 410

patent exploitation rates, 316-318

patent filings by, 128, 314

patent licensing by, 314-316, 320

patent sales or assignments by, 314, 318-319

role in $\mathrm{R} \& \mathrm{D}, 300-301$

in WIPO, 305

Xi'an S\&T Market, 312

Zhangjiang Hi-Tech Park, 321

Zhejiang Online Technology

Market, 312

Zhongguancun Science Park, 320-321

Cho, H.-D., 240-242

Closs, L.Q., 270-271

Cohen-Boyer patents, 55, 395

Collaborative research. See also specific country

in Brazil, 267

as channel of knowledge transfer, 380,460

as channels of knowledge transfer, 364-365, 368-369

in China, 313

firms and, 372

in Germany, 219

IP licensing model and, 387-388

in Korea, 248, 249, 251

metrics of knowledge transfer and, 52, 428-429, 430-431 public research institutes and, 372

in South Africa, 349

in United Kingdom, 149, 154

Colombia

income level, patent filings by, 93

public research institute, patent filings by, 114

universities

knowledge transfer policy, 8

patent filings by, 114

Columbia University, 395

Comin, D., 219-220

Commercialization of IP. See also specific country

conflicts regarding, 9-11

decline of public research institutes and, 10-11

diversification of, 411

effect on funding, 9-10

firms, absorptive capacity of, 11

incentives for, 69

lack of opportunities in middleincome countries, 413

Mertonian norms and, 10

metrics of knowledge transfer and, 55-56

patent protection policies and, 81

socially responsible research commercialization, 32-33, 34

universities and, 398

Community engagement, 361

Company S (Korea), 247-249, 251

Computer technology, patent filings in, 111

Conceptual framework of knowledge transfer

channels of knowledge transfer, 36-39

downstream outcomes and, 69

financial benefits, profits distinguished, 68-69

formal channels of knowledge transfer, 36-37, 38-39, 76

hiring of university graduates and, 36 incentives for investor involvement and commercialization and, 69

informal channels of knowledge transfer, 36-37, 38-39, 76 
overview, 21, 35-36

patents, differing impact on research incentives and, 69-70

Consultancies. See also specific country

in Brazil, 290-291

in Brazil, 293-294

as channel of knowledge transfer, 38, 290-291, 293-294, 341, 380, 398-400, 460

in Korea, 249

metrics of knowledge transfer and, 50-52, 430-431, 460

in South Africa, 341

in United Kingdom, 174

Contracts. See also specific country as channel of knowledge transfer, 38, 50-52, 380, 439-440, 460

in Germany, 219

in Korea, 251

metrics of knowledge transfer and, 50-52, 428-429, 430-431

in South Africa, 341

in United Kingdom, 154, 414

Convergence of knowledge transfer policies and practices, 393-394, 397-398, 413-415

Cooper, D., 338

Costa Rica channels of knowledge transfer in, 38 university knowledge transfer policy in, 8

Criscuolo, P., 366, 367

Cross-country trends in public R\&D, $11-13$

Cuntz, A., 200, 205

Cusmano, L., 341, 343-344

Czarnitzki, Dirk, 191, 200-206, 209, 215, 216-218

Czech Republic pre-emption rights principle in, 154-155

university ownership of patents in, 397

de Castro, P.G., 266, 267

Declaration on the Fourth Industrial Revolution, 454-455

Demand pull firms, 374
De Negri, F., 263, 265, 275-276

Denmark

Danish Agency for Science, Technology and Innovation (DASTI), 426

metrics of knowledge transfer in, 426

Ministry of Higher Education in Science, 426

pre-emption rights principle in, 154-155

professor's privilege, abolition of, 7, 397

De Wet, G., 339

Digital communications, patent filings in, 111

Distell Group (South Africa), 343-344

Dos Santos, M.E.R., 267

Dutrénit, G., 265

Economic growth as rationale for public R\&D, 5

Edler, J., 191

Education and training. See also specific country

in Brazil, 265

as channel of knowledge transfer, 398-400, 460

in Korea, 249

in middle-income countries, 405-406

public R\&D and, 4

in South Africa, 335, 337, 340-341

in United Kingdom, 174

WIPO university applicant names,

Egypt verifying accuracy of, 137

universities

knowledge transfer policy, 8-9

patent filings by, 114

Electrical engineering, patent filings in, 108, 109

Eom, B.-Y., 228, 258

Equifinality, 362

Es-Sadki, Nordine, 452, 453, 455, 459, 461-462

European Commission

Commission's Competence Centre on Technology Transfer (CC TT), 458 
European Commission (cont.)

Expert Group on KT Metrics, 458

Expert Group on Metrics for Knowledge Transfer, 458-459

Joint Research Centre, 458

National Associations Advisory Committee (NAAC), 458

European Molecular Biology

Laboratory (EMBL), 220

"European paradox," 457

European Union. See also specific country

China compared, 300

Community Innovation Surveys (CIS), 195, 344, 345, 440, 453-454

European Patent Office (EPO), 81-82, 128-131

KTOs in, 457-458, 459

metrics of knowledge transfer in, 457-459

Multiannual Financial Framework (MFF), 457

PATSTAT database (See PATSTAT database)

surveys of KTOs in, 53, 56

university knowledge transfer policies in, 7

Eurostat, 345

Fedderke, J.W., 338

Ferreira, G.C., 270-271

Financial incentives

firms and, 372

for investor involvement and commercialization, 69

in middle-income countries, 394

for participation in knowledge transfer, 31-32, 34

public research institutes and, 372

for universities, 412

Finland

pre-emption rights principle in, 154-155

professor's privilege in, 7

Firms. See also specific firm barriers to knowledge transfer, 372-373

characteristics of, 374

collaborative research and, 372

commercialization of IP and absorptive capacity of, 11

demand pull firms, 374

financial incentives and, 372

knowledge capabilities gap and, 366-369, 380

knowledge transfer and absorptive capacity of, 38, 267

linkage with public research institutes, 371-372, 380-381

mode 1 conception of knowledge transfer, absorptive capacity in, 363

patent licensing and, 381

policies and practices of, 22, 374

R\&D intensity of, 38

successful knowledge transfer policies and practices, 369-371

surveys of, 429-430, 439-441, 461-462

Firm survivor bias, 218

Florida State University, 395

Fongwa, N.S., 339

Foreign-oriented patent filings, 90-92

Formal channels of knowledge transfer, 36-37, 38-39, 50-52, 76, 372, $443,445,446$

France

Centre National de la Recherche Scientifique (CNRS), 111-112

Commissariat à l'Energie Atomique et aux Energies Alternatives (CEA), 111, 114

income level, patent filings by, 93, 97, 104, 106

Institut national de la santé et de la recherche médicale (INSERM), 111,128

IP office, patent filings by, 131-132

public research institute, patent filings by, 114, 128

universities

ownership of patents, 397

patent filings by, 128 
patenting activities of, 155

Freeman, Christopher, 4, 226

Freitas, I.M.B., 429

Friedman, J., 256

Friedrich-Schiller-University, 220, 221

Fudan University, 322

\section{Germany}

CarLa Catalytics Research Lab, 222

collaborative research in, 219

commercialization of IP in, 393-394

contracts in, 219

demand pull in, 365

displacement effects in, 413-414

EXIST program, 208

Federal Ministry of Economics (BMWi), 205

Federal Ministry of Education and Research (BMBF), 183-184, 196-199, 205

Federal Statistical Office, 183

Fraunhofer Association, 111, 114, $182,183,185,186-187$, 191-193, 195, 196, 209, 213, 219-220, 221, 361, 365

German Cancer Research Institute, 220

German Meteorological Office (DWD), 193

German National Account, 218

German Patent and Trademark Office (DPMA), 200

German University Excellence Initiative, 206-207, 222

Helmholtz Association, 182, 183, 184-185, 186-187, 195, 198, 209, 213, 365

Helmholtz Centre for Research on Environmental Health, 221

Helmholtz Institute, 221

Helmholtz Society, 220

income level, patent filings by, 93, 97

InnovationLab, 222

Innovative Hochschule scheme, 208

IP office, patent filings by, 131-132

knowledge capabilities gap in, 368

"Knowledge Creates Markets" campaign, 196-199, 205 knowledge transfer in benefits to business of, 217-220

case study, 379-380

changes in, 196-199

channels of, 209-214

economic literature on, 214

funding schemes, 206-208

historical background, 185-187

innovation, effect on, 219

job creation, effect on, 218-219

leading users of, 195-196

legislation patterned on Bayh-

Dole Act in, 404

limitations to, 215-217

opportunity cost of, 215-217

overview, 22, 182-183,

223-224

patent valorization agencies, 205-206

policies and practices, 378-379, 403

by public research institutes, 191-195

spin-offs, effect on, 217-218

supporting interviews, 220-223

by universities, 187-191, 220-223

Leibniz Association, 182, 183, 185, 192-195, 198, 209, 213, 365

Max Planck Association, 182, 183, 184-185, 186-187, 191-193, 195, 196, 209, 213, 221, 365

Max Planck Institute for Medical Research, 220

metrics of knowledge transfer in, 426, 432-433, 436

Ministry of Health, 193

Ministry of Transport and Digital Infrastructure, 193

National Center for Tumor Diseases Heidelberg, 220

patent licensing in, 393-394

patent metrics in, 86

patent valorization agencies, 205-206

pre-emption rights principle in, 154-155

professor's privilege, abolition of, 7 , 41, 163, 199-205, 397, 403 
Germany (cont.)

public research institutes channels of knowledge transfer in, 209-214

expenditures by, 183-185

knowledge transfer by, 191-195

overview, 182

patent filings by, 128

rationale for inclusion in study, 18-21

$\mathrm{R} \& \mathrm{D} / \mathrm{GDP}$ ratio in, $25-26$

research publications in, 219

Robert Koch Institute, 193

SIGNO program, 205

Spitzencluster initiative, 207, 222

universities

channels of knowledge transfer in, 209-214

expenditures by, 184

knowledge transfer by, 187-191, 220-223

overview, 182

patent filings by, 200-205, 403

statistics on, 183

supporting interviews, 220-223

Geuna, A., 432

Ghana, university knowledge transfer policy in, 8

Gibbons, M., 362-363

Goldberg, I., 338

Government funding of $\mathrm{R} \& \mathrm{D}, 12-13$

Graff, G.D., 396

Greece, pre-emption rights principle in, 154-155

Haas, M.R., 366

Harbin Institute of Technology, 128

Harvard University, 112

Hendry, John, 149

High-income countries. See also specific country

challenges for public R\&D in, 17-18

convergence of knowledge transfer policies and practices in, 393, 413-415

demand-side incentives supporting knowledge transfer in, 407-411 displacement effects in, 411-412, 413-414

diversification of knowledge transfer policy in, 411-412

firms, linkage with public research institutes and universities, 402

ideal knowledge transfer policy mix, 411-413

income level, patent filings by, 93-107

knowledge transfer policies and practices in, 402-404

legislation patterned on Bayh-Dole Act in, 413-415

metrics of knowledge transfer in, 440

middle-income countries, knowledge transfer compared, 400-402

public research institutes, linkage with firms and universities, 402 supply-side incentives supporting knowledge transfer in, 407-411 timing and sequence of knowledge transfer policy changes, 410

universities, linkage with firms and public research institutes, 402

Huang, Can, 300

Hunan University of Chinese Medicine, 308

Hungary

pre-emption rights principle in, 154-155

university ownership of patents in, 397

Huya Bioscience International, 322

Hvide, Hans K., 69

Hybrid Model, 171

Impala Platinum (South Africa), 343

Income level, patent filings by, 92-93

India

Council for Scientific and Industrial

Research (CSIR), 413

Department of Science and

Technology, 461

government funding of $\mathrm{R} \& \mathrm{D}$ in, 13

income level, patent filings by, 93,

100-101, 106-107 
IP office, patent filings by, 131-132 legislation patterned on Bayh-Dole Act in, 396

metrics of knowledge transfer in, 461

National Knowledge Commission, 395

public research institute, patent filings by, 114

university knowledge transfer policy in, 8

Indonesia, university knowledge transfer policy in, 8

Industry. See Firms

Informal channels of knowledge transfer, 36-37, 38-39, 50-52, $76,372,445$

Initech (Korea), 244, 247, 251

Innovation

IP licensing model, stifling effects of, $47-48$

patents, effect of, 82

as rationale for public $\mathrm{R} \& \mathrm{D}, 4-5$

International Property Rights Index (IPRI), 252

Invention patents, 303

Investment in public R\&D

conflicts between old and new rationales for, 9-11

economic growth as rationale for, 5 innovation as rationale for, $4-5$ rationales for, $3-5,21$

social rate of return of, 5

trade-offs between old and new rationales, 9-11

IP licensing model. See also specific country

advantages of, 45-47

alliances with industry and, 387-388

as channel of knowledge transfer, 36 , 39, 398-400

collaborative research and, 387-388

collection of knowledge transfer metrics, 53-56

disadvantages of, 47-49

as discouraging collaboration, 49

division of revenues, 388

indicators, 70-71 innovation, stifling effects on, 47-48

institutional policies and, 50

KTO characteristics, metrics of, 60

legislation and, 50

low-income countries, disadvantages in, 46,49

metrics of knowledge transfer and, $52,60,78$

middle-income countries, disadvantages in, 46, 49

minimizing costs of knowledge transfer, $49-50$

non-financial disadvantages of, 48

open IP policies, 50

patent valorization and, 205-206, 386-387

public research institutions, effects on, $42-43$

research publications and, 47,48

restrictions on licensing, 49

secondary benefits of, 47

signaling function, 47

socioeconomic effects of, 44-45

standardized indicators, 59-60

supplementary metrics from KTOs, $56,57-58$

support of new industry, 45-46

surveys of KTOs, 53-56

tacit knowledge and, 387

undue influence of industry and, 48

universities, effects on, $42-43$

IP office, patent filings by, 128-132. See also specific office

Ireland, metrics of knowledge transfer in, 436

Israel

income level, patent filings by, 106

IP office, patent filings by, 131-132

universities

knowledge transfer policy, 6, 394

patent filings by, 114

Italy

IP office, patent filings by, 131-132

metrics of knowledge transfer in, 426, 436

NetVal, 426

professor's privilege in, 7

universities 
Italy (cont.)

ownership of patents, 397

patenting activities of, 155

Japan

income level, patent filings by, 93, 99, 104

IP office, patent filings by, 131-132

Japan Patent Office (JPO), 128-131

metrics of knowledge transfer in, 436

public research institute, patent filings by, 128

universities

knowledge transfer policy, 7

patent filings by, 128

Jenoptik, 220

Jiang, Y., 313

Johns Hopkins University, 111, 112

Jones, Benjamin F., 69

Jongwanich, J., 321

Jordan, legislation patterned on BayhDole Act in, 396

Kahn, M.J., 338

Kaplan, D., 339, 341, 364

Kenney, M., 47

Kenya, M-PESA payment system, 455

Kim, L.-S., 227, 235-236

Kim, Sun-Young, 249, 250

Knowledge capabilities gap, 366-369, 380

Knowledge transfer. See also specific country

barriers to, 372-373, 381

best practices, 77

channels of, 36-39

conceptual framework of (See Conceptual framework of knowledge transfer)

convergence of policies and practices, 393-394, 397-398, 413-415

cultural factors, 418-419

demand pull in, 364-365

demand-side incentives supporting, 155-156, 407-411, 420

downstream outcomes and, 69

ecosystem, understanding of, 76 enabling environment, importance of, 77

financial benefits, profits distinguished, 68-69

financial factors, 419-420

flexibility of policies, 77

formal channels of, 36-37, 38-39, 76, $372,443,445,446$

geography and, 27-28

high-income countries, policies and practices in, 402-404

hiring of university graduates and, 36 ideal policy mix, 411-413

improved evidence for policymaking, 71-72

incentives for investor involvement and commercialization and, 69

incentives for participation in, 31-32, 34

informal channels of, 36-37, 38-39, $76,372,445$

institutional factors, 419

institutional policies and practices supporting, 40-41

institutional versus national policies and practices, 374-375

institutions and, 26-27

IP licensing model (See IP licensing model)

knowledge capabilities gap and, 366-369, 380

linear model, 362-363, 365-366

metrics of (See Metrics of knowledge transfer)

mode 1 conception, 362-363, 365-366

mode 2 conception, 363-364

mode 3 conception, 364-365, 380

national policies and practices supporting, 40-41

national versus institutional policies and practices, $374-375$

overview, 21

patent metrics (See Patent metrics)

patents, differing impact on research incentives and, 69-70

policy priorities, 76-77

public R\&D in context of, 37 
questions regarding policies and practices, 414

$\mathrm{R} \& \mathrm{D} / \mathrm{GDP}$ ratio and, $25-26$

role of policies and practices in promoting, 39-40

specialization of innovation and, 27 startups and, 373

structural characteristics of, 25-28

successful policies and practices, 361-362, 369-371

supply-side incentives supporting, 152-155, 407-411, 420

systemic failures, heterogeneous remedies for, 28-29

technology push and, 362-363

timing and sequence of policy changes, 410

"two-way flow" of ideas and, 418

Knowledge transfer offices (KTOs)

characteristics of, 60, 373-374

improved evidence for policymaking and, 71-72

linear model of knowledge transfer and, 365-366

metrics of knowledge transfer characteristics, metrics of, 60 data from, 430-431 metrics regarding, 73-75 policies and practices supporting knowledge transfer, 431-436 surveys of, 53-56

metrics regarding, 60, 73-75 mode 1 conception of knowledge transfer and, 365-366

nexus function of, 73-74 overview, 35 policies and practices of, 373-374 in public research institutes, 35 recruitment policies, 413 return on investment (ROI) of, 74-75

revenue and, $74-75$

role of policies and practices in promoting knowledge transfer, 39

standardized indicators, 59-60 supplementary metrics from, 56 , $57-58$ surveys of, 53-56, 73, 428-429, 461-462

in universities, 35

Kochenkova, A., 55

Kolmar BNH (Korea), 246-247, 251

Kolmar Korea, 245, 246, 247

Korea, Republic of

Act on the Promotion of Industrial

Education and Industry-

University Collaboration 2003, 227, 229

collaborative research in, 248 , 249, 251

commercialization of IP, efficiency of, 233-236

Connect Korea project, 230

consultancies in, 249

contracts in, 251

education and training in, 249

ETRI, 244-245

goals of patent system in, 424

government-funded non-practicing entities (NPEs), 250-251

Hub University for Industrial Collaboration (HUNIC) project, 230

income level, patent filings by, 93, 97, 100, 104, 106

Intellectual Discovery (ID), 250-251, 252

IP office, patent filings by, 131-132

knowledge capabilities gap in, 368

knowledge transfer in

case study, 376-377

challenges relating to public research institutes, 255-256

channels of knowledge transfer generally, 238-242, 258

collaborative R\&D and, 248, 258

contracts, 251

expenditures on public R\&D, 231-233

foreign firms and, 238

formal channels of, 242-244

government-funded nonpracticing entities (NPEs) and, 250-251 
Korea, Republic of (cont.) graduate students, hiring of, 250 immature government capabilities as challenge, 253, 258-259

important factors in, 251-252 informal channels of, 247-250, 258

innovation, effect on, 238

institutional challenges, 252-253

laboratory companies and, 243-244

license income and, 236 methodology of survey on, 260 national versus institutional policies and practices, 375 new technologies and, 233 overview, 22, 257-259 patent licensing and, 242, 244-245, 248, 375-376

policies and practices, 376-377, 404

policies to improve, $228-231$ public key infrastructure (PKI) and, 244-245

by public research institutes, 248-249, 250, 257-258 sector distribution of, 238 seminars and, 247-248 SMEs, challenges relating to, 253-255

spin-offs and, 243

startups and, 243-244, 245-247

statistics, 231-238

supporting interviews, 260

by universities, $257-258$

university knowledge transfer policy, 7

venture capital and, 249-250

Korea Atomic Energy Research Institute (KAERI), 245-247, 248

Korea Institute for Advancement of Technology (KIAT), 229-230, 260

Korean Intellectual Property Office (KIPO), 128-131, 422

Korea Technology Exchange, 229
KTOs in, 373, 376-377

Leaders in Industry-University Cooperation (LINC) project, 230

Market-Driven IP and Technology Transfer Promotion Plan, 230-231

metrics of knowledge transfer in, 426, 432-433

Ministry of Food and Drug Safety, 246

Ministry of Information and Communication, 244-245

National Research Council of Science \& Technology (NST), 243

patent licensing in, 242, 244-245, $248,375-376$

patent metrics in, 86 professors, startups and, 423

public goods, public R\&D as, 423

public research institutes

bureaucracy versus, 424

challenges in knowledge transfer relating to, 255-256

channels of knowledge transfer generally, 238-242

collaboration with firms, 400 , 402, 411

investments by, 229-230

knowledge transfer by, 248-249, 250, 257-258

KTOs in, 228-229, 231, 255-256

ownership of patents, 422 , 423-424

patent filings by, 128, 233

public R\&D, role in, 226-227

startups and, 422

technology holding companies, 229

rationale for inclusion in study, 18-21

$\mathrm{R} \& \mathrm{D} / \mathrm{GDP}$ ratio in, $25-26$

Science and Technology Policy Institute (STEPI), 238

small and medium-sized enterprises (SMEs) in, 228, 236-238, 253-255, 377, 411, 424 
Special R\&D Zone Promotion Act 2006, 243, 246

Special Research Institute Promotion Law 1973, 227

Technology Transfer and Commercialization Promotion Act 2006, 229-230, 256, 422

Technology Transfer Promotion Act 2000, 227, 228-229, 233, 246, 257, 376

"twin dominance" of industry and government in, 226, 228

universities

channels of knowledge transfer generally, 238-242

collaboration with firms, 411

knowledge transfer by, 257-258

knowledge transfer policy, 7

KTOs in, 227-229, 231

ownership of patents, 397, 422, 423-424

patent filings by, $128,422-423$

public $\mathrm{R} \& \mathrm{D}$, limited role in, 226-228

sector distribution of knowledge transfer by, 238

Korea Electronics Telecomm, 111, 128

Kotha, R., 366-367

Kroll, H., 322

Kruss, G., 338, 341

KTOs. See Knowledge transfer offices (KTOs)

Kuriakose, S., 338

Kwon, K.-S., 238

Lan, X., 313

Latin America. See also specific country metrics of knowledge transfer in, 440 university knowledge transfer policies in, 8

Lee, Keun, 228, 258

Legislation regarding university knowledge transfer policies, 6-9, 80

LG (Korea), 253-254

Licensing of IP. See IP licensing model Liefner, I., 322
Linear model of knowledge transfer, 362-363, 365-366

Lissoni, F., 155

Liu, C., 321

Liu, H., 313

Livesey, F., 266, 268

Low-income countries. See also specific country

basic economic needs as challenge for public R\&D in, 16

challenges for public R\&D in, 14-18

heterogeneity as challenge for public $\mathrm{R} \& \mathrm{D}$ in, 16

IP licensing model, disadvantages of, 46,49

metrics of knowledge transfer in, 440

structural challenges for public R\&D in, $16-17$

Lubango, L.M., 342

Ludwig-Maximilian University, 220, 221

Lula da Silva, Luiz Inácio, 273

Lundin, N., 312-313

Lundvall, Bengt-Åke, 4

Ma, J., 313

Malaysia

channels of knowledge transfer in, 38 government funding of $R \& D$ in, 13 income level, patent filings by, 93, 102-103, 106-107

legislation patterned on Bayh-Dole Act in, 396

public research institute, patent filings by, 114

universities

knowledge transfer policy, 8

patent filings by, 114

Malerba, F., 342-344

Mannheim Innovation Panel (MIP), 195,219

Marais, L., 339

Massachusetts Institute of Technology, 112,282

Materials, patent filings in, 109-111

Mazzucato, Mariana, 391

Measurement, patent filings in, 108, 109-111 
Medical technology, patent filings in, 109

Mello, J.M.C., 267

Merck Serono, 221

Mertonian norms, 10

Metallurgy, patent filings in, 109-111

Metrics of knowledge transfer. See also specific country

academics, surveys of, 429-430, 436-439, 461-462

annual reports and, 462

benefits of knowledge transfer, 442-445

"big data," 441-442

collaborative research and, 52, 428-429, 430-431

collection of metrics for IP licensing model, 53-56

commercialization of IP and, 55-56

consultancies and, 50-52, 430-431, 460

contracts and, 50-52, 428-429, 430-431

cost-benefit analysis, 442-445, 462-463

costs of, 446

data collection, 78

data discrepancies, 462

disproportionate focus of, 78,79

economic relevance of, 428

"European paradox," 457

financial benefits of knowledge transfer, 443-444

firms, surveys of, 429-430, 439-441, 461-462

formal channels of knowledge transfer, 443, 445, 446

full functionality of knowledge transfer and, 427-428

Higher Education-Business and Community Interaction (HEBCI) survey, 430-431

in high-income countries, 440 indicators, 70-71

informal channels of knowledge transfer, 445

institutional level, data collection at, 434-436, 445-446 international comparability of, 427

IP licensing model and, 52, 60, 78

KTOs

characteristics, metrics of, 60

data from, 430-431

metrics regarding, 73-75

policies and practices supporting

knowledge transfer, 431-436

surveys of, 53-56, 461-462

limitations of, 428

in low-income countries, 440

in middle-income countries, 428 , 440

non-financial benefits of knowledge transfer, 444-445

non-IP-mediated knowledge transfer, 347-349, 429, 452-454, 460-461

normalizing of data, 79

“open science," 50-52, 439-440

overview, 21, 22, 35-36, 77-78, 79, 445-446

patent metrics (See Patent metrics)

publicly available data, 441-442

public research institutes

benefits of knowledge transfer to, 431

policies and practices supporting knowledge transfer, 431-436

surveys of, 461-462

reluctance to provide data, 462

research publications and, 441-442

standardized indicators, 59-60

supplementary metrics from KTOs, $56,57-58$

types of metrics, 425

universities

data from, 430-431

policies and practices supporting knowledge transfer, 431-436

value of measured activities, 427

"vanity" metrics, 78

WIPO Assessment Questionnaire for Stakeholders from Academic and Research Institutions, 464-474 (See also WIPO Assessment Questionnaire for 
Stakeholders from Academic and Research Institutions)

Mexico

channels of knowledge transfer in, 38 government funding of $R \& D$ in, 13 income level, patent filings by, 93, 102

university knowledge transfer policy in, 8

Middle-income countries. See also specific country

basic economic needs as challenge for public R\&D in, 16

challenges for public R\&D in, 14-18

collaboration between universities and industry, 412-413

convergence of knowledge transfer policies and practices in, 413-415

demand-side incentives supporting knowledge transfer in, 407-411

education and training in, 405-406

financial incentives in, 394

heterogeneity as challenge for public R\&D in, 16

high-income countries, knowledge transfer compared, 400-402

ideal knowledge transfer policy mix, 411-413

income level, patent filings by, 93-107

IP licensing model, disadvantages of, 46,49

knowledge transfer policies and practices in, 405-407

lack of commercialization opportunities in, 413

lack of research capacity in universities, 412

legislation patterned on Bayh-Dole Act in, 413-415

metrics of knowledge transfer in, 428, 440

public research institute knowledge transfer policy in, 394 structural challenges for public R\&D in, $16-17$

supply-side incentives supporting knowledge transfer in, 407-411

timing and sequence of knowledge transfer policy changes, 410

university knowledge transfer policy in, 394

Miller, K., 364-365

Mode 1 conception of knowledge transfer, 362-363, 365-366

Mode 2 conception of knowledge transfer, 363-364

Mode 3 conception of knowledge transfer, 364-365, 380

Mondi (South Africa), 343

Morocco

income level, patent filings by, 93

public research institute, patent filings by, 114

universities

knowledge transfer policy, 8-9

patent filings by, 114

M-PESA payment system, 455

Munari, F., 374-375

Munich Innovation Group, 187-188

National technology exchanges, 374

Nelson, Richard R., 4

Netherlands, metrics of knowledge transfer in, 436

New Zealand, surveys of KTOs in, 53

Nigeria

channels of knowledge transfer in, 38

National Office for Technology Acquisition and Promotion (NOTAP), 8-9

university knowledge transfer policy in, 8-9

Non-IP-mediated knowledge transfer, metrics of, 347-349, 429, 452-454, 460-461

Northwestern University, 128

North-West University (South Africa), 349-350

Norway

metrics of knowledge

transfer in, 436 
Norway (cont.)

pre-emption rights principle in, 154-155

professor's privilege, abolition of, 7 , 69,397

Ok, J.-Y., 235-236

Oliveira, P., 268-269

Onderstepoort Biological Products (South Africa), 331

Open IP policies, 50

“Open science," 50-52, 169, 266-267, 439-440

Organic chemistry, patent filings in, 109

Organisation for Economic Cooperation and Development (OECD), 300

O'Shea, R.P., 364

Oslo Manual, 430, 440

Oxford Biomedica, 249

PACEC, 154

Pakistan, university knowledge transfer policy in, 8

Panasonic, 114-128

Paris Convention for the Protection of Industrial Property, 305

Patent Cooperation Treaty (PCT)

advantages of use in patent metrics and, 84

as data source for patent metrics, 81 , 84-85, 132-134

disadvantages of use in patent metrics and, 84-85

identifying universities and public research institutes for purposes of patent metrics, $86-89$

income level, patent filings by, 92-103

South Africa and, 331-333, 349

statistical trends in patent filings under, 90

supplementary metrics regarding, 56 technology field, patent filings by, 108-109, 111

university, patent filings by, 112-128

Patent metrics academia, focus on, $81-82$

applicability to universities and public research institutes, 83

data sources, $84-86$

foreign-oriented patent filings and, 90-92

identifying universities and public research institutes for purposes of, 86-89

income level, patent filings by, 92-93 individual patent holders, $82-83$ innovation, effect of patents on, 82 IP office, patent filings by, 128-132 lack of standardized information, 86-87

low-income countries, patent filings by income level in, 93-107 middle-income countries, patent filings by income level in, 93-107

name-cleaning and, $87-88$

name-matching and, 88

overview, $21,80-81$, 132-134

Patent Cooperation Treaty (PCT) as data source, 81, 132-134 (See also Patent Cooperation Treaty (PCT))

patent family definition and, 85 , 88-89

PATSTAT database as data source, 81, 132-134 (See also PATSTAT database)

public $R \& D$ versus private $\mathrm{R} \& \mathrm{D}, 82$

public research institute, patent filings by, 114, 128

quality checks, 89

residence and, 89

statistical trends in patent filings, 90

technology field, patent filings by, 107-112

underestimation, 83

university, patent filings by, $112-128$

WIPO university and public research institute applicant names, verifying accuracy of, 137 
Patents

differing impact on research

incentives, 69-70

goals of patent system, 424

invention patents, 303

resident versus non-resident applications, 280

valorization, 205-206, 386-387

PATSTAT database

advantages of use in patent metrics and, 85

as data source for patent metrics, 81 , 85-86, 132-134

disadvantages of use in patent metrics and, 85

Germany

knowledge transfer in, 187-188

patent filings in, 200

identifying universities and public research institutes for purposes of patent metrics, $86-89$

income level, patent filings by, 104-107

quality checks in patent metrics, 89

statistical trends in patent filings in, 90

technology field, patent filings by, 109-111

Patton, D., 47

People's Republic of China. See China

Pereira, F.C., 267

Peru

government funding of $\mathrm{R} \& \mathrm{D}$ in, 13

university knowledge transfer policy in, 8

Phaho, D., 339

Pharmaceuticals, patent filings in, 109-112

Philippines government funding of R\&D in, 13

public research institute, patent filings by, 114

universities

knowledge transfer policy, 8

patent filings by, 114

Pinheiro-Machado, 268-269

Poland, university ownership of patents in, 397
Porto, G.S., 270, 271

Portugal, failures of knowledge transfer in, 364

Pouris, A., 339, 342

Póvoa, L.M.C., 265, 266-267, 269, 270

Private R\&D, public R\&D contrasted, 6,82

Professor's privilege, abolition of, 7, 41, 69, 163, 199-205, 397, 403

Public goods, public R\&D as, 4, 5, 423

Public R\&D

commercialization of IP (See Commercialization of IP)

in context of knowledge transfer, 37

cross-country trends in, 11-13

economic growth as rationale for public R\&D, 5

education and training and, 4

government funding of, 12-13

high-income countries, challenges in, $17-18$

innovation as rationale for public $\mathrm{R} \& \mathrm{D}, 4-5$

investment in (See Investment in public R\&D)

low-income countries, challenges in, 14-18

middle-income countries, challenges in, $14-18$

private $\mathrm{R} \& \mathrm{D}$ contrasted, 6,82

as public good, 4, 5

socially responsible research commercialization, 32-33, 34

Public research institutes. See also specific country

barriers to knowledge transfer, 372-373

best practices, 381

collaborative research and, 372

decline of, 10-11

financial incentives and, 372

foreign-oriented patent filings by, 90-92

incentives for participation in knowledge transfer, 31-32, 34

income level, patent filings by, 92-93 
Public research institutes (cont.)

IP licensing model, effect of, 42-43

knowledge capabilities gap and, 380

KTOs in, 35

linkage with firms, 371-372, 380-381

metrics of knowledge transfer

benefits of knowledge transfer to, 431

policies and practices supporting knowledge transfer, 431-436

middle-income countries, knowledge transfer policy in, 394

patent filings by public research institute, 114, 128 (See also specific institute)

patent licensing and, 381

patent metrics (See Patent metrics)

questions regarding knowledge transfer policies and practices, 414

role in public $\mathrm{R} \& \mathrm{D}, 12$

statistical trends in patent filings by, 90

successful knowledge transfer policies and practices, 369-371

surveys of, 461-462

technology field, patent filings by, 107-112

WIPO applicant names, verifying accuracy of, 137

QS World Ranking of Universities,

Quality checks in patent metrics, 89

Quan, X.H., 311

Ramaphosa, Cyril, 355

Rammer, C., 191

Rapini, M.S., 264-265, 266, 270, 271

Rationales for investment in public R\&D

conflicts between old and new rationales, 9-11

overview, 3-5, 21

trade-offs between old and new rationales, 9-11

Rauen, C.V., 271, 292, 293
Ray, A.S., 172, 460-461

rDNA, 395

Research publications. See also specific country

in Brazil, 266, 287

as channel of knowledge transfer, 303, 398-400

in China, 303

in Germany, 219

IP licensing model and, 47, 48

metrics of knowledge transfer and, 441-442

in South Africa, 347-349

in United Kingdom, 169

use as metrics, 59

Return on investment (ROI) of KTOs, 74-75

Roche, 221

Rogers, M., 171, 172

Romania, government funding of $R \& D$ in, 13

Rorwana, A., 342

Rosli, A., 150

Rossi, Federica, 150, 432

Russian Federation

government funding of R\&D in, 13

industry financing of R\&D in, 48

university knowledge transfer policy in, 7,8

Saha, S., 461

Samsung, 253-254

SAP, 221

Sappi (South Africa), 343

Sasol (South Africa), 343, 349-350, 368

Schmoch, U., 191, 199-200

Science Citation Index (SCI), 303

Scimago Institutions Rankings World Report, 88

Scopus (database), 88

Seminars

in Brazil, 266

as channel of knowledge transfer, $209,266,267,287,398-400$

in Korea, 247-248

Sengupta, A., 172, 460-461

Seoul National University, $112-114,236$ 
Shanghai Jiao Tong University, 128

Shapiro, M.A., 50

Shenzhen University, 114

Sibanda, M., 338

Siegel, D.S., 429

Silberman, J., 256

Silicon Valley, 396-397

Singapore

Agency of Science, Technology and Research (ASTAR), 111, 114

public research institute, patent filings by, 114

recruitment policies of KTOs, 413

university, patent filings by, 114

Slovakia, university ownership of patents in, 397

Slovenia, university ownership of patents in, 397

Socially responsible research commercialization, 32-33, 34

Social rate of return of investment in public R\&D, 5

South Africa

Agricultural Research Council

(ARC), 330-331, 347, 349, 352

apartheid in, 328-329

Armscor, 331

Bio-economy Strategy, 340

Biotechnology Regional Innovation Centres, 336

business sector

linkage with public R\&D, 337, 345-347

scient, technology, and innovation policy, 336-337

Centres of Competence, 335, 342-344

Centres of Excellence, 335

collaborative research in, 349

consultancies in, 341

contracts in, 341

Council for Geosciences, 330-331

Council for Mineral Technology, 330-331

Council for Scientific and Industrial Research (CSIR), 330-331, 335, 343, 347, 349-350, 352, 410-411, 413
Denel, 331, 349-350

Department for Planning, Monitoring and Evaluation (DPME), 352

Department of Science and Technology (DST), 333, 335, 339-340, 350, 354

Department of Trade and Industry (DTI), 333, 337, 340, 354

education and training in, 335, 337, 340-341

Elsenburg Agricultural Training Institute, 343-344

Eskom, 331, 349-350

Global Entrepreneurship Monitor, 335-336

government funding of R\&D in, 13,330

Higher Education National Funding Formula, 335

Human Sciences Research Council (HSRC), 330-331, 350

income level, patent filings by, 93, 101, 107

Industrial Development Corporation, 333

Industrial Policy Action Plan, 337

innovation

financing of, 333

in oil and gas sector, 343

outputs, 345

in platinum, 343

policy, 333-334

in pulp and paper sector, 343

surveys, 344

in viticulture, 343-344

“innovation chasm," 339

Innovation Fund, 333-334, 335-336, 355

Intellectual Property Rights from Publicly Financed Research and Development Act, 9, 333-334, 389, 390, 391

IP office, patent filings by, 131-132

knowledge capabilities gap in, 368

knowledge transfer in

barriers to, 353

case study, 378 
South Africa (cont.)

consultancies and, 341

demand-side incentives supporting, 410-411

failures of, 337-339, 364

impacts of, 352-353

informal channels of, 341

IP-mediated knowledge transfer, 341-342, 349-352

KTOs, 351-352

legislation patterned on Bayh-

Dole Act in, 406-407

metrics of, 344-352

non-IP-mediated knowledge transfer, 347-349

overview, 22, 328-329, 353-355, 389-392

patent licensing, 375-376

policies and practices, 378

policies to address failures of, 339-341

by public research institutes, 349-352

by universities, 349-352

university knowledge transfer policy, 8, 9

legislation patterned on Bayh-Dole Act in, 396

Medical Research Council, 330-331

metrics of knowledge transfer in, 426, 432-433, 436

Ministry of Higher Education and Training, 330

Mintek, 347, 349-350

National Advisory Council on Innovation, the Technology Innovation Agency (TIA), 334

National Development Plan (NDP), 329, 334, 355, 389

National Foundry Technology Network, 337

National Intellectual Property Management Office (NIPMO), 334, 340-341, 350, 353, 389-390, 391

National R\&D Strategy, 333-334, 340
National Research Foundation, 330, $331,334,335,336,338$

NECSA, 331

New Growth Path, 334

Office of Auditor General, 347

Office of Technology Transfer

Support Fund, 389-390

oil and gas sector, innovation in, 343

Patent Cooperation Treaty (PCT) and, 331-333, 349

patent licensing in, 375-376

patent metrics in, 86

platinum, innovation in, 343

Public Investment Corporation, 333

public R\&D in

linkage with business sector, 337 , 345-347

scient, technology, and innovation policy, 335-336

public research institutes

collaboration with industry, 405

expenditures on R\&D, 331, 332-333, 348

historical background, 330

IP management policies, 354

knowledge transfer by, 349-352

overview, 330-331

Public Research IP Act, 340, 353-354, 355

pulp and paper sector, innovation in, 343

rationale for inclusion in study, 18-21

R\&D/GDP ratio in, $25-26$

R\&D Tax Incentive, 333-334, 355

Researcher Rating Scheme, 335

research publications in, 347-349

sanctions against, 328-329

science and technology policy, 333-334

Sector Innovation Fund, 339-340

Sector Innovation Programme, 339-340, 355

South Africa Bureau of Standards Design Institute, 337

South Africa Bureau of Standards (SABS), 330-331 
South African Patent Office (SAPO), 330, 331

South African Research Chairs Initiative, 335, 336

Southern African Research and Innovation Managers Association (SARIMA), 340-341, 350

specialization of innovation in, 27

state-owned enterprises in, 331

technikons, 330

Technology and Human Resources for Industry Programme (THRIP), 340, 343-344, 374

"technology colony," 339

Technology Innovation Agency, 336, 352, 355

Telkom, 331

Ten-Year Innovation Plan, 333-334, 337, 339

Transnet, 331

Transnet Design, Innovation and Research Centre, 337

universities collaboration with industry, 398, 405-406 expenditures on $R \& D, 331$, 332-333, 348

historical background, 330

IP management policies, 354

knowledge transfer by, 349-352

knowledge transfer policy, 8, 9

KTOs in, 353

patent filings by, 114

research in, 330

USPTO and, 331-333, 349-350

viticulture, innovation in, 343-344

White Paper on Science and

Technology, 333, 334, 340, 355, 363

South African Wine and Brandy Company, 343-344

Southeast University of China, 128

Southern African Development Community (SADC), 454-455

South Korea. See Korea, Republic of

Korea

failures of knowledge transfer in, 364 income level, patent filings by, 106 metrics of knowledge transfer in, 426, 436

RedOTRI, 426

universities ownership of patents, 397

patent filings by, 114

Spin-offs. See also specific country

as channel of knowledge transfer, 217-218, 243, 266, 309, 398-400

universities and, 158-164, 398

Squeff, F.H.S., 265, 275-276

Stand-Alone Company Model, 171

Standardized indicators, 59-60

Stanford University, 236, 395

Startups

knowledge transfer and, 243-244, 245-247, 373

public research institutes and startups and, 422

Stellenbosch University, 343-344, 349, 352

Sunbiotech (Korea), 246

Surveys

of academics, 429-430, 436-439, 461-462

of firms, 429-430, 439-441, 461-462

Higher Education-Business and Community Interaction (HEBCI) survey, 430-431

of KTOs, 53-56, 73, 428-429, 461-462

of public research institutes, 461-462

WIPO Assessment Questionnaire for Stakeholders from Academic and Research Institutions, 464-474 (See also WIPO Assessment Questionnaire for Stakeholders from Academic and Research Institutions)

Sweden

inventor ownership in, 397

metrics of knowledge transfer in, 436

national and institutional policies and practices supporting knowledge transfer in, 40 
Sweden (cont.)

professor's privilege, abolition of, 7, 397

universities

patent filings by, 114

patenting activities of, 155

Switzerland, university ownership of patents in, 397

Takara Shuzo, 249

Tan, J., 320-321

Tan, L., 319, 322

Tang, P., 171-172

Taxol, 395

Technical University of Denmark, 442

Technical University of Munich, 221

Technology field, patent filings by, 107-112. See also specific field

Telecommunications, patent filings in, 111

Telles, L.O., 270

Tengeh, R.K., 342

Thailand

channels of knowledge transfer in, 38 government funding of R\&D in, 13

university knowledge transfer policy in, 7,8

“Third mission” policies, 6-9

Thursby, G., 48

Thursby, M.C., 48

Todo, Y., 320-321

Tokyo University, 111-114

Toole, A., 218-219

Torkomian, A.L.V., 269-270

Toyota Jidosha, 114-128

TRL scale, 254

Tsinghua University, 128, 313, 320, 322

Tunisia, university knowledge transfer policy in, 8-9

Turchi, L.M., 271, 292, 293

Turkey, patent filings by income level in, 93

“Two-way flow" of ideas, 418

Uganda, channels of knowledge transfer in, 38

United Kingdom
British Technology Group (BTG), 149, 403, 404

Catalyst Fund, 153

Catapult Centres, 153

channels of knowledge transfer in, 52

Charities Act 2006, 144

Co-Investment Fund, 155-156

collaborative research in, 149, 154

commercialization of IP in

comparison of universities and public sector research establishments (PSREs), 166-168

KTOs and, 163

patent licensing, 393-394

public sector research establishments (PSREs)

and, 164

universities and, 158-164

Community Innovation Survey

(CIS), 168-169

consultancies in, 174

contracts in, 154, 414

demand pull in, 365

Department for Business, Energy

and Industrial Strategy

(BEIS), 144

Department for Business, Innovation and Skills, 164

Department for Education

(DfE), 144

Department for Employment and Learning Northern Ireland (DELNI), 144

Department for Trade and Industry (DTI), 150

Department of Culture, Media and Sport, 146

displacement effects in, 413-414

education and training in, 174

Education Reform Act (ERA)

1988, 143

Enterprise Capital Funds, 155-156

Enterprise Investment Scheme (EIS), 155-156

government regulation of IP rights, 154-155 
Higher Education-Business and Community Interaction (HEBCI) survey, 430-431, 460-461

Higher Education Funding Council for England (HEFCE), 144, 145, 153, 172

Higher Education Funding Council for Wales (HEFCW), 144

Higher Education Funding Council (HEFC), 143

Higher Education Innovation Fund (HEIF), 152-153, 156

Higher Education Reach-out to Business and the Community (HEROBAC) Fund, 152

Higher Education Statistics Agency (HESA), 168, 169

income level, patent filings by, 93, 99

Industrial Strategy Challenge Fund, 156

Industrial Strategy White Paper, 156

Innovate UK, 153

knowledge capabilities gap in, 368

Knowledge Exploitation

Programme, 152

knowledge transfer in case study, 378-379 commercialization activities, 157-158

community-based activities, 157-158

demand-side incentives supporting, 155-156

historical background of policies and practices, 148-151 incentives regarding, 173-176 legislation patterned on BayhDole Act in, 404 national versus institutional policies and practices, 375 organizational practices, 169-173 overview, 22, 141-142, 173-176 path dependency and, 174 people-based activities, 157-158 policies and practices, 378-379, 403-404 problem-solving activities, 157-158

promotion of, 173-174

public sector research establishments (PSREs) and, 154

supply-side incentives supporting, 152-155

symbiotic relationship with socioeconomic structure, 174

universities and, 152-154

Knowledge Transfer Partnership (KTP) Scheme, 153

Lambert Agreements, 154

LINK Scheme, 149

local enterprise partnerships (LEPs), 151

Medical Research Council (MRC), 146

metrics of knowledge transfer in, 425-426, 427, 428, 430-431, 432-433, 436, 437, 460-461

National Centre for Universities and Business (NCUB), 157, 166-167

National Enterprise Board, 149

National Research Development Corporation (NRDC), 149

Office of Science and Technology (OST), 150

open funding competitions in, 155

Patent Law 1977, 154

patent licensing in, 393-394

patent metrics in, 86

Polytechnics and Colleges Funding Council (PCFC), 143

professor's privilege in, 163

public sector research establishments (PSREs)

commercialization of IP in and, $164-168$

funding of, 146-148

governance agreements, 148 knowledge transfer and, 154 overview, 146-147 spin-offs and, 164 
United Kingdom (cont.)

Public Sector Research Exploitation Fund, 154

rationale for inclusion in study, 18-21

$\mathrm{R} \& \mathrm{D} / \mathrm{GDP}$ ratio in, $25-26$

R\&D tax credits in, 155

regional development agencies

(RDAs), 151

Regional Innovation Fund, 151

research publications in, 169

Royal Society, 153-154

Science and Technology

Committee, 156

Science Enterprise Challenge (SEC) Fund, 152

Scottish Funding Council (SFC), 144

Seed Enterprise Investment Scheme (SEIS), 155-156

Small Business Research Initiative (SBRI), 155

Social Investment Tax Relief (SITR), 155-156

Teaching Company Scheme, 149, 153

Teaching Excellence Framework (TEF), 145

UK Innovation Investment Fund, 155-156

UK Research Partnership Investment Fund, 153

universities

commercialization of IP and, 158-164

diversification of knowledge transfer policy, 411-412

funding of, 144-146, 148

geographic distribution of, 143-144

historical background, 142-143

incentives regarding knowledge transfer, 173-176

industry demand for knowledge from, 168-169

knowledge transfer and, 152-154

KTOs in, 169-171, 172

organizational practices, 169-173

ownership of patents, 397 patent filings by, 114

patenting activities of, 155

public versus private, 144

spin-offs and, 158-164

University Challenge Seed Fund, 152

University Funding Council, 143

Wellcome Trust, 153-154

United States of America

Advanced Technology Program, 396

Bayh-Dole Act, 6-7, 39, 71, 80, 83,

229, 257, 340, 362-363, 380,

394-398, 413-415, 457, 460

Defense Department, 396

Defense Industrial and Technology

Base Initiative, 396

Engineering Research Centers, 396

Federal Technology Transfer Act, 396

improved evidence for policymaking in, 71

income level, patent filings by, 93, 97, 104

industry financing of R\&D in, 48

IP licensing model in, 39, 394

IP office, patent filings by, 131-132

knowledge transfer in, 394-397

Manufacturing Extension Program, 396

metrics of knowledge transfer in, 426-427, 436, 444

mode 1 conception of knowledge transfer in, 363

national and institutional policies and practices supporting knowledge transfer in, 40

National Institutes of Health (NIH), 395

Silicon Valley, 396-397

Small Business Innovation

Development Act, 396

Small Business Research and

Development Enhancement

Act, 396

standardized indicators in, 59

Stevenson-Wydler Technology

Innovation Act, 396

surveys of KTOs in, 53, 56 
United States Patent and Trademark Office (USPTO), 81-82, 128-131, 331-333, 349-350

universities

commercialization of IP and, 394-395

knowledge transfer policy, 6-7

patenting activities of, 155, 394-395

Universidade de São Paulo, 269, 277, 282-284

Universidade Estadual de Campinas, 269, 282-284, 290, 291

Universidade Federal de Minas Gerais, 282-284, 291

Universidade Federal de São Carlos, 269

Universidade Federal do Paraná, 282-284

Universidade Federal do Rio de Janeiro, 282-284

Universities. See also specific country; specific university

commercialization of IP and, 398

convergence of knowledge transfer policies and practices in, 397-398

diversification of knowledge transfer policy, 411-412

financial incentives for, 412

foreign-oriented patent filings by, 90-92

incentives for participation in knowledge transfer, 31-32, 34

income level, patent filings by, 92-93

IP licensing model, effect of, 42-43

knowledge capabilities gap and, 366-369, 380

knowledge transfer policies and practices, 22

KTOs in, 35

lack of research capacity in middleincome countries, 412

leaves of absence in, 398

legislation regarding IP policies, $6-9,80$

metrics of knowledge transfer data from, 430-431 policies and practices supporting knowledge transfer, 431-436

middle-income countries, knowledge transfer policy in, 394

patent filings by university, 112-128 (See also specific university)

patent licensing and, 397-398

patent metrics (See Patent metrics)

patent ownership and, 397

professor's privilege, abolition of, 7 , 41, 69, 163, 199-205, 397,403

questions regarding knowledge transfer policies and practices, 414

role in public $\mathrm{R} \& \mathrm{D}, 12$

spin-offs and, 158-164, 398

statistical trends in patent filings by, 90

successful knowledge transfer policies and practices, 369-371

technology field, patent filings by, 107-112

WIPO applicant names, verifying accuracy of, 137

University of California, 111, 112

University of Cape Town, 347, 349-350

University of Heidelberg, 220-221

University of Manchester, 149

University of Pretoria, 343, 349

University of Texas, 111, 112

University of Witwatersrand, 343, 349-350

Valorization, 205-206, 386-387

"Vanity" metrics, 78

Velez, M., 338

ViroMed Inc., 249-250, 251

Von Proff, S., 200

Wang, B., 313

Wang, Y.D., 311, 314

WIPO Assessment Questionnaire for Stakeholders from Academic and Research Institutions, $464-474$ 
WIPO Assessment (cont.)

financial incentives, 469

funding of R\&D, 471

general information, 464-465

IP and technology management, 467-469

ownership of IP rights, 465-466

policy awareness, 472

problems, challenges, and strategic issues, 473-474

publication and dissemination policy, 472

third-party engagement, 470

Woltmann, S., 442

World Intellectual Property

Organization (WIPO)

Assessment Questionnaire

for Stakeholders from

Academic and Research

Institutions, 464-474 (See also

WIPO Assessment

Questionnaire for Stakeholders from Academic and Research Institutions)

China in, 305

Patent Cooperation Treaty (PCT)

(See Patent Cooperation

Treaty (PCT))

public research institute applicant names, verifying accuracy of, 137

university applicant names, verifying accuracy of, 137

World University Rankings, 330

Wuhan University, 322

Wunsch-Vincent, Sacha, 282

Yale University, 33

Yoon, C.-M., 230

Zhang, C., 339

Zhang, M.X., 323

Zhao, W.X., 320

Zhejiang University, 128, 309, 322

Zou, Y.H., 320 